Verena Straub
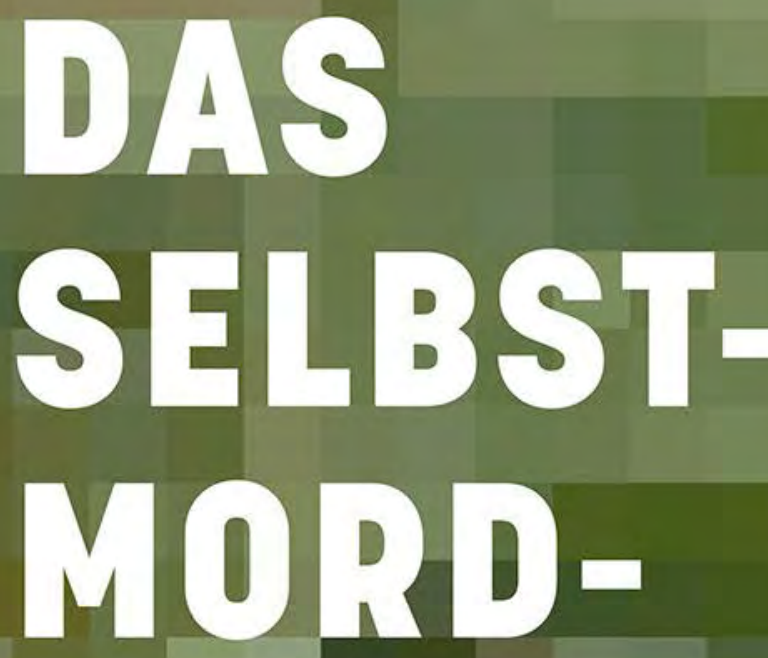

AT
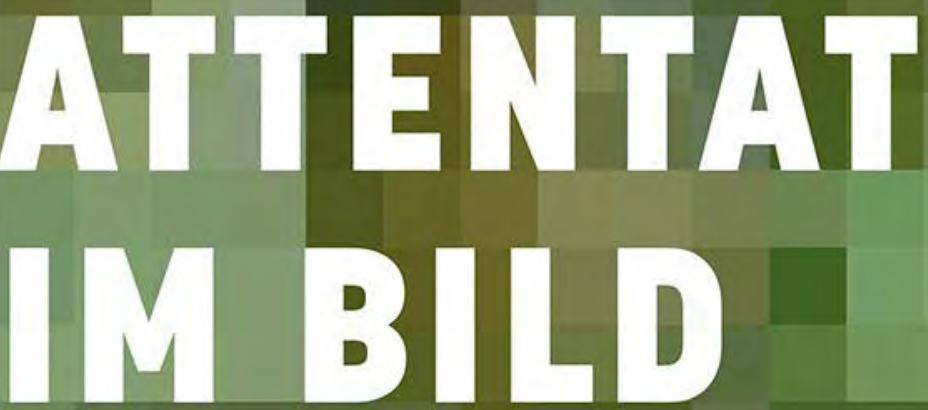

Aktualitüt und Geschichte von Mürtyrerzeugnissen

[transcript] Image 
Verena Straub

Das Selbstmordattentat im Bild

Image | Band 194 
Verena Straub, geb. 1986, ist Kunst-und Bildhistorikerin in Berlin. Sie forscht zu Bildern im Kontext politischer Agitation und zu populären Bildpraktiken in den Sozialen Medien. 2019 promovierte sie an der Humboldt-Universität zu Berlin. Zuletzt arbeitete sie als wissenschaftliche Mitarbeiterin am SFB Invektivität an der Technischen Universität Dresden sowie am SFB Affective Societies an der Freien Universität Berlin. 
Verena Straub

\section{Das Selbstmordattentat im Bild}

Aktualität und Geschichte von Märtyrerzeugnissen 
Der Druck des vorliegenden Buches wurde gefördert durch einen Druckkostenzuschuss der Deutschen Forschungsgemeinschaft - SFB 1171: »Affective Societies « der Freien Universität Berlin.

Zugleich Dissertation, Kultur-, Sozial- und Bildungswissenschaftliche Fakultät, Humboldt-Universität zu Berlin.

\section{Bibliografische Information der Deutschen Nationalbibliothek}

Die Deutsche Nationalbibliothek verzeichnet diese Publikation in der Deutschen Nationalbibliografie; detaillierte bibliografische Daten sind im Internet über http://dnb.d-nb.de abrufbar.

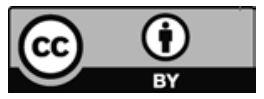

Dieses Werk ist lizenziert unter der Creative Commons Attribution 4. ० Lizenz (BY). Diese Lizenz erlaubt unter Voraussetzung der Namensnennung des Urhebers die Bearbeitung, Vervielfältigung und Verbreitung des Materials in jedem Format oder Medium für beliebige Zwecke, auch kommerziell. (Lizenztext:

https://creativecommons.org/licenses/by/4.o/deed.de)

Die Bedingungen der Creative-Commons-Lizenz gelten nur für Originalmaterial. Die Wiederverwendung von Material aus anderen Quellen (gekennzeichnet mit Quellenangabe) wie z.B. Schaubilder, Abbildungen, Fotos und Textauszüge erfordert ggf. weitere Nutzungsgenehmigungen durch den jeweiligen Rechteinhaber.

\section{Erschienen 2021 im transcript Verlag, Bielefeld () Verena Straub}

Umschlaggestaltung: Maria Arndt, Bielefeld

Druck: Majuskel Medienproduktion GmbH, Wetzlar

Print-ISBN 978-3-8376-5715-9

PDF-ISBN 978-3-8394-5715-3

https://doi.org/10.14361/9783839457153

Buchreihen-ISSN: 2365-1806

Buchreihen-eISSN: 2702-9557

Gedruckt auf alterungsbeständigem Papier mit chlorfrei gebleichtem Zellstoff. Besuchen Sie uns im Internet: $h$ ttps://www.transcript-verlag.de Unsere aktuelle Vorschau finden Sie unter www.transcript-verlag.de/vorschau-download 


\section{Inhalt}

1 Einleitung: Das Selbstmordattentat im Bild | 7

1.1 Vom Bilderkrieg zur Bildoperation | 9

1.2 Bezeugen - Erzeugen - Überzeugen | 16

1.3 Selbstmordattentat, Terrorismus, Martyrium.

Problematisierung der Begrifflichkeiten | 21

1.4 Von den Assassinen zum Islamischen Staat?

Konturen einer Geschichte des Selbstmordattentats | 30

2 Märtyrerposter als sekundäre Zeugnisse | 39

2.1 Das Märtyrerposter zwischen Bezeugen und Erzeugen | 41

2.2 Kamikaze, Fedajin, Schahid? Die Fotografien palästinensischer Selbstmordattentäter*innen ab 1974 | 51

2.3 Kopieren und Überzeugen. Palästinensische Märtyrerposter als Pop-Ikonen $\mid 60$

2.4 Der `Erfolg « von Bildoperationen.

Die ersten Selbstmordattentate von Hisbollah und Amal | 73

2.5 Bildoperationen im Raum. Märtyrerposter in Serienproduktion | 80

2.6 Rahmenwechsel. Das Märtyrerposter im Kunstkontext | 86

3 Videotestamente. Das eigene Martyrium bezeugen? | 99

$3.1 » I$ am the martyr«. Die `Erfindung des Videotestaments im Libanon ab 1985 | 102

3.2 »The stuttering of the martyr«. Elias Khourys und Rabih Mroués

Performances Three Posters (2000) und On Three Posters (2004) | 145

3.3 Vom Märtyrertestament zu einer Dramaturgie der Zeugenschaft. Die Fernsehproduktionen der Hisbollah | 153

$3.4 » I$ am the female martyr«. Videotestamente palästinensischer Selbstmordattentäterinnen ab 2002 | 176 


\section{Digitale Postproduktionen.}

Simulation und Interaktivität im Videotestament 2.0 |213

4.1 Selbstmordattentäter in der Blue Box.

Die Videotestamente der al-Qaida seit 9/11 | 214

4.2 Die Simulation des Paradieses.

Die Postproduktion als Augenzeugnis? | 225

4.3 Das Videotestament im Zeitalter des Ego-Shooters | 236

4.4 Medienzeugenschaft. Ethik und Selbstreflexion |261

5 Schluss: Das Märtyrerzeugnis als Selfie im Livestream | 271

Literatur | 285

Abbildungsnachweis | 303

Dank | 311 


\section{Einleitung: Das Selbstmordattentat im Bild}

Am Morgen des 9. April 1985 verübte eine 17-jährige Anhängerin der Syrischen Sozial-Nationalistischen Partei ein Autobombenattentat auf einen israelischen Militärkonvoi im Süden Libanons und riss zwei israelische Soldaten mit sich in den Tod. Wenige Stunden später wurde in den Abendnachrichten des Fernsehsenders Télé Liban ein kurzes Video ausgestrahlt, in dem sich die junge Frau zu ihrem Selbstmordattentat bekannte. Vor einer mit Parteiemblemen präparierten Kulisse verkündete sie: »Ich bin die Märtyrerin Sanaa Yusif Muhaydli. Ich bin nicht tot, sondern lebendig unter euch« (Abb. 3.1, S. 100). Der kurze, in einer einzigen Einstellung aufgenommene Clip kann als eines der ersten Videotestamente gelten, in dem eine Selbstmordattentäterin die politischen und persönlichen Gründe für ihre bevorstehende Tat darlegt und sich bereits zu Lebzeiten als (arab.) »Schahida«, als »Märtyrerin« bezeichnet. ${ }^{1}$

Mit ihrer Videoaufnahme hat die Libanesin einen Bildtypus eingeführt, der sich bis heute in unserer Medienlandschaft wiederfindet. Mehr als drei Jahrzehnte später gehören Märtyrerzeugnisse wie dieses weltweit zum Standardrepertoire militanter Bewegungen, die Selbstmordanschläge verantworten. Während das Video von Sanaa Muhaydli im staatlichen Fernsehen gezeigt wurde und anschließend in Form von Videokassetten zirkulierte, begegnen uns heutige Märtyrerzeugnisse fast ausschließlich im Internet. Insbesondere die Medienstellen des Islamischen Staats verbreiten Videotestamente ihrer Selbstmordattentäter als aufwendige Produktionen, die teils auf Spielfilmlänge ausgedehnt sind. Im Zeitalter Sozialer Medien posten Selbstmordattentäter ihre Testamente aber auch in Form amateurhafter Handyclips und inszenieren sich im Selfie-Modus als Märtyrer. So auch der dschihadistische Attentäter Larossi Abballa, der am 13. Juni 2016 einen Polizisten und eine Polizistin in ihrem privaten Wohnhaus in einem Pariser Vorort tötete und anschließend damit drohte, sich selbst zusammen mit dem dreijährigen Sohn des

1 Für eine ausführliche Diskussion dieses Videotestaments siehe Kapitel 3.1. 
ermordeten Paars als Selbstmordattentäter in die Luft zu sprengen. Vom Tatort streamte er ein Video live per Facebook (Abb. 5.1, S. 276), in dem er sich zu seinen Taten bekannte und seine Absicht verkündete, als »Märtyrer « des Islamischen Staats zu sterben, bevor er schließlich von der französischen Polizei getötet wurde. $^{2}$

Zwischen den beiden skizzierten Beispielen liegt nicht nur ein großer zeitlicher Abstand und medialer Kontrast. Sie verdeutlichen auch, dass die politischen und religiösen Zusammenhänge, in denen solche Videotestamente entstanden sind, kaum unterschiedlicher sein könnten: sie reichen von nationalem Widerstandskampf (wie im Kontext des libanesischen Bürgerkriegs) bis hin zu global agierenden Terrororganisationen; von Anschlägen gegen militärische Ziele bis hin zu Attentaten gegen Zivilpersonen; von säkularen Motiven (wie im Fall der Syrischen Sozial-Nationalistischen Partei) bis hin zur Propagierung eines »Heiligen Kriegs«. Ebenso vielfältig ist der Bezug zum selbst benannten »Martyrium« der Dargestellten, das nicht immer religiös konnotiert ist, sondern teilweise auch in einem rein politischen Sinne ausgelegt wird. Dass das Videotestament des selbst ernannten »Märtyrers« (und teilweise auch der »Märtyrerin«) eine lange und durchaus ambivalente Bildgeschichte aufweist, wird in aktuellen Debatten um islamistisch motivierte Selbstmordattentate und deren Online-Bilderflut jedoch häufig vergessen. Das vorliegende Buch verfolgt erstmals die Genese und Wandlung dieses speziellen Bildtypus und zeigt die mediale wie ästhetische Bandbreite der militanten Selbstinszenierungen auf.

Leitend sind für mich dabei Fragen nach den vielgestaltigen Funktionen und operativen Dimensionen dieser Bilder: Was motiviert eine Selbstmordattentäterin wie Sana Muhaydli, Bildmaterial zu produzieren, das zum Zeitpunkt der Aufnahme als belastendes Beweismaterial gelten kann? Inwiefern sind die (audio-)visuellen Märtyrerzeugnisse selbst als Akteure zu begreifen, die die Selbstmordoperationen entscheidend mitprägen? Welche Rolle kommt uns als Medienpublikum zu, wenn das militante Handeln vom physischen Tatort auf den digitalen Raum ausgeweitet wird? Und schließlich: Welches Vokabular, welche Beschreibungsmodi lassen sich finden, um über solche Bilder zu sprechen?

Wie die Kunsthistorikerinnen Sigrid Schade und Silke Wenk betont haben, sollte das »Interpretieren und Zeigen« stets »den eigenen Blick mit bedenken ebenso wie den Ort, von dem aus interpretiert und gezeigt wird, und dessen Relationen zu anderen Orten oder Feldern $\aleph^{3}$. Dies gilt umso mehr, wendet man sich

2 Für eine ausführliche Diskussion dieses Livestreams siehe Kapitel 5.

3 Sigrid Schade und Silke Wenk: Studien zur visuellen Kultur: Einführung in ein transdisziplinäres Forschungsfeld, Bielefeld: transcript 2011, S. 10. 
dem emotional wie politisch hoch aufgeladenen Diskurs um Selbstmordattentate zu. Um meinen eigenen Zugriff auf diese Bilder im Kontext der bisherigen Forschungen zu positionieren, soll daher zunächst eine kritische Diskussion der geläufigsten Interpretationsrahmen, Begrifflichkeiten und Historisierungen erfolgen.

\subsection{VOM BILDERKRIEG ZUR BILDOPERATION}

Ist vom »Selbstmordattentat im Bild« die Rede, denkt man vermutlich zuerst an die Bilder, die durch den eigentlichen Anschlag entstehen: An die Nachrichtenbilder vom Tatort, an Aufnahmen von Bombenexplosionen und einstürzenden Gebäuden oder an Bilder, auf denen Verletzte und Todesopfer zu sehen sind. Die Wirkmacht dieser Bilder, insbesondere die Frage nach dem symbiotischen Verhältnis von Terrorismus und Medien, wurde seit den Selbstmordanschlägen vom 11. September 2001 vermehrt diskutiert. ${ }^{4}$ Umso überraschender ist es, dass es bislang nur wenige Versuche gibt, auch die Bildproduktionen der militanten Akteure systematisch zu untersuchen und die Funktionen (audio-)visueller Märtyrerzeugnisse zu erklären.

Von Seiten der Kunst- und Kulturwissenschaft wurden einige Stimmen laut, die den Bildproduzent*innen eine Nähe zur Kunst attestieren. So schreibt der libanesische Filmemacher und Theoretiker Jalal Toufic im Jahr 2012 über die eingangs erwähnte Selbstmordattentäterin: »I consider Sana' Muhaydli, who introduced the genre of videotaped testimonies of soon-to-be-martyrs [...] as the first Lebanese video artist. $«^{5} \mathrm{Zu}$ einer ähnlichen Einschätzung kommt auch der Philosoph und Kunstkritiker Boris Groys, wenn er angesichts der Videoproduktionen von al-Qaida und Islamischem Staat urteilt: »The terrorists and warriors

4 Zum symbiotischen Verhältnis von Terrorismus und Medien siehe v.a. Bruce Hoffman: Terrorismus. Der unerklärte Krieg, Frankfurt am Main: S. Fischer Verlag 2008. Eine kritische Einordnung dieser, seit den 1980er Jahren dominierenden Sichtweise bieten David Cook und Olivia Allison: Understanding and Addressing Suicide Attacks: The Faith and Politics of Martyrdom Operations, Westport: Praeger 2007, S. 87.

5 Jalal Toufic: »I Am the Martyr Sanâ' Yûsif Muhaydlî«, in: Maria Hlavajova, Jill Winder und Cosmin Costinas (Hg.): Rabih Mroué: A BAK Critical Reader in Artists' Practice, Utrecht/Rotterdam: BAK 2012, S. 126-143, hier S. 173. 
themselves begin to act as artists nowadays. $\ll^{6}$ Bei Videotestamenten von Selbstmordattentäter*innen handele es sich Groys zufolge um »consciously and artistically staged events that have their own easily recognizable aesthetics «? Wenn militante Gruppen selbst Bilder produzieren und in Umlauf bringen, ist die Frage nach deren Einordnung und dem ethischen Umgang mit ihnen besonders kritisch. Werden die Medienproduktionen der Selbstmordattentäter*innen in den Bereich der Kunst verlagert - wie die Äußerungen von Toufic und Groys nahelegen - läuft man Gefahr, die Bilder als rein ästhetische Artefakte zu betrachten und dabei ihre operative Macht innerhalb der gewaltvollen Konflikte zu vernachlässigen.

Eine zweite Lesart, die in der Literatur zu Märtyrerzeugnissen vorherrscht, ist deren Interpretation als $>$ Waffen $<$ in einem Bilderkrieg. Dies schließt an weit verbreitete Theorien aus der Terrorismusforschung an. Folgt man den Standardwerken von Bruce Hoffman, Herfried Münkler oder Peter Waldmann, lässt sich Terrorismus in erster Linie als Kommunikationsstrategie auffassen, in der Bilder eine Schlüsselposition einnehmen. ${ }^{8}$ Der Politikwissenschaftler Herfried Münkler beschreibt terroristische Attentate etwa als »eine Form der Kriegführung [...], in welcher der Kampf mit Waffen als Antriebsrad für den eigentlichen Kampf mit Bildern fungiert $\ll^{9}$. Fotografien und Videos, die im Kontext militärischer Konflikte entstehen, werden zunehmend als effektive Waffen ernst genommen, die einerseits affizieren und öffentliche Meinungen beeinflussen, andererseits aber auch Gegenbilder provozieren und so eine regelrechte $» v i s u e l l e ~ R u ̈ s t u n g s s p i r a l e «{ }^{10}$ auslösen können ${ }^{11}$ In diesem Sinne wurden auch die nach Selbstmordattentaten zirkulierenden Videotestamente als an den Feind gerichtete »Gegenbild-

6 Boris Groys: »The Fate of Art in the Age of Terror«, in: Manon Slome und Joshua Simon (Hg.): The Aesthetics of Terror, Ausst.-Kat., Mailand: Charta 2009, S. 54-59, hier S. 54.

7 Ebd., S. 54.

8 Hoffman: Terrorismus. Der unerklärte Krieg; Herfried Münkler: Die neuen Kriege, Hamburg: Rowohlt 2003; Peter Waldmann: Terrorismus. Provokation der Macht [1998], 3. Aufl., Hamburg: Murmann 2011.

9 Münkler: Die neuen Kriege, S. 197.

10 Gerhard Paul: Der Bilderkrieg. Inszenierungen, Bilder und Perspektiven der »Operation Irakische Freiheit«, Göttingen: Wallstein Verlag 2005, S. 158ff.

11 Vgl. dazu auch die kritische Diskussion dieses >Bilderkrieg〈-Topos von Ben O’Loughlin: »Images as Weapons of War: Representation, Mediation and Interpretation«, Review of International Studies 37/1 (2011), S. 71-91. 
Munitionen $\aleph^{12}$ beschrieben. Dem Medienwissenschaftler Nathan Roger zufolge veröffentlichen die verantwortlichen Milizen ihre Märtyrertestamente zu einem Zeitpunkt, an dem die Aufmerksamkeit der Medien bereits nachgelassen hat - einerseits mit dem Ziel, das öffentliche Interesse erneut anzukurbeln, andererseits, um unerwünschter Berichterstattung wieder >eigene $<$ Bilder entgegenzusetzen und damit die Deutungshoheit über die Anschläge zurückzugewinnen. ${ }^{13}$ Selbst wenn dies in einigen Fällen durchaus plausibel erscheint, ${ }^{14}$ trifft Rogers Einschätzung keineswegs auf alle Videotestamente zu. Zunächst lässt sich festhalten, dass Märtyrerzeugnisse typischerweise noch am selben Tag direkt nach dem Anschlag veröffentlicht werden - und nicht erst als zeitversetzte Reaktion auf eine schwindende Medienöffentlichkeit oder als »Gegenbild-Munition « gerichtet auf unerwünschte Darstellungen in den feindlichen Medien. ${ }^{15}$ Schon ein erster Blick auf das Video von Sana Muhaydli legt außerdem nahe, dass Märtyrerzeugnisse auch (und vielleicht sogar primär) an die eigenen Reihen adressiert sind: Neben Drohungen an die israelische Besatzungsmacht richtet die junge Frau persönliche Abschiedsworte an ihre Familie, beschwört ihre Treue zur Partei und formuliert einen direkten Appell zur Nachahmung (siehe dazu ausführlich Kapitel 3.1).

Im Unterschied zu Pressebildern, die das zerstörerische Ausmaß des Selbstmordanschlags festhalten und damit vor allem an der Verbreitung von Angst und Terror beteiligt sind, können die Videotestamente daher nur bedingt als $>$ Waffen< verstanden werden. ${ }^{16}$ Stattdessen rückt ein Video wie das von Muhaydli gerade die Vielzahl der Adressat*innen in den Fokus, die bei Selbstmordattentaten involviert werden. Von der Forschung wurde mehrfach betont, dass die Kommunikation nach sinnen< bei Selbstmordattentaten mindestens ebenso entscheidend ist wie die Kommunikation nach >außen $`$ mit dem jeweiligen Feind. Als wegweisend kann hierfür die Arbeit der Politikwissenschaftlerin Mia Bloom gelten, die am Beispiel der zweiten palästinensischen Intifada argumentiert, dass der Anstieg von

12 Nathan Roger: Image Warfare in the War on Terror, New York: Palgrave Macmillan 2013, S. 82.

13 Roger: Image Warfare in the War on Terror, S. 85.

14 So zitiert Roger das Bekenntnis von Mohammad Sidique Khan, einem der Selbstmordattentäter der Londoner U-Bahn Anschläge vom 7. Juli 2005, der explizit auf die erwartete negative Darstellung seiner Person in den Medien eingeht. Ebd., S. 93.

15 Wie die folgenden Analysen zeigen werden, stellt die zeitverzögerte Veröffentlichung der 9/11-Testamente in dieser Hinsicht eine Ausnahme dar.

16 Damit unterscheiden sich die hier untersuchten Bilder von anderen Bildern des Terrors wie sie etwa von Charlotte Klonk erforscht wurden. Charlotte Klonk: Terror: Wenn Bilder zu Waffen werden, Frankfurt am Main: S. Fischer Verlag 2017. 
Selbstmordattentaten vor allem durch den Konkurrenzdruck zwischen den rivalisierenden Parteien zu erklären sei, die um Aufmerksamkeit innerhalb der Zivilbevölkerung wetteiferten. ${ }^{17}$ Versteht man das Selbstmordattentat als vielschichtigen Kommunikationsakt, der mehrere Gruppen zugleich adressiert, ${ }^{18}$ so erweisen sich auch die Funktionen der Märtyrerzeugnisse als weitaus vielfältiger, als es die Metapher der Waffe auszudrücken vermag. Wird das Märtyrerzeugnis allein als provokatives, an den Feind adressiertes Gegenbild verstanden, gerät zum einen dessen mobilisierende und legitimierende Wirkmacht aus dem Blick. Zum anderen bleibt die Frage unbeantwortet, ob und inwiefern Märtyrerzeugnisse schon zum Zeitpunkt ihrer Aufnahme handlungsleitend wirken.

Weder die Definition als Kunst noch die Erklärung als Bilderkrieg kann die komplexe Funktion der Märtyrerzeugnisse vollständig erfassen. Wie ich im Folgenden argumentieren werde, eignen sich die Konzepte der Bildoperation und die der Zeugenschaft weitaus besser, um die unterschiedlichen Handlungsmodi dieser Bilder in den Blick zu rücken. Der Operationsbegriff hat zunächst den Vorteil, den Kontext gewaltvoller politischer Konflikte mit anzuzeigen - ohne dabei auf die problematischere Darstellung eines Bilderkriegs rekurrieren zu müssen. Im militärischen Kontext dient der Terminus meist zur Beschreibung von Kampfeinsätzen, die räumlich wie zeitlich aufeinander abgestimmt sind und einem festgelegten Plan folgen. ${ }^{19}$ Als Operationen werden aber nicht nur staatliche Militäreinsätze bezeichnet. So taucht der Begriff im arabischsprachigen Raum auch im Zusammenhang mit Selbstmordattentaten auf, die von den Verantwortlichen mitunter als >Märtyrertod-Operationen ( 'amalīya istišhādìya) beschrieben wurden. ${ }^{20}$ Auch in

17 Vgl. Mia Bloom: Dying to Kill: The Allure of Suicide Terror, New York: Columbia University Press 2005.

18 Cook und Allison zufolge lassen sich die Adressaten von Selbstmordattentaten in drei Gruppen einteilen: »(1) organization members (or strong ideological supporters of the organization), (2) sympathetic publics (including potential recruits), and (3) unsympathetic publics (enemies). « David Cook und Olivia Allison: Understanding and Addressing Suicide Attacks: The Faith and Politics of Martyrdom Operations, Westport: Praeger 2007, S. 88.

19 Vgl. die Bedeutungsübersicht »Operation« auf Duden online, https://www.duden.de/ rechtschreibung/Operation (zugegriffen am 6.6.2021).

20 Ein Begriff, der erstmals von der libanesischen Hisbollah in den 1980er Jahren geprägt wurde. Joseph Croitoru: Der Märtyrer als Waffe: Die historischen Wurzeln des Selbstmordattentats, München: Hanser 2003, S. 152. Die Umschrift des arabischen Alphabets richtet sich hier und im Folgenden nach den Normen der Deutschen Morgenländischen Gesellschaft (DIN 31635). 
der englischsprachigen Berichterstattung ist der Begriff der ssuicide operation geläufig. ${ }^{21}$ Analog dazu erscheint der Begriff der Bildoperation in diesem Kontext besonders geeignet, um die funktionellen Zusammenhänge zwischen Bild, Martyrium und Gewalttat zu erfassen.

Das Konzept der Bildoperation wurde erstmals im Rahmen einer interdisziplinären Konferenz zur Diskussion gestellt, die 2014 vom Medienwissenschaftler Jens Eder und der Kunsthistorikerin Charlotte Klonk in Berlin veranstaltet wurde. ${ }^{22}$ Ein von ihnen herausgegebener Sammelband mit dem Titel Image Operations. Visual Media and Political Conflict (2017) stellt erste theoretische Überlegungen dazu vor. Zentraler Ausgangspunkt ist die Beobachtung, dass Bilder nicht nur reflektieren oder abbilden, sondern performative und konstitutive Rollen übernehmen - und damit in politische und militärische Handlungszusammenhänge eingebettet sind. ${ }^{23}$ Damit schließt das Konzept an eine der zentralen Debatten der Bild-, Kultur- und Medienwissenschaften an. Im Jahr 2005 diagnostizierten Andreas Beyer und Markus Lohoff eine »handlungsorientierte Wende« in der Kunst- und Bildwissenschaft, die den »iconic turn« zunehmend ablöse. ${ }^{24}$ Es gehe nicht mehr nur um den Befund einer ominösen Wirkmächtigkeit der Bilder, dem vielbeschworenen Mythos der >Bilderflut<, sondern um eine Untersuchung der vielfältigen Praktiken, an denen Bilder beteiligt sind. Die Frage nach den operativen Zusammenhängen von Bildern ist jedoch keineswegs neu. In seinem Buch Art and Agency unternahm Alfred Gell bereits 1998 den Versuch, Kunstwerke von ihrer Performativität her zu definieren, also weniger durch das was sie bedeuten, sondern durch das was sie tun. Er schreibt: »I view art as a system of action, intended to change the world rather than encode symbolic propositions about it. $1^{25}$

$21 \mathrm{Zu}$ den Begrifflichkeiten siehe Assaf Moghadam: »Defining Suicide Terrorism«, in: Ami Pedahzur (Hg.): Root Causes of Suicide Terrorism. The Globalization of Martyrdom, London: Routledge 2006, S. 13-24, hier S. 15.

22 Die Konferenz Image Operations fand in Kooperation mit dem ici Berlin. Institute for Cultural Inquiry vom 10.-12. April 2014 in Berlin statt. Siehe https://www.ici-berlin.org/events/image-operations/ (zugegriffen am 6.6.2021).

23 Vgl. Jens Eder und Charlotte Klonk: »Introduction«, in: Dies. (Hg.): Image Operations. Visual Media and Political Conflict, Manchester: Manchester University Press 2016, S. 1-22, hier S. 3.

24 Andreas Beyer und Markus Lohoff (Hg.): Bild und Erkenntnis: Formen und Funktionen des Bildes in Wissenschaft und Technik, München: Deutscher Kunstverlag 2005, S. 9.

25 Alfred Gell: Art and Agency: An Anthropological Theory, Oxford: Clarendon Press 1998, S. 6. 
In der neueren Bildwissenschaft der letzten Jahre hat die Frage nach der Handlungsmacht von Bildern wieder Konjunktur. Die Frage, wer hier handelt, wird jedoch ganz unterschiedlich beantwortet und es lassen sich grob zwei Pole aufzeigen: Auf der einen Seite wird das Bild als wirksames Instrument in Menschenhand aufgefasst - also das Handeln mit dem Bild in den Vordergrund gestellt; auf der anderen Seite rückt das Bild selbst als autonom handelnder Akteur in den Fokus. Wie oben bereits deutlich wurde, ist ein Großteil der kommunikations- und medientheoretischen Terrorismusforschung dem ersteren Pol zuzurechnen. Ist von Bildern als »Waffen« oder »Munitionen« die Rede, so wird damit in der Regel suggeriert, dass es ein menschliches Subjekt gibt, das >den Finger am Abzug hält (auch wenn anerkannt wird, dass Bilder - wie Waffen - in gegnerische Hände geraten und folglich in unterschiedliche Richtungen wirken können). Ähnlich verhält es sich auch mit dem Begriff des >Bildhandelns〈. Allein in der Etymologie des Wortes - im Bezug zur Hand - scheint sich bereits die Annahme eines menschlichen Akteurs zu verbergen. Diese Grundannahme zieht sich auch durch weite Teile der theoretischen Begriffsbestimmung. So geht die Philosophin Silvia Seja in ihrer Systematisierung verschiedener Handlungstheorien des Bildes (2009) stets stillschweigend von einem Subjekt aus, das auf unterschiedliche Weise mit Bildern agiert. ${ }^{26}$ Eine eigene agency oder Handlungskompetenz wird den Bildern damit abgesprochen.

Schon aus diesem Grund bietet sich der Begriff der Bildoperation als weitaus offenere Beschreibungskategorie an. Im Gegensatz zur anthropozentrierten >Handlung` umfasst das Begriffsfeld der ১Operation` auch nicht-menschliche Aktionen wie mathematische Rechenvorgänge oder Verfahren der elektronischen Datenverarbeitung, und kann somit auch müheloser auf die Operationen der Bilder selbst erweitert werden. ${ }^{27}$ Wie Eder und Klonk deutlich gemacht haben, geht das Konzept der Bildoperation weit über die Vorstellung eines intentionalen Handelns mit Bildern hinaus; gerade im Kontext politischer Konflikte können Bilder eine Eigendynamik entwickeln, die sich der Kontrolle derer entzieht, die sie hervorbringen, instrumentalisieren oder verbreiten. In ihrer Einleitung zu Image Operations betonen sie: »There are not only operations on images, with images and through images, but also operations by images. $\ll^{28}$

Mit der Einsicht, dass Bilder selbst als Akteure zu begreifen sind, die politische Konflikte beeinflussen oder überhaupt erst hervorbringen, ist der zweite der

26 Vgl. Silvia Seja: Handlungstheorien des Bildes, Köln: Halem Verlag 2009.

27 Vgl. die Bedeutungsübersicht »Operation« auf Duden online, https://www.duden.de/ rechtschreibung/ Operation (zugegriffen am 6.6.2021).

28 Eder/Klonk: »Introduction«, S. 13. 
beiden Pole angesprochen. Diese Position wurde auf unterschiedliche Weise von Kunsthistorikern wie Hans Belting, Horst Bredekamp oder W.J.T. Mitchell vertreten. ${ }^{29}$ Ihre Arbeit hat entscheidend dazu beigetragen, die Wirk- und Handlungsmacht der Bilder ernst zu nehmen - eine Perspektive, auf der auch das vorliegende Buch basiert. Im Extremfall kann eine solche Sichtweise jedoch einer »Re-Mythisierung der Bildermacht $\ll^{30}$ Vorschub leisten. So lautete der wiederholte Vorwurf an die neuere Bildwissenschaft, sie laufe Gefahr, Bilder als isolierte, scheinbar vom Menschen unabhängige Akteure zu betrachten. Damit gerate nicht nur deren kulturelle Gemachtheit aus dem Blickfeld, sondern auch die mit den Bildern verbundenen Machtpolitiken. Kunsthistorikerinnen wie Sigrid Schade und Silke Wenk wenden sich daher "gegen die Vorstellung von gleichsam aus sich heraus agierenden Bildern $\aleph^{31}$.

Mit dem Begriff der Bildoperation soll schließlich der Versuch unternommen werden, beide Pole des Bildhandelns zu vereinen. In der Einleitung zu Image Operations heißt es dazu: »[...] the causal field of image operations extends beyond the intentions of individual human agents who are >doing things with pictures ( as in Kjørup 1974; cf. also Seja 2009; Schöttler 2013). Yet it also exceeds the immediate agency of images themselves (as in Bredekamp 2010). « ${ }^{32}$ Bilder werden also weder als passive Instrumente aufgefasst, die sich wie Waffen oder Schussmunitionen beherrschen lassen, noch können sie als vom Menschen losgelöste, autonom handelnde Akteure verabsolutiert und von ihren Produktions- und Rezeptionskontexten isoliert werden. Ähnliche Gedanken finden sich schon bei Alfred Gell, der Kunstobjekte als »secondary agents« beschreibt, die zwar durchaus über eine eigene »agency« verfügen, diese jedoch stets im Austausch mit den menschlichen »primary agents« entfalten. ${ }^{33}$ Den Bildern selbst wird demzufolge keine eigene, >intrinsische Natur zugesprochen, die unabhängig von ihrem relationalen Kontext existieren könnte. In diesem Spannungsfeld zwischen Instrumentalisierung einerseits und Eigendynamik oder Widerständigkeit andererseits sollen die Märtyrerzeugnisse in den folgenden Kapiteln untersucht werden.

29 Vgl. Hans Belting: Bild-Anthropologie: Entwürfe für eine Bildwissenschaft, München: Fink 2001; W. J. T. Mitchell: What Do Pictures Want? The Lives and Loves of Images, Chicago: The University of Chicago Press 2005; Horst Bredekamp: Theorie des Bildakts, Frankfurt am Main: Suhrkamp 2010.

30 Schade/Wenk: Studien zur visuellen Kultur, S. 8.

31 Ebd.

32 Eder/Klonk: »Introduction«, S. 12.

33 Gell: Art and Agency, S. 20. 


\subsection{BEZEUGEN - ERZEUGEN - ÜBERZEUGEN}

Wie können die vielfältigen Operationen, die in und mit den Bildern, aber auch durch die Bilder wirksam werden, nun aber konkret gefasst werden? Wenn hier von Bildern die Rede ist - wie zunächst grundlegend geklärt werden soll - ist eine ganze Bandbreite an audiovisuellen Phänomenen gemeint: Von zweidimensionalen Bildern wie Fotografien, Grafiken oder den Bild-Schrift-Montagen der Poster (Kapitel 2), über videografische Aufnahmen (Kapitel 3) bis hin zu computergenerierten Produktionen, interaktiven Simulationen oder virtuellen Realitäten (Kapitel 4). ${ }^{34}$ Auch wenn der Fokus im Folgenden auf der visuellen Qualität der Bilder liegt, ist mein Verständnis von einem Bild nicht ausschließlich auf diese Ebene beschränkt, sondern bezieht die Materialität des jeweiligen Bildträgers sowie die auditive Gestaltung selbstverständlich als integrale Bestandteile in die Analysen mit ein.

Um die operativen Funktionen der Märtyrerzeugnisse genauer zu bestimmen, will ich im Folgenden den Versuch unternehmen, das Konzept der Bildoperation mit dem der Bildzeugenschaft ${ }^{35}$ zusammenzudenken. Der Bezug zur Zeugenschaft drängt sich beim Thema Selbstmordattentat gleich in mehrfacher Hinsicht auf: Zentraler Ausgangspunkt ist dabei das Konzept des Martyriums, das bei Selbstmordattentaten häufig bemüht wird, und sowohl im griechischen als auch im arabischen Wortlaut auf die Figur des Zeugen zurückzuführen ist (Kapitel 2.1). Der Märtyrer wird in der Regel als >Blutzeuge verstanden, der mit seinem Tod für ein höheres - politisches oder religiöses - Ziel einsteht. Wie ich im zweiten Kapitel zeigen werde, ist das Martyrium immer auch von der Zeugenschaft anderer abhängig, die den Märtyrertod durch Berichte oder Darstellungen bestätigen. Wird das Selbstmordattentat aus Perspektive der Verantwortlichen als das eigentliche, primäre Zeugnis verstanden, so sind die posthum produzierten Poster oder Videomontagen als sekundäre Bildzeugnisse des Martyriums zu verstehen.

34 Im weitesten Sinne folgt die vorliegende Arbeit damit einem, auf die komplexeren Bildwelten des Virtuellen erweiterten Bildbegriff wie er unter anderem vom Kunsthistoriker Oliver Grau vertreten wird. Oliver Grau: »New Perspectives for the (Digital) Humanities«, in: G. Ulrich Großmann und Petra Krutisch (Hg.): The Challenge of the Object: 33rd Congress of the International Committee of the History of Art, Nürnberg: Verlag des Germanischen Nationalmuseums 2013, S. 990-994.

35 Für eine diskursive Verortung und Konzeptualisierung von Bildzeugenschaft siehe Kerstin Schankweiler, Verena Straub und Tobias Wendl: »Image Testimonies: Witnessing in Times of Social Media«, in: Dies. (Hg.): Image Testimonies - Witnessing in Times of Social Media, London: Routledge 2019, S. 1-13. 
Bildzeugnissen wird in der Regel das Vermögen zugesprochen, Wahrheiten ans Licht zu bringen, aufzudecken, oder Belege zu liefern. Durch die ihnen zugeschriebene >Beweiskraft`können Bildzeugnisse auf unterschiedliche Art und Weise zu Akteuren werden. Ihre Veröffentlichung kann politische, juristische oder militärische Aktionen zur Folge haben: Bildzeugnisse prägen öffentliche Meinungen, formieren Proteste und können bei Gerichtsurteilen entscheidend sein. Teilweise ziehen sie aber auch weitere Gewalt in Form militärischer Vergeltungsschläge nach sich. Dieser operative Modus der Bildzeugenschaft entspricht der »epistemischen Kausalität « ${ }^{36}$ von Bildern, wie sie Jens Eder beschrieben hat. Dazu zählt er Bilder, die im weitesten Sinne zur Konstruktion von Wissen beitragen und dadurch bestimmte Handlungen beeinflussen. ${ }^{37}$

Die grundsätzliche Annahme des vorliegenden Buches ist nun, dass mit dem Bezeugen immer auch etwas erzeugt wird - eine These, die an weite Teile der jüngeren Forschung zur Zeugenschaft anschließt. Hier hat sich die Einsicht durchgesetzt, dass Zeugnisse weit mehr sind als >Belege oder >Beweismittel , die in einem kausalen Verhältnis zum Ereignis stehen. Besonders deutlich wird dies bei Bildern, die als Reaktion auf Selbstmordattentate entstanden sind. Mit Märtyrerpostern ist zwar ein Anspruch auf 〉Beweiskraft ` (in diesem Fall für das Martyrium der Gestorbenen) verbunden, sie sind aber immer auch als Fiktionen zu begreifen, die durch die jeweilige Absicht der Bezeugenden geprägt sind und das Martyrium eigentlich erst herstellen (siehe insbesondere Kapitel 2.1). Damit rückt gerade der relationale Charakter des Martyriums in den Blick, das stets als Zuschreibung zu verstehen ist. Der Religionssoziologe Paul Middleton hat dies folgendermaßen auf den Punkt gebracht: »Martyrdom is essentially created when a narrative about a death is told in a particular way. The central character is not the most important element in the creation of martyrdom; it is the narrator. ${ }^{38}$ Nicht die Umstände des Todes selbst entscheiden, ob jemand zum Märtyrer wird oder nicht, sondern die Art und Weise, wie dieser Tod erzählt bzw. dargestellt wird. Die analytische Frage nach der >Erzeugung < des Martyriums ist daher keineswegs in einem essentialistischen Sinne zu verstehen, sondern als Versuch einer Annäherung an die jeweilige Erzählung der Bildzeug*innen.

Neben dem Erzeugen geht es bei den Märtyrerbildern aber immer auch darum, zu überzeugen. Das heißt, Bilder zu schaffen, die gleichzeitig als Mittel zur

36 Jens Eder: Vorüberlegungen zu »Image Operations. Visual Media and Political Conflict«. Unveröffentlichtes Manuskript, 2016, o.S.

37 Ebd.

38 Paul Middleton: Martyrdom: A Guide for the Perplexed, London: Bloomsbury Publishing 2011, S. 30 . 
Rekrutierung funktionieren. Folgt man erneut der Kategorisierung von Jens Eder, lässt sich diese operative Dimension auch im Sinne einer »appellativen Kausalität $«{ }^{39}$ der Bilder beschreiben. Damit sind Bildoperationen gemeint, die eine affektive, rhetorische oder didaktische Macht auf die Betrachtenden ausüben, und diese zu bestimmten Verhaltensweisen auffordern. Neben Propagandabildern trifft dies etwa auf Instruktionsvideos zu, aber auch auf Videos von Geiselnahmen, die als Druckmittel für politische Verhandlungen eingesetzt werden. Am deutlichsten wird das Streben nach Überzeugung wohl durch die expliziten Aufrufe zur Nachahmung innerhalb der Videotestamente (Kapitel 3.1). Die mobilisierende Absicht zeigt sich aber auch auf der Ebene der audiovisuellen Gestaltung, wie die Analysen der einzelnen Kapitel deutlich machen werden. Entlang der Trias aus Bezeugen, Erzeugen und Überzeugen sollen die Bildoperationen in dieser Arbeit untersucht werden.

Folgt man Eder und Klonk, so sind Bildoperationen immer auch als Medienoperationen zu begreifen: »The specific potential of different media for producing, manipulating, storing, spreading and interacting with images leads to different operations. $\ll^{40}$ Auch die Bildzeugnisse des Selbstmordattentats werden auf ganz unterschiedlichen Bildträgern gespeichert und durch diverse Kommunikationstechnologien verbreitet. Wurden die ersten Videotestamente über regionale Fernsehsender oder durch den Verkauf von VHS-Kassetten öffentlich gemacht, ${ }^{41}$ sind die Bilder heute fast ausschließlich im Internet zu finden. Sie werden auf den Webseiten der verantwortlichen Organisationen gezeigt, auf Twitter, YouTube und Facebook oder in diversen Onlineforen gepostet und geteilt. Märtyrerbilder sind aber bis heute auch in Form gedruckter Poster im öffentlichen Raum sichtbar oder werden im Kunstkontext auf vielfältige Weise angeeignet. Geht man davon aus, dass mit den unterschiedlichen Medien, ihren materiellen Eigenheiten und spezifischen Möglichkeiten der Verbreitung auch unterschiedliche Bildoperationen einhergehen, erscheint es sinnvoll, diese gesondert zu betrachten, was in den in den folgenden Kapiteln geschieht. Wenngleich die Kapitelstruktur einer groben Chronologie folgt - von den Märtyrerpostern der ersten palästinensischen Selbstmordoperationen in den 1970er Jahren, bis hin zu den aktuellen Videoproduktionen des Islamischen Staats - wird jedes der drei Hauptkapitel den Fokus auf andere Medien der Bildzeugenschaft legen.

39 Eder: Vorüberlegungen zu »Image Operations«, o.S.

40 Eder/Klonk: »Introduction«, S. 5.

41 Vgl. Zeina Maasri: Off the Wall: Political Posters of the Lebanese Civil War, London: I.B. Tauris 2009, S. 123, Anm. 5. 
Im zweiten Kapitel sind dies zunächst die Märtyrerposter. Hier werden vor allem die Operationen an und in den Bildern in den Vordergrund rücken: Insbesondere Verfahren der Bild- und Textmontage, durch die das Martyrium der Dargestellten posthum be- und erzeugt wird. Dabei machen gerade die heterogenen, teils widersprüchlichen Aussagen in der Aneignung der Bilder deutlich, dass das Martyrium mit jeder Montage neu definiert und (um)gedeutet wird. Untersucht werden aber auch die Handlungen mit den Bildern, also die Art und Weise, wie die Poster zum Einsatz kommen, ihre Instrumentalisierung, Popularisierung und Mobilisierung. Dies umfasst auch den Gebrauch der physischen Bildobjekte selbst. Als Beispiel können die Märtyrerposter gelten, die während des libanesischen Bürgerkriegs von den Kriegsparteien massenhaft im umkämpften Stadtraum plakatiert wurden, um geografische Machtansprüche zu markieren, und so in ihrer Eigenschaft als materielle Objekte ganz direkt in militärische Operationen eingebunden waren.

Das dritte Kapitel widmet sich den eigentlichen Videotestamenten, wie sie seit Mitte der 1980er Jahre zunächst im Libanon und dann vermehrt in Palästina aufgenommen wurden. Im Unterschied zu den Märtyrerpostern treten die Dargestellten hier nun selbst als Zeug*innen ihres eigenen Martyriums auf. Durch die Aussage >Ich bin der Märtyrer/Ich bin die Märtyrerin`sprechen die Verantwortlichen in der (unmöglichen) Rolle von Überlebenden - als wäre ihr Martyrium bereits vollzogen. Videotestamente nehmen dadurch eine besonders paradoxe zeitliche Position ein: sie sind nicht länger als sekundäre Bild-Zeugnisse zu verstehen, die dem Selbstmordattentat nachgeordnet sind, sondern gehen dem bezeugten Ereignis voraus. Sie sollen daher als antizipative Zeugnisse definiert werden. Damit erhält auch die Frage nach der Handlungsmacht dieser Bilder ganz neue Brisanz. Das vorweggenommene Märtyrerzeugnis verpflichtet die Dargestellten in letzter Konsequenz zur Durchführung des Attentats und macht dieses unausweichlich.

Hier rückt vor allem die performative Dimension der Bildoperation in den Blick - das Operieren durch Bilder. Eder spricht in diesem Zusammenhang auch von einer $»$ performativen Kausalität $\aleph^{42}$ der Bilder. Er geht dabei von der Beobachtung aus, dass Bilder nicht nur Auslöser für bestimmte politische, juristische oder militärische Aktionen sind, sondern selbst als Instrumente für deren Durchführung dienen. Als Beispiele können visuelle Technologien des Militärs gelten, wie etwa Drohnenangriffe, bei denen die eigentliche Operation durch das Handeln am Bildschirm stattfindet. Inwieweit auch die Produktion der Videotestamente unter diesem bildoperativen Modus zu fassen ist, wird Gegenstand des dritten Kapitels sein. Während die Rede vom Bild als $>$ Waffe $<$ meist das Bildprodukt betont, das dann auf unterschiedliche Weise instrumentalisiert wird, wird hier deutlich, dass

42 Eder: Vorüberlegungen zu »Image Operations«, o.S. 
Bildoperationen auch Prozesse bezeichnen können, in deren Verlauf Bilder erst hervorgebracht werden. Der Moment, in dem ein Selbstmordattentäter oder eine Selbstmordattentäterin vor die Kamera tritt, um das eigene Testament aufzunehmen, wird zum Auslöser, zum Katalysator für die eigentliche >Märtyrertod-Operation', und ist damit auf erschreckend direkte Art und Weise in das Feld realpolitischer Konflikte involviert - so meine zentrale These. Inwiefern die performativen Bildoperationen auch mit der Konstruktion bestimmter Geschlechterbilder zusammenhängen, wird ein Schwerpunkt des dritten Kapitels sein.

Das vierte Kapitel will die Frage nach dem Zeugnischarakter der Videotestamente schließlich noch einmal anders stellen. Insbesondere mit Blick auf aktuelle Beispiele fällt auf, dass die nach Selbstmordattentaten in Umlauf gebrachten Videos zu komplexen digitalen Produktionen geworden sind, die weit über die Aufnahme des eigentlichen Testaments hinausgehen. In den letzten Jahren wurde die Postproduktion der Videotestamente immer aufwendiger und schien zunehmend an Bedeutung zu gewinnen. Durch Nachbearbeitungsprozesse wie Bildmontage, Untertitelung, Voiceover, aber auch das Hinzufügen digitaler visueller Effekte oder computergenerierter Sequenzen werden die Videotestamente zum Austragungsort zahlreicher Bildoperationen, mit denen ein Anspruch auf Zeugenschaft verbunden ist. Im Unterschied zu den Postermontagen gehen hier mehrere Modi der Zeugenschaft eine komplexe Verbindung ein: das antizipative Zeugnis der Sprechenden, die scheinbar objektiven Bildzeugnisse der Tat, sowie computersimulierte Szenarien, die den Eintritt ins Paradies visuell vor Augen führen. Der vermehrte Rekurs auf die Ästhetik von Ego-Shooter-Spielen legt außerdem die Vermutung nahe, dass sich die Bildoperationen durch die interaktive Struktur des Web 2.0 grundlegend verändert haben. Gerade durch die Involvierung des Publikums, das in den Videos selbst als Gamer*innen bzw. als Bild-Operateure angesprochen werden, stellt sich die Frage nach einem Handeln in Bildern noch einmal aus einer ganz anderen Perspektive. Eine Perspektive, die uns letztlich auch auf unsere eigene Position als Medienzeug*innen zurückwirft und eine Reihe an ethischen und selbstreflexiven Überlegungen anstößt.

Die Frage nach der Involvierung des Medienpublikums wird im fünften und letzten Kapitel am Beispiel des (eingangs bereits zitierten) Livestream-Testaments noch einmal zugespitzt. Durch die scheinbar zeitgleiche Präsenz mit dem Attentäter auf Facebook wurden die User*innen zumindest prinzipiell in die Lage versetzt, mit ihm in Kontakt zu treten, das Video unmittelbar zu kommentieren und damit aktiv in den Verlauf des Geschehens einzugreifen. Wird der physische Tatort auf diese Weise in den digitalen Raum erweitert, erhält das Argument von einer Mittäterschaft durch Anblicken und Anklicken neue Brisanz. 
Das Bezeugen, Erzeugen und Überzeugen ist folglich als Bildpraxis zu verstehen, die mehrere Ebenen umfasst: von der Aufnahmesituation und Bildproduktion, über die verschiedenen Wege der Zirkulation, bis hin zu Prozessen der Rezeption, sowie zahlreichen Appropriationen und Neurahmungen. Eine besondere Rolle kommt dabei den künstlerischen Aneignungen zu. Einige Bilder, die im Mittelpunkt der folgenden Analyse stehen, wurden auch von zeitgenössischen Künstler*innen aufgegriffen und neu verhandelt. Dieser $»$ Rahmenwechsel $\aleph^{43}$ in den Kontext der Kunst zieht sich als zweiter Strang durch die drei Hauptkapitel; er ermöglicht es, die untersuchten Bilder aus anderen Blickwinkeln neu zu beleuchten und bisher verhandelte Themen in Bewegung zu bringen (Kapitel 2.5, Kapitel 3.2 und 3.4, sowie Kapitel 4.3). Inwiefern eröffnen künstlerische Arbeiten alternative Zugänge zu den Märtyrerzeugnissen? Kann der Macht der militanten Bildoperationen hierdurch eine Bildkritik entgegengesetzt werden, die letztlich auch andere Operationen mit, in und durch die Bilder ermöglicht? Zugleich stellt sich aber auch die Frage nach den ethischen Herausforderungen, die mit der Neurahmung der militanten (Selbst-)Bilder verbunden sind. Gerade die künstlerischen Aneignungen verdeutlichen, wie unkontrollierbar die Eigendynamik dieser Bildzeugnisse ist, welche durch zahlreiche Bedeutungsverschiebungen charakterisiert sind. Dass deren bezeugte $>$ Wahrheiten $<$ keineswegs stabil sind, sondern beständig neu konstruiert werden, soll in den einzelnen Kapiteln deutlich werden.

\subsection{SELBSTMORDATTENTAT, TERRORISMUS, MARTYRIUM. PROBLEMATISIERUNG DER BEGRIFFLICHKEITEN}

Ausgangspunkt dieser Arbeit ist die mediale Inszenierung des Selbstmordattentäters als Märtyrer, bzw. der Selbstmordattentäterin als Märtyrerin. Damit sind gleich mehrere begriffliche Unschärfen verbunden: Wer wird von wem unter welchen Bedingungen als Selbstmordattentäter*in definiert? Und wer wird von wem unter welchen Bedingungen in den Status eines Schahids oder einer Schahida erhoben? Klar ist, dass beide Bezeichnungen mit einer Positionierung einhergehen und eine bestimmte Perspektive markieren: Wer für die einen als $>$ Selbstmordattentäter`oder gar als >Terrorist gilt, kann von anderen als `Freiheitskämpferく,

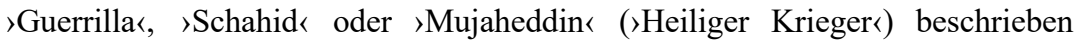
werden. Das politisch wie affektiv hoch aufgeladene Bedeutungsfeld des

43 Mit dem Begriff des Rahmens beziehe ich mich auf Judith Butler: Frames of War: When is Life Grievable?, London/New York: Verso 2010. 
Selbstmordattentats erfordert daher zuallererst eine Problematisierung jener Begrifflichkeiten, die in den folgenden Kapiteln immer wieder auftauchen und teilweise ausführlicher diskutiert werden.

Zuvor muss jedoch die grundlegende Frage gestellt werden: Was wird unter einem Selbstmordattentat verstanden? ${ }^{44}$ Wie Assaf Moghadam in seinem Text $D e$ fining Suicide Terrorism herausgearbeitet hat, lassen sich zwei grundlegende Definitionsstränge sondieren: ein eng gefasster und ein weiter. Im ersten Sammelband zum Thema Selbstmordattentat, der noch vor dem 11. September 2001 erschien, formuliert der israelische Terrorismusexperte Yoram Schweitzer folgende Begriffsbestimmung, die bis heute viel zitiert wird:

$»[\ldots .$.$] a suicide terror attack is defined as a politically motivated violent attack perpetrated$ by a self-aware individual (or individuals) who actively and purposely causes his own death through blowing himself up along with his chosen target. The perpetrator's ensured death is a precondition for the success of his mission. « $^{45}$

Es gilt als unumstrittene Prämisse für Selbstmordattentate, dass der Akt des Tötens und der Akt des Sterbens als Teil ein und derselben Mission aufgefasst werden. ${ }^{46}$ Als $»$ politisch motivierte $«{ }^{47}$ Anschläge sind Selbstmordattentate dabei grundlegend von Amokläufen zu unterscheiden, in denen zwar ebenfalls häufig das Töten anderer mit dem eigenen Tod einhergeht, meist jedoch persönliche Motive ausschlaggebend sind. Folgt man Schweitzers Definition, so hängt der »Erfolg« einer Selbstmordoperationen notwendigerweise vom Tod der Angreiferin oder des Angreifers ab: Die Selbsttötung wird dabei zur eigentlichen Waffe, mit

44 Einen kritischen Forschungsüberblick zur Begriffsbestimmung gibt Claudia Brunner: Wissensobjekt Selbstmordattentat: Epistemische Gewalt und okzidentalistische Selbstvergewisserung in der Terrorismusforschung, Wiesbaden: VS Verlag für Sozialwissenschaften 2011, Kapitel 3.1.2.

45 Yoram Schweitzer: »Suicide Terrorism. Development and Main Characteristics«, in: ICT/ADL (Hg.): Countering Suicide Terrorism, Herzliya: ICT/ADL 2002, S. 77-88, hier S. 78. Der Sammelband wurde bereits 2001 in einer ersten Ausgabe veröffentlicht und versammelt die Beiträge der internationalen Konferenz »Countering Suicide Terrorism«, die am 21. Februar 2000 am International Institute for Counter-Terrorism in Herzeliya, Israel abgehalten wurde.

46 Vgl. Moghadam:»Defining Suicide Terrorism«, S. 17.

47 Lorenz Graitl: Sterben als Spektakel: Zur kommunikativen Dimension des politisch motivierten Suizids, Wiesbaden: Springer 2012, S. 311; vgl. auch Schweitzer: »Suicide Terrorism. Development and Main Characteristics«, S. 78. 
der andere getötet werden. Dieser engen Definition folgend wurden Selbstmordattentate häufig auch als >suicide bombings ` verstanden, bei denen die Attentäterin oder der Attentäter den eigenen Körper als Bombe einsetzt und die Selbsttötung somit zwangsläufig zusammenfällt mit der Tötung des Feindes. Zunächst kamen dafür vor allem sprengstoffbeladene Autos oder LKWs zum Einsatz. Das Jahr 1981 wird dieser engen Definition zufolge häufig als der Beginn von Selbstmordattentaten im Nahen Osten gehandelt, als im Zusammenhang des Iran-Irak-Kriegs ein schiitischer, vom Iran unterstützter Attentäter mit einer Autobombe in die irakische Botschaft in Beirut fuhr. ${ }^{48}$ Ein Jahr später wurde diese Taktik schließlich auch von der Hisbollah gegen die israelischen Besatzungstruppen im Libanon eingesetzt (siehe Kapitel 2.4). Als `suicide bombings im engeren Sinne werden heute vor allem die Anschläge mit Sprengstoffgürteln oder -westen bezeichnet, die ab 1993 insbesondere im Kontext des Israel-Palästina-Konflikts Verbreitung fanden.

In einer breiteren Definition wurden als Selbstmordattentate aber auch jene Anschläge gefasst, bei denen der Tod des Attentäters bzw. der Attentäterin nicht unmittelbar mit dem »Erfolg« der Aktion verknüpft ist, das heißt, nicht notwendigerweise simultan zum Tötungsakt stattfindet. Der Politikwissenschaftler Robert Pape weist auf die Möglichkeit einer breiteren Definition hin, in der offen bleibt, wodurch, wann genau und durch wessen Hand der Attentäter oder die Attentäterin letztlich ums Leben kommt. ${ }^{49}$ Entscheidend ist hierbei lediglich, dass die jeweiligen Akteure eine prinzipielle Bereitschaft ankündigen, im Zuge des geplanten Anschlags zu sterben. Schwierig wird es jedoch dann, wenn die Absicht zu sterben nicht klar nachgewiesen werden kann (beispielsweise durch zuvor verfasste Testamente). In manchen Fällen lässt sich nicht genau bestimmen, ob der Tod der angreifenden Person wirklich Teil des Operationsplans war oder ob dieser erst im Nachhinein so gedeutet wurde. Nach Papes Definition ist die Grenze zwischen Selbstmordattentat und sogenannten high-risk-Operationen, bei denen ein Entkommen der Verantwortlichen zwar unwahrscheinlich, aber prinzipiell möglich ist, nicht eindeutig zu ziehen. Luca Ricolfi und Paolo Campana bemühen sich hingegen um eine präzisere Grenzziehung. Die von ihnen vorgeschlagene Definition schließt nur jene Operationen ein, die eindeutig zum Tod der Angreifenden führen,

48 Vgl. Assaf Moghadam: The Globalization of Martyrdom: Al Qaeda, Salafi Jihad, and the Diffusion of Suicide Attacks, Baltimore: John Hopkins University Press 2008, S. 17; Graitl: Sterben als Spektakel, S. 85.

49 »A broader definition could include any operation that is designed in such a way that the terrorist does not expect to survive it, even if he or she is actually killed by police or other defenders. « Robert Pape: Dying to Win: The Strategic Logic of Suicide Terrorism, New York: Random House 2005, S. 10. 
öffnet die Bestimmung aber gleichzeitig für Attentate, die nicht im engeren Sinne als >suicide bombings` gefasst werden können:

»By suicide mission we signify an attack against an enemy target in which the agent has no chance of escaping or saving himself. The crucial element in this definition is the certainty of the agent's death, and not the means used to carry out the attack. [...] The definition thus excludes extreme risk missions, but it includes various forms of attacks differing from selfexplosion, and in particular all kinds of actions that do not contemplate an escape plan (attacks against military facilities, infiltrations in protected settlements, etc.). The suicide mission (SM) concept is broader than that of suicide bombing (SB). $\ll^{50}$

Grundprämisse einer solchen Definition ist, dass der Tod der angreifenden Person fest in den Operationsplan integriert ist, der keine Möglichkeit zur Flucht vorsieht. Falls eine Attentäterin oder ein Attentäter dennoch überlebt, dann nur, weil er oder sie es nicht geschafft hat, sich vor einer Festnahme selbst zu töten (oder töten zu lassen). Folgt man dieser Definition, sind bereits die palästinensischen Anschläge auf israelischem Boden ab 1972 als Selbstmordanschläge zu bezeichnen, bei denen sich die Attentäter*innen zusammen mit ihren Geiseln in die Luft sprengten oder nach der Tat selbst töteten (Kapitel 2). Sowohl die Testamente der Attentäter*innen, die im Vorfeld die Gewissheit des eigenen Todes proklamierten, wie auch die darauffolgende Bekanntgabe der Aktionen als »Selbstmord-Kommandos« (arab. »mağmū 'a intiharīya«) legen in diesen Fällen nahe, dass der eigene Tod von Anfang an als Teil der Missionen mit eingeplant war. ${ }^{51}$ Auch wenn die meisten Forscher*innen, darunter auch Robert Pape, in ihren auf Statistiken beruhenden, empirischen Studien meist auf eine enge, weil pragmatischere Definition des Selbstmordattentats zurückweichen, macht es gerade mit Fokus auf die Bildproduktionen Sinn, Selbstmordattentate in dieser breiteren Perspektive zu betrachten. Mit Assaf Moghadam lässt sich daher argumentieren, dass die Label >suicide

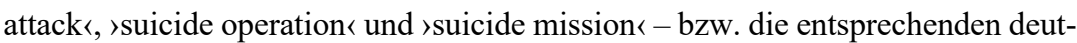
schen Übersetzungen 〉Selbstmordattentat`, >Selbstmordoperation « und >Selbstmordmission < - die größtmögliche Bandbreite dieses Attentatstypus umfassen und daher der Bezeichnung >suicide bombing (vorzuziehen sind. ${ }^{52}$

50 Luca Ricolfi und Paolo Campana: »Suicide Missions in the Palestinian Area: A New Database«, 2004, S. 2, https://www.prio.org/Global/upload/CSCW/Violence\%20in\% 20civil\%20war/suicide_missions.pdf (zugegriffen am 6.6.2021).

51 Vgl. Croitoru: Der Märtyrer als Waffe, S. 82.

52 Moghadam: »Defining Suicide Terrorism«, S. 15f. 
Wird in der westlichen Öffentlichkeit über Selbstmordattentate gesprochen, schwingt bis heute - wie selbstverständlich - der Begriff des `Terrorismus` mit. Schon in Schweitzers Definition von »suicide terror attacks « fällt auf, dass sich das zwischengeschobene Wort >terror beinahe unbemerkt als Teil der Begriffsbildung eingeschrieben hat. Wie Claudia Brunner in ihrem Buch Wissensobjekt Selbstmordattentat treffend bemerkt hat, zieht sich die oftmals stillschweigende Gleichsetzung von Selbstmordattentat und Terrorakt als grundsätzliche Annahme und politische Vorverurteilung durch weite Teile der Forschung. ${ }^{53}$ Spätestens seit Erscheinen von Robert Papes einflussreichem Buch, das die Bezeichnung Suicide Terrorismus bereits im Titel trägt, lasse sich eine Begriffsvermischung beobachten, die das Selbstmordattentat beinahe ausschließlich als »terroristisch« einstuft, »ohne dass die einzelnen Anschläge aus völkerrechtlicher Perspektive in Bezug auf ihre unumstritten problematische, aber immerhin theoretisch mögliche Legitimierbarkeit bewertet bzw. voneinander in diesem Punkt unterschieden werden«, so Brunner. ${ }^{54}$

Wie könnte eine solche Differenzierung zwischen terroristischen und nichtterroristischen Selbstmordattentaten aussehen? Obwohl der Begriff des Terrorismus keiner einheitlichen Definition unterliegt, wird er meist in Abgrenzung zu staatlich legitimierter Gewalt bestimmt. ${ }^{55}$ Das Begriffspaar »suicide terrorism « ist daher schon allein deshalb problematisch, weil Selbstmordoperationen auch als Teil staatlich angeordneter Kriegsstrategien zum Einsatz kamen (ein prominentes Beispiel sind die Kamikazeeinsätze der Japaner während des Zweiten Weltkriegs). Assaf Moghadam ist einer der ersten, der auf diesen Widerspruch hingewiesen hat ${ }^{56}$ Doch selbst wenn das Selbstmordattentat von nicht-staatlichen Gruppen ausgeht, sollte Moghadam zufolge nur dann von einem >terroristischen $<$ Anschlag die Rede sein, wenn sich dieser gegen die Zivilbevölkerung richte. Bombenanschläge, die uniformierte Soldaten und Soldatinnen zum Ziel haben, wären hingegen als Teil eines Guerilla-Kriegs, als politischer Aufstand oder low intensity conflict (Gewalt unterhalb der Kriegsschwelle) zu bezeichnen. ${ }^{57}$ Auch Brunner sieht den

53 Brunner: Wissensobjekt Selbstmordattentat, S. $93 \mathrm{ff}$.

54 Ebd., S. 97.

55 So argumentiert etwa der Philosoph Michael Walzer: Arguing About War, New Haven: Yale University Press 2004, S. 51. Für eine Begriffsdiskussion siehe auch Hoffman: Terrorismus. Der unerklärte Krieg, S. 80; Michael C. Horowitz: The Diffusion of Military Power: Causes and Consequences for International Politics, Princeton: Princeton University Press 2010, S. 168.

56 Moghadam: »Defining Suicide Terrorism«, S. 14.

57 Vgl. ebd. 
Angriff auf Zivilpersonen als ausschlaggebendes Merkmal für sterroristische< Selbstmordattentate: »Dass im Zusammenhang mit zivilen Opfern von Terrorismus die Rede ist«, erscheint der Sozialwissenschaftlerin »verständlich und korrekt $\kappa^{58}$. Die Frage, ob ein Selbstmordanschlag als politisch legitimer Widerstand oder als illegitimer Terrorakt einzustufen ist, müsste damit in jedem Einzelfall neu diskutiert werden. Dass der Begriff des Terrorismus in weiten Teilen der Forschung zum Selbstmordattentat dennoch generalisierend und unhinterfragt verwendet wird, verweist vielmehr auf eine politische Positionierung der Schreibenden. Denn »indem man bestimmte Gewalthandlungen `terroristisch` nennt, will man ihnen [...] in der Regel jegliche politische Legitimation absprechen«, so betont auch Herfried Münkler. ${ }^{59}$ Nimmt man die palästinensischen Selbstmordattentate als Beispiel, so wird deutlich, dass mit der generellen Betitelung als ıterroristisch < - egal ob sich die Anschläge gegen Zivilpersonen oder Militärstützpunkte richten - eine politische Delegitimierung einhergeht, die eine unvoreingenommene Auseinandersetzung mit dem Israel-Palästina-Konflikt unmöglich macht. Der Umstand, dass durch das israelische Militär verübte Angriffe, denen ebenfalls Zivilpersonen zum Opfer fallen, im Westen so gut wie nie als terroristische Akte bezeichnet werden, führt die Problematik des Terrorismus-Begriffs besonders deutlich vor Augen. »All attacks on Israelis, whether inside the 1967 border or outside, whether targeting soldiers or civilians, are dubbed terrorist attacks «, so bringt die Medienwissenschaftlerin Dorit Naaman diesen offensichtlichen Widerspruch auf den Punkt, und fährt fort: »But dropping a one-ton bomb from an Israeli airplane on a five-story Palestinian house, in which a militant may be present, knowing full well that dozens of civilians will be killed, is hardly ever described in Western media as terrorism. $\ll^{60}$

Geht man davon aus, dass sich Staaten derselben extremen Mittel von Gewalt bedienen, nur dass diese mit Verhältnismäßigkeit, Humanität und Notwendigkeit gerechtfertigt werden, ist die Frage, was als >legitime und was als >illegitime Gewalt gilt, keine Frage von festgelegten Kriterien (etwa dem Töten unbeteiligter Zivilpersonen oder dem Verbreiten von Angst und Schrecken); es ist vielmehr eine Frage der Argumentation, wie Talal Asad in seiner kritischen Studie On Suicide Bombing überzeugend darlegt. ${ }^{61}>$ Terrorismus ist folglich kein analytischer

58 Brunner: Wissensobjekt Selbstmordattentat, S. 94.

59 Münkler: Die neuen Kriege, S. 175.

60 Dorit Naaman: »Brides of Palestine/Angels of Death: Media, Gender, and Performance in the Case of the Palestinian Female Suicide Bombers«, Signs 32/4 (2007), S. 933955, hier S. 939.

61 Talal Asad: On Suicide Bombing, New York: Columbia University Press 2007, S. 21. 
Terminus, der (wie auch immer definierte) Kategorien über die Legitimität von Selbstmordattentaten liefert, sondern ein rhetorischer Begriff, mit dem eine bestimmte politische Bewertung verbunden ist. Aus diesen Gründen wird er im Folgenden vermieden, auch wenn ich mich an mehreren Stellen auf die Terrorismusforschung, vor allem auf deren kommunikationstheoretische Überlegungen beziehe. Dagegen sind die Bezeichnungen >Selbstmordattentat $<$ bzw. >Suizidattentat politisch neutraler und offen für verschiedene Anwendungsweisen, ohne dabei den Gewalt-Aspekt zu schmälern oder gar zu rechtfertigen. ${ }^{62}$

Das Bemühen um weitgehende Neutralität stößt bei einem Thema wie diesem jedoch auch an seine Grenzen. Insbesondere mit Blick auf die Selbstmordattentate radikal-islamischer Bewegungen wie al-Qaida und dem Islamischen Staat, die einen globalen Dschihad proklamieren, der sich nicht mehr nur gegen eine politische (Besatzungs-)Macht, sondern unmissverständlich und primär gegen ganze Gruppen der Zivilbevölkerung richtet, erscheint eine klare Positionierung unabdingbar. Würde ein Verzicht auf die Benennung dieser Gruppierungen als >TerrorOrganisationen` nicht sogar Gefahr laufen, eine Legitimierung ihrer Taten zu begünstigen? Wie Charlotte Klonk argumentiert, hat das Wort >Terror im Unterschied zum schwammigen Etikett des >Terrorismus $`$ den Vorteil, lediglich auf den Effekt der Gewalttaten hinzuweisen, also auf die Verbreitung von Angst und Schrecken in der Zivilgesellschaft, ohne damit den problematischen TerrorismusDiskurs mitzuführen. ${ }^{63}$ Auch wenn die Verbreitung von Terror nicht in allen Fällen das primäre Ziel von Selbstmordattentaten darstellt - etwa, wenn diese gezielt gegen Militärstützpunkte eingesetzt werden - so lassen sich Selbstmordanschläge auf Orte des zivilgesellschaftlichen Lebens in diesem Sinne als Akte des Terrors bezeichnen, unabhängig davon, ob sie von staatlichen oder nicht-staatlichen Akteuren ausgeführt werden.

Im Unterschied zur Kategorie des Terrors ist der Terrorismus-Begriff aber noch aus einem weiteren Grund problematisch. Auch wenn mit der Betitelung eines Attentats als >terroristisch für gewöhnlich eine klare Außenperspektive verbunden ist, wurde der Terminus in jüngster Zeit von al-Qaida- und ISSympathisierenden teilweise wieder angeeignet und für Propagandazwecke umgedeutet. ${ }^{64}$ In seiner Analyse dschihadistischer Internetforen verweist Nico Prucha etwa auf eine Fotomontage aus Bildern von zerstörten Häusern und Schockbildern

62 Vgl. Brunner: Wissensobjekt Selbstmordattentat, S. 93.

63 Klonk: Terror: Wenn Bilder zu Waffen werden, S. 16ff.

64 Eine ähnliche Aneignung des Begriffs lässt sich schon bei den Anarchist*innen des 19. Jahrhundert beobachten, die sich ebenfalls selbst als »Terrorist*innen« ausgaben. Hoffman: Terrorismus. Der unerklärte Krieg, S. 51. 
getöteter Kinder, die ein User in dem Forum Shumukh al-Islam postete, um auf die angeblichen Schreckenstaten des US-amerikanischen Feindes hinzuweisen. ${ }^{65}$ Das letzte Bild zeigt einen schwarz maskierten und bewaffneten Kämpfer mit der dazugehörigen arabischen Bildunterschrift »der Terrorist; ich bin Muslim; ich bin mit ihm«. Prucha zufolge habe dieser Slogan in den letzten Jahren zunehmend an Popularität gewonnen und werde verstärkt in pro-dschihadistischen Internetforen verbreitet: »It [the slogan] runs along the lines that if terrorism is the term applied by the enemies then I am a terrorist, fighting for justice and against injustice, tyranny and oppression. $\ll^{66}$ Dass Unterstützer*innen von al-Qaida und IS die verurteilende Fremdbezeichnung 〉Terrorist $\prec$ heute für sich selbst beanspruchen und mit neuen Bedeutungen versehen, verkompliziert die ohnehin schon aufgeladene Debatte um den Diskurs des Terrorismus und liefert einen weiteren Grund, den Begriff zu vermeiden.

Abgesehen von dieser begrifflichen Aneignung unterscheiden sich die Selbstbezeichnungen, die die verantwortlichen Milizen für ihre Suizidattentate wählen, teils grundlegend voneinander. Während die säkularen palästinensischen Widerstandsgruppen ihre frühen Einsätze ab 1974 als `Selbstmordkommandos` (arab. mağmū'a intiharīya) bezeichneten (Kapitel 2.2), wurde diese Bezeichnung aus der Perspektive islamischer Akteure später energisch zurückgewiesen (Kapitel 2.4). Grund ist das strikte islamische Selbstmordverbot, wie es in mehreren Koranversen und den Prophetenberichten formuliert wird. ${ }^{67}$ Stattdessen hat sich immer mehr die Bezeichnung der >Märtyrertod-Operationen ২ (arab. 'amalīya istišhādīya) durchgesetzt - ein Begriff, der vor allem von der libanesischen Hisbollah geprägt wurde. ${ }^{68}$ Der arabische Begriff des Schahid ( $(\check{s} a h \bar{\imath} d)$, bzw. der Schahida ( $\left.\check{s} a h \bar{\imath} d a\right)$ (Pl. Schuhada/Schahidat, šuhāda/šahìdāt) tauchte als Bezeichnung für Selbstmordattentäter*innen bereits unter säkularen Organisationen auf, die das Konzept des Martyriums allerdings nicht religiös konnotierten und häufig mit dem Kampf im Namen eines nationalen Widerstandes gleichsetzten (auf die verschiedenen Konzeptionen des Martyriums werde ich in Kapitel 2 ausführlicher zu sprechen kommen). Natürlich wird auch der Begriff des Martyriums (istiš $\bar{a} d$ ) normativ

65 Nico Prucha: »Worldwide Online Jihad versus the Gaming Industry Reloaded - Ventures of the Web«, in: Rüdiger Lohlker (Hg.): New Approaches to the Analysis of Jihadism: Online and Offline, Göttingen: V\&R Unipress 2012, S. 153-182, hier S. 159.

66 Ebd., S. 159, Anm. 21.

$67 \mathrm{Zu}$ den textlichen Überlieferungen des Suizidverbots im Islam siehe Christoph Günther: »Corpus delicti - der Körper als Tatwerkzeug. Märtyreroperationen im irakischen Kontext«, Arbeitstitel. Forum für Leipziger Promovierende 3, Heft 1 (2011), S. 21-33.

68 Croitoru: Der Märtyrer als Waffe, S. 152. 
verwendet und dient als Argumentationsfigur, um die für Selbstmordanschläge Verantwortlichen zu glorifizieren und deren Taten zu legitimieren. Vermehrt findet der Begriff aber auch Eingang in die Forschungsliteratur, ablesbar etwa an Titeln wie Der Märtyrer als Waffe (Croitoru) oder The Globalization of Martyrdom (Pedahzur). ${ }^{6}$ Der Politikwissenschaftler Mohammed Hafez steht dieser Übernahme der Akteursbezeichnung im wissenschaftlichen Kontext kritisch gegenüber. Ihm zufolge sind istišhād und $\breve{s} a h \bar{i} d »$ highly charged, normative terms that do not aid in the effort to analyze and explain this deadly phenomenon ${ }^{70}{ }^{0}$. Um darauf zu verweisen, dass auch mit dem Begriff des \Selbstmordattentäters $<$ bzw. der >Selbstmordattentäterin scheint es mir dennoch notwendig, auf die Selbstbezeichnungen Bezug zu nehmen: nicht als Erklärungsmuster oder analytische Kategorie, sondern als wichtiger Verweis auf die Perspektive der Akteur*innen. Ausschließlich in diesem Sinne werden die Begriffe in der vorliegenden Arbeit verwendet. Wenn im Folgenden beide Bezeichnungen, Selbstmordattentat und Martyrium, nebeneinander auftauchen, dann gerade um auf die heterogene Wahrnehmung und perspektivabhängige Bewertung aufmerksam zu machen.

Die deutsche Übersetzung des arabischen >Schahid/Schahidaく als >Märtyrer/Märtyrerin` (bzw. die englische Übersetzung als `martyr $`$ ) ist jedoch nicht ganz unproblematisch, zumal dies in weiten Teilen der Forschungsliteratur meist ohne Verweis auf die unterschiedlichen Konzeptionen des Martyriums muslimischer und christlicher Prägung erfolgt. Auch wenn sowohl das griechische martyr als auch das arabische $\check{s} a h \bar{l} d$ etymologisch auf >Zeugenschaft rekurrieren, sind die damit verbundenen Konzepte grundlegend verschieden. ${ }^{71}$ Im Gegensatz zu christlichen Märtyrer*innen kann ein Schahid oder eine Schahida im arabisch-islamischen Kontext etwa auch einen unbeabsichtigten Tod sterben. ${ }^{72}$ Dies wird gerade im palästinensischen Kontext deutlich, wenn auch Menschen als Schuhada oder Schahidat bezeichnet werden, die aufgrund von (Umwelt-)Katastrophen oder Unfällen ums Leben kamen. Dass diese Formen des Martyriums nichts mit einer freiwilligen Selbstopferung im Sinne des christlichen Märtyrertods zu tun haben, liegt auf der Hand. Aber auch die arabische Verwendung des Schahid-Begriffs ist keineswegs eindeutig oder allein im Rekurs auf religiöse Schriften zu beantworten. Vor allem in Bezug auf die säkulare Verwendung des Begriffs im palästinensi-

69 Croitoru: Der Märtyrer als Waffe; Pedahzur: Root Causes of Suicide Terrorism.

70 Vgl. die E-Mail von Mohammed Hafez an Assaf Moghadam vom 17. Mai 2005, zitiert in Moghadam: »Defining Suicide Terrorism«, S. 16.

71 Vgl. dazu insbesondere Asad: On Suicide Bombing, S. 51 f.

72 Vgl. ebd., S. 51. 
schen Kontext der 1970er Jahre zeigt sich die Vielschichtigkeit des arabischen Märtyrer-Begriffs (siehe dazu ausführlich Kapitel 2.2). Die folgenden Kapitel bemühen sich daher um eine möglichst differenzierte Begriffsbestimmung, die das Konzept des Schahid bzw. der Schahida im jeweiligen ideologischen und politischen Zusammenhang verortet.

\subsection{VON DEN ASSASSINEN ZUM ISLAMISCHEN STAAT? KONTUREN EINER GESCHICHTE DES SELBSTMORDATTENTATS}

Die überwiegende Mehrheit der Studien zum Thema beschäftigt sich mit den aktuellen Wellen dschihadistischer Selbstmordattentate und tendiert dazu, das Selbstmordattentat in islamischen Traditionen und einer islamischen »Kultur des Martyriums $~^{73}$ zu verankern. Eine ganze Reihe an Standardwerken zum Selbstmordattentat führt die Feldzüge der schiitisch-muslimischen Assassinen (10901275) als historische >Vorläufer $<$ heutiger Selbstmordattentate an ${ }^{74}$ Claudia Brunner hat zu Recht auf die Problematik dieser historischen Referenz hingewiesen, die im wissenschaftlichen Diskurs seit den Ereignissen vom 11. September 2001 eine »bemerkenswerte Renaissance« erfahren hat. ${ }^{75}$ Der Vergleich mit aktuellen Suizidanschlägen hinkt schon allein deswegen, weil die Selbsttötungen der Assassinen weder hinreichende noch notwendige Voraussetzung für die Anschläge waren und somit inkompatibel mit den geläufigsten engen Definitionen des Selbstmordattentats (vgl. S. 24) erscheinen. Den wiederholten Verweis auf die schiitischen Assassinen entlarvt Brunner als Modus einer »okzidentalistischen

73 Von einer »Kultur des Martyriums«, die ausschließlich in islamischen Gesellschaften begründet liege, spricht etwa Mohammed Hafez: »Dying to Be Martyrs: The Symbolic Dimension of Suicide Terrorism«, in: Pedahzur, Root Causes of Suicide Terrorism, S. 54-80, hier S. 72.

74 Vgl. Bloom: Dying to Kill, S. 5-7 und Pape: Dying to Win, S. 11-13. Die Assassinen waren eine schiitisch-muslimische Gruppe, die eine radikale Version des Islam verkündete und ihre Missionierung durch selektive Attentate auf sunnitische Machthaber durchsetzen wollte. Viele Ermordungen schlossen den Tod des Attentäters mit ein, der mit hoher Sicherheit festgenommen und hingerichtet wurde. Vgl. dazu Mario Ferrero: »Martyrdom Contracts«, Journal of Conflict Resolution 50/6 (2006), S. 855-877, hier S. 871.

75 Brunner: Wissensobjekt Selbstmordattentat, S. 288. 
Selbstvergewisserung ${ }^{76}$. Vor der Folie der mittelalterlichen Assassinen erscheint das heutige Selbstmordattentat seinem Wesen nach als >islamisches` Phänomen und wird durch den knapp tausend Jahre zurückreichenden Vergleich als das geradezu ahistorische >Andere $<$ markiert. Nach Ansicht Brunners ist diese Abgrenzungsbestrebung der eigentliche Grund, warum die Assassinen »als das >role model « für gegenwärtige und vor allem für befürchtete zukünftige SelbstmordattenäterInnen ${ }^{77}$ herangezogen werden. Verweise auf säkulare und nicht-arabische Beispiele von Selbstmordattentaten treten - wenn überhaupt - nur am Rande und als Abweichungen dieser Modellbeispiele auf. Als Ausnahmen können die Studien von Mario Ferrero und Diego Gambetta gelten, die in den Bombenanschlägen der russischen Anarchist*innen um 1900 die ersten >suicide bombings` im engeren Sinne sehen. ${ }^{78}$ Auch Lorenz Graitl datiert das erste Suizid-Sprengstoffattentat auf das Jahr 1881, als sich ein Attentäter der russischen Gruppe Narodnaya Volya bei einem Anschlag auf Zar Alexander II durch eine Bombe selbst tötete. ${ }^{79}$ Obwohl die russischen Anarchist*innen nicht aus religiösen Motiven heraus handelte, sondern für soziale Gerechtigkeit im Diesseits kämpften, wurden auch sie als Märtyrer*innen glorifiziert. Wie Ferrero beschrieben hat, entwickelte sich um ihre Namen und Taten ein regelrechter Märtyrerkult, der vor allem durch Publikationen der anarchistischen Presse verbreitet wurde, und sich schon damals als effektive Propagandastrategie etablierte. ${ }^{80}$

Wie diese frühen Beispiele zeigen, traten Selbstmordattentate selbst in ihrer engen Definition als >suicide bombings $<$ bereits Ende des 19. Jahrhunderts auf. Im Unterschied zu diesen vereinzelten, häufig spontan durchgeführten Anschlägen, wurde mit den japanischen Kamikaze-Aktionen der Jahre 1944-45 das Selbstmordattentat jedoch erstmals zu einer systematischen Kriegsstrategie erhoben. Joseph Croitoru zeigt in seiner Studie Der Märtyrer als Waffe ebenfalls eine historische Kontinuität auf, die eine säkulare Tradition des Selbstmordattentats unterstreicht. Bei seiner Suche nach den »historischen Wurzeln des Selbstmordattentats $\ll^{81}$ (so der Untertitel seiner Studie) spannt Croitoru einen Bogen von den Kamikaze-Einsätzen der Japaner während des Zweiten Weltkriegs bis hin zu den

76 Brunner: Wissensobjekt Selbstmordattentat, S. 288.

77 Ebd., S. 289.

78 Vgl. Ferrero: »Martyrdom Contracts«, S. 865; Diego Gambetta: »Can We Make Sense of Suicide Missions?«, in: Ders. (Hg.): Making Sense of Suicide Missions, Oxford: Oxford University Press 2005, S. 259-300, hier S. 285.

79 Graitl: Sterben als Spektakel, S. 82.

80 Ferrero: »Martyrdom Contracts«, S. 866.

81 Croitoru: Der Märtyrer als Waffe. 
Anschlägen vom 11. September 2001 und führt damit erneut die Bandbreite unterschiedlichster Selbstmordeinsätze vor Augen, die nicht zuletzt auch in Europa Geschichte machten. Ein ganzes Kapitel widmet er den sogenannten »Totaleinsatzmännern« oder »Selbstopfermännern « Hitlers, die in den letzten Monaten des Zweiten Weltkriegs aktiv wurden und nach dem japanischen Vorbild Todeseinsätze flogen ${ }^{82}$ Obwohl die japanischen Kamikaze in fast allen Forschungen zum Selbstmordattentat als Vorläufer Erwähnung finden, zieht Croitoru erstmals eine direkte historische Verbindungslinie zwischen der Kamikazetradition Japans und den ersten Selbstmordeinsätzen ab 1972 im Nahen Osten. ${ }^{83}$

Indem Croitoru diese säkulare Vorgeschichte des nahöstlichen Selbstmordattentats betont, wendet er sich gegen eine selektive Historisierung, die das moderne Selbstmordattentat ausschließlich in einer islamischen Tradition begründet. Denn abgesehen vom historischen Vergleich mit den Assassinen wird als Ursprungserzählung des modernen Selbstmordattentats häufig die Märtyrerkampagne Ayatollah Khomeinis während des Iran-Irak Kriegs ab 1980 an den Anfang gestellt, die als Inspirationsquelle für die kurze Zeit später stattfindenden Autobombenanschläge der schiitischen Hisbollah gilt. Die militärische Instrumentalisierung des schiitischen Märtyrerdiskurses für Selbstopfer-Aktionen erscheint so als die Erklärung schlechthin für den weitreichenden `Erfolg` des Selbstmordattentats im Nahen Osten. ${ }^{84}$ Dass die Anschläge im Libanon ab 1982 jedoch nicht nur von iranischen Vorbildern, sondern auch von säkularen palästinensischen Selbstmordoperationen der 1970er Jahre inspiriert waren - wie die historische Untersuchung von Joseph Croitoru überzeugend darlegt -, bleibt hier wie in vielen anderen Studien unerwähnt. ${ }^{85}$

Ungeachtet dieser Vorgeschichte wird die Hisbollah häufig als einer der zentralen $»$ Knotenpunkte $\aleph^{86}$ beschrieben, durch die sich die Taktik des Selbstmordattentats weltweit verbreitete. Mia Bloom spricht in diesem Zusammenhang von

82 Croitoru: Der Märtyrer als Waffe, S. 55-70.

83 Wie Croitoru zeigt, gelangte die Taktik des Selbstmordanschlags vermittelt über Nordkorea und die Japanische Rote Armee bereits in den frühen 1970er Jahren in den Nahen Osten. Ebd., S. 72-77.

84 Eine solch einseitige Argumentation findet sich beispielsweise in Assaf Moghadam: The Globalization of Martyrdom, S. 17.

$85 \mathrm{Zu}$ den Verbindungen zwischen palästinensischen Widerstandsgruppen und libanesischen Schiiten siehe Croitoru: Der Märtyrer als Waffe, S. $123 f$.

86 Horowitz: The Diffusion of Military Power, S. 194. Eine ähnliche Argumentation findet sich auch bei Bloom: Dying to Kill, S. 120ff und Pedahzur: Suicide Terrorism, Cambridge: Polity Press 2005. 
überregionalen, teils multilinearen $»$ Ansteckungseffekten ${ }^{87}$, die dazu geführt haben, dass die Taktik des Selbstmordattentats in unterschiedlichen regionalen Kontexten für politische Zwecke genutzt wurde. Ab Ende der 1980er Jahre wurden Suizidanschläge von so diversen Akteuren wie den Liberation Tigers of Tamil Eelam (LTTE) in Sri Lanka, der kurdischen Arbeiterpartei PKK in der Türkei, oder der tschetschenischen Separatistenbewegung verübt. Dass auch diese Gruppen in internationale Netzwerke verstrickt sind und Kontakte in den Nahen Osten unterhalten, haben mehrere Forschungsarbeiten ausführlich dargestellt. ${ }^{88}$

Als eigentliche »Globalisierung des Selbstmordattentats « ${ }^{89}$ wird jedoch häufig eine Entwicklung beschrieben, die ab Ende der 1990er Jahre einsetzte und einen Wandel von lokalpolitischem Konflikt zu globalem Dschihad markiert. Der Beginn dieser neuen Phase wird insbesondere mit den Selbstmordattentaten der radikal-sunnitischen al-Qaida in Verbindung gebracht, die ab 1998 weltweit Selbstmordattentate, vor allem gegen US-amerikanische Einrichtungen verübte. Waren die bisherigen Anschläge meist auf die `Befreiung` eines bestimmten Territoriums ausgerichtet und verliefen entlang nationaler oder ethnischer Grenzen, war mit den Selbstmordattentaten der al-Qaida erstmals ein überregionaler >heiliger Krieg`gegen >den Westen $<$ verbunden. Der arabische Name al-Qaida bedeutet übersetzt >die Basis $`$ und weist damit bereits auf die Struktur dieser Organisation hin: Unter dem Banner al-Qaida und der zentralen Figur Bin Ladens sind eine Vielzahl lokaler Gruppierungen aus über 45 Ländern vereint, darunter Pakistan, Irak, Türkei, Saudi-Arabien, Marokko und Indonesien sowie weitere Länder des Nahen Ostens, Asiens und Europas. ${ }^{90}$ Sie verbindet eine gemeinsame dschihadistische Rhetorik gegen >die Ungläubigen`, wenngleich sich die Gründe für Selbstmordattentate unter den affiliierten Gruppen im Einzelnen durchaus unterscheiden. ${ }^{91}$ Gabriel Weimann spricht in diesem Zusammenhang auch von einem »neuen«, »postmodernen Terrorismus $«{ }^{92}$, der sich vor allem durch dezentrale Organisationsstrukturen auszeichne - und gerade dadurch weitaus gefährlicher und schwerer zu kontrollieren sei. Weimann war auch einer der Ersten, der betonte, dass diese Entwicklung aufs

87 Bloom: Dying to Kill, Kapitel 6 »Terror 101: The Transnational Contagion Effects of Suicide Bombing«, S. 120-141.

88 Vgl. Croitoru: Der Märtyrer als Waffe; Bloom: Dying to Kill; Pedahzur: Suicide Terrorism; Horowitz: The Diffusion of Military Power.

89 Moghadam: The Globalization of Martyrdom, S. 38.

90 Pedahzur: Suicide Terrorism, S. 97.

91 Vgl. ebd., S. 98.

92 Gabriel Weimann: Terror on the Internet: The New Arena, the New Challenges, Washington, D.C: United States Institute of Peace Press 2006, S. 5. 
Engste mit den veränderten Kommunikationstechnologien des Internetzeitalters verbunden war, die neue Möglichkeiten der Vernetzung und des überregionalen Austauschs boten.

Trotz der häufig konstatierten `Neuartigkeit` des global verstandenen Dschihads folgten auch die Selbstmordattentate der al-Qaida dem Vorbild der palästinensischen und libanesischen Gruppen. ${ }^{93}$ Als erste Selbstmordattentate der alQaida gelten die Autobombenanschläge auf die US-amerikanischen Botschaften in Kenia und Tansania am 7. August 1998, deren Durchführung unmissverständlich an den Hisbollah-Attentaten der 1980er Jahre orientiert war. ${ }^{94} \mathrm{Ab}$ den späten 1990er Jahren richtete die al-Qaida schließlich selbst mehrere Trainingslager in Afghanistan ein, in denen bis zum Jahr 2001 rund 20.000 Menschen aus 47 Ländern eine militärische Ausbildung und dschihadistische Indoktrinierung durchliefen. ${ }^{95}$ Für die Globalisierung des Selbstmordattentats waren diese Camps von zentraler Bedeutung. Neben der Hisbollah wurde die al-Qaida daher als zweiter wichtiger »Knotenpunkt « ${ }^{96}$ in der Verbreitung dieser Taktik beschrieben.

Mit den Anschlägen in New York und Washington am 11. September 2001 schien schließlich eine neue Ära des globalen Terrors zu beginnen. Sowohl die Größenordnung der Selbstmordattentate als auch die mediale Verbreitung des Ereignisses, dessen Bilder live um die ganze Welt gingen, waren beispiellos. Es war das erste Mal, dass die westliche Welt von einem Anschlag dieser Tragweite auf eigenem Boden, noch dazu mitten im Herzen einer Großstadt, getroffen wurde. Für zahlreiche westliche Politiker*innen und Kommentator*innen, die die Ereignisse unmittelbar verfolgten, stand fest, dass diese die Welt für immer verändert hatten. ${ }^{97}$ Auch in der Forschung zum Terrorismus werden die Selbstmordattentate auf das World Trade Center in New York als entscheidende Zäsur wahrgenommen. Als Antwort auf die vielfach gestellte, fassungslose Frage, wie amerikanische Regierung und Geheimdienste die Planung der Anschläge nicht bemerken, geschweige denn verhindern konnten, betonte das FBI in seinen Berichten immer

93 Vgl. Pedahzur: Suicide Terrorism, S. 100; Croitoru: Der Märtyrer als Waffe, S. 215.

94 Vgl. ebd., S. 200; Pedahzur: Suicide Terrorism, S. 100.

95 Vgl. Bloom: Dying to Kill, S. 138.

96 Horowitz: The Diffusion of Military Power, S. 194; vgl. Bloom: Dying to Kill, S. 138.

97 Vgl. etwa die Stellungnahme des damaligen deutschen Bundespräsidenten Johannes Rau, der am Abend der Anschläge verkündete: »Dieser Tag hat die Welt verändert. Ein schreckliches Ereignis, dessen Ausmaß wir noch nicht kennen.«Zitiert in Sophie Koch und Sven Felix Kellerhoff: »11. September 2001: Das Protokoll des Tages, der die Welt veränderte«, Die Welt, 09.09.2011, https://www.welt.de/kultur/history/article135896 16/Das-Protokoll-des-Tages-der-die-Welt-veraenderte.html (zugegriffen am 6.6.2021). 
wieder die Schlüsselrolle, die das Internet für die Terroristen spielte, welches die überregionale Koordination und erfolgreiche Durchführung der Attentate erst möglich gemacht hatte. ${ }^{98}$ Die Anschläge des 11. September 2001 führten der Weltöffentlichkeit damit auch vor Augen, dass militante Akteure das nur schwer zu kontrollierende Internet zu ihren Gunsten zu nutzen wussten. ${ }^{99}$ Die veränderten Kommunikations- und Informationsstrukturen hatten jedoch nicht nur einen Einfluss auf die Art und Weise, wie ein dezentrales Terrornetzwerk weltweit Anschläge plante und Informationen koordinierte. Das Internet veränderte auch die Möglichkeiten der Propaganda und Rekrutierung, die sich nicht mehr nur auf eine bestimmte Region beschränkten, sondern auf eine weltweite Mobilisierung abzielten. Besonders der Islamische Staat, dem sich die jüngsten Publikationen zum Thema widmen, bediente sich verstärkt dieser Mittel. ${ }^{100}$ Die weltweite digitale Vernetzung hat dazu geführt, dass sich transnationale »Ansteckungseffekte ${ }^{101}$ in der Verbreitung des Selbstmordattentats heute umso mehr bemerkbar machen: Suizidanschläge wurden in den vergangenen Jahren nicht nur von Rekruten aus Ländern der MENA-Region, sondern zunehmend auch von Europäern verübt, die dem Aufruf des Islamischen Staats folgten. ${ }^{102}$ Abgesehen von den Anschlägen des IS, der wie die al-Qaida über weltweit verstreute Ableger verfügt und bis heute in dutzenden Ländern von Westafrika bis Südostasien aktiv ist, wurden Selbstmordattentate zuletzt aber auch von der afghanischen und pakistanischen Taliban, sowie von afrikanischen Gruppen wie Boko Haram in Nigeria oder al-Shabaab in Somalia durchgeführt. ${ }^{103}$

98 Vgl. Weimann: Terror on the Internet, S. 3f.

99 Vgl. Ebd., S. 4.

100 Vgl. Abdel Bari Atwan: Islamic State: The Digital Caliphate, Berkeley: University of California Press 2015. Charlie Winter: Documenting the Virtual \Caliphate`, Quilliam Foundation 2015, http:/www.quilliaminternational.com/wp-content/uploads/2015/ 10/FINAL-documenting-the-virtual-caliphate.pdf (zugegriffen am 6.6.2021).

101 Bloom, Dying to Kill, Kapitel 6, S. 120-141.

102 Nach Tunesien, Saudi-Arabien und Jordanien stellen Europäer die größte Gruppe der Rekruten dar, die sich zwischen 2011 und 2014 dem Islamischen Staat anschlossen. Raniah Salloum: »Rekruten für den 〉Islamischen Staat «: Die Weltkarte des Terrors«, Spiegel Online, 28.11.2014, http://www.spiegel.de/politik/ausland/is-islamischerstaat-zehntausende-auslaendische-kaempfer-machen-mit-a-1001193.html (zugegriffen am 6.6.2021).

103 Vgl. die statistische Übersicht aller Selbstmordattentate bis 2019 in Chicago Project on Security and Terrorism (CPOST): Suicide Attack Database. 
Angesichts der zeitlichen Kontinuität und der globalen Verbreitung von Selbstmordattentaten stellt sich schließlich die Frage nach der historischen und geografischen Eingrenzung der vorliegenden Arbeit. Obwohl Selbstmordattentate keineswegs ein >nahöstliches` Phänomen darstellen, fällt auf, dass die (audio-) visuelle Inszenierung als Märtyrer/Märtyrerin überwiegend dort ihren Ausgang nimmt. Auch wenn vermutet werden kann, dass einzelne fotografische Abschiedsaufnahmen der japanischen Kamikaze als Vorbild für die Aufnahmen palästinensischer 〉Selbstmordkommandos $<$ dienten (Kapitel 2.2), hat sich die Gestaltung von Märtyrerpostern erst mit den palästinensischen Selbstmordeinsätzen der frühen 1970er Jahre als Praxis etabliert. Die Aufnahme von Videotestamenten findet ihren Ursprung primär unter libanesischen und palästinensischen Gruppen, bevor sie sich durch global agierende Akteure wie al-Qaida oder IS weltweit verbreiteten. Im Vergleich sind von den Selbstmordattentäter*innen der Liberation Tigers of Tamil Eelam (LTTE) oder der PKK weitaus weniger Darstellungen bekannt. Wenngleich einzelne Fotografien tschetschenischer Selbstmordattentäter*innen nach palästinensischem Vorbild im Internet kursieren, entwickelte sich auch hier kein vergleichbarer visueller Kult um deren Martyrium. »In Grozny«, so bemerkt Mia Bloom, «there are neither posters nor graffiti celebrating the martyrs ${ }^{104}$. Wenn der geografische Fokus dieser Arbeit zunächst also schwerpunktmäßig auf den Ländern des Nahen Ostens (insbesondere auf Palästina und dem Libanon) liegt, dann um den historischen Vorbildern dieses Bildtypus nachzuspüren - nicht, um das Phänomen Selbstmordattentat auf diesen Raum einzugrenzen oder eine spezifische palästinensische, libanesische oder arabische Bildkultur des Martyriums zu identifizieren, die einer swestlichen Kultur ' gegenüberstünde. Ganz im Gegenteil geht es darum, die Poster und Videotestamente als transkulturelle Objekte in den Blick zu nehmen; so etwa die frühesten Beispiele palästinensischer Märtyrerposter, die im Dialog mit Diskursen und Ästhetiken anderer Befreiungsbewegungen weltweit entstanden (Kapitel 2.3).

Spätestens mit der Verbreitung des Selbstmordattentats durch dschihadistische Netzwerke scheint eine geografische Eingrenzung obsolet geworden zu sein. Nicht nur die Rezeption, auch die (Post-)Produktion der Märtyrerbilder verteilt sich zunehmend auf eine Vielzahl von Orten und medialen Kontexten. So werden die Videotestamente der al-Qaida und des Islamischen Staat heute nicht nur in Afghanistan, Irak oder Syrien, sondern auch in London oder Paris aufgenommen, in weltweit verstreuten Medienbüros nachbearbeitet und anschließend über 
Onlineforen, Twitter, Facebook oder YouTube verbreitet. ${ }^{105}$ Mit der digitalen Zirkulation der Bilder im Internet, die immer wieder neue Formen der Aneignung und Kontextualisierung ermöglicht, ${ }^{106}$ wird deutlich, dass Märtyrerzeugnisse als Teil einer globalen visuellen Ökonomie zu verstehen sind (Kapitel 3.3, Kapitel 4). ${ }^{107}$ So knüpfen die Videos an globale popkulturelle Phänomene an, indem sie etwa auf die Ästhetik von Computerspielen rekurrieren und diese mit islamischen Vorstellungen von Martyrium verbinden (Kapitel 4.3). Um kulturelle Essenzialisierungen zu vermeiden, wird im Folgenden daher nicht von einer (scheinbar feststehenden) >Bildkultur des Martyriums $<$ die Rede sein, sondern von diversen Bildphänomenen, die sich im Austausch miteinander entwickeln und sich einer kulturellen, religiösen oder geografischen Festschreibung widersetzen.

105 Vgl. Brendan I. Koerner: »Why ISIS Is Winning the Social Media War«, WIRED (2016), https://www.wired.com/2016/03/isis-winning-social-media-war-heres-beat/ (zugegriffen am 6.6.2021).

$106 \mathrm{Zu}$ den Remediationen der Bilder vom 11. September 2001 in Afrika siehe etwa Heike Behrend und Tobias Wendl (Hg.): 9/11 and its Remediations in Popular Culture and Arts in Africa, Berlin: LIT Verlag 2015.

107 Der Begriff der »visuellen Ökonomie« hat im Vergleich zur »visuellen Kultur« den Vorteil, Bilder als Teil eines globalen, transkulturellen Systems der Vernetzung zu markieren. Er wurde 1997 von der Anthropologin Deborah Poole eingeführt: Deborah Poole: Vision, Race, and Modernity: A Visual Economy of the Andean Image World, Princeton: Princeton University Press 1997. 



\section{Märtyrerposter als sekundäre Zeugnisse}

Bis heute stellen Poster die wichtigste Form der Sichtbarkeit von Märtyrer*innen in Palästina dar. ${ }^{1}$ Insbesondere in den Jahren der zweiten Intifada (2000-2005), als sich der gewaltvolle Konflikt zwischen Israel und Palästina einmal mehr zuspitzte, wurden beinahe täglich neue Poster mit Portraits verstorbener Palästinenser*innen publiziert und an Häuserwände, in Cafés oder Läden geklebt. In Städten wie Ramallah und Nablus verwandelten sich öffentliche Mauern in dicht plakatierte Ausstellungsflächen, auf denen die Verstorbenen in eine scheinbar unendlich fortsetzbare Märtyrer-Galerie eintraten. Auch wenn die Präsenz von Märtyrerpostern während der zweiten Intifada zweifelsohne ihren Höhepunkt erfuhr, scheint diese Galerie mit jeder neu aufflammenden Auseinandersetzung zwischen den Palästinenser*innen und dem israelischen Militär, mit jeder Person, die im Westjordanland oder im Gazastreifen ums Leben kommt, weiter anzuwachsen. ${ }^{2}$ So schnell die Poster auch verblassen, von Wind und Wetter beansprucht, zerrissen oder von Werbeplakaten überklebt werden, so schnell ersetzen die Portraits neuer Märtyrer*innen die Bilder der alten und verwandeln viele palästinensischen Flüchtlingslager und Städte in eine nicht enden wollende Kundgebung des Todes.

An den palästinensischen Märtyrerpostern lässt sich zuallererst die Komplexität des Märtyrerbegriffs ablesen, der heute als Sammelbecken für Opfer- und Täterbilder, für säkularen politischen Widerstand und religiösen Dschihad gleichermaßen dient. Gerade weil es im Folgenden ausschließlich um die Märtyrerbilder von Selbstmordattentäter*innen gehen soll, erscheint es hier umso notwendiger,

1 Dies betont unter anderem der palästinensische Kulturwissenschaftler Mahmoud Abu Hashhash: »On the Visual Representation of Martyrdom in Palestine«, Third Text 20/34 (2006), S. 391-403, hier S. 391.

2 Ein Besuch des Westjordanlands im November 2016 zeigte, dass Märtyrerposter insbesondere in Flüchtlingslagern wie dem konfliktbeladenen Camp in Jenin, aber auch in Städten wie Ramallah nach wie vor zum Stadtbild gehören. 
die Polyvalenz des gegenwärtigen Märtyrerdiskurses im Nahen Osten zu betonen. ${ }^{3}$ Als Schahid bzw. Schahida werden in Palästina alle Menschen bezeichnet, die als Resultat des israelisch-palästinensischen Konflikts ums Leben kommen: von unbeteiligten Zivilpersonen, die unter den Trümmern israelischer Bombenangriffe sterben, über getötete Widerstandskämpfer*innen, bis hin zu Menschen, die ihre Körper gezielt als Bomben gegen Israel einsetzen. Aus palästinensischer Sicht umfasst die Figur des Schahid also all jene, die durch ihren Tod (freiwillig oder nicht) ihren Widerstand gegen die Unterdrückung bezeugen. ${ }^{4}$ Dementsprechend vielschichtig erscheint auch die soziale und politische Bedeutung der Märtyrerverehrung, so hat die Anthropologin Lori A. Allen festgestellt. ${ }^{5}$ Für den Großteil der palästinensischen Gesellschaft ist die Verehrung von Märtyrer*innen mit persönlichen, emotionalen und teilweise religiösen Werten verbunden. Zeremonielle Märtyrerbegräbnisse oder die Veröffentlichung von Märtyrerpostern stellen für die Angehörigen eine Möglichkeit dar, den Verlust eines geliebten Menschenlebens zu beklagen und dem allgegenwärtigen Tod einen Sinn zu verleihen. ${ }^{6}$ Gleichzeitig wird das Martyrium der Gestorbenen aber auch von unterschiedlichen politischen Akteur*innen für ihre jeweilige Agenda vereinnahmt und zu Rekrutierungszwecken instrumentalisiert. Dass die Figur des Schahid bzw. der Schahida mitunter auch als »Waffe« zum Einsatz kommt, wurde in der Forschung zum Selbstmordattentat wiederholt betont. ${ }^{7}$

Diese grundlegende Offenheit des Märtyrerbegriffs führt teilweise auch zu Schwierigkeiten in der Abgrenzung des Bildkorpus, um den es im Folgenden gehen soll. Mit Blick auf palästinensische Kämpfer bemerkt Yoram Schweitzer beispielweise, dass diese vor militärischen Konfrontationen teils ähnliche Vorbereitungen treffen wie sie bei Selbstmordattentaten geläufig sind. ${ }^{8}$ So werden auch von ersteren Fotografien und Videos aufgenommen, die im Fall ihres Todes verbreitet werden und als Vorlage für Märtyrerposter dienen. Es könnte daher

3 Lori A. Allen: »The Polyvalent Politics of Martyr Commemorations in the Palestinian Intifada «, History and Memory 18 (2006), S. 107-138.

4 Didier Fassin: »The Humanitarian Politics of Testimony: Subjectification through Trauma in the Israeli-Palestinian Conflict«, Cultural Anthropology 3 (2008), S. 531558, hier S. 541.

5 Allen: »Polyvalent Politics«. Zur sozialen Bedeutung von Märtyrerritualen vgl. auch Abu Hashhash: »On the Visual Representation of Martyrdom in Palestine«.

6 Vgl. ebd., S. 391.

7 Vgl. Croitoru: Der Märtyrer als Waffe.

8 Email-Kommunikation zwischen Yoram Schweitzer und Assaf Moghadam, 29. Mai 2005, zitiert in Moghadam: »Defining Suicide Terrorism«, S. 17. 
argumentiert werden, dass die Poster, die nach Selbstmordattentaten im Umlauf kommen, lediglich einen Teil des allgemeinen palästinensischen Märtyrerkults darstellen und folglich mit anderen Märtyrerpostern auf eine Stufe zu stellen sind. Doch auch wenn sich deren Gestaltung häufig kaum von den Postern gefallener Kämpfer*innen oder getöteter Zivilopfer unterscheidet, so geht die vorliegende Arbeit von der Hypothese aus, dass die damit verbundenen Bildpolitiken und operativen Zusammenhänge grundlegend andere sind. Gerade in der Gleichzeitigkeit von Selbstopfer und Täterschaft liegt der besondere Status dieser speziellen Märtyrerposter begründet, die eine Differenzierung innerhalb dieses Bildtypus notwendig erscheinen lassen.

\subsection{DAS MÄRTYRERPOSTER ZWISCHEN BEZEUGEN UND ERZEUGEN}

Dass Martyrien auf ihre mediale Sichtbarmachung angewiesen sind, wurde in der Forschung zur Zeugenschaft mehrfach betont. ${ }^{9}$ Ebenso wie das griechische Wort martys kann auch der arabische Begriff $\check{s} a h \bar{\imath} d$ auf die Bedeutung >Zeuge< zurückgeführt werden. Der Begriff ist abgeleitet vom arabischen $\hat{s} a h \bar{a} d \bar{a}$, was sowohl >sehen und >bezeugen`, als auch >ein Vorbild werden` bedeuten kann. ${ }^{10}$ Trotz der unterschiedlichen Traditionen des Konzepts werden Märtyrer*innen sowohl im arabischen als auch im europäisch-westlichen Kontext allgemein als >Blutzeug*innen « verstanden, die mit ihrem Tod für ein höheres, religiöses oder politisches, Ziel einstehen. Das Martyrium als `Blutzeugnis` ist jedoch immer auch von der Zeugenschaft anderer abhängig, die das Martyrium erst bestätigen müssen und somit am Prozess der Märtyrerwerdung beteiligt sind. Francis Guerin und Roger Hallas zufolge ist ein Zeuge erst dann ein Zeuge, wenn es einen anderen oder eine andere gibt, »a listener who consequently functions as a witness to the original

9 War die Literatur zur Zeugenschaft lange Zeit auf erkenntnistheoretische Fragestellungen fokussiert, wurde die Diskussion in letzter Zeit zunehmend auch auf politische und medienkritische Fragen ausgeweitet. Für einen Forschungsüberblick siehe Sibylle Schmidt, Sybille Krämer und Ramon Voges (Hg.): Politik der Zeugenschaft: zur Kritik einer Wissenspraxis, Bielefeld: transcript 2011.

10 Abul Ezzati: »The Concept of Martyrdom in Islam«, Al-Islam.org 12 (1986), o.S., www.al-islam.org/al-serat/vol-12-1986/concept-martyrdom-islam (zugegriffen am 6.6.2021). 
witness $\aleph^{11}$. Ein gewaltsamer Tod wird folglich erst dann zu einem Märtyrertod, wenn er als solcher durch posthume Berichte und Darstellungen bestätigt wird. Auch Aleida Assmann betont, dass »der Zeuge-als-Märtyrer« einen »zweiten Augen-Zeugen [braucht], der seinen Tod wahrnimmt, ihn als Opfer (sacrificium) anerkennt und als sinnhaftes Zeugnis weiter tradiert $\aleph^{12}$. Wird Zeugenschaft in diesem Sinne als kommunikativer und relationaler Akt definiert, hängen Martyrien notwendigerweise von ihrer medialen Vermittlung, von schriftlichen Überlieferungen oder bildlichen Sichtbarmachungen ab. ${ }^{13}$ Mit Assmann gesprochen »verdoppelt« sich damit »das Zeugen in zwei Akte: das Bekennen und das Bezeugen des Bekenntnisses $\aleph^{14}$.

Die Märtyrerposter, die im Zentrum dieses Kapitels stehen, sollen als solche zweiten Akte - als sekundäre Zeugnisse - diskutiert werden. Die unzähligen BildText-Montagen, die seit den 1970er Jahren als Reaktion auf Selbstmordattentate angefertigt wurden, führen vor Augen, dass das »Bezeugen des Bekenntnisses « nicht nur durch wörtliche Berichte oder schriftliche Überlieferungen geschieht, sondern auch mithilfe von Bildern. Auch wenn man an dieser Stelle bereits festhalten kann, dass sekundäre Zeugnisse grundsätzlich einen entscheidenden Anteil an der Konstitution des Martyriums haben, stellt sich die Frage, wie sich dies im Fall der Märtyrerposter konkret realisiert. Inwiefern kann das Bezeugen in diesem Sinne als eine Bildoperation beschrieben werden, die in den Bildern selbst stattfindet - etwa durch Mittel der Montage? Welche Operationen werden aber auch mit diesen Postern im öffentlichen Raum vollzogen? Am Beispiel der Märtyrerposter von Wafa Idris, die als erste Frau während der zweiten Intifada ein Selbstmordattentat in Israel verübte, sollen diese grundlegenden Problemfelder aufgezeigt und diskutiert werden.

11 Francis Guerin und Roger Hallas: The Image and the Witness: Trauma, Memory and Visual Culture, London: Wallflower Press 2007, S. 10.

12 Aleida Assmann: »Vier Grundtypen von Zeugenschaft«, in: Michael Elm und Gottfried Kössler (Hg.): Zeugenschaft des Holocaust. Zwischen Trauma, Tradierung und Ermittlung, Frankfurt am Main: Campus 2007, S. 33-51, hier S. 15.

13 Vgl. Sigrid Weigel (Hg.): Märtyrer-Porträts. Von Opfertod, Blutzeugen und Heiligen Kriegern, München: Wilhelm Fink 2007; Carolin Behrmann und Elisabeth Priedl: „Vor Augen stellen. Zeugenschaft und Imitation«, in: Dies. (Hg.): Autopsia: Blut- und Augenzeugen: Extreme Bilder des christlichen Martyriums, München: Wilhelm Fink 2014, S. 9-19.

14 Assmann: »Vier Grundtypen von Zeugenschaft«, S. 15. 


\section{Die Märtyrerposter von Wafa Idris}

Wafa Idris war die erste Frau, die nach dem Ausbruch der zweiten Intifada ein Selbstmordattentat gegen Israel verübte. Am Morgen des 27. Januar 2002 betrat die 28-Jährige ein Jerusalemer Schuhgeschäft und zündete den Sprengstoffgürtel, den sie unter ihrer Kleidung trug. Durch die Explosion wurde ein israelischer Staatsbürger zusammen mit Wafa Idris in den Tod gerissen, zahlreiche Passant*innen wurden schwer verletzt. Unmittelbar nach dem Attentat tauchten an mehreren Orten im Westjordanland Poster mit dem Portraitfoto von Wafa Idris auf, in denen sich die al-Aqsa Märtyrer Brigaden zu dem Anschlag bekannten und weitere biografische Informationen zur Herkunft von Wafa Idris lieferten (Abb. 2.1). ${ }^{15}$ Mit der Veröffentlichung des Posters bezeugte die der Fatah zugehörige Partei ihre Verantwortung für Planung und Organisation des Selbstmordattentats. ${ }^{16}$ Auch wenn Poster nicht die einzigen Medien einer solchen Bekanntgabe darstellen (viele Parteien halten zusätzlich Pressekonferenzen ab oder verfassen schriftliche Bekenntnisse), sind sie zumindest als eine Informationsquelle zu betrachten, durch die sensible Daten preisgegeben werden. Mit der Bekanntgabe von Namen, Bild und Herkunft der Attentäterin lieferte das Poster von Wafa Idris Belege, die in letzter Konsequenz zur Verhaftung mehrerer Angehöriger, sowie zur Zerstörung ihres Familienhauses führten. ${ }^{17}$ Auf einer ersten Ebene hatte das Bildzeugnis (zusammen mit anderen Medien der Bekanntgabe) also ganz konkrete militärische Operationen der israelischen Armee zur Folge.

Darüber hinaus schien mit dem Poster aber vor allem der Anspruch verbunden, das Martyrium der Dargestellten zu bezeugen. So lautet die arabische Inschrift auf dem Poster: »Die al-Aqsa Märtyrer Brigaden betrauern voll Stolz ihre Märtyrerin, die Heldin aus dem Lager al-Am'ari. Die Märtyrerin Wafa Idris. ${ }^{18}$

15 Ich danke Johannes Gerloff für die Bereitstellung seiner Fotografie dieses Posters.

16 Die genaue Affiliation der al-Aqsa Märtyrer Brigaden mit der Fatah ist umstritten. Obwohl sie von der Fatah nicht offiziell anerkannt werden, setzt sich die Gruppe hauptsächlich aus Aktivisten dieses politischen Spektrums zusammen. Meist werden die alAqsa Märtyrer Brigaden daher als militanter Arm der Fatah angesehen. Vgl. Claudia Brunner: Männerwaffe Frauenkörper? Zum Geschlecht der Selbstmordattentate im israelisch-palästinensischen Konflikt, Wien: Braumüller 2005, S. 71f.

17 Marilyn Friedman: »Female Terrorists: Martyrdom and Gender Equality«, in: Ibrahim A. Karawan, Wayne McCormack und Stephen E. Reynolds (Hg.): Values and Violence. Intangible Aspects of Terrorism, Heidelberg: Springer 2008, S. 43-62, hier S. 50.

18 Al-Amari ist der Name des Flüchtlingslagers bei Ramallah, in dem Wafa Idris gemeinsam mit ihrer Mutter lebte. 
Abbildung 2.1: Fatah/Al-Aqsa-Märtyrer Brigaden: Märtyrerposter von Wafa Idris, Januar 2002.

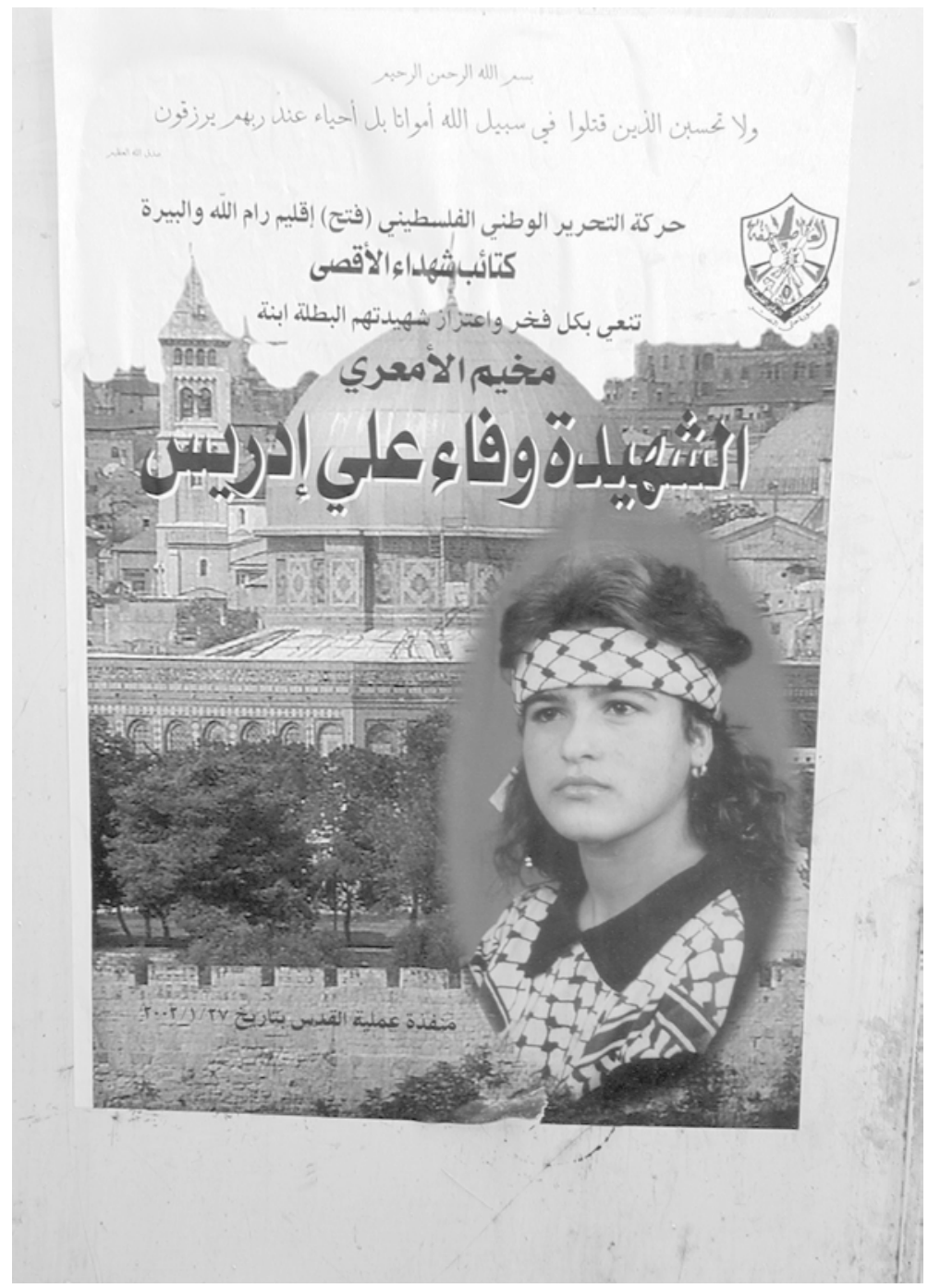

Auf der Fotografie, die für das Märtyrerposter ausgewählt wurde, ist Wafa Idris mit Stirnband und T-Shirt in Kufiya-Optik zu sehen - dem palästinensischen Tuch, das zum Symbol für den säkularen Widerstandskampf der Fatah wurde. Von einer roten Mandorla umfangen schwebt Idris' Konterfei in der rechten vorderen Bildhälfte, während das Hintergrundfoto den Blick auf die goldene Kuppel des 
Felsendoms freigibt und die Attentäterin damit zugleich als heldenhafte Verteidigerin der islamischen Stätte stilisiert. Politische und nationale Motive des Widerstands verschwimmen hier mit einer religiösen Symbolik, was selbst für die Poster der eigentlich eher säkularen Fatah während der zweiten Intifada typisch war.

Im Vergleich mit anderen Postern wird deutlich, dass es sich bei Wafa Idris' Poster um eine gängige Bildvorlage handelte, die bislang ausschließlich Männern vorbehalten war und in die das Portrait der ersten weiblichen Selbstmordattentäterin nun scheinbar bruchlos hineinkopiert wurde. ${ }^{19}$ Auf einem vom Fatah-Frauenkomitee organisierten Trauerzug, drei Tage nach dem Anschlag, wurde das Poster schließlich massenhaft als visueller Beweis für die geschlechtliche Gleichberechtigung emporgehalten, während die jungen Demonstrantinnen stolz verkündeten: »Der Dschihad ist nicht nur für Männer! « ${ }^{20}$ Während zahlreiche arabische Pressekommentare die säkularen und (angeblich) genderpolitischen Beweggründe der Märtyrerin betonten, wurde ihr Bild gleichzeitig auch von radikal-islamischen Parteien vereinnahmt und in explizit religiöse Zusammenhänge gestellt. ${ }^{21}$

War die islamische Rahmung der Attentäterin im Poster der Fatah zwar bereits angelegt, wurde dies von einem weiteren Poster auf die Spitze getrieben, das ebenfalls kurz nach dem Attentat in Ramallah gesichtet wurde. Friederike Pannewick zufolge war Wafa Idris auf der retuschierten Fotomontage mit einem grünen, Hamas-typischen Stirnband zu sehen, das die Aufschrift »Gott ist die Antwort« trug, während hinter ihr eine Flagge mit den Worten »Allahu akbar«/»Gott ist groß« ins Bild montiert wurde. ${ }^{22}$ Die Vereinnahmung durch die visuelle Sprache der Hamas erscheint in Wafa Idris' Fall besonders überraschend, da sie zu Lebzeiten von der radikal-islamischen Partei gerade aufgrund ihres säkularen, liberalen Lebensstils scharf kritisiert wurde. Eine Freundin von Wafa Idris, die der Journalist Johannes Gerloff interviewte, beschrieb die Attentäterin folgendermaßen: »Wafa war sehr auf ihr Äußeres bedacht, und eher liberal. Sie ist nie in die Moschee gegangen.« Ihrer Aussage zufolge haben »die Leute vom Dschihad und von der Hamas [...]

19 Vgl. Abu Hashhash: »On the Visual Representation of Martyrdom in Palestine«, S. 399.

20 Zitiert in Friederike Pannewick: »Wafa Idris. Eine Selbstmordattentäterin zwischen Nationalheldin und Heiliger«, in: Sigrid Weigel (Hg.): Märtyrer-Porträts, S. 110-116, hier S. 111.

21 Die palästinensische Debatte um den Einsatz weiblicher Selbstmordattentäterinnen wird in Kapitel 3.4 ausführlich Thema sein. Zur Rezeption von Wafa Idris siehe insbesondere S. 178f.

22 Pannewick: »Wafa Idris. Eine Selbstmordattentäterin zwischen Nationalheldin und Heiliger«, S. 111. 
sie gehasst, weil Wafa sich modern gekleidet hat $\aleph^{23}$. Auch die Privatfotografien, die als Grundlage für sämtliche Märtyrermontagen dienten, scheinen sich einer solchen islamischen Überschreibung eigentlich zu widersetzen. Sie weisen Wafa Idris als liberale Frau aus, die nie Kopftuch trug, mal mit Lederjacke und KufiyaStirnband, mal mit Hochsteckfrisur und Make-Up oder als Hochschulabsolventin mit akademischem Talar abgelichtet wurde. Obwohl es als äußerst unwahrscheinlich gelten kann, dass Idris aus religiösem Eifer heraus handelte, wurde ihr Bild durch das von Pannewick beschriebene Poster der Hamas im Sinne eines religiösen Dschihad umgedeutet. Dem Bildzeugnis der Fatah wurde damit ein konkurrierendes Bildzeugnis gegenübergestellt. Auch in zahlreichen digitalen Märtyrermontagen, die in den Folgejahren auf den Homepages der Hamas kursierten, wurde die Selbstmordattentäterin visuell als islamische Heilige konstruiert. Obwohl die Hamas den weiblichen Selbstmordattentäterinnen zu Beginn ablehnend gegenüberstand (vgl. S. 178f.), beanspruchten sie im Nachhinein ein `Copyright auf diese Welle weiblicher Märtyrerinnen. So tauchte das Bild von Wafa Idris auch in einer Montage mit dem Titel Die Märtyrerinnen (al-īstishādiāt) auf, die 2008, also rund sechs Jahre nach ihrem Attentat, auf der Hamas-Website Palestine-Info gepostet wurde (Abb. 2.2). ${ }^{24}$ Hier erscheint Idris als Teil eines ganzen Heers identischer Kämpferinnen, das von einer Selbstmordattentäterin der Hamas angeführt wird. Die Fotografie von Rim Riyashi, die als erste Frau der Hamas am 14. Januar 2004 ein Selbstmordattentat auf einen isrealischen Checkpoint verübte, diente in der Bildmontage als Blaupause, um im Copy-and-Paste-Verfahren auch die Körper der anderen Attentäterinnen zu generieren. Dank digitaler Bildbearbeitungsprogramme wurde auch der akademische Talar auf Wafa Idris' Kopf kurzerhand von einem ins Bild retuschierten Hijab samt Märtyrerstirnband ersetzt. Die säkulare Attentäterin wurde auf diese Weise in die virtuelle Genealogie der Hamas eingepasst.

23 Zitiert in Johannes Gerloff: Die Palästinenser: Volk im Brennpunkt der Geschichte, 2. Aufl., Holzgerlingen: SCM Hänssler 2011, S. 148.

24 Den Hinweis auf die Veröffentlichung der Montage auf der Hamas-Website verdanke ich der Internetseite Terrorism-info: http://www.terrorism-info.org.il/en/article/18419 (zugegriffen am 6.6.2021). Dieselbe Montage war schließlich auch auf anti-zionistischen Blogs und im Rahmen von Video- und Bildkompilationen auf YouTube zu finden, z.B.: https://www.youtube.com/watch?v=HlwM9t6kjgs, am 18. November 2012 von »bang jbareen« hochgeladen (zugegriffen am 14.5.2016, nicht mehr verfügbar). 
Abbildung 2.2: Hamas: Al-īstishādiāt, digitale Montage mit dem Portrait von Wafa Idris (zweite Reihe rechts).

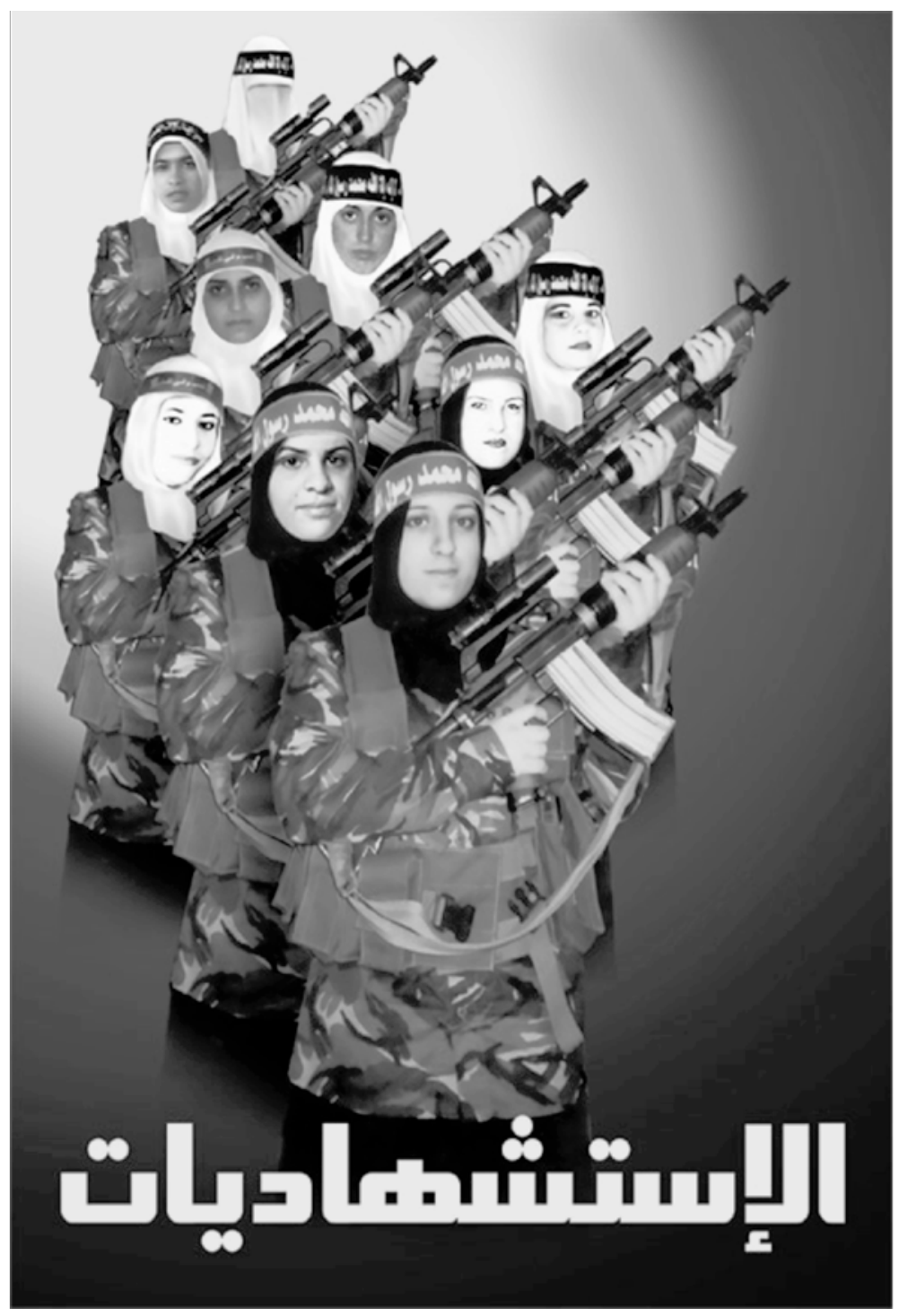

Die ambivalenten Aneignungen ihres Bildes machen deutlich, dass Märtyrerposter von Selbstmordattentäterinnen wie Wafa Idris weitaus mehr sind als Medien der Bekanntgabe, als Nachrufe oder Erinnerungsbilder für Familienangehörige. Den miteinander konkurrierenden Parteien dienen sie mitunter als Bühnen, auf denen 
politische Kämpfe um die Deutungshoheit von Selbstmordanschlägen ausgefochten werden. Gerade wenn Selbstmordattentäter*innen keine Videotestamente hinterlassen, wie auch im Fall von Wafa Idris, nehmen sekundäre Zeugnisse wie die posthum produzierten Märtyrerposter eine umso bedeutendere Rolle ein. Lori A. Allen hat auf die »semiotische Komplexität $\ll^{25}$ des Märtyrerposters hingewiesen, das sowohl die getötete Person, gleichzeitig aber auch die Märtyrerin oder den Märtyrer repräsentiert, in die oder den sich diese Person verwandelt hat. Die gewöhnlichen Privatfotografien von Wafa Idris werden textuell und visuell als Bilder einer Märtyrerin gerahmt, deren Lesart sich dadurch grundlegend verändert. Erst durch die Poster wird der Selbstmordanschlag Wafa Idris' als Operation einer $>$ Märtyrerin< bezeugt und gleichzeitig legitimiert. Das von den Parteien produzierte Bildzeugnis ist damit entscheidend an der 〉Märtyrerwerdung \der Attentäterin beteiligt.

Im Gegensatz zu Videotestamenten, in denen die Dargestellten selbst als Zeug*innen ihres eigenen Martyriums auftreten (Kapitel 3), sind es hier die diversen, teils miteinander in Konflikt stehenden Bildproduzent*innen, die dem Märtyrerstatus `Evidenz` verleihen und letztlich auch die Deutungshoheit über das Martyrium der Dargestellten erlangen. Die Poster sind damit zwangsläufig offener für unterschiedlichste Aneignungen. Gerade in der Transformation von Wafa Idris in eine verschleierte, islamische Märtyrerin der Hamas wird deutlich, dass das mediale Bezeugen des Martyriums gleichzeitig auch als ein Erzeugen zu verstehen ist. Als sekundäre Zeugnisse formulieren Märtyrerposter also einerseits einen Anspruch auf $>$ Beweiskraft (in diesem Fall für das Martyrium der Gestorbenen), sind andererseits aber als Fiktionen zu begreifen, die durch die jeweiligen Intentionen der Bezeugenden geprägt sind. Diese Beobachtung schließt an die Argumentation der Philosophin Sybille Schmidt an. In ihrem Buch Ethik und Episteme der Zeugenschaft (2015) beschreibt sie Zeugnisse als Sprechakte, die zugleich immer auch ein »Erzeugnis, ein Gebilde« darstellen: »Das Zeugnis ist nicht nur mit der Möglichkeit der Fiktion verbunden - es ist Fiktion, und zwar im buchstäblichen Sinn: Das Wort `fingiert stammt vom lateinischen >fingere $a b$, was \formen, bilden, gestalten < bedeutet. Das Zeugnis ist als Sprechakt immer ein Erzeugnis, ein Gebilde. $\ll^{26}$ Dass die Wahrheit eines Zeugnisses durch den performativen Akt der Zeugenschaft erst produziert wird, haben auch Francis Guerin und Roger Hallas in ihrer Einleitung des Sammelbandes The Image and the Witness hervorgehoben: »Thus the act of bearing witness is not the communication of a truth that is

25 Allen: »Polyvalent Politics«, S. 117.

26 Sibylle Schmidt: Ethik und Episteme der Zeugenschaft, Konstanz: Konstanz University Press 2015, S. 137. 
already known, but its actual production through this performative act. $\ll^{27}$ Die beiden Autor*innen betonen zwar, dass Bilder eine eigene Dynamik in diesen performativen Akt einbringen, sehen deren Rolle jedoch in erster Linie als mediale Vermittler der »intersubjektiven Relationen«, die das Zeugnis ausmachen. ${ }^{28}$ Am Beispiel der Märtyrerbilder von Wafa Idris lässt sich hingegen argumentieren, dass die Produktion der Evidenz - und damit die Erzeugung des Martyriums unter anderem in den Bildern selbst erfolgt. Für eine Analyse des relationalen (und medialen) Akts der Zeugenschaft erscheint es daher notwendig, nicht nur den performativen Gebrauch der Märtyrerposter, sondern auch deren ikonografische und ästhetische Dimensionen in den Blick zu nehmen.

Mit den Märtyrerpostern sind folglich mehrere Bildoperationen epistemischer Kausalität verbunden: In ihrem Anspruch auf 〉Beweiskraft und der Vermittlung eines bestimmten Wissens über das Attentat können die Bildzeugnisse zum einen ganz konkrete militärische Operationen der gegnerischen Seite (wie Vergeltungsanschläge oder Verhaftungen) nach sich ziehen. Zum anderen erheben die Poster aber vor allem den Anspruch, das Martyrium der Dargestellten zu bezeugen und die Selbstmordoperation damit als Märtyrer-Operation zu konstituieren.

Auf welch komplexe Weise `Blutzeugnis $\triangleleft$ und $\gg$ Bildzeugnis $\triangleleft$ miteinander verknüpft sind, zeigt schließlich auch das Beispiel eines undatierten Videotestaments, in dem das Märtyrerposter von Wafa Idris erneut eine zentrale Rolle spielt (Abb. 2.3). ${ }^{29}$ Die Videoaufnahme zeigt eine anonyme Frau, deren Gesicht durch eine Kufiya bis auf einen Augenschlitz verhüllt ist. Während sie ihr Testament verliest, sitzt sie an einem Tisch, auf dem ein Gewehr, eine Handgranate und ein verzierter Koran stehen. Hinter ihr, auf einem Tuch mit dem Logo der Fatah sind zwei Märtyrerposter von Wafa Idris angebracht, die den Kopf der Verhüllten links und rechts einrahmen und sie damit unmissverständlich in die Nachfolge der bereits zur Ikone gewordenen Märtyrerin rücken.

27 Guerin und Hallas: The Image and the Witness, S. 11.

28 Ebd.

29 Das Video wurde als Teil einer Sammlung von Videotestamenten zwischen 2003 und 2008 vom israelischen Künstler und Theoretiker Joshua Simon archiviert. Der Name der Frau, die Umstände der Tat ebenso wie das genaue Datum der Videoaufzeichnung sind unbekannt. Ich danke Joshua Simon für die Bereitstellung des Videomaterials. 


\section{Abbildung 2.3: Standbild aus einem undatierten und anonymen}

Videotestament mit zwei Märtyrerpostern von Wafa Idris im Hintergrund.

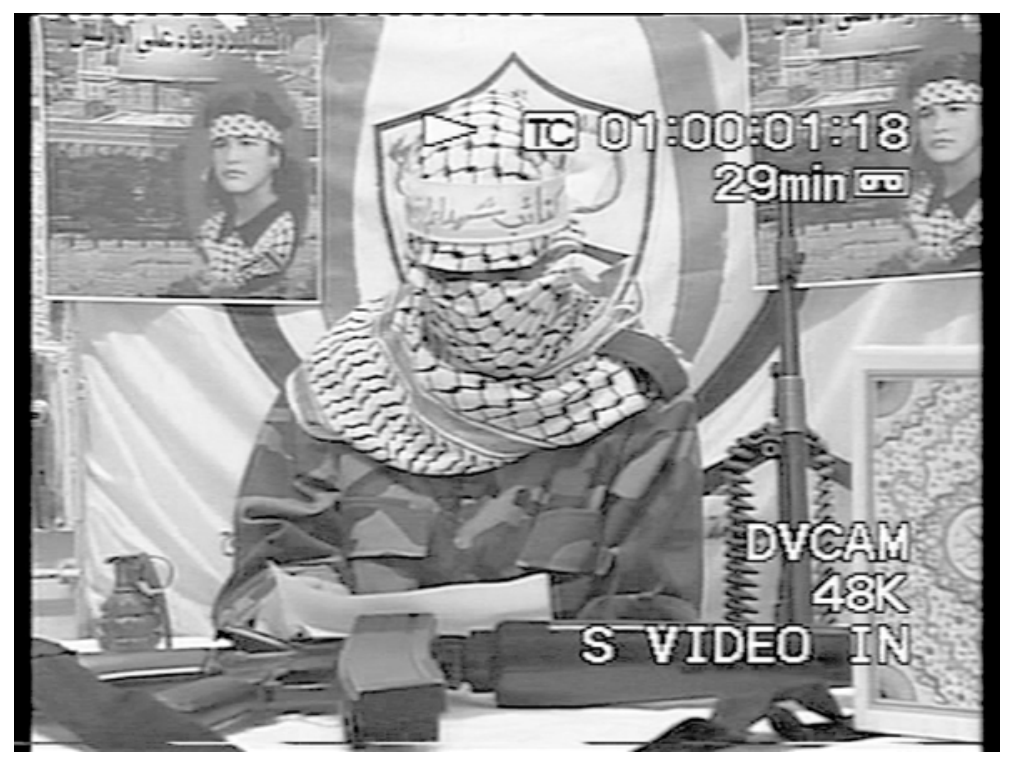

Das Poster der Vorgängerin wird hier als Legitimation der geplanten Tat ins Bild gesetzt und so für die visuelle Erzeugung einer neuen Märtyrerin instrumentalisiert. Waffen, Koran und Märtyrerposter - in dieser Konstellation von Attributen erscheint die verschleierte Frau im Video. Sind die Waffen als Machtdemonstration und der Koran als göttliche Legitimierung der Tat zu lesen, so verweist das Poster auf die Vor-Bilder, die dieser Tat voraus gingen und das Martyrium als Imitation, als Nachfolge definieren. In Bezug auf das christliche Martyrium wurde dieser Nachahmungscharakter - die Imitatio Christi - bereits ausgiebig erforscht. ${ }^{30}$ Unabhängig vom christlichen Kontext scheint die Idee der Nachahmung aber auch in nahöstlichen Märtyrerdarstellungen zentral zu sein, wie auch die Analysen in Kapitel 2.3 und 2.4 zeigen werden. Die Bildzeugnisse, die auf das Martyrium folgen, scheinen selbst wiederum neue $>$ Blutzeugnisse $<$ anzustoßen. Dies legt bereits das Videotestament der unbekannten Schahida und Nachfolgerin von Wafa Idris nahe. Wie hier deutlich wird, dienen Märtyrerposter nicht nur in einem übertragenen Sinne als Vorbilder, sondern eignen sich im Gegensatz zu Videotestamenten gerade in ihrer materiellen Präsenz für neue Handlungen mit dem Bild (siehe dazu vor allem Kapitel 2.5).

30 Vgl. insbesondere Sigrid Weigel: »Schauplätze, Figuren, Umformungen«, S. 12. 
Dass Selbstmordattentäter*innen durch Poster als Märtyrer*innen inszeniert und konstituiert werden, war jedoch keineswegs ein Novum der zweiten palästinensischen Intifada. Schon Mitte der 1970er Jahre etablierten sich Märtyrerposter zunächst unter palästinensischen, ab den 1980er Jahren dann auch unter libanesischen Milizen als primäres Medium der Präsentation und Popularisierung von Selbstmordattentaten. Insbesondere am Beispiel der frühen, säkularen Operationen palästinensischer Gruppen zeigt sich wie vielfältig und ambivalent die Bildgeschichte dieser sekundären Zeugnisse ist.

\subsection{KAMIKAZE, FEDAJIN, SCHAHID? DIE FOTOGRAFIEN PALÄSTINENSISCHER SELBSTMORDATTENTÄTER*INNEN AB 1974}

Als erstes Selbstmordattentat auf israelischem Boden gilt ein Anschlag, der nicht von Palästinenser*innen, sondern von Mitgliedern der Japanischen Roten Armee (JRA) durchgeführt wurde. Am 30. Mai 1972 stürmten drei japanische Attentäter die Gepäckausgabehalle des Tel Aviver Flughafen, schossen mit Maschinengewehren wild um sich und richteten ein Blutbad an, bei dem 26 Zivilpersonen ums Leben kamen. Einer der Täter sprengte sich anschließend mit einer Handgranate in die Luft, ein anderer wurde erschossen und der dritte lebend festgenommen. ${ }^{31}$ Sowohl die JRA als auch die PFLP bekannten sich zu dem Anschlag, den sie gemeinsam von Beirut aus geplant hatten. Im Gegensatz zu den Flugzeugentführungen der PFLP Ende der 1960er und Anfang der 1970er Jahre war der Tod der Attentäter zum ersten Mal Teil des Operationsplans, so hat Joseph Croitoru in seiner historischen Untersuchung gezeigt. ${ }^{32}$ Die Attentäter erhielten Anweisungen, sich nach dem Anschlag mit Handgranaten selbst zu töten, bevor sie festgenommen werden konnten. Der Plan beinhaltete außerdem die Vereinbarung, dass die Attentäter vor dem Angriff die Fotos aus ihren Pässen zerstörten und »möglichst versuchen sollten, ihre Gesichter zu verstümmeln, um ihre spätere Identifizierung zu erschweren ${ }^{33}$. Die Bildpolitik dieses Selbstmordattentats war zunächst also durch die ikonoklastische Zerstörung von Bildern gekennzeichnet. Portraitbilder ebenso wie die Gesichter der Attentäter wurden als Mittel der Identifikation

31 Diese und folgende Zusammenfassungen der ersten palästinensischen Selbstmordattentate basieren auf der Darstellung von Croitoru: Der Märtyrer als Waffe, S. 71-120.

32 Ebd., S. 74f.

33 Ebd., S. 75. Vgl. auch William R. Farrell: Blood and Rage: The Story of the Japanese Red Army, Lexington: Lexington Books 1990, S. 138. 
behandelt, die vernichtet werden sollten, um sie nicht dem Feind in die Hände zu spielen.

Die Japanische Rote Armee stellte den Anschlag in einen Zusammenhang mit den japanischen Kamikazefliegern während des Zweiten Weltkriegs. Der Attentäter, der sich mit einer Handgranate in die Luft sprengte, wurde von der Anführerin der JRA als »perfekter Kamikaze« gelobt, der mit seinem Aufopferungswillen sogar die Kamikazepiloten übertroffen habe. ${ }^{34}$ Während das Massaker weltweit heftige Ablehnung und Entsetzen hervorrief, wurde der Todesmut der Attentäter in Kommentaren libanesischer Zeitungen begrüßt. ${ }^{35}$ Positive Reaktionen kamen auch vom ägyptischen Außenminister Aziz Sidqi sowie dem libyschen Staatspräsidenten Muammar Gaddafi, der das Attentat zum Anlass nahm, mehr Opferbereitschaft auch von den palästinensischen Gruppen zu fordern. Nach Ansicht von Gaddafi zeige sich der wahre Geist der Fedajin - so die arabische Bezeichnung für Guerilla- oder Widerstandskämpfer*innen - erst in todesmutigen Aktionen wie dieser: »Why should a Palestinian not carry out such an operation? You will see them all writing books and magazines full of theories, but otherwise unable to carry out one daring operation like that carried out by the Japanese. $\aleph^{36}$

Die provokative Kritik an der mangelnden Opferbereitschaft blieb nicht lange ungehört. ${ }^{37}$ Zwei Jahre nach dem Selbstmordanschlag am Tel Aviver Flughafen schien die PFLP-General Command den japanischen Attentätern nachzueifern. Am 11. April 1974 stürmten drei Männer (ein Palästinenser, ein Syrer und ein Iraker) ein Wohnhaus in der israelischen Kleinstadt Kirjat Schmona nahe der libanesischen Grenze, feuerten mit Maschinengewehren um sich und töteten scheinbar wahllos Menschen, die sich in den Stockwerken des Gebäudes aufhielten. Anschließend sprengten sich die Attentäter zusammen mit ihren Geiseln in

34 Zitiert in Farrell: Blood and Rage, S. 106.

35 In einem Leitartikel der libanesischen Zeitung al-Anwar wurde beispielsweise ganz Palästina zu einem >Dir Jassin< erklärt. So lautete der Operationsname des Attentats, das sich damit als Vergeltungsschlag für ein israelisches Massaker ausgab, das 1948 von israelischen Soldaten an der palästinensischen Zivilbevölkerung im gleichnamigen Dorf 〉Dir Jassin` verübt wurde. Vgl. Croitoru: Der Märtyrer als Waffe, S. 78f.

36 Zitiert in Christopher Dobson und Ronald Payne: The Carlos Complex: A Pattern of Violence, London: Hodder and Stoughton 1977, S. 174f.

37 Die nur drei Monate später stattfindende Geiselnahme während der Olympischen Spiele in München kann bereits als Antwort auf den Vorwurf eines fehlenden palästinensischen Kampfgeistes gelten. Das erste eigentliche Selbstmordattentat von Palästinenser*innen, bei dem der Tod der Angreifenden Teil des Kalküls war, wurde jedoch erst zwei Jahre später verübt. 
die Luft. Von Seiten der Widerstandsgruppe und deren Anführer Ahmad Dschibril wird das Attentat bis heute als der erste palästinensische Selbstmordeinsatz betrachtet. ${ }^{38}$ Zum ersten Mal in der Geschichte des palästinensischen Widerstandes sprach die verantwortliche Organisation nicht nur vom Widerstandskampf der Fedajin, sondern bezeichnete den Einsatz als »Selbstmordkommando (arab. »mağmū'a intiharīya $\left.{ }^{39}\right)$. Wurde die PFLP noch dafür kritisiert, für ihren Todeseinsatz auf die Hilfe japanischer Kamikaze angewiesen zu sein, bewiesen die drei arabischen Attentäter der PFLP-GC nun die Entschlossenheit zu eigenen Selbstmordaktionen. Dschibrils Splitterpartei, die sich 1968 von der PFLP abspaltete und seither mit ihr konkurrierte, schien damit ihre Vorherrschaft im bewaffneten Widerstand behaupten zu wollen. Presse und Machthaber der mit Israel in Konflikt stehenden arabischen Länder äußerten sich überwiegend anerkennend zu der Tat und priesen die zunehmende Furchtlosigkeit der palästinensischen Nationalbewegung. ${ }^{40}$

Eine entscheidende Neuerung war aber auch die mediale Inszenierung der Attentäter, mit der sich die PFLP-GC von der ikonoklastischen Strategie des japanischen Vorbilds abgrenzten. Unmittelbar nach dem Anschlag veranstaltete die Partei eine Pressekonferenz in Beirut, bei der die Namen der Attentäter bekannt gegeben und eine ganze Reihe an Fotografien veröffentlicht wurden. Zudem wurde ein Tonband abgespielt, auf dem die Testamente der drei Attentäter zu hören waren. Wenige Monate später, so berichtet Joseph Croitoru, zeigte die Partei in einem Beiruter Kino auch einen Film, der angeblich die letzten Lebenstage der Attentäter begleitete. ${ }^{41}$ Filmaufnahmen, Tonbänder und Fotografien bildeten das mediale Spektrum mit dem die ersten palästinensischen Selbstmordattentäter der Öffentlichkeit präsentiert wurden.

38 Diese Version wird von der israelischen Seite jedoch heftig bestritten. Statt einem Selbstmordanschlag geht Israel davon aus, dass der Sprengstoff, den die Attentäter bei sich trugen, erst durch den Angriff durch israelische Geschütze zum Explodieren gebracht wurde. Vgl. die Darstellung in Croitoru: Der Märtyrer als Waffe, S. 81.

39 Zitiert in ebd., S. 82. Croitoru bezieht sich dabei auf die schriftliche Erklärung der PFLP-GC, die am 12. April 1974 in al-Anwar abgedruckt wurde.

40 So bemerkte der libysche Präsident Gaddafi lobend, dass die palästinensischen Fedajin nun erstmals ihre »Angstbarriere« überwunden hätten. Zitiert in ebd., S. 84.

41 Ebd., S. 82. Croitoru verweist in diesem Zusammenhang auf einen Bericht in Al-Hayat vom 17. August 1974. Der Film selbst konnte bisher allerdings nicht gefunden werden. 
Abbildung 2.4: Fotografie der Kirjat-Schmona-Attentäter, am 12. April 1974 auf der Titelseite von Al-Anwar abgedruckt.

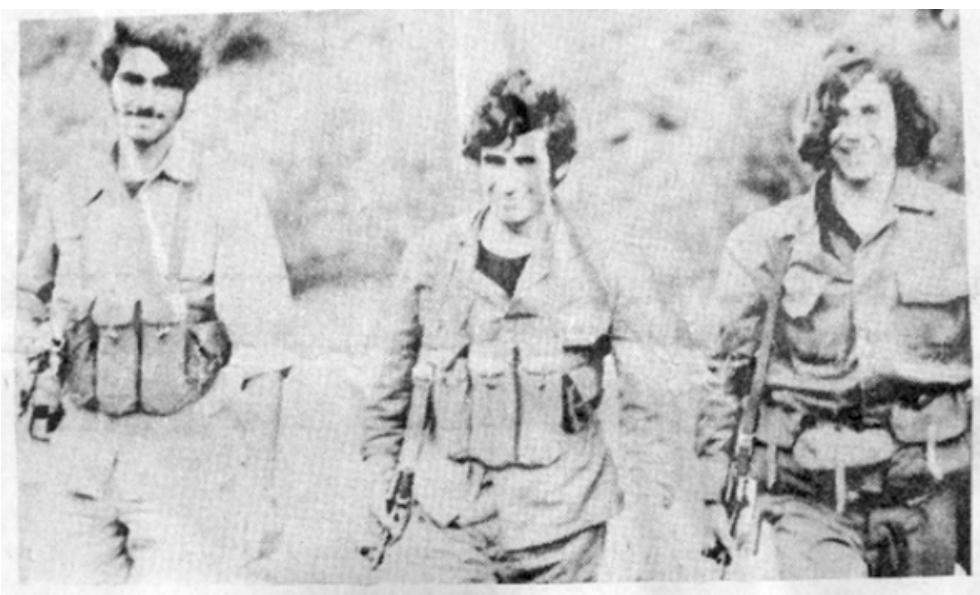

Abbildung 2.5: Fotografie der Kirjat-Schmona-Attentäter, am 12. April 1974 auf der Titelseite von An-Nahar abgedruckt.

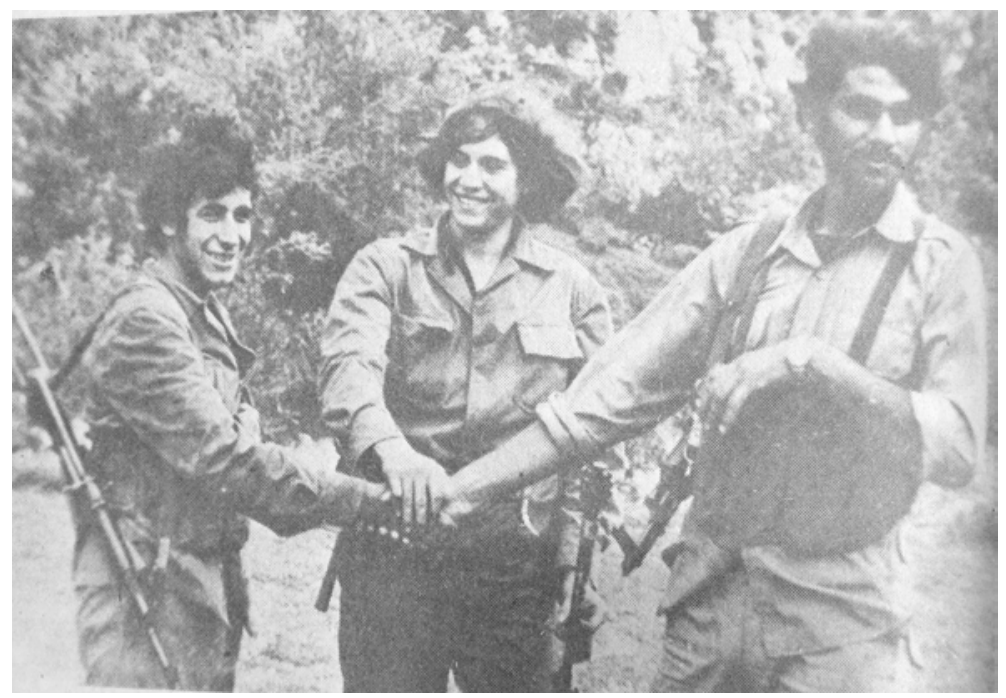

Auf der Titelseite der libanesischen Tageszeitung al-Anwar wurde am Tag nach dem Anschlag eines der Fotos abgedruckt. Es zeigt die drei jungen Männer in Militärmontur und mit Maschinengewehren bewaffnet, wie sie freudig entschlossen auf die Kamera zuschreiten (Abb. 2.4). Die libanesische an-Nahar druckte 
einen Tag später ein weiteres Foto ab, auf dem die Attentäter ihre bevorstehende Tat mit einem kameradschaftlichen Handschlag besiegeln (Abb. 2.5). Auch das dritte Bild dieser Serie, das am 13. April in al-Anwar abgedruckt wurde, zeigt die Attentäter in gelöster Stimmung, entspannt auf einer Wiese liegend und in die Kamera lachend, als würden sie ihrem Tod voller Vorfreude entgegenblicken (Abb. 2.6).

Abbildung 2.6: Fotografie der Kirjat-Schmona-Attentäter, am 13. April 1974 in al-Anwar abgedruckt.

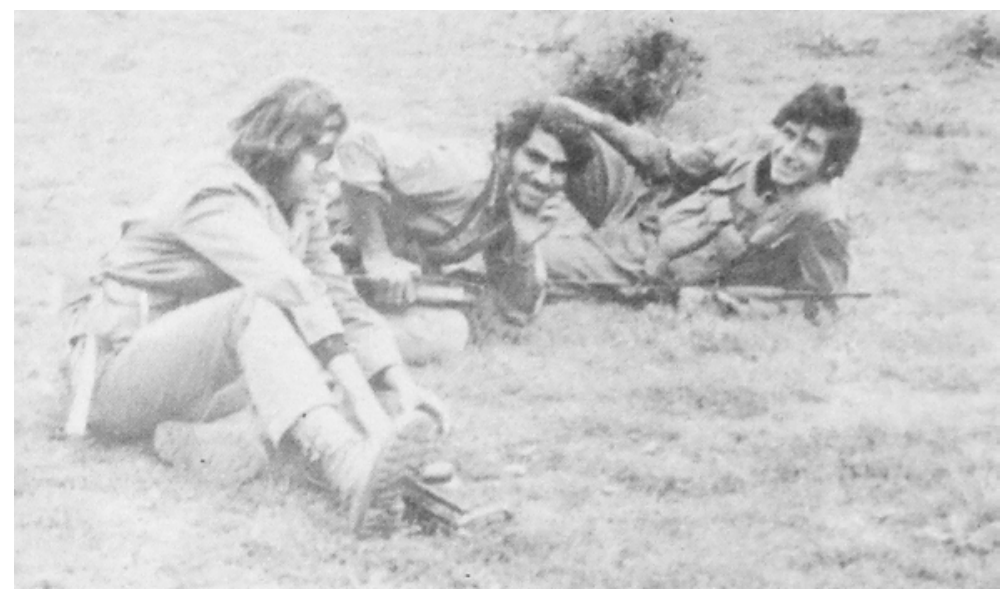

Die betont menschliche, geradezu sympathische Darstellung der Attentäter lässt es umso erstaunlicher erscheinen, dass die Bilder auch von israelischen Presseorganen vereinnahmt wurden. Unter der Überschrift »Eighteen Murdered in Kiryat Shmona Terror« druckte auch die Jerusalem Post am Tag nach dem Anschlag eines der Fotos (Abb. 2.5) auf ihrer Titelseite ab. ${ }^{42}$ Die Beschreibungen des Schlachtens, Mordens und Massakrierens, die im Artikel folgen und die Attentäter als »Terroristen« verurteilen, werden konterkariert von dem Bild der freundlich aussehenden Männer, die mit ihrem kameradschaftlichen Sieges-Handschlag einen Kontrapunkt zur beschriebenen Brutalität der Tat bilden. Gerade durch diesen Bruch scheint die Fotografie aber auch auf die besondere Perfidität und Skrupellosigkeit der Attentäter zu verweisen, die Gräueltaten scheinbar mit einem unschuldigen Lachen begehen. Die kritische Aneignung verweist auf die prinzipielle

42 Hirsh Goodman: »Eighteen Murdered in Kiryat Shmona Terror. Three Arabs Butcher Women and Children, then Die in Blast«, Jerusalem Post, 12.04.1974, Titelseite. 
Bedeutungsoffenheit der Aufnahmen, die je nach Kontextualisierung offenbar unterschiedliche Lesarten erlauben.

Nach dem Vorbild von Kirjat Schmona wurde das Selbstmordattentat - und mit ihm dessen mediale Inszenierung - auch von anderen palästinensischen Widerstandsgruppen institutionalisiert. Im Laufe eines Jahres führten neben der PFLP-GC auch die Demokratische Befreiungsfront (DFLP), die Fatah und die PFLP insgesamt acht weitere Anschläge durch, bei denen der Tod der Attentäter*innen nicht mehr nur in Kauf genommen, sondern zur eigentlichen Strategie erhoben wurde. ${ }^{43}$ Joseph Croitoru zufolge spielte der Konkurrenzdruck unter den rivalisierenden Widerstandsparteien bei der Konjunktur von Selbstmordeinsätzen eine entscheidende Rolle. ${ }^{44}$ Durch die Zersplitterung des palästinensischen Widerstands buhlten gleich mehrere Gruppen um politischen und gesellschaftlichen Einfluss. Die positive mediale Resonanz, die auf die Operation von Kirjat Schmona von arabischer Seite folgte, führte daher zu einem regelrechten Wetteifern um sogenannte Selbstmordkommandos.

Die Anschläge selbst waren dabei immer häufiger gegen Zivilpersonen gerichtet und ließen eine zunehmende Brutalisierung erkennen. Neben der Benennung der Attentate als »Selbstmordkommandos« etablierte sich die Veröffentlichung von Bildern innerhalb weniger Monate zu einem festen Bestandteil der Operationen. Wie die PFPL-GC verbreiteten auch die anderen Parteien Fotografien, auf denen die Attentäter*innen mit hochgehaltener Kalaschnikow und in heroischen Posen zu sehen waren, die auf Kampfbereitschaft, Sieg und Triumph hinweisen. ${ }^{45}$ Damit folgten sie dem damals gängigen Bild der palästinensischen Fedajin und schlossen an ein heroisches Narrativ an, das die Selbstdarstellung der palästinensischen Widerstandsbewegung zu dieser Zeit beherrschte. Ab Ende der 1960er Jahre entwickelte sich der palästinensische Widerstand zum revolutionären Projekt, das zunehmend auch den militanten Kampf befürwortete. ${ }^{46}$ In den

43 Die Attentate fanden am 15. Mai (DFLP), am 13. Juni (PFLP-GC), am 24. Juni (Fatah), am 19. November (DFLP), am 29. November (PFLP), am 6. Dezember (Fatah) sowie am 12 Dezember (PFLP/Fatah) des Jahres 1974 statt. Am 5. März 1975 folgte ein weiteres Selbstmordattentat der Fatah, das für drei Jahre lang das letzte bleiben sollte. Für eine ausführliche Darstellung der Ereignisse vgl. Croitoru: Der Märtyrer als Waffe, S. 71-120.

44 Vgl. ebd., S. 82.

45 Siehe etwa die Fotografien, die im Anschluss an das Attentat der DFLP am 16. und 21. Mai 1974 in al-Anwar abgedruckt wurden.

46 Vgl. Yezid Sayigh: Armed Struggle and the Search for State: The Palestinian National Movement 1949-1993, Oxford: Clarendon Press 1997, S. 195. 
Flüchtlingslagern wurden Guerilla-Kämpfer*innen ausgebildet, die die verlorene Ehre der palästinensischen Gesellschaft wiederherstellen sollten. Die Figur des Fedaji mit Kalaschnikow wurde zum zentralen Symbol für die Revolution und avancierte zur Ikone des erstarkenden Selbstbewusstseins der Palästinenser*innen. ${ }^{47}$ Die Ikonografie der (überwiegend männlichen) Widerstandskämpfer war im alltäglichen Leben der Flüchtlingslager omnipräsent: Fotografien von Männern, die mit Gewehren in der Hand über Hügel rennen, zirkulierten in Form von Postkarten und wurden in den Zeitungen der Fraktionen abgedruckt. ${ }^{48}$ Die Fedajin wurden in den Filmen des palästinensischen revolutionären Kinos gefeiert, aber auch von europäischen Filmemachern wie Jean-Luc Godard oder Autoren wie Jean Genet bewundert. ${ }^{49}$ In mehreren Berichten beschwört Genet etwa die »wahrhaftigen Gesten« sowie die heroisch-romantische Aura der Fedajin, denen er 1970 in Jordanien begegnet war. ${ }^{50}$

Dieses positive Bild wurde nun auch auf die ersten Selbstmordattentäter*innen übertragen. Neben den heroisch-kämpferischen Elementen trat dabei gerade das Zwischenmenschliche, Weiche und Nicht-Militärische der Darstellungen in den Vordergrund. Die Fotografien, die von der PFLP-GC im Anschluss an ihre zweite Suizidoperation vom 13. Juni 1974 veröffentlicht wurden, zeigen die vier zukünftigen Selbstmordattentäter in innigen, teils zärtlichen Posen. ${ }^{51}$ Mehr noch als in den Fotografien zuvor wurden die jungen Männer als freundschaftliche, einfühlsame Individuen gezeigt und keineswegs als angsteinflößende Attentäter, die ihre Macht durch militärische Härte demonstrieren.

47 Vgl. Laleh Khalili: Heroes and Martyrs of Palestine: The Politics of National Commemoration, Cambridge: Cambridge University Press 2007, S. 94.

48 Vgl. ebd., S. 143.

49 Vgl. Nurith Gertz und George Khleifi: Palestinian Cinema: Landscape, Trauma and Memory, Bloomington: Indiana University Press 2008, S. 22 f.

50 Jean Genet: »Affirmation of Existence through Rebellion«, Journal of Palestine Studies 12(3) (1987), S. 64-84, hier S. 70.

51 Bei der sogenannten »Om El Aakareb« Operation drangen vier Attentäter der PFLPGC vom Libanon aus in den israelischen Kibbuz Schamir ein, erschossen eine Bewohnerin und nahmen zwei weitere Frauen als Geiseln. Einer der Attentäter wurde bereits im Schusswechsel mit den Bewohner*innen getötet, ein anderer tötete sich mit dem mitgebrachten Sprengsatz. Eine halbe Stunde nach Beginn des Anschlags sprengten sich die zwei übrig gebliebenen Attentäter mit ihren Geiseln in die Luft. Vgl. Croitoru: Der Märtyrer als Waffe, S. 93. 
Abbildung 2.7 (links): Fotografie der Attentäter der Om El AakarebOperation, am 14. Juni 1974 auf der Titelseite von al-Anwar abgedruckt. Abbildung 2.8 (rechts): Kamikaze-Piloten der 72. Shinbu-Staffel, Fotografie vom 26. Mai 1945, erschienen in Asahi Shimbun.
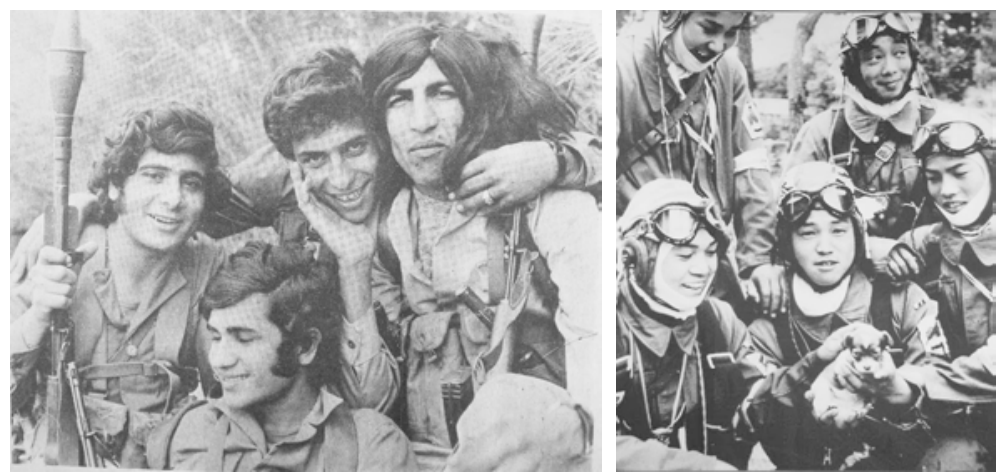

Besonders die Aufnahme, die am 14. Juni auf der Titelseite von al-Anwar abgedruckt wurde (Abb. 2.7), lässt dabei an die Abschiedsfotografien der japanischen Kamikaze-Piloten von 1945 denken. Das Foto, das fünf lächelnde junge Piloten einen Tag vor ihrem Lufteinsatz im Mai 1945 mit einem Hundewelpen zeigt, wurde zur berühmtesten Darstellung der Kamikazeflieger des Zweiten Weltkriegs (Abb. 2.8). Geht man mit Joseph Croitoru davon aus, dass die Taktik des Selbstmordattentats erst durch die Vermittlung der als »Kamikaze« bezeichneten Attentäter der Japanischen Roten Armee in den Nahen Osten importiert wurde, ist es durchaus denkbar, dass die palästinensischen Gruppen auch von diesen frühen japanischen Vorbildern inspiriert waren. ${ }^{52}$ Beide Fotografien (Abb. 2.7 und 2.8) zeigen die zukünftigen Todeskandidaten in geradezu kindlicher Unschuld und Friedfertigkeit, was einerseits durch den Welpen symbolisiert wird, andererseits durch die Berührungsgesten der Palästinenser zum Ausdruck kommt.

Neben dem Vorbild der Kamikaze trat jedoch eine weitere Figur auf den Plan, die erheblichen Einfluss auf den Diskurs um Selbstmordattentate im Nahen Osten nehmen sollte. Schon am Tag nach dem ersten Selbstmordanschlag vom 11. April 1974 wurden die Attentäter in al-Anwar als »šuhāda«, als »Märtyrer« bezeichnet. Auch wenn der arabische Begriff des ìstišhād (Martyrium) ursprünglich aus dem Islam stammt, findet er, wie bereits geschildert, bis heute sowohl in religiösen als auch säkularen Kontexten Verwendung. Am Beispiel der Attentäter von Kirjat

52 Dass diese Darstellungen den Palästinensern durchaus bekannt gewesen sein dürften, argumentiert Croitoru: Der Märtyrer als Waffe, S. 82f. 
Schmona wird die Bandbreite der möglichen Interpretationen des Märtyrerbegriffs besonders deutlich. Während einige Zeitungen und Kommentatoren das Martyrium der drei Männer in einem streng religiösen Sinne priesen und ihre Tat als Opfertod auf dem Weg Gottes betonten ${ }^{53}$ deuteten andere auf die rein nationale Verwendung des Wortes hin. Der Islamwissenschaftler Johnson Nels zitiert die Worte eines palästinensischen Kommentators, der als Reaktion auf das Selbstmordattentat von Kirjat Schmona den nicht-religiösen und überkonfessionellen Gebrauch des Wortes Schahid klarstellte: »It [shahid] was a word in religion, but now it means only a fida' $i$ who is killed. We don't use it as Muslims or as Christians because there is no difference - we are all Palestinians. ${ }^{54}$ Auch von den drei Attentätern selbst wurde das Motiv des Martyriums aufgerufen und im Sinne der nationalen Revolution ausgelegt. In einem an Jassir Arafat adressierten Brief betonten sie die säkulare Bestimmung ihres Märtyrertodes: »As we set out on our suicide mission [amaliyatina al-intihariayah] we declare that our blood [...], like that of all martyrs of the revolution [...] will be a constant reminder of the goal for which we were martyred [...] the liberation of Palestine. $\ll^{55}$

Schahid (in seiner Bedeutung als Märtyrer) und Fedaji, von arab. >al-fid $\bar{a} ' \bar{l}$, $>$ der sich Opfernde` abgeleitet, weisen eine enge semantische Nähe auf und wurden im palästinensischen Sprachgebrauch der 1960er und 1970er Jahren meist synonym verwendet. ${ }^{56}$ Dabei bleibt zu betonen, dass das Konzept des nationalen Martyriums keineswegs als rein palästinensisches Phänomen zu begreifen ist, sondern ebenso durch transnationale, zeitgenössische Diskurse und Repräsentationen beeinflusst war. Wie die iranische Politikwissenschaftlerin Laleh Khalili überzeugend dargestellt hat, war die Würdigung des Selbstopfers auch in anderen revolutionären Befreiungsbewegungen der 1960er und 1970er Jahren geläufig. So pries Che Guevara das Selbstopfer als »vollkommensten Ausdruck« einer Nation, die

53 Das Magazin Filastin (Mai 1974) bezeichnete die drei Männer als fromme Märtyrer, die ins Paradies eingetreten seien und schloss den Bericht mit dem Verweis auf den Koranvers 2:154: »Und sagt nicht von denen, die um der Sache Gottes willen getötet werden, (sie seien) tot. (Sie sind) vielmehr lebendig (im Jenseits)«. Vgl. Nels Johnson: Islam and the Politics of Meaning in Palestinian Nationalism, London: KPI Limited 1982, S. 78.

54 Stellungnahme eines (anonymen) Informanten in Reaktion auf die Attentäter von Kirjat Schmona, zitiert nach ebd., S. 79.

55 Zitiert nach ebd., S. 78.

56 Zur Geschichte der Fedajin in Palästina siehe Khalili: Heroes and Martyrs of Palestine, S. 142. 
für die »Verteidigung ihrer reinsten Ideen und nobelsten Ziele« kämpft. ${ }^{57}$ Der transnationale Befreiungsdiskurs knüpfte zwar an einen religiösen Märtyrerbegriff an, übertrug diesen jedoch in einen säkularen Kontext, bei dem die Nation anstelle der Religion zum Objekt der Verehrung wurde.

Der Aufopferungswille wurde zur höchsten Tugend palästinensischer Kämpfer*innen stilisiert und deren »Selbstsprengung geradezu zu einer Voraussetzung für das wahre Heldentum eines Fedayi« erklärt, so fasst Croitoru die Erkenntnisse seiner historischen Untersuchung zusammen. ${ }^{58}$ Der damit einhergehende Märtyrerkult war zu einem wichtigen Mobilisierungsfaktor innerhalb der bewaffneten Widerstandsbewegung geworden. Die Sichtbarkeit von Märtyrer*innen stellte für die Parteien folglich ein probates Mittel dar, um politische Macht zu demonstrieren. Während Croitoru allerdings nur die Fotografien erwähnt, die in den Parteipublikationen und Tageszeitungen veröffentlicht wurden, blieben die zahlreichen Poster, die in den Folgejahren von den palästinensischen Widerstandsparteien produziert wurden, bislang unbeachtet und zum großen Teil auch unveröffentlicht. Wie ich im Folgenden zeigen werde, entwickelten die Fotografien der ersten Selbstmordattentäter bald schon ein Eigenleben und lieferten das Material für zahlreiche Bildmontagen, mit denen die Parteien ihre Attentäter*innen als populäre Märtyrerikonen präsentierten. Wurde der Bezug zum »Martyrium« bei den Fotografien primär durch begleitende Bildunterschriften hergestellt, schufen die Poster erstmals Bühnen, auf denen das Martyrium der Dargestellten auch visuell bezeugt wurde.

\subsection{KOPIEREN UND ÜBERZEUGEN. PALÄSTINENSISCHE MÄRTYRERPOSTER ALS POP-IKONEN}

Wie ein Blick in die private Postersammlung des Beiruter Publizisten Abboudi Bou Jawdeh zeigt, ${ }^{59}$ veröffentlichte die PFLP-GC in den Jahren nach dem Selbstmordanschlag auf Kirjat Schmona gleich mehrere Poster zu Ehren der drei Attentäter. Auf einem dieser Poster ist auch die oben besprochene Fotografie

57 Ernesto Che Guevara: Venceremos! The Speeches and Writings of Che Guevara, hg. von John Gerassi, London: Panther Books 1969, S. 363 [meine Übersetzung].

58 Croitoru: Der Märtyrer als Waffe, S. 93.

59 Ich danke Abboudi Bou Jawdeh für den Einblick in sein Privatarchiv, das ich während meines Forschungsaufenthalts im Mai 2016 besuchen konnte, sowie für die Möglichkeit zur Reproduktion der bislang unveröffentlichten Poster im Kontext dieser Arbeit. 
wiederzuerkennen, die am 12. April 1974 auf der Titelseite von al-Anwar abgedruckt wurde und hier nun drei Mal hintereinander kopiert erscheint (Abb. 2.9, vgl. Abb. 2.4).

Abbildung 2.9: Poster zu Ehren der drei Attentäter von Kirjat Schmona, PFLP-GC, o.D.

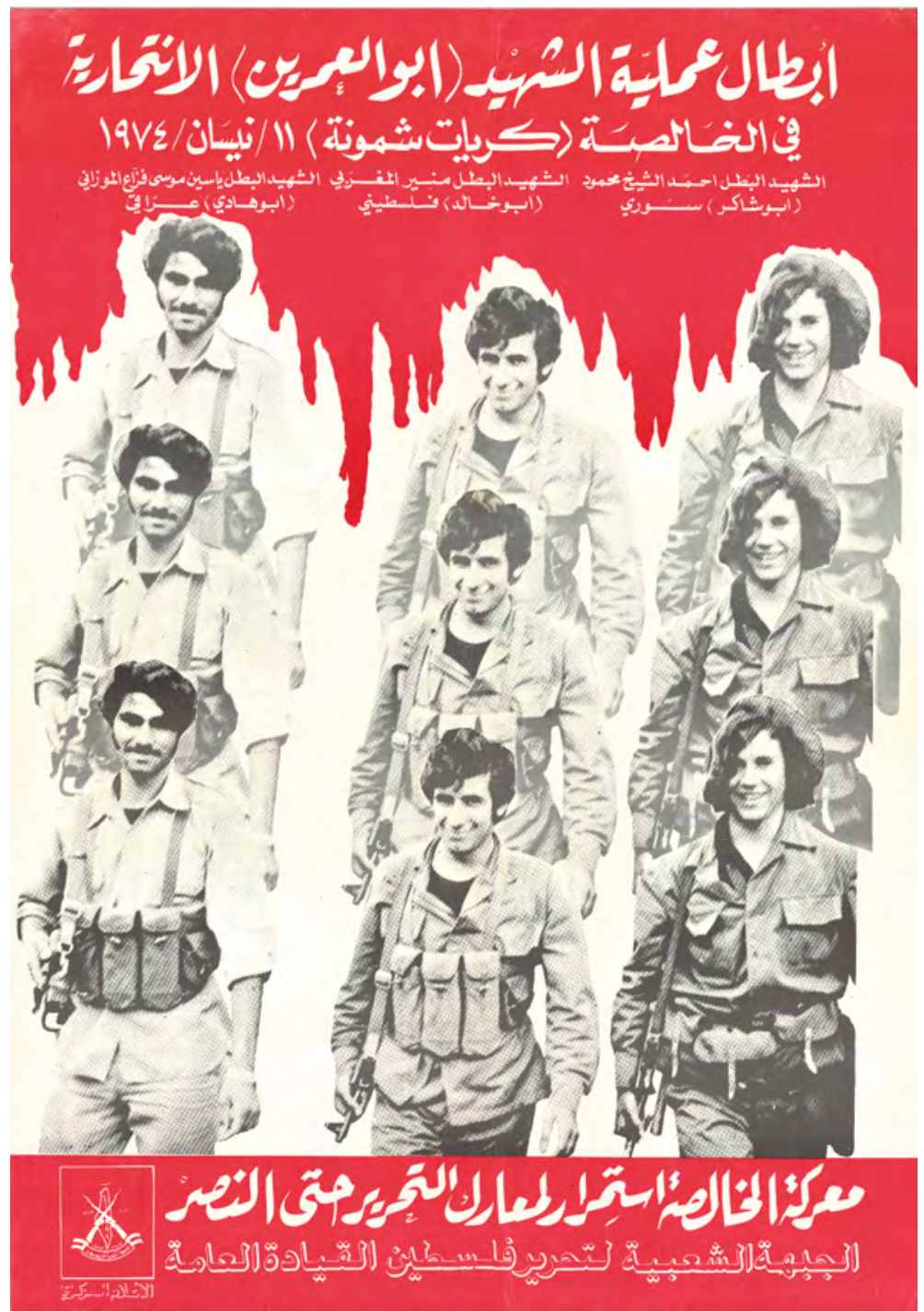


Über der Darstellung ist auf Arabisch zu lesen: »Die Helden der Märtyreroperation in Al-Khalisa (Kirjat Schmona), 11. April 1974. ${ }^{60}$ Darunter werden die Attentäter namentlich aufgezählt und als »Märtyrerhelden« (»al-šahīd al-bațal«) bezeichnet: »der Märtyrerheld Ahmed al-Schaikh Mahmoud, Syrer«, »der Märtyrerheld Mounir Al Maghrebi, Palästinenser« und »der Märtyrerheld Yassin Mousa Faza'a Almouzani, Iraker«. Das Poster wird oben und unten von einem roten Farbstreifen begrenzt, der wie Blut in die Fotoreproduktionen hineinzufließen scheint und auf das >Blutzeugnis` der drei Dargestellten verweist. Das Blut von Märtyrer*innen hat im Islam eine besondere Stellung, da es durch den Märtyrertod als gereinigt gilt. Im Gegensatz zur gängigen islamischen Begräbnispraxis, bei der Waschungen und die vollständige Entkleidung des Leichnams vorgesehen sind, werden Märtyrer*innen ungewaschen und mitsamt ihren Blut getränkten Kleidern begraben. ${ }^{61}$ Diese Praxis spiegelt sich nicht nur in religiösen, sondern auch in politischen Ritualen wider, etwa wenn die Leichname der Verstorbenen in blutigen Laken durch die Straßen getragen werden. Die Präsentation des als rein geltenden Märtyrerblutes dient dabei nicht nur als Beweis für das Martyrium der Gestorbenen, sondern auch als politisches Symbol des andauernden Widerstandskampfes, der keine Opfer scheut. ${ }^{62}$ Allein die Sichtbarkeit des Blutes im Poster, das im farblichen Kontrast zur blassen schwarz-weiß Fotografie besonders dominant hervortritt, kann in diesem Sinne als Zeugnis für den Märtyrerstatus der drei Dargestellten gelten.

Indem die Körper der drei Männer vom Hintergrund der Fotografie losgelöst und vervielfältigt wurden, bezeugt das Poster aber noch etwas Weiteres. Aus drei werden neun Märtyrer gemacht, die wie in einer Armee aufmarschieren und den Eindruck einer prinzipiell endlos erweiterbaren Serie vermitteln. Die Verdreifachung der Portraits im Bild scheint auf den vielfach betonten $\gg$ Nachahmungseffekt $\iota$ des Martyriums zu verweisen. Im Kontext des revolutionären Befreiungsdiskurses wurde das Selbstopfer nicht als ein Zelebrieren des Todes um seiner selbst willen verstanden, sondern als Aufforderung zum Widerstand und Antriebskraft

60 Das genaue Veröffentlichungsdatum des Posters ist unbekannt. Da es jedoch als Bildzitat in einem anderen Poster auftaucht, das zum vierten Jahrestag der Operation am 11. April 1978 veröffentlicht wurde (vgl. Abb. 2.10), muss es zumindest vor diesem Datum, also zwischen April 1974 und April 1978 publiziert worden sein.

61 Dieses Begräbnisritual wird sowohl von Sunnit*innen als auch von Schiit*innen praktiziert und findet sich in Palästina, Iran und im Libanon wieder. Vgl. Khalili: Heroes and Martyrs of Palestine, S. 126.

62 Vgl. ebd. 
für weitere Kampfhandlungen. ${ }^{63}$ In diesem Sinne formulierte auch Munir alMaghrebi, hier in der Mitte dargestellt, in seinem schriftlichen Testament die Überzeugung, dass sein Martyrium einen Anstoß für weitere Nachahmer*innen bieten wird: »Ich werde jetzt gehen und nicht zurückkehren, das weiß ich, und ich weiß auch, daß mir Millionen Revolutionäre dieser Welt auf diesem Weg folgen werden. $\aleph^{64}$ Dass al-Maghrebi mit seiner Einschätzung Recht behalten sollte, machen die acht Selbstmordoperationen deutlich, die allein im Laufe eines Jahres auf die Operation in Kirjat Schmona folgten und mehr als dreißig junge Männer zu Märtyrern werden ließen. Da das genaue Erscheinungsdatum des Posters nicht bekannt ist, bleibt offen, ob das Poster diesem Nachahmungsprozess vorausgreift, oder ihn im Nachhinein bezeugt.

Das Kopieren des Märtyrerbildes im Poster scheint das `Kopieren〈 der Märtyreroperation selbst widerzuspiegeln. Das wirft zwangsläufig die Frage auf, inwiefern der beschriebene Nachahmungseffekt auch von seiner medialen Darstellung abhängt. Für Sigrid Weigel ist der »Seriencharakter« des Martyriums aufs Engste mit der medialen Vervielfältigung verbunden; Gedenkrituale und insbesondere Märtyrerbilder wirkten »als Katalysatoren«, so Weigel, »die zur steten Fortsetzung der Kettenbildung beitragen $\aleph^{65}$. Auch der Philosoph Philipp Wüschner kommt zu dem Schluss, dass der »gefährliche zur Nachahmung einladende Reiz der Märtyrerfigur « unter anderem von dessen »verherrlichenden medialen Repräsentation« ausgehe ${ }^{66}$ Welchen tatsächlichen Anteil die Fotografien und Märtyrerposter an der Mobilisierung weiterer Selbstmordattentäter hatten, kann allerdings nur vermutet werden. Zumindest ansatzweise lässt sich rekonstruieren, in welchen Kontexten die Poster der Kirjat-Schmona-Attentäter produziert und rezipiert

63 Obwohl Che Guevara auf dem trikontinentalen Kongress in Bolivien 1967 betonte, dass unnötige Opfer zu vermeiden sind, stellte auch er das Selbstopfer als Startpunkt einer größeren Revolte dar: »Wherever death may surprise us, let it be welcome, provided that this, our battle cry, may have reached receptive ears and another hand may be extended to wield our weapon and other men may be ready to intone the funeral dirge with the staccato singing of the machine guns and new battle cries of war and victory.« Guevara: Venceremos! The Speeches and Writings of Che Guevara, S. $583 \mathrm{f}$.

64 Al-Anwar veröffentlichte das Testament des Attentäters Munir al-Maghribi am 12. April 1974 in ungekürzter Form. Zitiert nach Croitoru: Der Märtyrer als Waffe, S. 84.

65 Weigel: »Schauplätze, Figuren, Umformungen «, S. 20.

66 Philipp Wüschner: »Widerstand als Ereignis? Der Märtyrer als Beispiel für einen nichtintentionalen, nicht-subjektiven Widerstandsbegriff«, in: Junk, Julian und Christian Volk (Hg.): Macht und Widerstand in der globalen Politik, Baden-Baden: Nomos 2013, S. $31-48$, hier S. 43. 
wurden. Ein Exemplar des oben besprochenen Posters befindet sich im Privatarchiv des Beiruter Publizisten Abboudi Bou Jawdeh, der über Jahre hinweg politische Poster im Libanon sammelte, wo folglich auch dieses Poster verbreitet wurde. Die Mehrzahl palästinensischer Parteien verlagerte ihre Parteizentralen und Medienbüros in den 1960er Jahren nach Beirut, das damals als liberales Zentrum des Nahen Ostens galt. Obwohl die PFLP-GC ihre Hauptzentrale in Damaskus hatte, war auch sie in Beirut präsent, plante von dort ihre Selbstmordoperationen gegen Israel und unterhielt militärische Trainingslager im Libanon. ${ }^{67}$ Ebenso wie die Pressekonferenzen, die direkt nach den Selbstmordanschlägen in Beirut abgehalten wurden, fand wohl auch der Großteil der Posterproduktion hier seinen Ausgang. Wie Zeina Maasri in ihrer Studie zu politischen Postern im Libanon gezeigt hat, wurden Märtyrerposter wie dieses vor allem in Straßen palästinensischer Flüchtlingslager plakatiert, um die nationale Identität zu stärken und Jugendliche für den bewaffneten Widerstand zu mobilisieren. ${ }^{68}$ Unabhängig von der tatsächlichen `Effektivität` dieser Rekrutierungsmaßnahmen scheinen Zeugenschaft und Überzeugung in den Märtyrerpostern eine prinzipielle Verbindung einzugehen.

Noch deutlicher wurde dies in den folgenden Jahren, als dieselben Fotografien der drei Kirjat-Schmona-Attentäter auch in weiteren Postern reproduziert, angeeignet und bearbeitet wurden (vgl. Abb. 2.10, 2.11). ${ }^{69}$ Mit dem Medienwissenschaftler Reinhold Viehoff gesprochen durchliefen die Fotografien dadurch eine Art $»$ Kanonisierungsprozess $\aleph^{70}$. Die über einen längeren Zeitraum andauernde und in unterschiedlichen Medien stattfindende (Re-)Inszenierung von Fotografien beschreibt Viehoff als eine wesentliche Voraussetzung für die Herausbildung moderner Bildikonen. ${ }^{71}$ Dementsprechend ließe sich argumentieren, dass die Märtyrer- und Heldenposter der PFLP-GC dazu beitrugen, dass sich die Fotografien der

67 Vgl. Gary C. Gambill: »Sponsoring Terrorism: Syria and the PFLP-GC«, Middle East Intelligence Bulletin 4/9 (2002), https://www.meforum.org/meib/articles/0209_s1.htm (zugegriffen am 6.6.2021).

68 Maasri: Off the Wall, S. 38.

69 Ein weiteres Poster befindet sich in: https://www.palestineposterproject.org/poster/integrity-is-the-sign (zugegriffen am 6.6.2021).

70 Reinhold Viehoff: »Programmierte Bilder. Gedanken zur ritualisierten Zirkelstruktur von Wahrnehmung und Inszenierung durch die Bild(schirm)medien«, in: Ludwig Fischer (Hg.): Programm und Programmatik. Kultur- und medienwissenschaftliche Analysen, Konstanz: UVK 2005, S. 113-131, hier S. 117.

71 Ebd., S. 117f. 
Kirjat-Schmona-Attentäter in nur wenigen Jahren zu Pop-Ikonen mit hohem Wiedererkennungswert etablierten. ${ }^{72}$

Anlässlich des 4. Jahrestages der »heldenhaften Operation von Al Khalisa«, im April 1978, veröffentlichte die PFLP-GC ein Poster, das diese Ikonisierung selbst zum Motiv machte (Abb. 2.10). Unter der Überschrift »Und der Marsch geht weiter ...« ist eine kaleidoskopartige Montage verschiedener Bildfragmente zu sehen, die zu einem Rechteck aus 8 x 9 Bildquadraten zusammengesetzt sind. Es handelt sich erneut um Detailausschnitte der zuvor besprochenen Fedajin-Aufnahmen, die einerseits heroische Posen wie empor gestreckte geballte Fäuste oder Details von Kalaschnikows zeigen. Die meisten Close-Ups fokussieren jedoch die lachenden oder auch nachdenklich wirkenden Gesichter der drei Männer sowie romantische Naturszenen wie etwa die Darstellung einer Blüte in Mund und Hand eines Attentäters.

Die Details, die aus den Fotografien herausgehoben wurden, vermitteln den Eindruck spontaner Schnappschüsse, die teils unscharf, teils in schrägen Ausschnitten zu sehen sind. Im Gegensatz zur statischen, geradezu wehrhaften Anordnung der Schwarz-Weiß Portraits im Poster zuvor (Abb. 2.9), suggerieren die Ausschnitte aus den Farbfotografien hier eine vertraute Unmittelbarkeit. Dazwischen sind immer wieder auch Miniaturen bereits veröffentlichter Märtyrerposter zu sehen, unter ihnen das oben besprochene Poster sowie ein Poster, das die drei Konterfeis der Attentäter als kreisförmige Embleme auf einer Palästina-Flagge abbildet. ${ }^{73}$ Wie ein $>$ Best-Of^ der Fotografien und Poster entwirft diese Montage ein Panorama der Märtyrerverehrung der Attentäter, die hier als medial präsente Popstars gerahmt werden. Die bisherige Mediengeschichte der Märtyrer wird als Teil des neuen Posters integriert, wodurch die Ikonisierung der Attentäter selbst zur Schau gestellt wird. Durch den Titel »Und der Marsch geht weiter ...« wird außerdem auf die Unabgeschlossenheit des Widerstands hingewiesen, was erneut als Aufforderung zur Nachahmung verstanden werden kann.

72 Die Wiedererkennbarkeit eines Bildes, ebenso wie die hohe Frequenz seiner Veröffentlichung in unterschiedlichen Medien führt auch der Politik- und Kommunikationswissenschaftler David D. Perlmutter als wesentliche Kriterien für die Ikonisierung einer Fotografie an. David D. Perlmutter: Photojournalism and Foreign Policy. Icons of Outrage in International Crises, Westport: Praeger 1998, S. 11f.

73 Dieses Poster nimmt ebenfalls auf den 4. Jahrestag der Operation Bezug. Wenn es hier bereits als Miniatur zitiert wird, muss es nur kurze Zeit vorher erschienen sein. Ein Exemplar davon befindet sich in der Privatsammlung von Abboudi Bou Jawdeh. 
Abbildung 2.10: Poster anlässlich des vierten Jahrestages der Operation von Kirjat Schmona, PFLP-GC, April 1978.

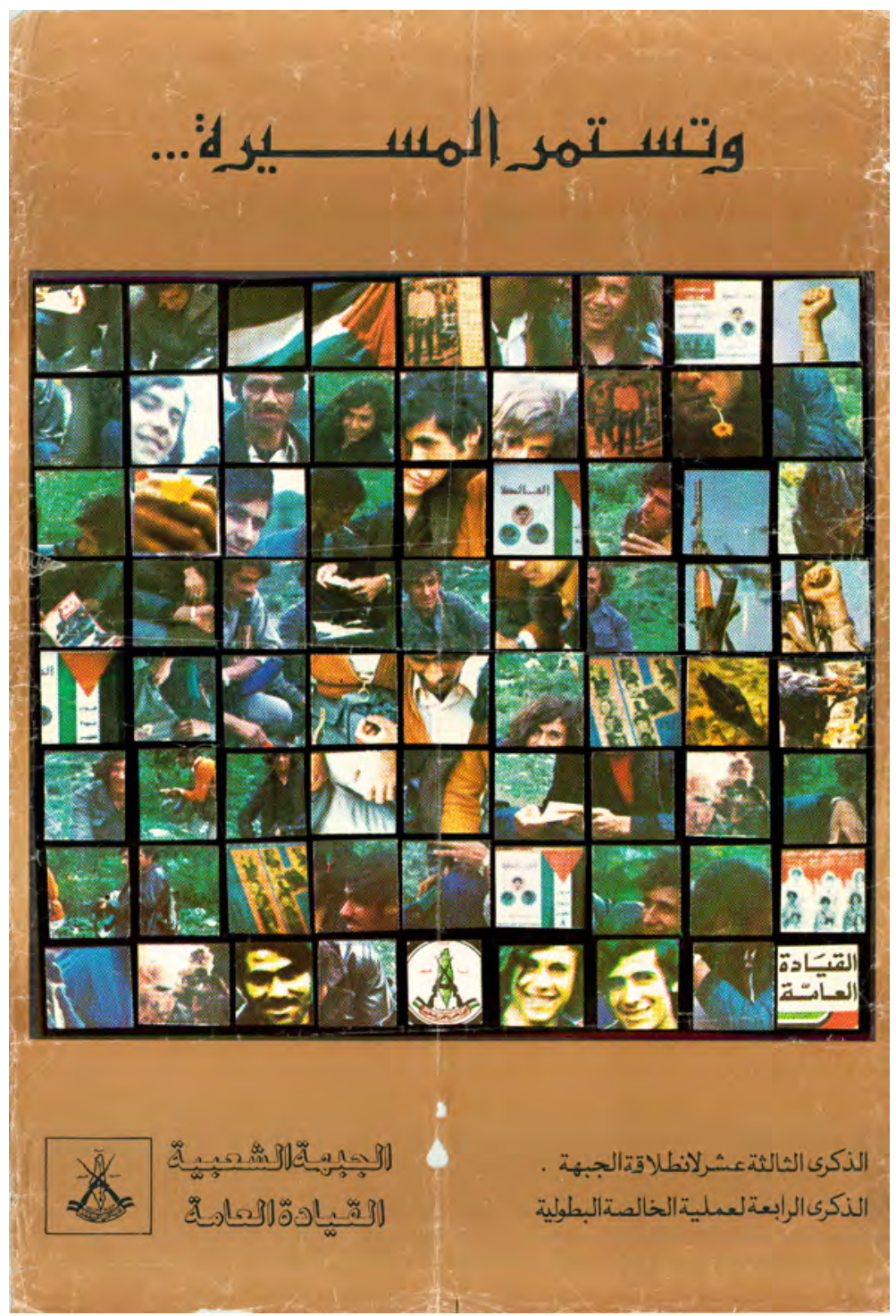

Waren die ersten Poster der Kirjat-Schmona-Attentäter ausschließlich auf Arabisch verfasst und damit an ein lokales, oder zumindest arabischsprachiges Publikum gerichtet, zielten spätere Poster offenbar auch auf internationale Verbreitung 
ab. Ein Poster, das anlässlich des sechsten Jahrestages der »Al-Khalisa-Operation« veröffentlicht wurde und die Fotografie der Attentäter (vgl. Abb. 2.5) mit dem Bild einer Feuerwerksexplosion kombiniert, integriert neben dem arabischen Titel auch eine englische Übersetzung (Abb. 2.11). Auch zwei weitere Poster der PFLP-GC, die dem Selbstmordanschlag auf den Kibbuz Schamir vom 13. Juni 1974 gedenken, bieten englische Übersetzungen der Titel an und machten die Poster damit für ein größeres Publikum zugänglich (Abb. 2.12 und 2.13). Folgt man der Aussage des Grafikers Marc Rudin, der unter dem Pseudonym Dschihad Mansour zwischen 1980 und 1991 zahlreiche Poster für die PFLP erst von Beirut, dann von Damaskus aus entwarf, wurden politische Poster damals auch in Europa, Asien, Afrika oder Lateinamerika verbreitet, um zur Solidarität mit dem palästinensischen Befreiungskampf aufzurufen. ${ }^{74}$ Die zusätzlichen englischen Titel legen nahe, dass dies zumindest teilweise auch für die Märtyrerposter der PFLP-GC galt.

Abbildung 2.11 (links) und 2.12 (rechts): Poster anlässlich des sechsten Jahrestages der Operation von Kirjat Schmona (links) und der Om El Aaakareb Operation (rechts), PFLP-GC, April und Juni 1980.
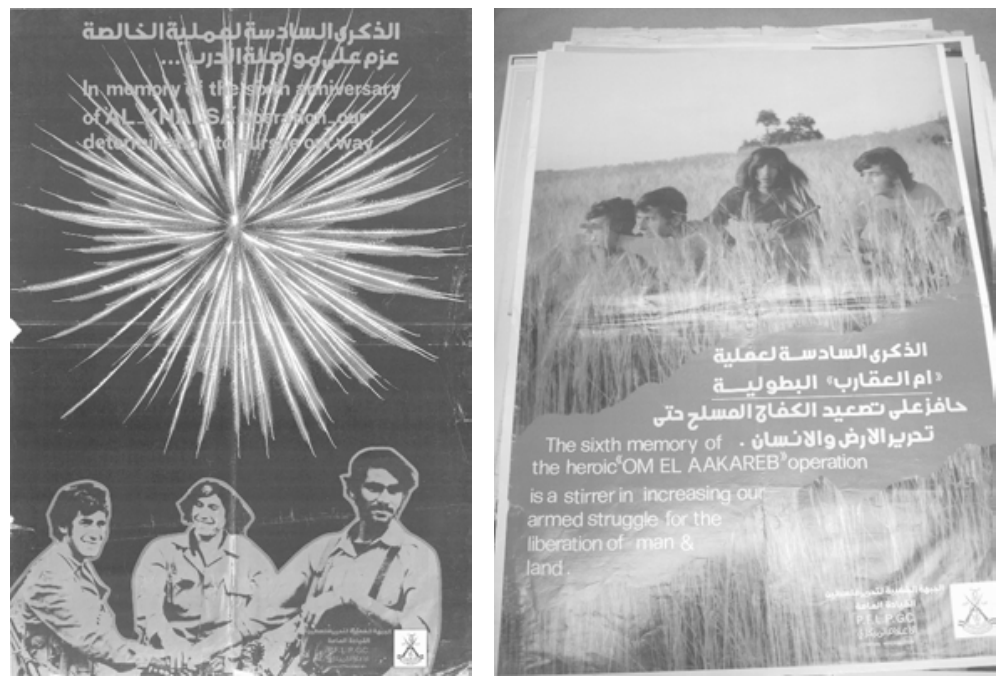

74 Vgl. ein Interview mit Marc Rudin: https://www.nadir.org/nadir/initiativ/rev_linke/sanat/jihad/jihad.htm (zugegriffen am 20.8.2016, nicht mehr verfügbar). 
Abbildung 2.13: Poster zu Ehren der Om El Aaakareb-Operation am 13. Juni 1974, PFLP-GC, o.D.

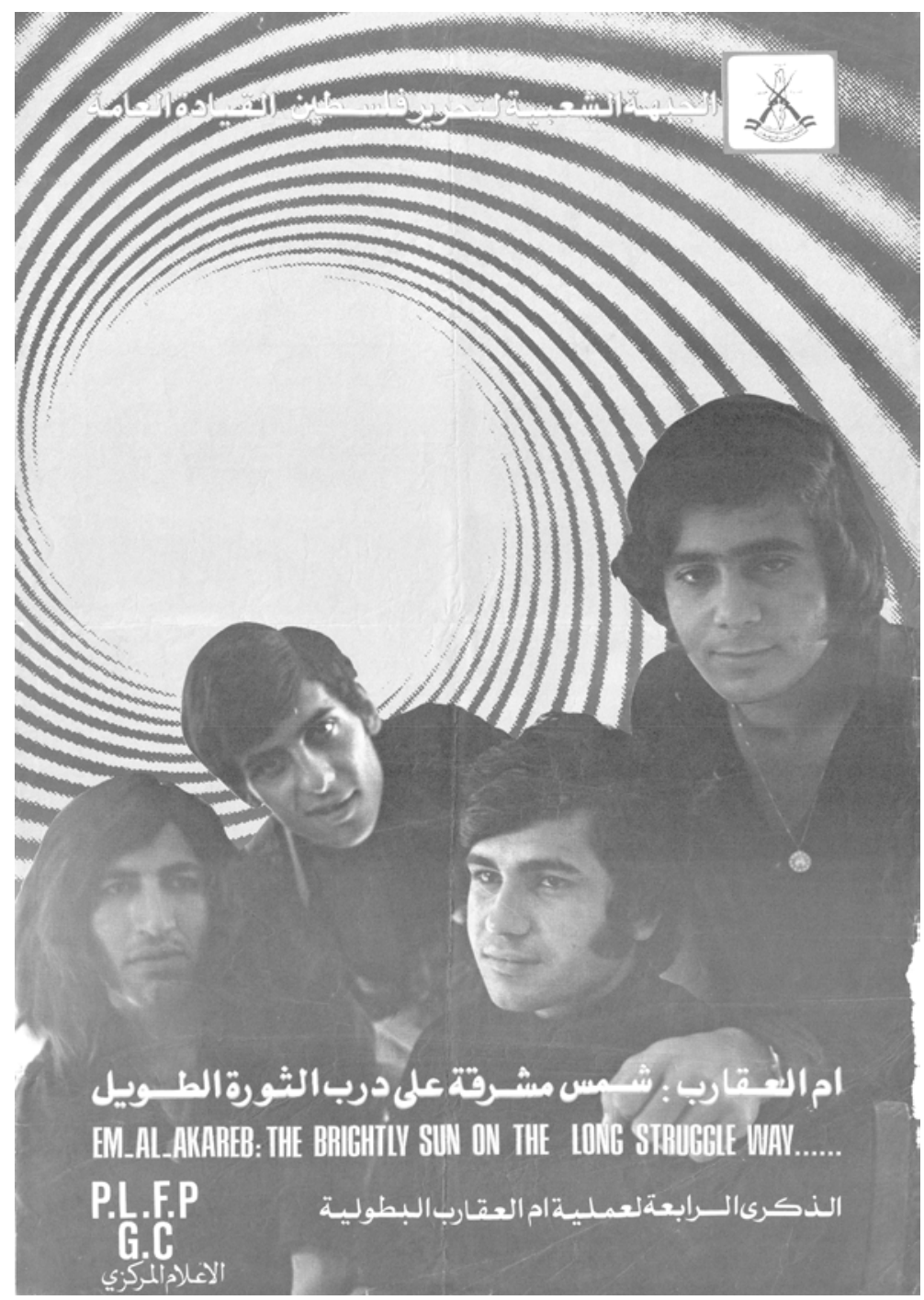

Die Ikonografie der bewaffneten Fedajin nimmt hier sehr deutlich Bezug auf eine internationale Pop-Ästhetik. Eines der bilingualen Poster zeigt ein Gruppenportrait der vier Attentäter, die mit ihren langen Haaren, bzw. Beatles-Frisuren an der Mode der Zeit orientiert sind. Vor einem grafischen Wirbel, der ganz nach $O p$ Art-Manier den Betrachter oder die Betrachterin förmlich ins Bild zu ziehen 
scheint, wirkt das Bild wie das Plattencover einer Musikband (Abb. 2.13). Ein weiteres Märtyrerposter, das anlässlich des 6. Jahrestages der Operation im Jahr 1980 veröffentlicht wurde, zeigt die vier Attentäter in einer Wiese stehend, die in goldenes Licht getaucht erscheint und den Kämpfern eine romantische, geradezu hippieeske Aura verleiht (Abb. 2.12). Das modische äußere Erscheinungsbild vieler Fedajin, gepaart mit der säkularen Auslegung des Martyriums, wurde nicht zuletzt von Vertretern der islamischen Widerstandsbewegung in Gaza scharf kritisiert. Ein gängiger Slogan der islamischen Mujama-Bewegung lautete: »How can uncovered women and men with Beatle haircuts liberate our holy places? $\ll^{75}$

Die Gestaltung der Poster verweist auf die Einbettung des säkularen palästinensischen Widerstands in einen transnationalen Kontext antikolonialer und marxistischer Befreiungskämpfe. ${ }^{76}$ Teilweise war auch schon die Entstehung der Poster durch globale Bewegungen geprägt. Neben prominenten arabischen Künstler*innen aus Ägypten, Syrien oder dem Irak, die Poster für palästinensische Parteien entwarfen, ${ }^{77}$ kamen auch Grafiker aus europäischen Ländern nach Beirut, um mit ihrer Kunst den palästinensischen Widerstandskampf zu unterstützen. Marc Rudin beispielsweise, der unter dem Pseudonym Dschihad Mansour im Auftrag der PFLP Poster (auch Märtyrerposter) entwarf, war ein Grafiker aus der Schweiz ohne arabische oder palästinensische Wurzeln. Nachdem er wegen linksradikalen Anschlägen in Europa gesucht wurde, setzte er sich 1979 nach Beirut ab und solidarisierte sich mit dem palästinensischen Widerstand der PFLP, den er als Fortführung seiner linksradikalen Aktionen in Europa sah. ${ }^{78}$

Die palästinensischen Plakate sind im Kontext einer internationalen Ästhetik politischer Poster zu sehen, die zunehmend als Kunstform wertgeschätzt und popularisiert wurden. Allein in Beirut gab es in den Jahren 1978 und 1979 zwei Ausstellungen, die sich unter anderem den politischen Postern des palästinensischen

75 Zitiert nach Beverley Milton-Edwards: Islamic Politics in Palestine, London: I.B. Tauris 1996, S. 111. Die Mujama al-Islamiya wurde 1973 als islamische Wohlfahrtsorganisation gegründet und kann als Vorläufer der Hamas betrachtet werden.

76 Zur Adaption von transnationalen Diskursen innerhalb der palästinensischen Widerstandsbewegung der 1960er und 70er Jahre siehe Khalili: Heroes and Martyrs of Palestine, S. 11-40.

77 Vgl. Maasri: Off the Wall, S. 39.

78 Vgl. Lucien Scherrer: »Das Leben des Jihad Mansour«, Neue Zürcher Zeitung, 25.01.2016, http://www.nzz.ch/zuerich/das-leben-des-jihad-mansour-1.18682946\#kom mentare (zugegriffen am 6.6.2021). 
Widerstands widmeten. ${ }^{79}$ Auch wenn die Märtyrerposter von Selbstmordattentäter*innen innerhalb dieses Korpus bislang keine Aufmerksamkeit erhielten, scheinen sie im gleichen Kontext entstanden zu sein. Gerade im Vergleich zu den Märtyrerpostern der zweiten Intifada, die sich einem relativ begrenzten Repertoire an nationalen und religiösen Symbolen bedienen und die Portraitbilder in standardisierte Vorlagen einfügen (vgl. Abb. 2.1), lassen die frühen Märtyrerposter der PFLP-GC ganz unterschiedliche gestalterische Mittel erkennen. Auch wenn meist nicht zurückverfolgt werden kann, wer für die Gestaltung der Poster im Einzelnen verantwortlich war, legt die individuelle, teils anspruchsvolle und medienreflexive Gestaltung nahe, dass es sich auch hier um Auftragsarbeiten professioneller Grafiker*innen oder Künstler*innen handelte.

Auch die anderen Parteien, die den Selbstmordattentaten der PFLP-GC nacheiferten, publizierten in den Folgejahren nach den Anschlägen zahlreiche Poster, die an der Ikonisierung ihrer Selbstmordattentäter*innen arbeiteten. Eine Fotocollage der Fatah zeigt unter der Überschrift $»$ Dalal und ihre Kameraden ... Fatah und Palästina/Vereint bis zum Sieg « die 13 Attentäter*innen, die unter Anführung der 19-jährigen Dalal Mughrabi am 11. März 1978 vom Libanon über den Seeweg nach Israel eindrangen (Abb. 2.14). Auf der Küstenstraße nach Tel Aviv entführten sie einen Linienbus und feuerten auf vorbeifahrende Autos und Passant*innen. Während eines Schusswechsels mit dem israelischen Militär, das den Bus kurz vor Tel Aviv stoppen konnte, sprengten sich die Attentäter*innen mitsamt der Buspassagiere selbst in die Luft. ${ }^{80}$ Der von Israel sogenannte >Blutbus-Anschlag ging als das bis dahin brutalste Attentat auf israelische Zivilpersonen in die Geschichte ein. Das Poster, das noch im selben Jahr von der Fatah veröffentlicht wurde, entwirft durch Mittel der Fotocollage ein fiktives Gruppenbild der Verantwortlichen, die zuvor nur durch Einzelfotografien bekannt waren. Obwohl zwei Attentäter bereits vor dem eigentlichen Anschlag auf dem Seeweg ertranken und zwei weitere lebend festgenommen wurden, ${ }^{81}$ konstruiert das Poster das Bild einer geschlossenen, siegreichen Heldentruppe. An diesem Beispiel zeigt sich besonders deutlich, inwiefern die Poster dazu beitrugen, die Anschläge im Nachhinein zu fiktionalisieren und $>$ Wahrheiten $<$ zu erzeugen, die den Fakten der Berichterstattung teilweise entgegenstehen.

79 Die Ausstellung International Exhibition for Palestine wurde 1978 von der PLO Unified Information Office organisiert und fand in der Beirut Arab University statt. 1979 wurde eine zweite Ausstellung am gleichen Ort organisiert, die sich den palästinensischen Postern der Jahre 1967-1979 widmete.

80 Vgl. Croitoru: Der Märtyrer als Waffe, S. 106.

81 Vgl. ebd. 
Abbildung 2.14 (links): Poster zu Ehren des Anschlags vom 11.3.1978, Fatah, 1978. Abbildung 2.15 (rechts): Bildmontage mit Portraits von Dalal Mughrabi und Selbstmordattentäterinnen der zweiten Intifada, FacebookSeite der Fatah, Juli 2014.
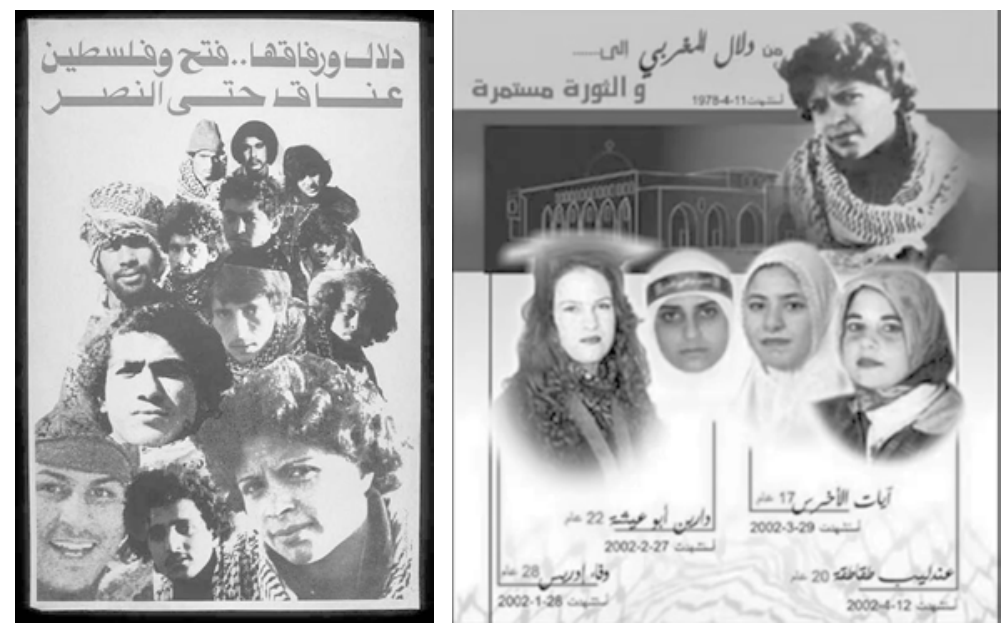

Im Anschluss an das Attentat der Fatah war es jedoch vor allem das Bild von Dalal Mughrabi, das in Form von zahlreichen Postern und Gemälden verbreitet wurde. ${ }^{82}$ Die 19-jährige Attentäterin avancierte schon in kürzester Zeit zu einer Ikone des weiblichen palästinensischen Widerstands und wird bis heute in Musikvideos und Fernsehsendungen der Fatah als heldenhafte Märtyrerin und als Vorbild präsentiert. ${ }^{83}$ So mag es nicht verwundern, dass ihr Bild schließlich auch in Märtyrermontagen der Selbstmordattentäterinnen von 2002 wieder auftauchte. Auf der Facebook-Seite der Fatah wurde im Juli 2014 eine Montage veröffentlicht, das die Portraits der vier Selbstmordattentäterinnen der zweiten Intifada wie in einem

82 Allein das Palestine Poster Project verzeichnet 14 Poster zu Ehren Dalal Mughrabis: http://palestineposterproject.org/special-collection/dalal-mughrabi (zugegriffen am 6.6.2021).

83 Vgl. das Bekenntnis einer jungen Frau, die im Rahmen einer Fatah-Sondersendung zu Ehren Dalal Mughrabis am 3. Januar 2015 sagte: »Dalal Mughrabi has affected me greatly, because she gave me the hope that even though I am a girl, I can defend my homeland.« http://www.palwatch.org/main.aspx?fi=549\&doc_id=15377 (zugegriffen am 6.6.2021). 
Schaubild nebeneinander stellt und einschließlich ihrer Namen, Alter und Daten der Anschläge präsentiert (Abb. 2.15). ${ }^{84}$

Über ihren Portraits, vor einer schwarz-roten Grafik des Felsendoms, schwebt als ideelles Vorbild das Portrait von Dalal Mughrabi, die damit gleichzeitig in den islamisch geprägten Referenzrahmen der zweiten Intifada eingepasst wird. Ähnlich wie im Fall von Wafa Idris wird der säkulare Widerstand Mughrabis im Nachhinein als Akt einer muslimischen Märtyrerin bezeugt - mit dem Unterschied, dass diese Neurahmung nicht direkt nach ihrem Tod, sondern 24 Jahre später geschah. Unter der Überschrift »Die selbstaufopfernden Kämpferinnen der Fatah: Begonnen mit Dalal Mughrabi ... und die Revolution geht weiter« wird im Bild eine historische Kontinuität konstruiert, die den säkularen Widerstand der 1970er Jahre mit den aktuellen Selbstmordattentaten verbindet. Die im Bild konstruierte historische Kontinuität weiblicher Märtyrerinnen verweist dabei erneut auf den Nachahmungscharakter des Martyriums, der durch Ikonen wie Dalal Mughrabi angetrieben wird.

Die mediale Verbreitung des Selbstmordattentäters als Schahid bzw. der Selbstmordattentäterin als Schahida kann als Innovation der säkularen palästinensischen Gruppen gelten. Die konstante (Wieder-)Aneignung führte dazu, dass sich deren Fotografien im kollektiven Bewusstsein der palästinensischen Bevölkerung etablierten. Die ursprünglichen Fedajin-Fotografien wanderten durch zahllose Poster, wurden immer wieder neu als Bilder heldenhafter Märtyrer*innen bezeugt und etablierten sich so als Ikonen, die teilweise bis in die heutige Bildkultur hineinwirken. Die Ikonisierung der Selbstmordattentäter*innen durch Poster erwies sich als erfolgreich, um Aufmerksamkeit und Unterstützung aus den eigenen Reihen zu erzielen. Dies wurde schließlich auch von schiitischen Parteien im Libanon erkannt, die diese mediale Inszenierung für ihre Selbstmordattentate übernahmen und weiterentwickelten.

84 Palestinian Media Watch zufolge wurde das Bild am 20. Juli 2014 als Teil eines Videozusammenschnitts mehrerer Bilder der Selbstmordattentäterinnen auf der FacebookSeite der Fatah gepostet, http://palwatch.org/main.aspx?fi=458\&doc_id=12135 (zugegriffen am 6.6.2021). 


\subsection{DER >ERFOLG، VON BILDOPERATIONEN. DIE ERSTEN SELBSTMORDATTENTATE VON HISBOLLAH UND AMAL}

Eine zweite Welle von Selbstmordattentaten fand nicht auf israelischem Boden, sondern in Beirut während des Bürgerkriegs statt, der von 1975 bis 1990 andauerte. Nach der Invasion israelischer Truppen im Jahr 1982, die in den Libanon mit dem Ziel einmarschierten, die palästinensischen Stützpunkte im Land zu zerstören, beteiligten sich viele Bürgerkriegsparteien am Widerstand gegen die israelische Besatzung. Damit änderte sich auch die militärische Strategie im Libanon. Waren die Auseinandersetzungen der ersten Bürgerkriegsjahre vor allem durch Straßengefechte geprägt, wurden ab 1982 immer häufiger auch Selbstmordattentate gegen israelische oder westliche Ziele eingesetzt. Am 11. November 1982 verübte der 15-jährige Südlibanese Ahmad Qasir ein Attentat, das als das erste Selbstmordattentat im Kontext des libanesischen Bürgerkriegs gilt. ${ }^{85}$ In einem mit Sprengstoff beladenen Auto fuhr Ahmad Qasir in das Verwaltungsgebäude der israelischen Besatzungsarmee in Tyros und riss 75 israelische Soldaten und Geheimdienstmitarbeiter mit sich in den Tod. Der Attentäter und die genauen Umstände der Aktion blieben zunächst unbekannt und erst zweieinhalb Jahre später bekannte sich die Hisbollah zu dem Anschlag, die bis dahin unter dem Decknamen Islamischer Dschihad agierte.

Mit diesem Anschlag wurde das Selbstmordattentat nun auch von einer islamischen Partei als militärische Strategie gegen Israel eingesetzt. Im Unterschied zu den säkularen palästinensischen Parteien war die schiitische Hisbollah allerdings vor das Problem gestellt, ihre Anschläge mit dem strikten Suizidverbot im Islam zu vereinbaren, das in mehreren Koranversen und den Prophetenberichten ausgesprochen wird. ${ }^{86}$ Folglich wurden die Anschläge nicht mehr als »Selbstmordkommandos « (arab. »mağmū a intiharīya«) bezeichnet, wie dies noch im säkular-palästinensischen Kontext geläufig war, stattdessen prägte die Hisbollah erstmals den Begriff der »Märtyrertod-Operation« (arab. " 'amalīya istišsādiy $a{ }^{87}{ }^{87}$ ). Wie der Politikwissenschaftler Bashir Saade gezeigt hat, unterscheidet die Hisbollah mehrere Typen von Märtyrern, die abhängig von der Art ihres Todes

85 Die Taktik des Autobomben-Anschlags wurde schon ein Jahr früher, im ideologischen Zusammenhang mit dem Iran-Irak-Krieg eingeführt, als sich am 12.12.1981 ein vom Iran unterstützter Attentäter nahe der irakischen Botschaft in Beirut in die Luft sprengte. Mit der Hisbollah sollte sich diese Taktik jedoch in beispiellosem Ausmaß verbreiten.

86 Vgl. Günther: »Corpus delicti - der Körper als Tatwerkzeug«, S. 27.

87 Vgl. Croitoru: Der Märtyrer als Waffe, S. 38; 197. 
kategorisiert werden ${ }^{88}$ Im Unterschied zu gewöhnlichen Kämpfern, die bei militärischen Gefechten ums Leben kommen, werden Selbstmordattentäter von der Hisbollah als istišhädīyyūn bezeichnet, das abgeleitet vom Wortstamm šahāda so viel bedeutet wie: >diejenigen, die das Zeugnis/Martyrium suchen darauf hingewiesen, dass das Konzept des istišha $\bar{d}$ als Strategie des >heiligen Krieges` eine gänzlich moderne Idee ist, die nicht auf Schriften im Koran zurückzuführen ist. ${ }^{89} \mathrm{Im}$ Koran tauchte der Begriff des $\check{s} a h \bar{l} d$ ursprünglich nur in seiner Bedeutung als `Zeugnis auf - sowohl im juristischen Sinne als Zeugenaussage vor Gericht, als auch im religiösen Sinne als Bekenntnis des Glaubens. Dementsprechend wird mit Schahada ( $a \check{s}$-šahāada) gemeinhin das islamische Glaubensbekenntnis bezeichnet, das eine der fünf Säulen des Islam bildet. ${ }^{90}$ Obwohl das Konzept des Martyriums im Koran verwurzelt ist, wird es an keiner Stelle mit dem Wortstamm šahāda in Verbindung gebracht. Erst später hat sich die Etymologie des `Bezeugens` auch auf Märtyrer*innen übertragen, deren Tod als eine extreme Form des Glaubenszeugnisses beschrieben wurde. ${ }^{91}$

Für Schiit*innen liegt die Bedeutung des Martyriums ( $\breve{s} a h \bar{a} d \bar{a} t)$ vor allem im Opfertod des Imam Hussein begründet, der in der Schlacht von Kerbala im Jahr 680 v. Chr. von einem sunnitischen Kalifen getötet wurde. Sein religiöses Selbstopfer wird bis heute am Tag der Aschura, teils von Bußritualen und Selbstkasteiungen begleitet, verehrt. Der Ideologe der iranischen Revolution Ali Shariati war einer der ersten, der die Erzählung von Kerbala in ein Narrativ verwandelte, um militärische Selbstmordangriffstaktiken während des Krieges gegen den Irak (1980-88) zu mobilisieren. ${ }^{92}$ Kurze Zeit vor Ahmad Qasirs Attentat setzte der Iran bereits erste Selbstopfer-Aktionen als Kriegstaktik ein. Nach dem iranischen

88 Bashir Saade: »Martyrology and Conceptions of Time in Hizbullah's Writing Practices«, International Journal of Middle East Studies 47/04 (2015), S. 723-744, hier S. 731.

89 Asad: On Suicide Bombing, S. 52.

90 Die Schahada wird im Deutschen übersetzt mit: »[Ich bezeuge, dass...] Es gibt keinen Gott außer Gott, und [ich bezeuge, dass...] Mohammed ist der Gesandte Gottes «.

91 Einige Forscher*innen gehen davon aus, dass diese Begriffswandlung dem christlichen Einfluss geschuldet war. Vgl. Dominika Bennacer: »Bearing Witness to the (In)visible: Activism and the Performance of Witness in Islamic Orthopraxy«, Performance Research 13/3 (2008), S. 64-76, hier S. 69.

92 Vgl. Ervand Abrahamian: »Ali Shari'ati: Ideologue of the Iranian Revolution«, in: Edmund Burke und Ira M. Lapidus (Hg.): Islam, Politics, and Social Movements, Comparative Studies on Muslim Societies, Berkeley: University of California Press 1988, S. 289-297. 
Vorbild wurde der schiitische Gründungsmythos schließlich auch von der Hisbollah für militärische Zwecke instrumentalisiert. Der schiitische Geistliche und Hisbollah-Berater Muhammad Hussein Fadlallah pries die Selbstmordoperationen gegen die israelischen Truppen im Südlibanon als »Kerbala des Südens « ${ }^{93}$. Die Gewissheit der Gläubigen, das Martyrium im Paradies zu erlangen, wurde von der Hisbollah damit gezielt in ihre Kriegspläne integriert. Eine Strategie, die Martin Kramer als »Kalkül des Dschihad « bezeichnet hat. ${ }^{94}$ Im Jahr nach Qasirs Anschlag verübte die Partei mehrere groß angelegte Selbstmordattentate, darunter das Attentat auf die US-Botschaft in West-Beirut am 18. April 1983, das 63 Menschen das Leben kostete, sowie der Doppelanschlag auf das Hauptquartier der USMarines und den Sitz der französischen Fallschirmtruppen am 23. Oktober 1983 mit 241 Todesopfern. ${ }^{95}$ Bei keinem der Anschläge, die allesamt unter dem Decknamen Islamischer Dschihad erfolgten, wurden Namen oder Bilder der verantwortlichen Attentäter veröffentlicht. Mit dem Aufkommen dieser, im Libanon als erfolgreich gefeierten Selbstmordattentate sah sich auch die schiitische Amal im Zugzwang, ähnliche Aktionen durchzuführen. Zu dieser Zeit hatten sich die Rivalitäten zwischen der vom Iran unterstützten Hisbollah und der pro-syrischen Amal-Miliz zugespitzt, die einen »kompetitiven Guerilla-Krieg« gegen die westliche und israelische Präsenz im Land ausfochten. ${ }^{96}$

Am 16. Juni 1984 verübte schließlich auch die Amal ein Selbstmordattentat nach dem Vorbild von Ahmad Qasir. Der 17-jährige Bilal Fahs verübte, ebenfalls mit einer Autobombe, einen Anschlag auf ein israelisches Militärkonvoi nahe der südlibanesischen Stadt Sidon, bei dem außer ihm selbst niemand getötet wurde. Im Unterschied zu den Operationen der Hisbollah ließ das Attentat der Amal jedoch eine andere mediale Strategie erkennen, die eher am palästinensischen Vorbild orientiert war. Direkt nach dem Selbstmordanschlag bekannte sich die Partei offiziell zur Tat und veröffentlichte Namen und Testament ihres Attentäters. Nur

93 Zitiert in Martin Kramer: »Sacrifice and `Self-Martyrdom» in Shi'ite Lebanon«, in: Ders. (Hg.): Arab Awakening and Islamic Revival: The Politics of Ideas in the Middle East, New Brunswick, N.J.: Transaction Publishers 1996, S. 231-243, http://martinkramer.org/sandbox/reader/archives/sacrifice-and-self-martyrdom-in-shiite-lebanon/ (zugegriffen am 6.6.2021), hier o.S.

94 Martin Kramer: »Hisbollah: The Calculus of Jihad«, in: Martin E. Marty und R. Scott Appleby (Hg.): Fundamentalisms and the State: Remaking Polities, Economies, and Militance, Bd. 3, Chicago: University of Chicago Press 1993, S. 539-556.

95 Vgl. Pedahzur: Suicide Terrorism, S. 46ff.

96 Kramer: »Sacrifice and `Self-Martyrdom〈 in Shi'ite Lebanon«, o.S. 
wenige Zeit später muss auch das Poster entstanden sein, das Bilal Fahs als »Bräutigam des Südens « und »Märtyrer « feiert (Abb. 2.16). ${ }^{97}$

Abbildung 2.16: Nabil Kdouh (Künstler), Poster zu Ehren des Anschlags von Bilal Fahs, Amal, 1984.

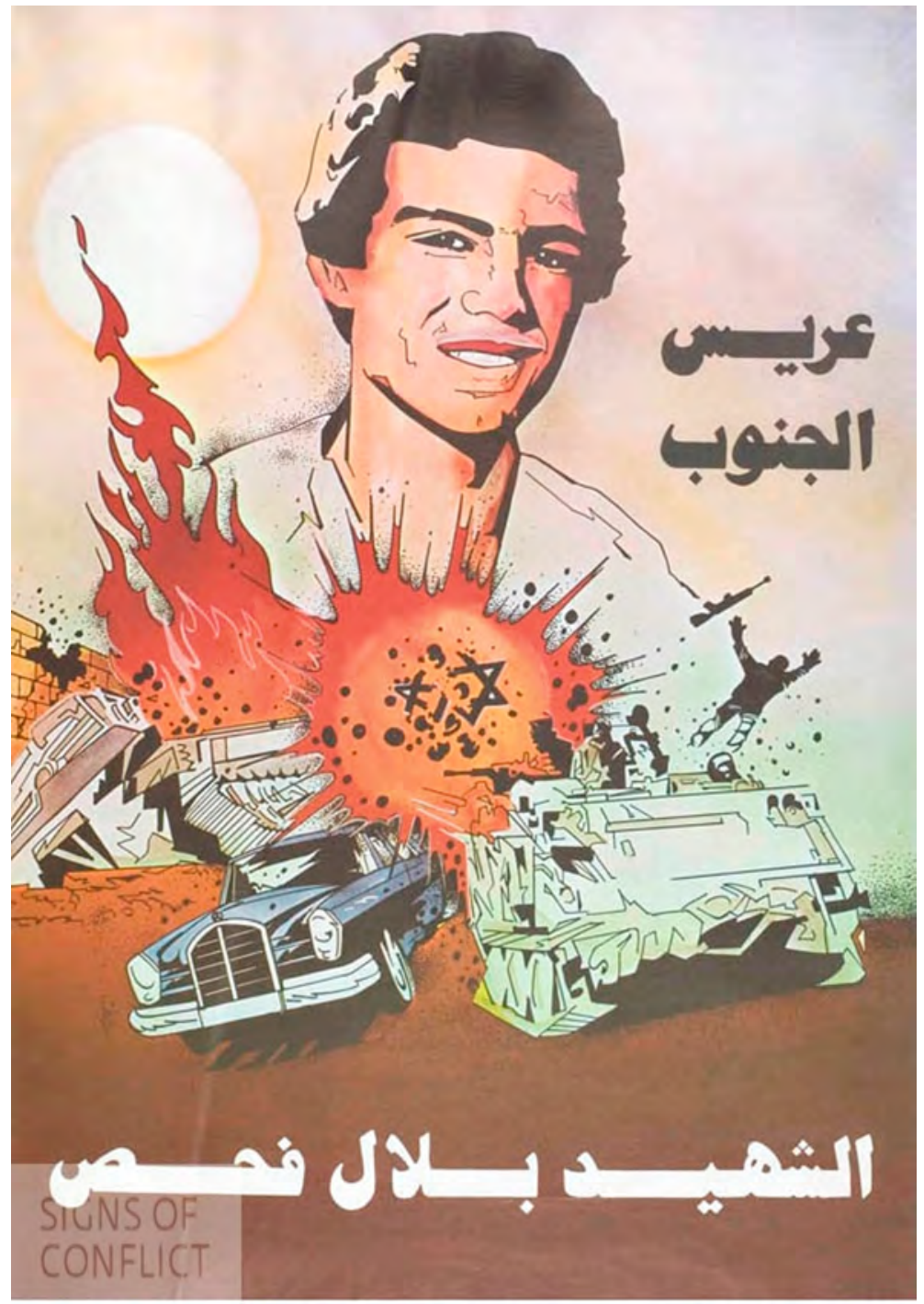

97 Siehe die Poster-Inschriften: »Bräutigam des Südens«/ »Der Märtyrer Bilal Fahs«. 
Das Poster wurde von Nabil Kdouh gestaltet, einem professionellen CartoonKünstler, der während des Bürgerkriegs Aufträge für verschiedene Parteien ausführte, vor allem aber mit der schiitischen Amal zusammenarbeitete. ${ }^{98}$ Die obere Bildhälfte lässt das Konterfei von Bilal Fahs erkennen, das detailgetreu nach einem Portraitfoto des Attentäters gestaltet wurde. Neben einer weißen Sonne schwebt sein Bild scheinbar in himmlischen Sphären, während sich unter ihm eine dramatische Szene in Comic-Ästhetik abspielt. Aus dem ansonsten unversehrt dargestellten Täterauto ragen Flammen auf, in deren Mitte ein Davidstern in mehrere Teile zerbricht. Rechts davon ist ein israelischer Panzer abgebildet, von dem der Körper eines Soldaten durch den Druck der Explosion in die Luft katapultiert wird.

Dass die Zerstörung selbst im Märtyrerposter erscheint, stellt eine Neuerung im Vergleich zu den palästinensischen Postern dar. Das visuelle Bezeugen des Martyriums wird so mit einem weiteren Zeugnis - einem vermeintlich abbildhaften >Beweis` für die erfolgreiche Tat - verbunden. Angesichts des eigentlichen militärischen Scheiterns der Operation, bei der kein Feind ums Leben kam und auch das Gebäude des israelischen Außenpostens nur leichten Schaden nahm, ${ }^{99}$ wird deutlich, dass die dargestellte Heldentat des Märtyrers ausschließlich im Bild konstruiert wird. Obwohl die Operation der Amal militärisch unbedeutend war, avancierte Bilal Fahs innerhalb kürzester Zeit zu einer Ikone des südlibanesischen Widerstands. Folgt man Joseph Croitoru, so war das Poster von Nabil Kdouh nach dem Anschlag an allen Straßenecken im schiitisch geprägten Südlibanon präsent. ${ }^{100}$ Die (aus Sicht der Amal) >erfolglose « militärische Operation schien paradoxerweise von einer umso >erfolgreicheren` Bildoperation gekrönt. In den Folgejahren wurden zahlreiche weitere Poster mit dem Portrait des Selbstmordattentäters veröffentlicht, die bis heute in den von der Amal dominierten Gegenden im Libanon präsent sind. ${ }^{101}$

Vieles spricht dafür, dass die schnelle Popularität des Märtyrerbildes von Bilal Fahs schließlich auch die Hisbollah dazu veranlasste, von einer Strategie der Unsichtbarkeit zu einer Strategie der Sichtbarkeit zu wechseln. Wie Joseph Croitoru dargestellt hat, bekannte sich die Partei mit über zweijähriger Verspätung am 24. Mai 1985 erstmals offiziell zu dem Attentat von Ahmad Qasir und veröffentlichte sowohl den Namen als auch ein Bild des Attentäters, dem das bekannte Poster Bilal Fahs' offensichtlich als Vorlage diente. Das »aus den Trümmern des

98 Vgl. Maasri: Off the Wall, S. 47.

99 Vgl. Kramer: »Sacrifice and \Self-Martyrdom〈 in Shi'ite Lebanon«, o.S.

100 Croitoru: Der Märtyrer als Waffe, S. 138.

101 Vgl. Kramer: »Sacrifice and `Self-Martyrdom〈 in Shi'ite Lebanon«, o.S. 
zerbombten Ziels aufragende Konterfei« Ahmad Qasirs »prangte zunächst im organisationseigenen Presseorgan Al-Ahd und dann einige Zeit später in der Hizbullah nahestehenden Zeitschrift Al-Muntalaq « ${ }^{102}$. Bei dem von Croitoru erwähnten Bild handelt es sich offenbar um dieselbe Fotomontage, die anschließend auch in Form eines Posters Verbreitung fand (Abb. 2.17). ${ }^{103}$ Die rote Schrift im Zentrum des Posters preist Ahmad Qasir als »den ersten in der Herrschaft des Heldentums « und als »Pionier der Märtyrer-Operationen«. Weiter unten wird er namentlich als »der glückliche Märtyrer Ahmad Qasir« benannt. Gerade in Reaktion auf die mediale Verbreitung Bilal Fahs beansprucht die Hisbollah damit nachträglich die Urheberschaft der »Märtyrer-Operationen«.

Ikonografisch schließt das Bild an das Poster der Amal an, das den exakt selben Bildaufbau mit anderen Mitteln imitiert. In den Rauchwolken über den Trümmern des Tatorts erscheint das Portraitbild des Attentäters, das von einem strahlenförmigen Lichtkranz nach unten hin abgegrenzt ist. Das im Himmel schwebende Portrait kann bereits als Verweis auf die islamische Vorstellung des Weiterlebens von Märtyrer*innen im Jenseits gelesen werden, auch wenn die Paradies-Symbolik in späteren Hisbollah-Postern noch weitaus deutlicher zutage treten wird. Im Gegensatz zu den Darstellungen der palästinensischen Attentäter*innen präsentiert die schiitische Partei ihren Märtyrer nicht als Guerilla-Kämpfer mit Kalaschnikow, der im Diesseits für die Revolution kämpft, sondern eingebettet in eine Szene, die trotz ihrer Betonung der materiellen Zerstörung geradezu mystisch entrückt wirkt. Während das Poster der Amal durch die Comic-Ästhetik noch an die popkulturelle Bildsprache der palästinensischen Märtyrerposter anschließt, wirkt die Szene im Hisbollah-Poster, nicht zuletzt durch die zurückhaltende Sepia-Färbung und den ernsten Gesichtsausdruck des 15-Jährigen, weitaus ehrwürdiger. Dass hier statt einer Comiczeichnung auf Fotografien des Tatorts zurückgegriffen wurde, scheint der Darstellung zudem mehr Beweiskraft zu verleihen. Als wollte sie belegen, dass von ihrem Anschlag (im Gegensatz zu dem von Bilal Fahs) tatsächliche fotografische Augenzeugnisse der erfolgreichen Zerstörung existieren, nutzt die Hisbollah eine Pressefotografie als Grundlage für ihr

102 Croitoru: Der Märtyrer als Waffe, S. 146.

103 Die Inschrift rechts oben verweist auf die »zweite Gedenkfeier der ersten Märtyreroperation in Jabal'Amel«. Nimmt man dies als Verweis auf das Publikationsdatum des Posters, müsste es bereits zum zweiten Jahrestag der Operation, also am 11. November 1984 erschienen sein. In beiden Fällen - der Veröffentlichung am 11. November 1984 oder nach dem 24. Mai 1985 - ist das Poster jedoch nach dem Attentat von Bilal Fahs entstanden. 
Märtyrerposter, die kurz nach dem Anschlag vom zerbombten Verwaltungsgebäude in Tyros im November 1982 aufgenommen wurde.

Abbildung 2.17: Märtyrerposter zu Ehren des Anschlags von Ahmad Qasir, $50 \times 70 \mathrm{~cm}$, Hisbollah, Mai 1985 oder November 1984.

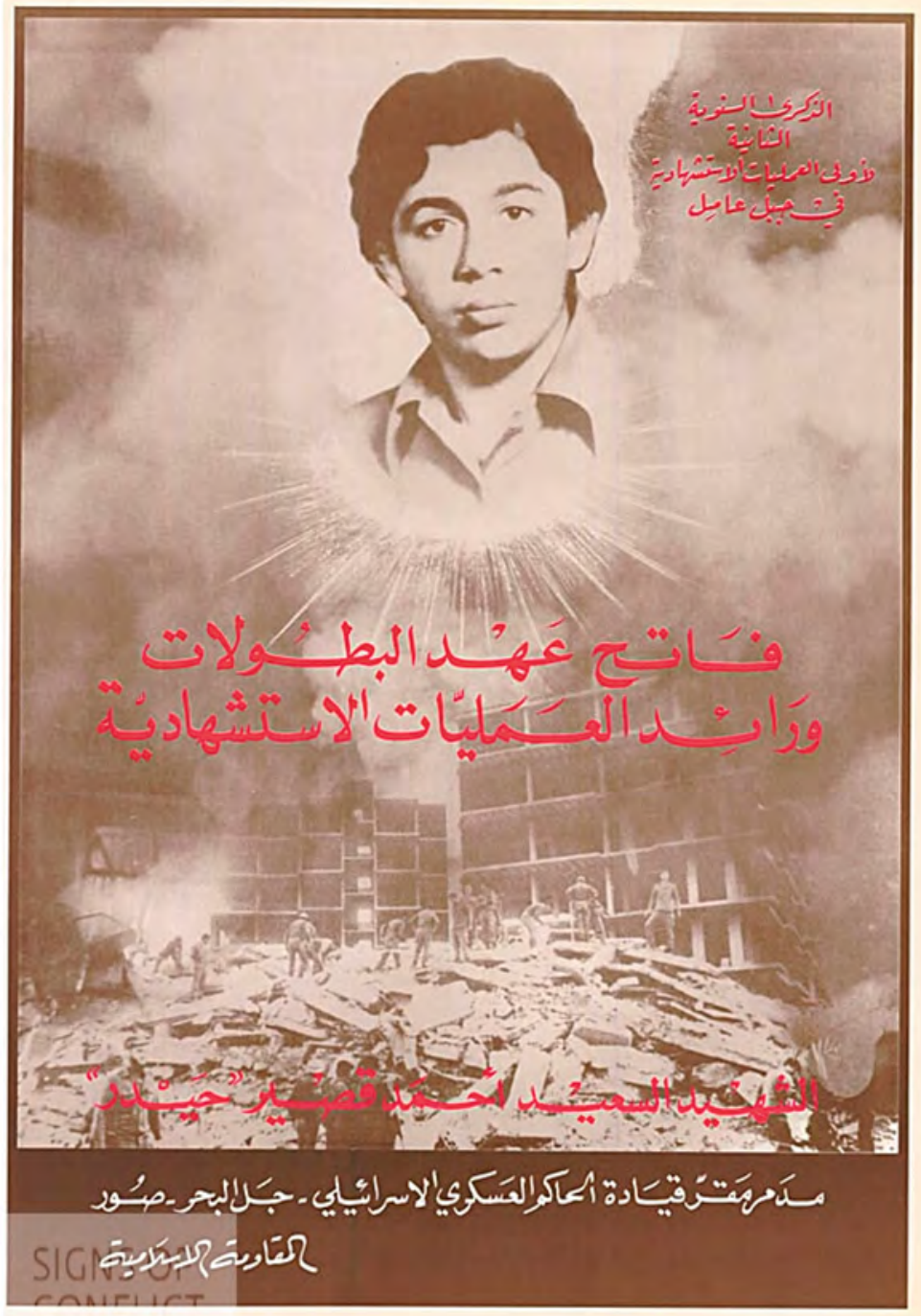


Das Märtyrerposter der Hisbollah ist damit als unmissverständliche Antwort auf das Poster der Amal zu verstehen, deren machtpolitischer Kampf nun auch mit visuellen Mitteln ausgetragen wurde. Obwohl die Hisbollah für das erste Selbstmordattentat im Libanon verantwortlich war, gelang es der Amal zuerst, ihren Selbstmordattentäter auch als wiedererkennbaren Märtyrerheld zu profilieren. Gerade angesichts des aus militärischer Sicht >gescheiterten ` Attentats von Bilal Fahs wird deutlich, dass der 〉Erfolg< einer Märtyreroperation nicht nur an ihren militärischen Resultaten, sondern auch an der Popularität ihrer Akteure gemessen wurde. Im Vergleich zu den Attentaten von Ahmad Qasir und Bilal Fahs forderten die Anschläge der Hisbollah auf die US-amerikanischen und französischen Stützpunkte im April und Oktober 1983 wesentlich mehr Todesopfer und auch in der westlichen Berichterstattung erreichten diese Anschläge eine weitaus größere mediale Aufmerksamkeit. In ihrer physischen wie psychologischen Schlagkraft gegenüber dem Feind können diese Attentate für die Hisbollah daher als weitaus effektiver gelten als der Anschlag von Ahmad Qasir. Die Attentäter von 1983 sind jedoch bis heute anonym und damit unsichtbar geblieben, was Martin Kramer zufolge eine größere Distanz zwischen der südlibanesischen Bevölkerung und diesen Taten etablierte. ${ }^{104}$ Die Gesichter von Ahmad Qasir und Bilal Fahs hingegen sind in den schiitisch geprägten Gegenden im Süden Libanons als Nationalhelden und Märtyrerikonen bekannt und auch heute noch in Form von Postern oder Gedenktafeln omnipräsent. ${ }^{105}$ Zumindest im Konkurrieren um langfristige Aufmerksamkeit und Unterstützung innerhalb der lokalen schiitischen Bevölkerung scheinen diese Bildoperationen - hier: die Verwandlung der Attentäter in populäre Märtyrerikonen - >erfolgreicher gewesen zu sein als die eigentlichen Selbstmordoperationen.

\subsection{BILDOPERATIONEN IM RAUM. MÄRTYRERPOSTER IN SERIENPRODUKTION}

Nach den ersten Autobombenanschlägen der Hisbollah und Amal nutzten bald auch andere libanesische Parteien das Selbstopfer als Waffe gegen die israelische Besatzung. Neben den schiitischen Organisationen im Süden des Landes konkurrierten insbesondere die säkularen Parteien der Libanesischen Nationalen

104 Kramer: »Sacrifice and \Self-Martyrdom〈 in Shi'ite Lebanon«, S. o.S.

105 Siehe etwa die zahlreichen Gedenktafeln mit Portraitbildern von Ahmad Qasir in: David Batty und Kevin Toolis (Regie): The Cult of the Suicide Bomber, Dokumentarfilm, 96 min, Vereinigtes Königreich 2005. 
Widerstandsfront (LNRF), darunter die Libanesische Kommunistische Partei (LCP) und die Syrische Soziale Nationalistische Partei (SSNP), um sogenannte Märtyrertod-Operationen und überboten sich in ihrer Bereitschaft zum Selbstopfer. ${ }^{106}$ Wie schon unter den palästinensischen Widerstandsparteien der 1970er Jahre, wurde die Anzahl der Märtyrer*innen zur entscheidenden Währung im Konkurrenzkampf der rivalisierenden Parteien: »The number of fallen heroes becomes an indicator of a party's share of participation on a front and a proof of its commitment and sacrifice in the defence of an existential cause «, so beschreibt Zeina Maasri die Dynamik zwischen den libanesischen Parteien: »Martyrs are hence attributed a great deal of importance within parties and factions. $\ll^{107}$

Im Gegensatz zu den bisherigen Beispielen, in denen einzelne wenige Märtyrer*innen ikonischen Status erhielten, war es nun vor allem die schiere Masse an Individuen, die zum bestimmenden Gestaltungsmerkmal der Poster wurde. Jede getötete Person, die eine Partei zu beklagen hatte, egal ob diese unbeabsichtigt während der Gefechte ums Leben kam oder als Selbstmordattentäter*in den eigenen Tod gezielt als Waffe einsetzte, wurde durch Märtyrerposter erinnert. Das mediale Bezeugen der Martyrien wurde zu einer Maschinerie, die in der Serienproduktion von Postern ihren Ausdruck fand. Diese entstanden meist unter erschwerten Kriegsbedingungen und angesichts der hohen Anzahl der Todesopfer unter enormem Zeitdruck, was zu einer Standardisierung der Produktionsprozesse führte. ${ }^{108} \mathrm{Im}$ Gegensatz zu anderen Genres politischer Poster, die etwa einzelnen Parteiführern oder bedeutsamen Gedenktagen gewidmet waren, wurden die Märtyrerposter nicht mehr von professionellen Künstler*innen gestaltet, sondern von den Medienbüros der Parteien selbst produziert und häufig direkt in den Druckereien hergestellt. Zeichneten sich die frühen palästinensischen Poster, ebenso wie die von Bilal Fahs und Ahmad Qasir, noch durch eine individuelle Gestaltung mit teils künstlerischem Anspruch aus, standardisierte sich das Layout der Märtyrerposter während des Bürgerkriegs zunehmend. Es wurden grafische Vorlagen mit dem jeweiligen Logo der Partei erstellt, in die das Portraitbild, häufig ein gewöhnliches Passbild, des jeweiligen Märtyrers bzw. der jeweiligen Märtyrerin nur noch hineinkopiert werden musste. Jede Partei entwickelte so ihre eigene visuelle Märtyreridentität, die in den Straßen Beiruts schon von weitem wiedererkennbar war.

Die Poster setzten sich meist aus nur wenigen grafischen Elementen zusammen: Einem Logo der Partei, den Märtyrerportraits, deren Namen sowie spärliche

106 Vgl. Maasri: Off the Wall, S. 93.

107 Ebd., S. 87.

$108 \mathrm{Zu}$ den Produktionsbedingungen der libanesischen Poster während des Bürgerkrieges siehe Zeina Maasri, auf deren Ausführungen ich mich hier beziehe. Ebd., S. 37. 
Informationen zum Zeitpunkt und Ort des Todes. Eine typische Schablone der Hisbollah bestand beispielsweise aus dem typografischen Emblem der Partei von dem eine geballte Faust mit Kalaschnikow emporragt, sowie einem kreisrunden Platzhalter für das schwarz-weiße Märtyrerportrait (Abb. 2.18-2.19). Die SSNP entwickelte eine Postervorlage, die ausschließlich in den Parteifarben Schwarz, Weiß und Rot gehalten war und die rötlich eingefärbten Portraitfotografien vor einem schwarzen Hintergrund mit weißer Schrift zeigte. ${ }^{109}$ Wiedererkennbar war nicht mehr die einzelne Märtyrerin oder der einzelne Märtyrer, sondern die corporate identity der Partei, in die alle Fotografien fortan eingepasst wurden.

Abbildung 2.18 (links) und 2.19 (rechts): Märtyrerposter der Hisbollah, $40 \times 55 \mathrm{~cm}, 1986$.
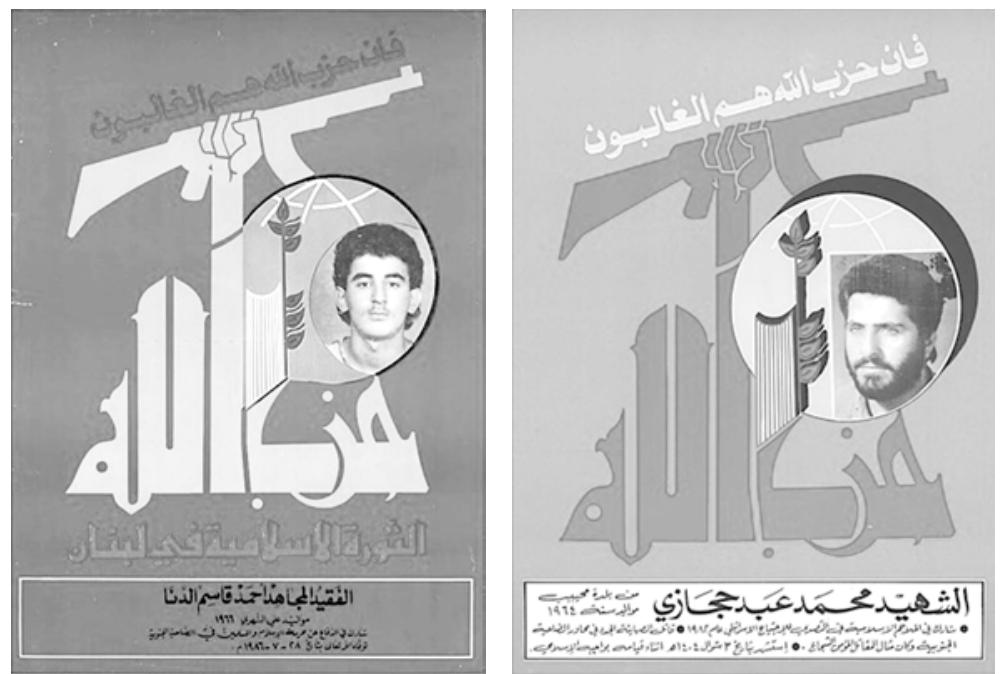

Obwohl die Märtyrer*innen durch ihre Portraits, die Nennung des Namens, sowie Datum und Ort des Selbstopfers persönlich in den Postern erinnert wurden, trat deren Individualität zunehmend hinter der Uniformität der Poster zurück, was in der Konstruktion einer kollektiven Identität des Martyriums resultierte. »For the most part«, so hat auch Elias Chad angesichts der libanesischen Märtyrerposter festgestellt, »the individual identity of the martyr was subsumed into the logic of

109 Allein die Postersammlung von Abboudi Bou Jawdeh zählt mehrere Dutzende dieser Märtyrerposter mit identischem Design. 
collective sacrifice and popular resistance $\ll^{110}$. Anstelle der individuellen Märtyrerikone trat nun ein überpersönliches Bild des Martyriums, das mit immer neuen Gesichtern und Namen gefüllt und aktualisiert wurde. Diese Austauschbarkeit suggerierte, dass jede und jeder potenziell zur Märtyrerin oder zum Märtyrer werden konnte: »It is hard for a youth impassioned by the same cause to pass by these posters without being affected and probably, if only for a brief moment, imagining $\mathrm{him} /$ herself in the photograph with his/her name praised as the martyr hero, $\ll^{111}$ so beschreibt Zeina Maasri die affektive Kraft der libanesischen Märtyrerposter, die damit immer auch den Zweck erfüllten, potenzielle Kandidat*innen für Märtyrertod-Operationen zu rekrutieren. Der appellative Charakter dieser Poster bestand nicht mehr nur darin, aus der Masse herausgehobene, und dadurch nachahmenswerte Pop-Ikonen zu erschaffen, sondern - im Gegenteil - ein Template bereit zu stellen, das den Märtyrertod als erreichbares Ziel für alle erscheinen ließ.

Die Bewegung hin zu einer Kollektivierung des Märtyrerbildes lässt sich jedoch nicht nur auf der Gestaltungsebene der Poster erkennen. Die hohe Frequenz, mit der neue Märtyrerposter, kaum plakatiert, schon wieder durch andere ersetzt wurden, verweist auf die ephemere Dimension des einzelnen Posters, das keine Beständigkeit mehr hatte, sondern in einer Serie von ähnlichen Märtyrerbildern aufging. Der libanesische Dichter Machmud Darwisch verglich die Produktion der Märtyrerposter während des libanesischen Bürgerkriegs mit der Schnelllebigkeit der Tagespresse:

»Möglicherweise war Beirut die erste Stadt der Welt, in der Plakate den Stellenwert von Tageszeitungen bekamen. [...] Gesichter an den Wänden, Märtyrer, die gerade erst die Lebenden und die Druckerei verlassen hatten. Reproduktionen des Todes. Ein Märtyrer vertrieb den anderen von der Wand, nahm dessen Stelle ein, solange bis er dem nächsten Märtyrer oder dem Regen zum Opfer fiel. $\ll^{112}$

Das kollektive Bild >des Märtyrers〈 konstituierte sich während des Bürgerkriegs folglich nicht nur durch die uniforme Gestaltung der einzelnen Poster, sondern auch durch die zeitliche Sequenz ihrer Abfolge im Raum.

110 Elias Chad: »Review: Signs of Conflict: Political Posters of Lebanon's Civil War (1975-1990)«, Journal of Visual Culture 8/1 (2009), S. 116-120, hier S. 119.

111 Maasri: Off the Wall, S. 88.

112 Machmud Darwisch: Ein Gedächtnis für das Vergessen. Beirut, August 1982, übers. von Kristina Stock, Basel: Lenos Verlag 2001, S. $60 f$. 
Abbildung 2.20: Märtyrerposter der Hisbollah, Beirut, 2006, Fotografie aus Rabih Mroué: The Inhabitants of Images (2009).

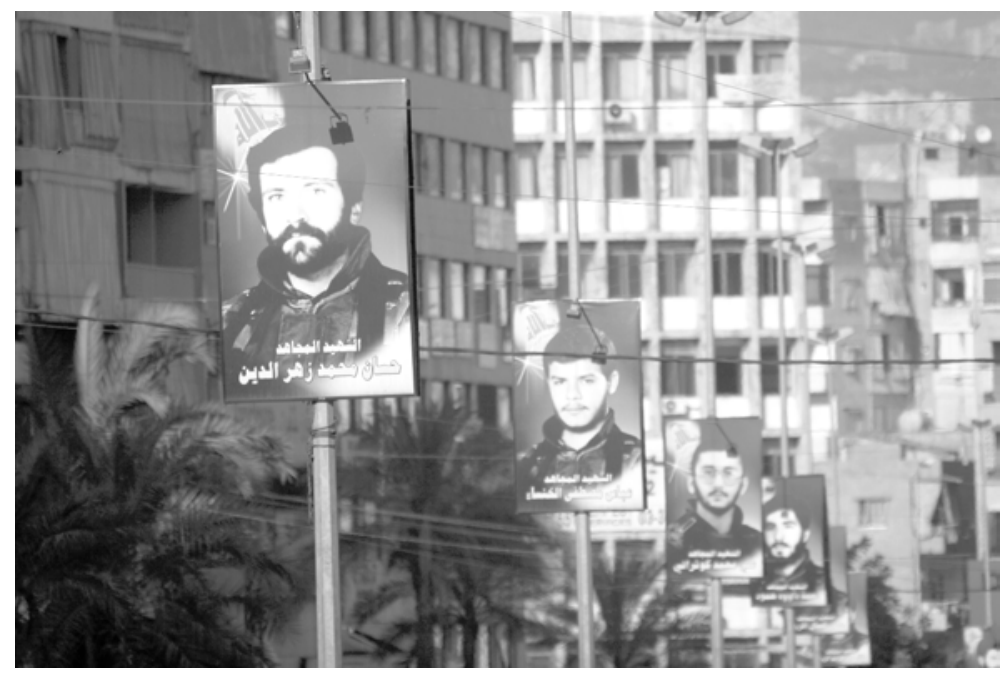

Eine ähnliche Situation hat der libanesische Künstler Rabih Mroué auch mit Blick auf aktuellere Poster von Märtyrern der Hisbollah beschrieben, die während des Israel-Kriegs im Jahr 2006 getötet wurden. In einer Sektion der Lecture-Performance The Inhabitants of Images (2009), auf die ich später noch einmal ausführlich eingehen werde, zeigt der Künstler mehrere Fotografien der Märtyrerposter, die direkt nach dem Krieg im Juli 2006 auftauchten und entlang etlicher Straßen in den südlichen, schiitisch geprägten Vierteln Beiruts hingen (Abb. 2.20). In regelmäßiger Abfolge sind die uniformen, fast identischen Bilder der Märtyrer in Metallrahmen an Straßenlaternen auf genau drei Metern Höhe angebracht. Beim Vorbeifahren, so beschreibt Mroué seine subjektive Erfahrung mit diesen Postern, werden die Märtyrer nicht singulär, sondern als Teil einer visuellen Sequenz des Martyriums wahrgenommen: »Since the frames are all similar, except for the head and the name, we end up seeing only one, still image; the image of the martyr Mujahid, in the body of a warrior, without a name or a face. The speed of motion will erase both the names and the faces. ${ }^{113}$ Die individuellen Poster der Märtyrer werden durch die grafische Uniformität und die schnelle Abfolge in das Bild eines kollektiven Märtyrers kondensiert: »the image of `The Martyr` with a capital

113 Rabih Mroué: »The Inhabitants of Images«, in: CA2M Centro de Arte Dos de Mayo (Hg.): Rabih Mroué. Image(s), mon amour. Fabrications, Ausst.-Kat., Madrid: CA2M Centro de Arte Dos de Mayo 2013, S. 338-356, hier S. 354. 
$\mathrm{M} \ll^{114}$. Durch die gestalterische Standardisierung ebenso wie die serielle Produktion und Anbringung der Poster wird nicht mehr nur das Martyrium eines Einzelnen bezeugt, sondern dessen Auftreten als breite Bewegung, die auf eine scheinbar endlose Reihe an Märtyrern verweist.

Im Gegensatz zu Videotestamenten, die ab 1985 erstmals im libanesischen Fernsehen ausgestrahlt wurden und heute vor allem im Internet kursieren (Kapitel 3 und Kapitel 4), zeichnen sich Märtyrerposter oft gerade durch ihre materielle Präsenz an einem bestimmten Ort aus. Mit der Allgegenwärtigkeit von Märtyrerpostern im libanesischen Bürgerkrieg waren folglich auch Operationen verbunden, die sich auf den konkreten Stadtraum bezogen. Oft wurden Poster gezielt in den Gegenden platziert, in denen die jeweilige Partei militärisch präsent war. ${ }^{115}$ Eine geografische Bildpolitik, die von der Hisbollah auch im Jahr 2006 noch praktiziert wurde, wie Mroués Beispiel eindrücklich zeigt. Elias Chad zufolge schufen die Poster während des libanesischen Bürgerkriegs auf diese Weise »geographically defined communities of witnessing " $^{116}$ : lokale Gemeinschaften, die sich über das mediale Bezeugen von Märtyrer*innen definierten und bestimmten Fraktionen angehörten. Märtyrerposter wurden damit für die Parteien auch zu einem Instrument, um Gebiete innerhalb des umkämpften Stadtraums zu definieren und geografische Machtansprüche zu behaupten. Mit der Konjunktur von Selbstmordanschlägen galt die Anzahl der eigenen Toten nicht mehr als Zeichen der Niederlage, sondern als Zeichen militärischer Überlegenheit. Die Anzahl der Märtyrerposter stellte dementsprechend ein visueller Beweis der militärischen Stärke einer Fraktion dar. Je mehr Märtyrerposter diese in einem bestimmten Gebiet platzieren konnte, desto größer schien dort auch deren militärischer und politischer Einfluss zu sein. In diesem Sinne sind die Märtyrerposter weitaus mehr als nur symbolische Orte eines Kampfes um politische Bedeutung (»symbolic sites of struggle over meaning and political discourse $\aleph^{117}$, wie Zeina Maasri die libanesischen Poster beschrieb). Indem sie konkret an den geografischen Grenzziehungen Beiruts teilhatten, waren Märtyrerposter auch ganz materiell in das Kriegsgeschehen involviert. Konnten die tatsächlichen militärischen Auseinandersetzungen und Selbstmord-Operationen meist nur von wenigen Augenzeug*innen beobachtet werden,

114 Ebd., S. 349.

115 Vgl. Maasri: Off the Wall, S. 88.

116 Elias Chad: »Martyrdom and Mediation«, in: Ders. (Hg.): In Focus: On Three Posters 2004 by Rabih Mroué, London: Tate 2014, https://www.tate.org.uk/research/publications/in-focus/on-three-posters-rabih-mroue/martyrdom-and-mediation (zugegriffen am 6.6.2021), o.S.

117 Maasri: Off the Wall, S. 7. 
wurden diese nun durch die Märtyrerposter im Stadtraum sichtbar - und visuell dupliziert. Dass Märtyrerposter während des Bürgerkriegs als Stellvertreter für die Präsenz militärischer Truppen angesehen wurden, belegen auch die ikonoklastischen Angriffe auf die Poster, mit denen die anonymen Bilderstürmer*innen wiederum ihre eigenen Leben aufs Spiel setzten: »These members of the public sometimes risked their lives to tear the posters down, or to deface them, in an effort to reclaim their neighborhoods « ${ }^{118}$, so schreibt Elias Chad über die Poster-Kämpfe in Beirut, bei denen Märtyrerbild und Körper nahezu gleichwertige Positionen einnahmen und mit ihrer jeweiligen Präsenz Macht über einen bestimmten Stadtteil beanspruchten. Die Operationen der posthum verbreiteten Poster sind folglich nicht nur im Sinne einer Märtyrerwerdung im Bild zu verstehen. Mitunter werden die Märtyrerposter auch zu physischen Akteuren im umkämpften Raum und damit ganz direkt in die militanten Geschehnisse eingebunden.

\subsection{RAHMENWECHSEL. DAS MÄRTYRERPOSTER IM KUNSTKONTEXT}

Die Bildpraxis während des libanesischen Bürgerkriegs macht deutlich, dass der Präsentationsort von entscheidender Bedeutung für die Wirk- und Handlungsmacht der Märtyrerposter ist. Bilder von Selbstmordattentäter*innen werden heute jedoch nicht nur in den umkämpften Gebieten Libanons und Palästinas wahrgenommen, sondern auch im Kunstkontext rezipiert, wie der Verweis auf Rabih Mroués Lecture-Performance bereits zeigte. Obwohl der Märtyrerdiskurs im Nahen Osten politisch wie emotional stark aufgeladen ist und in öffentlichen Debatten häufig noch ein Tabuthema darstellt, ${ }^{119}$ gibt es einige palästinensische und libanesische Künstler, die sich diese Bilder aneignen und in ihrer Arbeit reflektieren. Inwiefern solche künstlerischen Rahmenwechsel neue Zugänge zu diesen

118 Die wechselseitige Austauschbeziehung zwischen Bild und Körper wurde von Horst Bredekamp auch als »substitutiver Bildakt« beschrieben. Bredekamp: Theorie des Bildakts, S. 171-230.

119 Rabih Mroué schreibt über die libanesischen Märtyrerposter: »Normally, it's taboo to talk about them [...] because it's a taboo to discuss anything having to do with martyrs. They are heroes; they're half saints.« Rabih Mroué: »1000 Words«, Artforum 48/3 (2009), S. 194. Ähnliches bemerkt auch Elias Chad: »Yet despite their ubiquity within Lebanese public life, posters of martyrs are not a topic of open discussion. Their silence presence gives them a paradoxical status; they are both commonplace and taboo.« In Chad: »Martyrdom and Mediation«, S. 2. 
Märtyrerbildern, speziell zu denen der Selbstmordattentäter*innen, erlauben, soll im Folgenden untersucht werden.

Abbildung 2.21: Ahlam Shibli, untitled (Death no. 22), Al-Am'ari

Flüchtlingslager nahe Ramallah, 18.10.2011, Chromogendruck, $38 \times 57 \mathrm{~cm}$.

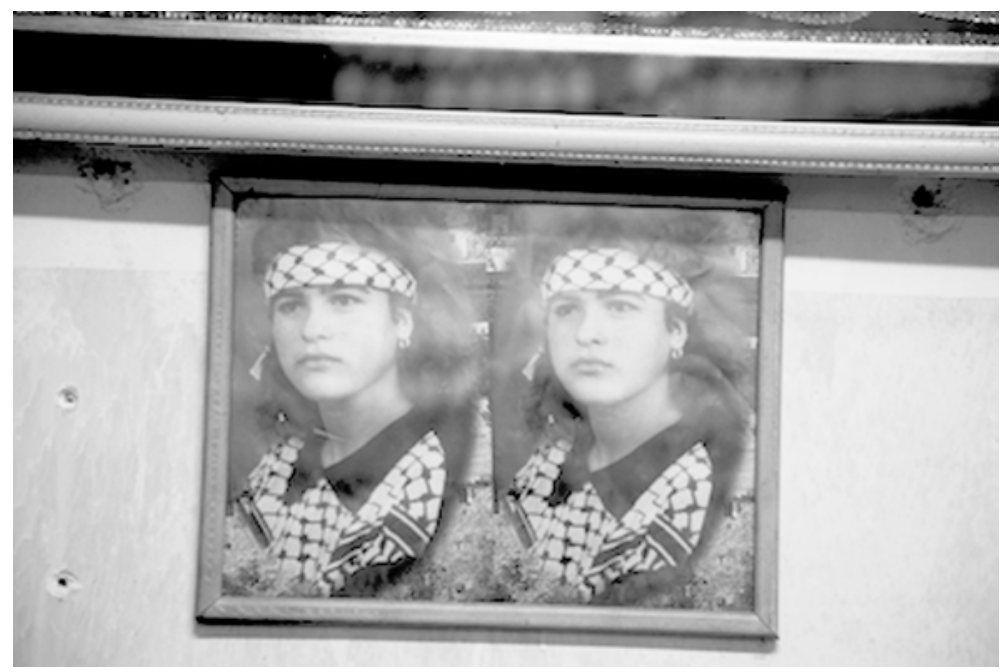

Dass die Neurahmung von Märtyrerpostern im europäischen Kunstkontext nicht immer unproblematisch aufgenommen wurde, zeigen die heftigen Proteste in Reaktion auf eine Ausstellung der palästinensischen Künstlerin Ahlam Shibli. ${ }^{120} \mathrm{Im}$ Mai 2013 eröffnete in der Pariser Galerie Jeu de Paume eine Ausstellung, die unter anderem Fotografien aus ihrer Serie Death (2011-12) zeigte, für die Shibli über zwei Jahre hinweg die Präsenz von Märtyrerpostern in Nablus und Ramallah dokumentierte. Auf den Postern sind typischerweise die Portraits schwer bewaffneter Männer (seltener auch Frauen) mit Kalaschnikow zu sehen, die in digital bearbeiteten Fotomontagen, neben Abbildungen des Felsendoms, Koranversen oder vor dem Hintergrund anderer Märtyrerportraits erscheinen. Die 68 Fotografien der Serie dokumentieren sowohl die öffentliche Präsentation dieser Poster im Stadtraum, portraitieren aber auch den privaten Gebrauch in den Häusern sogenannter

120 Die folgenden Überlegungen basieren auf Verena Straub: »A Gallery of Martyrs - the Martyr in the Gallery: Public Display and the Artistic Appropriation of Martyr Images in the Middle East«, in: Stylianou, Elena und Theopisti Stylianou-Lambert (Hg.): Museums and Photography: Displaying Death, London: Routledge 2017, S. 179-199. 
Märtyrerfamilien. Die Begleittexte, die in der Ausstellung neben den Fotografien an der Wand angebracht waren, verweisen dabei erneut auf die Bandbreite derer, die in den Postern als Märtyrer*innen verehrt werden: Neben militärisch Unbeteiligten oder Widerstandskämpfer*innen, die in gewaltvollen Auseinandersetzungen vom israelischen Militär getötet wurden, zeigen die Fotografien auch Bilder von Selbstmordattentäter*innen wie Wafa Idris. Ein Ausschnitt desselben Posters, das bereits zu Beginn des Kapitels Thema war, taucht auch in einer der Fotografien wieder auf, die Ahlam Shibli im Haus der Familie von Wafa Idris aufnahm und das dort gerahmt an der Wohnzimmerwand hängt (Abb. 2.21). Von der Plakatierung im Stadtraum, über die politische Agitation während Demonstrationen, bis hin zu familiärer Erinnerungskultur, hat das Poster in Palästina bereits unterschiedliche Rahmungen erfahren. Dass es - vermittelt durch eine Fotografie - nun auch im Kontext einer europäischen Kunstausstellung auftauchte, warf jedoch ganz neue Fragen auf.

Allein das Ausstellen der fotografierten Märtyrerposter wurde von einigen Ausstellungskritiker*innen als Unterstützung und Glorifizierung der palästinensischen Selbstmordattentate gewertet. Wenige Tage nach der Eröffnung wurde die Ausstellung vom Dachverband der jüdischen Organisationen Frankreichs als »Rechtfertigung für Terrorismus « ${ }^{121}$ denunziert. Pro-israelische Gruppierungen forderten die sofortige Schließung der Ausstellung und riefen zu Protesten gegen die Galerie auf, die in den Folgetagen mehrere Bombendrohungen erhielt. Als schließlich auch das französische Kulturministerium eine Stellungnahme von Jeu de Paume verlangte, wurden mit »Warnung « betitelte Schilder in der Ausstellung aufgestellt, die deutlich machen sollten, dass es sich hier weder um Propaganda noch um Unterstützung militanter Gruppen handelte. Die Tafeln beinhalteten auch ein Statement von Ahlam Shibli, mit dem sie den rein dokumentarischen Anspruch ihrer Fotografien betonte, sich gleichzeitig aber einer Bewertung der Märtyrerdarstellungen verweigerte: »I am not a militant. My work is to show, not to denounce or to judge. $\ll^{122}$ In der Folge wurden auch von Seiten der Kunstkritik Stimmen laut, die zwar die Meinungsfreiheit betonten, gleichzeitig jedoch ethische Zweifel äußerten, ob Poster, in denen Selbstmordattentäter*innen als Märtyrer*innen glorifiziert werden, eine öffentliche Bühne in Kunstinstitutionen erhalten sollten. So schrieb Jürg Altwegg in der Frankfurter Allgemeinen Zeitung: »Dass Hinter-

121 Vgl. die Pressemitteilung des Conseil Représentatif des Institutions Juives de France (CRIF) vom 6. Juni 2013, http://www.crif.org/fr/lecrifenaction/une-exposition-inacceptable-au-musée-du-jeu-de-paume/ 37353 (zugegriffen am 6.6.2021).

122 Monika Vykoukal: »Review: Ahlam Shibli. Phantom Home«, Springerin 3 (2013), https://www.springerin.at/2013/3/review/ahlam-shibli/ (zugegriffen am 6.6.2021). 
bliebene von Selbstmordattentätern trauern dürfen, ist eine Selbstverständlichkeit. Aber vielleicht gehören diese Szenen nicht unbedingt in ein staatliches Museum. $\ll^{123}$ Und auch eine Autorin der Art in America fragte sich »if the questions that >Death poses are best served by its presentation in the rarefied context of a contemporary art museum $\aleph^{124}$. Die Empörung der Kritiker*innen bringt die Haltung zum Ausdruck, dass allein das Ausstellen der Märtyrerposter zugleich deren Affirmation bedeute. Damit ist ein grundlegender Glaube an die Macht dieser Bilder verbunden, die, ungeachtet der Medien- und Rahmenwechsel, die Verherrlichung der Selbstmordattentäter*innen scheinbar ungebrochen weiterschreiben.

Im Sinne Judith Butlers ist es jedoch gerade die Neukontextualisierung, die eine veränderte moralische Bewertung von Bildern der Gewalt ermöglicht. ${ }^{125}$ Das Beispiel der Folterbilder aus Abu Ghraib hat gezeigt, dass gerade die diskursive Neurahmung der Bilder in den Medien zu einem ethischen Aufschrei geführt hat, der letztlich auch die Verurteilung der Fotograf*innen zur Folge hatte. Von der ursprünglichen Funktion der Aufnahmen, die zu Brutalität im Gefängnis anspornten und als beschämende Waffe gegen die Gefangenen eingesetzt wurden, wendeten sich dieselben Fotografien schließlich gegen die Intentionen der Folternden und wurden zu Zeugnissen für Menschenrechtsverletzungen. Statt einer Wiederholung des sadistischen Blicks ließen die Kontextwechsel neue, kritische Blicke auf die Bilder zu, $»[\ldots]$ and so we probably need to accept that the photograph neither tortures nor redeems, but can be instrumentalized in radically different directions, depending on how it is discursively framed and through what form of media presentation it is displayed. $\ll^{126}$

Die Folterbilder aus Abu Ghraib wurden schließlich auch als Teil einer von Brian Wallis kuratierten Ausstellung im International Center of Photography in New York ausgestellt und vollzogen damit einen weiteren institutionellen Wechsel in den Kunstraum. Als Urheber*innen der Bilder wurden hier jedoch nicht die eigentlichen Fotograf*innen angegeben, sondern die Medien- und Presseagenturen, die die Bilder erstmals publizierten. Zusammen mit Kommentaren zur Entstehungs- und Rezeptionsgeschichte der Bilder wurden die Fotograf*innen damit selbst zu einem Teil der abgebildeten Szene und als Kompliz*innen der darge-

123 Jürg Altwegg: »Vom Martyrium der Opfer ist keine Rede. Frankreichs Juden protestieren gegen eine Fotoausstellung, die Selbstmordattentäter als Helden feiert«, Frankfurter Allgemeine Zeitung, 13.06.2013, S. 31.

124 Kim Bradley: »Review: Ahlam Shibli«, Art in America (2013), http://www.artinamericamagazine.com/reviews/ahlam-shibli/ (zugegriffen am 6.6.2021).

125 Butler: Frames of War, S. 63-100.

126 Ebd., S. 92. 
stellten Foltertaten markiert. Die Neurahmung innerhalb der Ausstellung schuf so die Möglichkeit, dem triumphierenden Blick und den ursprünglichen, beschämenden Funktionen der Bilder einen anderen, kritischen Blick entgegenzusetzen. Butler schreibt: »That scene now becomes the object, and we are not so much directed by the frame as directed toward it with a renewed critical capacity. $\ll^{127}$

Inwiefern sind Butlers Beobachtungen auf die Fotografien in Jeu de Paume übertragbar? Anders als bei den Folterbildern aus Abu Ghraib ist die Grenze zwischen Opfer und Täterschaft bei den palästinensischen Märtyrerpostern weitaus weniger klar zu ziehen, da das Genre nicht zwischen Bildern getöteter Zivilpersonen und Bildern von Selbstmordattentäter*innen unterscheidet. Auch wenn es hier also keineswegs darum gehen soll, die Folterbilder von Abu Ghraib mit den Märtyrerpostern zu vergleichen, lässt sich Butlers Beobachtung für meine Überlegungen fruchtbar machen. Im Fall von Selbstmordattentäter*innen wie Wafa Idris zeigen die Poster zwar nicht die Gewalttat an sich, sind aber ähnlich wie die Abu Ghraib-Bilder an der Glorifizierung der Täter*innen und der Legitimierung ihrer Taten beteiligt. Geht man jedoch mit Judith Butler davon aus, dass dem Bild selbst keine unveränderliche Wirkmacht anheftet, sondern kontextabhängig zu anderen Lesarten und Bewertungen führen kann, kann auch Jeu de Paume nicht automatisch als affirmative Bühne für die Verherrlichung von Selbstmordattentaten abgewertet werden. Was die Kritiker*innen der Ausstellung übersahen, war die Tatsache, dass die Fotografien keineswegs die Märtyrerposter per se fokussieren, sondern die Art und Weise wie diese im alltäglichen Leben in Palästina präsentiert und wahrgenommen werden.

In der Ausstellung und im Ausstellungskatalog begegnen uns die Märtyrerposter in doppelter Neurahmung: Neben dem institutionellen Wechsel in den Kunstkontext, ist es vor allem der fotografische Blick der Künstlerin, der den Postern neue Deutungshorizonte abgewinnt. Viele Fotografien zeigen von der Sonne vergilbte und verwitterte Märtyrerposter, die das Bild des Märtyrers teilweise nur noch in Papierfetzen zu sehen geben. Mitunter hängen die Poster auch an menschenleeren, verlassenen Orten wie der Mauer hinter einem abgerissenen Marktstand (Abb. 2.22). Dies verleiht den Postern eine geradezu melancholische Aura der Vergänglichkeit. Werden die (vorwiegend männlichen) Widerstandskämpfer und Selbstmordattentäter in den Postern als starke Helden dargestellt, die vor militanter Potenz nur so strotzen, entwerfen Shiblis Fotografien stattdessen ein Bild des Martyriums, das ephemer, angreifbar und letztlich dem Vergessen preisgegeben ist. Andere Poster rücken hingegen die popkulturelle Rahmung der Märtyrerposter in den Fokus. Untitled (Death, no. 59) zeigt ein Märtyrerposter der Fatah,

127 Butler: Frames of War, S. 96. 
das, umringt von weiteren Postern, an einer Ladentür angebracht wurde. ${ }^{128}$ Direkt neben ihm hängt ein Plakat mit dem Bild von Jassir Arafat. Die Aufschrift »Wir folgen deinem Weg « lässt den Märtyrer als beispielhaften Nachfolger des verstorbenen Fatah-Anführers erscheinen. Direkt unter seinem Poster klebt ein vergilbter Sticker eines Comic-Helden, der mit seinem Arm gerade zum Schlag ausholt, während darunter wiederum das Werbebild einer arabischen Barbiepuppe zu sehen ist, deren Kopf mit einer Kufiya verhüllt ist. Die unmittelbare Platzierung des Märtyrerposters neben Actionheld und Barbie suggeriert, dass dieser zur neuen Identifikationsfigur palästinensischer Jugendlicher geworden ist. Indem der Märtyrer auf einer Ebene mit der Kommerzialisierung des nationalen Widerstands gezeigt wird, wird sein quasi-heiliger Status gleichzeitig in die banale Welt popkultureller Ikonen übersetzt und für kritische Lesarten geöffnet.

Abbildung 2.22 (links) und 2.23 (rechts): Ahlam Shibli, Untitled (Death no. 53), 22.11.2011, $57 \times 38 \mathrm{~cm}$ (links) und Untitled (Death no. 37), 12.2.2011, $100 \times 66,7 \mathrm{~cm}$ (rechts), beide: Balata Flüchtlingslager, Chromogendruck.
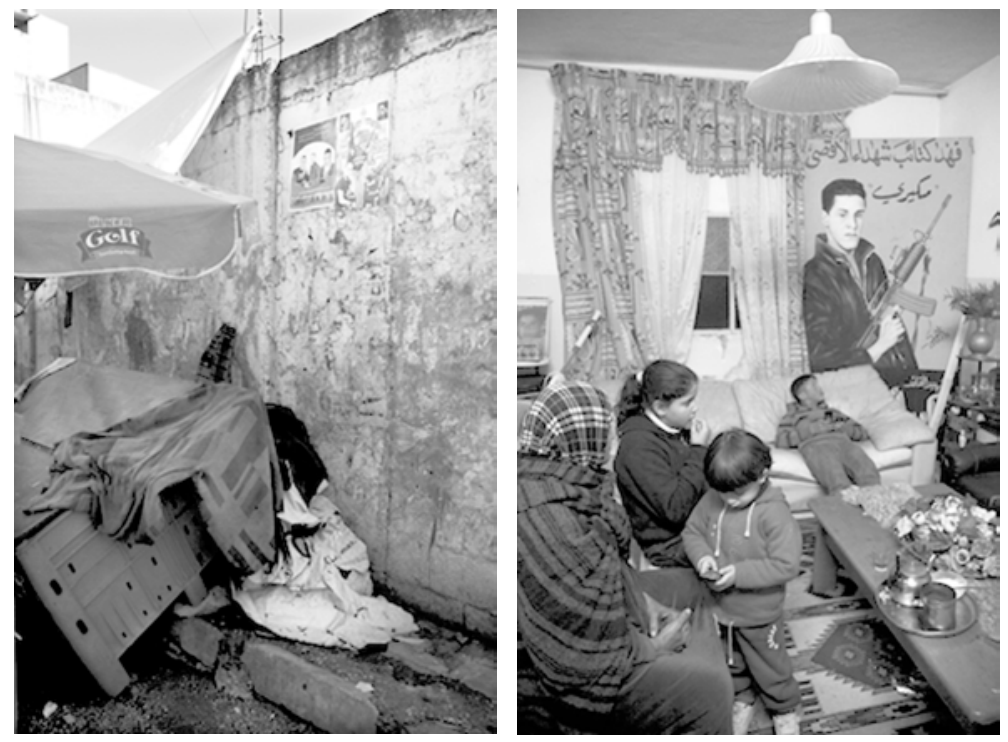

128 Es handelt sich um eine Fotografie, die am 6. März 2012 im Balata Flüchtlingslager entstanden ist (100 x $66,7 \mathrm{~cm}$, Chromogendruck). Siehe die Abbildung in http://www.ahlamshibli.com/photography/death.htm (zugegriffen am 6.6.2021). 
Abbildung 2.24: Ahlam Shibli, Untitled (Death no. 33), Old Askar

Flüchtlingslager, 15.2.2012, Chromogendruck, $38 \times 57 \mathrm{~cm}$.

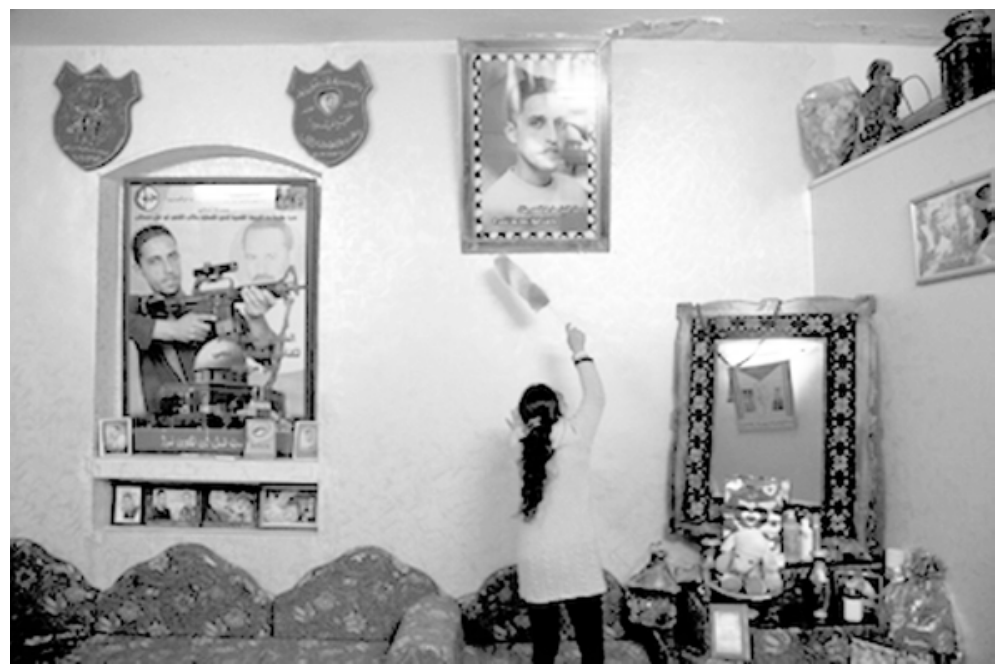

Die Fotografien, die Shibli im Privatraum der Familienangehörigen aufgenommen hat, erzählen wiederum Geschichten, die eher auf persönlicher Ebene anrühren. Ihre dokumentarischen Aufnahmen zeigen die Art und Weise, wie die Bilder Teil der familiären Erinnerungskultur und Trauerarbeit werden. Die Fotografien eröffnen damit Perspektiven, die westlichen Betrachter*innen für gewöhnlich verborgen bleiben. In den Häusern der Angehörigen werden die Märtyrer*innen aus der Serialität ihrer uniformen Darstellung herausgelöst und wieder als Individuen, als Brüder, Väter oder Töchter sichtbar. Der Platz, den sie in ihren Familien hatten, wird nun von den Bildern eingenommen, die mitunter in Lebensgröße neben der Wohnzimmercouch stehen und so Teil des Familienalltags werden. Wenn in Untitled (Death no. 37) ein kleiner Junge - möglicherweise der Bruder oder Sohn des Verstorbenen - bewundernd zum lebensgroßen Gemälde des schwer bewaffneten Märtyrers aufblickt, rückt dies gerade die soziale Funktion dieser Bilder in den Vordergrund (Abb. 2.23). Für T. J. Demos veranschaulicht diese Fotografie einen Kommentar, der während der zweiten palästinensischen Intifada häufig wiederholt wurde und der besagte: »For every activist killed, ten more would become involved in life. ${ }^{129}$ Die Ausweglosigkeit aus diesem scheinbar endlosen Kreislauf

129 T. J. Demos: »Disappearance and Precarity: On the Photography of Ahlam Shibli«, in: MACBA (Museu d'art contemporani de Barcelona), Jeu de Paume und Museu de 
weiterer Martyrien ist in vielen Fotografien Ahlam Shiblis präsent. Der allgegenwärtige Tod in Palästina wird durch diese fotografischen Rahmungen keineswegs glorifiziert, sondern mit nachdenklichen Tönen versehen, die gerade die Tragik des Märtyrerkults in den Vordergrund rücken. Teilweise zeigen die Fotografien aber auch unfreiwillig komische Seiten auf den privaten Märtyrerkult im Privatraum der Familien. So etwa, wenn ein Mädchen den goldenen Rahmen des Märtyrerbildes ihres Bruders mit einem bunten Staubwedel reinigt und die verehrte Ikone damit wieder in die Banalität alltäglicher Hausarbeit zurückholt (Abb. 2.24).

Ähnlich wie Judith Butler dies am Beispiel der Abu Ghraib-Ausstellung beschrieben hat, lenkt auch Ahlam Shibli unseren Blick auf die Blicke der Anderen, auf die räumlichen und gesellschaftlichen Kontexte und Rahmen, in denen Märtyrer*innen in Palästina präsentiert und verehrt werden. Statt die Verherrlichung der Dargestellten zu reproduzieren, treten gerade die Ambivalenzen und Brüche des Märtyrerkults in den Vordergrund. Anders als im Fall der in New York ausgestellten Abu Ghraib-Fotografien richten sich Shiblis Fotografien jedoch keineswegs als Waffe gegen die Urheber*innen der Poster. Stattdessen eröffnen die Aufnahmen einen Reflexionsraum, der ganz unterschiedliche und teils widersprüchliche Lesarten zulässt. Indem die Fotografien sowohl kritische als auch empathische Zugänge zu den Verstorbenen und ihren Familien erlauben, verweigern sich die Aufnahmen nicht nur einer Glorifizierung der Dargestellten, sondern auch einer allzu einfachen Feindbild-Projektion. Statt einer Umkehrung des Blicks - wie Butler dies am Beispiel der Folterbilder beschrieben hat - ermöglicht die künstlerische Neurahmung hier eine Multiplikation der Blicke, die nicht zuletzt auch westliche Rezeptions- und Bewertungsmuster herausfordert.

Mit ganz anderen ästhetischen Mitteln holt auch der libanesische Künstler Rabih Mroué Märtyrerposter von der Straße in den Kunstraum. Im Gegensatz zu Ahlam Shibli, die für ihre Arbeiten eine dokumentarische Position beansprucht, zeichnet sich Mroués Ansatz gerade durch betont subjektive Aneignungen aus. In der bereits erwähnten Lecture-Performance The Inhabitants of Images (2009) dekonstruiert er die Bildoperation selbst, die den Postern der Hisbollah zugrunde liegt. Die Lecture-Performance, in deren Rahmen Mroué seine Argumentation entwickelt, ist ein Format, das der Künstler seit 2004 nutzt. Mroué sitzt dabei an einem Tisch und liest von einem Skript ab, während auf eine Leinwand im Hintergrund Bilder projiziert werden (Abb. 2.25). Der pseudo-wissenschaftliche Gestus des Vortrags verleiht seinen Bildanalysen einen Anspruch auf Wahrheit, die

arte contemporanea de serralves (Hg.): Ahlam Shibli. Phantom Home, Ausst.-Kat., Ostfildern: Hatje Cantz 2013, S. 11-26, hier S. 11. 
jedoch kontinuierlich durch persönliche Einwürfe gebrochen werden und teils imaginäre, surreale Wege einschlagen.

Abbildung 2.25: Rabih Mroué, The Inhabitants of Images, Lecture Performance, 2009.

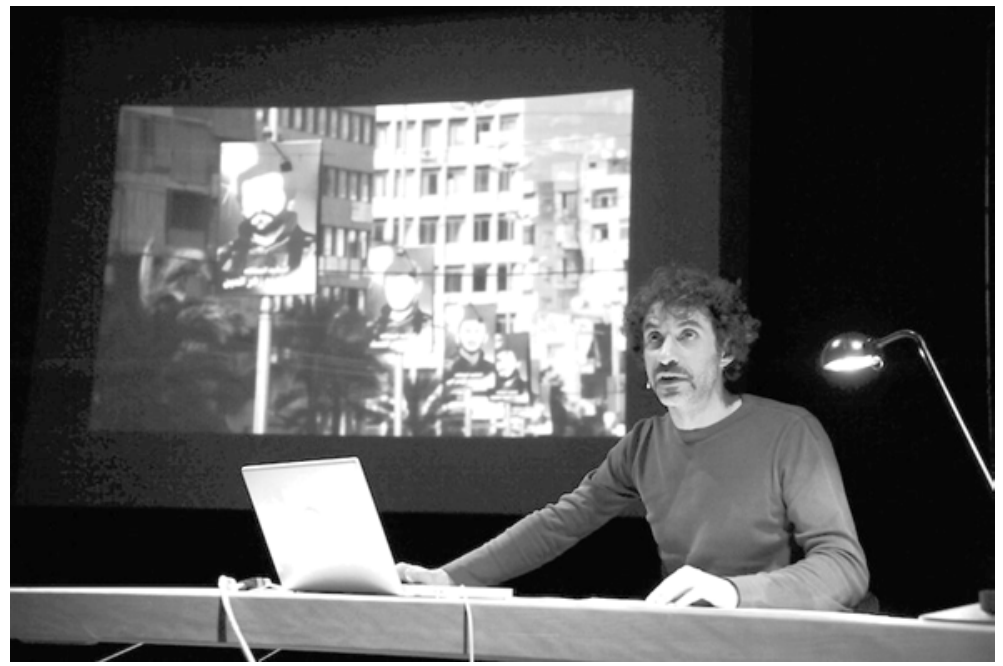

The Inhabitants of Images besteht aus drei Sektionen, in denen Mroué unterschiedliche Bilder gestorbener Märtyrer*innen in den Blick nimmt: von einem imaginären Treffen zwischen Gamal Abdel Nasser und Rafik Hariri in einem Poster, über Bilder säkularer Selbstmordattentäter*innen während des libanesischen Bürgerkriegs, bis hin zu besagten Postern der Hisbollah-Märtyrer, die während des Krieges mit Israel im Juli 2006 ums Leben kamen. Die Omnipräsenz, ebenso wie die uniforme Gestaltung dieser Poster ist für Mroué zunächst nicht überraschend: »In Lebanon, we are used to seeing posters of martyrs, almost everywhere, in any street or area, and belonging to any political party. I also did not notice anything strange about the sameness and identicalness of the posters. This is also something that we used to see in Lebanon [...].« ${ }^{130}$ Bei näherem Hinsehen jedoch identifiziert Mroué den mit einer Militäruniform bekleideten Körper der einzelnen Märtyrer als Kopie ein und desselben Bildes: »Thanks to Photoshop, the head in the original photo is cut and pasted on the readymade body in the poster. « ${ }^{131}$ (Vgl. Abb. 2.20). Mroué beschreibt dies als »a very violent, sadistic act, the fact that someone would

130 Mroué: »The Inhabitants of Images«, S. 347.

131 Ebd., S. 349. 
willingly cut and mutilate the picture of a dead person, even with good intentions ${ }^{132}$. Der Angriff auf das Bild wird von Mroué mit einem Angriff auf den Körper des Dargestellten gleichgesetzt. Das erinnert an die ikonoklastischen Akte gegenüber Märtyrerpostern während des libanesischen Bürgerkriegs. Hier ist der "gewaltvolle, sadistische Akt« jedoch in die Gestaltung des Posters selbst eingeschrieben und wird von der eigenen Partei vollzogen, so der argumentative Kniff der Lecture-Performance. Damit suggeriert Mroué, dass die Hisbollah ihre Toten durch die Poster keineswegs zu unsterblichen Märtyrern mache, sondern stattdessen ein zweites Mal gewaltsam töte. Dass die Poster in letzter Konsequenz zum Verschwinden der Individuen beitragen, stellt Mroué auch mit Blick auf die räumliche Anordnung der Poster fest. Wie schon weiter oben beschrieben, folgen die Poster in konstanter Abfolge auf gleicher Höhe aufeinander und werden beim Vorbeifahren als das Bild eines einzigen Märtyrers wahrgenommen: »The speed of motion will erase both the names and the faces. $\ll^{133}$ Die Nerstümmelung« der Portraits, die uniforme Gestaltung und serielle Anordnung der Poster sind für Mroué demnach Teil einer Bildoperation, die im unausweichlichen Tod der Dargestellten resultiert. Damit dekonstruiert Mroué die verherrlichende Intention der Poster, die den Märtyrerstatus der Dargestellten - und damit gerade ihr Weiterleben im Jenseits - bezeugen sollen. Die Verwandlung des Individuums in einen überpersönlichen Märtyrer wird von Mroué stattdessen als gewaltvoller, tödlicher Bildakt beschrieben.

In einem weiteren Schritt vollzieht Mroué diese digitale Bildoperation schließlich an seinem eigenen Portraitbild, das er vor den Augen der Zuschauer auf denselben Körper der Hisbollah-Märtyrer montiert: »This is my photo. I will remove my face from it, and put it on this body, as for my own body, I don't need it anymore, so I will put it in the trash, and empty it « ${ }^{134}$, so demonstriert Mroué Schritt für Schritt an seinem Laptop (Abb. 2.26). Er resümiert schließlich: »It is as if I'm witnessing a crime, taking place in a virtual world. ${ }^{135}$ Dass Mroué sein eigenes Bild in die Reihe der Hisbollah-Kämpfer einfügt und sich mit ihnen gewissermaßen als 〉Opfer` einer gewaltvollen Bildoperation identifiziert, scheint aus politischer Sicht gewagt. Zugleich führt Mroué jedoch das Virtuelle dieser Bildoperation vor Augen, die offensichtlich ohne Auswirkungen auf seinen realen Körper bleibt und nur im Bild stattfindet. Schon im nächsten Satz wird diese Fiktionalisierung jedoch schon wieder gebrochen, wenn er über die Hisbollah-Poster

132 Mroué: »The Inhabitants of Images«, S. 350.

133 Ebd., S. 354.

134 Ebd., S. 350.

135 Ebd. 
mutmaßt: »Personally, I would like to think that these posters are not fabricated, that they are real. And since these picture were never taken in real life, I would propose that they were taken after their death. $\ll^{136}$ In einem provokativen Gedankenexperiment geht Mroué nun davon aus, dass nach dem Tod der Individuen tatsächlich ein neuer Körper auf die Märtyrer warte. Ein militärischer Körper, der gerade durch seine Gleichheit und Serienproduktion die Dargestellten als Teil einer starken, soliden Armee erscheinen lasse. Seine Argumentation vom Anfang nimmt damit eine überraschende Wendung: Wurde die Montage zunächst als tödliche Bildoperation beschrieben, liefert sie nun scheinbar abbildhafte Evidenz für das Weiterleben der Dargestellten im neuen Körper des Märtyrers. Ultimatives Ziel dieser Poster-Armee von Märtyrern sei schließlich ihre Rückkehr zu den Lebenden, um dort erneut als Märtyrer zu sterben. Die Lecture-Performance führt das Märtyrerposter damit als verwirrende, widersprüchliche Bildoperation vor, bei der nicht nur die Grenzen zwischen Bild und Körper verschwimmen, sondern auch die zwischen Leben und Tod.

\section{Abbildung 2.26: Rabih Mroué, The Inhabitants of Images, Lecture}

\section{Performance, 2009, Detail.}

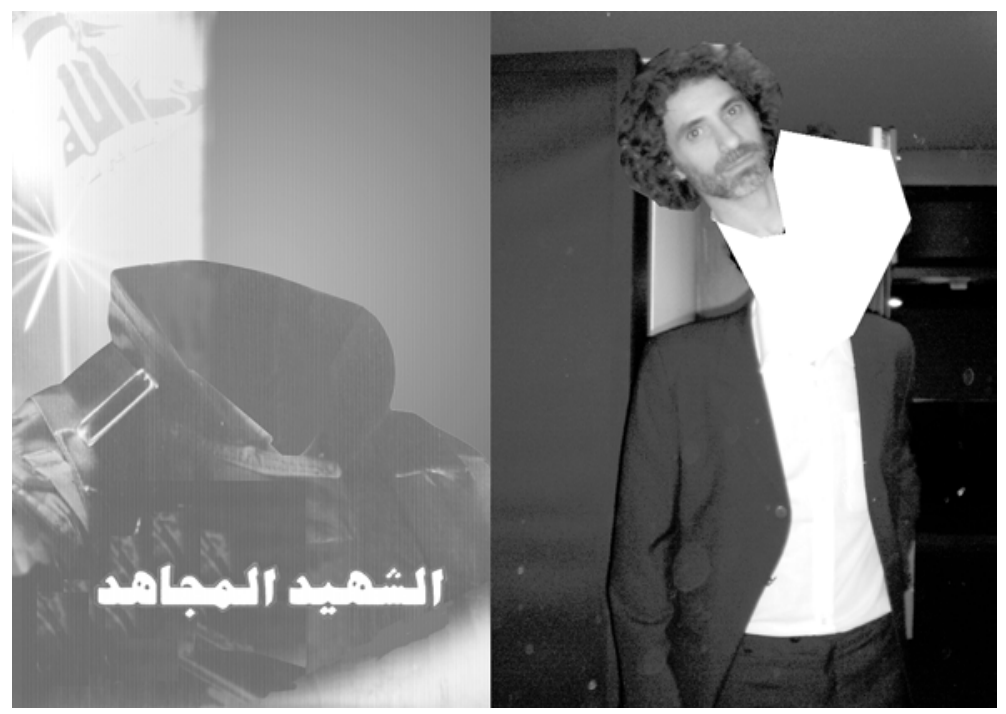

Mroués Bildanalysen und Gedankenexperimente bieten weder eine klare Dekonstruktion, noch eine klare Sakralisierung der Märtyrerikonen an. Ähnlich wie

136 Mroué: »The Inhabitants of Images«, S. 351. 
Ahlam Shibli lässt auch Mroué die Poster der militanten Hisbollah-Kämpfer gerade in ihren Ambivalenzen bestehen und verweigert seinem Publikum eine eindeutige Interpretation oder Bewertung. Das ständige Hin- und Herwechseln zwischen pseudo-wissenschaftlicher Bildanalyse und fiktiven, teils widersprüchlichen Spekulationen hat im Gegensatz zu Shibli jedoch zur Folge, dass der dokumentarische Status der Poster selbst in Zweifel gezogen wird. Es wird zunehmend unklar, was diese Bilder eigentlich zeigen, bezeugen oder erzeugen. Werden Märtyrerposter als Bildzeugnisse verstanden, so wird spätestens hier deutlich, dass es sich dabei um äußerst instabile Zeugnisse handelt. Die Evidenz des Martyriums wird nicht nur im Poster selbst hergestellt - und damit je nach Montage neu definiert und (um)gedeutet. Auch abhängig von Kontext und Rahmung erzeugen die Poster ganz andere >Wahrheiten`, die teilweise gebrochen werden und eine kritische Neubewertung des bezeugten Martyriums ermöglichen.

Ein Blick auf die Geschichte der Märtyrerposter von Selbstmordattentäter*innen hat gezeigt, dass Suizidoperationen nicht nur zerstörerische, tödliche und militärische Folgen haben. Sie lösen auch eine Reihe von Bildoperationen aus, die im Bild selbst, aber auch durch Handlungen mit dem Bild stattfinden. Dienten die Poster der ersten - säkularen wie schiitischen - Selbstmordattentäter*innen vor allem dazu, diese als wiedererkennbare Ikonen zu etablieren, so resultierte die Standardisierung und Serienproduktion von Märtyrerpostern während des libanesischen Bürgerkriegs umgekehrt gerade in einer Entindividualisierung der Gestorbenen. Durch ihre massenhafte Präsenz im Stadtraum markierten die Märtyrerposter hier teilweise sogar geografische Machtansprüche und wurden damit zu Akteuren von Bildoperationen im Raum. Neben den unterschiedlichen Operationen und Praktiken zeigt sich aber auch mit Blick auf Ikonografie und Ästhetik wie heterogen die Darstellungen sind, die von Bildmontagen mit künstlerischem Anspruch bis hin zu generischen Vorlagen reichen. Gerade im Vergleich zwischen den palästinensischen Postern der 1970er Jahre und denen der zweiten Intifada ab 2000 zeigt sich eine grundlegende Wandlung des Märtyrerbildes: Schlossen die früheren säkularen Poster zum Teil an eine transnationale Pop-Ästhetik an, werden heute sogar die Selbstmordattentäter*innen der eigentlich säkularen Fatah in einen islamischen Kontext eingebettet und erscheinen in standardisierten Fotomontagen neben religiösen Symbolen wie dem Felsendom. Mit der Aufnahme von Videotestamenten entstand ab 1985 schließlich ein weiterer Bildtypus, bei dem Suizidattentäter*innen erstmals selbst als Zeug*innen ihres Martyriums auftreten und noch zu Lebzeiten Deutungshoheit über ihr eigenes Bild erlangen. Inwiefern sich die damit verbundenen Bildoperationen von denen der Märtyrerposter unterscheiden, wird im Folgenden zu zeigen sein. 



\section{Videotestamente. Das eigene Martyrium bezeugen?}

Fernsehzuschauer*innen, die am 9. April 1985 die Abendnachrichten des libanesischen Senders Télé Liban sahen, waren mit einer irritierenden Situation konfrontiert. Eine junge Frau, die wie eine Fernsehsprecherin hinter einem Tisch saß, hob zu einer Ansprache in die Kamera an (Abb. 3.1). Statt der Nachrichten verkündete sie jedoch ihr eigenes Martyrium: »Ana ǎ̌ššhīda Sanā' Yūsif Muhaydlī« - »Ich bin die Märtyrerin Sana Yusif Muhaydli«. Zu diesem Zeitpunkt war bereits klar, dass die 17-jährige Frau, deren Video über die Bildschirme flirrte, nur wenige Stunden zuvor bei einem Selbstmordanschlag im Namen der Syrischen Sozialen Nationalistischen Partei (SSNP) an einem südlibanesischen Checkpoint ums Leben kam und dabei zwei israelische Soldaten mit sich in den Tod riss. ${ }^{1}$ Als würde sie ihrem eigenen Tod trotzen, verkündete sie im Video indes weiter: »Ich bin nicht tot, sondern lebendig unter euch. « ${ }^{2}$ Es lässt sich nur darüber spekulieren, wie die Worte der Attentäterin auf die Fernsehzuschauer*innen an jenem Abend gewirkt haben müssen. War ihre Aussage zum Zeitpunkt der Videoaufnahme noch als Imagination der Zukunft zu werten, schien derselbe Satz (»Ich bin die Märtyrerin«) zum Zeitpunkt der Ausstrahlung in den Status eines Zeugnisses gerückt zu sein. Je nachdem, welche Perspektive man in den Blick nimmt, wechselt die Lesart dieses Videos zwischen Antizipation (>Ich werde den Märtyrertod sterben`) und

1 Vgl. Chicago Project on Security and Terrorism (CPOST): Suicide Attack Database, Attack ID: 2013076846.

2 Vgl. die englische Übersetzung des arabischen Testaments in Khalili: Heroes and Martyrs of Palestine, S. 13f. Khalili bezieht sich auf Rafiq Nasrallah (Hg.): Al Muqawama al-Wataniyya al-Lubnaniyya 1982-1985: Al-Amaliyyat al-Istishhadiyya - Wathai'q wa Suwar (Lebanese National Resistance 1982-1985: Martyrdom Operations Documents and Images), Beirut: al-Markaz al-Arabi lil-Ma'lumat 1985, S. 123. 
Bezeugen des Martyriums (`Seht her, ich bin als Märtyrerin lebendig〈), zwischen Vergangenheit, Gegenwart und Zukunft.

Abbildung 3.1 a-c: Videotestament von Sana Muhaydli, SSNP, Aufnahme am oder vor dem 9. April 1985, 16:28 min, arabisch.
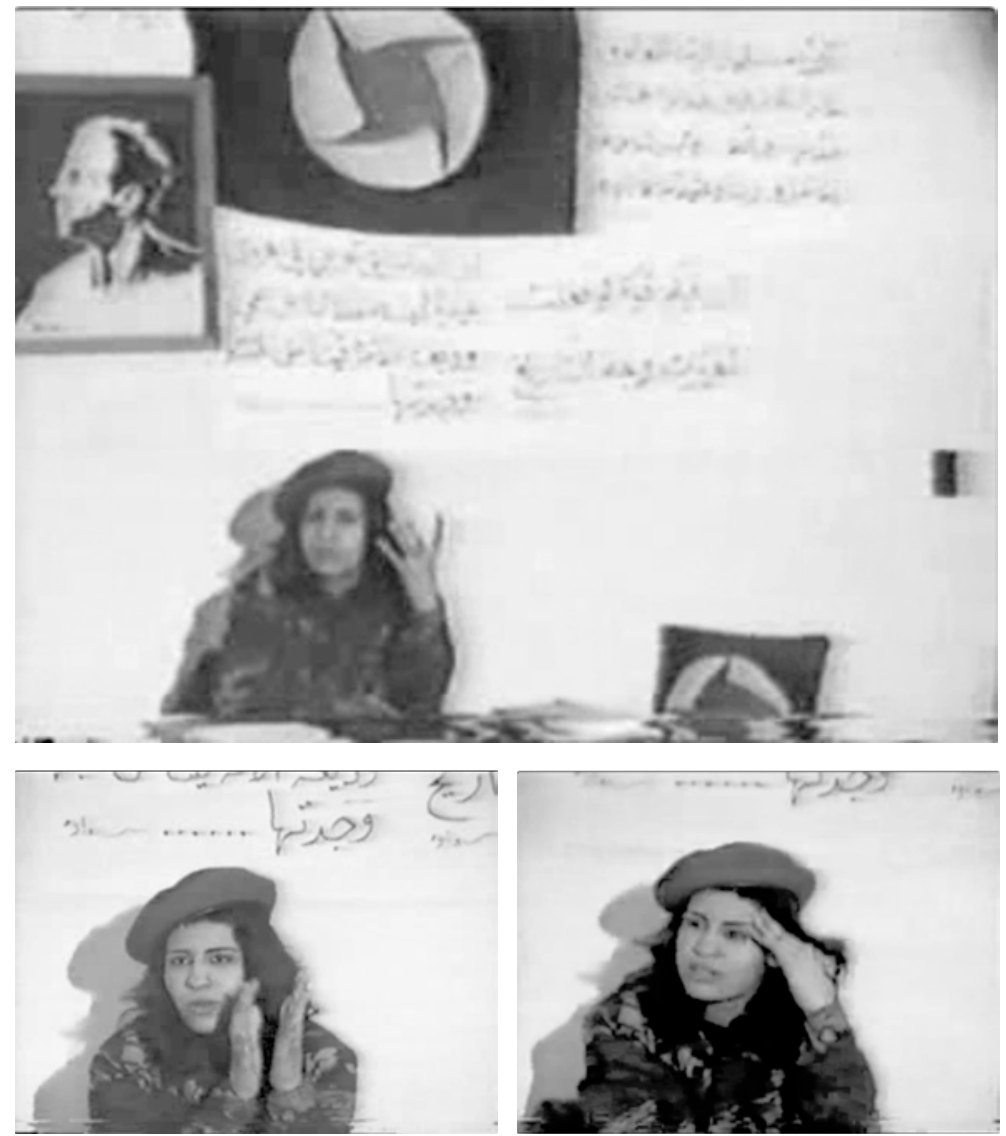

Durch diese verwirrende Zeitlichkeit nehmen Videotestamente wie dieses eine besonders paradoxe Position ein. Vermittelt durch das Medium des Videos scheinen die Dargestellten nun selbst als Zeug*innen ihres eigenen Martyriums aufzutreten. Im Unterschied zu den posthum gestalteten Postern handelt es sich hier jedoch um Bildzeugnisse, die dem eigentlichen `Blutzeugnis` (dem Martyrium) vorausgehen. Die Videos werfen damit ganz neue Fragen nach dem Verhältnis zwischen Bild und Attentat, zwischen Zeugnis und Bezeugtem auf. Welchen Einfluss hat die 
Aufnahme des Videos auf die Durchführung der militärischen Operation selbst? Inwiefern sind die Videotestamente nicht nur an der 〉Erzeugung \es Martyriums beteiligt, sondern in einem viel direkteren Sinne auch in die eigentliche Märtyrertod-Operation involviert?

Die spezifische Operativität der Videotestamente wird im Folgenden auf mehreren Ebenen in den Blick genommen. Abhängig davon, ob man die Ebene der Rezeption oder die der Produktion betrachtet, sind die Videotestamente in appellative oder performative Bildoperationen eingebunden. Zum einen formulieren die zukünftigen Märtyrer*innen in ihren Videos teils konkrete Handlungsaufforderungen. Wie eine Analyse der sprachlichen und visuellen Dimensionen der Videos zeigen wird, sind die Aufnahmen unter anderem darauf angelegt, bestimmte Verhaltensweisen bei verschiedenen Adressat*innen auszulösen und weitere militärische Operationen anzustiften. Zum anderen wirken die Videos aber bereits im Moment ihrer Produktion operativ - so die zentrale These dieses Kapitels. Die Videotestamente sind als antizipative Zeugnisse zu verstehen, die dem eigentlichen Attentat vorausgehen. Damit rücken notwendigerweise die Praktiken der Videoaufnahme selbst - das heißt: die performativen Dimensionen der Bildproduktion ins Zentrum der Aufmerksamkeit.

Im Unterschied zum Großteil der bisherigen Forschungen, die Videotestamente als primär textbasierte »Abschiedsnachrichten « untersucht haben, ${ }^{3}$ soll mit dem Konzept der Bildoperation der Versuch unternommen werden, gerade die Eigenheit oder den >Mehrwert` videografischer Aufzeichnungen gegenüber schriftlich verfassten Testamenten hervorzuheben. Neben den Operationen, die für Videotestamente generell als charakteristisch gelten können (Kapitel 3.1), werden in den folgenden Kapiteln zugleich die Unterschiede und Spezifika der jeweiligen Aneignungen in den Vordergrund treten. Auch wenn die ersten Videotestamente der säkularen Parteien bis heute richtungsweisend sind, so erfuhr das neu entstandene audiovisuelle Genre seitdem auch grundlegende Erweiterungen, Transformationen oder Umdeutungen. Eine entscheidende Weiterentwicklung fand im Laufe der 1990er Jahre statt, als auch die Hisbollah begann, Videotestamente ihrer (ausschließlich männlichen) Selbstmordattentäter aufzunehmen und zu verbreiten.

3 So die Kategorisierung von Graitl: Sterben als Spektakel, S. 126. Auch die Videoanalyse der Islamwissenschaftlerin Britt Ziolkowski hebt primär auf die Ebene des Textes ab. Britt Ziolkowski: Palästinensische Märtyrerinnen. Selbstdarstellung und innerislamische Wahrnehmung weiblicher Selbstmordattentäter, Berlin: Klaus Schwarz 2012. Eine reine Textanalyse palästinensischer Videotestamente findet sich auch bei Mohammed M. Hafez: Manufacturing Human Bombs: The Making of Palestinian Suicide Bombers, Washington, D.C.: United States Institute of Peace Press 2006, S. 87-92. 
Die statischen One-Shot-Aufnahmen der säkularen Parteien wichen komplexen Videomontagen, in denen das einzelne Märtyrerzeugnis in eine vielschichtige Dramaturgie der Zeugenschaft eingebettet wurde (Kapitel 3.2). Die islamische Auslegung der \Märtyrer〈-Operationen zog aber auch Veränderungen auf ikonografischer Ebene nach sich. Mit den Videos der Hisbollah erhielt erstmals eine explizit schiitische Symbolik Einzug in die Bildsprache dieser Aufnahmen. Geht es im zweiten Unterkapitel um die schiitische Aneignung des von säkularen Parteien begründeten Videogenres, wird das dritte Unterkapitel (Kapitel 3.3) den Blick auf Geschlechterkonstruktionen lenken, die in den Videotestamenten zum Ausdruck kommen. Traten die Selbstmordattentäterinnen der säkularen Parteien noch Seite an Seite mit ihren männlichen Parteikollegen auf, ließen islamische Parteien zunächst nur Männer für ihre Märtyrertod-Operationen zu. Dies galt zunächst für die libanesische Hisbollah, später auch für palästinensische Gruppen wie die Hamas oder den Islamischen Dschihad in Palästina. Als ab 2002 auch radikal-islamische Parteien Frauen für Selbstmordattentate rekrutierten, wurde die männlich konnotierte Ikonografie des Märtyrers mit weiblich konnotierten Bildtraditionen durchkreuzt. In einigen Fällen nutzten die weiblichen Attentäterinnen das Videotestament zudem als Bühne, um geschlechterspezifische Fragen zu verhandeln. Inwiefern die `Erzeugung 〈 des Martyriums immer auch mit der `Erzeugungく bestimmter Geschlechterbilder verbunden ist, werde ich am Beispiel der Selbstmordattentäterinnen während der zweiten palästinensischen Intifada untersuchen.

\section{1 »I AM THE MARTYR«. DIE ১ERFINDUNG، DES VIDEOTESTAMENTS IM LIBANON AB 1985}

Das Jahr 1985 kann als Ausgangspunkt der Videotestamente gelten, die im Zentrum der folgenden Kapitel stehen werden. Zu diesem Zeitpunkt war die israelische Armee seit drei Jahren im Libanon präsent und provozierte damit heftigen Widerstand mehrerer Konfliktparteien im Bürgerkrieg. Wie im zweiten Kapitel bereits geschildert, war es in den ersten Jahren nach der israelischen Besatzung ab 1982 zunächst die schiitische Hisbollah, die mit ihren Attentaten auf israelische und amerikanische Ziele für Schlagzeilen sorgte. Ab 1985 folgten schließlich auch die säkularen Parteien der Libanesischen Nationalen Widerstandsfront diesem Vorbild und begannen ebenfalls Selbstmordanschläge gegen Israel zu verüben. Wie das Beispiel von Sana Muhaydli bereits andeutete, waren es letztere, die zum ersten Mal vor eine Videokamera traten um Botschaften zu hinterlassen, bevor sie sich mit Autobomben in die Luft sprengten. Videotestamente wurden zunächst 
von der Syrischen Sozialen Nationalistischen Partei (SSNP), kurz danach auch von der Libanesischen Kommunistischen Partei (LCP) verbreitet. Anders als es der aktuelle, einseitige Fokus auf die Videotestamente islamistischer Selbstmordattentäter vermuten ließe, waren es also säkulare Parteien, die diese Form der medialen Inszenierung einführten.

Das erste bekannte Videotestament stammt von einem Selbstmordattentäter der SSNP. Am 12. März 1985 fuhr der 19-jährige Wajdi al-Sayigh mit einem mit Sprengstoff beladenen Auto in eine israelische Militärpatrouille nahe der südlibanesischen Stadt Jezzin. Verschiedenen Presseberichten zufolge kamen bei dem Anschlag drei israelische Soldaten ums Leben, eine Person wurde verwundet. ${ }^{4}$ Joseph Croitoru geht davon aus, dass es sich hier um eine sorgfältig orchestrierte Aktion handelte, da zur selben Zeit der damalige syrische Präsident Hafez al-Assad im Parlament in Damaskus »eine enthusiastische Rede hielt, in der er den Widerstand gegen die israelische Besatzung pries und den Aufopferungsgeist beschwor $~^{5}$. Die SSNP, die sich zur Tat bekannte, wurde zu dieser Zeit von der syrischen Regierung unterstützt, die damit ihren politischen Einfluss im Libanon erweitern wollte. ${ }^{6}$ Die 1932 von Antun Saada gegründete SSNP vertrat eine radikale Form des säkularen Nationalismus und verfolgte die Vision eines großsyrischen Reiches, das unter anderem auch den Libanon, Palästina und Jordanien umfassen sollte. $^{7}$

In diesem ideologischen Kontext standen auch die Selbstmordanschläge der Partei ab 1985. Die technische Durchführung des Attentats von Wajdi al-Sayigh folgte im Wesentlichen den Vorbildern der Konkurrenten Hisbollah und Amal. Neu war jedoch, dass neben einer schriftlichen Abschiedsnachricht, neben Fotografien und Postern zum ersten Mal auch ein Video des Attentäters verbreitet wurde. Folgt man einer libanesischen Chronik aus dem Jahr 1985, wurde Wajdi al-Sayighs Video von eben jener 17-Jährigen aufgenommen, die nur wenige Wochen später ein eigenes Autobombenattentat verübte und deren Videotestament

4 Vgl. die internationalen Presseberichte zitiert in Chicago Project on Security and Terrorism (CPOST): Suicide Attack Database, Attack ID: 2056898343.

5 Croitoru: Der Märtyrer als Waffe, S. 139.

6 Zur Geschichte der SSNP und ihrem Verhältnis zu Syrien siehe Daniel Pipes: »Radical Politics and the Syrian Social Nationalist Party«, International Journal of Middle East Studies 20/03 (1988), S. 303-324.

7 Die SSNP steht für drei wesentliche Grundsätze, so Pipes: »radical reform of society along secular lines, a fascist-style ideology, and Greater Syria«. In ebd., S. 304. 
ein breites Fernsehpublikum erreichen sollte. ${ }^{8}$ Im Unterschied zu Joseph Croitorus Darstellung, der davon ausgeht, dass das erste Videotestament der SSNP von Sana Muhaydli hinterlassen wurde, war sie selbst also bereits einige Wochen zuvor an der Produktion eines anderen Videotestaments beteiligt. ${ }^{9}$ Den Berichten ihrer Angehörigen zufolge arbeitete Sana Muhaydli zu diesem Zeitpunkt in einem Videoladen in West-Beirut - angeblich derselbe Ort, an dem sie wenige Wochen später auch ihr eigenes Videotestament mit einer VHS-Kamera aufnahm. ${ }^{10}$

Welche Rolle diese Verbindung zum Videoladen - und damit zur populären Videokultur der 1980er Jahre - konkret spielte, ist nicht abschließend zu klären. Dass diese Information aber überhaupt wichtig genug erschien, um in der im selben Jahr publizierten Chronik der »Märtyrertod-Operationen« des »libanesischen Widerstands 1982-1985 « ${ }^{11}$ aufzutauchen, verweist bereits auf die Bedeutung, die dem Medium Video beigemessen wurde. Für die libanesischen Parteien der Widerstandsfront, die seit 1982 gegen die militärisch weit überlegene Besatzungsmacht Israel und ihre Verbündeten kämpften, schien sich die Videotechnik als geradezu ideales Mittel für ihre Repräsentation >von unten schied zur Filmtechnik waren Videokameras zu dieser Zeit bereits relativ günstig, einfach zu handhaben und die Aufnahmen konnten schnell und ohne großen technischen Aufwand im Fernsehen ausgestrahlt werden. Nicht ohne Grund wurde das Medium daher in seiner frühen Phase für diverse Guerilla-Aktivitäten eingesetzt. Weltweit wurden Videoaufnahmen als Instrument der Gegensteuerung zum konventionellen Fernsehprogramm genutzt. ${ }^{12}$ Gleichzeitig machten tragbare Videokameras aber auch frühe Formen des Bürgerjournalismus oder >citizen witnessing

8 »Prior to her martyrdom, Sanā' worked in a video store in al-Muṣayṭ̂̄ area in West Beirut. During this time, she recorded 36 videotapes of the martyr Wajdī as-Șāyigh, who performed his operation against enemy forces in an area close to that where Sanā' did her martyring operation. It is in that store that Sanā' videotaped her testimony using a VHS camera. « Nasrallah (Hg.): Al Muqawama al-Wataniyya al-Lubnaniyya 19821985, S. 122. Zitiert nach Toufic: »I Am the Martyr Sanâ' Yûsif Muhaydlî«, S. 173.

9 Das Video von Wajdi al-Sayigh wird von Joseph Croitoru nicht erwähnt. Croitoru: Der Märtyrer als Waffe, S. 139ff.

10 Vgl. Scheherezade Faramazi: „Girl Who Crashed Car Bomb Into Israelis First Sent Mother Present«, Associated Press, 11.04.1985; Nasrallah (Hg.): Al Muqawama alWataniyya al-Lubnaniyya 1982-1985, S. 122.

11 Ebd.

12 Vgl. Yvonne Spielmann: Video: Das reflexive Medium, Frankfurt am Main: Suhrkamp 2005, Kapitel »Guerilla Television«, S. 136-138. 
möglich. ${ }^{13}$ Obwohl 1969 häufig als das Geburtsjahr des Home-Video bezeichnet wird, als die ersten Videorekorder mit Kassettentechnik (VCR-System) auf den Markt kamen, setzte sich das bis heute gebräuchliche VHS-Format - das der libanesischen Chronik zufolge auch für die ersten Videotestamente der SSNP genutzt wurde - erst Ende der 1970er Jahre durch. ${ }^{14}$ Ab 1982 wurde die VHS-Technologie noch einmal entscheidend revolutioniert, als Camcorder durch das kompakte VHS-C Kassettenformat erstmals kleiner und auch für den Privatgebrauch erschwinglich wurden. Dass militante Parteien wie die SSNP die VHS-Technologie für ihre Zwecke nutzten, ist im Kontext dieser `Videorevolution ‘ der 1980er Jahre zu sehen. Für die Entstehung des Videotestaments von Wajdi al-Sayigh ist das Jahr 1982 also von doppelter Bedeutung: Während die Invasion der israelischen Armee radikale Formen des Widerstands im Libanon provozierte, bei dem vermehrt auch Selbstmordattentate zum Einsatz kamen, boten die technologischen Entwicklungen auch neue Möglichkeiten der medialen Darstellung und Sichtbarmachung.

Anders als beim bereits erwähnten Video von Sana Muhaydli sind im Fall von Wajdi al-Sayigh keine Informationen überliefert, ob und wann genau sein Videotestament im Fernsehen zu sehen war. Die mir vorliegende Version ist Teil einer Zusammenstellung von Videotestamenten auf einer VHS-Kassette, die aus dem Büro eines Parteimitglieds der SSNP in Beirut stammt. ${ }^{15}$ Im Unterschied zu vielen nachfolgenden Videos, in denen das Testament von einem Zettel abgelesen wird, folgt dieses zu großen Teilen der Struktur eines offenen, scheinbar spontanen Interviews. Es zeigt Wajdi al-Sayigh in einem Innenraum auf einem grauen Sofa vor einer Wand sitzend, während er die Fragen seines Interviewpartners beantwortet, der zu seiner Rechten, überwiegend außerhalb des Bildfelds der Kamera, sitzt (Abb. 3.2). Während die meiste Zeit nur der linke Arm des Interviewenden ins Bild ragt und seine Stimme aus dem Off zu hören ist, sieht man an einigen Stellen (etwa bei 4:33 $\mathrm{min}$ ) auch sein Profil am Bildrand erscheinen.

13 Vgl. etwa Paul Garrin: »The 1988 Tompkins Square Police Riot - A Video Point of View«, Tactical Media Files (2011), http://www.tacticalmediafiles.net/articles/3460/ The-1988-Tompkins-Square-Police-Riot-_-A-Video-Point-of-View (zugegriffen am 6.6.2021).

14 Nasrallah (Hg.): Al Muqawama al-Wataniyya al-Lubnaniyya 1982-1985, S. 122. Zur Entwicklung der Videotechnik vgl. Spielmann: Video: Das reflexive Medium, S. 125.

15 Die VHS-Kassette wurde dem Londoner Journalisten Kevin Toolis im Rahmen seiner Recherchen für die Dokumentation The Cult of the Suicide Bomber 2005 ausgehändigt und mir freundlicherweise zur Digitalisierung zur Verfügung gestellt. Das Video (33:28 min) versammelt die Testamente von elf Selbstmordattentäter*innen der SSNP. 
Abbildung 3.2: Videotestament von Wajdi al-Sayigh, SSNP, Aufnahme am oder vor dem 12.3.1985, Ausschnitt, 4:55 min, arabisch.

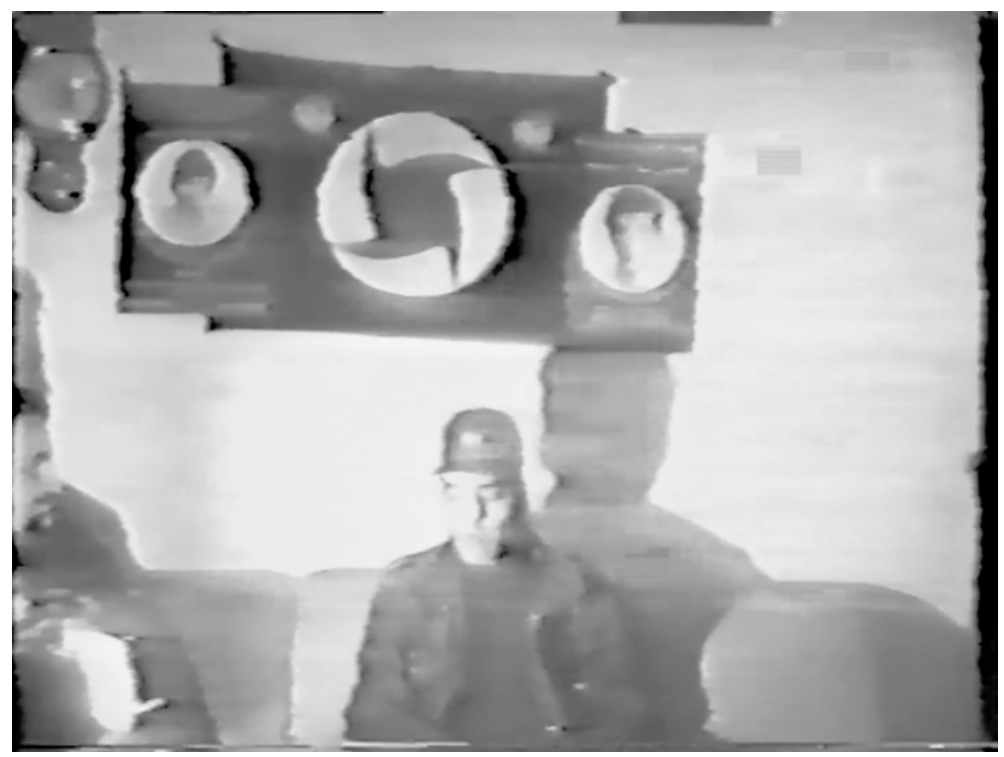

Obwohl im Verlauf des Videos drei Schnitte erkennbar sind, wurden alle Sequenzen aus derselben, fixierten Kameraposition gefilmt, die den Protagonisten im Bildzentrum platziert. Al-Sayigh trägt eine dunkle Baseballmütze, ein schlichtes schwarzes T-Shirt und eine schwarze Jacke. Mehr als die Hälfte des oberen Bildraums wird von der Wand hinter ihm ausgefüllt, auf der ein Tuch mit dem Logo der SSNP - ein vor schwarz-weißem Hintergrund rotierendes rotes Hakenkreuz zu sehen ist. ${ }^{16}$ Flankiert wird das Parteiemblem von je zwei Postern mit Portraits, die dem standardisierten Template entsprechen, das die SSNP für ihre Märtyrer entwickelt hat (siehe Kapitel 2.5). ${ }^{17}$ Neben den offiziellen Parteisymbolen gibt es aber auch Elemente, die weniger klar einzuordnen sind: So etwa die dekorative Uhr, die an der Wand links neben den Postern zu sehen ist. Als Teil einer Wohnzimmereinrichtung scheint sie darauf hinzuweisen, dass das Video in einem

16 Das Logo, ebenso wie der von der SSNP abgewandelte $>$ Hitlergruß< und die auf der Melodie des Deutschlandliedes basierende Parteihymne, weisen auf die ideologische Verbindung zur faschistischen NSDAP hin. Vgl. Croitoru: Der Märtyrer als Waffe, S. 140.

17 Die schlechte Qualität des Videos lässt es nicht zu, die Gesichter der dargestellten Märtyrer*innen zu erkennen. 
privaten Umfeld aufgenommen wurde. Gerade angesichts der bevorstehenden Selbstmordoperation rückt die Uhr aber auch in ihrer symbolischen Dimension als Zeichen der Vergänglichkeit in den Vordergrund. Ob diese Lesart von den Videoproduzent*innen beabsichtigt war, lässt sich allerdings nicht sagen. Neben der Ausstattung scheint auch die Beleuchtung der Szene eher auf Amateur*innen, denn auf professionelle Filmemacher*innen hinzuweisen. So wirft die Lampe, deren Licht direkt auf al-Sayigh gerichtet ist, einen dominanten Schlagschatten auf die weiße Wand. Dort ist auch der Schatten des Interviewpartners zu sehen, der auf diese Weise erneut - und wohl eher unfreiwillig - im Bild sichtbar wird. Nach 4:55 min bricht al-Sayighs Testament abrupt ab. Dies lässt vermuten, dass es sich hier um eine geschnittene und eventuell gekürzte Version der Videoaufnahme handelt. Der libanesischen Chronik zufolge wurden von al-Sayigh tatsächlich nicht nur ein Videotape, sondern gleich 36 (!) angefertigt. ${ }^{18}$ Handelte es sich hierbei um mehrere Probedurchläufe desselben Interviews? Oder verweist die schiere Anzahl der Videotapes darauf, dass zunächst mit unterschiedlichen Settings und anderen Formaten als dem Interview experimentiert wurde? Abgesehen von der hier besprochenen Version, die in gekürzter Fassung später auch auf dem YouTube-Kanal der SSNP veröffentlicht wurde, ${ }^{19}$ ist über den Verbleib der anderen Videoaufnahmen nichts bekannt, weshalb diese Fragen unbeantwortet bleiben müssen.

\section{Appellative Bildoperationen}

Die statische Gestaltung dieses ersten Videotestaments rückt zunächst die gesprochenen Worte ins Zentrum der Aufmerksamkeit. Zunächst beginnt das auf Arabisch geführte Interview mit Fragen nach der allgemeinen Befindlichkeit: »How are you today comrade Wajdi? - Good. - You're good? How's your spirit? Thanks to God it is very high and strong. $[\ldots] \ll .{ }^{20}$ Daran schließen mehrere Fragen zur bevorstehenden Selbstmordoperation an: »Comrade Wajdi, you know what you are going to do. Are you convinced with the job you are going to execute? « Wajdi al-Sayigh beschreibt die bevorstehende Operation daraufhin als seine Bestimmung, der er unweigerlich folgen wird: »Every human being that has this

18 Nasrallah (Hg.): Al Muqawama al-Wataniyya al-Lubnaniyya 1982-1985, S. 122.

19 Siehe das Video, das am 16.11.2011 von SSNP Online hochgeladen wurde, https://www.youtube.com/watch?v=ah_mYA-3c48 (zugegriffen am 6.6.2021).

20 Ich danke Shahed Naji für die englische Übersetzung aller elf Videotestamente, die auf der VHS-Kassette der SSNP zusammengefasst sind. Wenn nicht anderes angegeben, beziehen sich alle folgenden Zitate der SSNP-Testamente auf dessen Übersetzung. 
certain ambition in life, would execute the job he is destined to. And I am here for some reason. Whatever that reason was, I totally believe in this thing I am doing." Teilweise bohrt der Interviewende durchaus kritisch nach, um die Überzeugung al-Sayighs besonders herauszufordern: »Comrade Wajdi, the Israelis didn't harm you. They didn't occupy your land, nor your village. So what makes you care?« Mit seiner Antwort verweist der Attentäter auf die Ideologie der SSNP, der es nicht nur um die $>$ Befreiung $<$ Libanons von Israel geht, sondern um die $>$ Befreiung der gesamten großsyrischen Nation:

"What makes me care is that the Israeli enemy is the enemy of my nation, not only of my country. [...] The people of the south [gemeint ist der von Israel besetzte Süden Libanons], all the people of my village, as well as all my brothers and my comrades. I wish they all defend the south, because we have a great cause. Once we are done with the south, we can go on to Palestine. We want to annihilate them once and for all. This is the best thing to do.«

Auf die Nachfrage «Force them [the Israelis] to the sea?« antwortet al-Sayigh als Verweis auf das bevorstehende Sprengstoffattentat $-»$ To the sea, or to the sky«, woraufhin er in die Kamera lacht, als wolle er die Absurdität dieses Wortspiels unterstreichen. Das Lachen angesichts der bevorstehenden Tode kann zugleich aber auch als Ausdruck einer geradezu lustvollen Skrupellosigkeit gedeutet werden. Es folgen Detailfragen nach dem genauen technischen und logistischen Ablauf der geplanten Operation, sowie nach seiner persönlichen Biografie und seinem politischen Werdegang. Mit seinen Antworten wollte al-Sayigh offenbar seine unerschütterliche Entschlossenheit zur Tat bekräftigen, die er als heroischen Akt des Widerstands beschrieb. Auf der Tonebene wird diese sprachliche Performance jedoch mehrfach durch einen, wohl eher unbeabsichtigten, Subtext durchkreuzt und konterkariert. Im Laufe der Videoaufnahme ist immer wieder das Weinen eines Babys im Hintergrund zu hören (erstmals bei 0:58 min) sowie eine Frauenstimme, die zwar unverständlich, aber offenbar beruhigend auf das Baby einredet. Die `Störgeräusche` des Babygeschreis verweisen erneut auf das private Umfeld des Videos, das möglicherweise im Wohnzimmer von al-Sayighs Familie, möglicherweise sogar in Anwesenheit seiner Eltern und jüngerer Geschwister aufgenommen wurde. So sehr Wajdi al-Sayigh darum bemüht war, sich als furchtloser Rächer und Held darzustellen, der das Wohl der Nation über sein persönliches Leben stellt, so irritierend wirkt dieser unvermittelte Einbruch des Privaten, des Unschuldigen und Verletzlichen, das sich in Form des Babygeschreis in das Videotestament mit einschreibt.

Nach einem Schnitt bei ca. 2:42 min wechselt der Sprech-Modus für ca. 20 Sekunden von der ansonsten dialogischen Interviewsituation zu einer frontaleren 
Ansprache, bei der Wajdi al-Sayigh die Kamera direkt adressiert. Die Szene be-

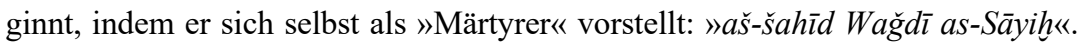
Direkt im Anschluss listet er die Namen weiterer »Märtyrer« auf: »Martyr Nidal Hassanieh, and martyr Hassan Darwish, and martyr Bilal Fahs. I am going to meet them all in the south. On the soil of the south, the land of dignity and pride.« Bei den ersten zwei Namen könnte es sich um die beiden SSNP-Märtyrer handeln, die auch auf den Postern hinter ihm an der Wand zu sehen sind und in deren Nachfolge sich der zukünftige Attentäter portraitiert. ${ }^{21}$ Es mag auf den ersten Blick erstaunen, dass al-Sayigh nicht nur Märtyrer seiner eigenen Partei als Vorbilder erwähnt, sondern auch Bilal Fahs, der am 16. Juni 1984 ein Selbstmordattentat für die schiitische Amal verübte. Dass ausgerechnet sein Name fällt - obwohl Bilal Fahs weder der SSNP nahestand noch mit seiner Aktion einen besonderen militärischen Erfolg erzielte - verweist erneut darauf, dass dieser im libanesischen Süden zu einer besonders populären Märtyrerikone avanciert war (siehe Kapitel 2.4). Obwohl al-Sayigh mit dem Begriff des Martyriums auf das Weiterleben nach dem Tod verweist, kann dieses imaginierte Treffen »auf dem Boden des Südens, dem Land der Ehre und des Stolzes« auch in einem nicht-religiösen, rein metaphorischen Sinne verstanden werden. Der von Israel besetzt Süden Libanons war seit Beginn der palästinensischen Widerstandskämpfe von besonderer symbolischer Bedeutung, die in engem Zusammenhang mit dem Befreiungskampf stand. ${ }^{22}$ Darüber hinaus galt die Region als besonders fruchtbar, weswegen sich in der Symbolik des Südens häufig die Mythisierung von Land und politischem Kampf überschnitten. $^{23}$

Ähnlich wie im Fall der palästinensischen Fedajin, propagierte auch die SSNP einen säkularen militärischen Kampf im Namen des nationalen Widerstands. Parteigründer Antun Saada, ein christlich orthodoxer Libanese, befürwortete einen radikalen Rückzug der Religion aus dem öffentlichen Leben und machte den Säkularismus und Anti-Konfessionalismus zu einem der Grundsätze der SSNPIdeologie. ${ }^{24}$ Der Aufruf zum Martyrium wurde folglich nicht an religiöse oder

21 Zumindest von Hassan Ahmad Darwish existiert in der Tat ein Märtyrerposter, das demselben Muster entspricht, das verschwommen im Video zu sehen ist. Der Inschrift auf dem Poster zufolge starb Darwish »als Märtyrer und Held« während der »Angriffsoffensive von Akka« am 13. Oktober 1984. Vgl. das Poster in: http://www.signsofconflict.com/Archive/poster_details/2187 (zugegriffen am 6.6.2021).

22 Beispielsweise wurde der Selbstmordattentäter Bilal Fahs von der Amal als »Bräutigam des Südens« bezeichnet, siehe Kapitel 2.4.

23 Vgl. Maasri: Off the Wall, S. 111.

24 Vgl. Pipes: »Radical Politics and the Syrian Social Nationalist Party«, S. 304. 
konfessionelle Inhalte geknüpft, sondern als Opfertod für die Nation und für die politischen Ziele der Partei verstanden. Dementsprechend finden sich auch im Videotestament von Wajdi al-Sayigh keinerlei religiösen Verweise, etwa auf Belohnungen im Jenseits. Als abstraktes Streben nach »Ehre und Stolz« (»the land of dignity and pride«) ist das Martyrium hier vielmehr als diesseitiges Vermächtnis denn als religiöse Auferstehung zu verstehen.

Neben dem Bekenntnis zur eigentlichen Tat und der Selbsternennung zum nächsten Märtyrer waren mit dem Video schließlich mehrere Appelle und teils sehr konkrete politische Forderungen verbunden. Mit dem Video wurden im Wesentlichen zwei Adressatengruppen angesprochen und zu einem bestimmten Verhalten aufgefordert: Zum einen richtete sich der Aufruf an alle Feinde Israels, alle "Söhne der Nation « (die in diesem Fall als großsyrische Nation imaginiert wurde), Widerstand zu leisten und nach seinem eigenen Vorbild Selbstmordanschläge durchzuführen. Gleich zu Beginn seiner Absichtserklärung (»I totally believe in this thing I am doing «), fügt al-Sayigh hinzu: »And Insha'Allah [Redewendung: So Gott will], others have the same ambition as I do.« Gegen Ende des Videointerviews ruft al-Sayigh seine Kameraden erneut dazu auf, es ihm gleich zu tun und Widerstand zu leisten: »I would like to encourage all the people to resist, all the sons of our nation.« Zum anderen enthält sein Testament aber auch Botschaften an Israel und seine Verbündeten, die den Feind einschüchtern sollten und auf die Erzeugung von Angst und Terror abzielten (»Once we are done with the south, we can go on to Palestine. We want to annihilate them once and for all«). Abgesehen von allgemeinen Drohgebärden wie diesen formuliert al-Sayigh auch ganz konkrete Appelle an den Feind. So endet das Video mit der Forderung an die maronitisch-christliche Kata'ib-Partei (die zu dieser Zeit mit Israel koalierte), einen Gefangenen der SSNP freizulassen.

»My last will is that the party [gemeint ist die Kata'ib-Partei] should set Habib al-Shartouni free from jail. They better do it, or else we will send them around 15 men to their headquarter. That would drive them crazy. We will send them 15 men to their headquarter to see if they would set Habib Al Shartouni free or not, and this is my will. «25

Wajdi al-Sayighs Videotestament wurde zwar nicht selbst als Druckmittel eingesetzt, um den SSNP-Gefangenen freizupressen (zum Zeitpunkt der Ausstrahlung

25 Habib al-Shartouni war ein SSNP-Mitglied, der für den Mord an Kata'ib-Präsident Bachir Gemayel verantwortlich gemacht und im September 1982 verhaftet wurde. Neben dem Videotestament existieren auch Fotografien von Wajdi al-Sayigh, in denen er vor mehreren Postern des Gefangenen Habib al-Shartouni posiert. 
des Videos war der Anschlag ja bereits vollzogen), sein Attentat nahm aber die Rolle eines Vorboten ein, der auf die Bereitschaft der Partei hinwies, auch vor weiteren drastischen militärischen Aktionen mit eigenen Opfern nicht zurückzuschrecken.

Das erste Videotestament der SSNP ist folglich als vielschichtiger Kommunikationsakt zu begreifen, der mit ganz unterschiedlichen appellativen Zielen verbunden war. Dies schließt im Wesentlichen an die kommunikationstheoretischen Überlegungen von Lorenz Graitl an, der in seiner Studie zum politisch motivierten Suizid auch einige Videotestamente von Selbstmordattentäter*innen untersucht hat. ${ }^{26}$ In Bezug auf deren kommunikative Funktionen und den damit verbundenen Handlungserwartungen unterscheidet Graitl drei grundlegende Typen oder Modi, die in den meisten Fällen als Mischformen auftreten: Erstens, der »Heldenmärtyrer«, der primär die eigene Gemeinschaft adressiert und auf eine Stärkung der Solidarität, sowie Mobilisierung innerhalb der eigenen Kreise abzielt. Zweitens, der »Racheengel«, dessen Botschaft gegen den Feind gerichtet ist und in Form einer Anklage, Einschüchterung oder Drohung vorgetragen wird. Und drittens, der »egoistische Märtyrer«, der in seinem Testament auf Belohnungen im Paradies verweist, die Vorzüge des Jenseits lobt und seine Abschiedsnachricht mit einer religiös-missionarischen Botschaft verbindet. ${ }^{27}$ Spielt der letzte Typ mit Blick auf das säkulare Selbstverständnis der SSNP eine eher unwesentliche Rolle, treten die beiden anderen kommunikativen Funktionen umso deutlicher hervor. Mit seinen heterogenen Appellen übte das Videotestament eine affektive und rhetorische Macht auf die Betrachtenden aus und forderte diese zu bestimmten Verhaltensweisen auf, die sich je nach Adressatengruppe unterschieden. Das Videobild 〉operiert also zunächst auf sprachlicher Ebene, als konkreter Aufruf zum Handeln. Diese »appellative Kausalität« der Videobilder wurde von Jens Eder als ein Modus von Bildoperationen beschrieben. In seinen Vorüberlegungen zu Image $O p$ erations konkretisiert Eder dies folgendermaßen: »In contexts of appellative causality images take part in more specific and direct calls to action: By way of their affective, rhetorical, or didactic force, images demand, incite, invite, or instruct spectators to do something. $\ll^{28}$

Trotz der Androhung weiterer Militäroperationen wurde der Gefangene alShartouni jedoch nicht frei gelassen. In dieser Hinsicht blieb al-Sayighs Videoappell folgenlos. Innerhalb der eigenen Reihen schienen die Aufforderungen ihre Wirkung hingegen nicht verfehlt zu haben. Der Selbstmordanschlag war nur der

26 Graitl: Sterben als Spektakel, S. 198-215.

27 Ebd., S. 250.

28 Eder: Vorüberlegungen zu »Image Operations«, o.S. 
Startpunkt einer ganzen Serie von Attentaten, die die SSNP in den darauffolgenden Wochen und Monaten auf israelische Stützpunkte verübte.

\section{Eine Selbstmordattentäterin wird zur Nationalikone: Sana Muhaydlis Video »Braut des Südens»}

Nur wenige Wochen nachdem Sana Muhaydli dieses Videotestament ihres Kameraden Wajdi al-Sayigh aufgenommen hatte, sollte sie am 9. April 1985 ein eigenes Selbstmordattentat begehen und ihrerseits ein Videotestament hinterlassen (vgl. S. 99f). Ihre Ansprache wurde gleich von mehreren libanesischen und syrischen TV-Sendern und an mindestens zwei aufeinanderfolgenden Tagen im Fernsehen ausgestrahlt. ${ }^{29}$ Die Ausstrahlung in den Fernsehnachrichten war offenbar schon bei der Gestaltung des Videos mitgedacht: Im Unterschied zur Home-Video-Ästhetik des vorherigen Testaments, das al-Sayigh informell plaudernd auf einem Sofa zeigte, saß Sana Muhaydli nun wie eine professionelle TV-Kommentatorin hinter einem Tisch (Abb. 2.1). Ähnlich wie im Video von Wajdi al-Sayigh diente die Wand hinter ihr als Präsentationsfläche für ihre Parteizugehörigkeit: Unter der SSNP-Fahne war ein Poster mit dem Portrait des Parteigründers Antun Saada zu sehen, der von der SSNP nach faschistischem Vorbild als `Führer verehrt wurde. Darüber hinaus wurde das Setting mit weiteren Partei-Requisiten ausgestattet, wie beispielsweise einem Kissen mit dem roten SSNP-Logo, das neben Muhaydli auf einem Stuhl lag. Die Szene wurde zudem durch einen handschriftlichen Text ergänzt, der, auf weiße Plakate geschrieben, ebenfalls an der Wand hinter ihr zu sehen war.

Im Gegensatz zur schwarzen Kleidung al-Sayighs trug Muhaydli eine Militärjacke, sowie ein rotes Barett auf dem Kopf: beides vermutlich mit der Absicht, ihr angekündigtes Attentat als Militäraktion zu legitimieren. Auch der Sprech-Modus erscheint in Muhaydlis Videoaufnahme weitaus formeller. Die lockere Interviewstruktur, wie sie im Video von al-Sayigh noch vorherrschte, wich nun einer frontal ausgerichteten Rede für die Kamera. Muhaydli formulierte ihre Botschaft nicht mehr als spontane Reaktion auf Fragen, sondern hatte vor sich auf dem Tisch einen Zettel liegen, auf den sie immer wieder blickte und der offensichtlich

29 Zunächst wurde das Video am 9. April 1985 in den Abendnachrichten auf Télé Liban ausgestrahlt. Vgl. die Berichte in al-Anwar vom 10. April 1985 und der israelischen Haaretz vom 11. April 1985, zitiert in Croitoru: Der Märtyrer als Waffe, S. 142. Folgt man dem Bericht von Daniel Pipes, wurde das Video erneut am Tag danach, am 10. April 1985 vom syrischen TV-Sender Damascus Television ausgestrahlt. Pipes: »Radical Politics and the Syrian Social Nationalist Party«, S. 318; 324. 
Stichpunkte für ihre Rede enthielt. Wichtige Textpassagen unterstrich sie mit emphatischen Gesten, die ihrer Ansprache den Anschein einer gut vorbereiteten Rede gaben. Wie eingangs erwähnt, begann ihr Videotestament mit den Worten:

»I am the martyr Sana Yusif Muhaydli. I am 17 years old, from the South, from the occupied and oppressed Lebanese South, from the resisting, resurgent South. I am not dead, but alive among you. Sing, dance, realise my dreams. Don't cry; don't be sad for me, but exult and laugh for a world in which there are heroes. $\ll^{30}$

Wie Wajdi al-Sayigh identifizierte sich auch Sana Muhaydli in ihrem Video selbst als »Märtyrerin«. An den Anfang des Testaments gestellt, erhält diese Selbstidentifikation nun jedoch weitaus mehr Gewicht als im Video ihres Vorgängers. Das Statement »Ich bin die Märtyrerin Sana Yusif Muhaydli« rückt in den Status einer Eröffnungsthese. Damit wird eine ganze Reihe an Fragen aufgeworfen. Eine Märtyrerin kann per definitionem nur eine Person sein, die bereits gestorben ist. Wie kann sich eine Lebende als Märtyrerin inszenieren, wenn bisher weder die angekündigte Märtyreroperation vollbracht wurde noch der eigene Tod eintrat? Muhaydli sagt nicht: >Ich werde als Märtyrerin sterben`, sondern behauptet: »Ich bin die Märtyerin«. Ist dieser Ausspruch nicht gleichbedeutend mit dem Satz 〉Ich bin tot«? Im Unterschied zu al-Sayighs Botschaft treibt Muhaydli die Unmöglichkeit dieser Behauptung zudem auf die Spitze, indem sie die Perspektive der bereits gestorbenen Märtyrerin auch in den darauffolgenden Sätzen beibehält: »I am not dead, but alive among you. « Die Fernsehzuschauer*innen, die das Videotestament noch am selben Abend in den Nachrichten verfolgten, wurden dadurch zu Adressat*innen einer unheimlichen Botschaft: Nur wenige Stunden nach dem Selbstmordanschlag sprach die Attentäterin aus der Perspektive einer Gestorbenen - also scheinbar in Jetzt-Zeit - zu ihnen und versicherte zugleich ihr Überleben im Jenseits. Während der Großteil ihrer Videoansprache im Futur formuliert ist (»I am so relieved that I am going to execute this operation [...]«) und damit den Status einer in der Vergangenheit liegenden Absichts-Bekundung hat, nimmt Muhaydli zu Beginn ihrer Botschaft die unmögliche Sprecherposition einer zukünftigen Gegenwart ein.

Im Arabischen erinnert Muhaydlis Aussage »I am not dead, but alive among you « an die viel zitierte Koransure 3:169, mit der das Weiterleben der Märtyrer*innen im Jenseits bestätigt wird: »Und du darfst ja nicht meinen, daß diejenigen, die um Gottes willen getötet worden sind, (wirklich) tot sind. Nein, (sie sind)

30 Englische Übersetzung zitiert nach Khalili: Heroes and Martyrs of Palestine, S. 13f. 
lebendig (im Jenseits) [...]. «11 Die Anlehnung an eine religiöse Sprache mag angesichts der säkularen Ideologie der SSNP zunächst verwundern. Auch wenn Muhaydli in ihrem Testament nicht explizit auf Gott oder den Islam verwies, schien sie fest an ein Weiterleben im Jenseits zu glauben - auch wenn unklar ist, ob dies in einem religiösen Sinne oder metaphorisch gemeint war. Noch deutlicher wird dies anhand des Textes, der auf der Wand hinter ihr zu lesen ist und wie als Subtext ihre gesprochene Botschaft ergänzt (vgl .Abb .33.) ${ }^{32}$ Hier steht geschrieben: »We are all submitted to God. Some of us believe in God through the Bible. Some believe also in God, through the Quran. And some believe in God through the wisdom. We have no enemy that fights against us in our religion and our faith except for the Jews $[\ldots]$. (13 $^{33}$

Die betonte Gotteshingabe scheint auf den ersten Blick dem säkularen Grundsatz der SSNP zu widersprechen. Gleichzeitig lässt der Text eine anti-konfessionelle Haltung erkennen, die Unterschiede zwischen Christentum und Islam scheinbar einebnet. Dies ist auf die unorthodoxe Lehre des SSNP-Gründers Antun Saadas zurückzuführen, der Christentum und Islam als zwei Manifestationen derselben Religion betrachtete. ${ }^{34}$ Diesem konfessionslosen Glauben wurde schließlich das Judentum als gemeinsamer Feind gegenübergestellt. Saada ersetzte damit die konventionelle Lehre des Islam durch neue Prinzipien, die sich an nationalsozialistischen Ideen orientierten. Die faschistische Ausrichtung der SSNP spiegelt sich auch weiter unten im handschriftlichen Text in Muhaydlis Video wider, wenn ein mystischer, auf »Blut« basierender Nationalismus beschworen wird. ${ }^{35}$

31 Zitiert nach Rudi Paret (Hg.): Der Koran. Kommentar und Konkordanz von Rudi Paret, 8. Aufl., Stuttgart: Kohlhammer 2001, Koransure 3:169, online abrufbar unter https://corpuscoranicum.de/index/ index/sure/3/vers/169 (zugegriffen am 6.6.2021).

32 Aufgrund der schlechten Qualität ist die Schrift im Video kaum zu entziffern. Ein Märtyrerposter von Muhaydli zeigt jedoch eine bessere Fotografie vor derselben Wand, auf der Muhaydli zusätzlich mit einer Geste auf den Text verweist, vgl. Abb. 3.3.

33 Shahed Naji, der den Text freundlicherweise für mich übersetzt hat, weist auf das Wortspiel im ersten Satz hin, der im engeren Wortsinn lautet: »We are all muslims to God «. Das Wort »muslim« bedeutet im Arabischen »submitted«. In diesem Sinne (»We are all submitted to God«) wird das Wort hier verwendet. Email an die Autorin, 22.8.2017.

34 Diese Ansicht wurde in Saadas Buch »Islam in Its Two Messages: Christianity and Muhammadism« vertreten. Vgl. dazu Pipes: »Radical Politics and the Syrian Social Nationalist Party«, S. 315.

35 »The blood that flows in our veins is not our own property. It is the trust of the nation. When it is called upon, it answers the call.« 
Abbildung 3.3: Poster zu Ehren von Sana Muhaydli, SSNP, 1985, $51 \times 71 \mathrm{~cm}$.

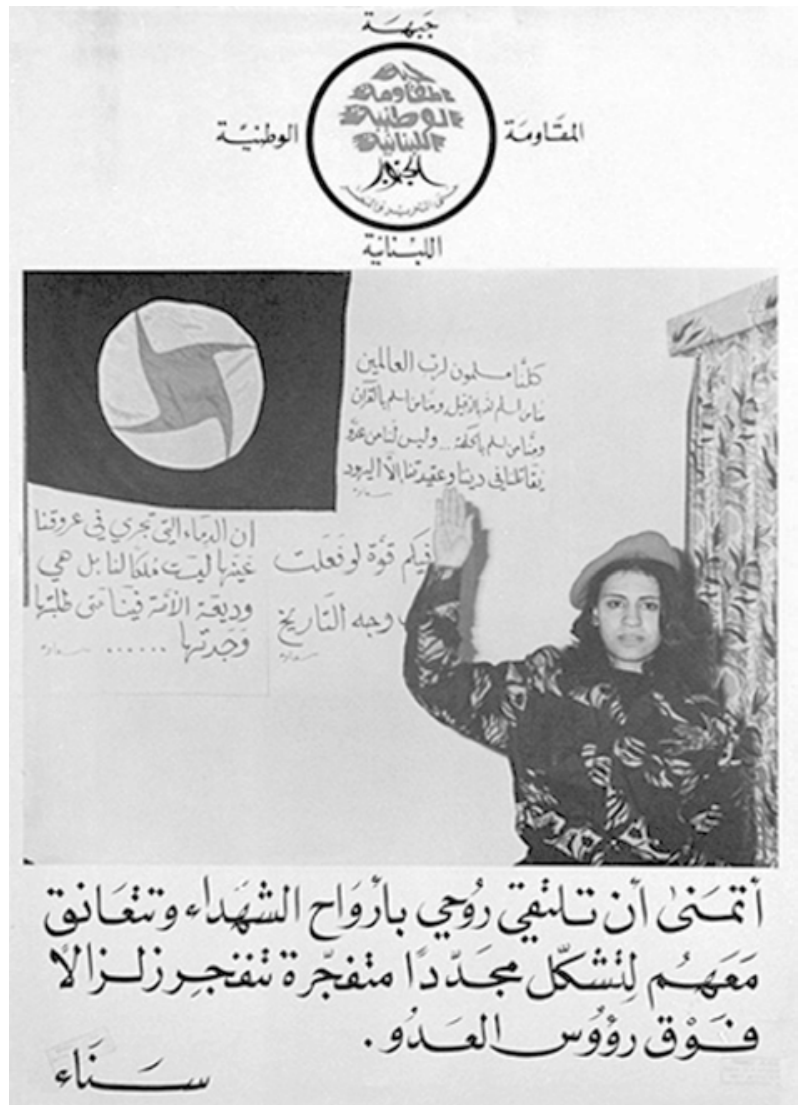

Abgesehen von diesem handschriftlichen Verweis auf Gott, betonte Muhaydli in ihrem Videotestament eindeutig die nationalistische Motivation, mit ihrer bevorstehenden Tat die Gewalt und das Unrecht der israelischen Besatzung zu vergelten und zur Befreiung der Nation beizutragen. ${ }^{36}$ Immer wieder versicherte sie ihre Entschlossenheit und Freude angesichts der bevorstehenden Operation, die sie als Pflichterfüllung gegenüber ihrem Volk beschreibt: »I am so relieved that I am going to execute this operation that I have chosen. Because I am doing my duty

36 »Because I have seen the misery of my people caused by the occupation. The injustice and the killing of the children, the women and the old men. The destruction of houses on the heads of the inhabitants. And for this reason, we decided to fight for redemption.« 
towards my land, my people.« Während in ihrem Videotestament Drohungen an den Feind eine eher untergeordnete Rolle spielten, sprach sie zusätzliche Adressat*innen an: Zunächst richtete sie ihre Grußworte direkt an Hafez al-Assad, «the leader of the liberation march and resistance«, und brachte damit die Gefolgschaft der SSNP zu Syrien unmissverständlich zum Ausdruck. Das Buhlen um die Gunst des syrischen Machthabers war sicherlich auch als parteipolitische Strategie zu werten, mit dem Ziel, die finanzielle Unterstützung durch Syrien zu sichern. ${ }^{37} \mathrm{Ne}-$ ben weiteren offiziellen Grußworten an die Nationale Libanesische Widerstandsfront richtete Muhaydli zum Ende der Ansprache aber auch persönliche Abschiedsworte an ihre Eltern, verbunden mit dem Wunsch nach Vergebung und der Bitte, ihrem Martyrium nicht mit Trauer, sondern mit Freude zu begegnen:

»I would like to send a special message to my mother; I ask her for forgiveness and to wish peace for my soul, because I left without saying goodbye. You, my mother, taught me to love, sacrifice and respect. And there I am, I love my country, I love my life and I respect my people and land. And to my father, I left you a written note, I hope you don't get sad or grieve me at all. On the contrary, I'd like you to wed me and dance. I tell you again, father, to wed me and dance, because my blood will wash the land of south from the ordure of the Jews. This is what I have to ask from you.«

Muhaydli war darauf bedacht, ihr Martyrium nicht als Tat aus Verzweiflung, Hass oder (egoistischer) Todessehnsucht darzustellen, sondern im Gegenteil als selbstlosen Akt, der in der »Liebe« zu ihrem Volk begründet lag. Die Ansprache an ihre Eltern erfüllte einerseits die Funktion einer persönlichen Abschiedsnachricht und war andererseits mit der Bitte um Vergebung angesichts ihres selbst gewählten Todes verbunden.

Der Verweis auf ihr Martyrium als »Hochzeit« scheint indes an den AmalSelbstmordattentäter Bilal Fahs anzuschließen, der ebenfalls als »Bräutigam des Südens « bezeichnet wurde und den Muhaydli in ihrem Videotestament auch namentlich als Vorbild erwähnte. Wie Joseph Croitoru bemerkt, verwies dieser Beiname im Fall von Bilal Fahs auf seine tatsächlich bevorstehende Heirat. ${ }^{38}$ Folgt man der Darstellung von Amir Taheri, besteht bei Muhaydli aber auch ein Zusammenhang zum schiitischen Brauch der sogenannten >Blut-Bräute $<$ - so werden im schiitischen Kontext Frauen bezeichnet, die bereit sind ihr Leben zu lassen, um

37 In den 1980er Jahren erstarkte die Partei insbesondere durch die Patronage der syrischen Regierung, die die SSNP mit Geld und Waffen versorgte. Pipes: »Radical Politics and the Syrian Social Nationalist Party«, S. 318.

38 Vgl. Croitoru: Der Märtyrer als Waffe, S. 142. 
Rache für den Tod von Imam Hussein zu üben. ${ }^{39}$ Muhaydli wuchs in einer schiitischen Familie in der schiitisch dominierten südlibanesischen Stadt Qanun auf; es liegt daher nahe, dass ihr diese Konnotation bewusst war, als sie den Topos der Hochzeit aufrief. Obwohl Muhaydli ihr Attentat im Namen einer säkular-nationalistischen Partei verübte und zumindest in ihrem gesprochenen Testament um eine weitgehend säkulare Wortwahl bemüht war, wurde auch sie nach ihrem Selbstmordattentat von religiösen schiitischen Gruppen als "'Arūs ad-Damm«, als »Blut-Braut« verehrt. Taheri berichtet von einer Zeremonie am 25. März 1986 in einer schiitischen Moschee im Süden Beiruts, bei der sowohl Sana Muhaydli als auch die angebliche Hisbollah-Selbstmordattentäterin Sumayah Saad als »BlutBräute « geehrt wurden. ${ }^{40}$ Als solche würden sie im Jenseits mit einem (von Imam Hussein ausgewählten) Mann vermählt, der »the most pious and shapely of young men, free of all blemish ${ }^{41}$ darstelle, so versicherte ein islamischer Geistlicher auf einer weiteren Zeremonie ein knappes Jahr nach Muhaydlis Selbstmordattentat.

Die Brautsymbolik war jedoch nicht nur in Muhaydlis Worten angelegt. Das romantische Bild der schönen Braut im Jenseits wurde vor allem durch die Weiterbearbeitung ihres Videos vorangetrieben. Die ursprüngliche Testament-Aufnahme wurde von der SSNP in einzelne Sequenzen geschnitten und mit weiteren Aufnahmen kombiniert - darunter dokumentarisches Footage von Bürgerkriegsszenen, abgefilmte Fotografien und Poster von Muhaydli und anderen Märtyrer*innen, sowie grafische Animationen und eine, offenbar von einer Schauspielerin nachgestellte Sequenz, die die Attentäterin am Steuer des Tatfahrzeugs zeigen sollte. Die 16:28 min lange Videoproduktion wurde schließlich unter dem Titel Die Braut des Südens ( 'Arūs al-Ġanüb) von der SSNP verbreitet. ${ }^{42}$ Die letzten Minuten des Videos zeigen mehrere Aufnahmen einer Braut von hinten, die mit weißem Kleid und wehendem Brautschleier in einer grünen Naturlandschaft steht und ihren Arm zum faschistischen Gruß der SSNP erhebt (Abb. 3.4 d). Eingeleitet wird diese Sequenz durch eine Animationsgrafik der Explosion aus extremer Vogelperspektive, die Muhaydlis Bombenattentat als Ereignis von globaler Bedeutung erscheinen lässt (Abb. 3.4 b). Die Zoombewegung weg von der Erdkugel mündet schließlich in der grafischen Darstellung einer transzendenten

39 Vgl. Amir Taheri: Holy Terror: The Inside Story of Islamic Terrorism, London: Hutchinson 1987, S. 117.

40 Ebd., S. 115-17. Ob es sich bei Sumayah Saad tatsächlich um eine Selbstmordattentäterin der Hisbollah handelte, kann durch andere Quellen jedoch nicht belegt werden. Vgl. S. 145, Anm. 495.

41 Zitiert in ebd., S. 116.

42 Diese Version befindet sich auch auf der mir vorliegenden VHS-Kassette der SSNP. 
Himmelszene über den Wolken (Abb. 3.4 c), die dann auf das filmische Bild der in ebenfalls gleißendem Licht stehenden Braut überblendet. Begleitet werden die Bilder von Gitarrenklängen und poetischen Lobesworten auf die »Braut des Südens«. Die von einer Schauspielerin gestellte Szene verweist unmissverständlich auf Sana Muhaydli, die nun - so die bildliche Imagination - als schöne Braut im Jenseits ihr Glück erlebe. Entsprechend wird die fiktive Brautszene immer wieder von Fotografien Sana Muhaydlis überblendet. Das Video endet erneut mit den Worten der Attentäterin »Ich bin die Märtyrerin Sana Yusif Muhaydli«, die als Tonspur über das Videobild der Braut gelegt wurden, begleitet von einem weiteren roten Schriftzug »Braut des Südens«, der sich als eine Art Abspann von unten ins Bild schiebt.

Wann genau diese Videomontage entstanden ist, lässt sich nicht sagen. Die zahlreichen Lobeshymnen, die kurze Zeit nach Muhaydlis Attentat von säkularen wie schiitischen Stimmen zu vernehmen waren, wirken jedoch bereits, als wären sie vom Anblick dieser romantischen Videoszenen inspiriert gewesen. So veröffentlichte ein Hisbollah-Anhänger im Jahr 1986 ein Gedicht über die »wunderschöne Braut«, in dem er ihren Opfertod in verliebten Tönen schilderte..$^{43}$ Das Bild einer mutigen Märtyrerin, die den männlichen Kämpfern in nichts nachsteht, wurde mit dem heteronormativen Bild der wunderschönen und jungfräulichen Braut verbunden. Das Video schien auf diese Weise eine ganze Bandbreite von Identifikationsmöglichkeiten für Frauen bereit zu stellen.

Schon kurz nach ihrer Tat wurde Muhaydli im Libanon zur Nationalheldin erklärt und von mehreren, eigentlich miteinander konkurrierenden politischen Lagern verehrt. ${ }^{44}$ Lob kam nicht nur, wie erwartet, vom syrischen Präsidenten Hafez al-Assad, der die Schönheit und Heldenhaftigkeit der Attentäterin hervorhob. ${ }^{45}$ Auch im Iran wurde Muhaydlis Attentat - und ganz besonders ihr Video - mit Begeisterung aufgenommen. Am 13. April 1985, nur vier Tage nach der ersten Veröffentlichung ihres Videotestaments, wurde dieses in der iranischen Nationalzeitung Jomhuri Islami als ein »geschätzter Teil der islamischen Geschichte«

43 »What a beautiful bride you became, San'ah!/ The envy of the full moon you became, San'ah!/ Wearing your bridal dress, your eternal shroud,/ You strolled amid the stars, San'ah!/ You scattered your body over the sacred land.../ But angels came to collect the fragments, San'ah!/ Is there anything more beautiful than death?/ You say: >Yes! To kill the enemy! You say San'ah!« In: Gozideh I az assar shoaray Hezb Allah (A Selection of Work by the Poets of the Party of Allah), Teheran, 1986. Zitiert in: Taheri: Holy Terror, S. 272, Anm. 10.

44 Ebd., S. 117.

45 Vgl. Croitoru: Der Märtyrer als Waffe, S. 143. 
beschrieben. ${ }^{46}$ Ihr Videobild wurde also sowohl vom schiitischen, als auch vom säkular-nationalistischen Lager für die eigenen Zwecke angeeignet. Mehreren Berichten zufolge wurde Muhaydlis Videotestament nicht nur an den Tagen nach dem Attentat im Fernsehen ausgestrahlt, sondern auch in Form von VHSKassetten verbreitet, die sich offenbar schnell zu einer begehrten Ware entwickelten. ${ }^{47}$ Die Aufmerksamkeit, die das erste Video einer weiblichen Selbstmordattentäterin erregte, führte wohl dazu, dass Muhaydlis Testament bis heute häufig als das >erste < Videotestament dieser Art bezeichnet wird und die Videoaufnahme von Wajdi al-Sayigh weitgehend in Vergessenheit geriet.

Abbildung 3.4 a-d: Videotestament von Sana Muhaydli: Die Braut des Südens, SSNP, 16:28 min, arabisch, o.D.
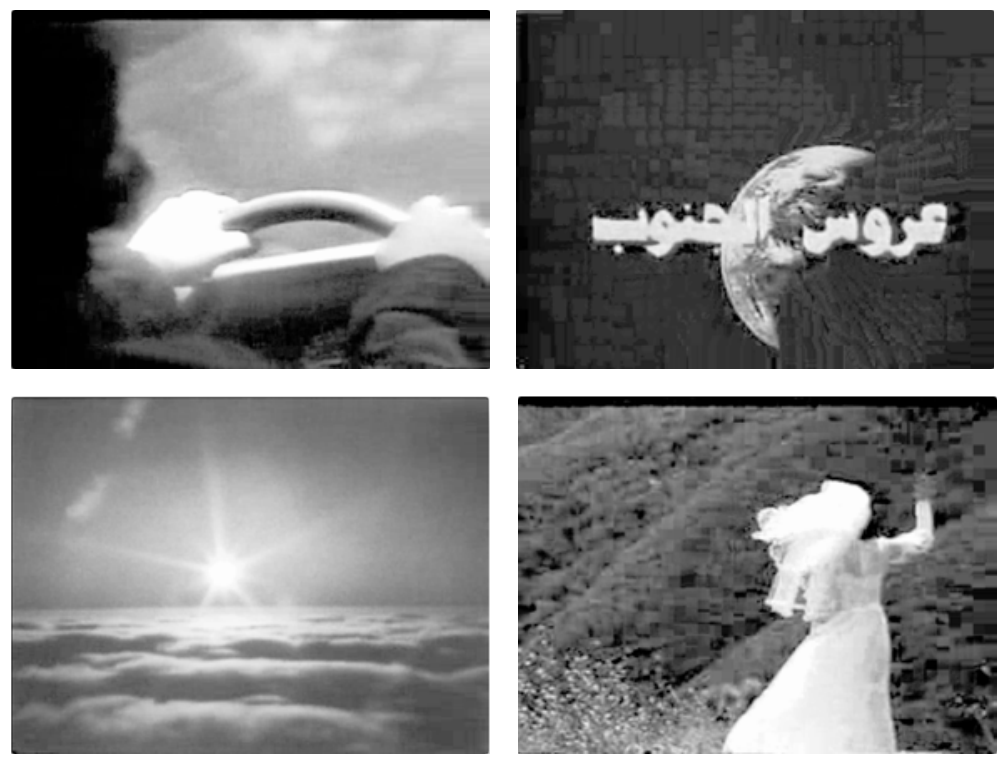

Mit ihrem Märtyrerzeugnis schloss Muhaydli ausdrücklich an das Vorbild alSayighs an, indem sie gleich zu Beginn ihrer Rede auf eine lange Reihe von Märtyrern verwies, die ihr vorangegangen waren - darunter auch Bilal Fahs und, »last

46 Jomhuri Islami, Teheran, 13. April 1985. Zitiert in Taheri: Holy Terror, S. 117.

47 Zur Verbreitung des Videos siehe Ehud Ya'ari: »Behind the Terror«, The Atlantic 259/6 (1987), S. 18-22, https://www.theatlantic.com/magazine/archive/1987/06/behind-theterror/376326/ (zugegriffen am 6.6.2021), hier o.S.; Croitoru: Der Märtyrer als Waffe, S. 142; Maasri: Off the Wall, S. 123, Anm. 5. 
but not least, [...] the martyr, the hero Wajdi al-Sayegh. « Damit beteuerte sie, keineswegs die Einzige gewesen zu sein, die den Schritt des Martyriums wählte: »I wasn't the only one who took this decision. I am within a group that chose redemption and martyrdom to liberate our land and people. $\kappa^{48}$ Die Analyse der Serienproduktion und Standardisierung von Märtyrerpostern im zweiten Kapitel hat bereits gezeigt, dass das Bild des einzelnen Märtyrers oder der einzelnen Märtyrerin im libanesischen Bürgerkrieg zunehmend als Teil einer ganzen Reihe betrachtet wurde, die sich scheinbar unendlich fortsetzen ließ. Ein ähnlicher Effekt lässt sich auch für die gesprochenen Bekenntnissen feststellen. Al-Sayigh und Muhaydli präsentierten sich in ihren Videos nicht als singuläre Held*innen, sondern stellten ihr Martyrium als aktuellstes Glied in einer Kette von Vorbildern dar. Im selben Atemzug wurde diese Genealogie von Märtyrer*innen auch in die Zukunft projiziert und mit expliziten Handlungsaufforderungen verbunden. So rief auch Muhaydli die Parteifreund*innen auf, ihrem Vorbild zu folgen: «I ask you to carry through this march of sacrifice and redemption until the full liberation of our land and people.«

Tatsächlich sollte nur elf Tage später ein weiterer Selbstmordattentäter der SSNP eine »Operation im Namen Sana Muhaydli« verüben. ${ }^{49}$ Der neunzehnjährige Malek Wehbi, der am 20. April 1985 einen mit Sprengstoff beladenen Laster in einen israelischen Militärkonvoi am Checkpoint Qasmiyya Bridge fuhr, ${ }^{50}$ setzte die Reihe der Märtyrer-Videotestamente der SSNP fort (Abb. 3.5). Die dialogische Gestaltung des Videointerviews folgte dem Beispiel seines Vorgängers Wajdi al-Sayigh. Auch hier sind die Fragen zum Teil an journalistischen Konventionen orientiert und lassen den (im Bild dieses Mal nicht sichtbaren) Interviewenden als scheinbar unbeteiligten Reporter erscheinen (»We are having a dialogue with one of the combatants at the national resistance front, we would like to know who you are [...] «). Ähnlich wie im Videotestament von Wajdi al-Sayigh wurden die Fragen auch hier teils kritisch formuliert: »What is the reason behind your operation in the south, when you are out of the circle of suffering from the Israeli occupation?« Dies suggeriert einerseits Neutralität, andererseits wurde dem

$48 \mathrm{Ob}$ »Erlösung« hier in einem religiösen oder rein politisch-nationalen Sinne gemeint ist, kann nicht eindeutig festgestellt werden.

49 Siehe die abgefilmte Überschrift, die auf der VHS-Kassette der SSNP kurz vor Malek Wehbis Videotestament eingeblendet wird (32:00).

50 Vgl. Nasrallah (Hg.): Al Muqawama al-Wataniyya al-Lubnaniyya 1982-1985, S. 144. Zitiert in: Toufic: »I Am the Martyr Sanâ' Yûsif Muhaydlî«, S. 167. 
zukünftigen Attentäter dadurch eine Bühne bereitete, seine Motivation und Überzeugung ausführlich darzulegen. ${ }^{51}$

\section{Abbildung 3.5: Videotestament von Malek Wehbi, SSNP, Aufnahme am} oder vor dem 20. April 1985, Ausschnitt, 1:58 min, arabisch.

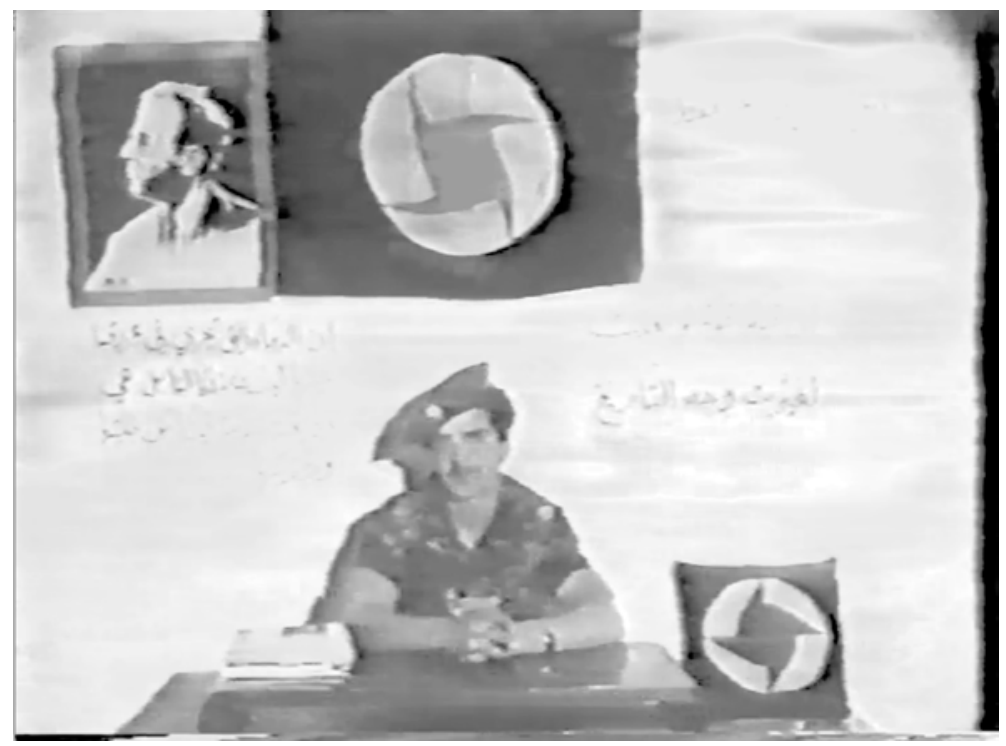

Das visuelle Setting seines Videotestaments gleicht dem von Sana Muhaydli bis ins Detail. Angefangen bei der Militärjacke und dem roten Barett, bis hin zu den Postern im Hintergrund und dem links neben ihm platzierten SSNP-Kissen, entspricht die Szenerie im Wesentlichen der >Bühneく seiner Vorgängerin (vgl. Abb. 3.1). Womöglich wurde sein Video sogar am selben Ort (im Videoladen?) aufgenommen, und lediglich der Text im Hintergrund ausgetauscht. In seiner Videoansprache stellte er seine bevorstehende Tat dann auch als direkte Antwort auf Muhaydlis Appell zur Nachahmung dar - einen Appell, den er im selben Atemzug wiederum an seine Nachfolger*innen weitergab: «My happiness is great because I know that this path won't stop, as it was confirmed by the martyr Sanaa that she's not the only one nor the last.«

51 Malek Wehbi antwortete: «Why wondering? I believe that every village, every part of my country is my land and my home. [...] I feel the suffering and grief, the destruction of houses, the killing of children and women, our people in the south. This confirms that the only enemy of our land, our home and our religion is the Jews." 
Die appellierenden Botschaften der ersten Videotestamente wurden schließlich auch von Hafez al-Assad unterstrichen. Am 4. Mai 1985 hielt dieser eine Rede, in der er die Effektivität solcher Märtyrertod-Operationen betonte und weitere »Wellen« von Märtyrer*innen prophezeite:

»Such attacks can inflict heavy losses on the enemy. They guarantee results, in terms of scoring a direct hit, spreading terror among enemy ranks, raising people's morale, and enhancing citizens' awareness of the importance of the spirit of martyrdom. Thus, waves of popular martyrdom will follow successively and the enemy will not be able to endure them. $\ll^{52}$

Zwischen Juni 1985 und Juni 1987 folgten elf weitere Männer und Frauen ihren Vorbildern und verübten Selbstmordattentate gegen israelische Stützpunkte im Namen der SSNP. Sie alle hinterließen Videos, die im Wesentlichen dem Muster folgten, das von al-Sayigh und Muhaydli eingeführt wurde. Das nahezu bewegungslose und streng frontale Setting am Tisch vor einer mit Parteiemblemen und Märtyrerpostern geschmückten Wand wurde schließlich auch von anderen Parteien adaptiert, die innerhalb der Nationalen Libanesischen Widerstandsfront (LNRF) um Einfluss konkurrierten. Darunter die libanesische prosyrische BaathPartei, die bis zum Ende des Jahres 1985 fünf weitere Selbstmordattentate beging, sowie die Libanesische Kommunistische Partei (LCP). Angeblich zögerte die LCP zunächst, Selbstmordattentate als militärische Strategie einzusetzen, da sie dies als »Verschwendung « der eigenen Kämpfer betrachtete. ${ }^{53} \mathrm{Ob}$ die Aufmerksamkeit, die insbesondere dem Videotestament von Sana Muhaydli entgegenkam, ihren Teil dazu beitrug, dass die LCP ihre Meinung änderte, kann nur vermutet werden. Zwischen Mai und Oktober 1985 verübten schließlich auch drei Mitglieder der kommunistischen Partei Selbstmordattentate auf israelische Stützpunkte und hinterließen ebenfalls Videotestamente nach dem Vorbild der SSNP.

52 Die Rede wurde am 4. Mai 1985 auf Damascus Radio übertragen. Zitiert nach Pipes: »Radical Politics and the Syrian Social Nationalist Party«, S. 319. Das Lob des syrischen Machthabers war sicherlich auch eine Reaktion auf Muhaydlis und Wehbis Videotestamente, in der sie beide ihre Grußworte direkt an Hafez al-Assad als «leader of the liberation march and resistance« richteten.

53 Vgl. Sevag Kechichian: »The Many Faces of Violence and the Social Foundations of Suicide Bombings, Lebanon 1981-2000«, http://cas.uchicago.edu/workshops/cpolit/ papers/kechichian1.doc (nicht mehr verfügbar), zitiert in Graitl: Sterben als Spektakel, S. 251. 
Mehrere Topoi sollten sich als wiedererkennbare Charakteristika dieser frühen Videotestamente etablieren. Am auffälligsten war sicherlich die Selbstidentifikation »ana a ̌̌s $\breve{s} a h \bar{i} d / a \ll$ - »Ich bin der Märtyrer/die Märtyrerin«, die in den meisten Videotestamenten der SSNP und LCP als Eingangsfloskel verwendet wurde: »I am the martyr comrade Khaled Azraq « - $\gg I$ am the martyr comrade Ibtissam Harb $\aleph^{54}$ $-» \mathrm{I}$ am the martyr Ali Ghazi Taleb $\aleph^{55}-» \mathrm{I}$, the martyr comrade Jamal Sati $\aleph^{56}$ oder $» I$ am the martyr comrade Mariam Kheir el-Dine [...], « ${ }^{57}$ um nur einige zu zitieren. War ein Teil der SSNP-Videos anfänglich noch als Interview aufgebaut, wich diese dialogische Struktur zunehmend einem vorformulierten Skript, das kaum mehr Raum für spontane Reaktionen ließ. Auch wenn das Testament in vielen Fällen frei vorgetragen wurde, war den Bekenntnissen eine zunehmende Formalisierung anzumerken; manchmal lag eine schriftliche Vorlage auch sichtbar auf dem Tisch. Als weitere Gemeinsamkeit ist das vehemente Bekunden von Freude angesichts der bevorstehenden Märtyrertod-Operation zu nennen sowie der (in säkularer Rhetorik vorgetragene) Glaube an ein Weiterleben nach dem Tod. Damit war zugleich die Aufforderung an die Familienangehörigen verbunden, den Tod nicht zu betrauern, sondern ihm mit Freude und Stolz zu begegnen. Wie Sana Muhaydli richtete auch der Selbstmordattentäter Ali Ghazi Taleb folgende Worte an seine Mutter: »Don't be sad for me, because I shall not die. I shall be a martyr and there is a lot of difference between dying and martyrdom. My last request to you is not to wear black on my death - because I am still alive. ${ }^{58}$

54 Khaled al-Azraq (geb. 1966) und Ibtissam Harb (geb. 1957) verübten am 9. Juli 1985 im Namen der SSNP einen Doppelanschlag auf zwei Checkpoints der mit Israel verbündeten Südlibanesischen Armee (SLA). Vgl. Chicago Project on Security and Terrorism (CPOST): Suicide Attack Database, Attack IDs: 401886063 und 1097669349.

55 Ali Ghazi Taleb (geb. 1967) verübte am 31. Juli 1985 ein Selbstmordattentat im Namen der SSNP auf einen israelischen Militärkonvoi in Arnun, Nabatiyya. Vgl. Nasrallah (Hg.): Al Muqawama al-Wataniyya al-Lubnaniyya 1982-1985, S. 180. Zitiert in Toufic: »I Am the Martyr Sanâ' Yûsif Muhaydlî«, S. 167.

56 Jamal Sati (geb. 1962) verübte am 6. August 1985 ein Selbstmordattentat im Namen der LCP auf einen Militärstützpunkt der SLA in Hasbayya. Vgl. Chicago Project on Security and Terrorism (CPOST): Suicide Attack Database, Attack ID: 1919800447.

57 Mariam Kheir el-Dine (geb. 1967) fuhr am Morgen des 11. September 1985 mit einer Autobombe in einen Checkpoint der SLA in Hasbayya. Auch sie verübte ihren Anschlag im Namen der SSNP. Vgl. ebd., Attack ID: 1026727620.

58 Ali Ghazi Taleb verübte am 31. Juli 1985 ein Selbstmordattentat im Namen der SSNP. Auszüge aus seinem Videotestament wurden in The New York Times am 1. August 1985 abgedruckt. Zitiert in Graitl: Sterben als Spektakel, S. 234. 
Ähnlich wie im Videotestament von Sana Muhaydli übernahm das Testament auch hier die Funktion eines Lebenszeichens (»I am still alive«), das den Hinterbliebenen Trost spenden sollte und mit einer klaren Verhaltens- und Gefühlsanweisung verbunden war. Auch Jamal Sati, der sich am 6. August 1985 im Namen der Libanesischen Kommunistischen Partei in die Luft sprengte, verkündete per Videotestament sein Weiterleben im Jenseits: »Now, I am departing my country, in body only; I will still exist in the souls of all the honest patriots in Lebanon. ${ }^{59}$ Gegen Ende wiederholte er die Worte seiner Vorgängerin Muhaydli nahezu eins zu eins, als er seine Familie aufforderte: »As for you, the dearest and finest mother and father in existence, my beloved brothers and sisters: my wish for you is not to mourn and wail, but rejoice and dance as you would do at my wedding, for I am the proud groom of martyrdom, and that is the happiest wedding I could hope for." Der Hochzeitsvergleich diente erneut dazu, das Martyrium als freudiges und erstrebenswertes Ereignis darzustellen, das viel mehr mit dem Leben als mit dem Tod verbunden war.

Insbesondere der Verweis auf eine Genealogie vorangegangener Märtyrer*innen sollte sich zu einer Formel etablieren, die in den Videos kontinuierlich fortgeschrieben wurde - und die Videos in eine besondere Beziehung zueinander setzte. Auch der Kommunist Jamal Sati reiht sich in eine solche Abfolge ein, die nicht nur Namen seiner eigenen Partei, sondern auch Selbstmordattentäter*innen der schiitischen Amal (Bilal Fahs), sowie der SSNP umfassten:

»Following the example of the great Farajallah El-Helou and the other heroic martyrs of the Party, those who chose the most noble death, the death for the sake of the survival of the nation; martyrs such as Nazeeh, Bilal, Wajdi, Sanaa', Yasar Mroueh, Ibtisam Harb, Khaled Azraq, Hisham Abbas, Lola Abboud, Wafaa' Noureddine, and others, and others...«

Mit jedem neuen Selbstmordattentäter und jeder neuen Selbstmordattentäterin, die in den darauffolgenden Jahren ein Videotestament hinterließen, wuchs diese Liste weiter an. Mehr als zwei Jahre nach dem ersten Videotestament von Wajdi alSayigh verkündet Zahra Abu Assaf, die am 18. Juni 1987 ein Selbstmordattentat für die SSNP verübte, in ihrem Videotestament: »The caravans of martyrs moved from Wajdi, to Sanaa, to Malek and Khaled and Ibtissam and Ali and Mariam and Ammar and Norma and Mohammed Kana'a and others." Die scheinbar

59 Englische Übersetzung des arabischen Videotestaments zitiert nach Rabih Mroué und Elias Khoury: »Three Posters: Reflections on a Video/Performance«, The Drama Review 50/3 (2006), S. 182-191, hier S. 189. Sofern nicht anders angegeben, beziehen sich alle weiteren Zitate dieses Videotestaments auf diese Übersetzung. 
unerschöpflichen Aufzählungen suggerieren, dass die Reihe der Märtyrer*innen prinzipiell endlos in die Zukunft erweiterbar wäre. Der Verweis auf die Namen der Vorgänger*innen war damit nicht nur eine rhetorische Strategie, um die eigene Darstellung als Märtyrer oder Märtyrerin zu konsolidieren und die bevorstehende Tat als Märtyrertat zu legitimieren, sondern diente gleichzeitig zur Mobilisierung anderer, die »Karawane« weiterzuführen.

\section{Operationen mit dem Bild im Bild}

Diese Märtyrer-Genealogie wurde in den Videos nicht nur sprachlich, sondern auch mit bildlichen Mitteln etabliert. Schon das erste Videotestament von Wajdi al-Sayigh ließ einen gezielten Einsatz von Bildern erkennen, die in die Komposition des Videosettings integriert wurden. Vor dem Hintergrund der Märtyrerposter wurde al-Sayighs bevorstehende Tat - auch ohne Worte - als >Märtyrertat〈 in Szene gesetzt, die im Geiste und in der Nachfolge seiner Vorbilder geschehen war. Die Libanesische Kommunistische Partei (LCP) sollte dieses Handeln mit dem Bild im Bild in ihren Videotestamenten zu einer regelrechten visuellen Dramaturgie zuspitzen.

Am 9. Mai 1985 verübte die 23-jährige Wafa Noureddine ein Selbstmordattentat im Namen der LCP auf eine israelische Straßensperre in der Nähe der südlibanesischen Stadt Hasbaya, bei dem zwei Israelis ums Leben kamen. ${ }^{60}$ Sie hinterließ eine Videoaufnahme, in deren Hintergrund nicht nur zwei, sondern mindestens acht Poster zu sehen sind, die eng neben- und teils übereinander plakatiert wurden (Abb. 3.6). Diese Posterschicht wird von zwei weiteren gerahmten Portraitbildern überdeckt, von denen eines neben Wafa Noureddine an der Wand lehnt. Auf mindestens drei dieser Bilder ist die LCP-Kämpferin Lola Abboud zu erkennen, die sich am 19. April 1985 in einer spontanen, von der Partei nicht geplanten Aktion mit einer Handgranate tötete, um einer Gefangennahme zu entgehen. ${ }^{61}$ Im Nachhinein wurde ihr Konterfei als Vorbild einer Märtyrertod-Operation instrumentalisiert und diente als Startpunkt einer Bilderkette, die sich in den darauffolgenden Videotestamenten der LCP fortsetzte. Im August und Oktober 1985 sprengten sich zwei weitere Selbstmordattentäter der Libanesischen Kommunistischen Partei, Jamal Sati und Elias Harb, an israelischen Stützpunkten in

60 Erstmals verübte eine Attentäterin ihren Anschlag nicht mit einer Autobombe, sondern versteckte den Sprengstoff in einem Koffer. Vgl. Croitoru: Der Märtyrer als Waffe, S. 145.

61 Vgl. Kechichian: »The Many Faces of Violence and the Social Foundations of Suicide Bombings, Lebanon 1981-2000«. Zitiert in Graitl: Sterben als Spektakel, S. 212. 
die Luft und hinterließen Videotestamente, in denen die jeweiligen Poster der vorangegangenen Selbstmordattentäter*innen in die neuen Videos integriert wurden (Abb. 3.7 und 3.8).

Abbildung 3.6: Videotestament von Wafa Noureddine, LCP, Aufnahme am oder vor dem 9. Mai 1985, 4:30 min, arabisch.

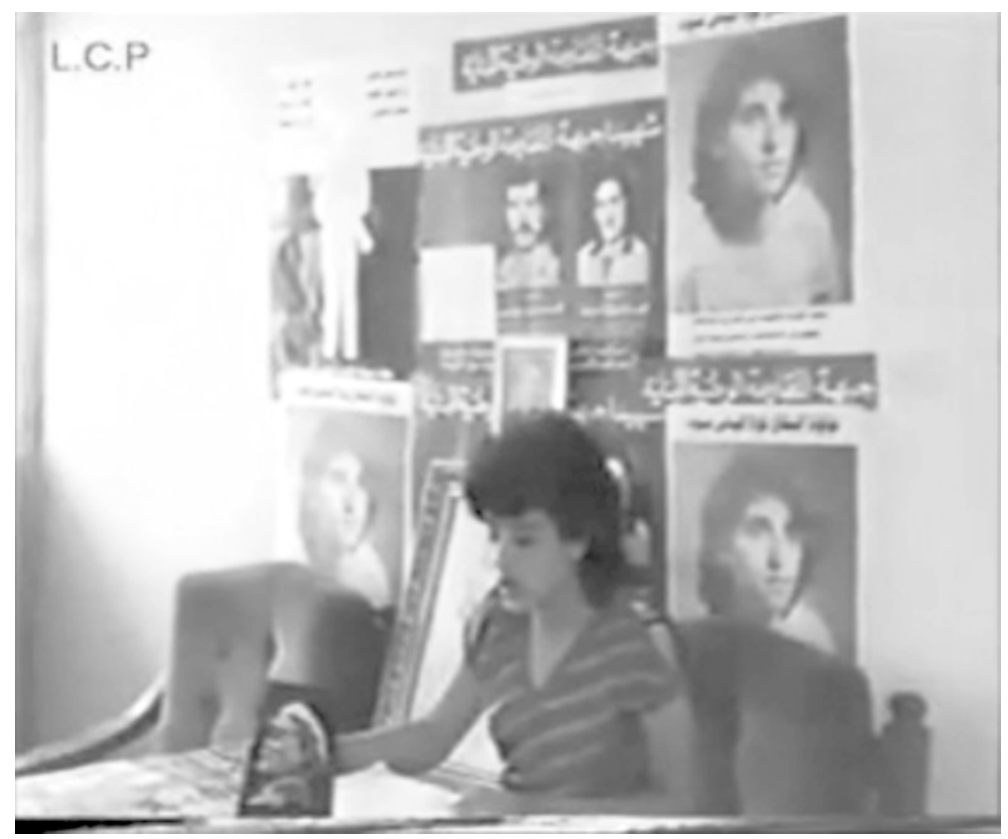

Rabih Mroué hat die interpikturalen Bezüge zwischen den Videotestamenten der LCP folgendermaßen beschrieben: »Lola died, and became a picture behind Wafaa, who died in her turn, and both of them became pictures behind Jamal, who died in his turn, and the three of them became pictures behind Elias, who died in his turn, $[\ldots]$ and so on and so forth. $\ll^{62}$ Die fortdauernde $>$ Anreicherung $<$ der Videos mit mehr und mehr Märtyrerbildern markierte eine zeitliche Kontinuität, die sich sichtbar im Bild abzeichnete. Das Video des einzelnen Märtyrers/der einzelnen Märtyrerin verdichtete sich auf diese Weise zunehmend zu einem Kompositbild, dessen Qualität gerade in der Überlagerung mehrerer Portraits bestand.

62 Mroué: »The Inhabitants of Images«, S. 355. 
Abbildung 3.7: Videotestament von Jamal Sati, LCP, Aufnahme am oder vor dem 6. August 1985, Ausschnitt, 5:07 min, arabisch.

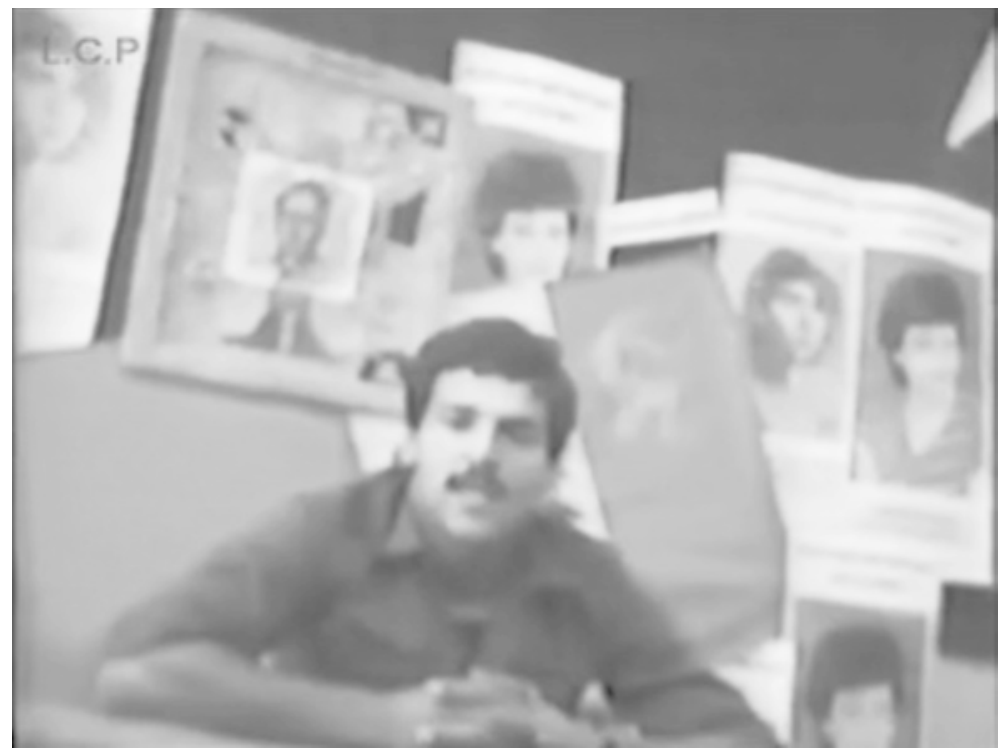

Abbildung 3.8: Videotestament von Elias Harb, LCP, Aufnahme im Oktober 1985, arabisch.

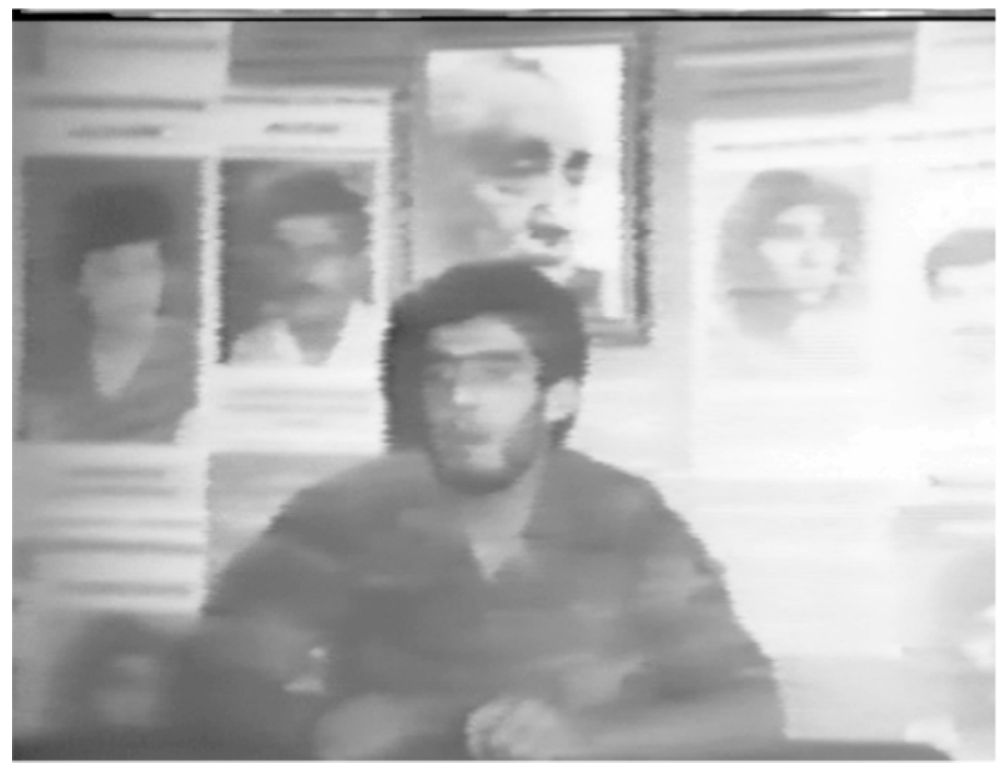


Dieselbe visuelle Dramaturgie wurde kurz nach Wafa Noureddines Anschlag auch von der SSNP adaptiert. So ist der Hintergrund des Videotestaments von Khaled al-Azraq, der am 9. Juli 1985 zusammen mit seiner Ehefrau Ibtissam Harb einen Doppelanschlag verübte, durch eine ähnlich dichte Schichtung von Bildern gekennzeichnet (Abb. 3.9). Neben der Flagge mit dem Logo der SSNP und dem Portrait des Parteigründers Antun Saada, sind mehrere Poster der drei Vorgänger*innen Wajdi al-Sayigh, Sana Muhaydli (vgl. Abb. 3.3) und Malek Wehbi auf der Wand hinter ihm zu erkennen.

\section{Abbildung 3.9: Videotestament von Khaled al-Azraq, SSNP, Aufnahme am} oder vor dem 9. Juli 1985, Ausschnitt, 0:29 min, arabisch.

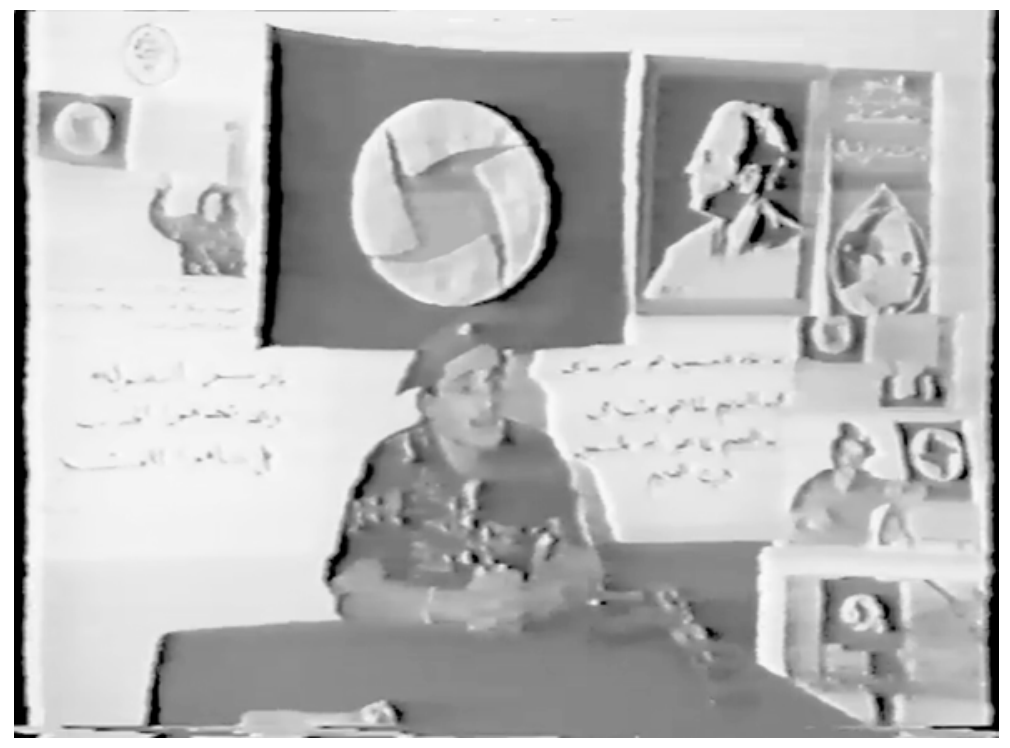

Das Videotestament von Mohammed Mahmoud Qanaa, der am 8. Juli 1986 ein Selbstmordattentat für die SSNP verübte, treibt diese Darstellung von Bildern im Bild zusätzlich auf die Spitze. Abgesehen von den 9 Postern, die an der Wand hinter ihm hängen, trägt er ein weißes T-Shirt, auf das ein weiteres Portraitbild gedruckt wurde (Abb. 3.10). Das abgebildete Gesicht bleibt allerdings hinter Qanaas gefalteten Händen verborgen und ist dadurch nicht zu identifizieren. Der arabische Schriftzug auf dem T-Shirt weist das Portrait als »Symbol des nationalen libanesischen Widerstands« aus (vgl. die Fotografie auf Qanaas Märtyrerposter, Abb. 3.11). Man kann also davon ausgehen, dass es sich hier um das Bild eines weiteren Märtyrers oder einer weiteren Märtyrerin handelt, der oder die im Widerstand gegen die israelische Besatzung ums Leben gekommen war und zu 
dessen oder deren Ehren dieses T-Shirt produziert wurde. Damit ging Qanaa in seiner Märtyrerinszenierung noch einen Schritt weiter. Das Vorbild erschien nicht mehr nur im Hintergrund des Videos, sondern übertrug sich direkt auf den Körper des neuen Märtyrers.

Abbildung 3.10: Videotestament von Mohammed Mahmoud Qanaa, SSNP, Aufnahme am oder vor dem 8. Juli 1986, Ausschnitt, 0:17 min, arabisch.

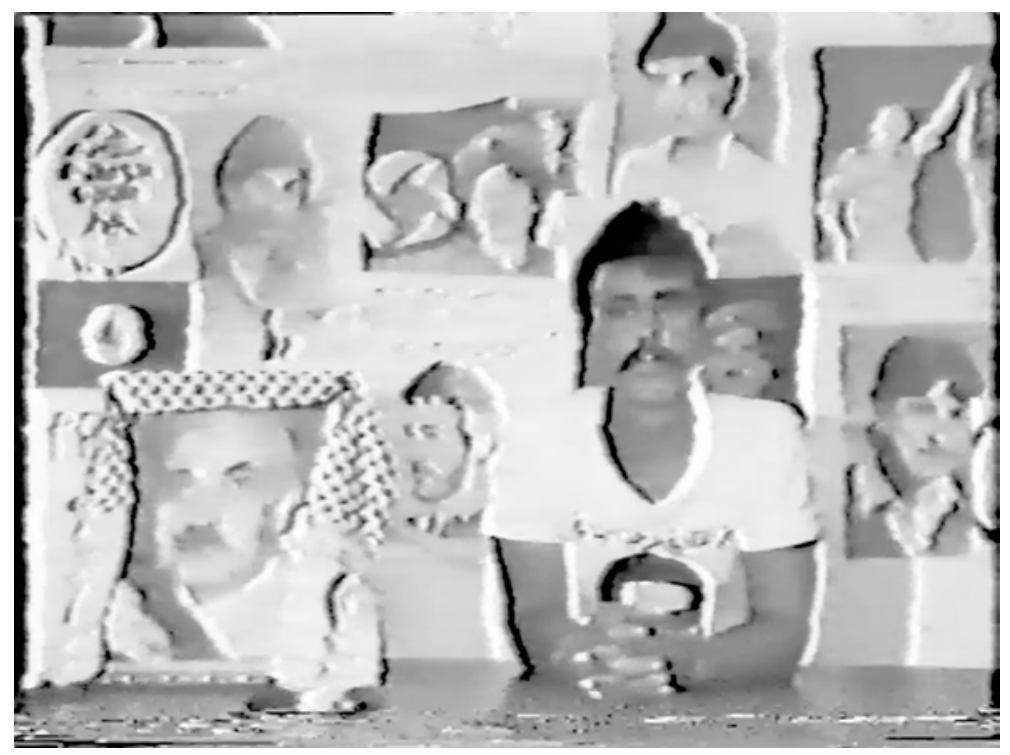

Für sein Märtyrerposter wurde schließlich eine Fotografie verwendet, die im selben Setting entstanden ist und Qanaa umringt von weiteren Märtyrerbildern zeigt (Abb. 3.11). Sein Bildzeugnis als Märtyrer schien in gesteigertem Maße mit denen seiner Vorbilder zu verschmelzen und war von diesen kaum mehr abzulösen. Das besondere Design der SSNP-Märtyrerposter, die häufig auf Standbilder der Testamentaufnahmen zurückgriffen, führte in späteren Videos dazu, dass sich eine mehrfache Staffelung von Bildern im Bild ergab: Ein »mise en abîme illusory game «, wie Zeina Maasri dies in ihrer Analyse der Poster beschreibt. ${ }^{63}$ Besonders deutlich wird dies etwa im Videotestament von Zahra Abu Assaf, die das Poster von Mohammed Mahmoud Qanaa wiederum als Hintergrund ihrer Märtyrerinszenierung wählte - und damit nicht nur ihn, sondern auch Amar al-Asar, Mariam

63 Maasri: Off the Wall, S. 96. 
Kheireddine, Khaled Azraq, Ibtissam Harb und all die anderen ins Bild holte, die auch auf Qanaas Poster zu sehen sind. ${ }^{64}$

Abbildung 3.11: Märtyrerposter von Mohammed

Mahmoud Qanaa, SSNP, 1986, $45 \times 60 \mathrm{~cm}$.

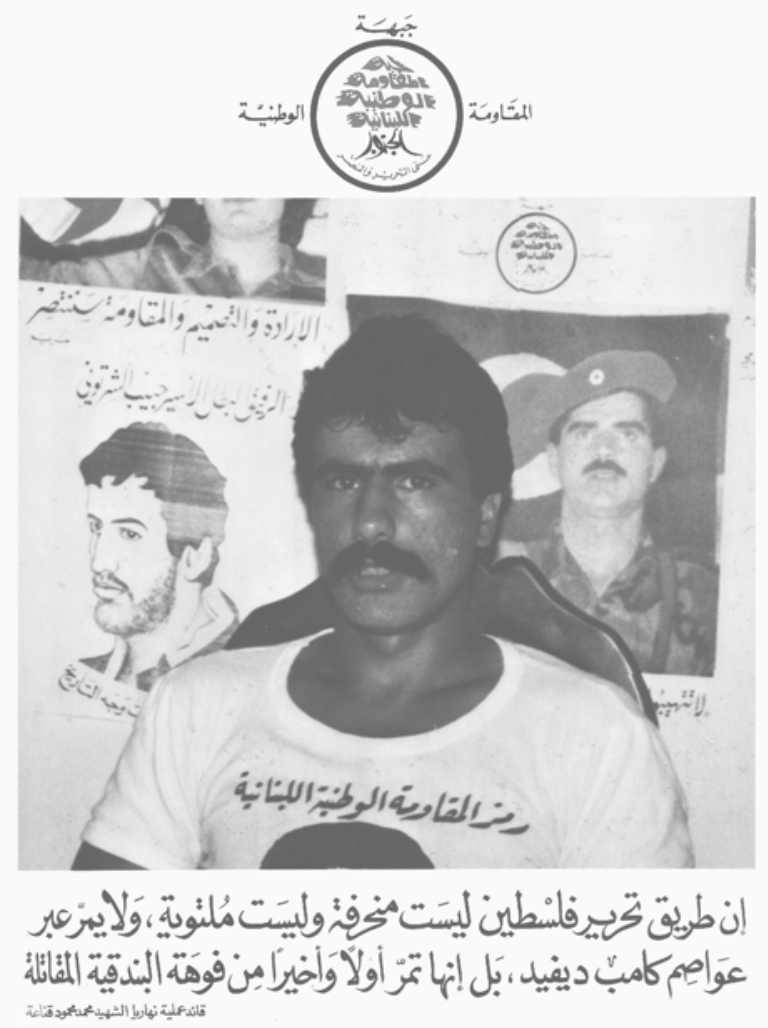

Die Metapher von einer unendlichen »Karawane« von Märtyrer*innen wurde von Zahra Abu Assaf also nicht nur sprachlich aufgerufen (»The caravans of martyrs moved from Wajdi, to Sanaa, to Malek and Khaled and Ibtissam and Ali and Mariam and Ammar and Norma and Mohammed Kana'a and others«), sondern durch die visuelle Gestaltung ihres Videotestaments noch verstärkt. Der mise en abîme-

64 Ein 2:50 min langer Ausschnitt des Videotestaments von Zahra Abu Assaf, das am oder vor dem 18.7.1987 aufgenommen wurde, befindet sich ebenfalls auf der mir vorliegenden VHS-Kassette der SSNP. 
Effekt verweist dabei nicht nur auf die Vergangenheit, sondern führt gerade die prinzipiell endlose Erweiterbarkeit dieser Bild-im-Bild-Verschachtelungen vor Augen. Die Überzeugung, dass diese Kette auch in Zukunft nicht abbrechen werde, scheint in der visuellen Gestaltung dieser Videos bereits angelegt zu sein. Die appellierende Rhetorik der Videotestamente wurde damit auch auf visueller Ebene - als appellative Bildoperation - vermittelt.

Angesichts dieser vielfältigen und teils expliziten Aufrufe zur Nachahmung mag es kaum überraschen, dass Mitglieder der SSNP die Videoaufnahmen ganz gezielt zu Rekrutierungszwecken einsetzten. In einem 1987 erschienenen Artikel über die SSNP berichtet Ehud Ya'ari von einer jungen SSNP-Rekrutin, die ein geplantes Selbstmordattentat überlebte und anschließend von den Vorbereitungen ihres Attentats erzählte. Glaubt man der Aussage der damals 19-Jährigen, so wurde sie weder zum Attentat gezwungen, noch wurden ihr Belohnungen im Paradies versprochen. ${ }^{65}$ Als einzige Strategie der Überzeugung setzte man sie wiederholt den Videotestamenten ihrer Vorgängerinnen aus: »Over and over again she was shown videotapes of the >last will and testaments< recorded by other young women before they set out on their suicide missions«, so Ya'ari. ${ }^{66}$ Die Videotestamente zirkulierten aber auch außerhalb der engeren Parteikreise und wurden in Form von VHS-Kopien in Beirut und anderen libanesischen Städten verbreitet. Ya'ari beschreibt einen regelrechten Handel mit diesen Videokassetten, die sich anscheinend großer Beliebtheit erfreuten: „Video cassettes of the bombers' $>$ wills $<$ are available at sidewalk kiosks, and sales are consistently brisk. ${ }^{67}{ }^{67}$ Auch Zeina Maasri erinnert sich an die ungeheure Popularität der ersten Videotestamente, die vielfach kopiert wurden: »VHS-format copies of SSNP martyrs' video statements were widely accessible in west Beirut in the mid-eighties, most often in very bad condition, as a result of multiple copying. ${ }^{68}{ }^{6}$ Woraus sich diese Popularität speiste, ist allerdings nur schwer zu sagen; die genauen Gründe für den Kauf und die Rezeption dieser Videos mögen ganz unterschiedlich gewesen sein. Auch wenn die Präsentation der Videos von Seiten der SSNP offensichtlich darauf abzielte, weitere Selbstmordoperationen anzustiften, muss die Frage nach der tatsächlichen `Effektivitätı dieser appellativen Bildoperationen hier unbeantwortet bleiben.

65 Vgl. Ya' ari: »Behind the Terror«, o.S.

66 Ebd.

67 Ebd.

68 Maasri: Off the Wall, S. 123, Anm. 5. 


\section{Performative Bildoperationen}

Die Handlungsmacht der Videotestamente beschränkt sich aber nicht nur auf ihre kommunikative Funktion, beziehungsweise auf die Frage, inwiefern die Bilder auf die Mobilisierung weiterer Selbstmordoperationen abzielen. Wie ich im Folgenden argumentieren werde, entfaltet sich die Operativität dieser Videos nicht erst im Moment der Rezeption, sondern bereits zum Zeitpunkt der Videoaufnahme selbst. Schon die Performance vor der Kamera kann als Auslöser, als Antrieb oder transformativer Moment betrachtet werden, der Auswirkungen auf das darauffolgende Attentat hat, so die zentrale These dieses Kapitels.

Den Ausgangspunkt für die folgenden Überlegungen bildet die Aussage »ana $a \check{s}$-šahīd/a« (»Ich bin der Märtyrer/die Märtyrerin«), die bis heute charakteristisch für viele Videotestamente von Selbstmordattentäter*innen ist. Die Selbstbezeichnung als Märtyrer oder Märtyrerin rückt erneut die Frage nach der Zeugenschaft in den Fokus. ${ }^{69}$ Nun jedoch in doppelter Hinsicht: Denn neben ihrem bevorstehenden >Blutzeugnis`scheinen die Dargestellten zusätzlich als Zeugen ihres eigenen Martyriums vor die Videokamera zu treten. Wie lässt sich der eigenwillige Status dieser Bildzeugnisse nun aber genauer fassen? Zunächst erscheint es sinnvoll, einen Blick auf die verschiedenen Formen der Zeugenschaft zu werfen, die mit je unterschiedlichen Positionen und Erwartungen verbunden sind. Die Märtyrerfigur wird in der Forschung häufig als eine von drei Zeugentypen theoretisiert. ${ }^{70}$ Von etymologischen Analysen ausgehend, nimmt der Soziologe Didier Fassin eine Typologie verschiedener Zeugen-Konfigurationen vor und bestimmt diese in Abgrenzung zueinander. Neben der Märtyrerfigur beschreibt Fassin zwei weitere archetypische Zeugenfiguren, die sich im Laufe der Zeit aus den zwei lateinischen Termini für >bezeugen ausdifferenziert haben. Der Begriff des testis (von lat. testare, >bezeugen`, abgeleitet von tertius, >der Dritte $<$ ) verweist auf das Konzept des Augenzeugen, der als unbeteiligter Beobachter gilt und eine scheinbar neutrale Perspektive auf das bezeugte Geschehen verbürgt. Insbesondere im Rechtskontext

69 Teile dieses Unterkapitels basieren auf Verena Straub: „)Living Martyrs - Testifying What is to Come«, in: Kerstin Schankweiler, Verena Straub und Tobias Wendl (Hg.): Image Testimonies - Witnessing in Times of Social Media, London: Routledge 2019, S. 139-153.

70 Vgl. Fassin: »The Humanitarian Politics of Testimony«, S. 531; Michal Givoni: »Witnessing/Testimony«, Mafte'akh. Lexical Review of Political Thought (2011), S. 147174. Eine ähnliche Kategorisierung nimmt auch Aleida Assmann vor, die zusätzlich vom »moralischen Zeugen« als vierten Typus spricht. Assmann: »Vier Grundtypen von Zeugenschaft«. 
hat die Figur des testis eine lange Tradition erfahren und verwies im römischen Recht etwa auf eine dritte Person, die eine Aussage vor Gericht bezeugt. Das Modell des juristischen Zeugen migrierte schließlich auch in die naturwissenschaftliche Forschung und gewann ab dem 17. Jahrhundert im Kontext der Experimentalwissenschaft an Bedeutung. ${ }^{71}$

Wird das Zeugnis des testis an seiner Evidenz- und Beweisfunktion gemessen und für gewöhnlich mit einem Anspruch auf Objektivität verbunden, zeichnet sich das Zeugnis des superstes gerade durch persönliche Erfahrung aus. Der superstes (abgeleitet vom lateinischen Begriff für >bezeugen` und >überleben`) hat das bezeugte Ereignis selbst erlebt, bzw. erlitten, und wird häufig auch als >Überlebenszeuge $<$ beschrieben. ${ }^{72}$ Dieser Zeugentypus wurde insbesondere mit den HolocaustÜberlebenden in Verbindung gebracht, wobei gerade die epistemischen Grenzen und Unmöglichkeiten des Zeugnis-Gebens betont wurden. ${ }^{73}$ Beruht das Augenzeugnis des testis also auf dem Versprechen, objektive Fakten zu vermitteln, so liegt die >Wahrheit des superstes gerade in seiner subjektiven und körperlichen Involviertheit. Fassin bringt die Unterschiede zwischen beiden Idealtypen (die, so betont er gleichzeitig, heute oft nicht mehr so klar voneinander abgetrennt werden können) folgendermaßen auf den Punkt: »The truth of the testis, expressed in the third person, is deemed objective. The truth of the superstes, expressed in the first person, is deemed subjective. The latter has merit by virtue of the affects it involves, the former by virtue of those it eliminates. ${ }^{74}$

Als dritte und zugleich radikalste Ausprägung der Zeugenfigur gilt schließlich die Figur des Märtyrers bzw. der Märtyrerin. Deren Zeugnis bestehe weder im Bericht objektiver Fakten noch im Vortragen subjektiver Erfahrungen, so Fassin, sondern realisiere sich durch die Tat selbst, durch den Akt der Selbstaufopferung. ${ }^{75}$ Paul Ricoeur hat das Märtyrerzeugnis daher auch als »Umkehrung« des

71 Vgl. Steven Shapin: A Social History of Truth: Civility and Science in SeventeenthCentury England, Chicago: University of Chicago Press 1994.

72 Aleida Assmann hat die Zeugenfigur des superstes auch als »historischen Zeugen« bezeichnet, der nicht als unparteiischer Beobachter zu beschreiben sei, sondern sich im Gegenteil durch eine engagierte und Partei ergreifende Haltung auszeichne. Assmann: »Vier Grundtypen von Zeugenschaft«, S. 17.

73 Vgl. Giorgio Agamben: Was von Auschwitz bleibt: Das Archiv und der Zeuge (Homo sacer III), Frankfurt am Main: Suhrkamp 2003; Shoshana Felman und Dori Laub: Testimony: Crises of Witnessing in Literature, Psychoanalysis, and History, London: Routledge 1992.

74 Fassin: »The Humanitarian Politics of Testimony«, S. 535.

75 Ebd., S. 541. 
Augenzeugnisses beschrieben: Das äußerlich wahrnehmbare Ereignis (der Märtyrertod) wird hier selbst zum Zeugnis, das auf etwas Inneres verweist, etwa einen religiösen Glauben oder eine politische Überzeugung. ${ }^{76}$ Im Unterschied zu anderen Formen der Zeugenschaft handele es sich beim Martyrium daher um ein Zeugnis ohne Worte, so schreibt Fassin: »Unlike the survivor or the observer, who speak in the first or third person, the martyr bears witness without speaking: he testifies through the sacrifice of his life. ${ }^{17}$

Was, wenn die Märtyrer*innen nun aber selbst als Sprechende auftreten, wie dies in den Videotestamenten der Selbstmordattentäter*innen der Fall ist? Korrespondiert die Ich-Perspektive der Verkündung »Ich bin der Märtyrer/die Märtyrerin « nicht vielmehr mit der Perspektive des superstes, des subjektiven Überlebenszeugen? Zwei Modi von Zeugenschaft scheinen hier in eins zu fallen und sich gegenseitig zu bedingen. Im Kapitel über die Märtyrerposter wurde bereits für ein relationales Verständnis des Martyriums argumentiert, das notwendigerweise auf sekundäre Zeugnisse durch Dritte angewiesen und somit immer schon mit anderen Formen der Zeugenschaft vermischt ist. Ein Zeugnis, das einzig und allein im Akt des Selbstopfers begründet liegt, das heißt ein Märtyrerzeugnis in Reinform, kann es so also nicht geben. Die verschiedenen Typen der Zeugenschaft sind demzufolge vielmehr als Modalitäten aufzufassen, die stets in Mischformen auftreten, sich gegenseitig bedingen und durchdringen ${ }^{78}$ Dies zeigt sich umso mehr in den besprochenen Videoaufnahmen, in denen die Dargestellten nun selbst als Zeug*innen ihres eigenen Martyriums auftreten. Im Unterschied zu den Postern handelt es sich bei diesen Bildzeugnissen nicht mehr um Zeugnisse durch Dritte (testis), sondern um scheinbare Überlebenszeugnisse (superstes), die in Ich-Perspektive vorgetragen werden. Das eigentlich Entscheidende ist nun aber, dass diese Bildzeugnisse nicht länger als sekundär zu bezeichnen sind, da sie das eigentliche >Blutzeugnis` des Märtyrers vorwegnehmen und dadurch noch einmal ganz andere, drängende Fragen aufwerfen: Wie kann etwas bezeugt werden, das noch gar nicht stattgefunden hat? Welchen Status erhält das Video dadurch in Relation zum bezeugten Ereignis des Martyriums?

76 Paul Ricoeur: »The Hermeneutics of Testimony«, in: Lewis S. Mudge (Hg.): Essays on Biblical Interpretation, London: SPCK Publishing 1981, S. 119-154, hier S. 130.

77 Fassin: »The Humanitarian Politics of Testimony«, S. 541.

78 Dass die Grenzen zwischen testis und superstes nicht immer klar voneinander abzutrennen sind, hat Fassin am Beispiel der Holocaust-Überlebenden hervorgehoben, die einerseits als Überlebende (superstes), andererseits als Stellvertreter*innen für die Toten, also als testis, sprechen. Vgl. ebd., S. 536. 
Am Beispiel des Videos von Sana Muhaydli wurde die zeitliche Paradoxie der Selbstbezeichnung als Schahida bereits angedeutet. In ihrer wörtlichen Ansprache wechselt Muhaydli mehrmals zwischen verschiedenen zeitlichen Ebenen. Während sie ihre Tat einerseits als zukünftiges Ereignis ankündigt (»I am so relieved that I am going to execute this operation «, »I am going to meet them all [the martyrs] in the south «), nimmt sie gleichzeitig die unmögliche Sprecherposition einer Märtyrerin ein, die ihr Weiterleben im Jenseits bekundet, als wäre sie bereits schon dort: »I am the martyr Sana Yusif Muhaydli [...] I am not dead but alive among you.« Statt im Futur II zu sprechen (etwa: >Wenn ihr dieses Video seht, werde ich als Märtyrerin gestorben sein (), was der zeitlichen Logik der Videoaufnahme entsprechen würde, sind Teile ihrer Ansprache in der ersten Person Präsens formuliert. Auf den ersten Blick könnte man den Videoauftritt Muhaydlis als Schauspiel interpretieren: sie redet >als ob< sie eine Märtyrerin wäre. Das eigentlich Verstörende an dieser Aufnahme ist allerdings, dass Muhaydlis Performance den sicheren Rahmen eines fiktiven Schauspiels sprengt. Zwischen der Aufnahme und der Veröffentlichung des Videos liegt das Selbstmordattentat - und damit der tatsächliche Tod der Protagonistin. Videos von >gescheiterten Selbstmordattentäter*innen, deren Operationen im letzten Moment abgebrochen oder verhindert wurden, gelangen oft gar nicht erst an die Öffentlichkeit. ${ }^{79}$ Der Tod ist somit die Bedingung für die öffentliche Sichtbarkeit dieser Bilder, die dadurch erst >gültig ‘ werden. Mit dem Wissen um den tatsächlichen Tod der Dargestellten verändert sich auch die Lesart dieser Videos. Denn auch wenn wir als Betrachter*innen natürlich wissen, dass Muhaydlis Video zu Lebzeiten aufgenommen wurde, kann man sich kaum gegen den unheimlichen Eindruck erwehren, als spräche sie zum Zeitpunkt der Videorezeption als >Überlebenszeugin $<$ aus dem Jenseits zu uns.

Im Unterschied zum Konzept des superstes bezieht sich die >lebende Märtyrerin in ihrem Video jedoch nicht auf eine Erfahrung in der Vergangenheit, sondern auf ein Ereignis, das zum Zeitpunkt der Rede noch gar nicht stattgefunden hat. Die Logik der `Evidential View $>$ von Zeugenschaft wird damit radikal verkehrt. Die mit dieser Sichtweise verbundene Annahme, dass der Bericht eines Zeugen oder einer Zeugin faktische Erkenntnisse über ein vergangenes Ereignis

79 Beispielsweise sind von den Palästinenserinnen, deren Selbstmordattentate vereitelt wurden und die Yoram Schweitzer in israelischen Gefängnissen interviewte, keinerlei Bilder bekannt, obwohl davon auszugehen ist, dass auch hier Videotestamente vor dem geplanten Attentat aufgenommen wurden. Yoram Schweitzer: »Palestinian Female Suicide Bombers: Reality vs. Myth«, in: Ders. (Hg.): Female Suicide Bombers. Dying for Equality?, Tel Aviv 2006, S. 25-41. 
liefern kann, ${ }^{80}$ wird in Muhaydlis Videotestament ad absurdum geführt. Aber auch die Perspektive, die sich in der Zeugenschafts-Forschung als >Assurance View durchgesetzt hat, erweist sich in diesem Zusammenhang als wenig hilfreich. Vertreter der >Assurance View`, allen voran Angus Ross und Richard Moran, beschreiben Zeugenschaft als interpersonalen Akt im Sinne einer Versicherung. ${ }^{81}$ "Der spezifische epistemische Wert des Zeugnisses, « so fasst Schmidt diese theoretische Perspektive zusammen, »gründet nicht in einer kausalen Relation zwischen Zeichen und Bezeichnetem, sondern in der ethischen Selbstverpflichtung der Sprecher*innen, die Wahrheit zu sagen. $\ll^{82}$ Gleichzeitig beruht das Zeugnis damit auch auf dem Vertrauen der Zuhörerschaft, die den Bezeugenden glauben müssen. Obwohl die aktuelle Zeugenschafts-Forschung nicht mehr von einer kausalen Relation zwischen Zeugnis und Bezeugtem ausgeht und die Möglichkeit mitdenkt, dass das Zeugnis selbst an der Konstitution von >Wahrheit beteiligt ist (siehe S. 48f.), so gilt es dennoch als selbstverständlich, dass der Akt des Bezeugens erst nach dem bezeugten Ereignis erfolgen kann. Erst dann kann ein Zeugnis überhaupt als glaubwürdig gelten und Teil des relationalen sozialen Prozesses von Zeugenschaft werden.

Der Theoretiker Jalal Toufic hat auf die grundsätzliche Unglaubwürdigkeit der Selbstaussagen libanesischer Selbstmordattentäter hingewiesen: »I cannot believe Jamāl Sāțī on TV telling me, >I am the martyr comrade Jamāl Sāțị ...८, even if I am told that he had died in a martyring operation by the time I saw him on TV. $\ll^{83}$ Schnell wird deutlich, dass die Frage nach der Glaubwürdigkeit in diesem Zusammenhang wenig fruchtbar, ja geradezu abwegig erscheint. Denn natürlich ist den Rezipient*innen des Videos bewusst, dass die `Wahrheit dieses Zeugnisses zum Zeitpunkt des Sprechens erst noch eingelöst werden musste (ganz unabhängig davon ob der Tod der Dargestellten als Martyrium anerkannt wird oder nicht). Spricht man hier also weiterhin von `Zeugnissen` (bzw. `testimonies`), kann es weder um die Frage gehen, ob deren Verhältnis zum bezeugten Ereignis >wahr ist, noch ob das Zeugnis der Sprechenden >glaubwürdig` erscheint. Stattdessen gewinnt eine ganz andere Frage an Bedeutung: Die Frage, was dieses Video-

80 Vgl. Schmidt: Ethik und Episteme der Zeugenschaft, Kapitel 4.

81 Angus Ross definiert den relationalen Prozess der Zeugenschaft folgendermaßen: »The speaker, in taking responsibility for the truth of what he is saying, is offering his hearer not evidence, but a guarantee that it is true, and in believing what he is told the hearer accepts this guarantee.« Angus Ross: »Why Do We Believe What We Are Told?«, Ratio 28, Nr. 1 (1986), S. 69-88, hier S. 79.

82 Schmidt: Ethik und Episteme der Zeugenschaft, S. 117.

83 Toufic: »I Am the Martyr Sanâ' Yûsif Muhaydlî«, S. 168. 
zeugnis `tut . Durch die paradoxe zeitliche Konstellation der Märtyertestamente rückt gerade der konstruktive und operative Charakter der Zeugenschaft in den Fokus. Die Einsicht, dass Zeugnisse immer auch er-zeugen, verstärkt sich hier umso mehr. Indem das bezeugte Ereignis nicht als Anlass, sondern als Folge des Videozeugnisses erscheint, erhält die Frage nach der Handlungsmacht dieser Aufnahmen ganz besondere Brisanz. Die Videotestamente können daher als antizipative Zeugnisse beschrieben werden, bei denen nicht mehr die Frage nach der Beweiskraft oder Evidenz im Vordergrund steht, sondern stattdessen die Frage nach ihrer Operativität.

Entscheidend ist dabei, dass es sich um Zeugnisse für die Kamera handelt. Wie bereits deutlich wurde, erhalten die Worte ihre eigentliche >Gültigkeit` erst nach dem Anschlag. Wenn Sana Muhaydli sagt, »I am not dead, but alive among you« oder Ali Ghazi Taleb versichert »I am still alive«, dann richten sie sich explizit an ein zukünftiges Publikum. Werden die Testamente jedoch vor dem Attentat rezipiert (etwa vom Publikum, das während der Videoaufnahme im selben Raum präsent ist), können sie lediglich als Ankündigungen, nicht jedoch als Zeugnisse, wahrgenommen werden. Darin liegt ein wesentlicher Unterschied zu anderen medial vermittelten Zeugnissen, etwa den Videotestamenten von Holocaustüberlebenden. Bei letzteren folgt die Aufzeichnung im Wesentlichen dem Anspruch, die Zeugnisse der Überlebenden zu archivieren und auch späteren Generationen zugänglich zu machen. ${ }^{84}$ Unabhängig davon sind die Worte der Überlebenden aber bereits zum Zeitpunkt des Sprechens als Zeugnisse zu begreifen. Im Gegensatz dazu handelt es sich bei den Videotestamenten von Selbstmordattentäter*innen keineswegs um archivierte Zeugnisse, die genauso gut auch hätten live erfahren werden können, sondern um Zeugnisse die ausschließlich für ein zukünftiges Publikum Sinn ergeben und damit notwendigerweise von ihrer medialen Vermittlung abhängen. Der Sprechakt des Märtyrers oder der Märtyrerin wird erst durch die Kamera zu einem >funktionierenden` Sprechakt. Obwohl sich die Kamera außerhalb des Bildfeldes befindet, schreibt sich ihre Anwesenheit daher konstitutiv in die Aufnahmeszene mit ein. Zwei Aspekte machen also die Besonderheit dieser Märtyrerzeugnisse aus: Erstens, die Umkehrung der zeitlichen Abfolge von Zeugnis und Bezeugtem und die damit einhergehende Perspektivverschiebung hin zur Operativität der Zeugenschaft. Und zweitens, die notwendige Bindung an ein Medium zur zeitlichen Vermittlung.

84 Ein solches Ziel verfolgt etwa das Fortunoff Video Archive for Holocaust Testimonies der Yale University, das mehr als 4.400 Zeugnisse von Holocaust-Überlebenden auf Video aufgezeichnet, gesammelt und zugänglich gemacht hat. 
Auch wenn gerade im englischen Diskurs sehr häufig von »video testimonies $\ll,{ }^{85}$ also von Video-Zeugnissen, die Rede ist, wurde diese Terminologie bislang nicht näher diskutiert oder erläutert. Dasselbe gilt auch für die anderen Begriffe, die für die Beschreibung dieser Videos gewählt und in den meisten Fällen austauschbar verwendet werden. Robert Pape bezeichnet die Videos der Selbstmordattentäter*innen in seinem Buch teilweise als »testimonials«, teilweise als »statements«, »martyr videos« oder »testaments «. ${ }^{86}$ Auch Lorenz Graitl spricht in seiner Studie wahlweise von »Videotestamenten«, »Märtyrervideos«, "Videobotschaften«, $»$ Videonachrichten« oder »Abschiedsvideos $«{ }^{87}$ Beschreibungskategorien wie »Botschaft« oder »Nachricht« wirken auf den ersten Blick zwar sehr weit und unspezifisch, bergen aber die Gefahr, die Funktion der Videos auf ihre sprachlichkommunikativen Aspekte zu reduzieren - und sowohl visuelle als auch performative Elemente außer Acht zu lassen. Im Kontext der vorliegenden Arbeit erscheinen diese Begriffe daher unzureichend.

Ebenfalls geläufig ist die Rede von »Videobekenntnissen« oder »BekennerInnenvideos « ${ }^{88}$ Auch wenn deutlich wurde, dass die Videos durchaus Statements enthalten, in denen sich die Dargestellten zu ihren zukünftigen Taten (oder auch zu einem Glauben, einer Überzeugung) ১bekennen`, übernehmen die Videos weitaus komplexere Funktionen, als es dieser Begriff anzeigen könnte. Die Rede vom >Märtyrervideo< scheint in dieser Hinsicht offener zu sein; gleichzeitig muss dabei betont werden, dass mit der Übernahme des Märtyrerbegriffs ausschließlich die Perspektive der Akteure abgebildet wird und der Begriff daher keine neutrale Beschreibungskategorie darstellt. Vor dem Hintergrund dieser Überlegungen erscheint die Bezeichnung als >Videotestament für eine wissenschaftliche Auseinandersetzung geeigneter. Im Gegensatz zum reinen Bekenntnis umfasst der Testament-Begriff ein breiteres Bedeutungsspektrum und hat den Vorteil, den Bezug zur Zeugenschaft mit anzuzeigen (sowohl die englischen Begriffe >testimony < und >testament $\measuredangle$ als auch das deutsche >Testament< sind abgeleitet vom lateinischen testare, >bezeugen (). Gleichzeitig meint das Wort im juristischen Sprachgebrauch eine rechtsverbindliche Willenserklärung oder "Verfügung « und bezieht sich insbesondere auf den letzten Willen einer Person, der im Fall des Todes seine

85 Für diesen Sprachgebrauch siehe beispielhaft Hasso: »Discursive and Political Deployments by/of the 2002 Palestinian Women Suicide Bombers/Martyrs«.

86 Pape: Dying to Win.

87 Graitl: Sterben als Spektakel.

88 Diesen Terminus verwendet beispielsweise Claudia Brunner in ihrer Studie. Er wird aber auch von ihr nicht näher bestimmt. Brunner: Wissensobjekt Selbstmordattentat. 
Wirkung entfaltet. ${ }^{89}$ Unter einem >Testament $\triangleleft$ wird folglich ein medial vermittelter Wille oder eine Absichtsbekundung verstanden, die erst in der Zukunft operativ wirkt (und damit über ein reines Bekenntnis hinausgeht, das ein Einstehen für etwas in der Gegenwart bezeichnet). In mehrfacher Hinsicht bietet sich der Begriff des Videotestaments daher als passende Beschreibungskategorie an.

\section{Sprechakt, Vertrag, Bildoperation}

Wie lässt sich die performative Operativität dieser Videotestamente nun aber konkret beschreiben $?^{90}$ In welchem Verhältnis steht die Performance vor der Kamera mit dem bezeugten Ereignis, dem Selbstmordattentat? Die antizipativen Zeugnisse und wörtlichen Ankündigungen der bevorstehenden Tat können zuallererst als Sprechakte im Sinne Austins beschrieben werden. Der britische Philosoph und Begründer der Sprechakttheorie J.L. Austin hat in How to Do Things With Words (1962) erstmals das Argument vorgetragen, dass Sprechen eine Praxis mit Konsequenzen ist, in der eine sprachliche Äußerung immer auch eine Handlung darstellen kann. Statt lediglich etwas zu beschreiben, das außerhalb und unabhängig von der Sprache existiert, kann ein >erfolgreicher Sprechakt etwas tun, das Auswirkungen auf die Realität hat. Eine besondere Form dieses »performativen« Sprechakts sieht Austin in der »kommissiven Äußerung « ${ }^{91}$; dazu zählen etwa Versprechen, Bürgschaften, sowie Willens- und Absichtserklärungen, die alle mit der Haltung verbunden sind, eine Verpflichtung für die Zukunft zu übernehmen: »Der Sinn der kommissiven Äußerung « nach Austin »ist, den Sprecher auf ein bestimmtes Verhalten festzulegen $\aleph^{92}$.

Auch die Videotestamente der Selbstmordattentäter*innen enthalten eine Vielzahl unterschiedlicher Absichtsbekundungen, die in Austins Sinne als kommissive Sprechakte funktionieren, etwa wenn Wajdi al-Sayigh verkündet: «I will get in the car. I'll drive all the way to where the buses of the Jews are. And when I am near the buses of the Jews, then I just press the button.« Oder wenn Sana

89 Vgl. § 1937 »Erbeinsetzung durch letztwillige Verfügung« des BGB (Bürgerliches Gesetzbuch).

90 Teile dieses Unterkapitels basieren auf Verena Straub: »The Making and Gendering of a Martyr: Images of Female Suicide Bombers in the Middle East«, in: Jens Eder und Charlotte Klonk (Hg.): Image Operations. Visual Media and Political Conflict, Manchester: Manchester University Press 2016, S. 137-150.

91 John L. Austin: Zur Theorie der Sprechakte, hg. von Eike Savigny, Stuttgart: Reclam 1972, S. 173.

92 Ebd. 
Muhaydli versichert: $» I$ am going to execute this operation. « Noch vor ihrer appellierenden Wirkmacht, haben die Worte der selbst ernannten Märtyrer*innen also Auswirkungen auf die eigentliche, unmittelbar bevorstehende Tat. Die Absichtserklärungen allein können jedoch kaum als verbindliche Form der >Verpflichtung< gelten. Es ist ein Leichtes, wörtlich gegebene Versprechen wieder zu brechen. Erst durch die Aufzeichnung dieser Sprechakte auf Video werden Dokumente mit verhängnisvoller Beweiskraft geschaffen, die eine Umsetzung der Ankündigungen - und damit den eigenen Tod - nahezu unumgänglich machen. Folgt man dem israelischen Künstler und Theoretiker Joshua Simon, erhalten die Videoaufnahmen der zukünftigen Selbstmordattentäter*innen den Status von »Todesurteilen«. Mit Blick auf die Videoaufnahmen palästinensischer Selbstmordattentäter*innen stellt er fest: »When filmed, the Shaheeds do sentence themselves to death, simply because the existence of tapes in which they are seen swearing to die as martyrs in Israeli cities makes them what military intelligence calls `ticking bombs $<$, meaning they will be tracked down and targeted. ${ }^{93}$

Betrachtet man die videografisch festgehaltenen Sprechakte als derart belastende Beweismittel, stellt sich die Frage, warum die Beteiligten ein solch hohes Risiko überhaupt eingehen. Immerhin bergen Videoaufnahmen stets die Gefahr, in feindliche Hände zu geraten und von Polizei, Militär oder Geheimdiensten entdeckt zu werden bevor die Selbstmordoperation überhaupt durchgeführt werden konnte. Dies gilt nicht nur für den palästinensisch-israelischen Kontext, sondern kann als Besonderheit und inhärentes >Risiko< von Videotestamenten allgemein gelten. Welchen Nutzen verbinden die Parteien und zukünftigen Attentäter*innen also mit diesen Aufnahmen? Im Jahr 2009 hat der Psychologe Ariel Merari mit seinem Team mehrere Hamas- und Fatah-Männer in israelischen Gefängnissen interviewt, die vor ihrer Festnahme Selbstmordattentate organisierten und im Gespräch Aufschlüsse über die Funktion der Videoaufnahmen gaben. Ein FatahMitglied betonte: »The videotaped reading of the testament creates a situation of commitment to complete [the mission]. There is no way back! $\ll{ }^{94}$ Und auch ein Hamas-Organisator beschrieb die eigentliche Funktion der Videotestamente als bindenden »Vertrag «: »The videotaping is actually a contract between the candidate and the organizer. ${ }^{95}$ Die Videos, die für gewöhnlich wenige Tage vor dem

93 Joshua Simon: »Thoughts on the Aesthetics of Terror in General and Suicide Bombers' Videos in Particular«, in: Slome/Simon: The Aesthetics of Terror, S. 28-47, hier S. 43.

94 Ariel Merari u.a.: »Making Palestinian \Martyrdom Operations $/>$ Suicide Attacks $২$ Interviews With Would-Be Perpetrators and Organizers«, Terrorism and Political Violence 22/1 (2009), S. 102-119, hier S. 113.

95 Ebd. 
geplanten Anschlag aufgenommen werden, dienen der Organisation als Absicherung und sollen verhindern, dass der Rekrut oder die Rekrutin in letzter Minute die Meinung ändert. ${ }^{96}$ Folgt man den Einschätzungen der interviewten Akteure, stehen die Videotestamente damit in einem kausalen Verhältnis zur militärischen Operation; sie werden zum Druckmittel und gleichsam zum Motor für die Durchführung der Operation.

Der Ökonom Mark Harrison geht noch einen Schritt weiter, indem er das Selbstmordattentat an sich als vertragliche Vereinbarung zwischen Individuum und Organisation interpretiert. Ein Vertrag, der Harrison zufolge in einem Tausch von »Leben gegen Identität« besteht und von dem nicht nur die Organisationen, sondern auch die Rekrut*innen profitieren: »Under the terms of the contract the volunteer agrees to trade life for identity. She will die to promote the faction's terrorist objectives. In return the faction endorses the volunteer's identity as a warrior martyr. ${ }{ }^{97}$ Auf der einen Seite dieses Vertrags stehen die zukünftigen Selbstmordattentäter*innen, die bereit sind, das eigene Leben für die Ziele der Organisation zu opfern. Als Gegenleistung verleiht die Organisation ihnen eine neue Identität als heroische und ehrenhafte Märtyrer*innen. Im Versprechen der Märtyreridentität sieht Harrison einen entscheidenden Beweggrund, warum Individuen ein Selbstmordattentat begehen. Dabei geht es keineswegs nur um den Glauben, ins Paradies einzutreten. Viel wichtiger erscheint Harrison das Versprechen, im Diesseits verehrt zu werden und Anerkennung innerhalb der eigenen Partei, Gesellschaft oder Familie zu erlangen. ${ }^{98}$ Dies gilt umso mehr für Mitglieder säkularer Parteien, bei denen religiöse Versprechungen oder Belohnungen im Jenseits nicht im Vordergrund stehen. Schenkt man den Worten der bereits erwähnten SSNP-Rekrutin Glauben, die nach ihrem vereitelten Attentat interviewt wurde, so war der ausschlaggebende Grund für ihren Schritt die Anerkennung von Seiten der Partei: »They just explained to me how important the mission was, how much they would respect me if I stood up to the test. $1^{99}$

Die Suche nach einer eindeutigen Motivation - und damit nach einer einzigen `Erklärung $<$ - für Selbstmordattentate erweist sich jedoch als äußerst schwierig. Harrisons Argument läuft an manchen Stellen Gefahr, die Komplexität und Widersprüchlichkeit des Selbstmordattentats auf einen allzu einfachen Nenner

96 Zahlreiche weitere Interviews mit verhinderten Selbstmordattentätern und Organisatoren legen denselben Schluss nahe. Vgl. ebd.

97 Mark Harrison: »An Economist Looks at Suicide Terrorism«, World Economics 7/3 (2006), S. 1-15, hier S. 10.

98 Vgl. ebd., S. 8.

99 Zitiert in Ya'ari: »Behind the Terror«, o.S. 
(»trade life for identity«) zu reduzieren. Auch wenn das Streben nach sozialer Anerkennung ein Beweggrund für die Individuen darstellen mag, erscheint es wichtig, dies im Zusammenspiel mit weiteren politisch-strategischen, persönlichen oder religiösen Motiven zu betrachten. ${ }^{100}$ Auch die Frage, ob und inwiefern die zukünftigen Selbstmordattentäter*innen tatsächlich `freiwillig $<$ und aus rationalen Überlegungen heraus in diesen Vertrag einwilligen, kann (wenn überhaupt) wohl nur im Einzelfall beantwortet werden. Die Annahme eines quasi-gleichberechtigten Vertrags »between consenting parties [...] in the expectation of mutual benefit ${ }^{101}$ könnte außerdem dazu führen, ungleiche Machtverhältnisse zwischen Führungsmitgliedern der Partei und Rekrut*innen aus dem Blick zu verlieren. Es bleibt höchst fraglich, ob die Durchführung eines Selbstmordattentats in allen Fällen auf gegenseitigem Einverständnis beruht.

Doch auch wenn es problematisch erscheint, das Selbstmordattentat an sich als Vertrag zu beschreiben, sind Harrisons Überlegungen in Bezug auf die Videoaufnahmen und insbesondere auf deren performative Dimensionen ausgesprochen hilfreich. Das Auftreten der Individuen als »living martyrs« stellt für Harrison die Bedingung dar, dass der Vertrag für beide Seiten bindend ist. ${ }^{102}$ Gerade weil die neue Märtyeridentität eigentlich erst nach dem Tod verkündet werden kann, stellt die Performance vor der Videokamera eine Möglichkeit dar, die Verwandlung des sterblichen Individuums in einen unsterblichen Märtyrer oder eine unsterbliche Märtyrerin schon vor dem Tod zu vollziehen. In diesem Sinne funktioniert das Videotestament nicht nur als Verpflichtung und Druckmittel für die Rekrut*innen, sondern gewährleistet die Einhaltung des Vertrags auch von Seiten der Partei, so argumentiert Harrison überzeugend. Die Videoaufnahme verschafft dem oder der zukünftigen Attentäter*in die Gewissheit, von anderen als Märtyrer*in bezeugt zu werden - und zwar nicht erst nach dem Tod, sondern bereits zu Lebzeiten: »The institution of the >living martyr «", so betont Harrison, »meets the attacker's need

100 Statt monokausaler Erklärungen plädieren immer mehr Forscher*innen für einen multikausalen Ansatz, der sowohl die Motive der Parteien als auch die vielfältigen Motivationen der Individuen berücksichtigt. Vgl. Bader Araj: »The Motivations of Palestinian Suicide Bombers in the Second Intifada (2000 to 2005)«, Canadian Review of Sociology and Anthropology 49/3 (2012), S. 211-233; Assaf Moghadam: »The Roots of Suicide Terrorism: A Multi-Causal Approach«, in: Ami Pedahzur (Hg.): Root Causes of Suicide Terrorism: The Globalization of Martyrdom, London: Routledge 2006, S. 81-108.

101 Harrison: »An Economist Looks at Suicide Terrorism«, S. 10.

102 Ebd., S. 1. 
for an audience (Merari 1998) which is assembled in advance, before the event ${ }^{103}$. Das Bemerkenswerte an diesem Vertrag ist also, dass dieser nicht nur auf wörtlichen Ankündigungen oder Versprechen im Sinne eines kommissiven Sprechakts basiert, sondern als verkörperte Vorwegnahme zu begreifen ist. Muhaydlis Behauptung »Ich bin nicht tot, sondern lebendig unter euch « scheint durch die Sichtbarkeit ihres lebendigen Körpers zusätzlich bekräftigt zu werden. Der Körper, den wir vor der Videokamera sehen, wird als Körper einer >lebenden Märtyrerin` präsentiert. Die (erhoffte) Identität einer unsterblichen Märtyrerin wird folglich nicht nur sprachlich vorweggenommen, sondern preenacted. ${ }^{104}$

Dass diese vorzeitige >Verwandlung ‘ am eigenen Körper eine ungeheure Macht auf die jeweiligen Individuen ausübt, schien auch den Ausbildern bewusst gewesen zu sein, die für Selbstmordattentate rekrutierten. Folgt man den Berichten etlicher Hamas-Mitglieder, die Nasra Hassan zwischen 1996 und 1999 in Palästina interviewte, spielte man die Videos den zukünftigen Attentätern wie ein Mantra immer und immer wieder vor: »The young man repeatedly watches the video of himself, as well as the videos of his predecessors. >These videos encourage him to confront death, not fear it, $\prec$ one trainer told me. $>$ He becomes intimately familiar with what he is about to do. Then he can greet death like an old friend. « ${ }^{105}$ Nicht nur die körperliche Performance vor der Kamera, auch das wiederholte Betrachten des eigenen Märtyrerbildes sollte den Rekruten emotional und psychisch auf das Attentat >einstimmen`. Die Präsentation der eigenen >Märtyrerwerdung ist zum einen als Erinnerung an das abgegebene Versprechen zu interpretieren, als demonstratives Vorführen des besiegelten Vertrags. Zum anderen muss das Video auf den Protagonisten in diesem Moment wie eine Verheißung aus der Zukunft gewirkt haben - und dürfte damit als weiterer Ansporn für die tatsächliche Durchführung der Tat gedient haben. Das Selbstzeugnis wurde von den Organisatoren der Hamas hier also gleich in mehrfacher Hinsicht als (Druck-)Mittel der Überzeugung eingesetzt das ein Zurück kaum mehr möglich erscheinen ließ.

Durch die Videoaufnahme werden also zwei Prozesse oder Operationen in Gang gesetzt: Die >Märtyrerwerdung` der Dargestellten sowie die eigentliche

103 Harrison: »An Economist Looks at Suicide Terrorism«, S. 10.

104 Zum Begriff des Preenactments siehe Adam Czirak, Friederike Oberkrome, Sophie Nikoleit, Verena Straub, Robert Walter Jochum und Michael Wetzels: »(P)Reenactment«, in: Jan Slaby und Christian von Scheve (Hg.): Affective Societies - Key Concepts, London: Routledge 2019, S. 200-209.

105 Nasra Hassan: »An Arsenal of Believers«, The New Yorker (2001), http://www. newyorker.com/magazine/2001/11/19/an-arsenal-of-believers (zugegriffen am 6.6. 2021). 
Selbstmordoperation selbst. Mit Blick auf die Poster wurde bereits deutlich, dass die sekundären Bildzeugnisse das Martyrium ebenso sehr erzeugen als dass sie es bezeugen: Ein Prozess, der im zweiten Kapitel als epistemische Bildoperation beschrieben wurde (vgl. S. 49). Im Fall der besprochenen Videotestamente sind es nun allerdings die zukünftigen Märtyrer*innen selbst, die als Zeug*innen auftreten und ihr Martyrium schon vor der Tat konstituieren. Damit wird schließlich eine zweite Operation angestoßen: Die eigentliche Märtyrertat, die nun geradezu unumkehrbar erscheint (»There is no way back!«).

Das Videotestament der Märtyrerin nimmt folglich nicht nur Einfluss auf die posthume Wahrnehmung und Bewertung ihres Attentats, sondern hat auch konkrete Auswirkungen auf die eigentliche Selbstmordoperation. Im Unterschied zur epistemischen Bildoperation geht es nicht mehr nur darum, inwiefern die Bilder an der Konstruktion einer bestimmten $>$ Wahrheit $<$ beteiligt sind, sondern auch inwiefern die Bilder ganz konkret in militante Praktiken eingebunden sind. Wie im ersten Kapitel bereits angedeutet, spricht Jens Eder in diesem Zusammenhang von einem weiteren bildoperativen Modus, der von einer »performativen Kausalität« der Bilder ausgeht. ${ }^{106}$ Fotos, Grafiken oder Videos, so die Annahme, können nicht nur zu militärischen Aktionen aufrufen (im Sinne appellativer Bildoperationen), sondern sind zum Teil auch viel direkter an deren Durchführung beteiligt. Wie oben deutlich wurde, trifft dies zu einem gewissen Grad auch auf die Videotestamente von Selbstmordattentäter*innen zu, die weit mehr sind als Propagandabilder. Die Videoaufnahmen verpflichten die Dargestellten in letzter Konsequenz zu ihrer Tat und wirken damit als Druckmittel oder Motor für deren Realisierung. Geht man davon aus, dass Videotestamente Funktionen eines Vertrags übernehmen, dann erscheint das Argument plausibel, dass die Aufnahmen selbst Bestandteil der tödlichen Operation sind. Nichtsdestotrotz muss betont werden, dass nicht jeder Märtyrertod-Operation eine solche Bildoperation vorausgeht. Nicht jeder Selbstmordattentäter, nicht jede Selbstmordattentäterin hinterlässt ein Videotestament - und umgekehrt führt nicht jede Videoaufnahme zwangsläufig zur angekündigten Tat. ${ }^{107}$ Denn trotz der geschilderten Risiken besteht auch nach Aufnahme des Testaments zumindest prinzipiell noch die Möglichkeit zum Abbruch oder zur Umkehr. Damit unterscheiden sich die Videotestamente wesentlich von anderen performativen Bildoperationen wie etwa Drohnenangriffen, bei denen Bildhandeln und militärisches Handeln ohneeinander nicht möglich sind. Anders

106 Eder: Vorüberlegungen zu »Image Operations«, o.S.

107 So berichtete mir der Journalist Kevin Toolis etwa von Videotestamenten, die er 2005 im Büro eines SSNP-Funktionärs sichtete, deren Protagonist*innen jedoch nicht als Selbstmordattentäter*innen bekannt waren und deren Taten wohl nie zustande kamen. 
als bei Drohnenangriffen ist die bildoperative Wirkung der Videotestamente also keineswegs als Kausalität im Sinne einer direkten oder unmittelbaren Folge zu verstehen. Auch wenn die Videoperformance die militärische Märtyrertod-Operation teilweise bedingt und zusätzlich befördern kann, sind die Zusammenhänge zwischen beiden `Operationen « weitaus vielschichtiger und weniger unilinear.

\section{2 »THE STUTTERING OF THE MARTYR«. ELIAS KHOURYS UND RABIH MROUÉS PERFORMANCES THREE POSTERS (2000) UND ON THREE POSTERS (2004)}

Angesichts der vielfältigen Bildoperationen der militanten Akteur*innen stellt sich schließlich die Frage: Inwiefern lässt sich der epistemischen, appellierenden und performativen Wirkmacht der Videotestamente etwas entgegnen? Oder anders gefragt: Lässt sich im Umgang mit denselben Bildern das Martyrium der Dargestellten nicht nur erzeugen, sondern auch dekonstruieren?

Der libanesische Schriftsteller Elias Khoury und der Künstler Rabih Mroué haben einen Versuch unternommen, die epistemische Operation der frühen libanesischen Videotestamente vorzuführen: Und zwar im doppelten Wortsinn einer Aufführung und Demaskierung zugleich. In ihrer Performance Three Posters, die auf dem Ayloul Festival im Jahr 2000 in Beirut uraufgeführt wurde, brachten die Künstler einen >lebenden Märtyrer $<$ auf die Theaterbühne. ${ }^{108} \mathrm{Zu}$ Beginn wurde das Theaterpublikum Zeuge eines Videotestaments, das auf einem kleinen Bildschirm auf der Bühne abgespielt wurde. Die Videoaufnahme zeigte Rabih Mroué, der zunächst in seiner Funktion als Schauspieler klar markiert wurde. Hinter einem Tisch sitzend, mit Militärjacke und Barett bekleidet nahm er die Rolle eines Mitglieds der Libanesischen Kommunistischen Partei namens Khaled Rahhal ein, der vor der Kamera sein Testament als Märtyrer verkündete (Abb. 3.12): »I am the martyr comrade Khaled Rahhal. ${ }^{109}$ Danach folgten Informationen zur politischen Biografie, Ankündigungen der geplanten Selbstmordoperation sowie Abschiedsfloskeln und Grußworte.

108 Die folgenden Beschreibungen stützen sich auf fotografische Dokumentationen sowie auf das englische Transkript der Performance in Mroué/Khoury: »Three Posters: Reflections on a Video/Performance $\ll$.

109 Ebd., S. 185. 
Abbildung 3.12-3.14: Elias Khoury und Rabih Mroué, Three Posters, 2000, Performance, Ayloul Festival Beirut.
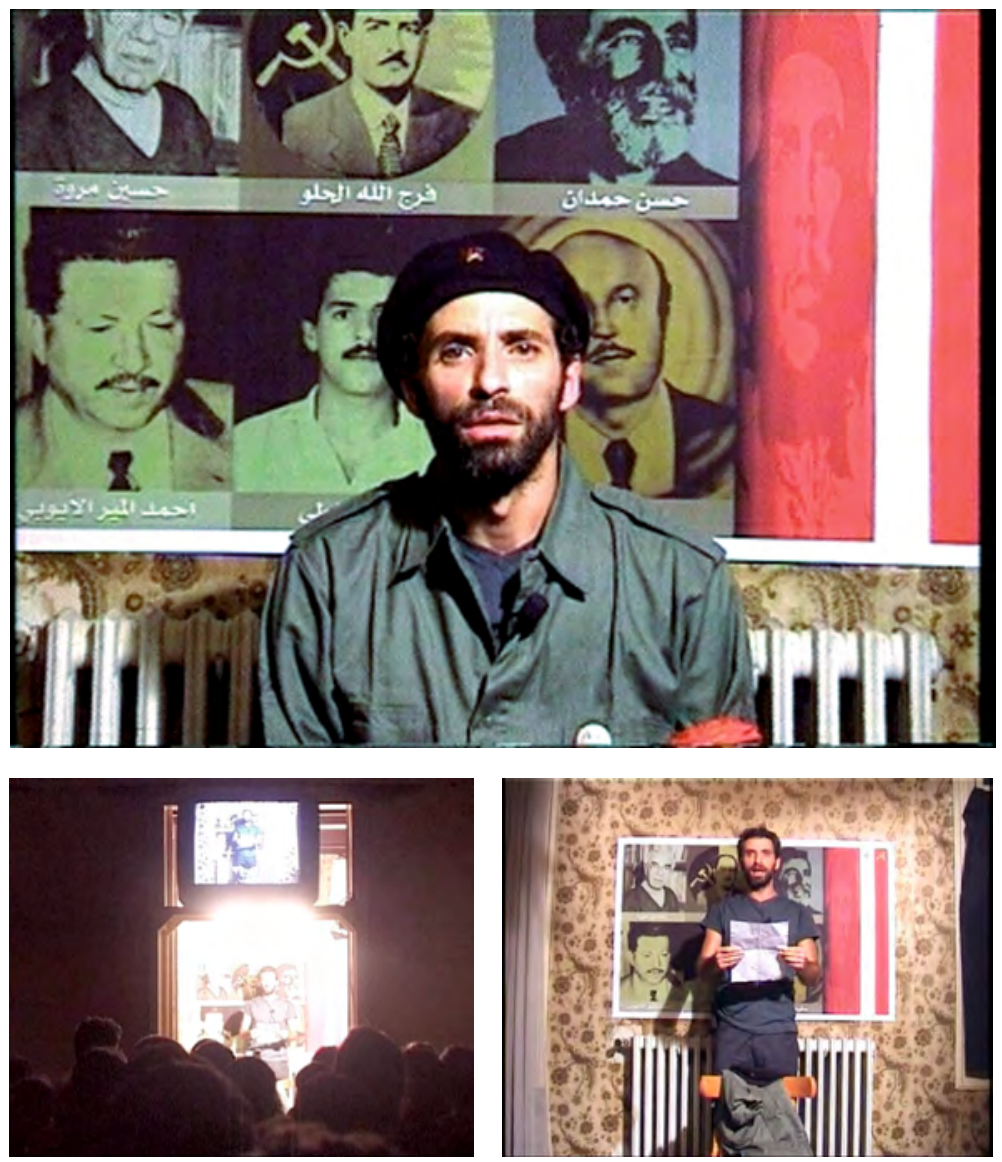

Das gesprochene Testament sowie das Setting der Aufnahme erinnerten an die Videotestamente der Libanesischen Kommunistischen Partei, wie sie im Laufe der 1980er Jahre im libanesischen Fernsehen immer wieder ausgestrahlt wurden. Dem Großteil des Beiruter Theaterpublikums muss die Bildsprache dieses Videos daher vertraut gewesen sein. ${ }^{110}$ Wie in den sechten Videotestamenten hingen auch an

110 Da fast alle Videotestamente im damals einzigen staatlichen TV-Sender Télé Liban ausgestrahlt wurden, waren sie einem großen Teil der libanesischen Bevölkerung bekannt. Mroué und Khoury beschreiben die Videotestamente dementsprechend auch 
der Wand hinter Mroué diverse Bilder vorangegangener Märtyrer. Im Unterschied zu den finalen und geschnittenen Versionen der veröffentlichten Videotestamente konnten die Zuschauer*innen nun jedoch die ungeschnittene Performance eines selbst ernannten Märtyrers beobachten. Auf dem Bildschirm waren drei Takes desselben Testaments zu sehen, in denen der (fiktive) Khaled Rahhal seine Erzählung kontinuierlich modifizierte. Seine Performance wurde dabei immer wieder durch Sprechpausen, Satzabbrüche, scheinbar technische Pannen oder direkte Anweisungen an die Person hinter der Kamera unterbrochen (»Turn it on. Turn it on.«). ${ }^{111}$ Noch während das Video abgespielt wurde, öffnete Elias Khoury eine Tür direkt unter dem an einer Wand hängenden Bildschirm auf der Bühne und gab den Blick frei auf Rabih Mroué vor der installierten Kamera (Abb. 3.13).

Für gewöhnlich werden Videotestamente nur unter der Voraussetzung veröffentlicht, dass das Selbstmordattentat und damit der Märtyrertod der Dargestellten bereits erfolgt ist. Der Zeitpunkt der Rezeption ist daher notwendigerweise vom Zeitpunkt der Produktion getrennt. Indem die Künstler das Videotestament jedoch als Live-Performance auf die Bühne verlagerten, führten sie das Paradox des >lebenden Märtyrers` vor Augen, der mit seinem antizipativen Zeugnis die Grenze zwischen Leben und Tod verwischt: »At that instant«, so Mroué in seinen späteren Überlegungen zur Performance, »the fabrication of the false moment was made apparent; it was as if the martyr had come to life before them ${ }^{112}$. Mit der Theateraufführung des Videotestaments wurde nicht nur die Trennung zwischen Leben und Tod, sondern auch die zwischen Realität und Fiktion in Frage gestellt. Noch deutlicher wurde dies im zweiten Teil der Performance. Nach seinem Schauspiel als Khaled Rahhal entledigte sich Rabih Mroué seiner Militärkleidung, stand von seinem Stuhl auf, kramte einen Zettel aus seiner Hosentasche, begann zu lesen und setzte scheinbar zu einem weiteren Take des Videotestaments an (Abb. 3.14). Dieses Mal jedoch in seinem eigenen Namen: »My name is Rabih Mroué, born in 1966, Beirut, became a member of the Lebanese Communist Party in $1983[\ldots] . \ll^{113}$ Im weiteren Verlauf des verlesenen 〉Testaments` richtete er seinen Gruß an »the martyr comrade Khaled Rahhal«, der angeblich während militärischer Auseinandersetzungen in West-Beirut im Jahr 1987 starb. Indem sich Rabih Mroué selbst als weiteres Glied in der Kette von Märtyrer*innen präsentierte, wurde der dokumentarische Charakter dieser Videos weiter in Zweifel gezogen und das Märtyrer-

als »a singular element in the memory of every Lebanese person. « Mroué/Khoury: »Three Posters: Reflections on a Video/Performance«, S. 183.

111 Ebd., S. 187.

112 Ebd., S. 184.

113 Ebd., S. 187f. 
testament als fiktives Spiel und rhetorische Strategie vorgestellt, die scheinbar von jedem angeeignet werden könne. Im Anschluss an Mroués Performance legten die Künstler eine Videokassette in den Recorder ein und es wurden drei Takes eines tatsächlichen Videotestaments auf der Bühne abgespielt, das sich als Vorlage der gerade gespielten Szene entpuppte. Auf dem Monitor war nun das (oben bereits ausführlicher diskutierte) Videotestament von Jamal Sati zu sehen, einem Mitglied der Libanesischen Kommunistischen Partei, der am Nachmittag des 6. August 1985 einen Suizidanschlag auf einen israelischen Militärstützpunkt in Hasbayya verübte (vgl. Abb. 3.7). Noch am selben Abend war sein Videotestament in den 20-Uhr-Nachrichten auf Télé Liban zu sehen gewesen. ${ }^{114} \mathrm{Im}$ Kontext der Kunstperformance erfuhr dasselbe Videotestament nun einen Rahmenwechsel, der ganz andere Lesarten zuließ. Während im libanesischen Fernsehen nur eine Version des Videotestaments zu sehen war, entdeckten die Künstler im Büro eines Parteifunktionärs ein Videotape mit drei unterschiedlichen Aufnahmen von Satis Testament, die sie nun auf der Bühne abspielten. Drei Mal setzte der zukünftige Selbstmordattentäter mit den Worten »I am the martyr comrade Jamal Sati« an, um eine möglichst überzeugende Version seines Testaments zu liefern. Obwohl sich die drei Versionen im Wesentlichen gleichen, enthalten sie etliche Korrekturen, verschieden gestaltete Ausschmückungen und Abweichungen in einzelnen Details der Erzählung. Fehlten im ersten Take noch wichtige biografische Infos wie sein Geburtsdatum, so ergänzte Sati diese in den darauffolgenden Takes. Auch in der Darstellung seiner politischen Affiliation lassen sich Unterschiede erkennen: Während Sati im ersten Take seine Identität als Kommunist hervorhob, lag die Betonung im zweiten Take vielmehr auf seiner Loyalität zur Libanesischen Befreiungsfront. Hintereinander abgespielt wirken die drei Takes wie Proben seiner Märtyrer-Performance. Darüber hinaus offenbaren die Aufnahmen Momente der Unsicherheit und des Zögerns, ablesbar an Satis suchenden Blicken, stockenden Formulierungen oder Satzabbrüchen. ${ }^{115}$

Es waren genau diese Fehlbarkeiten, die Khoury und Mroué faszinierten und die den Ausgangspunkt ihrer Performance darstellten. Die Künstler erinnern sich: »The instant we saw the >stuttering < of the martyr, we realized something simple, so simple that it was obvious - the martyr is not a hero but a human being. ${ }^{116}$ Vor

114 Mroué/Khoury: »Three Posters: Reflections on a Video/Performance«, S. 183, Anm. 1.

115 So endete etwa der zweite Take abrupt und mitten im Satz: »My spirit will dwell in the souls of all honest patriotic comrades, and thus take the opportunity to...«. Zitiert nach ebd., S. 189.

116 Ebd., S. 183. 
dem Hintergrund der gerade gesehenen Live-Performance musste auch Jamal Sati auf das Theaterpublikum wie ein Schauspieler gewirkt haben, der seine Identität als Märtyrer vor der Kamera konstruiert. Durch das Reenactment eines Videotestaments auf der Theaterbühne führten Khoury und Mroué vor Augen, dass die 〉Erzeugung〈des Märtyrers bzw. der Märtyrerin bereits vor dem eigentlichen Tod, nämlich mit der Performance vor der Kamera einsetzt. »Does the martyrdom then take place directly before us, through the filmic image of the videotape? «, so fragt Mroué in seinen späteren Reflexionen zu Three Posters: »Indeed, it seems that the martyrdom is actualised at the very instant when the young man announces his martyrdom before the camera [...]. $\ll^{117}$ Die $>$ Märtyrerwerdung $<$ wird durch die Performance als epistemische Bildoperation vorgeführt, die Mroué als »fabrication of truth « beschreibt. ${ }^{118}$ Das $>$ Martyrium wird als Ergebnis einer Videoperformance präsentiert: als Schauspiel, das gleichzeitig jedoch nicht von den faktischen Folgen zu trennen ist, die mit der »Erzeugung von Wahrheit« einhergehen. Indem Mroué und Khoury den selbst ernannten Märtyrer jedoch als ‘gewöhnlichen< Menschen entlarven, der seine neue Identität stotternd und unsicher vor der Kamera inszeniert, wird die `Effektivität $\iota$ dieser Bildoperation konterkariert und gebrochen. Durch die Perspektive der Künstler wird Sati vom heldenhaften Märtyrer wieder zu einer sterblichen, geradezu tragischen Figur. Führt die Performance also einerseits vor Augen, wie das Martyrium vor der Kamera konstituiert wird, so wird die Macht dieser Bildoperation im gleichen Moment wieder dekonstruiert.

Eher unbeabsichtigt wurde Three Posters aber auch zu einem Exempel dafür, wie unkontrollierbar und kontextabhängig die Wirkmacht von Videotestamenten ist. Sowohl der Zeitpunkt der Aufführung als auch der kulturelle und politische Hintergrund der Theaterbesucher*innen war ausschlaggebend für die Rezeption der Performance. Als Mroué und Khoury Three Posters für das Ayloul Festival in Beirut konzipierten, hatten die Künstler ein vorwiegend libanesisches Publikum vor Augen, das mit den politischen Nuancen des Bürgerkriegs und der Rolle der linken Bewegungen vertraut war. Die Videotestamente der Libanesischen Kommunistischen Partei dürften zumindest den älteren Theaterbesucher*innen in Beirut bekannt gewesen sein. Ein kritischer Diskurs über die Märtyrer*innen des Bürgerkriegs ist in weiten Teilen der libanesischen Öffentlichkeit jedoch bis heute ein

117 Rabih Mroué: »The Fabrication of Truth«, in: Fundació Antoni Tàpies (Hg.): Tamass: Contemporary Arab Representations, Bd. 1, Barcelona: Fundació Antoni Tapies 2002, S. 114-117, hier S. 115.

118 Ebd. 
Tabu. ${ }^{119}$ Aus Respekt vor den Gefühlen der Familien, die dem Tod ihrer Angehörigen auf diese Weise einen Sinn verleihen, sind Märtyrer*innen häufig mit einer Aura der Unantastbarkeit umgeben. Khoury und Mroué zufolge nehmen sie in der libanesischen Gesellschaft einen $»$ sacred space ${ }^{120}$ ein, einen geradezu heiligen Raum. In diesem Kontext stellte die Performance der beiden Künstler einen Versuch dar, das im Libanon allgegenwärtige (und häufig unhinterfragte) Konzept des Martyriums einer grundlegenden Kritik zu unterziehen. Mehr noch: Mit dem Videotestament des Kommunisten Jamal Sati wollten sie eine kritische Bestandsaufnahme der libanesischen Linken anregen, die sie zugleich als kritische Selbstbefragung verstanden: »Three Posters attempts to reevaluate the politics and role of the Lebanese Left during the civil war. It makes a critical and autocritical assessment of the Left's absense today in the Lebanese political arena - and in a way, declares our defeat. $\ll^{121}$

Die Verantwortung der Libanesischen Kommunistischen Partei wurde im letzten Teil der Performance explizit thematisiert, als die Künstler ein weiteres Video auf der Bühne abspielten. Es zeigte ein Interview mit Elias Attallah, einem der führenden Köpfe der LCP, der unter anderem an der Organisation von Jamal Satis Selbstmordattentat beteiligt war. Attallah räumte zwar ein, dass das Politbüro der LCP den Einsatz von Märtyrertod-Operationen befürwortete, deutete jedoch an, dass es intern durchaus Zweifel an der Sinnhaftigkeit und der Legitimation solcher Einsätze gab. ${ }^{122}$ Attallahs Bericht zeichnete das Bild einer linken Widerstandsbewegung, die ab 1986 zunehmend unter Druck geriet und durch eine Serie von Attentaten auf Führungspersönlichkeiten und linke Intellektuelle (darunter auch Hussein Mroué, der Großvater von Rabih Mroué) gezielt dezimiert und geschwächt wurde.

Diese Bandbreite der politischen und gesellschaftlichen Kontexte von Three Posters konnten einem nicht-libanesischen Theaterpublikum in unterschiedlichen Städten Europas jedoch kaum vermittelt werden. Die Anschläge vom 11. September 2001 führten außerdem dazu, dass Selbstmordattentate in der öffentlichen Wahrnehmung außerhalb des Nahen Ostens fast ausschließlich mit islamistischem Fundamentalismus gleichgesetzt wurden. Obwohl die Uraufführung der Perfor-

119 So hat beispielsweise Elias Chad festgestellt: »Yet despite their ubiquity within Lebanese public life, posters of martyrs are not a topic of open discussion. Their silent presence gives them a paradoxical status; they are both commonplace and taboo." Chad: »Martyrdom and Mediation«, S. 2.

120 Mroué/Khoury: »Three Posters: Reflections on a Video/Performance«, S. 184.

121 Ebd., S. 185.

122 Ebd., S. 190ff. 
mance bereits ein Jahr vor 9/11 stattfand, wurde Three Posters in der Presseberichterstattung überwiegend mit den aktuellen Ereignissen in Verbindung gebracht, so zeigte die Erfahrung der Künstler. ${ }^{123}$ Sowohl der spezifische Kontext des libanesischen Widerstandskampfs als auch die Tatsache, dass es sich bei Sati um das Mitglied einer säkularen und marxistischen Partei handelte, rückten in den Hintergrund. Dies war schließlich der Grund, warum die Künstler im Jahr 2004 beschlossen, die Performance nicht länger aufzuführen. Denn trotz aller Kritik an den Märtyrertod-Operationen der LCP, wollten sie das Anliegen des linken Widerstandskampfs nicht mit dem globalen >Terrorismus « islamischer Fundamentalisten vermengt wissen. In einem Interview mit Elias Chad erklärte Mroué:

»My refusal to perform this work again has to do with my desire to respect the memory of Jamal Sati and his cause. I do not want people to misunderstand his position and label him a terrorist (this is actually what happened several times when we performed the work outside Lebanon). I think that this is unfair and presents a very narrow view of his actions. Although I am against suicide operations, al-Sati was defending his rights. He undertook a military operation against an occupying army, not against civilians, and it was in his country, not on foreign land, so it was an act of political resistance. I think we have to respect this.« ${ }^{124}$

Aus diesen Gründen entwickelte Mroué ab 2004 eine Performance über die Performance, in der er diese Bedeutungsverschiebungen selbst zum Thema machte. On Three Posters wurde zum einen als Lecture-Performance konzipiert, zum anderen als 14-minütige Einkanal-Videoinstallation realisiert, die in Ausstellungen präsentiert wurde (Abb. 3.15). Gerade die Videoversion fügt Three Posters eine weitere Ebene der medialen Reflexion hinzu und verkompliziert die Relation zwischen Live-Performance und Video-Performance einmal mehr. Verlagerte Three Posters die Aufnahme eines Videotestaments live auf die Theaterbühne, konfrontiert uns On Three Posters wiederum mit einem medial vermittelten >Bekenntnis

$123 »$ Unfortunately, the foreign press inevitably linked the performance with >current events $<$ It was a challenge to keep Three Posters free from this line of interpretation and to insist on its Lebanese context.« Rabih Mroué: »Three Posters. Reflections on a Video-Performance«, in: CA2M Centro de Arte Dos de Mayo (Hg.): Rabih Mroué. Image(s), mon amour. Fabrications, Ausst.-Kat., Madrid: CA2M Centro de Arte Dos de Mayo 2013, S. 302-314, hier S. 313.

124 Elias Chad: »Interview with Rabih Mroué«, in: Ders. (Hg.): In Focus: On Three Posters 2004 by Rabih Mroué, London: Tate 2014, https://www.tate.org.uk/research/publications/in-focus/on-three-posters-rabih-mroue/interview-with-rabih-mroue (zugegriffen am 6.6.2021). 
über eine Performance. Mroué selbst bezeichnete die Arbeit als »video testimonial ${ }^{125}$, wodurch er erneut einen konkreten Bezug zum Videotestament von Jamal Sati herstellte.

Abbildung 3.15: Rabih Mroué, On Three Posters, 2004, Video, 17 min.
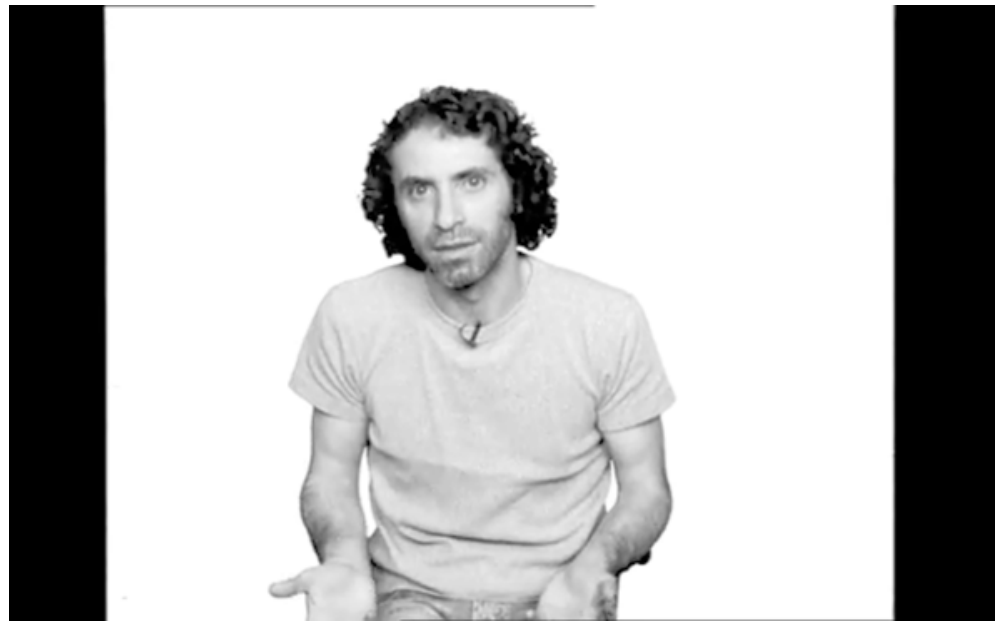

In seinem Meta-Videotestament ist Mroué, bekleidet mit einem schlichten grauen T-Shirt, auf einem Stuhl sitzend vor einer weißen Wand zu sehen, während er einen Monolog im Stil seiner Lecture-Performances hält. Was folgt, sind teils philosophische, teils ethische und medienreflexive Überlegungen, die die Konzeption von Three Posters von Anfang an begleitet hatten. Durchaus selbstkritisch verweist Mroué darin auch auf die moralischen Fragen, die ihnen bei der Aneignung des Videotestaments begegneten. Unter anderem: »Should we allow a public $>$ foreign to the party and the family « to witness a martyr's emotions before his death?«, »Could we present a tape that did not belong to us?« oder: »Were we exploiting this tape to make an rart-work ^ from which we would draw both moral and financial profit? « ${ }^{126}$ Die Berechtigung, das Videotestament im Kontext einer Kunstperformance anzueignen, wird grundlegend in Zweifel gezogen. Indem Mroué seine eigene Motivation als Künstler hinterfragt und Unsicherheiten offenlegt, verweist

125 Zitiert in Elias Chad, »Stage and Screen«, in: Ders. (Hg.): In Focus: On Three Posters 2004 by Rabih Mroué, London: Tate 2014, https://www.tate.org.uk/art/research-publications/rabih-mroue-on-three-posters/stage-and-screen-r1144499 (zugegriffen am 6.6.2021).

126 Rabih Mroué, On Three Posters, Video, 17min, 2004. 
er auf die Problematik, die ein solcher Kontextwechsel - von der Rezeption des Videos innerhalb des politischen Konflikts hin zu dessen künstlerischer Aneignung - mit sich bringt. Im weiteren Verlauf seiner Videoperformance verlegt Mroué jedoch den Fokus auf mediale Überlegungen und die aufgeworfenen ethischen Fragen bleiben unbeantwortet.

Auch die Bedeutungsverschiebungen und Umdeutungen der internationalen Presse, die Three Posters nach 9/11 erfuhr, werden im Video explizit zum Thema gemacht. Mroués »video testimonial« stellt in dieser Hinsicht eine weitere, kritische Instanz in der medialen Vermittlung des Videotestaments von Jamal Sati dar. Neben der Reflexion seiner eigenen Position als Künstler führt uns die Videoperformance damit auch unsere westliche Betrachterperspektive vor Augen. Dass die Bedeutung des Videos entscheidend vom zeitlichen, räumlichen, kulturellen und institutionellen Rezeptionskontext abhängt, wird im Video explizit gemacht. On Three Posters macht deutlich, dass die Auseinandersetzung mit Jamal Satis Videotestament nicht mit der Theaterperformance endet. Als work-in-progress verweigert sich Mroués künstlerische Auseinandersetzung abschließenden Antworten und lässt stattdessen immer wieder neue Aneignungen, Fragen und (Selbst-)Reflexionen zu. Der leere Stuhl vor der weißen Wand - so das letzte Bild der Videoperformance - scheint diese prinzipielle Unabgeschlossenheit auf den Punkt zu bringen.

\subsection{VOM MÄRTYRERTESTAMENT ZU EINER DRAMATURGIE DER ZEUGENSCHAFT: DIE FERNSEHPRODUKTIONEN DER HISBOLLAH}

Mroués und Khourys künstlerische Auseinandersetzung mit den Videotestamenten der Libanesischen Kommunistischen Partei war aber auch von einer politischen Frage getrieben. Ihrer eigenen Aussage nach ist die Performance Three Posters auch als Versuch zu werten, mit dem Bedeutungsverlust der Linken in ihrem eigenen Land umzugehen, insbesondere mit der Frage: »How did the secular resistance against the Israeli Occupation end up becoming a fundamentalist Islamic movement under the aegis of the Hezbollah? « ${ }^{127}$ Ende der 1980er Jahre führte der Aufstieg der Hisbollah im Libanon dazu, dass der Widerstandskampf gegen die israelische Besatzung zunehmend als >islamischer Widerstand wahrgenommen wurde. Der politische Niedergang der Linken ging mit einem steigenden Einfluss der »Partei Gottes« (arab. Hizbu'llāh) einher, die sich ab Ende der 1980er Jahre,

127 Mroué/Khoury: »Three Posters: Reflections on a Video/Performance«, S. 184. 
vor allem aber im Laufe der 1990er Jahre zur dominierenden militärischen Macht im Libanon entwickelte. Dieser `Siegeszug`der islamischen Partei sollte auch Einfluss auf das Bild der Selbstmordattentäter*innen haben, die fortan als Mudschāhidīn, als Glaubenskrieger >auf dem Weg Gottes` dargestellt wurden.

Nur kurze Zeit nach den ersten Videotestamenten der SSNP und LCP fing auch die Hisbollah an, die Videotechnik für ihre Zwecke zu nutzen - zunächst primär, um ihre Militäroperationen zu dokumentieren. Walid El Houri und Dima Saber datieren die erste »video operation« der Hisbollah auf das Jahr 1986, als der Angriff auf einen israelischen Militärposten erstmals mit einer tragbaren Videokamera festgehalten und anschließend im Libanon, in Israel und der restlichen arabischen Welt im Fernsehen übertragen wurde. ${ }^{128}$ Das Video zeigte eine Gruppe von Hisbollah-Kämpfern auf ihrem Weg zum Angriffsziel, begleitet von demonstrativen Victory-Zeichen und lachenden Blicken in die Kamera. Dieselben Kämpfer waren anschließend während des Schusswechsels im Inneren des Militärpostens zu sehen, der für mindestens zwei der israelischen Soldaten tödlich ausging. Für einen kurzen Moment rückten deren Leichen - wie zum Beweis - ins Blickfeld der Kamera. Das Video endete mit der demonstrativen Übernahme eines israelischen Panzers und emporgereckten Armen als Gesten des Sieges, die keinen Zweifel am `Erfolg dieser militärischen Operation lassen sollten. Die direkt in die Kamera gerichteten Blicke und Posen lassen vermuten, dass es sich hier nicht nur um eine Operation vor der Kamera, sondern um eine Operation für die Kamera handelte. Dieses Video war nur das erste in einer ganzen Reihe von Aufnahmen, die die Hisbollah von ihren militärischen Operationen anfertigte. Die verwackelten und grobkörnigen Aufnahmen der mobilen Videorecorder waren mit einem dokumentarischen und pseudo-journalistischen Anspruch verbunden und dienten dazu, den scheinbar erfolgreichen >Widerstand der Hisbollah zu bezeugen - und damit gleichzeitig zu konstituieren. Denn wie Ronald Schleifer gezeigt hat, täuschten die scheinbaren Heldentaten auf Video mitunter über den tatsächlichen Misserfolg der militärischen Operationen hinweg: »The visual media proved one of Hezbollah's most effective weapons « ${ }^{129}$, so folgert Schleifer. Und weiter:

128 Vgl. Walid El Houri und Dima Saber: »Filming Resistance: A Hezbollah Strategy«, Radical History Review 106 (2010), S. 70-85, hier S. 70. Die folgende Beschreibung des Videos basiert auf dieser Darstellung.

129 Ronald Schleifer: »Psychological Operations: A New Variation on an Age Old Art: Hezbollah versus Israel«, Studies in Conflict \& Terrorism 29/1 (2006), S. 1-19, hier S. 6 . 
»Stills, videos, and films became so central to the organization's military activities that it might reasonably be claimed that they dictated both the overall strategy and daily operations. Indeed, the organization's motto could be summed up in the words: >If you haven't captured it on film, you haven't fought.< In this context, the home video camera was king. $\ll^{130}$

Etablierten sich Videoaufzeichnungen der Militäroperationen schon recht früh zu einer zentralen Parteistrategie, hielt sich die Hisbollah mit der Aufnahme von Videotestamenten zunächst noch zurück. Nach den ersten spektakulären Selbstmordattentaten zwischen 1982 und 1985, darunter die Anschläge auf die US-Botschaft in Beirut und die französischen und US-Amerikanischen Militärstützpunkte im Jahr 1983, trat die Hisbollah erst ab 1988 mit einer zweiten Serie von Selbstmordattentaten wieder in Erscheinung. ${ }^{131}$ Im Unterschied zu den säkularen Gruppen, deren Videotestamente zu diesem Zeitpunkt bereits allgegenwärtig und populär waren, ${ }^{132}$ hinterließ der Hisbollah-Attentäter Haytham Subhi Dabbuq, der am 19. August 1988 mit einer Autobombe in ein israelisches Militärkonvoi fuhr, kein audiovisuelles Testament. Angesichts der eigentlichen Videoaffinität der Hisbollah mag das erstaunen und Joseph Croitoru zufolge war die Abwesenheit einer solchen Aufnahme letztlich auch der entscheidende Grund warum der Anschlag in den libanesischen Medien kaum Aufmerksamkeit erhielt. ${ }^{133}$ Bei ihrem nächsten Selbstmordanschlag genau zwei Monate später schien die Partei aus diesem medialen Misserfolg gelernt zu haben. Erstmals verbreitete nun auch die Hisbollah ein Videotestament, das zudem bei einer Gedenkveranstaltung in einer Beiruter Moschee einem großen Publikum vorgeführt wurde. ${ }^{134}$ Fortan sollte jeder der insgesamt sechs Attentäter, die bis 1999 Selbstmordanschläge im Namen der Hisbollah verübten, ein Videotestament hinterlassen.

130 Schleifer: »Psychological Operations«, S. 6.

131 Zwischen 1985 und 1988 war die Hisbollah von einer widersprüchlichen Einstellung zu Selbstmordattentaten geprägt und es wurde eine interne Debatte über den Nutzen solcher Anschläge geführt. Vgl. dazu Croitoru: Der Märtyrer als Waffe, S. 150ff.

132 Vgl. Maasri: Off the Wall, S. 123, Anm. 5; Ya'ari: »Behind the Terror«, o.S.

133 Vgl. Croitoru: Der Märtyrer als Waffe, S. 157.

134 Vgl. al-Anwar vom 24. Oktober 1988, zitiert in ebd. Das Autobombenattentat des 20jährigen Abdallah Attawi auf einen Militärstützpunkt nahe der israelischen Grenze kostete acht israelische Soldaten das Leben, drei weitere wurden verletzt. Das Videotestament selbst ist im Internet nicht mehr aufzufinden. 


\section{Das Videotestament als Vertrag mit Gott?}

Die visuelle Gestaltung der ersten Videotestamente der Hisbollah orientierte sich im Wesentlichen an dem Muster, das erstmals von Sana Muhaydli eingeführt wurde. So trat im August 1989 auch der Hisbollah-Attentäter Assad Barru an einem Tisch sitzend, vor einem mit Portraits und Flaggen behangenen Hintergrund in Erscheinung (Abb. 3.16). Am 9. August 1989 fuhr Barru mit einem sprengstoffbeladenen Auto in die Nähe eines vorbeifahrenden israelischen Panzers und verletzte dabei fünf israelische Soldaten. Aufgrund der weiten Entfernung des Autos kam während der Explosion außer dem Attentäter keine weitere Person ums Leben. ${ }^{135}$

Abbildung 3.16: Videotestament von Assad Barru, Hisbollah, Aufnahme am oder vor dem 9. August 1989, Ausschnitt, 1:26 min, arabisch mit englischen Untertiteln.

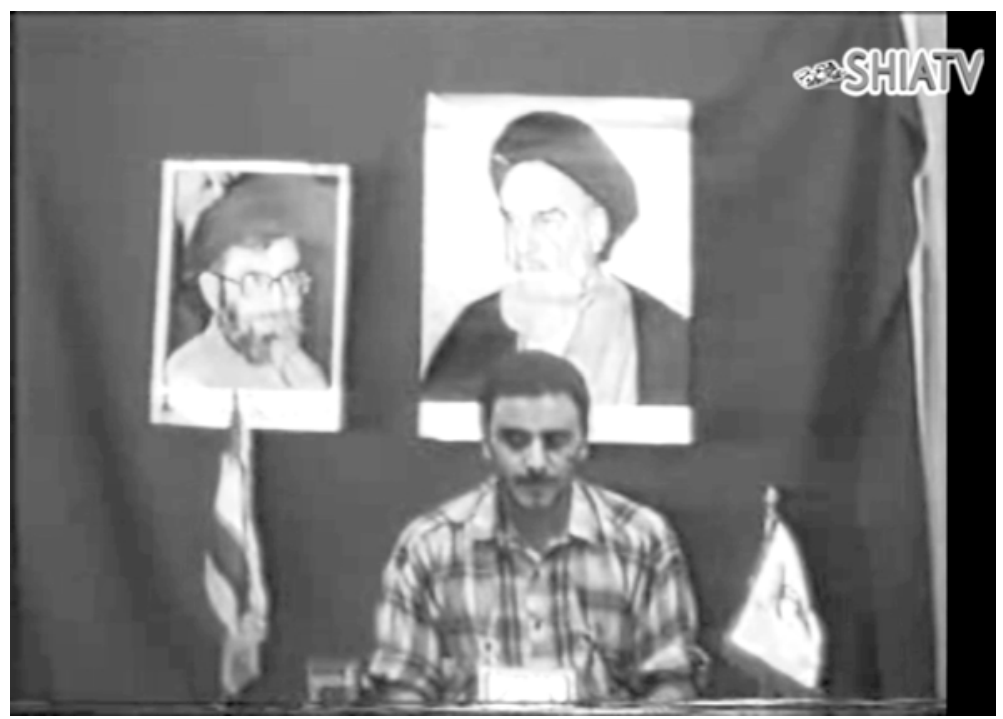

Noch am selben Tag bekannte sich die Hisbollah zu diesem Anschlag, den sie gegenüber einer Beiruter Nachrichtenagentur als »Geschenk an Imam Khomeini

135 Vgl. die Presseberichte zitiert in Chicago Project on Security and Terrorism (CPOST): Suicide Attack Database, Attack ID: 1260861891. 
zum Anlass der Aschura ${ }^{136}$ bezeichnete - dem Gedenktag an das Matyrium von Imam Hussein in Kerbala, der nur zwei Tage später von schiitischen Muslim*innen gefeiert werden sollte. Ruholla Musawi Khomeini, Gründer der Islamischen Republik Iran und Oberster Religionsführer, der am 3. Juni desselben Jahres verstorben war, war auch auf einem der zwei Poster im Hintergrund des Videotestaments zu sehen, während das andere dessen Nachfolger Sejjed Ali Khamenei zeigte. Damit signalisierte die Hisbollah ihre ungebrochene Verbundenheit mit der islamischen Republik Iran - auch nach dem Wechsel des Obersten Religionsführers.

Auch wenn das Setting dieser Aufnahme ganz offensichtlich an der Vorlage der säkularen Parteien orientiert war, ließ es gleichzeitig die Handschrift der iranischen Bildpropaganda erkennen. Die Portraits der beiden Religionsführer im Hintergrund erinnern an die Allgegenwart der Khomeini-Portraits, die während des Iran-Irak-Kriegs (1980-88) als Mittel der psychologischen Kriegsführung zum Einsatz kamen. An der Kriegsfront wurden überdimensionale Gemälde von Khomeini an Billboards angebracht, die den Kämpfern angeblich als Ansporn dienten und deren Opferbereitschaft stärken sollten. ${ }^{137}$ Auf etlichen Fotografien aus dieser Zeit sind iranische Soldaten zu sehen, die ein Portraitfoto des Obersten Religionsführers sogar direkt ans Gewehr oder die Militärjacke geheftet hatten und damit ihre bedingungslose Gefolgschaft zum Ausdruck brachten. ${ }^{138}$ Den Anhänger*innen der islamischen Revolution galt Khomeini nicht nur als politischer, sondern auch als religiöser Anführer und wurde im Iran zur quasi-heiligen Figur stilisiert. Am Beispiel der iranischen Poster und Wandmalereien hat Lina Khatib gezeigt, dass das Bild von Khomeini auch als Mittel der Sakralisierung eingesetzt wurde. Viele Märtyrer*innen des Krieges wurden zusammen mit dem Portrait von Khomeini dargestellt, dessen Präsenz allein für den >heiligen` Status der Dargestellten zu bürgen schien. ${ }^{139}$ Offenbar war das Videotestament von Assad Barru

136 Independent (London): »Shia Makes Suicide Attack on Israeli Convoy«, 10.08.1989. Zitiert in Chicago Project on Security and Terrorism (CPOST): Suicide Attack Database, Attack ID: 1260861891.

137 Ein ehemaliger iranischer Soldat erinnerte sich: »Other billboards, [...] especially those with pictures of our leaders and the Imam [Khomeini] were very effective in strengthening our morale.« Zitiert nach Peter Chelkowski und Hamid Dabashi: Staging a Revolution: The Art of Persuasion in the Islamic Republic of Iran, New York: New York University Press 1999, S. 283.

138 Ebd., S. 282-291, siehe insbesondere Abb. 18.2-18.4.

139 Lina Khatib: Image Politics in the Middle East: The Role of the Visual in Political Struggle, London: I. B. Tauris 2013, S. 83. 
ebenso sehr von dieser Bildpraxis iranischer Märtyrerdarstellungen inspiriert wie von den säkularen Vorbildern.

Ein klarer Bruch mit den säkularen Videotestamenten war zunächst weniger auf visueller Ebene, sondern auf der Ebene des gesprochenen Testaments auszumachen. Im Unterschied zu diesen stellte Assad Barru sein bevorstehendes Martyium nun unmissverständlich in einen schiitisch-religiösen Zusammenhang. Nach dem Vorbild der iranischen Propaganda zog er einen Vergleich zum Martyrium Husseins und rahmte seine bevorstehende Tat als »struggle for the sake of Allah $\aleph^{140}$. Zum ersten Mal handelte es sich bei dem Selbstmordattentäter außerdem um einen Scheich, also einen Geistlichen, der schon vor seinem Attentat sein Leben in den Dienst Gottes stellte. ${ }^{141}$ Umso mehr erschien sein Attentat daher im Kontext seiner religiösen Verpflichtung gegenüber Gott - und nicht nur als Kampf für die Befreiung der Nation.

Eine ähnliche schiitisch-dschihadistische Rhetorik ließ sich auch im Videotestament des nächsten Selbstmordattentäters feststellen, der sich fünfeinhalb Jahre später im Namen der Hisbollah in die Luft sprengte. Am 25. April 1995 fuhr der 27-jährige Familienvater Salah Ghandour mit einem sprengstoffbeladenen Mercedes in einen israelischen Militärkonvoi in Bint Jbeil und verletzte dabei 30 Personen, darunter viele Zivilpersonen. ${ }^{142}$ Entgegen der Aussagen der Hisbollah, die während einer Pressekonferenz von mehreren toten israelischen Soldaten sprachen, kam auch bei Ghandours Anschlag niemand außer ihm selbst ums Leben. ${ }^{143}$ Das Videotestament, das im Anschluss an sein Attentat in Umlauf gebracht wurde, zeigte ihn auf einer Wohnzimmercouch sitzend (Abb. 3.17 a-b).

Nach der Vorlage seines Vorgängers waren an der Wand im Hintergrund Portraitbilder des verstorbenen Khomeini sowie dessen Nachfolger Khamenei zu erkennen, die er in seinem Testament als »leader « hervorhob und damit erneut die Treue zum iranischen Regime zum Ausdruck brachte. Das grün-gelbe Emblem der Hisbollah im Hintergrund, sowie ein Portrait des Generalsekretärs Hassan Nasrallah bekräftigten indes die Zugehörigkeit zur »Partei Gottes«.

140 Zitiert nach der englisch untertitelten Version des Videos, http:/www.shiatv.net/ view_video.php?viewkey=63c90e74d8761976f322 (zugegriffen am 6.6.2021).

141 Vgl. Croitoru: Der Märtyrer als Waffe, S. 161.

142 Vgl. die internationalen Presseberichte vom 26. April 1995 zitiert in Chicago Project on Security and Terrorism (CPOST): Suicide Attack Database, Attack ID: 896612886.

143 Ebd. 
Abbildung 3.17 a-h: Videotestament von Salah Ghandour, Hisbollah, Aufnahme am oder vor dem 25. April 1995, verschiedene Ausschnitte.
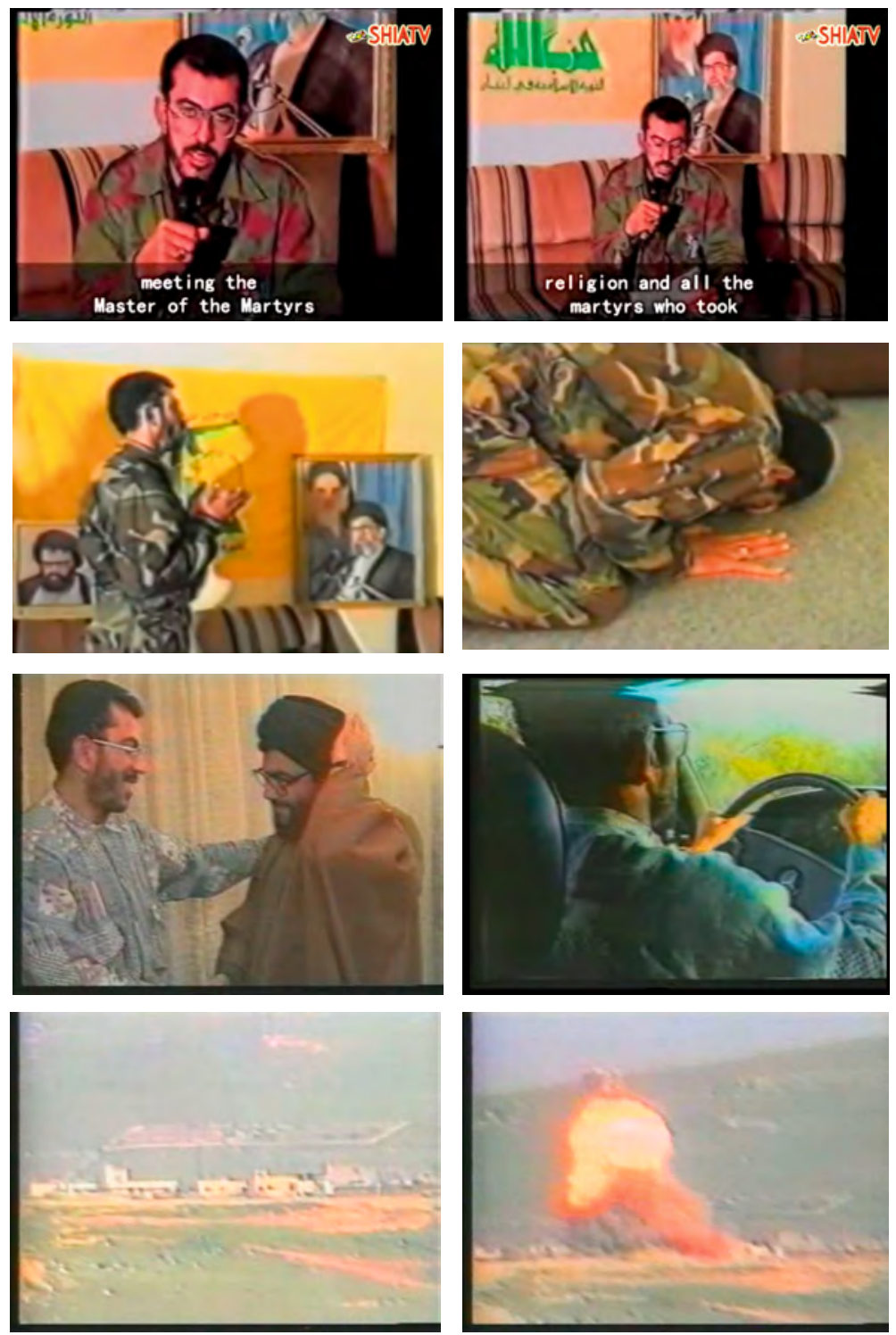

Wie die meisten Selbstmordattentäter*innen vor ihm trat auch Ghandour mit einer Militärjacke bekleidet vor die Kamera. Zusätzlich war er aber auch mit einem Mikrofon in der Hand ausgestattet, das seinen Worten zusätzliches Gewicht 
verlieh. Mehr noch als bei den Videotestamenten zuvor knüpfte diese Darstellung an die Ästhetik von TV-Reportern an und verlieh seiner Ansprache damit einen Anschein von Professionalität und Autorität (Abb. 3.17 a-b). Sein Testament begann mit den Worten:

»I, Salah Mohammad Ghandour known as `Malakı (angel) ask Allah to grant me the honor of meeting the Master of the Martyrs Imam Hussein, this great Imam who taught all the free people how to take revenge from their oppressors. After saying these words, I am, God willing, going to ascend to Allah with pride, after avenging my religion and all the martyrs who took this path before me. $\ll^{144}$

Im Unterschied zu den säkularen Attentäter*innen schreckten sowohl Barru als auch Ghandour offensichtlich davor zurück, sich vorzeitig selbst als Schahid, als Märtyrer zu bezeichnen. Dahinter stand vermutlich die im islamischen Glauben verankerte Überzeugung, dass nur Gott darüber entscheiden kann, wen er als Märtyrer oder Märtyrerin zu sich aufnimmt. ${ }^{145}$ In einem streng islamischen Sinne wäre das Selbstzeugnis >ana a ̌š-ašahīd />Ich bin der Märtyrer kaum anders zu verstehen als Blasphemie. Dennoch nahm auch Ghandour seine transzendentale Identität bereits vorweg, indem er sich mit dem Beinamen »malak«/»Engel« vorstellte und die feste Überzeugung aussprach, ins Paradies zu Gott aufzusteigen: »I am going to ascend to Allah with pride«. Auch wenn Ghandour sein Testament im Futur und unter der Bedingung »God willing « verkündete, ließ er keinen Zweifel an dessen Erfüllung. Die Rache-Versprechen, die er vor der Kamera abgab, richteten sich nicht nur an die Gemeinschaft der »Unterdrückten«, an politische und religiöse Führer des Iran und der Hisbollah, sondern waren gleichzeitig als Vereinbarung mit Gott formuliert: »As long as we work for Allah, learn for Allah, and martyr for Allah, Allah will implement His promise and support His servant, and for no doubt, He will strengthen the believers and humiliate the unbelievers [...].« Seine bevorstehende Operation, so die feste Überzeugung (»for no doubt«), werde eine doppelte Belohnung bereithalten: Die Unterstützung Gottes im Widerstands-

144 Dieses und folgende Zitate aus dem Videotestament entstammen der englisch untertitelten Version, abrufbar unter http://www.shiatv.net/video/424bc78667f18017bdf4 (zugegriffen am 6.6.2021).

145 Vgl. dazu ausführlich Hüseyin I. Cicek: Martyrium zwischen Gewalt und Gewaltfreiheit. Eine Kriteriologie im Blick auf Christentum, Islam und Politik, Berlin: LIT Verlag 2011, S. 195. Wie die Videotestamente palästinensischer Selbstmordattentäter*innen zeigen werden, wurde die Selbstbezeichnung als Schahid/a später durchaus auch von religiösen Parteien übernommen (Kapitel 3.4). 
kampf sowie die Aufnahme Ghandours als Märtyrer ins Paradies. Schon Jahre zuvor wurden sogenannte Märtyrertod-Operationen ('amalīyat istišhādīya) von Vertretern der Hisbollah als Abmachung zwischen den Gläubigen und Gott dargestellt. In der parteieigenen Zeitung al-Ahd erschien 1984 ein Text, in dem der stellvertretende Generalsekretär der Hisbollah Naim Kassim die MärtyrertodOperationen mit einer Koransure in Verbindung brachte. ${ }^{146}$ In der von ihm zitierten Sure 9, Vers 111 wird der Kampf »um Gottes Willen« (der unter Umständen auch den eigenen Tod miteinschloss) explizit als »Handel« mit Gott beschrieben:

»Gott hat den Gläubigen ihre Person und ihr Vermögen dafür abgekauft, daß sie das Paradies haben sollen. Nun müssen sie um Gottes willen kämpfen und dabei töten oder (w. und) (selber) den Tod erleiden. [...] Und wer würde seine Verpflichtung eher halten als Gott? Freut euch über (diesen) euren Handel, den ihr mit ihm abgeschlossen habt (indem ihr eure Person und euer Vermögen gegen das Paradies eingetauscht habt)! Das ist dann das große Glück. ${ }^{147}$

Durch den Verweis auf diese Koransure stellte Kassim den Akt des istišhād, des selbstgewählten Martyriums im Kampf (vgl. S. 74), als Teil eines Vertrags mit Gott dar, bei dem die Gläubigen ihre Leben gegen das Paradies eintauschen (bzw. ihre Person von Gott »abkaufen« lassen). Dieselbe ökonomische Logik des Martyriums liegt auch dem Videotestament von Ghandour zugrunde, wenn er davon ausgeht, dass Gott sein »Versprechen« halten wird, solange in Gottes Namen gekämpft und gestorben werde.

Erst durch die Videoaufzeichnung wird diese >Abmachung mit Gott $<$ jedoch festgehalten, vor Dritten bezeugt und damit eigentlich erst im Sinne eines Vertrags besiegelt. Die Worte »I, Salah Mohammad Ghandour known as >malak (angel) ask Allah to grant me the honor of meeting the Master of the Martyrs Imam Hussein $[. .$.$] « sind insofern als performative Sprechakte im Sinne Austins zu ver-$ stehen. Sie markieren das Eintreten in den Vertrag, dessen >Konditionen Ghandour im weiteren Verlauf seines Testaments verkündet. Mehr noch als bei den säkularen Selbstmordattentäter*innen scheint dieser > Vertrag mit Gott< - einmal ausgesprochen und aufgezeichnet - kein Zurück mehr zuzulassen. Denn ein

146 Auf diesen Text hat Bashir Saade in seiner Untersuchung der Hisbollah-Publikationen verwiesen. Saade: »Martyrology and Conceptions of Time in Hizbullah's Writing Practices «, S. 731.

147 Zitiert nach Paret (Hg.): Der Koran. Kommentar und Konkordanz von Rudi Paret, Sure 9:111, online abrufbar unter http://www.corpuscoranicum.de/index/index/sure/ 9/vers/111 (zugegriffen am 6.6.2021). 
Abbrechen der Operation hätte nicht mehr nur einen Vertrauensbruch mit der Partei zur Folge, sondern darüber hinaus einen Vertrauensbruch mit Gott selbst. Auch wenn die ersten Hisbollah-Videotestamente auf das wirkmächtige Selbstzeugnis (`Ich bin der Märtyrer $)$ verzichten, sind sie daher ebenso als kommissive Sprechakte zu verstehen, mit denen die Ausführung der Selbstmordoperation besiegelt wird.

Vermittelt durch das Medium Video rückt erneut gerade das Performative dieser Sprechakte in den Fokus, die keineswegs auf ihre sprachlich-textuelle Dimension zu reduzieren sind. Im Unterschied zu geschriebenen Testamenten (die auch früher schon von Hisbollah-Attentätern hinterlassen wurden), schließt der Vertrag vor der Kamera die körperliche Präsenz des Märtyrers mit ein - und damit die mimischen, gestischen und stimmlichen Qualitäten seiner Ansprache. Erstmals wurde die Aufnahme des Testaments aber auch um weitere Handlungsabläufe ergänzt, die über das Verlesen des Testaments hinausgingen. Nach seiner Ansprache erhob sich Ghandour vom Sofa und wurde von der Handkamera begleitet während er das rituelle Gebet in Richtung Mekka vollzog (Abb. 3.17 c-d). Die Frömmigkeit und absolute Unterwerfung unter Gottes Plan, die Ghandour in seinem gesprochenen Testament verkündet hatte, rückte auf diese Weise auch sichtbar ins Bild. Damit erweiterte sich auch der Aktionsradius des Protagonisten, der nicht mehr nur in der Pose des bewegungslosen Sprechers verharrte, sondern sein Testament durch non-verbale performative Elemente ergänzte. Während der zweiten palästinensischen Intifada sollten sich diese Elemente zu einer regelrechten Choreografie ausweiten, die neben dem rituellen Gebet weitere Posen und Bewegungen in die Videotestamente integrierte (siehe Kapitel 3.4).

\section{Eine Dramaturgie der Zeugenschaft}

Zum ersten Mal nahmen die Medienproduzenten der Hisbollah aber auch Szenen an weiteren Schauplätzen auf, die fernab der sorgfältig präparierten MärtyrerBühne lagen. Die eigentliche Testamentaufnahme von Salah Ghandour wurde mit zusätzlichem Videomaterial kombiniert und um weitere Dimensionen der Zeugenschaft erweitert. Handelte es sich bei den Videotestamenten der 1980er Jahre meist um statische, in einer einzigen Einstellung aufgenommene Clips, die mit nur wenigen Schnitten auskamen, sollten sich die Montagen der Hisbollah im Laufe der 1990er Jahre zu dramaturgisch komplexen Fernsehproduktionen weiterentwickeln. Diese Entwicklung war zu einem gewissen Grad auch der veränderten politischen Stellung der Hisbollah geschuldet, sowie den neuen medialen Möglichkeiten, die damit einhergingen. Nachdem das Abkommen von Taif den libanesischen Bürgerkrieg am 22. Oktober 1989 offiziell beendete, wurden alle Milizen 
mit Ausnahme der Hisbollah entwaffnet. Innerhalb kurzer Zeit etablierte sich die Hisbollah als die dominierende militärische Kraft im Süden des Landes, wo sie nun eine Monopolstellung im Kampf gegen die israelische Armee einnahmen. ${ }^{148}$ Auch nach Ende des Bürgerkriegs blieb Israel als Besatzungsmacht im Süden des Landes präsent und zog sich erst im Jahr 2000 aus dem Libanon zurück. In dieser veränderten politischen Situation wurden die Militäraktionen der Hisbollah von großen Teilen der libanesischen Gesellschaft allmählich als legitimer Widerstand gegen die israelische Besatzung anerkannt - auch wenn diese Legitimität bis heute von vielen bestritten wird. Um ihre neu gewonnene Unterstützung innerhalb der breiten Bevölkerung zu stabilisieren, setzte die Hisbollah ab Anfang der 1990er Jahre umso mehr auf mediale Strategien. ${ }^{149}$ Am 3. Juni 1991 nahm die Hisbollah ihren eigenen TV-Sender al-Manar (arab. »der Leuchtturm «) in Betrieb und schuf sich so eine eigene Plattform für die Verbreitung ihrer Videoproduktionen. ${ }^{150}$ Die großzügige finanzielle Unterstützung durch das iranische Regime ermöglichte es al-Manar von Anfang an einen Großteil der Ausstrahlungen selbst zu produzieren. ${ }^{151}$ Der Sender, der von der Hisbollah auch den Beinamen »Sender des Widerstands« (qanat al-muqawama) erhielt, widmete sich in den ersten zehn Jahren fast ausschließlich dem Kampf gegen die israelische Besatzung. Gezeigt wurden LiveBerichterstattungen und Videos von militärischen Operationen wie sie seit 1986 produziert wurden, aber auch Ansprachen religiöser Führer der Hisbollah oder

148 Vgl. Dina Matar und Farah Dakhlallah: »What it Means to be Shiite in Lebanon: Al Manar and the Imagined Community of Resistance «, Westminster Papers in Communication and Culture 3/2 (2006), S. 25.

149 Vgl. Avi Jorisch: Beacon of Hatred: Inside Hizballah's Al-Manar Television, Washington, D.C.: Washington Institute for Near East Policy 2004; Andrew Exum: »The Spectacle of War: Insurgent Video Propaganda and Western Response, 1990 -Present«, Arab Media and Society 5 (2008); Walid El Houri: The Meaning of Resistance: Hezbollah's Media Strategies and the Articulation of a People, Amsterdam: Rozenberg 2012.

150 Wie alle libanesischen Fernsehstationen zu dieser Zeit operierte al-Manar zunächst ohne offizielle Genehmigung. Im September 1996 erteilte die libanesische Regierung dem Sender schließlich die offizielle Lizenz zu Ausstrahlung. Vgl. Avi Jorisch: »AlManar: Hizbullah TV, 24/7«, Middle East Quarterly XI(1) (2004), S. 17-31, http://www.meforum.org/583/al-manar-hizbullah-tv-24-7 (zugegriffen am 6.6. 2021), hier o.S.

151 Im Jahr 1994 lag der Anteil der Eigenproduktionen bereits bei rund 50\%, im Jahr 2003 wurden rund $70 \%$ aller Ausstrahlungen selbst produziert. Ebd, o.S. 
Musikvideos, die zum Widerstand aufriefen. ${ }^{152}$ Die zahlreichen Märtyrer der Hisbollah, die bei den tausenden Militäroperationen zwischen 1990 und 2000 ums Leben kamen, wurden in eigenen Sendeformaten und Serien geehrt. Hier erhielten schließlich auch die Videotestamente von Selbstmordattentätern (wie das von Salah Ghandour) ihre Sendezeit. Entscheidend war, dass die Hisbollah für die Verbreitung ihrer Videotestamente nicht mehr auf parteifremde TV-Sender angewiesen war, die die Videos unter Umständen nur in gekürzter Version ausstrahlten. Dass Hisbollah-Funktionäre nun frei über die Länge und Sendezeit ihrer Produktionen verfügen konnten, mag ein Grund gewesen sein, warum sich auch das Format und die Gestaltung der Videotestamente veränderte.

Die Hisbollah war sichtlich darum bemüht, den bis dahin statischen Videotestamenten einen größeren `Unterhaltungswert $\mathbf{z u}$ verleihen. So wurden von Anfang an mehrere Szenen geplant, die Salah Ghandour an verschiedenen Schauplätzen zeigten und die anschließend das Material für die Videomontage lieferten. ${ }^{153}$ Für sein Videotestament wurde Ghandour von einem Kamerateam während der wichtigsten Stationen kurz vor seiner Selbstmordoperation begleitet. »Der erste Schauplatz des effektvoll in Szene gesetzten Propagandastücks«, so beschreibt Croitoru, »war das Büro des Generalsekretärs der Organisation, Hassan Nasrallah, der den Märtyrer vor dem Aufbruch zu seiner Todesmission zum Abschied segnete und küßte « ${ }^{154}$ (Abb. 3.17 e). Mehrere Szenen zeigten die beiden zudem in scheinbar vertrauter Unterhaltung und Umarmung. Die >Autorisierung〈 der Operation erfolgte nicht mehr nur durch die Portraitbilder im Hintergrund: Dieses Mal war es Nasrallah höchstpersönlich, der das bevorstehende Selbstmordattentat legitimierte und dem Testament des Märtyrers damit umso mehr Aufmerksamkeit sicherte. Der prominente Auftritt bereitete die Bühne für das eigentliche Testament, das direkt im Anschluss daran montiert wurde. Nach der bereits besprochenen Gebetsszene folgte dann der Mitschnitt eines Gesprächs während der (angeblichen) Fahrt zum Anschlagsziel. Ghandour war am Steuer des Tatfahrzeugs zu

$152 \mathrm{Zu}$ den Musikvideos siehe El Houri: The Meaning of Resistance, S. 149-172.

153 Die Videomontage ist bis heute in leicht unterschiedlichen Versionen im Internet zu finden. Während der dramaturgische Ablauf der hintereinander montierten Videoclips in allen Versionen gleich bleibt, wurden die Videos teils durch Fotografien, zusätzliche Aufnahmen oder Interviews mit Angehörigen ergänzt. Siehe etwa das Video »Das Martyrium von Salah El Din Mohammed Ghandour«, das in der Reihe Khaleda Beacons (»unsterbliche Leuchtfeuer«) am 9. Juni 2013 auf ShiaTV veröffentlicht wurde: www.shiatv.net/view_video.php?viewkey=be6d993ec2acbc865fa1\&page=\&viewtype $=\&$ category (zugegriffen am 6.6.2021).

154 Croitoru: Der Märtyrer als Waffe, S. 162. 
sehen, während die Kamera vom Rücksitz des Wagens aus filmte und den $\mathrm{Zu}-$ schauenden das Gefühl vermittelte, den Attentäter direkt auf seinem $>$ Weg zu Gott $<$ zu begleiten (Abb. 3.17 f). Das Bildmuster selbst war jedoch keineswegs eine Innovation der Hisbollah, wie Joseph Croitorus Darstellung nahelegen könnte. Wie bereits gezeigt, enthielt schon die erweiterte Version des Videotestaments von Sanaa Muhaydli Szenen einer Autofahrt (vgl. Abb. 3.4 a). ${ }^{155}$ Die entscheidende Neuerung lag nun jedoch in einem veränderten Anspruch auf Authentizität und Beweiskraft. Denn während die stumme Autofahrtszene in The Bride of the South lediglich den Hinterkopf einer Frau mit rotem Barett zeigt und ebenso wie die Brautszene - vermutlich von einer Schauspielerin gestellt wurde, lässt das Hisbollah-Video keinen Zweifel an der Identität Salah Ghandours. Sein Gesicht rückt während der Autofahrt klar erkennbar ins Visier der Kamera. Die Praxis, Militäroperationen mit einer tragbaren Videokamera zu dokumentieren, wurde von der Hisbollah erstmals auch auf ein Selbstmordattentat übertragen. Doch im Unterschied zu den videografisch festgehaltenen Schusswechseln, aus denen die Hisbollah-Kämpfer als scheinbar lachende und unversehrte Sieger hervorgingen (vgl. S. 154), waren dem Blick der Kamera in diesem Fall klare Grenzen gesetzt. So konnte das Filmteam zwar sämtliche Vorbereitungen bis hin zur Fahrt im sprengstoffbeladenen Auto mitverfolgen; der Bombenanschlag selbst ließ sich hingegen nur mit sicherem Abstand zeigen. Auf die Nahaufnahme der Autofahrt folgte daher ein weiterer Szenenwechsel. Die Kamera nahm nun die Perspektive einer distanzierten Beobachterin ein, die die Detonation aus weiter Entfernung filmte (Abb. $3.17 \mathrm{~g}$-h). Die imposante, aufsteigende Explosionswolke markierte zugleich den dramaturgischen Höhepunkt dieses Videos.

Mit der Aufnahme der Detonation wurde dem Testament des Märtyrers ein weiteres Zeugnis zur Seite gestellt: Die distanzierte Beobachterperspektive der Kamera korrespondierte auf den ersten Blick mit der Perspektive des testis, des unbeteiligten Augenzeugen, der das Geschehen vor Ort beobachtet. Vermittelt durch die Linse der Kamera wurden schließlich auch die Betrachter*innen zu Medienzeug*innen des Selbstmordanschlags, der nun mit eigenen Augen nachvollzogen werden konnte (zur Medienzeugenschaft siehe Kapitel 4.4). Während der Pressekonferenz am Tag nach dem Anschlag wurde diese Aufnahme von der

155 Auch wenn das genaue Datum der Montage unbekannt bleibt, so lässt der rasch aufflammende Kult um Sanaa Muhaydli vermuten, dass es nur kurze Zeit nach ihrem Attentat im April 1985 veröffentlicht wurde. Jedenfalls lässt sich mit hoher Wahrscheinlichkeit davon ausgehen, dass das Video zum Zeitpunkt von Salah Ghandours Attentat, ziemlich genau zehn Jahre später, den Medienverantwortlichen der Hisbollah bekannt gewesen sein durfte. 
Hisbollah dann auch ganz gezielt für die Beweisführung eingesetzt. Wie eine Journalistin der Nachrichtenagentur United Press International berichtete, demonstrierte ein Hisbollah-Funktionär den Pressemitgliedern zunächst anhand einer Landkarte, dann am Video der Explosion sämtliche Details der Selbstmordoperation. ${ }^{156}$ Derselbe Videoclip wurde schließlich mit der Testamentszene zusammengeschnitten. Auch in diesem Zusammenhang, als dramaturgischer Höhepunkt der Montage, schien die Aufnahme der Explosion den sichtbaren >Beweis` dafür zu liefern, dass Salah Ghandour sein Versprechen gehalten hat.

Die Wirkmacht dieses Videos scheint gerade im Zusammenspiel der unterschiedlichen Formen der Zeugenschaft zu entstehen. Auf der einen Seite lenkt das gesprochene Testament die Lesart der Detonationsszene, die daraufhin als angekündigte »lesson from Karbala « erscheint (zum Kerbala-Narrativ vgl. S. 74f). Auf der anderen Seite liefert die Detonationsszene eine scheinbare Verifikation dessen was im Testament lediglich angekündigt und versprochen wurde. Ohne dass sich Ghandour in seinem Testament also explizit als Schahid bezeichnen musste (und sich damit über die Kompetenz Gottes hinwegsetzen würde), schafft die Hisbollah ein Zeugnis, das keinen Zweifel am Martyrium des Dargestellten lassen sollte.

Und dennoch: Sieht man einmal von der suggestiven Kraft der Bildmontage $a b$, wird deutlich, dass der tatsächliche Informationsgehalt dieses Clips verschwindend gering ist. Die hügelige Landschaft bleibt unspezifisch und lässt keine markanten Strukturen erkennen, die den Ort eindeutig zuordnen ließen. Im Hintergrund sind zwar einzelne Gebäudekomplexe auszumachen, deren Konturen verschwimmen durch die extreme Zoombewegung der Kamera jedoch zu unscharfen Farbfeldern. Im Unterschied zu den eingangs erwähnten Videos von Militäroperationen rückt weder der 〉besiegte〈 Feind noch der >siegreiche〈 Hisbollah-Kämpfer identifizierbar ins Blickfeld. Die Aufnahme liefert weder einen Beweis dafür, ob die Autobombe ihr Angriffsziel erreicht hat, noch wer zu den Opfern des Anschlags zählt oder ob es sich hier überhaupt um die Detonation handelt, die Salah Ghandour auslöste. Durch das extreme Heranzoomen der Videokamera wird stattdessen jede kleinste Bewegung des Filmenden, jede Erschütterung im Bild sichtbar. Die Aufregung überträgt sich durch das verwackelte Bild und die mehrfachen Zoombewegungen geradezu körperlich auf die Betrachter*innen des Clips. Die lauten »Allahu Akbar«/»Gott ist groß«-Rufe des Kameramanns, die im Moment der Explosion auf der ursprünglichen Audiospur des Videos zu hören waren,

156 Vgl. Nayla Razzouk: »Hezbollah Says 30 Wounded in Attack«, United Press International (UPI), 26.04.1995. Zitiert in: Chicago Project on Security and Terrorism (CPOST): Suicide Attack Database, Attack ID: 896612886. 
verstärken diesen Eindruck zusätzlich. ${ }^{157}$ Die objektive \Wahrheit des testis vermischt sich hier also mit der subjektiven >Wahrheit des superstes, den das Geschehen merklich erregt und der es unmittelbar am eigenen Körper miterlebt. Allein die überwältigende und affizierende Wucht der Explosion und deren sublime Ästhetik scheinen hier für den 〉Erfolg \der Operation zu zeugen. Dass die von der Hisbollah gefilmte Explosion so generisch ist, dass sie im Grunde nichts Faktisches beweisen kann, scheint diesem Effekt keinen Abbruch zu tun. Hito Steyerl hat diese Dynamik als »Unschärferelation des modernen Dokumentarismus « ${ }^{158}$ beschrieben: Je unschärfer das Videobild, je weniger es außer der Aufgeregtheit der Filmenden zu zeigen vermag, desto intensiver und damit rauthentischer des- $^{-}$ sen Wirkung. Man kann davon ausgehen, dass dieser Effekt nicht nur den technologischen oder finanziellen Möglichkeiten geschuldet war. Zu diesem Zeitpunkt betrieb die Hisbollah schon seit vier Jahren ihren eigenen Fernsehsender und verfügte über ausreichend finanzielle Mittel, die eine professionellere Aufnahmetechnik mit Stativ eigentlich möglich gemacht hätten. ${ }^{159}$ Ebenso wenig handelte sich um eine spontane Videoaufnahme zufälliger Augenzeug*innen, die keine Zeit für den Aufbau von Equipment gehabt hätten, sondern um einen geplanten Anschlag bei dem Ort und Zeitpunkt im Voraus feststanden. Dennoch entschieden sich die Filmemacher der Hisbollah für eine Videoästhetik, die an die schlechte Qualität von Amateurbildern und an die Unmittelbarkeit einer Bürgerberichterstattung >von unten anschloss. Damit präsentierte sich die Hisbollah nicht als hegemoniale

157 In vielen Montagen, die heute im Internet zu finden sind, wurde das Footage der Detonation hingegen mit fremdem Audiomaterial wie Songs oder Ansprachen hinterlegt. Die ursprüngliche Audiospur dieses Videoclips wurde von Nayla Razzouk beschrieben, die das Video während der Pressekonferenz am 26. April 1995 gesehen hatte: »A Hezbollah military official explained details of the suicide operation on a map and ran a video tape showing the suicide bomber driving his car and hitting the Israeli convoy. >Allah Akbar«, or God is great, shouted the Hezbollah cameraman while shooting from afar his companion blowing himself against the convoy.« Razzouk: »Hezbollah Says 30 Wounded in Attack«, o.S.

158 Hito Steyerl: Die Farbe der Wahrheit: Dokumentarismen im Kunstfeld, Wien: Turia \& Kant 2008, S. 8.

159 Wie die Studie von Avi Jorisch zeigt, verfügte der Sender al-Manar zum Zeitpunkt seiner Gründung über ein jährliches Budget von \$1 Million, der Großteil davon durch finanzielle Unterstützung des iranischen Regimes. Eigenen Angaben zufolge lag das jährliche Budget des Senders im Jahr 2004 bei rund \$15 Millionen, was etwa der Hälfte des Jahresbudgets von al-Jazeera entspricht. Jorisch: »Al-Manar: Hizbullah TV, $24 / 7 \ll$, o.S. 
Macht, sondern als Teil des >unterdrückten $<$ Volkes, das Widerstand gegen die israelische Besatzung leistete. Dass ein einzelner Selbstmordattentäter (scheinbar) in der Lage sei, die militärische Großmacht Israel zu besiegen, kehrte das Machtverhältnis um und zeigte die >Unterdrückten`als Sieger. Ein solches Narrativ der Ermächtigung war im schiitischen Selbstverständnis seit je her fest verankert und wurde von der Hisbollah nun eingesetzt, um die Solidarität mit ihrem Widerstand gegen die israelische Besatzung zu stärken. ${ }^{160}$

Indem das gesprochene Testament erstmals durch Szenen der eigentlichen Operation ergänzt wurde, erweiterte sich auch die Funktion dieser Videos. Es ging nicht mehr nur darum, ein Versprechen zu besiegeln und einen >Vertrag « (zwischen Rekrut und Partei bzw. zwischen Rekrut und Gott) abzuschließen, sondern auch darum, eindrucksvolle Bilder des Selbstmordanschlags zu produzieren. Das Attentat selbst schien nun zu einer Performance für die Kamera zu werden. Diese Beobachtung schließt an die mittlerweile weit verbreitete Erkenntnis der Terrorismusforschung an, Terror sei in erster Linie als Kommunikationsstrategie zu verstehen (vgl. Kapitel 1.1). Natürlich zielen die Selbstmordanschläge immer auch darauf ab, den gegnerischen Parteien tatsächlichen militärischen Schaden zuzufügen. Wie die Terrorismusforscher Peter Waldmann und Bruce Hoffman betont haben, geht es bei solchen Anschlägen aber auch - und vielleicht sogar primär darum, wirkmächtige Bilder zu schaffen, die als Teil einer psychologischen Kriegsführung zu begreifen sind. ${ }^{161}$ In diesem Zusammenhang wurde häufig die enge Symbiose zwischen den Terroristen und den Massenmedien moniert, da der eigentliche `Erfolg 〈 der Operationen wesentlich von der medialen Berichterstattung abhängt. Indem die Hisbollah die Videokamera jedoch selbst in die Hand nahm, wurde die Darstellung der Operationen nicht den anderen überlassen, sondern eigenmächtig gelenkt und instrumentalisiert. Sowohl die Produktion als auch die Ausstrahlung dieser Bilder blieb in der Hand der verantwortlichen Partei, die sich damit unabhängig von einer externen Berichterstattung machte.

Obwohl Ghandours Selbstmordattentat keine israelischen Todesopfer forderte und unter militärischen Gesichtspunkten für die Hisbollah kaum als erfolgreich gelten konnte, zog der Anschlag im Libanon große mediale Aufmerksamkeit auf sich und war in dieser Hinsicht durchaus sehr effektiv. Bis heute wird der Attentäter in Videomontagen, Postern oder Gedenktafeln als einer der wichtigsten

160 Vgl. dazu auch El Houri: The Meaning of Resistance, S. 139.

161 Vgl. Hoffman: Terrorismus. Der unerklärte Krieg; Waldmann: Terrorismus. Provokation der Macht. Zur psychologischen Kriegsführung der Hisbollah siehe auch Schleifer: »Psychological Operations«. 
Märtyrer der Hisbollah gefeiert. ${ }^{162}$ Joseph Croitoru hat das Videotestament von Salah Ghandour sogar als "propagandistisches Meisterstück» beschrieben, das Ghandour zum bis dato »berühmtesten Selbstmordattentäter der Welt« machen sollte. ${ }^{163}$ Welchen tatsächlichen Anteil die Videoaufnahmen an der Popularität dieses Märtyrers hatten, kann nur vermutet werden. Ohne Zweifel setzte die Videomontage der Hisbollah jedoch den Grundstein für die heutigen, teils auf Spielfilmlänge ausgedehnten Videoproduktionen der al-Qaida und des Islamischen Staats (Kapitel 4). Die Aufnahme diverser Abschiedsszenen ebenso wie die - geradezu ikonisch gewordene - Fahrt im Tatfahrzeug und das Filmen der Explosion haben sich bis heute als wiedererkennbare Elemente von Videotestamenten etabliert. Zum ersten Mal wich der statische Aufbau der frühen Videotestamente einer filmischen Montage, die mehrere Szenen an unterschiedlichen Drehorten integrierte und einer durchdachten zeitlichen Dramaturgie folgte. Die verkörperte Testament-Performance des Märtyrers war nur noch ein Element innerhalb einer übergeordneten Narration, die mit filmischen Mitteln etabliert wurde.

\section{Das Videotestament wird ıschiitischı}

Die komplexer werdende Dramaturgie der Videos, die das Märtyrertestament durch weitere Modi der Zeugenschaft ergänzte, war nicht die einzige Neuerung, die die Hisbollah in das Genre des Videotestaments einbringen sollte. Allmählich fand auch eine genuin $>$ schiitische $<$ Bildsprache Einzug in deren Ikonografie. Dass es sich bei den Selbstmordattentaten der Hisbollah um religiös motivierte Operationen handelte, kam bislang vor allem auf sprachlicher Ebene zum Ausdruck. Mit einem Videotestament, das knapp ein Jahr nach Salah Ghandours Attentat aufgenommen wurde, erweiterte die Hisbollah schließlich auch das symbolische Repertoire ihrer Videos.

162 In vielen Märtyrer-Aufzählungen der Hisbollah taucht Salah Ghandour als zentrale Figur auf, so beispielsweise in der Serie Our Great Martyrs...Hallmark of Victory, die auf al-Manar ausgestrahlt wurde, siehe http://archive.almanar.com.lb/english/category.php?id=10 (zugegriffen am 6.6.2021). Wie die nachfolgenden Beispiele deutlich machen, schmückte sein Portrait auch den Hintergrund neuer Videotestamente der Hisbollah. Selbst elf Jahre später, im Juli 2006 präsentierte sich ein Hisbollah-Kämpfer in seinem Video vor einem Konterfei Salah Ghandours. Siehe die Standbilder des Videotestaments von Hussein Abbas Sabra in http://archive.almanar.com.lb/english/article.php?id=29396 (zugegriffen am 6.6.2021).

163 Croitoru: Der Märtyrer als Waffe, S. 162. 
Abbildung 3.18 a-e: Videotestament von Ali Munif Ashmar, Hisbollah, Aufnahme am oder vor dem 20. März 1996, Ausschnitte, arabisch.
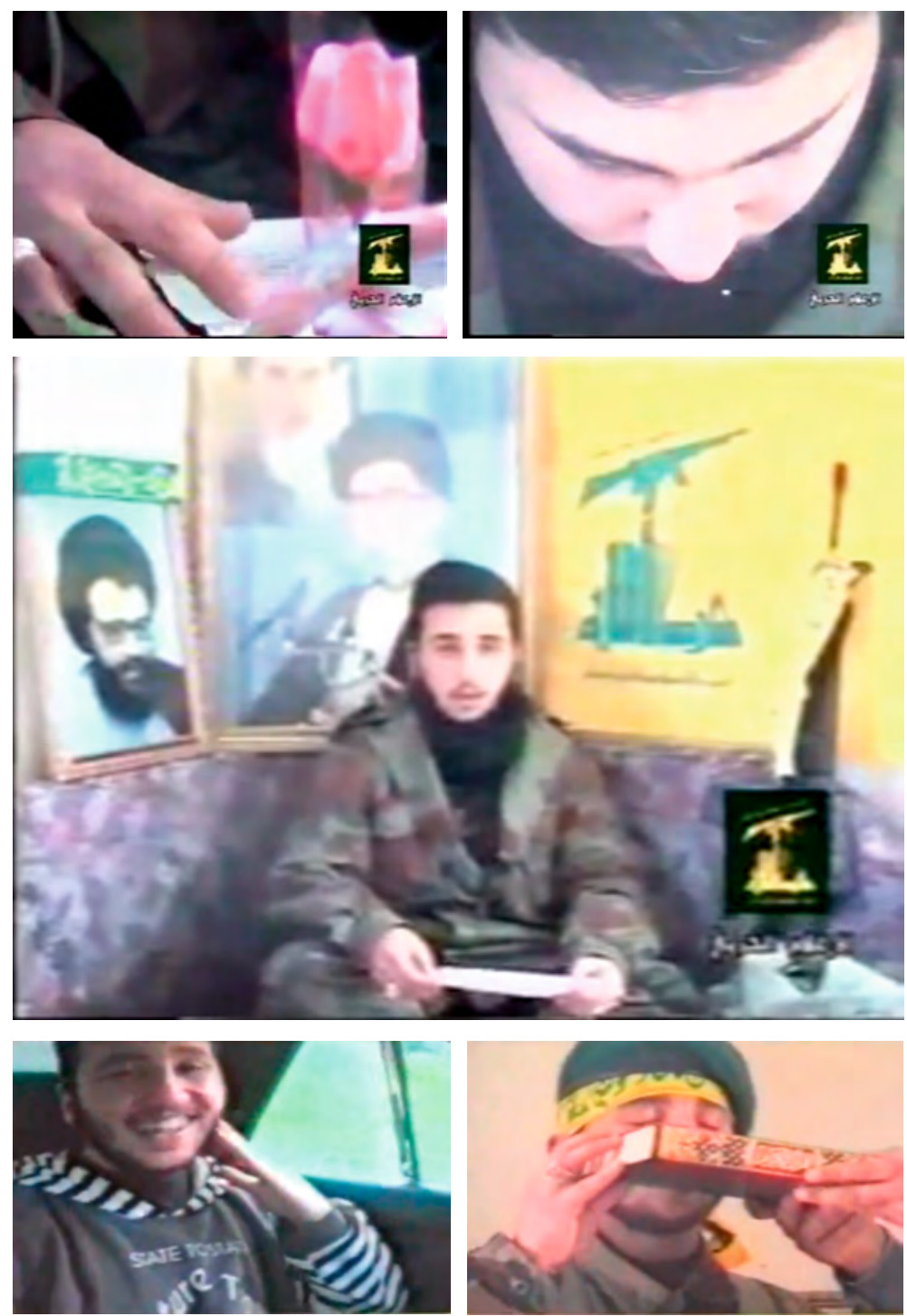

Am 20. März 1996 fuhr der 20-jährige Ali Munif Ashmar mit einer Autobombe in einen israelischen Militärkonvoi in der südlibanesischen Stadt Udaysah. Bei dem Selbstmordanschlag kam ein israelischer Soldat ums Leben, mindestens 
sechs weitere Soldaten wurden verletzt. ${ }^{164}$ Anders als bisher beginnt die Aufnahme seines Testaments nicht mit der halbnahen Einstellung des sitzenden Protagonisten, sondern mit dem extremen Close-Up einer pinkfarbenen Tulpe, die in eine durchsichtige Schutzfolie gehüllt war (Abb. 3.18 a). Hinter der Blüte ist ein Zettel mit einer handgeschriebenen Notiz erkennbar, die sich im Laufe des Videos als Ashmars Testamentvorlage entpuppt. Die rote Tulpe kann als eines der geläufigsten Symbole für Märtyrer*innen in der schiitisch-persischen Bildtradition gelten. Es basiert auf dem Glauben, dass überall dort, wo das Blut eines Kämpfers für sein Land vergossen wird, eine Tulpe wächst. ${ }^{165}$ Wann genau diese Symbolik auf das schiitische Märtyrer- und Kerbala-Narrativ übertragen wurde, ist historisch nicht eindeutig nachzuvollziehen. ${ }^{166}$ Bereits während der konstitutionellen Revolution im Iran (1903-11) evozierte der Dichter Arif Qazvini das Motiv in einem Gedicht, das vom Blut nationaler Revolutionäre handelte, aus denen Tulpen erwachsen. ${ }^{167}$ Spätestens im Kontext der islamischen Revolution ab 1979 war die Tulpe als Märtyrersymbol weit verbreitet und tauchte etwa auf Wandgemälden oder Postern von Märtyrern des Iran-Irak-Krieges auf. Nach diesem Vorbild wurde das Symbol schließlich auch von der Hisbollah übernommen und in zahlreiche Märtyrerposter integriert, die während der 1980er Jahre veröffentlicht wurden. ${ }^{168} \mathrm{Im}$ Fall von Ali Munif Ashmar erhielt die Tulpe nun also auch Einzug in die Gestaltung eines Videotestaments. Nach einigen Sekunden schwenkt die Kamera - immer noch im Zoom-Modus - von der Blüte direkt auf Ashmars Gesicht (Abb. 3.18 b). Noch vor seinem eigentlichen >Blutzeugnis` wurde er auf diese Weise mit dem typischen Attribut schiitischer Märtyrer in Verbindung gebracht und sein kommendes Martyrium auf symbolischer Ebene bereits angedeutet. Erst nach einem Schnitt wird schließlich die gesamte Szene sichtbar, die den

164 Vgl. United Press International (UPI): »Lebanon Bomber Attacks Israeli Convoy«, 20.03.1996. Zitiert in Chicago Project on Security and Terrorism (CPOST): Suicide Attack Database, Attack ID: 948847195.

165 Vgl. Staci Gem Scheiwiller: »In the House of Fatemeh: Revisiting Shirin Neshat's Photographic Series Women of Allah«, in: Dies. (Hg.): Performing the Iranian State: Visual Culture and Representations of Iranian Identity, London/New York: Anthem Press 2013, S. 201-220, hier S. 220, Anm. 66.

166 Vgl. ebd.

167 »From the blood of the youth of this homeland/ Tulips have grown/ Mourning their tall fallen figures $[. .$.$] «, zitiert nach Hamid Dabashi: The World of Persian Literary$ Humanism, Cambridge: Harvard University Press 2012, S. 268f.

168 Vgl. die Poster im Archiv Signs of Conflict, beispielsweise: http://www.signsofconflict.com/Archive/poster_details/1838 (zugegriffen am 6.6.2021). 
zukünftigen Attentäter auf einer gepolsterten Eckbank sitzend zeigt (Abb. 3.18 c). $\mathrm{Zu}$ seiner Linken lehnt eine Kalashnikow an der Wand, dahinter sind eine Flagge mit dem Zeichen der Hisbollah sowie zwei großformatige Portraits von Hassan Nasrallah und Ali Khamenei zu sehen. Ein weiterer Kameraschwenk nach rechts gibt den Blick frei auf ein Portraitfoto von Salah Ghandour, das aus seinem Videotestament stammt und nach dem Muster der säkularen Parteien als Vorbild ins Bild integriert wurde. Das Video von Ghandour stand ohne Zweifel auch Pate für Ashmars Videotestament, das ebenfalls durch weitere Szenen ergänzt wurde. So filmte die Kamera den zukünftigen Attentäter während des rituellen Gebets Richtung Mekka, begleitete ihn während eines Spaziergangs in der Natur, beim Schreiben seines Testaments und zeigte ihn schließlich lachend in ein Auto steigen (Abb. $3.18 \mathrm{~d}$ ). Im Unterschied zur Testamentszene, in der Ashmar mit einer Militärjacke bekleidet zu sehen ist, trug er während dieser Aufnahmen einen grau gestreiften Kapuzenpullover mit dem englischen Schriftzug: »State to State/Adventure Traveller «. Angesichts der bevorstehenden Selbstmordoperation sticht dieses kuriose Detail besonders ins Auge und man kann kaum anders als die Aufschrift als Kommentar zu Ashmars Martyrium zu lesen. Hinzu kommt, dass sein scheinbar vorfreudiges Lachen auf dem Rücksitz des Autos den Eindruck erweckt, als stünde ihm tatsächlich eine aufregende Abenteuerreise bevor. Eine Fahrt von »state to state - vom Diesseits ins Jenseits.

Dass es sich dabei um eine Todesfahrt handelte, die rauf dem Weg Gottes< stattfand - daran ließen die Produzenten des Videos keinen Zweifel. Viele der Videomontagen zu Ehren Ashmars, die bis heute im Internet kursieren, integrierten eine weitere Szene, die vermutlich im Anschluss an sein Testament aufgenommen wurde. ${ }^{169}$ Sie zeigt Ashmar, wie er sich ein gelbes Stirnband um den Kopf bindet und anschließend einen Koran küsst, der ihm von einer anderen Person vor das Gesicht gehalten wird (Abb. 3.18 e). Nachdem der Koran die Stirn des angehenden Selbstmordattentäters berührt hat, geht dieser - wie durch ein Tor - unter dem Buch hindurch. Die Abfolge der Bewegungen erinnert an eine Segnungsgeste und gibt der bevorstehenden Operation den Anschein einer göttlichen Sendung. Die Tat wurde nicht mehr nur von Hisbollah-Generalsekretär Hassan Nasrallah

169 Auch von Ali Munief Ashmars Videotestament kursieren unterschiedliche Montagen im Internet, die alle auf dasselbe Footage zurückgreifen. Der Originalton des Videos wurde in manchen Fällen nachträglich durch Songs ergänzt oder ersetzt. Einige davon sind auf YouTube zu finden, aber auch auf der schiitischen Videoplattform ShiaTV, siehe etwa das am 19.9.2013 hochgeladene Video Martyrdom Ali Munief der Serie Khaleda Beacons, http://www.shiatv.net/view_video.php?viewkey=e7d30e573244f $\mathrm{d} 7 \mathrm{c} 6 \mathrm{e} 0 \mathrm{f} \&$ page $=\&$ viewtype $=\&$ category $=($ zugegriffen am 6.6.2021 $)$. 
abgesegnet (wie etwa im Videotestament von Salah Ghandour), sondern zusätzlich durch die heilige Schrift des Islams autorisiert. Dasselbe Ritual tauchte auch in anderen Videos der Hisbollah auf. Joseph Croitoru zufolge startete die Hisbollah etwa zur selben Zeit eine Fernsehkampagne auf al-Manar, die eine ganze »Kompanie« junger Männer zeigte, die allesamt für Selbstmordattentate bereit gestanden hätten. »Der bei zahlreichen Anlässen über die Bildschirme flimmernde Fernsehclip,« so schreibt Croitoru,

»zeigt Bilder von einer Art Gelöbnisfeier, bei der rund fünfzig uniformierte junge Männer mit Sprengstoffgürteln der Reihe nach vor ihren Kommandanten treten und den Koran küssen, bevor dieser die künftigen Selbstaufopferer schließlich mit der symbolischen Scharfmachung eines Sprengsatzes in ihr Märtyrerschicksal entläßt. $\ll^{170}$

Wie Ashmar trugen auch die zukünftigen Märtyrer in diesem Videoclip gelbe Stirnbänder und durchliefen dieselbe rituelle Segnung, die mit dem Durchtreten unter dem Koran endete. Ähnlich wie die Aufnahme der Autofahrt, sollte sich auch diese Szene zu einem festen Bestandteil der Videotestamente von HisbollahAttentätern etablieren. Selbst Aufnahmen, die zehn Jahre später während des 2006-Kriegs mit Israel entstanden, griffen auf dieselben Darstellungskonventionen zurück. ${ }^{171}$

Vor allem das Märtyrerstirnband sollte sich zu dem ikonischen Attribut von Selbstmordattentäter*innen schlechthin entwickeln und schließlich auch von radikal-sunnitischen Gruppen wie der palästinensischen Hamas übernommen werden (siehe Kapitel 3.4). Der islamischen Überlieferung zufolge geht das Stirnband auf den frühislamischen Kämpfer Abu Duschana zurück (gest. 632 n. Chr.), ein Gefährte des Propheten Mohammed, der sich aufgrund seiner besonderen Opferbereitschaft auszeichnete und durch das rote Stirnband auffiel, das er sich

170 Croitoru: Der Märtyrer als Waffe, S. 163. Ein Ausschnitt desselben Clips ist auch in der Dokumentation von Batty und Toolis (Regie): »The Cult of the Suicide Bomber« von $2005 \mathrm{zu}$ sehen.

171 Siehe etliche Videotestamente, die in der Reihe Hizbullah Great Martyrs ... Hallmark Of Victory auf ShiaTV veröffentlicht wurden. Das rituelle Küssen des Korans findet sich beispielsweise im Testament von Mohammad Srour (01:20-01:28 min), der am 2. August 2006 ein Selbstmordattentat gegen Israel verübte, http://www.shiatv.net/ view_video.php?viewkey=7063e5a68e6616acc0ed\&page $=\&$ viewtype $=\&$ category $=$ (zugegriffen am 6.6.2021). 
angeblich vor jeder Schlacht um den Kopf band. ${ }^{172}$ Auch Imam Hussein, Gründungsfigur der schiitischen Märtyrererzählung, soll während der Schlacht von Kerbala (680 n. Chr.) ein solches Stirnband getragen haben. ${ }^{173}$ Als Teil des symbolischen Repertoires der Aschura - der schiitischen Trauer- und Bußrituale im Gedenken an Hussein - etablierte sich das Stirnband zunächst im Iran zu einem geläufigen Symbol für die Märtyrer*innen der islamischen Republik. Viele iranischen Kämpfer während des Iran-Irak-Kriegs (1980-88) trugen solche Stirnbänder, die mit politischen und religiösen Slogans versehen waren. Wie Chelkowski und Dabashi gezeigt haben, stellten die meisten dieser Slogans eine Verbindung zum Martyrium Husseins und dem schiitischen Kerbala-Narrativ her. ${ }^{174}$ Sie enthielten Parolen wie »O Hussein!«, »O God! O God!«, »In the Path of Karbala« oder »Martyrs are Candles Of the Muslim Community!«. Andere Stirnbänder identifizierten den Kämpfer als »The Karbala Soldier, «»The Karbala Traveller,« »The Ashura Epic-maker« oder bekundeten den Wunsch, als Märtyrer den Opfertod zu sterben: »May I Sacrifice Myself for You, O Hussein. $\ll^{175}$ Nach dem iranischen Vorbild wurde auch diese Ikonografie von der Hisbollah übernommen. Zahlreiche Poster, die im Laufe der 1980er Jahre entstanden sind, zeigten (die meist männlichen) Märtyrer mit dem ikonischen Band um den Kopf. ${ }^{176}$ Im Unterschied zu den roten Stirnbändern der iranischen Kämpfer war Ashmars Band nun allerdings in den Farben der Hisbollah-Flagge Gelb und Grün gehalten. ${ }^{177}$ Das symbolische Umbinden des Märtyrerstirnbands in seinem Videotestament kann ebenso wie das wörtliche Märtyrerzeugnis als Versprechen gedeutet werden, den Opfertod zu sterben. Dem Sprechakt des Märtyrers wird damit eine nonverbale Handlung zur Seite gestellt. Die Verwandlung des Sterblichen in einen schiitischen Märtyrer ist nun scheinbar auch sichtbar am Körper des Dargestellten abzulesen.

Am 30. Dezember 1999, also wenige Monate vor dem Rückzug der israelischen Armee aus dem Libanon im Mai 2000 und dem selbsterklärten 〉Sieg` der

172 Vgl. etwa die Darstellung in der »Enzyklopädie des Islam«, http://www.eslam.de/begriffe/a/aa/abu_dudschana.htm (zugegriffen am 6.6.2021).

173 Vgl. Chelkowski und Dabashi: Staging a Revolution, S. 289.

174 Vgl. ebd.

175 Zitiert nach ebd.

176 Vgl. die Poster im Archiv Signs of Conflict, beispielsweise: http://www.signsofconflict.com/Archive/poster_details/1716 (zugegriffen am 6.6.2021).

177 Aufgrund der schlechten Bildqualität ist der grüne Schriftzug nicht zu entziffern. Für gewöhnlich wurden die Märtyrerstirnbänder mit religiösen Slogans versehen, häufig handelte es sich dabei um das islamische Glaubensbekenntnis, die Schahada. 
Hisbollah, verübte diese ihr vorerst letztes Selbstmordattentat mit einer Autobombe. Das Videotestament des 20-jährigen Ammar Husayn Hammud, der mit einem sprengstoffbeladenen Auto in ein israelisches Militärfahrzeug fuhr, ${ }^{178} \mathrm{kann}$ im Wesentlichen als Nachahmung der vorangegangenen Videos gelten. ${ }^{179}$ Verschiedene Szenen und Symbole aus den Videotestamenten von Ghandour und Ashmar kommen hier zur Wiederaufführung und wurden nahezu eins zu eins durchexerziert. Nicht nur das Treffen im Büro des Generalsekretärs Nasrallah, auch die Aufnahmen Hammuds am Steuer des Tatfahrzeugs rekurrieren auf das mehr als vier Jahre zuvor entstandene Videotestament Ghandours, das zu diesem Zeitpunkt bereits ikonischen Status erlangt zu haben schien. Diesen Eindruck vermittelt auch die gerahmte Fotomontage, die links vor Hammud auf dem Tisch steht, während dieser sein Testament verliest. Das Bild stellt mehrere `Highlights aus dem Video Ghandours nebeneinander und lässt diese bildlich >Revue ২ passieren: Darunter das Treffen mit Nasrallah, die Verlesung des Testaments, ein Standbild der Autofahrt, sowie die aufsteigende Explosionswolke. Vor diesem Hintergrund wirkt der weitere Verlauf der Videomontage Hammuds wie ein Reenactment dieser Vorlage, die als eine Art Skript ins Bild integriert wurde und die Folgeszenen visuell vorwegnimmt.

Einmal mehr wird deutlich, dass Videotestamente in ein Geflecht von Bezügen zueinander eingebunden sind - mitunter ganz direkt, durch die Integration von Vorbildern im Bild. Wie die Videoproduktionen der Hisbollah gezeigt haben, wurden Darstellungsmuster der säkularen Parteien teils übernommen, teilweise aber auch weiterentwickelt und umgedeutet. Spricht man von den Videotestamenten als einem eigenen audiovisuellen $>$ Genre $<$, ist damit also keine Taxonomie gemeint, die sich anhand feststehender Darstellungsregeln bestimmen ließe, sondern ein wandelbares Set von Relationen. Stanley Cavell hat die Zugehörigkeit von Filmen zu einem Genre folgendermaßen beschrieben: »they are what they are in view of one another ${ }^{180}$. Im Fall der Videotestamente bezieht sich dies nicht nur auf die Darstellungsebene. Wie in diesem Kapitel argumentiert wurde, zeichnet

178 Verschiedenen internationalen Presseberichten zufolge kamen bei dem Anschlag sieben Menschen ums Leben. Chicago Project on Security and Terrorism (CPOST): Suicide Attack Database, Attack ID: 1657800286.

179 Eine Version dieses Videotestaments befindet sich auf einer VHS-Kassette, die dem Journalisten Kevin Toolis durch Mitarbeiter von al-Manar ausgehändigt wurde und die ich im Dezember 2016 in seinem Londoner Büro sichten durfte. Man kann davon ausgehen, dass das Video in dieser Version auf al-Manar ausgestrahlt wurde.

180 Stanley Cavell: Pursuits of Happiness: The Hollywood Comedy of Remarriage, Cambridge: Harvard University Press 2003, S. 29 [Hervorhebung im Original]. 
sich die Besonderheit dieses audiovisuellen Genres (neben bestimmten ästhetischen und ikonografischen Mustern) gerade - und in besonderem Maße - durch eine ganz eigene Operativität aus. Können die appellativen Operationen als charakteristisch für Propagandabilder allgemein gelten, sind es vor allem die performativen Operationen, die die besondere Handlungsmacht dieser Videoaufnahmen ausmachen.

\section{4 ॥I AM THE FEMALE MARTYR«. VIDEOTESTAMENTE PALÄSTINENSISCHER SELBSTMORDATTENTÄTERINNEN AB 2002}

Mit der islamischen Legitimierung des Selbstmordattentats ging noch eine weitere entscheidende Veränderung einher. Anders als die säkularen Parteien, die Frauen und Männer gleichermaßen für Suizidanschläge rekrutierten, waren die Märtyrertod-Operationen der schiitischen Hisbollah ausschließlich Männern vorbehalten. ${ }^{181}$ Obwohl Mitglieder der Hisbollah die SSNP-Attentäterin Sana Yusif Muhaydli zunächst als schiitische »Blut-Braut« priesen (vgl. S. 117), schienen sie ihre Position schon wenig später wieder zu revidieren. In einem Interview vom 28. Juni 1986 brachte Scheich Abd al-Karim Ubayd, ein Geistlicher der libanesischen Hisbollah, unmissverständlich zum Ausdruck:

»One of the nationalist women asked me, does Islam permit a woman to join in military operations of the resistance to the occupation, and would she go to paradise if she were martyred? The jihad in Islam is forbidden to women except in self-defense and in the absence of men. [...] My answer to this woman was that her jihad was impermissible

181 Folgt man der Darstellung von Amir Taheri, schickte die Hisbollah am 10. März 1985, also vier Wochen vor dem Attentat von Sana Muhaydli, bereits eine weibliche Attentäterin auf eine Selbstmordmission, bei der zwölf israelische Soldaten starben. Taheri zufolge war die 18-jährige Sumayah Saad Angehörige einer weiblichen Kommandogruppe der Hisbollah. Taheri: Holy Terror, S. 116. Allerdings lässt sich diese Information durch andere Quellen nicht belegen. So sprechen mehrere Presseberichte kurz nach dem Anschlag vom 10. März von einem männlichen Attentäter namens Hazem aka Abu Zenab, vgl. Chicago Project on Security and Terrorism (CPOST): Suicide Attack Database, Attack ID: 1905816468. 
regardless of motive or reason. She could not be considered a martyr were she killed, because the view of the law is clear. «182

Das nationalistisch-säkulare Verständnis des Martyriums wich einem Bild, das sich streng an frühislamischen Traditionen ausrichtete und auf Männer zugeschnitten war: »Das aus dem Frühislam stammende Konzept des Märtyrertums«, so die Arabistin Friederike Pannewick, beruht ursprünglich »auf einem eindeutig männlich codierten Heldentum und Ehrbewusstsein « ${ }^{183}$. Neben dem kämpferischen Aspekt spielen dabei auch islamische Paradiesvorstellungen eine Rolle, welche die Figur des Märtyrers geschlechtsspezifisch auf männliche Fantasien zuschneiden. Gleich mehrere Koransuren versprechen dem Märtyrer den Eintritt ins Paradies wo »neben Gärten und Weinstöcken gleichaltrige Paradiesjungfrauen mit schwellenden Brüsten « auf ihn warten - Beschreibungen, die in militanten, radikalislamischen Kreisen immer wieder zur Rekrutierung von jungen Männern herangezogen wurden. ${ }^{184}$

Auch in den palästinensischen Autonomiegebieten war seit den 1990er Jahren eine zunehmende Islamisierung des Widerstandskampfes zu beobachten, die mit einer klaren Geschlechterordnung einherging. Radikal-sunnitische Organisationen wie der Islamische Dschihad in Palästina oder die Hamas gewannen zunehmend an Bedeutung und verübten ab 1993 Suizidbombenanschläge gegen Israel nach dem Vorbild der Hisbollah. Das erste dieser Serie von Selbstmordattentaten wurde am 16. April 1993 von den Izz ad-Din al-Qassam-Brigaden, dem militanten Arm der Hamas, organisiert und zielte darauf ab, die laufenden Friedensverhandlungen zwischen Arafats PLO und Israel scheitern zu lassen. Es folgte eine ganze Welle von Selbstmordattentaten, die allesamt von Männern der Hamas und des Islamischen Dschihad in Palästina durchgeführt wurden. Häufig richteten sich die Attentate nicht mehr nur gegen israelische Militärstützpunkte, sondern fanden mitten im Zentrum von Tel Aviv oder Jerusalem statt und waren vermehrt gegen Orte des zivilen Lebens gerichtet, wie etwa Linienbusse oder Bushaltestellen. In den sieben Jahren bis zum Ausbruch der zweiten Intifada im September 2000 gab es 26 Selbstmordattentate, bei denen insgesamt 181 Menschen ums Leben

182 Interview mit Scheich Abd al-Karim Ubayd, Al-Safir (Beirut), 28.06.1986, zitiert in Kramer: »Sacrifice and 〉Self-Martyrdom〈 in Shi'ite Lebanon«, o.S.

183 Friederike Pannewick: »Tödliche Selbstaufopferung in der arabischen Literatur. Eine Frage von Macht und Ehre?«, in: Christina von Braun u.a. (Hg.): >Holy War« and Gender. `Gotteskrieg` und Geschlecht. Berlin: LIT Verlag 2006, S. 93-119, hier S. 101.

184 Ebd., S. 93. Vgl. Koransure 78:33. 
kamen. ${ }^{185}$ Mit seinem provokativen Besuch der für Muslim*innen heiligen alAqsa-Moschee am 28. September 2000 löste der damalige israelische Ministerpräsident Ariel Scharon eine heftige Protestwelle aus, die in eine Gewaltspirale von beiden Seiten mündete. Allein im ersten Monat der palästinensischen Aufstände wurden 107 Palästinenser*innen, darunter viele Kinder und Jugendliche, von der israelischen Armee getötet. ${ }^{186}$ Auf der anderen Seite griffen radikalislamische palästinensische Gruppen wieder vermehrt zur Waffe des Selbstmordattentats. Bis zum 27. Januar 2002 verübten Hamas und Islamischer Dschihad insgesamt 31 Selbstmordattentate gegen israelische Ziele, die ausnahmslos von Männern durchgeführt wurden. ${ }^{187}$

Als sich Wafa Idris am 27. Januar 2002 im Namen der al-Aqsa Märtyrer Brigaden als erste Frau der zweiten Intifada in die Luft sprengte (vgl. Kapitel 2.1), löste dies eine innerpalästinensische Debatte über den Einsatz von weiblichen Märtyrerinnen aus. ${ }^{188}$ Führende Vertreter der Hamas reagierten zunächst ablehnend gegenüber dem Attentat. Hamas-Gründer Scheich Ahmad Yassin sprach sich, ähnlich wie zuvor die Hisbollah, gegen einen aktiven militanten Widerstand der palästinensischen Frauen aus und betonte stattdessen: »The woman is the second defence line in the resistance to the occupation. She shelters the fugitive, loses the son, husband and brother, bears the consequences of this, and faces starvation and blockage. $\ll^{189}$ Gegenüber einer der internationalen arabischsprachigen Tageszeitung al-Sharq al-Awsat betonte Yassin außerdem, dass das islamische Gesetz Frauen verbiete, ohne Begleitung eines männlichen Verwandten eine Märtyrertod-Operation durchzuführen. ${ }^{190}$ Außerdem, so Yassin weiter, gebe es bei der hohen Anzahl freiwilliger Männer gar keinen Bedarf für weibliche Selbstmordattentäterinnen: »[...] I assert that the current stage does not need women's

185 Vgl. die Statistik in Chicago Project on Security and Terrorism (CPOST): Suicide Attack Database.

186 Allen: »Polyvalent Politics«, S. 133, Anm. 21.

187 Vgl. die Statistik in Chicago Project on Security and Terrorism (CPOST): Suicide Attack Database.

188 Die folgende Darstellung beruht in Teilen auf Verena Straub: »Lebende Tote? Die (Selbst-)Inszenierungen der palästinensischen Selbstmordattentäterinnen«, in: Philipp Stoellger und Jens Wolff (Hg.): Bild und Tod. Grundfragen der Bildanthropologie, Bd. I, Tübingen: Mohr Siebeck 2016, S. 401-424; sowie Straub: »The Making and Gendering of a Martyr «.

189 Zitiert nach Hasso: »Discursive and Political Deployments by/of the 2002 Palestinian Women Suicide Bombers/Martyrs«, S. 31.

190 Vgl. Graitl: Sterben als Spektakel, S. 213. 
participation in martyrdom operations, like men. We cannot absorb the growing number of applications from youths wanting to carry out martyrdom operations. ${ }^{191}$ Von der säkularen Fatah wurde Wafa Idris hingegen schon wenige Tage nach ihrem Anschlag als Ikone der Gleichberechtigung gepriesen. Wie bereits erwähnt, veranstaltete das Fatah-Frauenkomitee am 30. Januar 2002 eine Gedenkfeier zugunsten der Attentäterin, bei der die weiblichen Teilnehmerinnen stolz verkündeten: »Der Dschihad ist nicht nur für Männer! « (vgl. Kapitel 2.1). ${ }^{192}$ In den arabischen Medien wurde diese neue weibliche Beteiligung gleichzeitig als Gegenentwurf zur westlichen Emanzipationsbewegung gedeutet. ${ }^{193}$ So schrieb die ägyptische Zeitung al-Sha'ab am 1. Februar 2002:

»It's a woman who is showing you today, Muslim women, the meaning of true freedom, with which women's rights activists have tempted you...It's a woman who has now proved that the meaning of women's liberation is to free their body from this world's trials, and to accept death with a powerful brave embrace. $\ll^{194}$

Dasselbe Erklärungsmuster wurde auch von der jordanischen Zeitung al-Dustur aufgegriffen, die am 5. Februar schrieb: «Wasn't it the West that kept demanding that the Eastern woman become equal to men? Well, this is how we understand equality. ${ }^{195}$ Die arabischen Zeitungskommentare deuteten die westliche Emanzipationsbewegung als machtpolitische Bevormundung und Gefahr. Mit der weiblichen Selbstmordattentäterin wurde diesem Frauenbild ein anderes, arabisches Konzept von Geschlechtergleichheit entgegengesetzt.

191 Zitiert nach ebd. Graitl bezieht sich dabei auf die englische Übersetzung des arabischen Zeitungsartikels in BBC: «Hamas Founder on Role of Palestinian Women in Suicide Bombings«, 02.02.2002.

192 Zitiert nach Pannewick: »Wafa Idris. Eine Selbstmordattentäterin zwischen Nationalheldin und Heiliger«, S. 111.

193 Rivka Yadlin führt etliche Reaktionen aus islamistisch-arabischen Kreisen an, die sich auf diese Argumentationsstruktur stützen. Rivka Yadlin: »Female Martyrdom: The Ultimate Embodiment of Islamic Existence?«, in: Yoram Schweitzer (Hg.): Female Suicide Bombers. Dying for Equality?, Tel Aviv 2006, S. 51-61, hier S. 54f.

194 Al-Sha'ab, 01.02.2002, zitiert nach ebd., S. 54.

195 Al-Dustur, 05.02.2002, zitiert nach ebd. 


\section{Das ıweiblicher Videotestament?}

Dieser neue »feministische Stolz $\aleph^{196}$, der sich unter einigen Palästinenserinnen herausbildete, mag vielleicht ein Grund dafür gewesen sein, warum sich auch die Hamas-Aktivistin Darin Abu Aisheh dazu entschloss, dem Vorbild von Wafa Idris nachzueifern - trotz der Ablehnung durch ihre eigene Partei. Während die Märtyrerbilder von Wafa Idris nachträglich aus privaten Familienfotos montiert wurden und in Form von Postern ihre Verbreitung fanden, war Abu Aisheh die erste der palästinensischen Selbstmordattentäterinnen, die ein Videotestament hinterließ, in dem sie sich als »lebende Märtyrerin « bezeichnete. ${ }^{197}$ Die 20-jährige Studentin englischer Literatur galt als strenggläubige Muslima und engagierte sich für die radikalislamische Hamas. ${ }^{198}$ Nachdem ihr Wunsch, Märtyrerin zu werden jedoch sowohl von der Hamas als auch vom Islamischen Dschihad aufgrund ihres Geschlechts abgelehnt wurde, wandte sie sich an die al-Aqsa Märtyrer Brigaden, in deren Namen sie ihren Anschlag schließlich verübte. ${ }^{199}$ Am 27. Februar 2002, genau einen Monat nach dem Attentat von Wafa Idris, fuhr sie mit einer Autobombe in eine israelische Straßensperre unweit von Ramallah und verletzte dabei drei israelische Soldaten. ${ }^{200}$ Außer ihr selbst kam bei dem Attentat niemand ums Leben. In ihrem Videotestament, das bereits wenige Stunden nach dem Attentat im arabischen Satellitensender ANN ausgestrahlt wurde, ${ }^{201}$ kritisierte Abu Aisheh die konservative Haltung der Hamas gegenüber der Partizipation von Frauen. Sie verkündete in ihrem Videotestament: »Because the role of the Muslim Palestinian woman is no less important than the role of our fighting brothers, I have decided to be the second female martyr to continue in the path that was forged by the

196 Hasso: »Discursive and Political Deployments by/of the 2002 Palestinian Women Suicide Bombers/Martyrs«, S. 35.

197 So schloss sie ihr Videotestament mit den Worten: »Your daughter the living martyr: Dareen Muhammad Tawfiq Abu Ayshe.« Eine englische Übersetzung des arabischen Videotestaments findet sich in Hafez: Manufacturing Human Bombs, S. 89-90.

198 Vgl. Hasso: »Discursive and Political Deployments by/of the 2002 Palestinian Women Suicide Bombers/Martyrs«, S. 31.

199 Vgl. ebd., S. 28; Brunner: Männerwaffe Frauenkörper?, S. $98 .$.

200 Vgl. die internationalen Presseberichte zitiert in Chicago Project on Security and Terrorism (CPOST): Suicide Attack Database, Attack ID: 736217851.

201 Vgl. Sophie Claudet: »More Palestinian Women Suicide Bombers Could be on the Way«, Agence France Presse, 28.02.2002, http://www.metimes.com/2k2/issue20029/women/morepalestinianwomen.htm (zugegriffen am 23.4.2017, nicht mehr verfügbar). 
female martyr Wafa al-Idris. $\ll^{202}$ Eingeleitet wurde diese Absichtsbekundung mit der Rezitation eines Koranverses (3:195), wodurch Gott verkündet haben soll: "Ich werde keine Handlung unbelohnt lassen (w. verloren gehen lassen), die einer von euch begeht, (gleichviel ob) männlich oder weiblich. $\ll^{203}$ Lorenz Graitl geht in seiner Textanalyse des Testaments davon aus, dass diese Stelle von Abu Aisheh deshalb ausgewählt wurde, »weil sich daraus eine Gleichheit der Geschlechter ableiten lässt und sie so ihr eigenes Handeln unter Berufung auf den Koran legitimieren kann. $\ll^{204}$ Vor laufender Kamera betonte Abu Aisheh anschließend, dass die Rolle der Frau nicht länger darauf beschränkt sei, den Tod des Sohnes, Bruders oder Ehemannes zu betrauern. Ihre Worte schienen direkt gegen Yassin gerichtet zu sein, der wenige Wochen zuvor dem weiblichen Widerstand eine sekundäre Bedeutung beima $\beta$ und Frauen auf ihre Rolle als Trauernde verwies. Stattdessen rief Abu Aisheh auch die anderen Frauen dazu auf, ihre Körper in »menschliche Bomben« zu verwandeln:

»I call upon my sisters to continue on this path of all those who are free and honorable. [...] The role of the Palestinian woman will no longer be limited to grieving over the death of their husbands, brothers, and fathers; we will transform our bodies into human bombs that spread here and there to demolish the illusion of security for the Israeli people. « ${ }^{205}$

Im Unterschied zu vorangegangenen Videotestamenten zielte ihr Appell nicht nur darauf ab, Nachahmerinnen zu mobilisieren - es war zugleich als ein Aufruf zu verstehen, das traditionelle Geschlechterverständnis der Hamas und anderer radikal-islamischer Gruppen zu dekonstruieren. Die appellative Bildoperation des Videotestaments erhielt damit eine offensiv genderpolitische Dimension.

Ein iranischer Dokumentarfilm macht einige Sequenzen des Videotestaments auch visuell zugänglich. ${ }^{206}$ Bekleidet mit einem schwarzen Mantel und einem weißen Hijab liest Abu Aisheh ihr Testament von einem Zettel ab und blickt dabei immer wieder direkt in die Kamera (Abb. 3.19 a).

202 Zitiert nach Hafez: Manufacturing Human Bombs, S. 89f.

203 Paret (Hg.): Der Koran. Kommentar und Konkordanz von Rudi Paret, Sure 3:195, online abrufbar unter http://www.corpuscoranicum.de/index/index/sure/3/vers/195 (zugegriffen am 6.6.2021).

204 Graitl: Sterben als Spektakel, S. 201.

205 Zitiert nach Hafez: Manufacturing Human Bombs, S. 89f.

206 KAM (Komitee zur Achtung der Märtyrer der islamischen Bewegung), Dāhtarān-e Zaitūn, CD-Rom, Teheran, o.J. Ich danke Britt Ziolkowski für die Hilfe bei der Beschaffung dieses Dokuments. 
Abbildung 3.19 a-d: Videotestament von Darin Abu Aisheh, al-Aqsa Märtyrer Brigaden, Aufnahme am oder vor dem 27. Februar 2002, Ausschnitt, 0:57 min, arabisch.
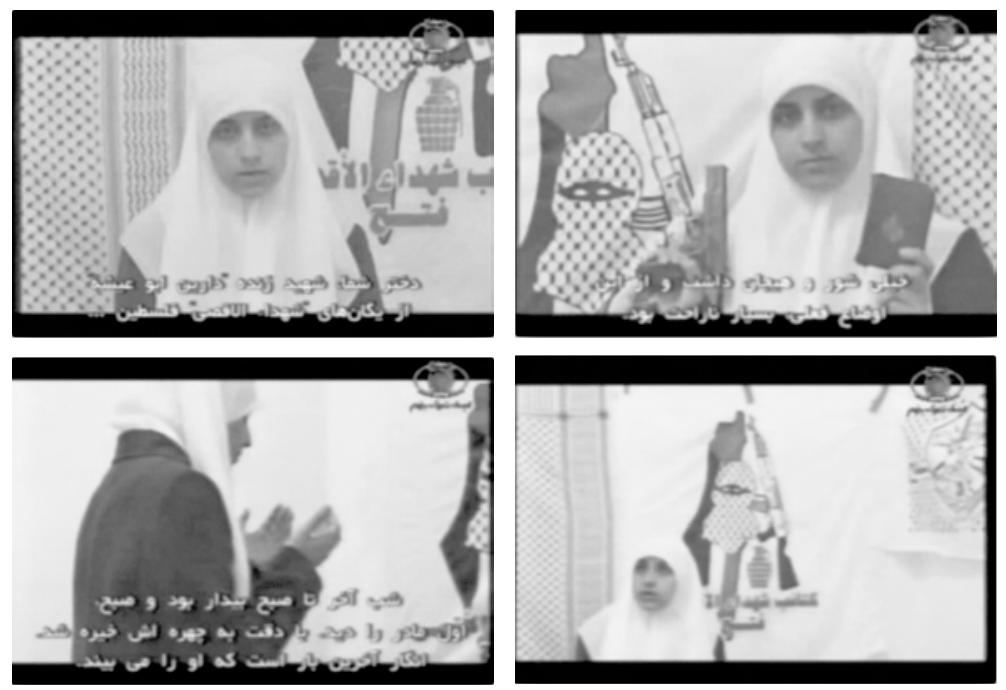

Im Unterschied zu ihren libanesischen Vorgängerinnen war Abu Aisheh die erste Frau, die mit einem Kopftuch vor die Kamera trat und damit ein sichtbares Zeugnis ihres Glaubens ablegte. ${ }^{207}$ In einer anderen Szene posiert sie mit einer Pistole in der linken Hand und einem Koran in der rechten frontal für der Kamera, wobei sie wie für ein Fotoshooting für kurze Zeit in unterschiedlichen Posen verharrt (Abb. 3.19 b). Eine weitere Szene zeigt die Close-Up-Aufnahme des Emblems der al-Aqsa Märtyrer Brigaden; von dort schwenkt die wacklige Handkamera nach links, wo Darin Abu Aisheh erneut von unten ins Bildfeld tritt. Aus einer knienden Gebetsposition steht sie auf und vollzieht das rituelle Gebet in Richtung Mekka, wobei ihr Körper dieses Mal der Kamera abgewandt ist (Abb. 3.19 c-d). Der Reihe nach werden unterschiedliche Handlungen aufgeführt, die unmittelbar als Reenactments vorangegangener Videotestamente zu erkennen sind. Das rituelle Gebet Richtung Mekka tauchte bereits in den Videotestamenten der Hisbollah auf (vgl. Abb. 3.17 c-d). Das Posieren mit Waffe und Koran avancierte hingegen in

207 Abu Aishehs strenge Religiosität kam auch im gesprochenen Testament immer wieder zum Ausdruck, so hat Lorenz Graitl in seiner Analyse ihres Testaments ausführlich dargestellt. Vgl. Graitl: Sterben als Spektakel, S. 198-211. 
den Videotestamenten der Hamas und des Islamischen Dschihad zu einer feststehenden Formel. ${ }^{208}$

Die Szenen des Videotestaments von Darin Abu Aisheh wurden allesamt vor einem großen weißen Tuch aufgenommen, auf dem verschiedene politische Insignien zu erkennen sind: Das Bildfeld wird links von einer an der Wand hängenden Kufiya begrenzt - dem ikonischen Palästinensertuch, das zum Symbol für den palästinensischen Freiheitskampf geworden war. Auf der rechten Seite ist das Logo der al-Aqsa Märtyrer Brigaden sichtbar, die sich zu diesem Selbstmordattentat bekannten. Gegen Ende des Videoausschnitts rückt ein weiteres Emblem ins Blickfeld, das auf den weiß bespannten Hintergrund gemalt wurde und eine PalästinaIsrael-Karte in den Farben der palästinensischen Flagge zeigte (Abb. 3.19 d). Der Bereich, der den besetzten palästinensischen Gebieten im Westjordanland entspricht, wurde mit dem schwarz-weiß karierten Muster der Kufiya ausgefüllt und mit einem Schlitz versehen, hinter dem zwei Augen zu erkennen sind. Aus der personifizierten Landkarte ragt eine Hand, die ein Maschinengewehr umfasst und auf die Kampfbereitschaft der Palästinenser*innen verweist. Unter der Abbildung einer grünen Granate ist schließlich ein roter arabischer Schriftzug zu lesen, der die Urheberschaft dieser Videoinszenierung erneut klarstellt: »al-Aqsa Märtyrer Brigaden, Fatah«. Die nationalistischen Symbole, insbesondere die Allgegenwart der Kufiya, sollten in weiteren Videotestamenten zum Erkennungsmerkmal der al-Aqsa Märtyrer Brigaden werden, die sich damit schon auf den ersten Blick von den Videos ihrer Konkurrenzparteien unterscheiden. Während sich die HamasMärtyrer meist vor grünen Parteiflaggen und mit grünem Märtyrerstirnband präsentierten, dominierten die Farben Schwarz und Gold in den Videotestamenten des Islamischen Dschihad in Palästina. ${ }^{209}$ Die Islamwissenschaftlerin Britt Ziolkowski geht dementsprechend davon aus, dass die Verantwortung für die bildliche Inszenierung dieses Videos bei den Organisator*innen der al-Aqsa Märtyrer Brigaden lag, zumal Abu Aisheh selbst eigentlich Hamas-Sympathisantin war: »Das Video zeigt wohl umso mehr ihre Anpassung an die Aqsa-Märtyrer-Brigade, in deren Namen sie die Märtyreroperation durchführte « ${ }^{210}$, so folgert Ziolkowski.

208 Vgl. dazu etwa die Sammlung von Videotestamenten männlicher palästinensischer Selbstmordattentäter der zweiten Intifada, die Joshua Simon für sein Projekt »Shahids« zusammengestellt hat (DVD, Laufzeit 52:04 min). Ich danke Joshua Simon für die Bereitstellung dieses Materials.

209 Vgl. ebd. Zum typischen Muster der Hamas-Videotestamente siehe auch Abb. 3.25.

210 Ziolkowski: Palästinensische Märtyrerinnen, S. 63. 
Abbildung 3.20: Fotografie von Darin Abu Aisheh, von ihrer Familie in Nablus am 28. Februar 2002 verbreitet.

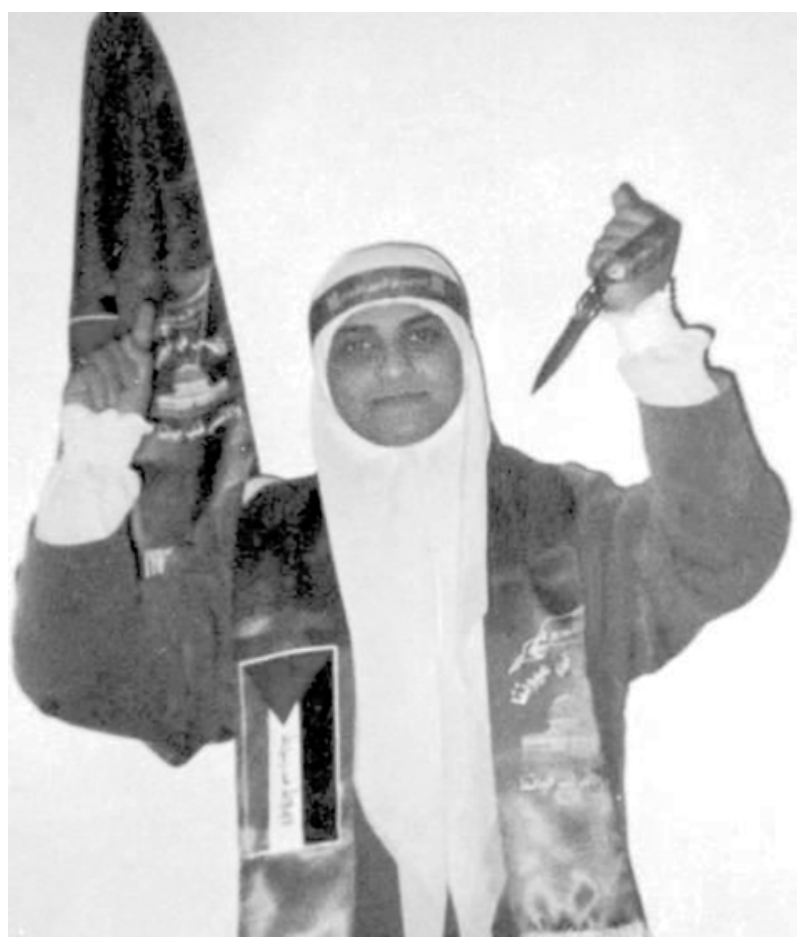

In diesem Zusammenhang ist allerdings eine weitere Serie von Fotografien interessant, die von Abu Aishehs Familie nach dem Attentat veröffentlicht wurde und die kopftuchtragende Frau überraschenderweise mit den grünen Bannern der Hamas zeigt (Abb. 3.20). ${ }^{211}$ In ihrer linken Hand hält die Attentäterin ein Messer, das auf ihren eigenen Körper gerichtet ist, während ihr rechter Zeigefinger nach oben weist. Diese Geste kann zum einen als symbolischen Verweis auf den >einen Gott< gedeutet werden, ${ }^{212}$ die geballte rechte Faust mit dem ausgestreckten Zeigefinger

211 Eine zweite Fotografie, die ebenfalls von ihrer Familie verbreitet wurde, zeigt Abu Aisheh in derselben Pose, dieses Mal jedoch mit ernsterem Gesichtsausdruck. Diese Version wurde für die Montagen der Hamas und Fatah (Abb. 2.2 und 2.15) verwendet.

212 Vgl. Hasso: »Discursive and Political Deployments by/of the 2002 Palestinian Women Suicide Bombers/Martyrs«, S. 31. 
wird aber auch als islamistisches Zeichen für Sieg gelesen. ${ }^{213}$ Wie auch die männlichen Hamas-Märtyrer trägt Abu Aisheh ein grünes Stirnband über ihrem Hijab, dessen Inschrift sie als »The Martyr 'Izz al-Din al-Qassam Brigades « ausweist. ${ }^{214}$ Über ihre Schultern legt sich ein weiteres dunkelgrünes Band: Auf der einen Seite ist die Nationalflagge Palästinas zu sehen, die andere Seite ist mit dem Emblem der Hamas verziert, das sich aus zwei gekreuzten Schwertern, einer Abbildung des Felsendoms sowie einer historischen Palästina-Karte zusammensetzt. Auch das grüne Tuch, das rechts hinter ihr an der Wand hängt, ist mit dem Hamas-Symbol geschmückt und folgt der Bildtypologie der männlichen Hamas-Attentäter.

Doch warum stellt sich Abu Aisheh als Märtyrerin jener Organisation dar, die sie wegen ihres Geschlechts für ein Attentat nicht zugelassen hat? Es ist anzunehmen, dass Abu Aisheh für diese Inszenierung selbst verantwortlich war und es sich um eine von der Hamas (zumindest zunächst) nicht autorisierte Aufnahme handelt. ${ }^{215}$ Durch die alternative Inszenierung brachte Abu Aisheh ihre eigentliche Überzeugung zum Ausdruck und lenkte damit die posthume Rezeption ihrer Tat: Sie wollte als Märtyrerin der Hamas und nicht der al-Aqsa Märtyrer Brigaden im Gedächtnis bleiben. Zugleich kann die Produktion eines solchen Bildnisses als bewusste Provokation gegenüber der Hamas gedeutet werden, die sich zu diesem Zeitpunkt noch radikal gegen den Einsatz weiblicher Selbstmordattentäter aussprach. Das Bild selbst wurde hier zu einem machtvollen Instrument mithilfe dessen sich Abu Aisheh der offiziellen Politik der Hamas widersetzte und sich trotz ihres Geschlechts zur Schahida in deren Namen machte. Im Unterschied zu Wafa Idris (Kapitel 2.1) nahm Abu Aisheh hier also die Erzengung ihres Martyriums selbst in die Hand - und brachte das Bild einer Hamas-Märtyrerin in Umlauf, lange bevor die Hamas Frauen für Märtyrertod-Operationen zuließ. Im Sinne einer epistemischen Bildoperation schuf ihr fotografisches Märtyrerzeugnis damit Fakten, die Einfluss auf die Geschlechterpolitiken in Palästina hatten.

Ironischerweise waren es ausgerechnet diese selbstautorisierten Aufnahmen mit fingierter Partei-Affiliation, die nach ihrem Attentat am häufigsten reproduziert wurden. Scheinbar ungeachtet der Tatsache, dass das grüne Märtyrer-

213 Vgl. Hassan: »An Arsenal of Believers«, o.S.: »[...] the islamist sign for victory right fist with raised forefinger $[\ldots] \ll$.

214 Die 'Izz al-Din al-Qassam Brigaden gelten als der militante Arm der Hamas. Englische Übersetzung des arabischen Schriftzugs in Hasso: »Discursive and Political Deployments by/of the 2002 Palestinian Women Suicide Bombers/Martyrs«, S. 31.

215 Die Fotografie wurde angeblich im Haus ihres Onkels aufgenommen, so berichtete die Schwester der Attentäterin, mit der Britt Ziolkowski am 3. Mai 2002 in Ramallah sprach. Ziolkowski: Palästinensische Märtyrerinnen, S. 61. 
stirnband auf die Konkurrenzpartei verweist, wurde eine der Fotografien (und nicht etwa ein Still aus dem Videotestament) auch von der Fatah für digitale Bildmontagen verwendet (vgl. Abb. 2.15). Die Eigendynamik, die diese spezifische Fotografie auch im Laufe weiterer Postproduktionen entwickelte, ist bemerkenswert. Was als unautorisierte, provokative Aneignung der Hamas-Ikonografie begann, wurde schließlich auch von der Hamas selbst vereinnahmt, als diese ab Januar 2004 ihre bisherige Linie revidierten und ebenfalls begannen, weibliche Selbstmordattentäterinnen einzusetzen (vgl. S. 193f). Trotz der einstigen Ablehnung wurde Abu Aishehs Bild retrospektiv in eine visuelle Genealogie von Märtyrerinnen integriert, die von Hamas-Sympathisierenden gestaltet wurde (vgl. Abb. 2.2). Gerade in dieser dreifachen Bewegung entgegengesetzter Aneignungen offenbart sich die instabile Bedeutung dieser Fotografie, die je nach Kontext mit anderen politischen Absichten verbunden wurde und damit ganz heterogene Bildoperationen auslöste.

Die Ausstattung und das Setting von Abu Aishehs fotografischer MärtyrerInszenierung unterscheiden sich zunächst kaum von den Videos der Hamas-Männer. Umso auffälliger erscheint deshalb die ungewöhnliche Waffe in Abu Aisheh Hand. Gegenüber dem Maschinengewehr, das in den meisten Videotestamenten der Hamas zu sehen ist, umgibt das Messer als Tatwaffe eine archaische, anachronistische Aura. Im Zeitalter hochtechnologisierter Kriege stellt das Messer keine ernstzunehmende Bedrohung dar und wird stattdessen als Zeichen der Rückständigkeit gelesen. Im Gegensatz zur Schusswaffe erscheint der Angriff mit dem Messer besonders brachial und körperlich. Warum Darin Abu Aisheh genau diese Waffe gewählt hat, um ihr zukünftiges Sprengstoffattentat zu symbolisieren, kann nicht beantwortet werden. Da die Inszenierung ohne Unterstützung der Hamas erfolgte, stand ihr möglicherweise keine andere Waffe als `Requisit $>$ zur Verfügung. Im Unterschied zu den Videos männlicher Märtyrer, die ihre Gewehre häufig zum Schuss auf den imaginierten Feind ansetzen und dadurch in erster Linie als Aggressoren dargestellt werden, ${ }^{216}$ richtet sich die militante Geste Abu Aishehs gegen sie selbst. Das Messer lenkt den Blick auf ihren eigenen Körper und verweist auf ihn als eigentliche Waffe. Die dem Selbstmord-Attentat zugrunde liegende Dichotomie von Täterschaft und gleichzeitigem Selbstopfer scheint sich hier geschlechterspezifisch aufzuspalten: Liegt die Betonung in den männlichen Videotestamenten auf der Täterschaft, tritt bei Abu Aishehs Fotografie der selbstzerstörerische Opferstatus in den Vordergrund. Obwohl Darin Abu Aisheh in ihrem

216 Vgl. dazu erneut die Videotestamente männlicher palästinensischer Selbstmordattentäter der zweiten Intifada, die Joshua Simon für sein Projekt »Shahids« zusammengestellt hat (DVD, Laufzeit 52:04 min). 
wörtlichen Bekenntnis die klassische Rolle der palästinensischen Frau als passiv Trauernde in Frage stellt, bleibt die bildliche Inszenierung - zumindest durch die Hervorhebung des Selbstopfers - typisch weiblichen Mustern verhaftet. ${ }^{217}$

Die auf den ersten Blick bruchlos erscheinende Assimilation der weiblichen Märtyrerin in ein männlich geprägtes Bildschema wird auch in den Darstellungen der nachfolgenden Selbstmordattentäterinnen immer wieder gestört. Die auffälligste Abweichung von den männlichen Bekennervideos zeigt sich in der expliziten, teils scharfen Geschlechterkritik, die ähnlich wie bei Darin Abu Aisheh in den meisten Videotestamenten der Frauen formuliert wird. So übt auch Ayat al-Akhras in ihrem Bekenntnis explizite Kritik an den männlichen Machthabern der arabischen Nachbarländer: »I say to the Arab leaders, Stop sleeping. Stop failing to fulfill your duty. Shame on the Arab armies who are sitting and watching the girls of Palestine fighting while they are asleep. It is intifada until victory. $"{ }^{218}$ Neben ihrem Widerstand gegen die israelische Besatzung soll ihre Tat - als Doppelbotschaft - gleichzeitig als Vorwurf an die arabischen Männer verstanden werden, die eigentlich an ihrer Stelle kämpfen sollten. Ebenso setzt die erste Hamas-Attentäterin Rim Riyashi ihr Videobekenntnis in einen genderpolitischen Kontext. Wie Britt Ziolkowski in ihrer Übersetzung des Textes deutlich macht, wirft Riyashi den muslimischen Männern vor, nur noch so genannte »Halbmänner« zu sein, die die palästinensische Gemeinschaft in »Unterwürfigkeit und Entblößtheit« geführt haben. ${ }^{219}$

Mit Blick auf die bildliche Darstellung kommt Britt Ziolkowski hingegen zu dem Schluss: »Anders als die Testamente scheint es für die Videos und die Fotos keine geschlechterspezifischen Aspekte zu geben. Die Gesichter der Frauen scheinen so austauschbar mit denen der Männer «. ${ }^{220}$ Sie resümiert: »Das einzige, womit sich Dārīn und die anderen Frauen von den Männern unterscheiden, ist ihre Kleidung, die allerdings der Konvention entspricht «.221 Obwohl die Inszenierungen der Schahidat grundsätzlich an die der männlichen Vorbilder anknüpfen, macht

217 Die Geschlechterforschung hat deutlich gemacht, dass Frauen in Kriegssituationen typischerweise als Opfer von Gewalt portraitiert werden, während Männern typischerweise die Rolle der Kämpfer und Verteidiger zugesprochen wird. Vgl. Elisabeth Anker, Silvia Arzt, Kirstin Eckstein und Julia Neissl (Hg.): Männerkrieg und Frauenfrieden: Geschlechterdimensionen in kriegerischen Konflikten, Wien: Promedia 2003.

218 Zitiert nach Hasso: »Discursive and Political Deployments by/of the 2002 Palestinian Women Suicide Bombers/Martyrs«, S. 29.

219 Zitiert nach Ziolkowski: Palästinensische Märtyrerinnen, S. 57.

220 Ebd., S. 122.

221 Ebd., S. 63. 
eine genaue Bildanalyse ihrer Videotestamente und Fotografien deutlich, dass diese Beobachtung zu kurz greift.

Abbildung 3.21 a-b: Videotestament von Ayat al-Akhras, al-Aqsa Märtyrer Brigaden, Aufnahme am oder vor dem 29. März 2002, 0:31 min, arabisch.
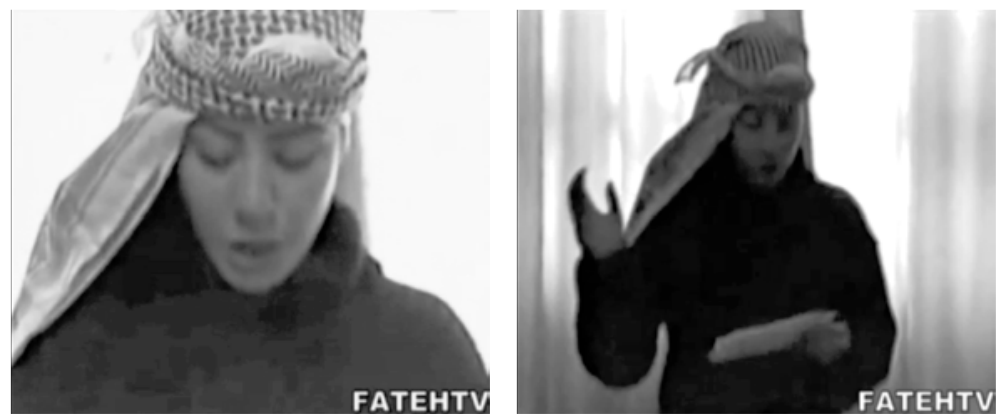

Zunächst muss die uneinheitliche Verschleierung der Attentäterinnen differenzierter betrachtet werden. Die Beobachtung Ziolkowskis, »dass nur die Frauen mit hiğāb und Mantel vor die Kamera treten $\aleph^{222}$, wird mit Blick auf Ayat al-Akhras in Frage gestellt, die in ihrem Videotestament die Kufiya nicht wie einen weiblichen Hijab, sondern auf traditionell männliche Weise um den Kopf gebunden trägt, so dass das Tuch links und rechts locker über ihre Schultern fällt. Das Video, das kurz vor ihrem Selbstmordattentat am 29. März 2002 aufgenommen wurde, ${ }^{223}$ zeigt die 18-Jährige in einem Innenraum stehend, vor einem mit hellen Vorhängen verdeckten Fenster (Abb. 3.21 a-b). Durch das Gegenlicht ist ihre Gestalt manchmal nur dunkel auszumachen, die Zoombewegungen der Kamera lassen ihr Gesicht jedoch mehrmals deutlich ins Bild treten. Abgesehen von der Kufiya verzichtet ihre Inszenierung auf nationale und religiöse Symbole (Felsendom, alAqsa-Moschee, Palästinakarte, Koranverse etc.) oder Attribute (Waffe, Koran), die in den meisten anderen palästinensischen Videotestamenten durchdekliniert werden. Obwohl sich auch in diesem Fall die al-Aqsa Märtyrer Brigaden zur Tat bekannten, erscheint deren Emblem nirgendwo im Bildraum. Die fehlenden Märtyrer-Requisiten lassen darauf schließen, dass al-Akhras' Inszenierung in Eigenregie und ohne die Hilfe der Organisation erfolgte. Die ganze Zeit über hält Akhras einen Zettel in der Hand, von dem sie ihren Text abliest; nur gegen Ende hin hebt

222 Ziolkowski: Palästinensische Märtyrerinnen, S. 122.

223 Ayat al-Akhras sprengte sich am 29. März 2002 in einem Supermarkt in Jerusalem in die Luft und tötete dabei ein siebzehnjähriges israelisches Mädchen. 
sie den Kopf und richtet ihre Augen für einige Sekunden in die Kamera. Die in maskuliner Manier getragene Kufiya kann als Betonung der von ihr angeprangerten verkehrten Geschlechterrollen interpretiert werden (»Shame on the Arab armies who are sitting and watching the girls of Palestine fighting while they are asleep«). Die Verschleierung folgt hier also gerade nicht der islamischen Kleidernorm für Frauen, sondern ist als politische Botschaft zu verstehen.

Abbildung 3.22 (links): Ayat al-Akhras, Fotografie am oder vor dem 29. März 2002 entstanden; Abbildung 3.23 (rechts): Leila Khaled, Fotografie aus den 1970er Jahren, unbekannter Fotograf.
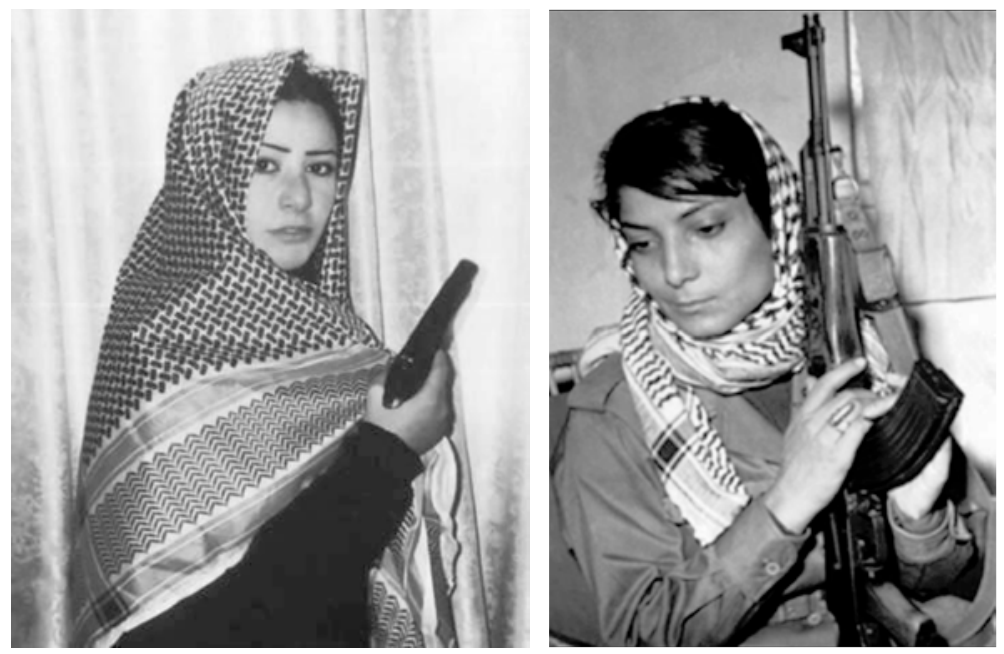

Neben der Videoaufnahme hinterließ Ayat al-Akhras eine Fotografie, die vermutlich im selben räumlichen Kontext entstanden ist und die junge Frau ebenfalls mit Kufiya zeigt (Abb. 3.22). Dieses Mal trägt sie das Tuch jedoch nicht auf die traditionell männliche Weise, sondern wie den Hijab der Frauen, der das Haupt vollständig bedeckt, hier aber nur locker um die Schultern geschwungen ist. Trat sie für das Video gänzlich unbewaffnet vor die Kamera, hält sie nun eine Pistole in ihrer Rechten, die in Brusthöhe vor ihrem Körper unbestimmt nach oben weist. Der intensive Blick in die Kamera sowie der leicht geöffnete Mund wirken auf geradezu verführerische Art herausfordernd; gleichzeitig entzieht sie sich durch die körperliche Abwendung den Augen der Betrachtenden. Obwohl die Pistole typischerweise als Zeichen maskuliner Aggression gelesen wird und ihr Posieren mit der Waffe an die männlichen Märtyrerbilder anschließt, greift al-Akhras’ kokettierende Körpersprache zusammen mit der Verschleierung auch auf stereotype Inszenierungen des Weiblichen zurück. 
Nähert sich al-Akhras mit ihrer Verschleierung im Video männlichen Konventionen an, orientiert sie sich in ihrer Inszenierung für das Foto in erster Linie an einem weiblichen Vorbild: der berühmten Fotografie von Leila Khaled, die durch ihre Beteiligung an zwei Flugzeugentführungen der PFLP in den Jahren 1969 und 1970 als weibliche Ikone des palästinensischen Widerstands in die Geschichte einging. Die bekannteste Darstellung zeigt sie mit einem Gewehr in der Hand und der Kufiya locker um Kopf und Schultern gehüllt (Abb. 3.23). Das Tragen der Kufiya war traditionell ausschließlich Männern vorbehalten und »hat in der palästinensischen Kultur des politischen Widerstands eine >macho<-spezifische Aura angenommen $\ll^{224}$, so die Islamwissenschaftlerin Angelika Neuwirth. Durch die prominente Aneignung dieses maskulinen Nationalsymbols rüttelte Khaled erstmals an den geschlechtlich festgeschriebenen Rollen im Widerstandskampf und setzte ein visuelles Exempel der Gleichberechtigung. ${ }^{225}$ In der Folge wurde Khaled von den Medien allerdings primär in Bezug auf ihren `Sexappeal wahrgenommen, der ihr den Ruf als »deadly beauty« oder »pin-up of armed struggle ${ }^{226}$ bescherte - und sie somit wieder in einen stereotypisch weiblichen Bezugsrahmen einbettete.

Nach Leila Khaled avancierte das Bild der bewaffneten, mit einer Kufiya umhüllten Frau in den 1980er-Jahren zu einer bekannten Ikonografie des weiblichen Widerstands und wurde durch zahlreiche Posterdrucke Teil der visuellen Tradition Palästinas. ${ }^{227}$ Nationalistische Poster, die erstmals in den 1960er-Jahren von der Palästinensischen Befreiungsorganisation (PLO) gedruckt wurden, bilden bis heute ein wichtiges Mittel der Mobilisierung zum Widerstand und werden

224 Angelika Neuwirth: »Blut und Tinte - Opfer und Schrift: Biblische und koranische Erinnerungsfiguren im vorderasiatischen Märtyrerdiskurs«, in: Andreas Kraß und Thomas Frank (Hg.): Tinte und Blut. Politik, Erotik und Poetik des Martyriums, Frankfurt am Main: Fischer 2008, S. 25-58, hier S. 52.

225 Im Interview mit dem Guardian 2001 sagte Leila Khaled rückblickend: »In the beginning, all women had to prove that we could be equal to men in armed struggle, so we wanted to be like men - even in our appearance.« Katherine Viner: »I made the ring from a bullet and the pin of a hand grenade«, The Guardian, 26.01.2001, http://www.guardian.co.uk/world/2001/jan/26/israel (zugegriffen am 6.6.2021).

226 Ebd.

227 Das von Dan Walsh gegründete Palestine Poster Project Archive versammelt allein knapp 1500 Poster mit weiblichen Figuren. Die Ikonografie der bewaffneten Frau bildet dabei ein häufig wiederkehrendes Motiv, http://www.palestineposterproject.org (zugegriffen am 6.6.2021). 
(ähnlich wie die Märtyrerposter) an Hauswände und in öffentliche Einrichtungen gehängt. ${ }^{228}$

Abbildung 3.24: Marc Rudin, Consolidating the Struggle for Equality, Poster der PFLP, 1985, ca. $58 \times 40,5 \mathrm{~cm}$.

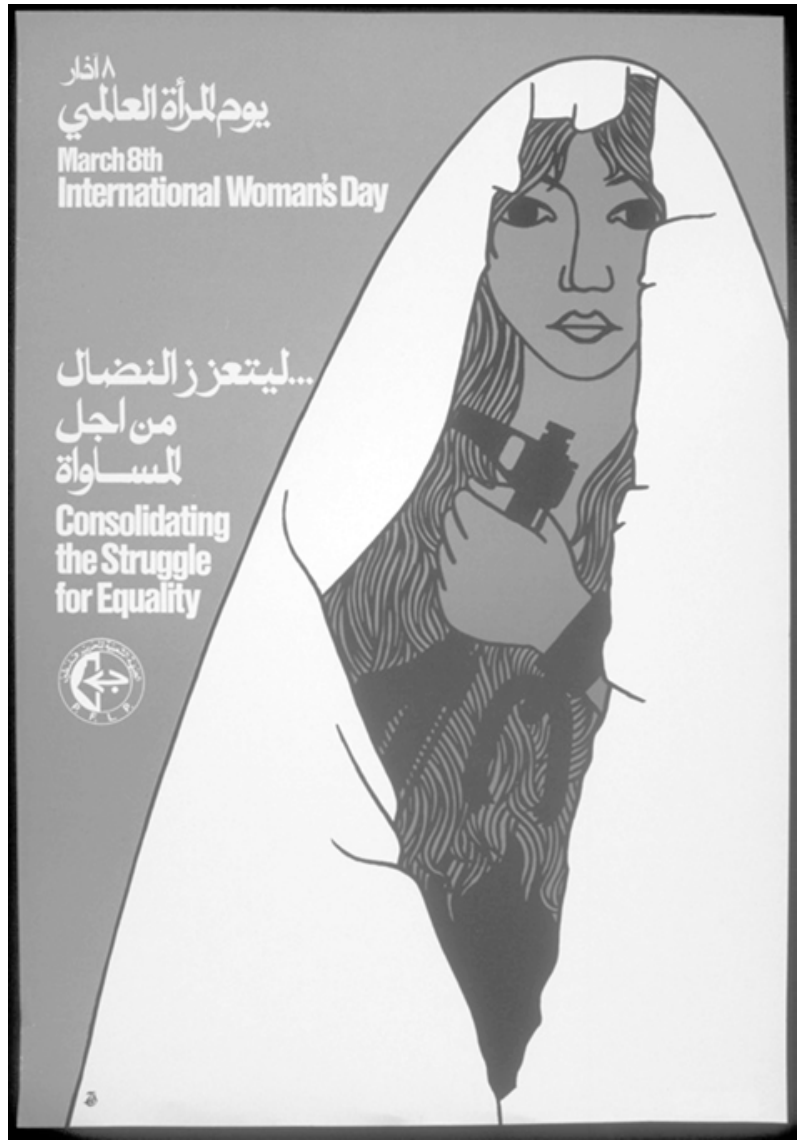

228 Vgl. Basma Guthrie: »Embodying a Stateless Nation: A Closer Look at Representations of Palestinian Women in Nationalist Posters - 1960's 1980’s» The Palestine Poster Project (2012), S. 1-35, hier S. 6, http://www.palestineposterproject.org/poster/ embodying-a-stateless-nation-a-closer-look-at-representations-of-palestinian-women -in (zugegriffen am 6.6.2021). 
Ein von der PFLP anlässlich des internationalen Frauentages 1985 in Auftrag gegebenes Plakat zeigt eine bewaffnete Frauenfigur mit Schleier, die eindeutige Parallelen zu al-Akhras' Inszenierung erkennen lässt (Abb. 3.24). Die Öffnung des weißen Tuches entspricht den Umrissen des historischen Palästinas, wodurch das Bild einen eindeutig nationalen Kontext bekommt. Durch den Titel Consolidating the Struggle for Equality wird der nationale Befreiungskampf hier gleichzeitig mit dem Kampf um Geschlechtergleichheit identifiziert. ${ }^{229}$ Am Handgelenk der Frau baumelt eine aufgebrochene Fessel als Zeichen der Befreiung, während ihre Hand ein Maschinengewehr umfasst. Die Waffe wird als Kontrast zur betont femininen Erscheinung der weiblichen Figur inszeniert - ein Gegensatz der auch in alAkhras' Bild hervorsticht. Wie Basma Guthrie in ihrer Studie dieser Poster deutlich macht, ist das Bild der bewaffneten Frau in der palästinensischen Kultur fest verankert: »While the PLO did not formally encourage women's military participation, many PLO posters portrayed women in arms. ${ }^{230}$ Bild-Symbolik und Realität klaffen dabei jedoch weit auseinander. Eine aktive Beteiligung am bewaffneten Widerstand war für die Frauen bis zur zweiten Intifada nicht vorgesehen und Figuren wie Leila Khaled blieben eine Ausnahme. Mit ihrer Inszenierung stellt sich Ayat al-Akhras eindeutig in diese Bildtradition und nimmt damit Bezug auf den säkularen und teilweise feministisch ausgerichteten Widerstand der 1970er und 1980er Jahre. Das männlich geprägte Bildschema der Videotestamente vermischt sich hier mit der nationalen Ikonografie der kämpfenden Palästinenserin.

Neben der Verschleierung treten in den Bildern weitere Besonderheiten auf, die sich von den Darstellungen der Männer unterscheiden und geschlechterspezifische Elemente einführen. Am auffälligsten ist sicherlich die Verschränkung von Militanz und Mutterschaft. Wenn auch nicht immer auf visueller Ebene vermittelt, so hat sich das Thema in die Tonspuren einiger Videobekenntnisse eingeschlichen (siehe dazu auch das Videotestament von Wajdi al-Sayigh, S. 108). Als Attentäterin des Islamischen Dschihad in Palästina sprengte sich Mirfat Mashud am 6. November 2006 in die Luft und hinterließ ein Video, das sich auf den ersten Blick weitgehend in die visuelle Schablone der männlichen Märtyrer des Islamischen

2291979 verkündete die PFLP, dass die Befreiung der Frau in den nationalen Befreiungskampf mit eingebunden werden sollte. Jedoch stellte dies lediglich ein nachgeordnetes Ziel dar, während Klassengleichheit und der Kampf um Landeigentum die primären Ziele der Befreiung waren. Vgl. Guthrie: »Embodying a Stateless Nation«, S. 18.

230 Ebd., S. 20. 
Dschihad einfügte. ${ }^{231}$ Eine Kalaschnikow fest in der Hand haltend, befindet sich die Attentäterin hinter einem Tisch, auf dem neben anderen schwer definierbaren Gegenständen (vermutlich Granaten) eine Koranausgabe liegt. Der Hintergrund wird von einem schwarzen Tuch mit goldenen arabischen Lettern begrenzt, wie es für die Videobekenntnisse des Islamischen Dschihad in Palästina bis heute typisch ist. Während die Attentäterin ihr Bekenntnis in ernstem Ton vorliest, sind im Hintergrund lebendige Kinderstimmen zu vernehmen. Eine ähnlich verstörende Verbindung von Mordbekundung und der gleichzeitigen Anwesenheit fröhlich spielender Kinder ist auch in Darin Abu Aishehs Video zu hören. Abu Aisheh hatte keine eigenen Kinder, daher ist zu vermuten, dass es sich hier um Geschwister oder Verwandte handelte. Die Settings der beiden Videoaufnahmen, die eine räumliche Kontextualisierung zunächst verweigern, werden durch diese unscheinbaren Details wieder in einen privathäuslichen - und insbesondere weiblichen Bezugsrahmen gestellt.

In den Bildern von Rim Riyashi erfährt diese Kollision einen grotesken Höhepunkt. Im Gegensatz zu ihren Vorgängerinnen, die meist alleinstehend und kinderlos starben, war die 22-jährige Riyashi verheiratet und Mutter von zwei Kindern. Mit ihrem Selbstmordattentat auf einen israelischen Checkpoint am 14. Januar 2004 war Riyashi außerdem die erste Märtyrerin der Hamas. Lehnte deren geistiger Führer, Scheich Ahmed Yassin, das weibliche Selbstmordattentat im Januar 2002 noch kategorisch ab, änderte er nun seine Meinung und befürwortete ihre Tat. ${ }^{232}$ Wie die Nahost-Historikerin Mira Tzoreff jedoch bemerkt, wurde gleichzeitig durch inoffizielle Quellen bekannt, dass Yassin weibliche Selbstmordattentäterinnen nur dann billigte, wenn diese zuvor die Ehre ihrer Familie >beschmutzt hatten. ${ }^{233}$ Kurze Zeit nach Rim Riyashis Attentat wurden Gerüchte über eine außereheliche Affäre laut, die Schande über sie und ihre Familie gebracht hätte. Ehemann und Liebhaber beschlossen angeblich gemeinsam, dass das Martyrium für Rim Riyashi der letzte Ausweg darstelle, die Ehre der Familie sowie ihr eigenes Ansehen wiederherzustellen. ${ }^{234}$ Die undurchsichtige, von

231 Das Video (1:52 min) wurde von der Autorin am 13.2.2014 von http://www.dailymotion.com/video/xjo2op heruntergeladen (nicht mehr verfügbar).

232 Vgl. Mira Tzoreff: »The Palestinian Shahida: National Patriotism, Islamic Feminism, or Social Crisis«, in: Yoram Schweitzer (Hg.): Female Suicide Bombers. Dying for Equality?, Tel Aviv 2006, S. 12-23, hier S. 21.

233 Vgl. ebd.

234 So der Bericht des israelischen Sicherheitsdienstes. Zitiert in Mia Bloom: »Terror's Stealth Weapon: Women«, Los Angeles Times, 29.11.2005, http://articles.latimes. com/2005/nov/29/opinion/oe-bloom29 (zugegriffen am 6.6.2021). Ähnlich wurde 
Gerüchten durchzogene Quellenlage, wie sie auch bei den anderen Selbstmordattentäterinnen zu beobachten ist, lässt es jedoch nicht zu, eindeutige Schlüsse in Bezug auf die tatsächliche Motivation und Selbstbestimmtheit der Selbstmordattentäterinnen zu ziehen. Anderen Berichten zufolge bezog Yassin eine weitaus pragmatische Position: Während die verschärften Sicherheitsbestimmungen an israelischen Checkpoints dazu führten, dass männliche Attentäter ihre Angriffsziele nur noch schwer erreichten, hätten es Frauen leichter, die Sperren zu passieren und `erfolgreiche< Attentate zu verüben. ${ }^{235}$

Das Videobekenntnis, das die Hamas nur wenige Stunden nach Rim Riyashis Attentat am 14. Januar 2004 veröffentlichte, folgt der vertrauten Inszenierung früherer (männlicher) Hamas-Videos: Hintergrund und Tisch, vor dem Riyashi wie eine Fernsehsprecherin sitzt, sind vollständig in grüne Tücher gehüllt auf denen Koranverse und das Zeichen der Hamas zu sehen sind (Abb. 3.25). Das grüne Stirnband, das über Riyashis schwarzen Hijab gebunden ist sowie die quer über die Brust gelegte Schärpe zitieren das islamische Glaubensbekenntnis. Auch ein beträchtliches Aufgebot an Waffen fehlt nicht: Auf dem Tisch liegen vier Handgranaten, die links und rechts von zwei länglichen Granatwerfern gesäumt werden. Während Riyashi Verse aus dem Koran und anschließend ihr Testament verliest, umfasst sie mit ihrer linken Hand ein Maschinengewehr. Im Unterschied zu ihren Vorgängerinnen trägt sie zudem eine Militäruniform. Die Uniform suggeriert eine aktive Beteiligung am Straßenkampf, obwohl dies für Frauen während der zweiten Intifada nicht üblich war. ${ }^{236}$ Während die Selbstmordattentäterinnen der al-Aqsa Märtyrer Brigaden meist mit Kufiya auftraten und die Attentäterinnen des Islamischen Dschihad streng muslimisch verschleiert blieben, bricht die Militärkluft der Hamas-Märtyrerin mit diesen Konventionen und macht stattdessen das Martialische ihrer Tat explizit.

dies auch von einem Hamas-Mitglied berichtet, den Yoram Schweitzer im Gefängnis interviewte. Schweitzer: »Palestinian Female Suicide Bombers: Reality vs. Myth«, S. 29.

235 Vgl. Hasso: »Discursive and Political Deployments by/of the 2002 Palestinian Women Suicide Bombers/Martyrs«, S. 34.

236 Vgl. Ziolkowski: Palästinensische Märtyrerinnen, S. 29f. 
Abbildung 3.25: Videotestament von Rim Riyashi, Hamas, Aufnahme am oder vor dem 14. Januar 2004, arabisch.

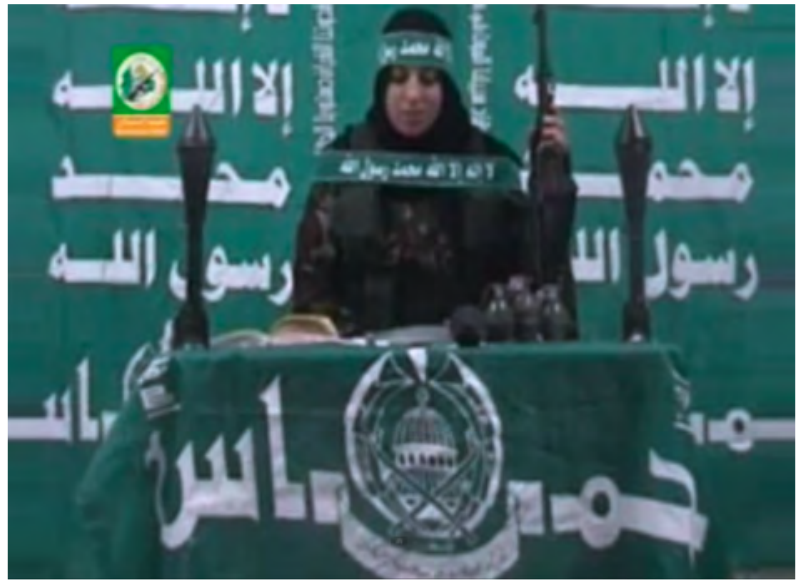

Abbildung 3.26: Fotografie von Rim Riyashi mit ihrer Tochter, am 26. Januar 2004 von der Hamas verbreitet.

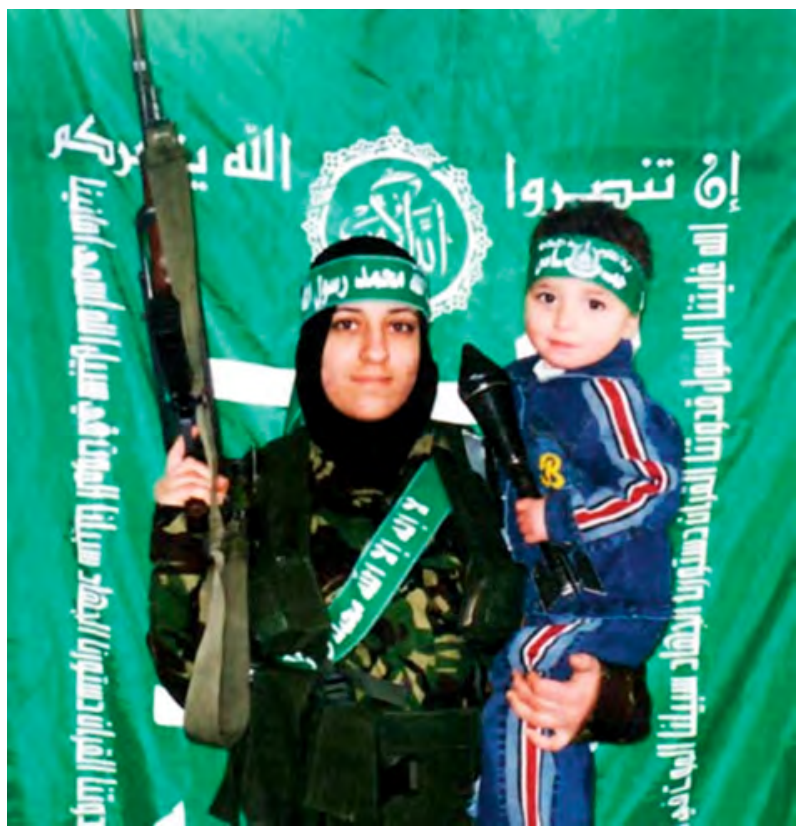


Demgegenüber stehen eine Reihe von Fotografien, die ebenfalls nach Riyashis Attentat von der Hamas veröffentlicht wurden und sie zusammen mit ihren einund dreijährigen Kindern zeigen (Abb. 3.27 a-b) ${ }^{237}$ Die zukünftige Attentäterin erscheint darauf in derselben militärischen Bekleidung mit Märtyrersymbolen wie im Video. Das Spielzeuggefährt und die Matratze mit Kissen im Hintergrund markieren die Umgebung eindeutig als privaten Wohnraum, auf dessen Teppichboden die glücklich lächelnde Rim Riyashi mit ihren beiden Kindern sitzt. Die Art und Weise ihrer Zuwendung erscheint zärtlich und fürsorgend; auf einer der Fotografien umarmt Riyashi ihre Tochter und küsst sie - wie zum Abschied - auf die Wange (Abb. 3.27 b). Das Bild dieser liebevollen Mutter-Kind-Beziehung erfährt durch die Anwesenheit der Waffen eine makabre Brechung. Neben dem Gewehr in Riyashis Hand, hält auch das Mädchen einen Granatwerfer wie ein unschuldiges Spielgerät in ihrer Linken. Die Insignien, die auf Riyashis Tat und das kommende Martyrium hinweisen, werden voller Stolz in Szene gesetzt, als ob sie Grund zur Freude darstellten. Der älteren Tochter wurde ebenfalls ein grünes Märtyrerstirnband umgebunden. Dies kann als Hinweis gelesen werden, dass durch die Tat der Mutter auch deren Familienmitglieder eine besondere Würdigung erfahren (ohne dass diese selbst den Märtyrertod sterben).

Abbildung 3.27 a-b: Fotografien von Rim Riyashi mit ihren Kindern, am 26. Januar 2004 von der Hamas verbreitet.
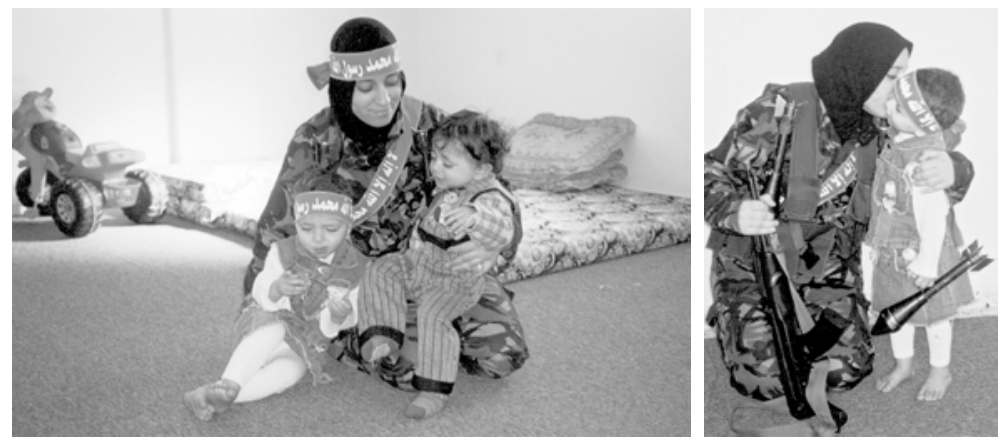

Mediale Bekanntheit erlangten jedoch weniger diese informellen Schnappschüsse, sondern eine weitere Fotografie, die durch ihren streng symmetrischen und formalisierten Bildaufbau besticht. Sie zeigt Riyashi vor demselben grünen Tuch, das

237 Das Alter der Kinder wird in den verschiedenen Publikationen unterschiedlich angegeben. Von einem ein- und dreijährigen Kind spricht Brunner: Männerwaffe Frauenkörper?, S. 105. 
auch in ihrem Videotestament zu sehen ist (Abb. 3.26). Auf ihrem linken Arm sitzt die dreijährige Tochter, die erneut eine Handgranate wie ein unschuldiges Spielgerät umklammert. Mutter und Kind blicken direkt in die Kamera, was dieser Szene eine besonders intensive Wirkung verleiht. Die weiße Schrift fungiert als Rahmung des Doppelportraits und das runde Ornament, welches die Worte $» \mathrm{Al}$ lahu Akbar« enthält, erscheint wie ein leicht nach rechts verrutschter Heiligenschein über Riyashis Kopf. Die frontale Stellung vor dem flachen Hintergrund, die Pose des Kindes und der in sich ruhende Gesichtsausdruck der verschleierten Frau evozieren - vielleicht unbeabsichtigt - den christlichen Bildtypus der Madonna-mit-Kind, der in diesem Kontext wie eine Provokation erscheint. Die Inszenierung erschüttert jedoch nicht nur vertraute westliche Bildformeln sondern irritiert (zumindest auf den ersten Blick) auch traditionelle palästinensische Geschlechterrollen. Britt Ziolkowski bemerkt in diesem Zusammenhang: »Vor allem in einer konservativ-traditionellen Gesellschaft, wie man sie in Palästina vorfindet, wird der Betrachter Gewehr und Granate nicht mit seinem Bild von Weiblichkeit und weiblichem Verhalten vereinen können. «"238 Auch wenn diese Beobachtung für den Kontext der zweiten Intifada zutreffen mag, ergibt sich ein ganz anderer Eindruck, wenn man sich erneut der Bildtradition des Landes zuwendet. Gerade in der nationalistischen Kunst Palästinas zeigt sich, dass kämpfende Mütter ein rekurrierendes Motiv darstellen. ${ }^{239}$ Ein Plakat das 1976 für die Fatah produziert wurde, zeigt etwa die weißen Umrisse einer Frau, die vor sich ein Bündel mit einem Baby trägt (Abb. 3.28). Zusätzlich ist um ihren Körper ein Maschinengewehr gebunden, das hinter ihrem Rücken sichtbar wird. Basma Guthrie bemerkt: »This poster seems riddled with ambiguity, with dichotomous representations of childrearing and warfare, as well as domesticity and armed struggle, side-byside. ${ }^{240}$ Gleichzeitig betont sie: »The woman in this poster does not appear prepared for battle. This indicates that the gun and the child share a symbolic rather than literal parallel. ${ }^{241}$ Auf einem anderen Poster, das 1986 für die PFLP gestaltet wurde, ist eine bewaffnete Frau zu sehen, die zusammen mit ihrem Baby in eine Kufiya gehüllt ist (Abb. 3.29). Während sie mit der einen Hand den Kopf des Kindes schützend umfasst, ragt aus der Öffnung des Tuches ein Gewehrlauf, dem sie mit ihrem wachsamen Auge folgt. Der Titel The Land sowie die Kufiya als nationales Symbol charakterisieren die Frau als idealtypische Verkörperung des

238 Ziolkowski: Palästinensische Märtyrerinnen, S. 63.

239 Vgl. Guthrie: »Embodying a Stateless Nation«, S. 13.

240 Ebd., S. 16.

241 Ebd. 
weiblichen Widerstandes, deren Aufgaben sowohl die Kindererziehung als auch den bewaffneten Kampf umfassen.

Abbildung 3.28 (links): Adnan al-Sharif: The Women Struggle a Corner Stone on the Road to Liberation, Poster der Fatah, 1976; Abbildung 3.29 (rechts): Marc Rudin, The Land, Poster der PFLP, 1986.
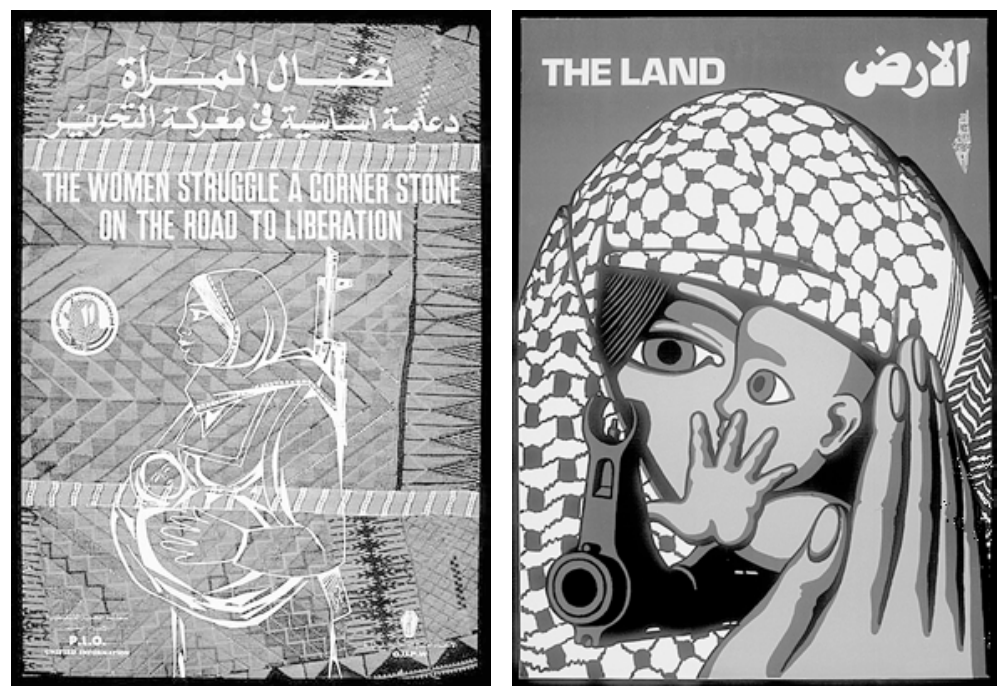

Wie die beiden Poster exemplarisch zeigen (und wie zahlreiche weitere Poster aus dem Archiv des Palestine Poster Project belegen), ${ }^{242}$ waren Mutterschaft und Militanz im Palästina der 1970er und 1980er Jahre symbolisch eng miteinander verknüpft. In Flugblättern der ersten Intifada wurden palästinensische Frauen als »Männerproduktionsmaschinen« (manabit) mit »militärischer Gebärmutter« (batn askari) bezeichnet. ${ }^{243} \mathrm{Als} »$ Mütter der Nation« sollten die Frauen in erster Linie zukünftige Kämpfer und Märtyrer gebären. ${ }^{244}$ Der weibliche Körper wurde als nationale Waffe stilisiert und als demografische Kriegsstrategie gegen Israel eingesetzt, wie Basma Guthrie ausführt. ${ }^{245}$ Trotz der militärischen Rhetorik und Bildsprache beschränkte sich das Aktionsfeld der Frau während der ersten Intifada

242 Vgl. das Online-Archiv des Palestine Poster Project, http://www.palestineposterproject.org (zugegriffen am 6.6.2021).

243 Zitiert in Tzoreff: »The Palestinian Shahida«, S. 13.

244 Ebd.

245 Vgl. Guthrie: »Embodying a Stateless Nation«, S. 17. 
jedoch ausschließlich auf den Privatraum und forderte ihre Teilnahme am nationalen Kampf nur innerhalb geschlechtsspezifischer Rollen. Die fotografische Inszenierung Riyashis scheint an diese Bildtradition anzuknüpfen; das Mädchen auf ihrem Arm kann neben dem Gewehr als weitere Waffe in diesem übertragenen Sinne begriffen werden. Allerdings wird die symbolische Militanz hier in die Tat umgesetzt: Als Subversion jenes Märtyrermutter-Ideals der ersten Intifada verwandelt Riyashi ihren Körper in eine Waffe, die nicht nur als »Männerproduktionsmaschine « dient, sondern auch zur Vernichtung von Menschenleben eingesetzt wird. Die Bilder der bewaffneten Märtyrerinnen - so ließe sich folgern - stellen für Palästinenser*innen kein schockierendes Novum dar (wie es aus westlicher Perspektive zunächst erscheinen mag), sondern knüpfen an eine bekannte Darstellungstradition an, die nun allerdings realisiert und damit radikalisiert wird.

Wie die medialen Inszenierungen der Selbstmordattentate von Dalal Mughrabi (1978) oder Sana Muhaydli (1985) gezeigt haben, waren Bilder von weiblichen Märtyrerinnen Anfang des neuen Jahrtausends an sich keineswegs neu. Das eigentlich Neue war nun jedoch, dass das Geschlecht zu einer zentralen Kategorie erhoben und explizit thematisiert wurde. Die Videotestamente der palästinensischen Selbstmordattentäterinnen ab 2002 enthalten teilweise genderpolitische Forderungen und üben offene Kritik an den arabischen Männern. Auch wenn ihre visuellen Inszenierungen zum Großteil auf männliche Vorbilder rekurrieren, knüpfen sie zum Teil auch an palästinensische Frauenbilder der 1970er und 1980er Jahre an und stellen das Bild der Märtyrerin damit in einen (mehr oder weniger expliziten) feministischen Zusammenhang. Insgesamt ergibt sich ein sehr heterogenes Bild der weiblichen Selbstmordattentäterin, das stereotypisch $>$ weibliche< Rollenzuschreibungen auch reproduziert, beispielsweise in der Betonung des Opferstatus bei Darin Abu Aisheh. Die von Ziolkowski formulierte Annahme, die Märtyrerportraits der Frauen reihten sich unterschiedslos in die ikonografische Tradition der Männer ein, ist vor diesem Hintergrund nicht haltbar, übersieht sie doch eine Reihe von Elementen, die ganz im Gegenteil typisch >weiblichen< Darstellungskonventionen folgen. Mit dem Motiv der Mutterschaft wurde etwa ein grundlegend neues Element in die Märtyrerikonografie eingeführt, das exklusiv auf weibliche Werte zugeschnitten ist. Bei den Bildern der Frauen handelt es sich also nicht nur um Imitationen der männlichen Märtyrer-Inszenierungen, sondern um eine Hybridisierung verschiedener Bildtraditionen und Geschlechterrollen. Die Portraits der Attentäterinnen konfrontieren uns mit einem Frauenbild, das zwischen Mutterschaft und militanter Gewalt, betonter Weichheit und kompromissloser Kampfbereitschaft changiert. 


\section{Digitale und künstlerische Postproduktionen}

Wurden die Videotestamente libanesischer Selbstmordattentäter*innen zunächst in den regionalen Nachrichten, über eigene Fernsehkanäle (zum Beispiel Hisbollahs al-Manar) oder durch den Verkauf von Videokassetten verbreitet, zirkulieren die palästinensischen Märtyreraufnahmen seit der zweiten Intifada fast ausschließlich im Internet. ${ }^{246}$ Sie werden auf den Webseiten der verantwortlichen Organisationen gepostet, auf YouTube, Facebook und Twitter hochgeladen oder in einschlägigen Foren geteilt. Videotestamente und Märtyrerfotografien, die von den verantwortlichen Parteien ins Netz gestellt werden, können prinzipiell von jedem internetfähigen Computer und Smartphone aus heruntergeladen, bearbeitet und neu in Umlauf gebracht werden, was einen kontinuierlichen Prozess des Austausches und der Wiederaneignung der Bilder zur Folge hat. Das gilt insbesondere für die Bilder weiblicher Selbstmordattentäterinnen ab 2002, über die in arabischen wie in westlichen Medien mit großem Interesse berichtet wurde. ${ }^{247}$ Die (Selbst-)Inszenierungen der Frauen lösten eine regelrechte Kaskade an digitalen Bildmontagen aus, die von affirmativen >Tribute Songs` auf YouTube bis hin zu radikalen Neukontextualisierungen reichten und den palästinensischen Märtyrerkult mit westlichen Geschlechterdiskursen in Verbindung brachten.

Die Macht der Bilder im digitalen Zeitalter, so argumentiert der Kunsttheoretiker und Kurator Nicolas Bourriaud, liegt nicht mehr allein in ihrer Produktion, sondern zunehmend im Bereich der Postproduktion. Damit bezieht sich Bourriaud auf einen technischen Terminus der Fernseh-, Film- und Videoproduktion, der sämtliche Nachbearbeitungsprozesse wie Bildmontage, Untertitelung, Voiceover sowie das Hinzufügen bestimmter Special Effects umfasst. Jedem Bildprodukt

246 Teile dieses Unterkapitels basieren auf Verena Straub: »Digitale Postproduktionen. Die Zirkulation von Bildern palästinensischer Selbstmordattentäterinnen im Internet, in: Isabelle Busch, Uwe Fleckner und Judith Waldmann (Hg.): Nähe auf Distanz. Eigendynamik und mobilisierende Kraft politischer Bilder im Internet, Hamburger Forschungen zur Kunstgeschichte, Berlin: De Gruyter 2020, S. 157-175.

247 Dies haben zahlreiche Medienanalysen eindrücklich gezeigt. Vgl. Hasso: »Discursive and Political Deployments by/of the 2002 Palestinian Women Suicide Bombers/Martyrs«; Avi Issacharoff: »The Palestinian and Israeli Media on Femal Suicide Terrorists «, in: Yoram Schweitzer (Hg.): Female Suicide Bombers. Dying for Equality?, Tel Aviv 2006, S. 43-50; Naaman: »Brides of Palestine/Angels of Death«; Brigitte L. Nacos: »The Portrayal of Female Terrorists in the Media: Similar Framing Patterns in the News Coverage of Women in Politics and Terrorism«, Studies in Conflict \& Terrorism 28 (2005), S. 413-419. 
gehen folglich schon eine Vielzahl von Bearbeitungen voraus, was die Existenz eines >ursprünglichen`, abgeschlossenen oder >originalen` Werks in Frage stellt. Ausgehend von der Beobachtung, dass auch zeitgenössische Künstler*innen zunehmend auf Techniken der Postproduktion zurückgreifen, indem sie beispielsweise vorgefundenes Bildmaterial >remixen`, erweitert Bourriaud den technischen Terminus im Hinblick auf sein kritisches Potenzial. Auch wenn künstlerische Praktiken des Zitierens, der Aneignung von Bildmaterial und des Détournements keineswegs erst mit der Zirkulation der Bilder im Internet auftauchten, erreichten sie dort eine neue Stufe. ${ }^{248}$ Die $» K u n s t$ der Postproduktion« im digitalen Zeitalter arbeite, so Bourriaud, nicht mehr auf der Basis von Bildern als »Rohmaterial« sondern ausgehend von Bildern, die bereits auf dem kulturellen Markt zirkulieren und durch andere Bilder geprägt, durch Aneignungen und Bearbeitungen geformt und damit immer schon postproduziert sind. ${ }^{249}$ Jede neue Postproduktion, jedes Sampling, jede Montage wird dann zum Ausgangspunkt neuer Bearbeitungen, wobei das Bild nicht mehr als fertiges Produkt zu begreifen ist, sondern als »site of navigation $\aleph^{250}$ (Navigationsort), als Portal und Auslöser immer neuer Bild-Aktivitäten. Die Schnelligkeit und Simultanität, mit der diese Prozesse ablaufen, wird durch die interaktive Struktur des Webs 2.0 auf nie zuvor dagewesene Weise potenziert. Traditionelle Unterscheidungen zwischen Produktion und Konsumption, zwischen Schöpfung und Kopie, zwischen Readymade und Original lösen sich dabei immer mehr auf. Mehr noch als der Begriff der Appropriation, der Bourriaud zufolge immer noch von einem originalen 〉Besitzer des Bildes ausgeht, wird das Konzept der Postproduktion einem kollektiven Ideal des `Sharing〈, des konstanten In-Bewegung-Setzens von Bildern gerechter. ${ }^{251}$

Was Bourriaud vor allem anhand künstlerischer Strategien zeigt, trifft auch auf den politischen Umgang mit digitalen Bildern zu - so soll im Folgenden deutlich werden. Schon die veröffentlichten Fotografien und Videotestamente der Selbstmordattentäterinnen, die von den verantwortlichen Parteien meist nachträglich geschnitten, mit digitalen Parteiemblemen, Überschriften und teilweise mit englischen Untertiteln versehen werden, sind Ergebnis etlicher Bearbeitungsprozesse. Wie die Beispiele von Wafa Idris und Darin Abu Aisheh bereits gezeigt

248 Détournement ist ein Begriff, der von der Situationistischen Internationale um Guy Debord geprägt wurde und unter anderem die Zweckentfremdung von Bildern durch veränderten Gebrauch meint.

249 Nicolas Bourriaud: Postproduction: Culture as Screenplay: How Art Reprograms the World, 2. Aufl., New York: Lukas \& Sternberg 2007, S. 13.

250 Ebd., S. 19.

251 Ebd., S. 11. 
haben, waren ihre Märtyrerbilder von Anfang an Teil widersprüchlicher Aneignungsprozesse, bzw. Postproduktionen.

Dank weit verbreiteter Bildbearbeitungssoftwares wie Adobe Photoshop oder Apple Final Cut können aber nicht nur militante Organisationen, sondern auch private Internet-User*innen ohne große technische Vorkenntnisse die Aufnahmen der Selbstmordattentäterinnen bearbeiten und mit wenigen Klicks neu kontextualisieren. Ausgehend von Bourriauds Überlegungen lässt sich das Bild der Selbstmordattentäterin daher als kollektiver, fluider und damit instabiler Prozess von Bedeutungszuschreibungen fassen. Die einzelnen Bilder sind nicht als Endpunkte zu begreifen, sondern stellen lediglich Stationen in einer Reihe von Bildbearbeitungen dar. Im Internet verbreitete Märtyrermontagen, die prinzipiell von jeder Person, überall auf der Welt hergestellt und weiterbearbeitet werden können, sind damit ebenso aktiv an der Konstitution der Selbstmordattentäterin als Märtyrerin (dem 〉Erzeugen $<$ ihres Martyriums) beteiligt wie die Bilder der militanten Parteien selbst.

Als anonyme Post-Postproduktion der bereits besprochenen Hamas-Genealogie (Abb. 2.2, S. 47) kursierte im Netz eine leicht veränderte Montage, die durch zwei weitere Attentäterinnen aus dem Jahr 2006 ergänzt wurde (Abb. 3.30). ${ }^{252}$ Während die teils retuschierten Hijabs der Hamas-Montage bestehen blieben, wurden sowohl die grünen Stirnbänder der Hamas, als auch die gold-schwarzen des Islamischen Dschihad restlos von den Portraits entfernt. Die Portraits erscheinen nicht mehr eingebettet in die corporate identity einer bestimmten Partei, sondern in einer transzendentalen Umgebung, die sich einem konkret politischen $\mathrm{Zu}$ sammenhang verweigert. Statt des grünen Hintergrunds, der auf die visuelle Identität der Hamas verweist, werden die Attentäterinnen nun vor einem violetten Farbverlauf präsentiert. Der vordere linke Bildrand wird zudem von einer Blumenranke begrenzt, die als Verweis auf den Eintritt ins Paradies zu lesen ist. Der Titel weist die Dargestellten als »Leuchttürme auf dem Weg ins Licht« aus, was diese Paradiessymbolik zusätzlich unterstreicht. Im Gegensatz zu den digitalen Montagen der Fatah und Hamas, die mit integrierten Parteiemblemen und der Verbreitung durch parteieigene Social-Media-Kanäle ihre Autorschaft zum Ausdruck bringen, sind Urheberschaft und Entstehungskontext dieses Bildes kaum nachzuvollziehen. 2008 wurde es zusammen mit anderen Bildern palästinensischer Selbstmordattentäterinnen im arabischen Forum »Die Welt der Frauen« von einer

252 In erster Reihe ist nun die 64-jährige Fatimah Omar Mahmoud Al-Najar zu sehen, die am 23. November 2006 ein Selbstmordattentat für die Hamas verübte; hinten rechts erscheint zusätzlich das Bild von Mirfat Mashud, die am 6. November 2006 ein Selbstmordattentat im Namen des Islamischen Dschihad in Palästina verübte. 
Person aus Saudi-Arabien gepostet; 2011 tauchte dieselbe Montage auf einem ägyptischen Blog zusammen mit Märtyrerbildern der ägyptischen Proteste auf. ${ }^{253}$ Schließlich kursierte die Montage auch als Teil mehrerer Clips auf YouTube, in denen sämtliche Bilder palästinensischer Selbstmordattentäterinnen wie in einer Ehrenprozession aufeinander folgen. ${ }^{254}$ Mit Liedern und kämpferischen Gesängen unterlegt, verstehen sich solche Clips häufig als >Tribute Songs` für die palästinensischen Märtyrerinnen und werden von anonymen Sympathisant*innen erstellt und hochgeladen.

Abbildung 3.30: Anonyme, undatierte Montage mit Fotos palästinensischer Selbstmordattentäterinnen (2002-2006).

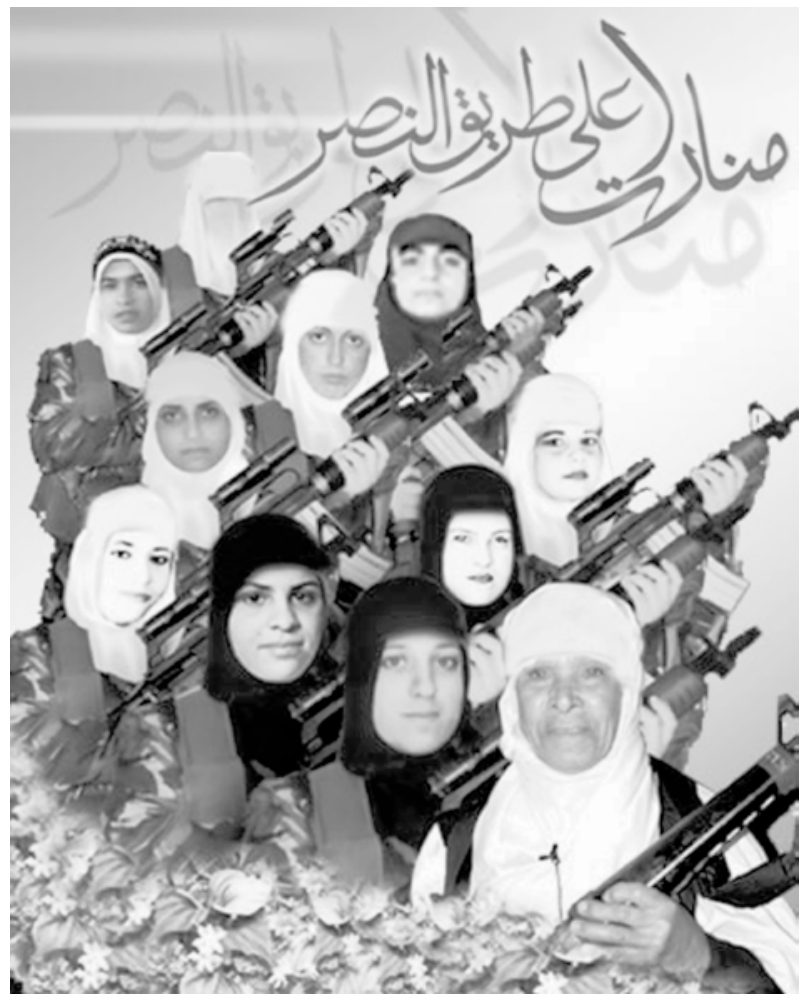

253 Vgl. http://www.4women.co/t100073.html (zugegriffen am 14. 5. 2016, nicht mehr verfügbar) und http://e 7sasmero.blogspot.de (zugegriffen am 6.6.2021).

254 Vgl. eine als »Tribute Song to Female Palestinian Martyr« betitelte Montage, die am 9.9.2009 von »2007Revolution« auf YouTube geladen wurde: http://www.youtube. $\mathrm{com} /$ watch? $\mathrm{v}=\mathrm{sfRpEbCJohU}$ (zugegriffen am 30.9.2012, nicht mehr verfügbar). 
Allein diese Beispiele machen deutlich, dass sich die Postproduktionen der palästinensischen Selbstmordattentäterinnen als transnationale Phänomene beschreiben lassen, die sich jenseits regionalpolitischer Ziele wie Memes im Internet verbreiten. Durch das Posten der Bilder realisiert sich einerseits eine internationale Gemeinschaft der Solidarisierung mit dem militanten Widerstand palästinensischer Frauen, gleichzeitig scheinen die Bilder aber auch in den Kontext anderer politischer Zusammenhänge gestellt zu werden (wie am ägyptischen Beispiel deutlich wird). Mit Nicholas Mirzoeff lässt sich hier auch von einer »Deterritorialisierung $\ll^{255}$ der Bilder sprechen, die durch unterschiedlichste gesellschaftliche und kulturelle Kontexte wandern und dadurch ihre Bedeutung verändern. Im Gegensatz zu den Fatah- und Hamas-Montagen (Abb. 2.2 und Abb. 2.15), deren Bildpolitiken in lokale Machtpolitiken eingebunden sind, werden die Kontexte dieser meist anonymen Postproduktionen zunehmend diffus. Gerade in Zeiten der digitalen Zirkulation der Videotestamente und Märtyrerfotografien im Internet sind die Grenzen zwischen Produktion und Rezeption nicht mehr klar voneinander zu trennen und Bildphänomene lassen sich am besten als kontinuierliche Bewegung von Postproduktionen fassen.

Mit der weltweiten Verbreitung der Videotestamente, Fotografien und Montagen im Internet wurden die Bilder palästinensischer Selbstmordattentäterinnen zunehmend auch in nicht-arabischsprachigen Kontexten rezipiert. In westlichen Medien lösten die Bilder der Selbstmordattentäterinnen ab 2002 in erster Linie Reaktionen der Verwunderung und des Schocks aus. Wie etliche Analysen der westlichen Berichterstattung bereits ausführlich gezeigt haben, wurde das Auftreten weiblicher Selbstmordattentäterinnen als >Anomalie und Abweichung von einem traditionellen Frauenbild angesehen, das muslimischen Gesellschaften vom Westen häufig zugeschrieben wird. ${ }^{256}$ Die ungleich höhere Aufmerksamkeit, die den weiblichen Selbstmordattentäterinnen im Vergleich zu ihren männlichen Mitstreitern in westlichen Medien zukam, verdeutlicht, dass das Bild der Selbstmordattentäterin offenbar immer noch spektakulärer und erklärungsbedürftiger

255 Nicholas Mirzoeff: »Von Bildern und Helden. Sichtbarkeit im Krieg der Bilder«, in: Lydia Haustein, Bernd M. Scherer und Martin Hager (Hg.): Feindbilder: Ideologien und visuelle Strategien der Kulturen, Göttingen: Wallstein 2007, S. 135-156.

256 Zur westlichen Berichterstattung über die palästinensischen Selbstmordattentäterinnen vgl. Brunner: Männerwaffe Frauenkörper?; Issacharoff: »The Palestinian and Israeli Media on Femal Suicide Terrorists«; Naaman: »Brides of Palestine/Angels of Death«; Nacos: »The Portrayal of Female Terrorists in the Media: Similar Framing Patterns in the News Coverage of Women in Politics and Terrorism«; Yadlin: »Female Martyrdom: The Ultimate Embodiment of Islamic Existence?« 
erscheint. Im Unterschied zu den männlichen Selbstmordattentätern, deren politisch-religiöse Motivation als selbstverständlich galt, wurde bei den Frauen immer auch nach persönlichen Beweggründen und psychologischen Erklärungsmustern gesucht. ${ }^{257}$ Neben dem äußeren Erscheinungsbild beschäftigten sich westliche und israelische Medien geradezu obsessiv mit dem sozialen Hintergrund der Attentäterinnen, mit individuellen Problemen (wie Scheidung oder unerfülltem Kinderwunsch) und traumatischen Erfahrungen (wie dem Tod von Familienangehörigen). ${ }^{258}$ Etliche journalistische wie akademische Texte stellten die Frauen zudem weniger als Täterinnen, sondern als Opfer patriarchaler Strukturen dar, als hilflose Waffen in Männerhand, die von den Drahtziehern manipuliert und missbraucht wurden. ${ }^{259}$ Eine rein politische Motivation wurde den Frauen dadurch häufig abgesprochen, stattdessen wurden sie wieder in stereotypisch weibliche und orientalistische Narrative eingepasst.

Ähnliches lässt sich über die meisten Kunstwerke sagen, die als Reaktion auf die weiblichen Selbstmordattentäterinnen entstanden sind. Grundsätzlich lassen sich zwei künstlerische Tendenzen erkennen, die die Frauen entweder sexualisieren oder mythisch überhöhen. Werke wie die Suicide Bomber Barbie (2002) des britischen Künstlers Simon Tyszko oder die Global Pinup Drawings (2008) von Ivana Spinelli setzen auf eine Kollision zwischen der sexualisierten Bildsprache der Werbe- und Modewelt und dem weiblichen Selbstmordattentat, das angeblich zu einer $»$ lifestyle choice $«{ }^{260}$ für junge Palästinenserinnen geworden sei. Auch der

257 Vgl. Brunner: Männerwaffe Frauenkörper?, S. 108; Issacharoff: »The Palestinian and Israeli Media on Femal Suicide Terrorists«, S. 43f.; Naaman: »Brides of Palestine/Angels of Death «, S. 936.

258 Vgl. Issacharoff: »The Palestinian and Israeli Media on Femal Suicide Terrorists«, S. 43f.; Nacos: »The Portrayal of Female Terrorists in the Media: Similar Framing Patterns in the News Coverage of Women in Politics and Terrorism«, S. 438f.

259 Als paradigmatisch kann hierfür das Buch der Journalistin Barbara Victor gelten, die Selbstmordattentäterinnen als »example of the exploitation of women taken to a cynical and lethal extreme« rahmt. Barbara Victor: Army of Roses: Inside the World of Palestinian Women Suicide Bombers, Emmaus: Rodale 2003, S. 8. Dorit Naaman nennt aber auch akademische feministische Positionen wie die von Andrea Dworkin oder Mia Bloom, die sich einer ähnlichen Argumentation bedienen. Vgl. Naaman: »Brides of Palestine/Angels of Death«, S. 943. Vgl. dazu auch Brunner: Männerwaffe Frauenkörper?, S. 23f.

260 Institute of Contemporary Arts (ICA): »Simon Tyszko, Suicide Bomber Barbie«, London 2002, in Simon Tyszko: »Suicide Bomber Barbie«, http://www.theculture.net/barbie/index.html\#texts (zugegriffen am 6.6.2021). Zu den Global Pinup 
norwegische Künstler Stahl Stenslie rahmte das Selbstmordattentat als Modeerscheinung, als »fashionable phenomenon $\aleph^{261}$. Für seine Performance S.U.F.I. Suicide Fashion International (2005) entwarf er »suizidtaugliche« und hypersexualisierte Kleidungsstücke, mit denen die Attentäterinnen selbst noch im Tod gut aussehen sollten (»looking great while dying «). ${ }^{262}$ Auch wenn die Werke als Kritik an der Glorifizierung der Selbstmordattentäterinnen angelegt sind, kommen sie kaum über einen oberflächlichen Schockeffekt hinaus. Durch die Verschränkung von Sex und Gewalt zielen diese Werke auf eine Provokation ab, die letzten Endes auf gewohnten westlichen Bildklischees beruht, die Kelly Oliver folgendermaßen beschrieben hat: »Indeed, the association between sex and violence trades on stereotypical images and myths of dangerous or threatening women upon which our culture was, and continues to be, built. $\ll^{263}$ Statt einer Bildkritik wird die Darstellung der Selbstmordattentäterin in einen radikalen `Chicく überführt. Zusätzlich wird die hypersexualisierte Selbstmordattentäterin wieder einem klischeehaft >männlichen` Blick unterworfen: Vom Täter-Subjekt wird sie in ein Sex-Objekt verwandelt, von dem keine ernstzunehmende Gefahr ausgeht. Dabei werden nicht zuletzt die genderkritischen Kommentare ignoriert, die die Attentäterinnen selbst in ihren Videotestamenten formulieren und die sich solchen Projektionen eigentlich widersetzen.

Als eigentliche Postproduktionen im Bourriaudschen Sinne können schließlich diejenigen künstlerischen Arbeiten gelten, die von den Fotos und Videos der Attentäterinnen selbst ausgehen - und damit eine weitere Stufe der kontinuierlichen Bearbeitung dieser Bilder darstellen. Die Portraitfotografie von Hanadi Jaradat diente als Ausgangspunkt einer Installation, die 2004 in Stockholm gezeigt wurde und einen regelrechten Skandal auslöste. Das Werk des israelisch-schwedischen Künstlerpaares Dror Feiler und Gunilla Sköld-Feiler wurde bei der

Drawings von Ivana Spinelli siehe Manon Slome: »The Aesthetics of Terror«, in: Slome/Simon: The Aesthetics of Terror, S. 8-29, hier S. 18.

261 Die Performance wurde als Teil des »Touch Me« Festivals 2005 in Zagreb, Kroatien präsentiert. Im Pressetext hieß es: »In this post-catastrophe decade of the 911, suicide has become a fashionable phenomenon.« In: http://www.kontejner.org/sufi-suicidefashion-international-presents-ka-boom-edition-english (zugegriffen am 26.9.2012, nicht mehr verfügbar).

262 »The S.U.F.I. project is developing fashion clothing custom fit for suicide. All models are quality controlled and fully functional. Six to ten models will be presented at the Zagreb venue, looking great while dying.« In ebd.

263 Kelly Oliver: Women as Weapons of War: Iraq, Sex, and the Media, New York: Columbia University Press 2007, S. 3. 
Ausstellungseröffnung in Stockholm vom israelischen Botschafter attackiert und beschädigt. Die Installation Schneeweiß und der Wahnsinn der Wahrheit (schwedisch: Snövit och sanningens vansinne) bestand aus einem langen, rechteckigen Pool, der mit blutrot gefärbtem Wasser gefüllt war und in Kontrast zur schneebedeckten Umgebung des Museumsgartens stand. ${ }^{264}$ In der Mitte des Pools schwamm ein kleines weißes Boot, dem die Künstler den Namen »Snövit« (»Schneeweiß«, bzw. »Schneewittchen«) gaben und das ein Portraitbild von Hanadi Jaradat trug. Die 27-jährige Jurastudentin aus Jenin verübte am 4. Oktober 2003 ein Selbstmordattentat mit einem Sprengstoffgürtel im Namen des Islamischen Dschihad in Palästina. Der Anschlag auf das Restaurant Maxim in Haifa kostete 21 Menschen das Leben, darunter vier Kinder; 51 weitere Personen wurden schwer verletzt. ${ }^{265}$ Bei der Portraitaufnahme handelt es sich nicht um ihre Märtyrer-Inszenierung, sondern um ein privates Passbild, auf dem Jaradat mit rot geschminkten Lippen und schwarzem Kopftuch in die Kamera lächelt, was die Künstler*innen offenbar an die Märchenfigur Schneewittchen erinnerte. ${ }^{266}$ Das Bild der Selbstmordattentäterin wurde durch diese Neurahmung einmal mehr in Bewegung versetzt und mit dem Bedeutungshorizont der westlichen Märchenwelt verschränkt. Die Texte an den Wänden verwoben israelische Presseberichte über Hanadi Jaradat mit Auszügen aus dem Märchen der Gebrüder Grimm. ${ }^{267}$ Schneewittchen wird vor allem durch ihre außergewöhnliche Schönheit, Unschuld und einen naiven Glauben charakterisiert - eine Beschreibung, die sich mit vielen westlichen Medienberichten überlagert, die sich ebenfalls auf das Aussehen der Attentäterin konzentrierten und sie als Opfer fanatischen Glaubens portraitierten. ${ }^{268}$ Die Kunstkritikerin Roberta Smith interpretierte die Installation folgendermaßen: »The work's title, `Snow White and the Madness of Truth,« suggests a

264 Die Installation wurde als Teil der Ausstellung »Making Differences« im Historischen Museum in Stockholm gezeigt, die im Januar 2004 begleitend zur Internationalen Anti-Genozid-Konferenz stattfand.

265 David Blair: »Revenge Sparked Suicide Bombing«, The Daily Telegraph, 06.10.2003. Vgl. auch die Presseberichte zitiert in Chicago Project on Security and Terrorism (CPOST): Suicide Attack Database, Attack ID: 1052966610.

266 Gunilla Sköld-Feiler: »Who is Snow White?«, Avantart (o.J.), S. 1-8. http://www. avantart.com/music/feiler/ snowwhite.htm (zugegriffen am 6.6.2021).

267 Ebd., S. 4.

268 Vgl. Daniel Berkowitz: »Promised Virgins and Princess Warriors: News and Mythical Archetypes of Palestinian Suicide Bombers«, Vortragsmanuskript, International Communication Association, New Orleans, 27.05.2004, http://www.allacademic. com/meta/p112565_index.html (zugegriffen am 12.4.2016, nicht mehr verfügbar). 
suicide bomber as a person driven by fairy-tale simplicity and pathological faith. It implies that such faith and simplicity have caused bloodshed all over the world, not just in Israel. $\aleph^{269}$

Die Konfrontation von weiblicher Schönheit und mörderischem Blutbad wurde in der künstlerischen Verarbeitung als Widerspruch und Paradox dargestellt. Wie bereits in den Medienberichten zu beobachten war, stand dahinter die fassungslose Frage: Wie konnte eine Frau trotz ihrer Schönheit eine solch mörderische Tat begehen? In Anspielung auf die Märchenfigur Schneewittchen wurde Hanadi Jaradat erneut in einen Opferdiskurs eingebettet und in einem mythischromantisierenden Licht präsentiert. In den Augen des israelischen Botschafters Zvi Mazel, der bei der Ausstellungseröffnung am 16. Januar 2004 die Stromzufuhr der Installation unterbrach, die Kabel in den Pool fallen ließ und einen Kurzschluss verursachte, richtete sich das Kunstwerk gegen Israel selbst. Zur Erklärung seiner Tat fügte er an:»There was the terrorist, wearing perfect makeup and sailing placidly along the rivers of blood of my brothers and the families that were murdered. $\ll^{270}$ Allein die Attraktivität der Selbstmordattentäterin wurde von ihm offensichtlich als Provokation wahrgenommen, da sie das vertraute Feindbild des männlichen Terroristen dekonstruierte.

Auf Provokation waren schließlich auch die Montagen der russischen Künstlerinnen Galina Bleikh und Lilia Chak angelegt, in denen die palästinensischen Selbstmordattentäterinnen der zweiten Intifada als christliche Madonnen mit Jesuskind erscheinen. Für die Serie Ferror (Female Terror) von 2009 kopierten die Künstlerinnen Portraitbilder der Attentäterinnen aus dem Internet, fügten diese in Reproduktionen verschiedener Madonnengemälde von Tizian, Botticelli oder Raffael ein und druckten die Montagen anschließend auf Leinwände. Die Assoziation zur Darstellungskonvention der Madonna-mit-Kind war bereits in Rim Riyashis (Selbst-)Inszenierung angelegt (Abb. 3.26). Überraschenderweise taucht jedoch ausgerechnet Riyashis Portrait in der Bilderserie nicht auf und es bleibt fraglich, ob den Künstlerinnen diese Fotografie bekannt war.

269 Roberta Smith für die New York Times, 13. Mai 2004. Zitiert in Sköld-Feiler: »Who is Snow White?«, S. 5.

270 Yossi Melman: »Swedish Envoy: We Cannot Constitutionally Remove Exhibit«, Haaretz, 19.01.2004, http://web.archive.org/web/20040201210331/http://www. haaretzdaily.com/hasen/spages/383944.html (zugegriffen am 6.6.2021). 
Abbildung 3.31: Galina Bleikh und Lilia Chak, Ferror

(Female Terror), 2009, digitale Montage mit einem Foto von Darin Abu Aisheh, Druck auf Leinwand, $180 \times 96 \mathrm{~cm}$.

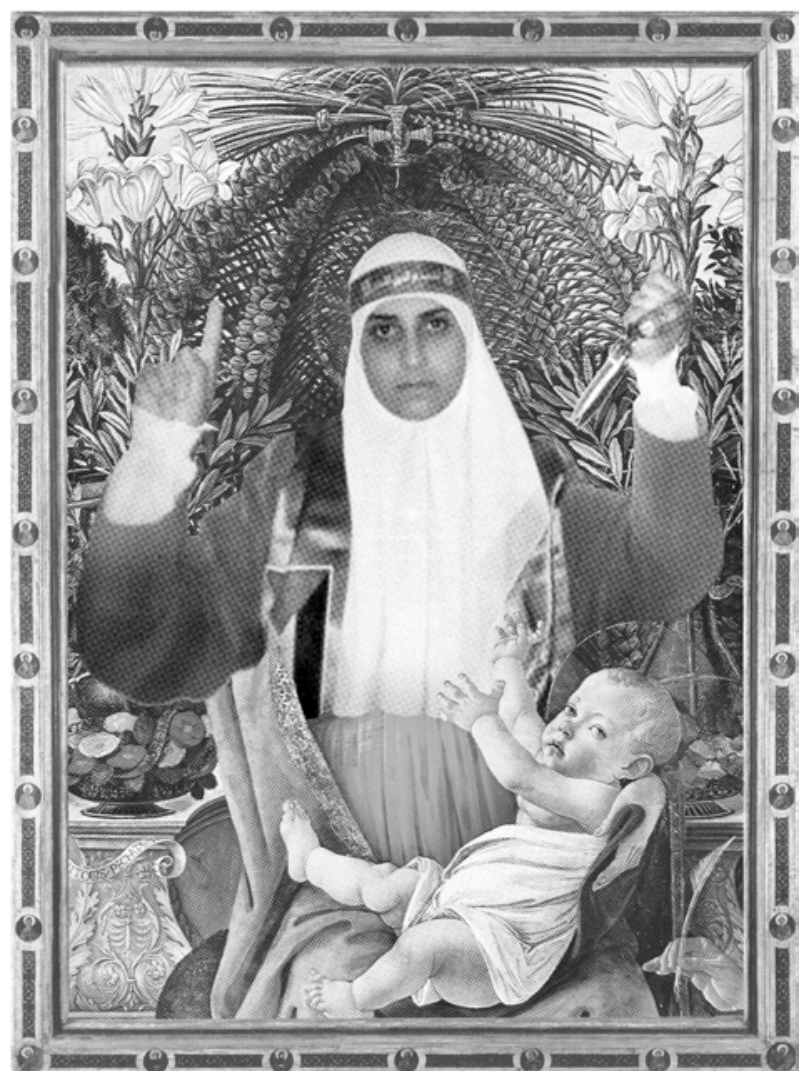

Wie die Diskursanalysen von Frances Hasso, Dorit Naaman oder Friederike Pannewick gezeigt haben, wurden die Märtyrerinnen in arabischen Medien häufig in einem mythischen Kontext als »Bräute Palästinas « oder als »Bräute des Himmels« wahrgenommen und damit teilweise in die Nähe von Heiligen gerückt. ${ }^{271}$ Diese Sakralisierung der Attentäterinnen wird in den Montagen von Galina Bleikh und Lilia Chak aufgenommen und überspitzt. Dies könnte auf den ersten Blick als

271 Hasso: »Discursive and Political Deployments by/of the 2002 Palestinian Women Suicide Bombers/Martyrs«; Naaman: »Brides of Palestine/Angels of Death«; Pannewick: »Wafa Idris. Eine Selbstmordattentäterin zwischen Nationalheldin und Heiliger«. 
Kritik an der quasi-religiösen Verherrlichung der Märtyrerinnen im arabischen Raum interpretiert werden. Indem die Attentäterinnen jedoch in einen christlichen Kontext überführt werden, scheint die arabische Rezeption der Bilder in den Hintergrund zu rücken. Der muslimische Hijab der Attentäterinnen überlagert sich mit dem Schleier der Madonna und verbindet die muslimische Frau mit der christlichen Bildtradition. Eine der Montagen zeigt die bereits besprochene Fotografie aus der Serie von Selbstdarstellungen Darin Abu Aishehs (vgl. Abb. 3.20), die in Botticellis Gemälde der thronenden Madonna des Bardi-Altars von 1485 hineinretuschiert wurde (Abb. 3.31). Das Messer, das Abu Aisheh gegen ihren eigenen Körper richtet, zielt in der Montage nun gleichzeitig auf das Jesuskind, dessen Handbewegung den Anschein eines abwehrenden Gestus erhält, während sein Blick geradezu hilfesuchend den Bildbetrachter*innen zugewandt scheint.

Anlässlich einer geplanten Ausstellung in einem journalistischen Zentrum in Tel Aviv, die den Titel Woman, Mother, Murderer: An Exhibit on Female Terror trug, sorgten die Montagen schon vor der Eröffnung weltweit für Empörung. ${ }^{272}$ Den Künstlerinnen wurde vorgeworfen, die Selbstmordattentäterinnen als »holy terrorists ${ }^{273} \mathrm{zu}$ idealisieren und weder Respekt noch Mitgefühl gegenüber den israelischen Opfern zu zeigen. Nachdem die israelische Tageszeitung Yediot Aharonot die Schließung der Ausstellung forderte und zum Protest aufrief, verteidigte Galina Bleikh ihre Werke und betonte: »It isn't at all a political issue, but a personal issue. We are trying to ask how a woman, who is meant to love and give birth, became a source of hatred and murder. $\aleph^{274}$ Die Bilder der palästinensischen Selbstmordattentäterinnen dienten Galina Bleikh und Lilia Chak offenbar als Projektionsfläche, um Klischees der angeblich friedliebenden `Natur` der Frau zu wiederholen, die hier auf ihre Rolle als fürsorgende Mutter reduziert wird. Interessanterweise (wenn auch sicherlich nicht beabsichtigt) nehmen die Künstlerinnen damit eine Position ein, die zum Zeitpunkt von Abu Aishehs Anschlag auch von der Hamas selbst vertreten wurde. Auch von der Hamas wurden Frauen zunächst auf ihre Rolle als >Märtyrermütter〈 beschränkt, die in erster Linie zukünftige Kämpfer und Märtyrer gebären sollten. Bis heute gelten Mütter von Märtyrern als besonders ehrwürdig und werden etwa von Aktivistinnen der Hamas zu Stolz

272 Die Ausstellung war vom 2. bis 23. September 2009 im journalistischen Zentrum Beit Solokov geplant und sollte neben den umstrittenen Werken auch Arbeiten anderer Künstler*innen umfassen.

273 Zitiert in Daniel Edelson: »Pictures of `Holy Terrorists〈 to Be Removed From Exhibition«, Ynetnews, 3.9.2009, http://www.ynetnews.com/articles/0,7340,L-3771667, 00.html (zugegriffen am 6.6.2021).

274 Zitiert in ebd. 
und Freude angehalten, wenn einer ihrer Söhne als Widerstandskämpfer oder Selbstmordattentäter sein Leben lässt. ${ }^{275}$ Indem sich Abu Aisheh jedoch selbst als Märtyrerin darstellt, widersetzt sie sich dieser Festschreibung weiblicher Rollen, was zumindest teilweise als Subversion des Märtyrermutter-Ideals der Hamas gelesen werden kann. Umso paradoxer mag es erscheinen, dass ausgerechnet diese Fotografie nun wieder mit dem Bild einer anderen Märtyrermutter kurzgeschlossen wird: dem Bild der christlichen Madonna. Die zunächst plakativ wirkende Provokation eines Gegenüberstellens von Maria - als Prototyp einer Frau »who is meant to love and give birth« - und den Attentäterinnen als »source of hatred and murder « wird durch den palästinensischen >Märtyrermutter/-Diskurs um eine weitere Bedeutungsdimension angereichert. In der Montage überlagern sich somit drei widersprüchliche Figurationen: die christliche Märtyrermutter, das politische Märtyrermutter-Ideal der Hamas und die Selbstmordattentäterin, die schließlich selbst zur Märtyrerin wird. Entgegen der Aussage von Galina Bleikh, mit ihren Montagen unpolitische Fragen aufzuwerfen, schreiben sich die Postproduktionen der beiden Künstlerinnen unfreiwillig in den hoch politischen Diskurs um Geschlechterrollen in der palästinensischen Gesellschaft ein.

Allein die Tatsache, dass die Darstellung einer palästinensischen Selbstmordattentäterin von russischen Künstlerinnen angeeignet, mit christlichen Madonnengemälden überlagert und in Israel ausgestellt werden sollte, verdeutlicht, wie unkontrollierbar die Eigendynamik dieser Bilder ist, die zu unterschiedlichen Assoziationen und Synthesen führten. Wie gezeigt wurde, war die Fotografie von Darin Abu Aisheh schon von Anfang an Teil komplexer Bildpolitiken und widersprüchlicher Aneignungsprozesse, die schließlich auch in Ferror (Female Terror) mitschwingen und dort als widerständige Dynamiken präsent sind.

275 Der Dokumentarfilm »Women of Hamas« der palästinensischen Filmemacherin Suha Arraf zeigt eindrücklich, inwiefern diese Performance der Freude zu einem sozialen Erwartungsdruck innerhalb der palästinensischen Gesellschaft im Gazastreifen geworden ist. Der Film zeigt darüber hinaus, dass sich bei der Hamas die Konvention etabliert hat, die Mutter des zukünftigen Märtyrers in das Videobekenntnis miteinzubeziehen: Zum einen wird den `Märtyrermüttern ‘ damit Respekt gezollt, zum anderen sollen sie vor laufender Kamera bezeugen, dass sie bereit sind, ihren Sohn für eine Märtyrertod-Operation zu opfern. Suha Arraf (Regie): »Women of Hamas«, Dokumentarfilm, 56 min, Israel 2010. 



\section{Digitale Postproduktionen. Simulation und Interaktivität im Videotestament 2.0}

Die heterogenen Bildmontagen der palästinensischen Selbstmordattentäterinnen haben bereits gezeigt, dass Videotestamente und Märtyrerfotografien zum Ausgangspunkt zahlreicher Bearbeitungsprozesse werden. Es werden Operationen am Bild vollzogen, die mitunter ganz neue Bedeutungshorizonte eröffnen. Was im vorhergehenden Unterkapitel mit Blick auf unbewegte Märtyrermontagen gezeigt wurde, trifft in zunehmendem Maße auch für die Videotestamente selbst zu. Im digitalen Zeitalter haben Verfahren der Postproduktion - wie Bluescreen-Montagen, Untertitelung, Voiceover oder das Hinzufügen computergrafischer Elemente und Special Effects - zunehmend an Bedeutung gewonnen. Die Videotestamente global agierender Terrornetzwerke wie al-Qaida oder Islamischer Staat sind zu komplexen und technisch professionalisierten Medienerzeugnissen geworden, deren (Post-)Produktion oftmals von unterschiedlichen Medienbüros auf der ganzen Welt übernommen wird.

Im Folgenden gehe ich von zwei wesentlichen Beobachtungen aus: Zum einen ergeben sich angesichts der hochgradig bearbeiteten Videotestamente ganz neue Fragen nach deren Zeugnischarakter. Stand im dritten Kapitel vor allem die Zeugen-Performance der Sprechenden vor der Kamera und für die Kamera im Vordergrund, verschiebt sich der Fokus nun notwendigerweise auf die Ebene des postproduzierten Bildes (Kapitel 4.1 und 4.2). Im Anschluss an die bisher vorgestellten Thesen lautet die Frage daher: Inwiefern sind die digitalen Nachbearbeitungsverfahren selbst an den Prozessen des Bezeugens, Erzeugens und Überzeugens beteiligt? Die Digitalisierung des Videotestaments birgt jedoch nicht nur neue Möglichkeiten der Postproduktion, sondern stellt auch neue Wege der medialen Zirkulation bereit - so die zweite Ausgangsbeobachtung. Der Kommunikationswissenschaftler und Terrorismusexperte Gabriel Weimann hat in seinem 2006 erschienenen Buch die strukturellen Parallelen zwischen dem »neuen Terrorismus« 
und dem »neuen Medium « Internet hervorgehoben. ${ }^{1}$ Globale Terrorakteure wie al-Qaida zeichnen sich Weimann zufolge ähnlich wie das Internet durch dezentrale Strukturen, sowie durch eine schnelle, flexible und anonyme Operationsweise aus. Insbesondere die interaktive und kollaborative Struktur des Web 2.0 trifft sich mit den Zielen dschihadistischer Gruppen, ein möglichst breites Publikum anzusprechen und potenzielle Rekrut*innen auf der ganzen Welt zu mobilisieren. In diesem Zusammenhang entwickelte sich auch das Genre des Videotestaments weiter. Analog zum Web 2.0 lässt sich daher vom Videotestament 2.0 sprechen, das auf eine zunehmende Involvierung der Rezipient*innen abzielt (Kapitel 4.3). Vermehrt kommen Computersimulationen zum Einsatz, die an Ego-ShooterSpiele erinnern und dazu führen, dass man sich beim Betrachten der Videos selbst in die Rolle einer Akteurin oder eines Akteurs versetzt fühlt. Damit rückt eine weitere Ebene der Bildoperation in den Vordergrund, die die Frage nach dem Handeln durch und in Bildern noch einmal ganz anders aufwirft. Die Fokusverschiebung auf die Seite der Bildrezeption soll schließlich zum Anlass dienen, unsere eigene Verantwortung zu reflektieren, die aus der Medienzeugenschaft der Videotestamente resultiert (Kapitel 4.4).

\subsection{SELBSTMORDATTENTÄTER IN DER BLUE BOX. DIE VIDEOTESTAMENTE DER AL-QAIDA SEIT 9/11}

Ähnlich wie schon bei den Militäroperationen der Hisbollah entwickelten sich die Kamera - und insbesondere der internetfähige Laptop - zu ständigen Begleitern der al-Qaida-Einheiten. Hamid Mir, ein pakistanischer Journalist und Biograf von Osama Bin Laden, beobachtete im November 2001 eine Gruppe von al-Qaida Mitgliedern, die vor dem US-Bombardement ihrer Trainingslager in Afghanistan floh, und von denen bereits jeder zweite neben seiner Kalaschnikow einen Laptop mit sich trug. ${ }^{2}$ Wie die Recherchen des al-Qaida-Experten Abdel Bari Atwan ergeben, wussten die Strategen des Terrornetzwerkes schon sehr früh - ab Mitte der 1980er Jahre - die Möglichkeiten des Internets für ihre Ziele zu nutzen. ${ }^{3}$ Auf den ersten Blick erscheine es paradox, so schreibt Atwan, dass ausgerechnet eine Organisation wie al-Qaida, die sich so vehement gegen die moderne Welt gestellt hat, auf die hochtechnologischen elektronischen Möglichkeiten des Internets angewiesen

1 Weimann: Terror on the Internet, S. 25.

2 Vgl. Abdel Bari Atwan: The Secret History of Al-Qa'ida, London: Saqi 2006, S. 122.

3 Vgl. ebd., Kapitel 4 »Cyber-Jihad«, S. 120-149. 
ist, um überhaupt operieren, expandieren und überleben zu können. ${ }^{4}$ Der Cyberspace wurde von Mitgliedern der al-Qaida zunehmend als effektiver Handlungsspielraum wahrgenommen und zu einem weiteren »Schlachtfeld« ausgerufen; so schrieb einer ihrer führenden Köpfe, Aiman al-Zawahiri, 2005 in einem abgefangenen Brief an den Anführer der al-Qaida im Irak al-Zarqawi: »More than half of this battle is taking place in the battlefield of the media. $\ll^{5}$

Das Internet bot nicht nur neue Möglichkeiten des Trainings, der Anschlagsplanung, Logistik und Propaganda - es nahm auch erheblichen Einfluss auf die digitale Bildproduktion. Mit nur einem Klick konnten Bilddateien an jeden erdenklichen Computer verschickt und weiterbearbeitet werden. Ein im Irak oder in Afghanistan aufgenommenes Video konnte so theoretisch von überall auf der Welt geschnitten, mit weiteren Aufnahmen oder Audiodateien kombiniert oder mit digitalen Effekten versehen werden. Der Ort der ursprünglichen Videoaufnahme lässt folglich keine Rückschlüsse mehr über den Ort der Postproduktion und das dort vorhandene technische Equipment zu: »The lack of Mac platforms in Iraq«, so betont etwa die Kommunikationswissenschaftlerin Cori E. Dauber, »does not mean that produced videos about Iraq were not made using Mac equipment and software « ${ }^{6}$. Insbesondere seit den Anschlägen vom 11. September 2001 kamen zahlreiche Videos der al-Qaida in Umlauf, die technisch gesehen immer ausgefeilter wirkten und visuelle Effekte der Film- und Fernsehtechnik (wie das Bluescreen-Verfahren) integrierten. Nach Ansicht des Dokumentarfilmers und Filmtheoretikers Gorham Kindham ist die zunehmende technische Komplexität dieser Videos unter anderem auf die weltweite Verfügbarkeit digitaler Bildbearbeitungssoftwares wie Adobe After Effects oder Apple's Final Cut Pro zurückzuführen, mit denen Verfahren der Postproduktion relativ einfach, ohne großes technisches Vorwissen oder ein professionelles Filmstudio, umsetzbar wurden. ${ }^{7}$ Dauber folgert daraus: So technisch versiert ein Video auf den ersten Blick auch wirken mag, so steckt dahinter häufig wenig mehr als ") a guy and a laptop< if it is the right guy with the right laptop $\ll^{8}$.

4 Vgl. Atwan: The Secret History of Al-Qa'ida, S. 122.

5 Economist: »A World Wide Web of Terror«, 12.07.2007, http://www.economist. com/node/9472498 (zugegriffen am 6.6.2021).

6 Cori E. Dauber: YouTube War: Fighting in a World of Cameras in Every Cell Phone and Photoshop on Every Computer, Carlisle, PA: Strategic Studies Institute, U.S. Army War College 2009, S. 101, Anm. 53.

7 Zitiert in ebd., S. 100, Anm. 53.

8 Ebd., S. 101, Anm. 53. 
Diese Entwicklung hatte schließlich auch Auswirkungen auf die Produktion von Videotestamenten. Hinterließen die Attentäter der ersten al-Qaida-Selbstmordanschläge auf die US-amerikanischen Botschaften in Kenia und Tansania am 7. August 1998 noch keine audiovisuellen Dokumente, sollte sich dies mit den Anschlägen vom 11. September 2001 schlagartig ändern. Erstaunlich war zunächst allerdings das Veröffentlichungsdatum der Videotestamente. Anders als es bisher üblich gewesen war, wurden die Videotestamente der 9/11-Attentäter nicht direkt am Abend nach dem Ereignis veröffentlicht, sondern erst Monate, teilweise erst Jahre später. ${ }^{9}$ Unmittelbar nach den Anschlägen waren es ausschließlich die Medienbilder der brennenden und einstürzenden Türme des World Trade Centers, die Aufsehen erregten und das visuelle Gedächtnis der Ereignisse bis heute prägen. Über den Grund dieser Entscheidung kann nur spekuliert werden. Folgt man der Argumentation von Nathan Roger, setzte al-Qaida die Videotestamente damit gezielt als »counter-image munitions« ein, um die Aufmerksamkeit der Medien in regelmäßigen Abständen neu zu entfachen und die Deutungshoheit über ihre Anschläge über einen möglichst langen Zeitraum zu behaupten. ${ }^{10}$

Das erste Videotestament eines 9/11-Attentäters wurde im April 2002 veröffentlicht. Es wurde dem katarischen Fernsehsender Al Jazeera zugespielt, der es eine Woche nach Erhalt, am 15. April 2002 ausstrahlte. ${ }^{11}$ Nach Informationen des Fernsehsenders soll das Video rund sechs Monate vor den Anschlägen in Kandahar in Afghanistan aufgenommen worden sein. ${ }^{12}$ An welchem Ort das Video jedoch nachträglich geschnitten und bearbeitet wurde, lässt sich nicht beantworten. Die Aufnahme zeigt Ahmed Ibrahim al-Haznawi, einen der Entführer der UnitedAirlines-Flug 93-Maschine, die am 11. September 2001 in der Nähe von Shanksville, Pennsylvania abgestürzt war und alle 44 Menschen an Bord in den Tod riss. Nathan Roger zufolge war es kein Zufall, dass ausgerechnet dieses Testament das

9 Bis heute sind Videotestamente von neun der insgesamt neunzehn mutmaßlichen Attentäter der Anschläge vom 11. September 2001 bekannt. In der zeitlichen Abfolge ihrer Veröffentlichung: Ahmed Ibrahim al-Haznawi (15.04.2002); Abdulaziz al-Omari (09.11.2002), Saeed al-Ghamdi (12.09.2003), Wail al-Shehri und Hamza al-Ghamdi (07.09.2006), Mohammed Atta und Ziad Jarrah (01.10.2006), Walid al-Sehri (11.09.2007), Ahmed al-Ghamdi (19.09.2008).

10 Roger: Image Warfare in the War on Terror, S. 85; 88.

11 Vgl. CNN: »New Bin Laden Tape Surfaces. Separate Video Apparently Shows September 11 Hijacker«, 16.04.2002, http://edition.cnn.com/2002/WORLD/meast/04/15/ terror.tape/index.html (zugegriffen am 6.6.2021).

12 Vgl. ebd. 
erste war, das von der al-Qaida zur Veröffentlichung freigegeben wurde. ${ }^{13}$ Die Entführer der UA93 wollten ursprünglich das Weiße Haus in Washington D.C. ansteuern, wurden jedoch von Flugzeugcrew und Passagieren daran gehindert, sodass die Maschine in einem Feld fernab von Kameras und Journalisten abstürzte und keinerlei medienwirksame Bilder produzieren konnte. Das Schicksal der UA93-Maschine wurde von der Bush-Administration schon früh dafür genutzt, um das mutige Eingreifen von Crew und Fluggästen hervorzuheben und damit ein heroisches Gegennarrativ zu den einstürzenden Türmen des World Trade Centers in Umlauf zu bringen. Die Veröffentlichung von al-Haznawis Videotestament, so vermutet Roger, ist daher als »kalkulierte Antwort« auf diese Heroisierung zu verstehen, die nun wiederum den Selbstmordattentäter als eigentlichen Helden proklamierte. $^{14}$

Abbildung 4.1: Al-Qaida/Medienbüro as-Sahāo, Videotestament von Ahmed Ibrahim al-Haznawi, arabisch mit englischen Untertiteln, am 16. April 2002 veröffentlicht.

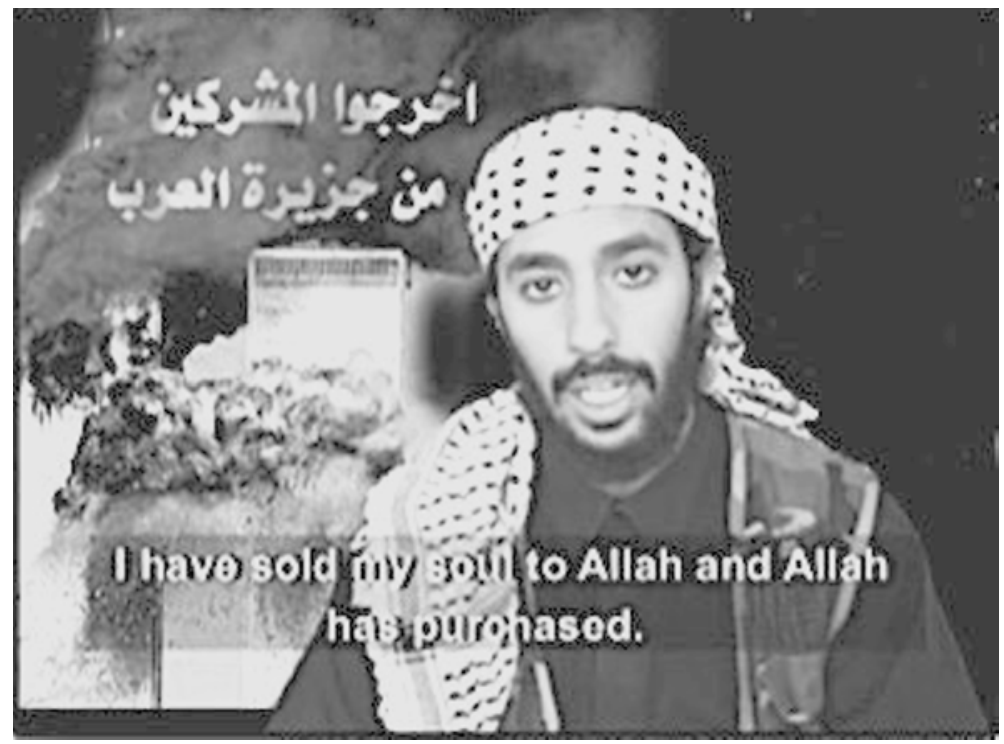

13 Vgl. Roger: Image Warfare in the War on Terror, S. 86.

14 Ebd., S. 86. 
Die Ansprache al-Haznawis wurde allem Anschein nach vor einem Bluescreen aufgenommen, der im Nachhinein durch eine Fotografie der brennenden Twin Towers überblendet wurde (Abb. 4.1). Über der schwarzen Rauchwolke ist zudem ein goldener Schriftzug auf Arabisch zu lesen, der besagt: „vertreibt die Polytheisten von der arabischen Halbinsel $\aleph^{15}$. Bei der Bluescreen- oder Bluebox-Technik handelt es sich um ein Verfahren der farbbasierten Bildfreistellung (engl. Chrome Keying), die es möglich macht, Personen oder Gegenstände nachträglich vor einem anderen Hintergrund zu positionieren. Dafür werden vorwiegend blaue oder grüne Hintergründe verwendet, die anschließend mithilfe einer Aussparungsmaske ausgeschnitten und durch andere Bilder (Fotografien, Filme oder Computergrafiken) ergänzt werden. ${ }^{16}$ Die Verwirrung verschiedener Zeitebenen, die im dritten Kapitel bereits ausführlich thematisiert wurde, verdichtet sich im Videotestament al-Haznawis und lässt dieses als paradoxes Kompositbild erscheinen. Die Darstellung des Attentats (die brennenden Türme) wird dem Videotestament nicht nur nachgeordnet, sondern erscheint simultan im Hintergrund desselben. Der Vertrag mit Gott, der auch in diesem Videotestament besiegelt wird - $\gg$ I have sold my soul to Allah and Allah has purchased. I have announced this with the color of the blood that has flowed, in order that it may reach every ear. « $^{17}(07: 49-08: 13$ min) - verschränkt sich mit dem Medienzeugnis, das im selben Moment bereits die Erfüllung dieses Vertrags bezeugt. Je nach Perspektive erhält das Video damit den Anschein einer zukünftigen Prophezeiung (als hätte al-Haznawi zum Zeitpunkt seiner Ansprache die ikonischen Bilder vom 11. September 2001 bereits vor Augen) oder einer unheimlichen Botschaft aus dem Jenseits (als würde der Attentäter im Wissen um die erfolgten Anschläge zu uns sprechen). Ungeachtet der Tatsache, dass al-Haznawi nicht an den Anschlägen auf das World Trade Center beteiligt war, sondern als Teil der UA93-Maschine bei Washington abstürzte, schmückte die Medienikone der brennenden Twin Towers auch sein Videotestament als $>$ Trophäe .

Durch die Bluescreen-Technik wird eine visuelle Konvention aufgerufen, die insbesondere im Fernsehen, speziell bei Nachrichten- und Wettersendungen weit verbreitet ist. Das Videotestament al-Haznawis wirkt damit wie ein spiegelverkehrtes Echo all der Nachrichtensendungen, die am 11. September 2001 und den darauffolgenden Tagen um die Welt gingen. Anstelle geschockter Fernseh-

15 Ich danke Christoph Günther für die Übersetzung des Schriftzugs.

16 Sowohl Blau als auch Grün kommen in der Hautfarbe eines Menschen fast nicht vor und lassen sich daher besonders gut von menschlichen Figuren abgrenzen. Analog ist auch von einer Greenscreen-Technik oder Green-Box die Rede.

17 Vgl. die englische Untertitelung des Videotestaments. 
sprecher*innen, die das Gesehene (angezeigt durch die eingeblendeten Videos und Fotografien) mit Hintergrundinformationen und Kommentaren einzuordnen versuchten, erscheint im Video der Attentäter selbst vor dem Bild der brennenden Türme und liefert seine eigene Interpretation der Ereignisse. Wiederholt macht Al-Haznawi in seinem Testament auf die Unterdrückung von Muslim*innen in Afghanistan, Kaschmir, Palästina und anderen Regionen der Welt aufmerksam. Sein Testament wird dabei mehrfach durch TV-Ausschnitte unterbrochen, die das Leiden der muslimischen Gemeinschaft illustrieren und seine Anklagen bekräftigen sollen. Er richtet seinen Aufruf schließlich an die muslimische Gemeinschaft, sich diesen Entwicklungen zu widersetzen, ihrer Verpflichtung zum Dschihad nachzugehen und den eigenen Märtyrertod anzustreben. Er schließt sein Testament mit der Drohung an die USA, weitere Selbstmordattentäter zu erwarten, die nicht verhandelten und bereit wären, ihr Leben für den Dschihad zu opfern.

In den darauffolgenden Monaten und Jahren wurden weitere Videotestamente der 9/11-Attentäter auf Al Jazeera publiziert. ${ }^{18}$ Bis auf eine Ausnahme wurden alle Testamente vor einem Bluescreen aufgenommen. ${ }^{19}$ Darunter auch das Video von Abdulaziz al-Omari, das am 9. September 2002 als Teil eines längeren Videos auf Al Jazeera ausgestrahlt wurde und den Attentäter vor einer Luftaufnahme des Pentagon zeigt (Abb. 4.2) ${ }^{20}$ Offensichtlich handelte es sich dabei um eine Fotografie, die einige Zeit nach dem Einschlag des American-Airlines-Flug 77 am 11. September 2001 aufgenommen wurde und bereits mehrere Baukranen zeigt, die die abgerissenen Gebäudeteile des Westflügels wieder errichteten. Unmittelbar nach dem Attentat wurden nur wenige Bilder vom Flugzeugeinschlag in das Pentagon publik und erst Jahre später kamen bis dato unter Verschluss gehaltene Fotografien an die Öffentlichkeit, die das tatsächliche Ausmaß des Schadens vom 11. September 2001 zeigten. ${ }^{21}$ Die Fotografie im Hintergrund des Videotestaments von al-Omari stellte zum Zeitpunkt seiner Postproduktion wohl eine der wenigen online verfügbaren Aufnahmen des Pentagon nach dem Anschlag dar. Dennoch ist

18 Vgl. Anm. 9 in diesem Kapitel.

19 Das Videotestament von Atta und Jarrah, das am 1. Oktober 2006 in Umlauf kam, wurde als einziges nicht vor einem Bluescreen, sondern vor einer weiß verputzten Wand aufgenommen.

20 Vgl. CNN: »Al-Jazeera: Bin Laden Tape Praises Hijackers«, 09.09.2002, http://articles.cnn.com/2003-09-12/us/hijack.tape_1_al-jazeera-bin-hijackers?Z_sZ=PM:US (nicht) mehr verfügbar).

21 Bild: »Das Pentagon kurz nach dem Anschlag«, 31.03.2017, https://www.bild.de/ news/ausland/terroranschlag-911/fbi-veroeffentlicht-aufnahmen-das-pentagon-kurznach-dem-anschlag-51088436.bild.html (zugegriffen am 6.6.2021). 
nur schwer zu erklären, warum ausgerechnet dieses Bild für die Montage ausgewählt wurde, zeigt es doch gerade die wiederhergestellte Ordnung und Kontrolle der US-Regierung und könnte als Gegenbild zum Chaos des Anschlagstages und den Einsturzschäden gedeutet werden. Zugleich wird die Fotografie hier wiederum flankiert von computergenerierten roten Flammen, die zu einer eigentümlichen Spannung zwischen Zerstörung und Wiederaufbau, zwischen Bild und Gegenbild führen und zur Verwirrung der verschiedenen Zeitebenen beitragen. Unerklärlich ist auch, warum gerade das Videotestament von Abdulaziz al-Omari mit diesem Bild hinterlegt wurde, da er den Angaben des FBI folgend nicht an der Entführung des American-Airlines-Flug 77 beteiligt war, sondern zusammen mit Mohammed Atta und drei weiteren Attentätern mit dem entführten American-Airlines-Flug 11 in den Nordturm des World Trade Centers stürzte. ${ }^{22}$

Abbildung 4.2: Al-Qaida, Videotestament von Abdulaziz al-Omari, am 9. September 2002 auf Al Jazeera veröffentlicht.

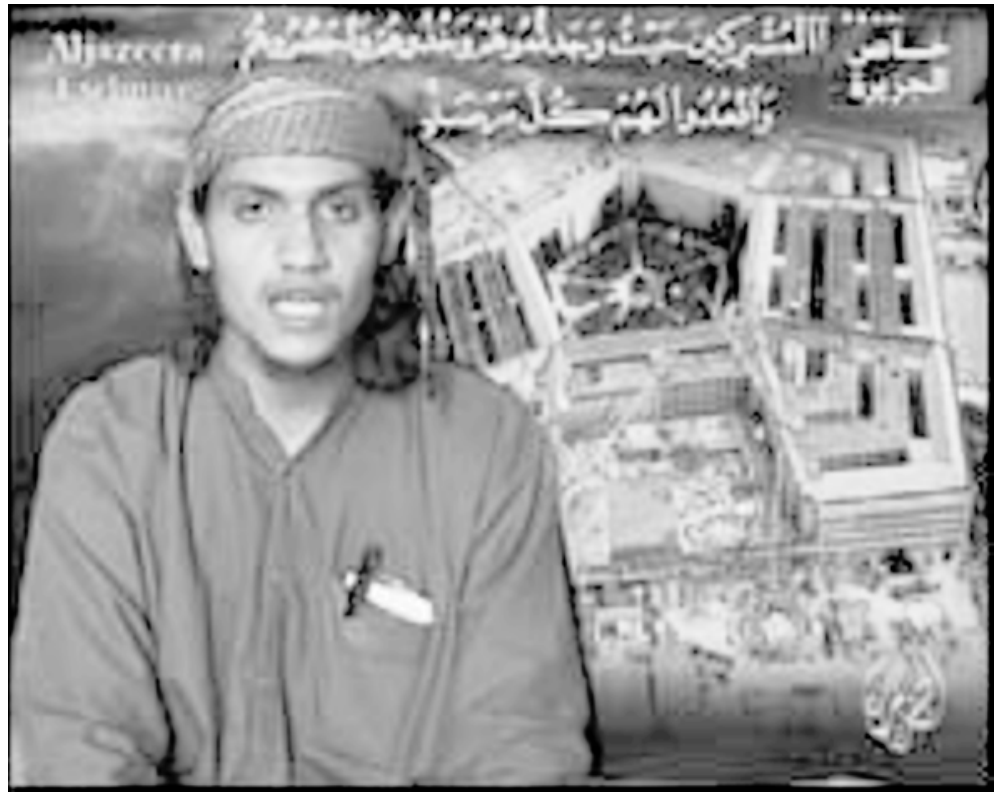

22 Vgl. Federal Bureau of Investigation (FBI): »Press Release: FBI Announces List of 19 Hijackers«, Pressemitteilung vom 14.09.2001, https://web.archive.org/web/2008030 5093133/http://www.fbi.gov/pressrel/pressrel01/091401hj.htm (zugegriffen am 6.6. 2021). 
Dieselbe Luftaufnahme des Pentagon, sowie drei Fotografien des brennenden World Trade Centers tauchen auch in den Videotestamenten von Wail al-Shehri und Hamza al-Ghamdi wieder auf, die als Teile eines längeren Videos am 7. September 2006 auf Al Jazeera ausgestrahlt wurden (Abb. 4.3). ${ }^{23}$ Erneut wird der Zeitpunkt des Sprechens damit suggestiv in die Zeit nach dem Anschlag verlagert. Die Illusion der Gleichzeitigkeit beider Bildebenen wurde dieses Mal aber noch weiter zugespitzt: Die Fotografien im Hintergrund scheinen auf dreidimensionalen, hochrechteckigen Stellwänden angebracht zu sein, die den Attentäter in eine räumliche Situation einbetten. Über den Bildstelen sind mehrere Scheinwerfer zu erkennen, die den Eindruck eines perfekt ausgeleuchteten, professionellen Fernsehstudios erwecken. Zwischen den Stellwänden und dem Sprecher ist zudem eine metallene Absperrung zu sehen, sowie ein dreidimensionales Modell eines Passagierflugzeugs, das auf einem Sockel mit Metallstab rechts hinter dem Attentäter zu stehen scheint. Das Flugzeug stellt eine neue `Requisite im Repertoire der Videotestamente dar und tritt hier an die Stelle der Kalaschnikow oder weiterer Waffen. Auf den ersten Blick ist nicht klar erkennbar, ob es sich bei dem Modellflugzeug um ein physisches Objekt handelt, das bereits Teil der Aufnahmekulisse war, oder um eine Computergrafik, die nachträglich eingefügt wurde. Im ersten Fall wäre das Flugzeug als modellhafte Vorwegnahme des Anschlags zu lesen, im zweiten Fall als Beleg für den erfolgten Anschlag oder als Trophäe, die nach dem Attentat ins Bild montiert wurde. Diese Ambivalenz verstärkt den Eindruck, dass die Zeitebenen zwischen Aufnahme und Postproduktion kollabieren und durch die Bluescreen-Montage geradezu ununterscheidbar miteinander verzahnt werden. Erst bei genauerem Hinsehen lässt sich erkennen, dass das gesamte dreidimensionale Studio ein virtuelles ist - und sich die Umrisse des Attentäters vom Rest des Hintergrunds abheben. Insbesondere das weitaus weniger realistisch dargestellte Mikrofon im Videotestament von al-Ghamdi, das sich etwas ungelenk von rechts unten vor das Bild des Attentäters schiebt, offenbart die `Fernsehstudio $<-A u f-$ nahme zweifelsohne als digital erzeugte Montage.

Die postproduzierten Kulissen dieser Videos stehen im Kontrast zu vielen der bisher diskutieren Videotestamente, in denen amateurhaft ausgeleuchtete Privaträume mithilfe von Tüchern, Postern und Waffen zu provisorischen Märtyrerbühnen umfunktioniert wurden (vgl. insbesondere die Videotestamente der Hisbollah der 1990er Jahre und die Videotestamente während der zweiten palästinensischen

23 Vgl. CNN: »Video is Said to Show Bin Laden Preparing for 9/11 Attacks«, 08.09.2006, http:/www.cnnworldclass.com/2006/WORLD/meast/09/07/alqaeda.911/index.html (nicht mehr verfügbar). Video von Wail Al-Shehri: https://www.dailymotion.com/video/x3wcon6 (zugegriffen am 09.06.2018, nicht mehr verfügbar). 
Intifada). Statt einer Selfmade-Ästhetik, die den Anschein eines Widerstandskampfes >von unten< erweckt, schließen die 9/11-Produktionen an die Bildsprache professioneller Nachrichtenagenturen an. Ob damit auch der Anspruch verbunden wurde, die Hegemonie westlicher Medieninstitutionen herauszufordern, lässt sich nur vermuten. Das Bluescreen-Verfahren lässt keine Rückschlüsse mehr auf die tatsächliche Aufnahmesituation zu und verlagert die Videotestamente an einen unspezifischen Nicht-Ort, der zugleich überall sein könnte. Die Ortlosigkeit der virtuellen Studios entspricht dabei der zunehmenden (und aus westlicher Sicht beängstigenden) Ortlosigkeit der Terrororganisation, deren Aktivitäten in Zeiten des Internets nicht mehr eindeutig zu lokalisieren sind.

Die durch das Bluescreen-Verfahren erzeugte Illusion wurde von den Machern dieser Videos jedoch selbst teilweise wieder gebrochen, so zeigt ein weiteres Videotestament der al-Qaida aus dem Jahr 2003. Die rund 45-minütige Produktion versammelt Testamente von vier Selbstmordattentätern, die am 12. Mai 2003 an den Bombenanschlägen auf drei Wohnkomplexe in Riad beteiligt waren. Die Attentate auf die vorwiegend von US-Amerikaner*innen bewohnten Gebäude forderten 29 Todesopfer, rund 200 weitere Personen wurden dabei verletzt. ${ }^{24}$ Die Videotestamente, die hier in schneller Abfolge zusammengeschnitten wurden und sich in ihrem Wortlaut gegenseitig ergänzen, enthalten Begründungen für die Taten sowie Aufrufe für Nachfolgende, es ihnen gleich zu tun. Ähnlich wie in den Videotestamenten der 9/11-Attentäter wurden alle vier Aufnahmen durch eine digitale Grafik im Hintergrund ergänzt: Vor einer blutroten Einfärbung erscheint der Ausschnitt einer Landkarte Saudi-Arabiens mit der Aufschrift »Die Polytheisten verließen die arabische Halbinsel« (Abb. 4.4 a-b). Verblüffend ist jedoch insbesondere eine Szene gegen Ende der Videoproduktion. Vor einer monochromen Landkarte Saudi-Arabiens werden wie in einer Art `Making Of<-Sequenz kurze Videoausschnitte der jeweiligen Testamente erneut eingespielt. Dieses Mal wurde jedoch auf die grafische Hintergrundeinblendung verzichtet und die Attentäter sind vor dem bloßgelegten Bluescreen zu sehen (Abb. 4.4 c-d). Einzig die Kalaschnikow, die links oder rechts hinter dem jeweiligen Attentäter lehnt - und sich damit als Teil der physischen Ausstattung der Szene entpuppt - ist vor der blauen Wand erkennbar.

24 Vgl. Chicago Project on Security and Terrorism (CPOST): Suicide Attack Database, [Attack IDs 1338726826; 730157966; 1917130864]. Auf Wikipedia ist von 39 Todesopfern die Rede: https://en.wikipedia.org/wiki/Riyadh_compound_bombings (zugegriffen am 6.6.2021). 
Abbildung 4.3: Al-Qaida, Videotestament von Hamza Al-Ghamdi, am 7. September 2006 auf Al Jazeera veröffentlicht.

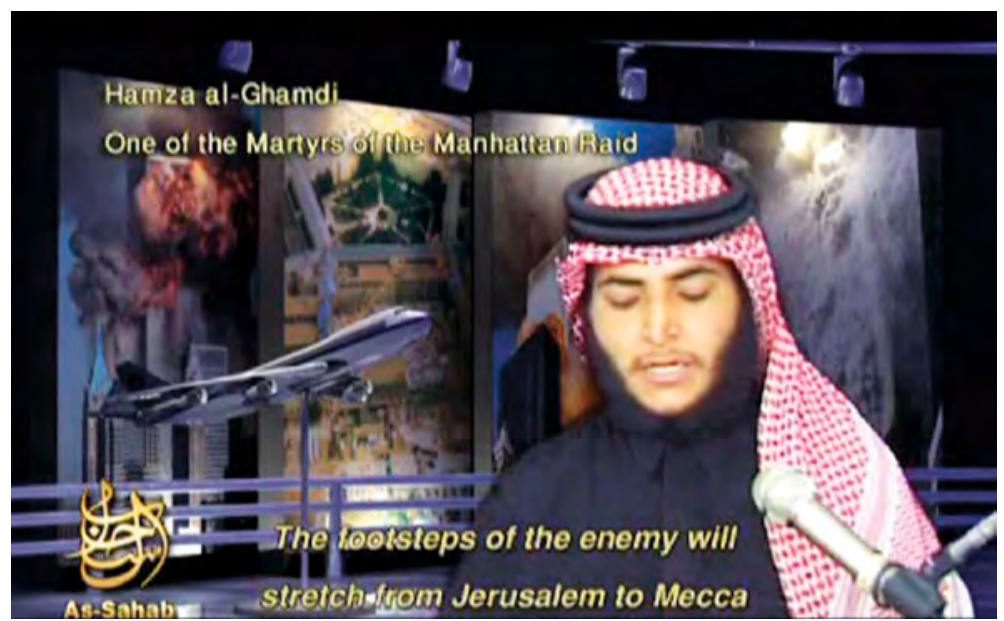

Abbildung 4.4 a-d: Al-Qaida/Medienbüro as-Sahāab, East Riyadh's Martyrs Wills, 2003, 45:21 min, arabisch.
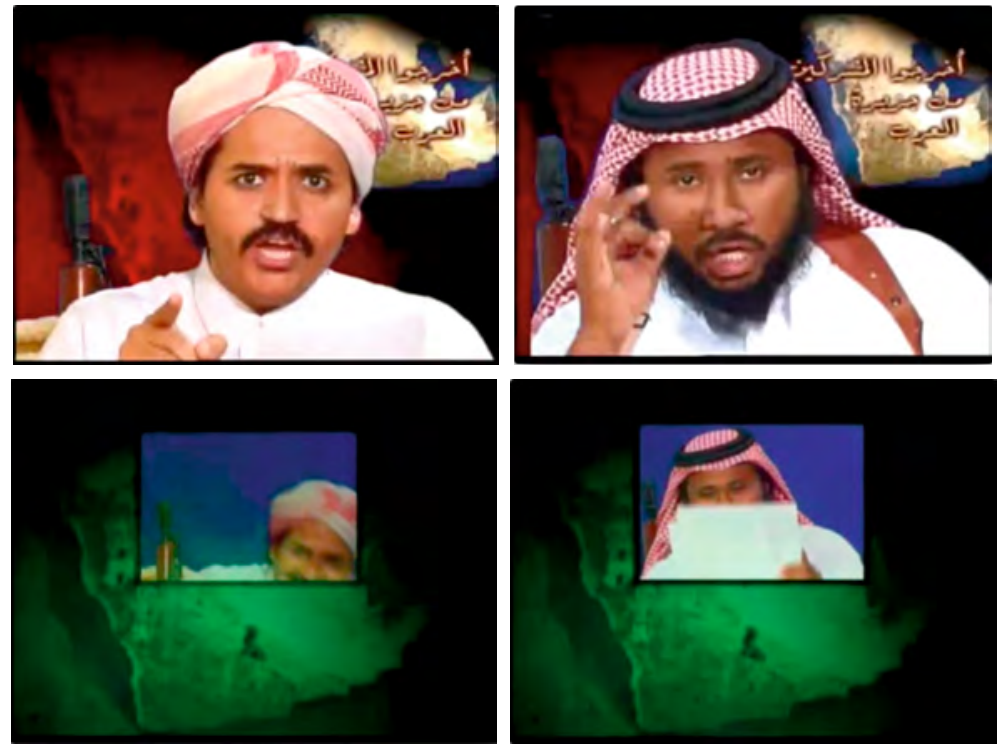
Dieser exponierte $>$ Blick hinter die Kulissen $\triangleleft$ bezieht sich nicht nur auf die technische Seite der Produktion, sondern scheint auch Einblicke in die soziale Situation der Aufnahme geben zu wollen. Die kurzen Clips knüpfen an die Konvention von Filmen und TV-Serien an, während des Abspanns oder als Bonusmaterial auf DVDs besonders komische Versprecher oder Pannen zugänglich zu machen, die es nicht in die offizielle Fassung geschafft haben, dafür aber ein besonders rauthentisches« Bild der Aufnahmesituation versprechen. Auch hier zeigen die Outtakes scheinbar heitere und gelöste Szenen, in denen die Sprecher regelrecht raus der Rolle< fallen. Die betonte Aggressivität der Testament-Performance, die ernsten Gesichtsausdrücke, strengen Gesten und durchdringenden Blicke (Abb. 4.4 a-b) weichen kurzen Momenten, in denen die Attentäter das Lachen nicht mehr unterdrücken können und immer wieder erfolglos versuchen, eine ernste Miene zu bewahren. Momente, in denen sie sich lachend aus dem Bild drehen, die Performance (sichtlich erleichtert) beenden oder die Zettel ihres Testaments neu ordnen (Abb. 4.4 c-d). Stand zuvor die unerschrockene und unnahbare Seite der zukünftigen Märtyrer im Vordergrund, werden die Attentäter hier von ihrer menschlichen Seite gezeigt, die bei ihrer Videoperformance auch Fehler machen und Spaß haben. Das »Stottern der Märtyrer«, das bislang aus den Videotestamenten verbannt wurde und das Rabih Mroué in seiner künstlerischen Performance bewusst aufgriff, um die Dargestellten zu entheroisieren (Kapitel 3.2), wurde hier von der al-Qaida selbst wiederum als Strategie der Authentifizierung genutzt. Durch die Offenlegung des Videotestaments als Schauspiel wird zugleich vermittelt, dass prinzipiell jeder die Rolle des Märtyrers verkörpern kann. Der Rekurs auf populäre Verfahren der TV und Filmbranche scheint dabei gerade für ein jüngeres, medienaffines Publikum ein hohes Identifikationspotenzial zu bieten. Interessanterweise - und im Unterschied zu den bisher analysierten, zur Veröffentlichung vorgesehenen Videotestamenten - wird das Rollenspiel hier jedoch nicht als stabile Identität der Dargestellten behauptet (>Ich bin der Märtyrer/Ich bin die Märtyrerin ); stattdessen ergibt sich durch die $>$ Making-Of $<$ Szene am Schluss ein fragiler Schwebezustand von Rollenspiel und Aus-der-Rolle-Treten. 


\subsection{DIE SIMULATION DES PARADIESES. DIE POSTPRODUKTION ALS AUGENZEUGNIS?}

Technische Verfahren der Postproduktion hatten aber nicht nur Einfluss auf das Selbstzeugnis der al-Qaida-Märtyrer. Bildmontagetechniken sowie grafische und computergenerierte Elemente kamen auch zum Einsatz, um das Videotestament mit zusätzlichen Modi der Zeugenschaft zu verbinden und simulierte Paradiesszenarien zu entwerfen. Wie im dritten Kapitel deutlich wurde, etablierte die Hisbollah bereits Ende der 1990er Jahre die Konvention, das Testament der jeweiligen Attentäter direkt vor die Aufnahmen der eigentlichen Tat, der Autobombenexplosion, zu montieren (Kapitel 3.3). Die Videoproduzenten der al-Qaida führten dasselbe Muster in zahlreichen ihrer Videotestamente fort, erweiterten dieses jedoch durch zusätzliche grafische Elemente.

Als paradigmatisches Beispiel kann ein Videotestament gelten, das von der alQaida im Irak anlässlich eines Autobombenanschlags am 8. Juli 2005 produziert wurde. ${ }^{25}$ Nach der Einblendung des al-Qaida-Emblems ist der Attentäter Abu Zubayr zunächst vor einer weißen Wand und umgeben von mehreren Panzerfäusten und Maschinengewehren zu sehen, während er sein Testament von einem Zettel abliest (Abb. 4.5 a). Danach folgt eine Abschiedsszene, in der mehrere vermummte Kämpfer an den Attentäter herantreten und ihn zum Abschied umarmen. Wie in den Videos der Hisbollah folgt daraufhin der Schnitt zur Aufnahme der eigentlichen Todesfahrt. Der durch eine Wüstenlandschaft fahrende LKW ist aufgrund der aufgewirbelten Staubwolke oft nur schemenhaft, teilweise gar nicht zu erkennen, was den >Beweischarakter` dieses Videos unterläuft (Abb. 4.5 b). Erst die Explosion - sichtbar an den orangerot aufsteigenden Flammen - scheint auf die erfolgte Detonation der Autobombe zu verweisen (Abb. 4.5 c). Im Unterschied zu den Hisbollah-Videos markiert die Explosion hier jedoch keineswegs das Ende der Bildmontage. Die Szene wird mit einer weiteren Videoaufnahme des Attentäters überblendet, dessen Konturen allmählich hinter den Flammen aufscheinen (Abb. 4.5 d). In seiner Linken hält er eine Kalaschnikow, während er mit dem Zeigefinger seiner rechten Hand nach oben weist und damit das geläufige »islamistische Zeichen für Sieg « ${ }^{26}$ aufruft. Das Video der Zerstörung kulminiert folglich in einer Auferstehungsvision, die den lebendigen Attentäter - wie zum >Beweis` seines Fortlebens - vor Augen führt. Die Montage erinnert an das Märtyrerposter von Ahmad Qasir, dessen Bild ebenfalls aus den Rauchwolken der

25 Das Video ist online abrufbar unter https://archive.org/details/MuKhLsS_004 (zugegriffen am 6.6.2021).

26 Hassan: »An Arsenal of Believers«, o.S. 
Zerstörung in himmlische Sphären aufzusteigen schien (Abb. 2.17). Durch die Bewegtbildmontage wird der Eindruck einer leibhaftigen Lebendigkeit indes noch verstärkt. Die in Märtyrertestamenten allgegenwärtige Koransure 3:169, in der das Weiterleben der Märtyrer*innen im Jenseits verkündet wird (»Und du darfst ja nicht meinen, daß diejenigen, die um Gottes willen getötet worden sind, (wirklich) tot sind. Nein, (sie sind) lebendig (im Jenseits) [...]. « $^{27}$ ), findet in der Bildmontage ihre visuelle Entsprechung. Das mediale Augenzeugnis der Detonation wird hier suggestiv in den Bereich des Jenseits erweitert: Die filmische Überblendung mit der portraithaften Videosequenz scheint bestätigen zu wollen, dass der Dargestellte durch seinen (parallel zu beobachtenden) Autobombenanschlag tatsächlich den Status eines Märtyrers erreicht und einen >Sieg` für die muslimische Gemeinschaft errungen hat.

Abbildung 4.5 a-d: Al-Qaida im Irak, Videotestament von Abu Zubayr, 8. Juli 2005, 4:24 min.
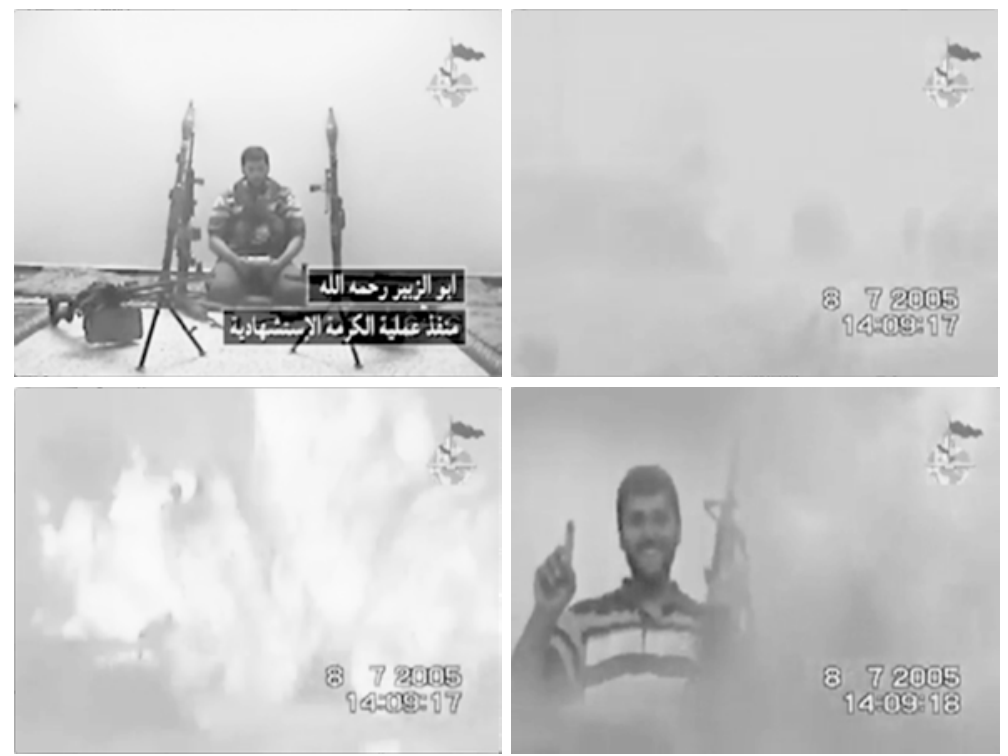

27 Zitiert nach Paret (Hg.): Der Koran. Kommentar und Konkordanz von Rudi Paret, Koransure 3:169, online abrufbar unter https://corpuscoranicum.de/index/index/sure/3/ vers/169 (zugegriffen am 6.6.2021). 
Ähnliche Strategien der Postproduktion lassen sich schließlich auch in den Videotestamenten des Islamischen Staats wiederfinden. Der Islamische Staat im Irak (dawlat al- 'Irāq al-islāmīyya), kurz ISI, entstand im Jahr 2006 aus dem Zusammenschluss mehrerer extrem-islamistischer Gruppen, unter denen die al-Qaida im Irak eine federführende Rolle spielte. ${ }^{28} \mathrm{Ab} 2013$ folgte die Umbenennung in Islamischer Staat im Irak und Syrien, bzw. Islamischer Staat von Irak und Sham, kurz ISIS. ${ }^{29}$ Seit der Ausrufung des Kalifats im Juni 2014 durch den selbsternannten Kalifen Abu Bakr al-Bagdadi nannte sich die Terrormiliz nur noch Islamischer Staat (dawlat al-islāmiyya) und erweiterte damit die bislang regional beschränkten Ziele zugunsten der Idee einer weltumspannenden Herrschaft. Zur selben Zeit distanzierte sich der IS endgültig von der Führungsspitze der al-Qaida. Viele Selbstmordattentate, vorwiegend im Irak, aber auch in Syrien, Libyen, dem Jemen und der Türkei, sowie in europäischen Ländern wie Frankreich, Belgien und auch in Deutschland, wurden seit 2006 vom IS verantwortet. Wie aus der Datenbank des Chicago Project on Security and Terrorism (CPOST) ersichtlich ist, haben der Islamische Staat und seine regionalen Ableger zwischen 2006 und 2016 insgesamt 796 Suizidanschläge durchgeführt, bei denen 10.509 Menschen getötet wurden. ${ }^{30}$

Dass auch der IS Videotestamente seiner Selbstmordattentäter produzierte und für seine propagandistischen Zwecke nutzte, mag nicht erstaunen. Zahlreiche Publikationen, die in den letzten Jahren zum Thema erschienen sind, betonen die hohe Medienaffinität der Terrormiliz, insbesondere deren Einsatz audiovisueller Produktionen. ${ }^{31}$ Ähnlich wie al-Qaida unterhält auch der IS zahlreiche unabhängig voneinander operierende Medienabteilungen, die von Westafrika bis in den Kaukasus auf der ganzen Welt verstreut sind. ${ }^{32}$ Bis heute haben diese eine schier

28 Zur Entstehungsgeschichte des IS siehe Christoph Günther: Ein zweiter Staat im Zweistromland? Genese und Ideologie des »Islamischen Staates Irak«, Würzburg: ErgonVerlag 2014.

29 »As-Sham« (»der Norden«) ist die arabische Bezeichnung für das geografische Gebiet der Levante, das die heutigen Staaten Syrien, Libanon, Israel, Palästina, Jordanien sowie Teile der Türkei umfasst.

30 Vgl. Chicago Project on Security and Terrorism (CPOST): Suicide Attack Database.

31 Vgl. insbesondere Atwan: Islamic State: The Digital Caliphate; Christoph Günther und Simone Pfeifer (Hg.): Jihadi Audiovisuality and its Entanglements: Meanings, Aesthetics, Appropriations, Edinburgh: Edinburgh University Press 2020; Winter: Documenting the Virtual 〉Caliphate〈; Bernd Zywietz (Hg.): Propaganda des »Islamischen Staats «. Formen und Formate, Wiesbaden: Springer VS 2020.

32 Einen Überblick über die 35 wichtigsten Medienproduktionsabteilungen des IS gibt Winter: Documenting the Virtual `Caliphate`, S. 31. 
unüberschaubare Anzahl an Fotografien, Postern und Videos publiziert, die von kurzen Clips bis zu Dokumentationen in Spielfilmlänge reichen. Aber auch Audiobotschaften, theologische Abhandlungen, dschihadistische Traktate sowie ganze Onlinemagazine gehören zum Output der IS-Pressekanäle. Einem Bericht der Quilliam Foundation zufolge veröffentlichte der IS im Jahr 2015 rund 38 neue Nachrichten und Artefakte pro Tag. ${ }^{33}$ Dabei sind weit über 80 Prozent aller veröffentlichten Medienprodukte visueller Natur, so der Islamwissenschaftler und Nahostexperte Aaron Y. Zelin. ${ }^{34}$ Wurden die Bilder und Videos Anfang des neuen Jahrtausends noch primär über passwortgeschützte Foren verbreitet, schien sich wenige Jahre später Twitter zu einer zentralen Distributionsplattform des IS entwickelt zu haben. ${ }^{35}$ Durch die Multiplikation der Accounts und ständige Namenswechsel gelang es dem IS immer wieder, Inhalte selbst dann online zu verbreiten, wenn einzelne Accounts von Twitter geschlossen wurden. Welchen Stellenwert der IS seinen Medienproduzenten beimisst, wird allein durch die zahlreichen Bilder deutlich, die Männer mit diversen digitalen Aufnahmegeräten (wie am Kopf befestigte Action-Kameras) heldenhaft in Szene setzen. Sämtliche Medienarbeiter, vom Kameramann bis zum IT-Spezialist, werden vom IS als »Media Brothers « bezeichnet und ebenso wie ihre bewaffneten Kameraden als »Mujahid«, als »heilige Kämpfer« gewürdigt. ${ }^{36}$ Die Medienproduktion und Onlineaktivität des IS ist zu einem der zentralen Pfeiler ihres dschihadistischen Kampfes geworden. Zu Recht bezeichnen sowohl Abdel Bari Atwan als auch Charlie Winter den Islamischen Staat daher als »digitales «, beziehungsweise »virtuelles Kalifat «. ${ }^{37}$ Die Annahme, hinter den audiovisuellen Medienprodukten stehe wenig mehr als »a guy and a laptop $\ll^{38}$, scheint für die IS-Produktionen nicht mehr zuzutreffen. Wie die Beispiele dieses Kapitels zeigen werden, handelt es sich bei vielen Videos um aufwendig produzierte Propagandastücke, die auch technisch gesehen immer versierter wurden.

33 Vgl. Winter: Documenting the Virtual `Caliphate`, S. 5.

34 Vgl. Aaron Y. Zelin: »Picture Or It Didn't Happen: A Snapshot of the Islamic State's Official Media Output«, Perspectives on Terrorism 9/4 (2015), S. 85-97, hier S. 85.

35 Ebd., S. 86.

36 Vgl. Alexandra Dick: »Anāshīd und der mediale Jihad des Islamischen Staates«, Zeitschrift für Semiotik 39/3-4 (2017), S. 55-70, hier S. 56.

37 Atwan: Islamic State: The Digital Caliphate; Winter: Documenting the Virtual $>$ Caliphate<.

38 Dauber: YouTube War, S. 101. 
Abbildung 4.6 a-h: Islamischer Staat im Irak/Medienbüro al-Furqān:

Ritter des Zeugnisses 5, 2008, 45:17 min, arabisch.
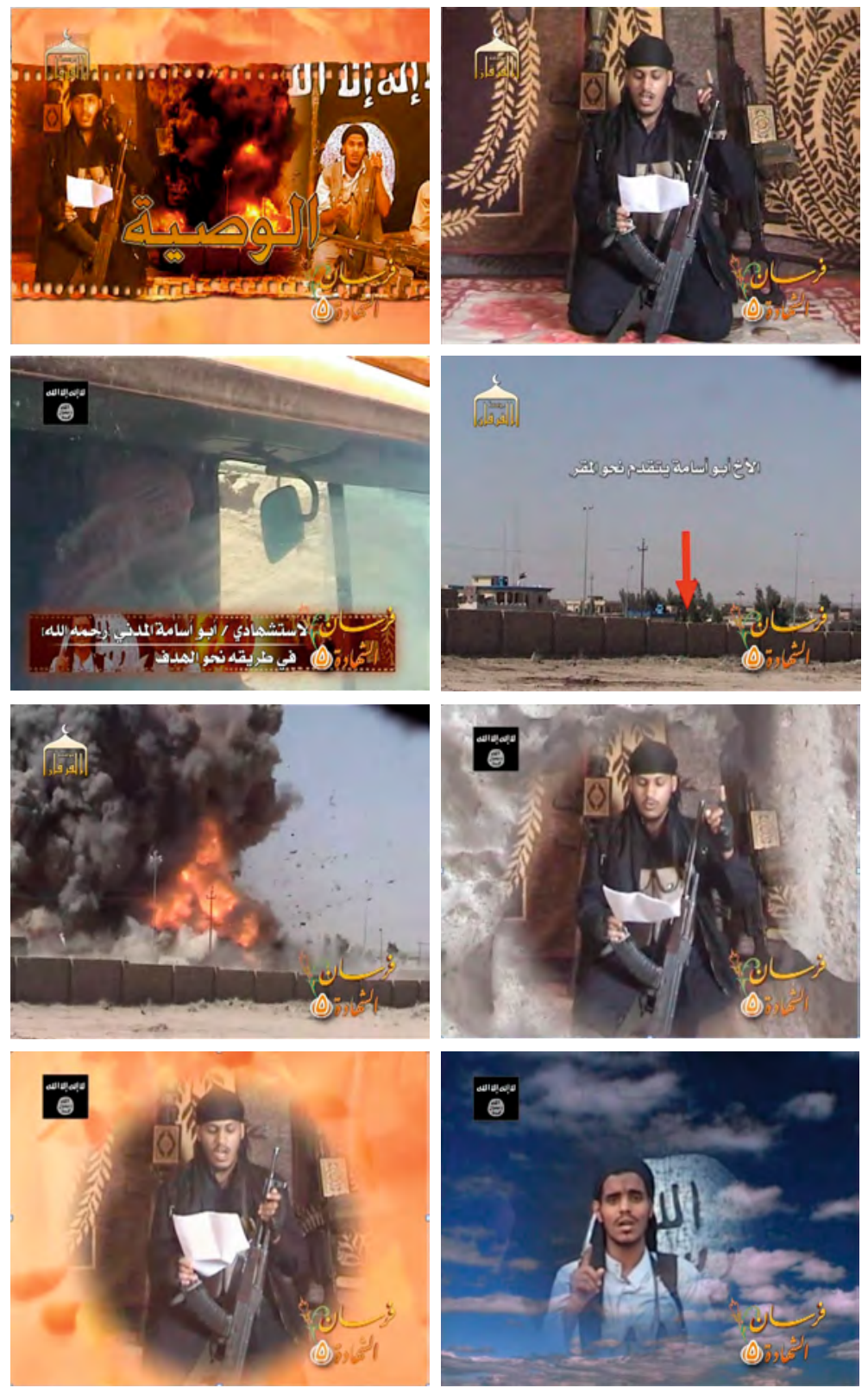
Das Video, um das es im Folgenden ausführlich gehen soll, wurde von der Medienproduktionsgesellschaft al-Furqān für den Islamischen Staat im Irak produziert und im Jahr 2008 verbreitet. ${ }^{39}$ Es ist insgesamt 45 Minuten lang und trägt den Titel Fursān aš-šahāda, was mit Ritter des Zeugnisses übersetzt werden kann. Das Video ist der fünfte Teil einer Videoreihe, die den >Märtyreroperationen ‘ des IS gewidmet ist, ${ }^{40}$ und steht beispielhaft für die technische und dramaturgische Komplexität dieser Produktionen.

In Ritter des Zeugnisses 5 werden drei saudische Selbstmordattentäter geehrt, die im Jahr 2008 Sprengstoffattentate im Irak durchgeführt haben. Das Kernstück des Videos bilden auch hier die Aufnahmen, in denen die Attentäter ihre jeweiligen Testamente verlesen. Das visuelle Setting, sowie der Ablauf dieser Sequenzen orientiert sich im Wesentlichen an früheren Beispielen: Der zukünftige Attentäter ist vor einem mit Tüchern behangenen Hintergrund zu sehen, gerahmt von mehreren Kalaschnikows und Koranausgaben, während er sein Testament verliest und sein eigenes Martyrium verkündet (Abb. 4.6 b). Die an sich eher konventionellen Testament-Szenen werden jeweils durch die Überschrift »al-wașiya«, arab. »das Testament«, eingeleitet und gerahmt (Abb. 4.6 a). Aufwendig gestaltete Zwischenüberschriften wie diese, aber auch grafische Inserts, die im Stil von Nachrichtensendungen wichtige Informationen oder Namen am unteren Rand des Bildes ankündigen, ziehen sich durch die gesamte Produktion (vgl. Abb. 4.6 c). Interessanterweise nehmen diese Text-Bild-Montagen durchweg die Gestalt von Filmstreifen an - erkennbar an den perforierten Rändern oben und unten. Obwohl das Material Film hier nirgendwo eine Rolle spielt und alle Bilder digital produziert sind, wird die Bedeutung der medialen Vermittlung auf diese Weise betont und prominent ins Bild gesetzt. Auf den eingeblendeten Filmstreifen sind Standbilder der Märtyrer und ihrer Operationen zu erkennen, die einzelne zentrale Sequenzen innerhalb des gesamten Videos wiederaufnehmen oder antizipieren. Die wiederkehrenden Filmstreifen kreieren dadurch eine Art 〉Best Of^des Videotestaments, das eine Ikonisierung der Märtyrer vorwegnimmt. Die drei Selbstmordattentäter werden präsentiert, als wären sie bereits zu Filmstars geworden. Gleichzeitig fällt auf, dass die Gestaltung der Filmstreifen Unregelmäßigkeiten aufweist: Die perforierten Ränder des entwickelten Films wellen sich als hätten sie einen Brand überstanden und vermitteln so den Eindruck, es handele sich um ein

39 Das Video ist online abrufbar unter https://archive.org/details/Forsan-Ashahada5 (zugegriffen am 6.6.2021).

40 Zur Serie »Fursān aš-šahāda« siehe Nico Prucha: »Hijacked Islam«, Online Jihad: Monitoring Jihadist Online Communities (18.11.2010), https://onlinejihad.net/2010/11/ 18/hijacked-islam/ (zugegriffen am 6.6.2021). 
authentisches materielles Überbleibsel vom Ort des Geschehens. Die häufig konstatierte $»$ Indexikalität $\aleph^{41}$ des Mediums Film rückt hier also in einem doppelten Sinne in den Vordergrund: Als filmische Spur auf der Ebene des entwickelten Bildes und als Brandspur auf der Ebene des Materials. Durch das technische Verfahren des Lichtabdrucks wird fotografischen und filmischen Bildern oftmals ein kausaler Bezug zur Wirklichkeit zugesprochen - und damit das Vermögen, objektiv Zeugenschaft abzugeben. Die Kamera gilt mitunter als der ultimative, scheinbar unfehlbare Augenzeuge (testis), dessen Verlässlichkeit weder durch eine lückenhafte Erinnerung oder durch subjektive Eindrücke beeinträchtigt ist. ${ }^{42}$ Der Filmstreifen im IS-Video, der durch die zusätzliche Brandspur gerade in seiner Materialität hervorgehoben wird, scheint einerseits auf diesen Modus der objektiven Zeugenschaft zu verweisen und die Authentizität des Gezeigten zu behaupten. Andererseits ist der Filmstreifen hier aber eindeutig als digital erzeugte Computermontage zu erkennen, wodurch die Frage nach der >Authentizität gleichzeitig wieder ad absurdum geführt wird. Die digitalen Filmstreifen scheinen vielmehr etwas anderes bezeugen zu wollen: Die virtuose Beherrschung der visuellen Inszenierung selbst, die sich scheinbar mühelos den ästhetischen Konventionen des Films, des Fernsehens und der Welt der Computersimulation bedient.

Ähnlich wie die Videos der Hisbollah und al-Qaida folgt auch diese Produktion einer übergeordneten Dramaturgie, die von der biografischen Vorstellung des jeweiligen Märtyrers, seinem Videotestament, letzten Umarmungen und Grußworten, bis hin zu den Aufzeichnungen des eigentlichen Anschlags führt. Dieser dramaturgische Ablauf wird im Laufe des Videos in Variationen drei Mal wiederholt, um alle drei saudischen Selbstmordattentäter vorzustellen und deren Operationen zu dokumentieren. Neu ist hier vor allem die vielschichtige Postproduktion, die das Video zu einem äußerst komplexen Medienerzeugnis macht. Das Footage wird nicht nur durch Titel oder grafische Einblendungen unterteilt, sondern

41 Der Begriff geht auf die Zeichentheorie von Charles S. Peirce zurück, der im indexikalischen Zeichen einen kausalen Zusammenhang zwischen Zeichen und Objekt sieht., Charles S. Peirce: Semiotische Schriften Bd. I-III, hg. von Christian J. W. Kloesel und Helmut Pape, Frankfurt am Main: Suhrkamp 2000. Die Vorstellung der Fotografie als Index wurde unter anderem von Theoretiker*innen wie Rosalind Krauss oder Roland Barthes vertreten. Rosalind Krauss: »Anmerkung zum Index: Teil 1 und Teil 2 [1976/77]«, in: Dies.: Die Originalität der Avantgarde und andere Mythen der Moderne, Amsterdam/Dresden: Verlag der Kunst 2000, S. 249-276; Roland Barthes: Die helle Kammer. Bemerkungen zur Photographie, Frankfurt am Main: Suhrkamp 1985.

42 Vgl. Renaud Dulong: Le témoin oculaire. Les conditions sociales de l'attestation personelle, hg. von l'École des hautes etudes des sciences sociales, Paris 1998. 
beständig neu geschnitten, in Slow-Motion verlangsamt, mit anderen Clips überblendet oder durch computergenerierte Sequenzen ergänzt. Die Reichweite dieser Eingriffe lässt sich anhand einer Szene paradigmatisch demonstrieren, die mit der Zwischenüberschrift (arab.) »tanfìd al- 'amalīya«, »Durchführung der Operation«, eingeläutet wird (ab 13:57 min). Die Szene beginnt mit der Aufnahme einer Kamera, die offenbar an der Außenseite eines LKW befestigt wurde und ins Innere des Führerhauses filmt. Sie zeigt einen der drei Attentäter, Abu Usama al-Maddani, am Steuer des LKWs. Sein Name erscheint auch auf der Einblendung am unteren Bildrand, die auf visuelle Konventionen des Fernsehens rekurriert und im Stil einer Nachrichtensendung verkündet: »Der Märtyrer Abu Usama al-Maddani (Gott erbarme sich seiner) auf dem Weg zum Ziel « ${ }^{43}$ (Abb. $4.6 \mathrm{c}$ ). Nach einem Schnitt wird das Geschehen aus einiger Entfernung gezeigt. Da der LKW hinter den Mauern teilweise kaum zu sehen ist, wird zusätzlich ein roter Pfeil eingeblendet, der die Bewegung des Fahrzeugs nachvollziehen soll (Abb. 4.6 d). Ergänzt wird der Pfeil zudem durch die Erklärung »Der Bruder al-Maddani fährt zur Zentrale«, wobei die Polizeizentrale in Tigris gemeint ist, die bei dem Anschlag in die Luft gesprengt wurde. Kurz vor der Explosion wird das Videobild dann extrem verlangsamt und die Explosionsszene mehrfach hintereinander abgespielt, beim dritten Mal in Zeitlupe (Abb. 4.6 e).

Die videografische Aufnahme allein vermag auch dieses Mal nichts zu >beweisen : Weder das Anschlagsziel noch der LKW sind über weite Strecken des Clips erkennbar. Selbst wenn man davon ausgeht, dass die sichtbare Explosion tatsächlich durch den LKW verursacht wurde, ist weder der genaue Ort noch das Ausmaß der Zerstörung aus den Bildern abzuleiten. Der didaktische Zeigegestus scheint die fehlende Evidenz des Videobildes zu kompensieren und die objektive Beweiskraft des Videos nachträglich zu behaupten. Diese fingierte $>$ Beweisführung $<$ im Bild wird im weiteren Verlauf des Videos noch einen entscheidenden Schritt weitergetrieben. Ähnlich wie im oben diskutierten Video der al-Qaida wird die Aufnahme der Explosion mit einem weiteren Videoclip überblendet. Es zeigt einen Ausschnitt aus dem Testament al-Maddanis, in dem er sagt: »Ich übergebe mich Gott; ich möchte diese Religion unterstützen und das Paradies gewinnen und Gott begegnen $\aleph^{44}$. Sein Bild erscheint zunächst umgeben von Trümmern, die auf die erfolgte Zerstörung hinweisen (Abb. 4.6 f). Kurz darauf verwandeln sich die Trümmer jedoch in rote Blütenblätter (Abb. $4.6 \mathrm{~g}$ ), die an das in der schiitischen Tradition geläufige Märtyrersymbol der roten Tulpe erinnern (vgl. Kapitel 3.3, S.

43 Ich danke Christoph Günther für die Übersetzung der sprachlichen Elemente dieses Videos. Sofern nicht anders angegeben, beziehen sich alle Zitate auf diese Übersetzung.

44 Übersetzung in Günther: »Corpus delicti - der Körper als Tatwerkzeug«, S. 31. 
171). Auch wenn es auf den ersten Blick erstaunen mag, dass eine radikal-sunnitische Gruppierung wie der Islamische Staat Anleihen aus der schiitischen Ikonografie nimmt, ist die Übernahme schiitischer Märtyrersymbole in den Propagandavideos des IS keine Seltenheit. ${ }^{45}$ Die letzten Silben der eingespielten TestamentSequenz (»Gott begegnen«) werden stakkatoartig drei Mal wiederholt, bis das Bild in einem Regen aus Blütenblättern verschwindet. Die Montage kulminiert schließlich in einer Koransure, die auch einen Wechsel auf der Tonebene markiert: Der zum Dschihad aufrufende a-capella Gesang, der seit Einblendung der Überschrift über die Szene gelegt wurde, endet an dieser Stelle und wird von der Rezitation der Sure 33:23-24 abgelöst, die mit den Worten beginnt: »Unter den Gläubigen gibt es Männer, die wahr gemacht haben, wozu sie sich Gott gegenüber verpflichtet hatten $[\ldots] . \ll^{46}$

Die behauptete Transformation vom Irdischen ins Himmlische wird hier durch die grafische und auditive Postproduktion sinnlich erfahrbar gemacht. Die Ankündigung al-Maddanis, durch seine Tat ins Paradies einzutreten, wird im Moment der Explosion durch die digitale Montage bekräftigt - so die visuelle Rhetorik dieser Postproduktion. Eine weitere Paradies-Montage findet sich auch gegen Ende des Videos wieder, wenn die Videobilder von allen drei Attentätern in einen computergenerierten, blauen Wolkenhimmel montiert werden (Abb. 4.6 h). Die gesprochenen Testamente der Selbstmordattentäter treten hier nun vollständig hinter den begleitenden Gesang zurück; zudem wird eine Ansprache des ISAnführers al-Baghdadi eingespielt. Auch hier handelt es sich gewissermaßen um ein konstruiertes Medienzeugnis, mit dem suggeriert werden soll, dass das Martyrium des Dargestellten tatsächlich eingetreten ist. Was mit dem oben besprochenen Video der al-Qaida von 2005 schon eingeführt wurde, wird hier zusätzlich verstärkt: Das Testament des Märtyrers scheint nur noch der Auftakt zu sein für das eigentliche, übergeordnete Märtyrerzeugnis, das mit Mitteln der Bild- und Tonmontage erzeugt wird.

Durch die stark affektive Bearbeitung des Videomaterials (durch Effekte wie Slow-Motion, Stakkato, Überblendung etc.) operiert Ritter des Zeugnisses 5 aber

45 Insbesondere das Symbol der roten Tulpe taucht in vielen Propagandavideos des IS auf. Zum Einfluss, den schiitische Märtyrerkonzepte auf sunnitische Gruppen in Pakistan und Afghanistan ausübten, siehe Simon Fuchs: Relocating the Centers of Shī'ī Islam: Religious Authority, Sectarianism, and the Limits of the Transnational in Colonial India and Pakistan, Dissertation, Princeton University 2015.

46 Zitiert nach Paret (Hg.): Der Koran. Kommentar und Konkordanz von Rudi Paret, Koransure 33:23-24, online abrufbar unter https://corpuscoranicum.de/index/index/ sure/33/vers/23 (zugegriffen am 6.6.2021). 
gerade nicht im Sinne eines objektiven Augenzeugnisses, sondern offensiv appellierend. Besonders die Gestaltung der Tonebene spielt hier eine entscheidende Rolle. So sind im Video fast durchweg sogenannte Anaschid im Hintergrund zu hören - islamische a-capella Gesänge von Männern, die sich in dschihadistischen Kreisen großer Beliebtheit erfreuen und heutzutage insbesondere auf YouTube massenhaft zirkulieren. Bezeichnete der arabische Begriff nāshīd (Pl. anāshīd) ursprünglich eine sufische Praxis der Rezitation religiöser arabischer Poesie, wurden Anaschid ab den 1970er Jahren zunehmend in radikal-islamistischen Kontexten angeeignet und erfuhren dort einen Wandel zu Kampfgesängen. ${ }^{47}$ Heute werden unter Anaschid überwiegend dschihadistische Hymnen verstanden. Nach dschihadistischer Auffassung gelten die Gesänge nicht als Musik - die in streng islamischer Auslegung als billiger Zeitvertreib gilt und teilweise sogar verboten wird -, sondern werden der religiösen Sphäre zugeordnet. Aus diesem Grund kommen auch keine Instrumente zum Einsatz. Stattdessen nutzt der IS für seine Anaschid häufig Tonaufnahmen von Explosionen oder Maschinengewehrsalven, um rhythmisierende Effekte zu erzeugen. In vielen Anaschid werden Themen wie »Opferbereitschaft, Blutvergießen und Zusammenhalt besungen«, darüber hinaus enthalten die Gesänge häufig auch direkte Aufrufe zum Dschihad. ${ }^{48}$ Der Islamwissenschaftler Behnam Said hat auf die mobilisierende Wirkung dschihadistischer Anaschid hingewiesen. Die Kampfhymnen seien als Propagandamittel gerade deshalb so effektiv, da sie Individuen auf einer affektiven Ebene ansprechen und »Emotionen mobilisieren « ${ }^{49}$. In mehreren Fällen ist bekannt, dass Attentäter noch auf dem Weg zu ihrem Anschlag Anaschid hörten, als sstimmten< sie sich dadurch - im wahrsten Sinne des Wortes - auf die Tat und das kommende Martyrium ein. ${ }^{50}$

47 Vgl. Behnam Said: Hymnen des Jihads: Naschids im Kontext jihadistischer Mobilisierung, Würzburg: Ergon Verlag 2016; Yassin Musharbash und Behnam Said: »Der Soundtrack des Dschihad«, Die Zeit, 01.07.2016, http://www.zeit.de/2016/28/islamismus-anaschid-musik/komplettansicht?print (zugegriffen am 6.6.2021).

48 Musharbash/Said: »Der Soundtrack des Dschihad«.

49 Behnam Said: »Hymns (Nasheeds): A Contribution to the Study of the Jihadist Culture«, Studies in Conflict \& Terrorism 35/12 (2012), S. 863-879, hier S. 876.

50 Beispielsweise soll der Frankfurter Flughafenattentäter Arid Uka, der am 2. März 2011 zwei US-Soldaten erschoss, auf dem Weg zum Attentat über Kopfhörer den deutschen Kampf-Naschid »Mutter bleibe standhaft ich bin im Jihad « gehört haben, in dem es unter anderem heißt: »Mutter wenn ich auf dem Schlachtfeld falle, dann glaub nicht ich sei tot - Vielmehr bin ich lebendig an einem besseren Ort.« Marwan Abou Taam et al.: »Anwerbungspraxis und Organisationsstruktur«, in: Janusz Biene et al. (Hg.): 
Wie bereits erwähnt, wurde auch die oben diskutierte Sequenz (von der Autofahrt des Attentäters bis hin zur Detonation) mit einem Naschid unterlegt. Er trägt den Titel sawfa am $\grave{l} \bar{l}$, was mit Ich werde weggehen übersetzt werden kann. ${ }^{51}$ Im Laufe des Gesangs wird diese eindringliche Zeile mehrfach, geradezu mantrahaft wiederholt, was den entschlossenen Aufbruch zur Märtyreroperation unterstreicht. An dieser Stelle wird deutlich, dass der Naschid im Video nicht nur zur Stimmungsuntermalung eingesetzt wird, sondern auch eine syntaktische Funktion erfüllt, indem er die Handlung des Videos strukturiert. ${ }^{52}$ Im Gesangstext heißt es weiter: »Wenn der Unglaube einer Flut mit reinem Blut ausweicht, werde ich standhaft bleiben und mich nicht beugen bis zu meinem Tod. Dann geht die Dunkelheit der Schande vorüber und es [erscheint] Glanz, der Glanz des Ruhmes. $\aleph^{53}$

Wie als Ansporn werden hier die positiven Effekte hervorgehoben, die die Märtyreroperation sowohl für die Gemeinschaft als auch für den Sprecher mit sich bringe. Der Verweis auf das »reine Blut« rückt bereits den (zukünftigen) Märtyrerstatus des Individuums in den Vordergrund. Der islamischen Vorstellung zufolge gilt das Blut eines Verstorbenen durch den Märtyrertod als gereinigt und wird - entgegen der gängigen Bestattungspraxis - offen zur Schau gestellt (siehe S. 58) ${ }^{54}$ Dass der Naschid durchgängig in der ersten Person Singular formuliert ist (»Ich werde weggehen«), kann zudem als Einladung an die Zuhörerschaft gedeutet werden, sich in die Innenperspektive des Märtyrers zu versetzen und sich mit dem Dargestellten zu identifizieren. Einmal mehr wird deutlich, dass die audiovisuellen Montagen, die das Zeugnis des Märtyrers mitunter ins computersimulierte Jenseits erweitern, in erster Linie darauf abzielen, die Betrachtenden affektiv in das Geschehen einzubinden und potenzielle Nachfolger im Diesseits zu überzeugen.

Salafismus und Dschihadismus in Deutschland: Ursachen, Dynamiken, Handlungsempfehlungen, Frankfurt: Campus Verlag 2016, S. 79-158, hier S. 98.

51 Ich danke der Religionssoziologin Alexandra Dick für die freundliche Bereitstellung ihrer Übersetzung aus dem Arabischen.

52 Zur Systematisierung der Funktionen von Filmmusik vgl.: Georg Maas und Achim Schudack: Musik und Film - Filmmusik, Mainz: Schott 1994.

53 Übersetzung aus dem Arabischen von Alexandra Dick.

54 Khalili: Heroes and Martyrs of Palestine, S. 126. 


\subsection{DAS VIDEOTESTAMENT IM ZEITALTER DES EGO-SHOOTERS}

Auf einen solchen Immersionseffekt zielt auch die Eingangssequenz des eben besprochenen Videos ab. Das Eintauchen in die Ich-Perspektive des Märtyrers wird hier allerdings nicht auf der Ebene des Tons, sondern auf der des Bildes forciert. Direkt nach dem Einblenden der Basmala (der arabischen Anrufungsformel, die jede Sure des Korans einleitet), der Schahada (dem muslimischen Glaubensbekenntnis), sowie dem schwarz-weißen Logo des ISI, wird eine rund 20 Sekunden lange computersimulierte Sequenz abgespielt, die als eine Art Intro der gesamten 45-minütigen Produktion funktioniert. Noch bevor die drei saudischen Selbstmordattentäter und ihre Testamente vorgestellt werden, entwirft der Islamische Staat hier eine rein virtuelle Szenerie, die auf die Ästhetik von First-Person-Computerspielen rekurriert. Die Sequenz zeigt eine paradiesische Landschaft, dargestellt durch Blütenfelder und saftig grüne Wiesen, in der ein sprengstoffbeladener Tanklaster zum Attentat aufbricht. Die virtuelle Kameraperspektive vollzieht zunächst den Weg zum Fahrzeug, dessen Tür sich wie von Geisterhand öffnet (Abb. 4.7 a). Es folgt der Blick ins Führerhaus, in dem die Betrachtenden nun die Perspektive des Fahrers einnehmen und durch die Frontscheibe des LKWs nach vorn blicken (Abb. 4.7 b). Durch die Konstruktion einer Ego-Perspektive werden zu Beginn dieser Sequenz die Betrachtenden selbst in die Position des zukünftigen Märtyrers versetzt. Die Computersimulation weist den Zuschauenden im wahrsten Sinne des Wortes einen `Platz` im filmischen Raum zu und bezieht sie damit auf geradezu körperlich erfahrbare Weise in das Geschehen mit ein. Diese »Erfahrung einer gefühlten Präsenz in künstlichen oder digital erzeugten Räumen« wird aus film- und medienwissenschaftlicher Sicht gemeinhin als »immersiv « bezeichnet. ${ }^{55}$ Mit dem eingeblendeten Vogelgezwitscher wird zudem ein natürliches Geräusch suggeriert, das im Sinne eines >on-screen-sound « mit dem Bild synchron erscheint und den Immersionseffekt noch steigert. ${ }^{56}$ Beim Betrachten des Videos rücken wir

55 Vgl. Robin Curtis: »Immersion und Einfühlung: Zwischen Repräsentationalität und Materialität bewegter Bilder«, montage AV. Zeitschrift für Theorie und Geschichte audiovisueller Kommunikation 17/2 (2008), S. 89-107, hier S. 90.

56 Das Vogelgezwitscher ist auch als Vorausgriff auf das erwartete Paradies zu deuten. Vögel nehmen in der islamischen Paradiesvorstellung eine besondere Position ein. Wie zahlreiche Hadithen berichten, finden die Seelen der Märtyrer*innen nach dem Tod Zuflucht in der Gestalt von Vögeln, die einen Ehrenplatz neben Gott im Paradies erhalten. Vgl. Jane Idleman Smith und Yvonne Yazbeck Haddad: The Islamic Understanding of Death and Resurrection, Oxford: Oxford University Press 2002, S. 49. 
folglich nicht nur in die Position von Augenzeug*innen, die das Selbstmordattentat aus sicherer Distanz beobachten, sondern erhalten zusätzliche Identifikationsangebote mit der Zeugen-Perspektive des zukünftigen Märtyrers oder der zukünftigen Märtyrerin. Wie bei Autorennspielen im First-Person-Modus sind Lenkrad und Armaturenbrett im unteren Teil des Bildes deutlich sichtbar. Damit wird eine Interaktivität simuliert, ganz so als könne man selbst das Steuer übernehmen und den sprengstoffbeladenen Laster virtuell lenken. Kurioserweise verharren jedoch alle Anzeigen, inklusive des Tachometers in der Standposition, auch nachdem der virtuelle LKW Fahrt aufgenommen hat. Wenige Sekunden später wechselt die Perspektive von der subjektiven Position in die Vogelperspektive und die Videorezipient*innen werden in die Position distanzierter Augenzeug*innen von oben versetzt (Abb. 4.7 c). Die Computersimulation zeigt wie der LKW auf einer geraden Anfahrtsschneise in Richtung einer befestigten Militäranlage fährt, in deren Zentrum ein rotes christliches Kreuz thront. Es folgt die Darstellung einer Explosion (Abb. 4.7 d), deren gleißendes Licht in einen roten Blütenregen übergeht, vor dem schließlich das hellgelbe Logo der Medienproduktionsfirma al-Furqān erscheint.

Abbildung 4.7 a-d: Islamischer Staat im Irak/Medienbüro al-Furqān:

Ritter des Zeugnisses 5, 2008, 45:17 min, arabisch, Eingangssequenz.

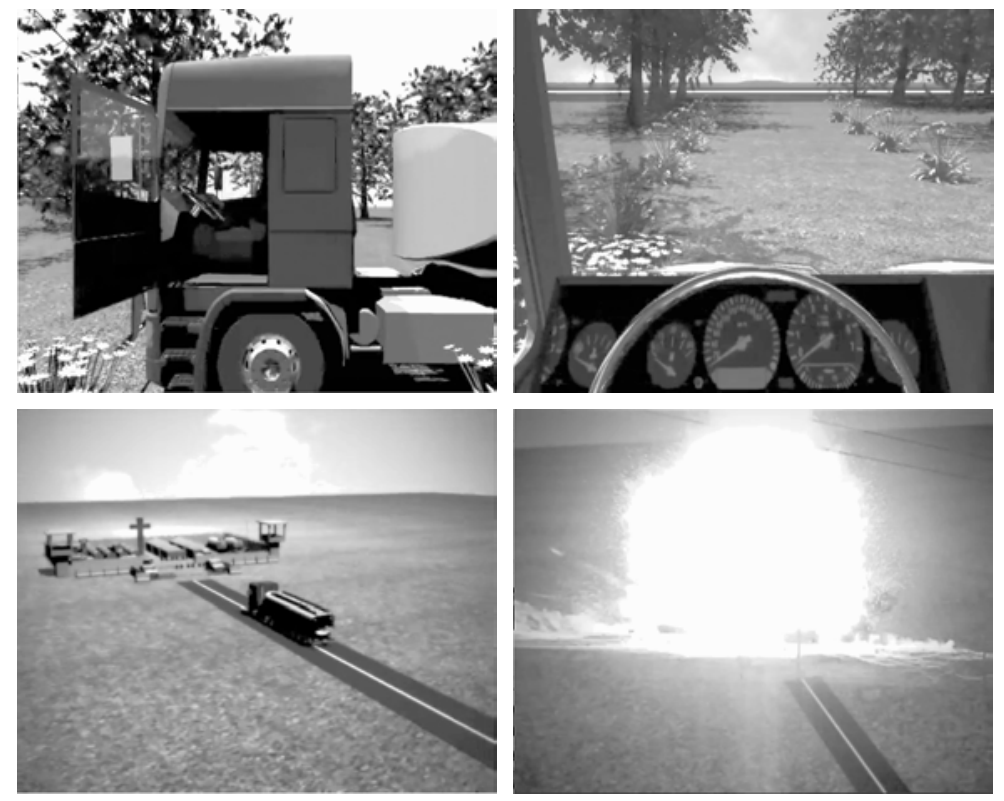


Der Rekurs auf First-Person-Computerspiele stellt mittlerweile eine gängige visuelle Strategie des IS dar. Zahlreiche Propagandavideos zeigen Gefechte, die mit sogenannten Action-Camcordern des US-amerikanischen Herstellers GoPro gefilmt wurden und dadurch die Ästhetik von Ego-Shooter-Spielen erhalten. So etwa die Szenen in einem IS-Video, das im August 2016 veröffentlicht wurde und mehrere Kämpfe nahe der syrischen Stadt Manbij dokumentiert (Abb. 4.8). ${ }^{57}$

Abbildung 4.8: Islamischer Staat/Medienbüro Wilayat Halab, Syrien, Video veröffentlicht am 4. August 2016, 12 min, arabisch.

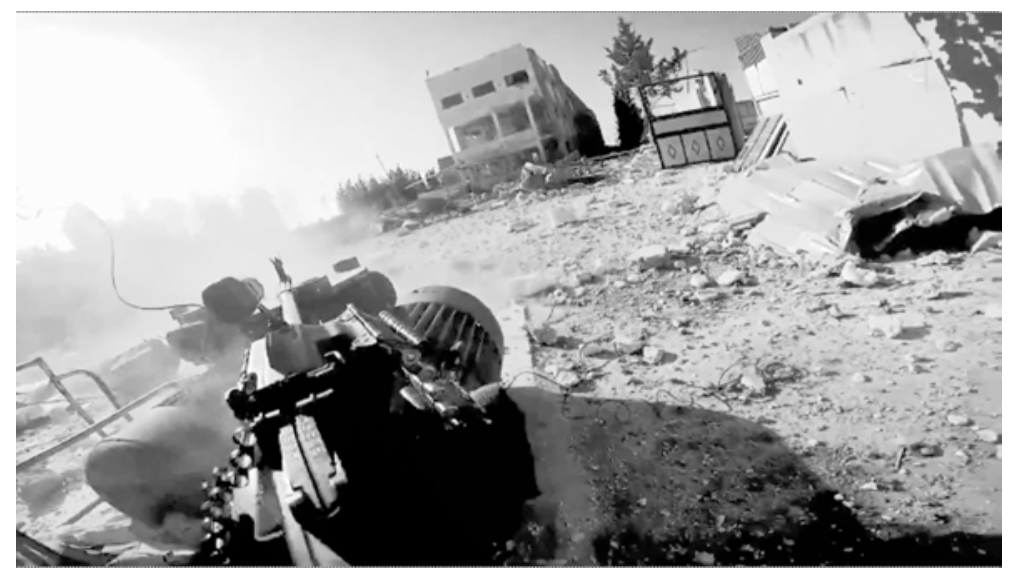

Im Gegensatz zur hyper-realistischen Aufnahmetechnik mit der GoPro-Kamera wird die digitale Simulation in Ritter des Zeugnisses 5 jedoch gerade in all ihrer Künstlichkeit ausgestellt. Es geht nicht darum, die Illusion einer realen Welt zu schaffen, sondern die Illusion eines virtuellen Computerspiels. Auch wenn die virtuelle Interaktion im Fall der Intro-Szene nur simuliert wird, spricht sie die Betrachtenden als potenzielle Gamer*innen - und damit als virtuell Handelnde - an. Von Seiten der Game Studies wurde mehrfach betont, dass Spielende durch die Handlungs- und Entscheidungsmöglichkeit in interaktiven Computerspielen eine besondere »emotionale Bindung « zum Ausgang des Spiels entwickeln. ${ }^{58}$ Allein

57 Video online abrufbar unter https://www.zerocensorship.com/uncensored/isis/first-person-shooter-style-syria-combat-footage-suicide-bombers-video-304429 (zugegriffen am 20.08.2017, nicht mehr verfügbar).

58 Jesper Juul: Half-Real: Video Games between Real Rules and Fictional Worlds, Cambridge: MIT Press 2005, S. 36. Zum Emotionalisierungspotenzial von Spielen siehe 
die Simulation einer virtuellen Handlungsfähigkeit scheint auf die positiven Stimuli abzuzielen, die mit dem Erreichen von Spielzielen einhergehen. Die ästhetische und perspektivische Gestaltung verknüpft das Videotestament mit denselben affektiven Registern, die auch in interaktiven Computerspielen aufgerufen werden und mit (zumeist positiven) Erfahrungen von Eigenwirksamkeit, Wettbewerb, Flow oder Immersion verbunden sind. ${ }^{59} \mathrm{Zu}$ einem ähnlichen Schluss kommt auch der Kunsthistoriker Oliver Grau in seiner Analyse virtueller Immersionserfahrungen. Wenngleich er einräumt, dass Immersion durchaus ein »intellektuell stimulierender Prozess« sein kann, beschreibt Grau Immersion als einen mentalen Zustand »gesteigerter emotionaler Involvierung «, die in den meisten Fällen mit einer verminderten kritischen Distanzfähigkeit zum Dargestellten einhergehe: »It [immersion] is characterized by diminishing critical distance to what is shown and increasing emotional involvement in what is happening. $"{ }^{60} \mathrm{In}$ diesem Sinne ließe sich argumentieren, dass der IS die Ästhetik der Ego-Perspektive hier gezielt als Mittel der Affizierung einsetzt, um sein Medienpublikum positiv zu involvieren und für die eigenen Ziele zu vereinnahmen. Aus rezeptionsästhetischer Sicht muss an dieser Stelle jedoch betont werden, dass die tatsächliche Seherfahrung je nach Perspektive der Betrachter*innen ganz unterschiedlich ausfallen kann. Statt das Publikum als »naive Masse« anzusehen, das von Immersionsangeboten scheinbar passiv gelenkt wird, betont Robin Curtis gerade die »Wahrnehmungskomplexität« immersiver Erfahrungen. ${ }^{61}$ Dies scheint umso mehr für die besprochene Videosequenz des IS zu gelten. So führt das >erzwungene` Eintauchen in die Sichtweise eines Selbstmordattentäters keineswegs automatisch zu affirmativen Identifikationseffekten, sondern kann ebenso sehr verstören und besonders heftige Gefühle des Befremdens, des Widerstands und der Abneigung auslösen.

Unabhängig davon, wie sich diese emotionale >Aktivierung ‘ auf subjektiver Ebene realisiert, werden die Betrachter*innen durch den Rekurs auf die Welt des Computerspiels - zumindest aus produktionsästhetischer Sicht - als Akteur*innen einer Bildoperation angesprochen. Die kurze Eingangssequenz des IS-Videos rückt daher eine weitere Dimension der Operativität von Videotestamenten in den Fokus. Denn: »Videospiele zu spielen ist in den meisten Fällen ein Handeln am

auch Katherine Isbister: How Games Move Us: Emotion by Design, Cambridge: MIT Press 2016.

59 Vgl. ebd. S. 4f.

60 Oliver Grau: Virtual Art: From Illusion to Immersion, Cambridge: MIT Press 2003, S. 13.

61 Curtis: »Immersion und Einfühlung«, S. 93. 
Bild und im Bild « ${ }^{62}$, so schreibt der Medienwissenschaftler Serjoscha Wiemer. Gerade im Kontext dschihadistischer Mobilisierung stellt sich dabei die Frage, in welchem Zusammenhang virtuelles Bildhandeln und militante Aktion zu sehen sind. In ihrem Buch Handlungstheorien des Bildes (2009) beschreibt die Philosophin Silvia Seja interaktive Bildhandlungen in virtuellen Realitäten als »Probehandlungen ${ }^{63}$. Als solche definiert sie Handlungen, deren Risiken und Konsequenzen auf die Welt des Computerspiels begrenzt bleiben und damit keine faktische Wirksamkeit außerhalb des Cyberspace entfalten »und dem Menschen insofern eine Entlastung von der harten Welt der Tatsachen gewähren « ${ }^{64}$.

Das besprochene IS-Video scheint diese Definition allerdings an ihre Grenze zu führen. Auf die simulierte Probehandlung, die man beim Betrachten der ersten 20 Sekunden von Ritter des Zeugnisses 5 durchläuft, folgen die Augenzeugenberichte der Märtyreroperationen, die tatsächlich stattgefunden haben. Die Spielsimulation bleibt also gerade nicht in der virtuellen Welt verhaftet, sondern wird mit fast identischen Videoaufnahmen der realen Todesfahrten kurzgeschlossen: Ganz wie in der Computerszene nähert sich die Kamera wenige Minuten später dem Führerhaus des LKWs, blickt dem Attentäter über die Schulter Richtung Lenkrad und Armaturenbrett, auf dem sich auch der Knopf zum Auslösen des Sprengsatzes befindet, und filmt schließlich die Detonation aus weiter Ferne (Abb. 4.9 a-c). An die imaginative Leerstelle der First-Person-Simulation - die von den Betrachtenden selbst ausgefüllt wurde - tritt in der gefilmten Sequenz allerdings der Selbstmordattentäter, der im Video mit dem Namen Abu Umar al-Najdi vorgestellt wird. Angesichts der visuellen Ähnlichkeit zu den im Video dokumentierten Anschlägen wirkt die Computeranimation zu Beginn wie eine Trainingssequenz, wie eine virtuelle Vorwegnahme eines Autobombenattentats. Die unterstellte »Folgenlosigkeit« virtueller Probehandlungen wird von den Machern dieses Videos scheinbar herausgefordert und in Frage gestellt.

Im Gegensatz zu Silvia Seja betont Richard Grusin in seinem Buch Premediation (2010) gerade die Kontinuität von medialen Vorwegnahmen und realen Ereignissen. ${ }^{65}$ Am Beispiel der US-amerikanischen Berichterstattung nach 9/11 zeigt er, dass der Krieg gegen den Irak schon Jahre zuvor in den öffentlichen

62 Serjoscha Wiemer: »Zeit. Ein Schlüsselbegriff für die Computerspielforschung«, in: Benjamin Beil, Thomas Hensel und Andreas Rauscher (Hg.): Game Studies, Film, Fernsehen, Neue Medien, Wiesbaden: Springer 2018, S. 27-45, hier S. 28.

63 Seja: Handlungstheorien des Bildes, S. 157.

64 Ebd.

65 Richard A. Grusin: Premediation: Affect and Mediality after 9/11, New York: Palgrave Macmillan 2010. 
Medien vielfach antizipiert wurde. Wie in einem Testlauf wurden unterschiedliche Szenarien der Berichterstattung durchgespielt, die ausloten sollten, wie man im Ernstfall über den tatsächlich eintretenden Krieg berichten sollte. ${ }^{66}$ Diese »Premediationen« des Krieges hatten Grusin zufolge die Aufgabe, die Zuschauer affektiv auf das tatsächliche Kriegsgeschehen vorzubereiten, sodass dieses nicht mehr als Schock, sondern als scheinbar unausweichliche Tatsache aufgefasst wurde. ${ }^{67}$ Ana$\log$ dazu ließe sich argumentieren, dass auch virtuelle Probehandlungen als Premediationen zu begreifen sind, die sowohl das affektive Erleben, als auch die Bewertung realer Ereignisse beeinflussen. Mehr noch als andere mediale Vorwegnahmen, scheinen militante Ego-Shooter vor diesem Hintergrund sogar als regelrechte >Pre-enactments zu funktionieren, die darauf abzielen, das Handeln vom virtuellen in den realen Raum zu verlagern. ${ }^{68}$

\section{Abbildung 4.9 a-d: Islamischer Staat im Irak/Medienbüro al-Furqān:}

Ritter des Zeugnisses 5, 2008, 45:17 min, arabisch.
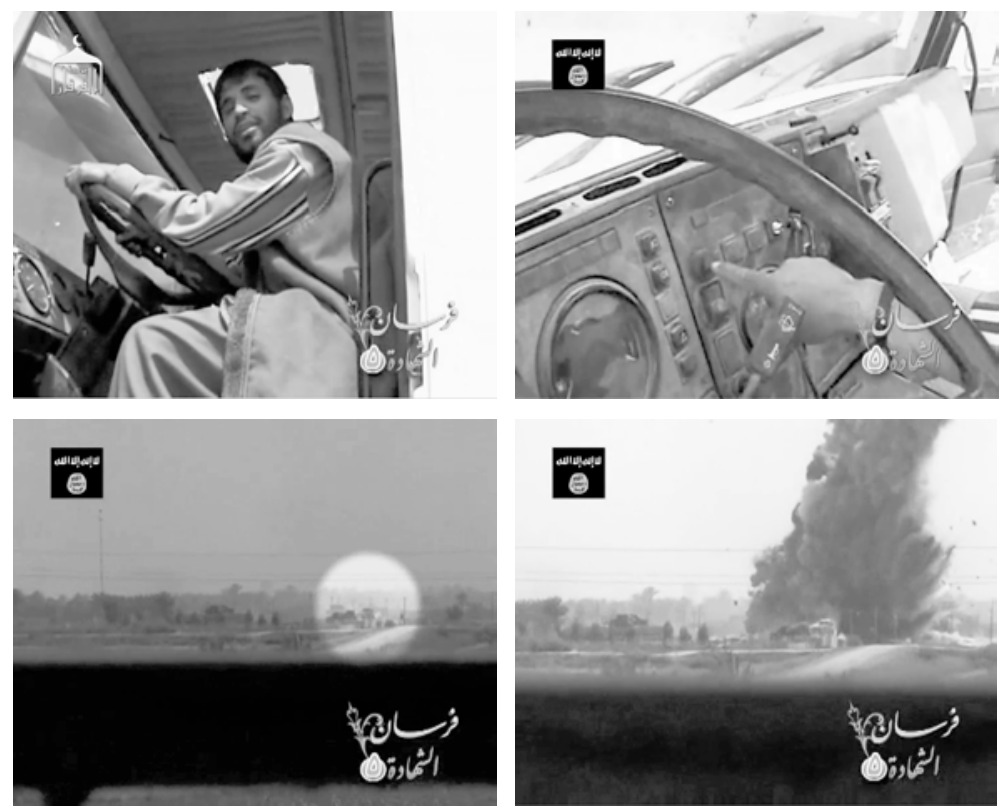

66 Vgl. Grusin: Premediation, S. 44.

67 Ebd., S. 46f.

68 Zum Begriff des Preenactments vgl. Czirak et al.: »(P)Reenactment«. 
Der Zusammenhang von Computerspielen und realer Gewalt wird insbesondere seit dem Aufkommen von Ego-Shootern äußerst kontrovers diskutiert. Dabei steht immer wieder die Frage im Mittelpunkt, inwiefern Spiele, in denen Tötungshandlungen gegen Menschen simuliert werden, auch zu einer erhöhten Aggressivität im realen Leben führen und mitunter eine Mitschuld an jugendlicher Gewaltkriminalität tragen. Sowohl Kritiker*innen als auch Verteidiger*innen von EgoShooter-Spielen können sich dabei auf empirische Studien der Medienwirkungsforschung stützen, die zu teils widersprüchlichen Ergebnissen kommen. Während eine ganze Reihe psychologischer Untersuchungen »a consistent relation between violent video game use and heightened aggressive behavior, aggressive cognitions, and aggressive affect ${ }^{69}$ diagnostiziert, gibt es ebenso viele Studien von Seiten der Psychologie und Medienwissenschaft, die diese Korrelation in Zweifel ziehen. ${ }^{70}$ Ein Ende dieses Streits, der sich zwischen einer »normativen Verurteilung « und einer »normalistischen Verharmlosung « virtueller Gewalthandlungen abspielt, ist nicht in Sicht. ${ }^{71}$ Im Folgenden soll es daher nicht darum gehen, Partei für die eine oder andere Seite dieser Kontroverse zu ergreifen. Ohne die Frage beantworten zu können, ob und inwiefern das Spielen eines Ego-Shooters tatsächlich Auswirkungen auf reale Handlungsmuster der Spielenden hat, wird deutlich, dass die Herangehensweise der Dschihadisten durch eben dieses Denken geprägt ist. Entscheidend ist daher nicht die Frage, ob das Spiel an sich zu gewalttätigem Handeln führt, sondern die Frage, inwiefern militante Akteur*innen Elemente des Computerspiels für ihre Aufrufe zur Gewalt instrumentalisieren.

Es gibt mehrere Beispiele dafür wie die Welt des Computerspiels von Terrororganisationen zur Rekrutierungs- und Propagandazwecken genutzt wird. Das Computerspiel Special Force, das von der libanesischen Hisbollah ab 2003 entwickelt wurde, kann als ein prominentes Exempel gelten (Abb. 4.10 a-b). Angeblich wurden »allein in den ersten acht Wochen nach Markteinführung im März 2003 im Libanon, in Syrien, Bahrain, den Vereinigten Arabischen Emiraten, in Kanada,

69 So resümiert eine Metastudie mit Blick auf die bisherige Forschung zum Thema. American Psychological Association: Technical Report on the Review of the Violent Video Game Literature, 2015, S. 18, http://www.apa.org/news/press/releases/2015/08/technical-violent-games.pdf (zugegriffen am 6.6.2021).

70 Einen guten Überblick über die Forschungslage zum Thema Gewalt und Computerspiel bietet Jochen Venus: »Gewalt«, in: Benjamin Beil, Thomas Hensel und Andreas Rauscher (Hg.): Game Studies, Film, Fernsehen, Neue Medien, Wiesbaden: Springer 2018,

S. 331-342.

71 Ebd., S. 332. 
Deutschland und Australien 10000 Kopien verkauft ${ }^{72}$. Auf der Originalverpackung des Computerspiels war zu lesen: »Sei ein Partner im Sieg. Kämpfe, leiste Widerstand, vernichte deinen Feind in diesem Spiel der Kraft und des Sieges. $\aleph^{73}$ 2007 wurde eine zweite Version des Spiels aufgelegt, die ebenfalls schnell ausverkauft war und dann online frei zur Verfügung gestellt wurde.

Abbildung 4.10 a-b: Hisbollah, Computerspiel Special Force 1, 2003,

Cover und Special Force 2, 2007, Standbild einer Spielsequenz.
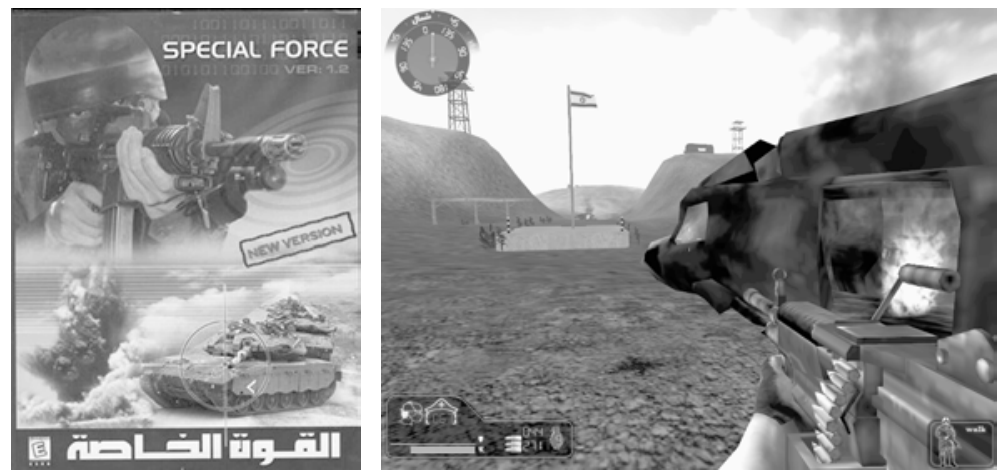

Das Spiel selbst basiert auf tatsächlichen Kämpfen zwischen der Hisbollah und der israelischen Armee, die in verschiedenen Levels nachgespielt werden können. Die virtuellen Landschaften sind den realen Schauplätzen im Südlibanon nachgebildet und geben den Spieler*innen damit die Möglichkeit, die Kämpfe möglichst >authentischく nachzuempfinden (Abb. 4.10 b). Gegenüber der libanesischen Tageszeitung Daily Star betonte ein Sprecher der Hisbollah, Mahmoud Rayya: »Special Force offers a mental and personal training for those who play it, allowing them to feel that they are in the shoes of the resistance fighters. $\ll^{74}$ Hier wird bereits deutlich, dass es den Entwickler*innen des Spiels um weitaus mehr als nur um Reenactments vergangener Kämpfe geht. Neben den regulären Spiellevels gibt es bei Special Force auch einen Trainingsmodus, bei dem die Spielenden Schießübungen absolvieren, während sie auf israelische Politiker und Militärfunktionäre zielen. Mit der Probehandlung im Spiel ist also - zumindest aus Perspektive der

72 Hoffman: Terrorismus. Der unerklärte Krieg, S. 321.

73 Verpackung »Special Force 1«, zitiert in ebd., S. 322.

74 Zitiert in World Net Daily (WND): »Hezbollah's New Computer Game«, 2003, http://www.wnd.com/ 2003/03/17550/ (zugegriffen am 25.06.2018, nicht mehr verfügbar). 
Hisbollah - das Ziel verbunden, zukünftige (männliche) Rekruten anzuziehen und sogar praktisch auszubilden. Es bleibt also fraglich, ob eine Trennung zwischen Bildhandeln im Cyberspace und Bildhandeln im realen Raum wirklich so scharf gezogen werden kann, wie Silvia Seja dies vorschlägt. Dieselbe Beobachtung kann ebenso für westliche Militäroperationen gelten. So betonte der Gründer des US-amerikanischen Simulationsnetzwerks SIMNET Jack Thorpe im Jahr 2004, dass die Grenze zwischen computersimulierter und >realer Operation angesichts der heutigen, netzwerkgestützten Kriege zunehmend verschwimmt: »Whereas it might feel like you and I are playing a game, we might actually be executing something, controlling something, solving a real-world problem. ${ }^{75}$ Thorpe bezog sich dabei unter anderem auf das Computerspiel America's Army, ein Simulationsspiel des US-Militärs, das speziell für Rekrutierungs- und Trainingszwecke entwickelt wurde. Verantwortliche des US-Militärs erkannten schon früh das militärische Potenzial, das in Computerspielen steckte. ${ }^{76}$ Spiele wie America's Army zielten darauf $\mathrm{ab}$, besonders IT- und medienaffine junge Menschen zu rekrutieren, da diese Fähigkeiten mitbrachten, die für die Herausforderungen einer hochtechnologisierten und vernetzten Armee unabdingbar waren. ${ }^{77}$ Dass dieses Potenzial schließlich auch von nicht-staatlichen militanten Organisationen erkannt wurde, liegt auf der Hand.

Besonders augenfällig wird die Verwischung der Grenze zwischen virtueller und realer Welt in einem Online »Trainingscamp«, das 2004 von der al-Qaida ins Leben gerufen wurde, kurz nachdem sie gezwungen war, ihre physischen Stützpunkte im Irak zu verlassen. Das an ein Onlinemagazin erinnernde Medienprodukt wurde unter dem Titel Mu'askar al-Battar veröffentlicht, was mit Trainingscamp des al-Battar übersetzt werden kann (der Kampfname des 2003 getöteten Chefs der saudischen al-Qaida, Yusuf al-Uyari).$^{78}$ Das Trainingscamp bestand unter anderem aus Video-Lektionen für die Benutzung von automatischen Waffen oder

75 Margaret Davis: »He Saw It Coming: An Interview with Jack Thorpe«, in: Dies. (Hg.): America's Army PC Game: Vision and Realization: United States Army and the MOVES Institute 2004, S. 30-32, hier S. 31.

76 Für eine Diskussion dieser Entwicklung siehe Timothy Lenoir und Luke Caldwell: »Image Operations: Refracting Control From Virtual Reality to the Digital Battlefield«, in: Jens Eder und Charlotte Klonk (Hg.): Image Operations. Visual Media and Political Conflict, Manchester: Manchester University Press 2016, S. 89-100.

77 Lenoir/Caldwell: »Image Operations: Refracting Control From Virtual Reality to the Digital Battlefield«, S. 92.

78 Vgl. Yassin Musharbash: Die neue al-Qaida: Innenansichten eines lernenden Terrornetzwerks, Köln: Kiepenheuer \& Witsch 2006, S. 123. 
zum Bau von Sprengstoffgürteln, aber auch aus Fitness-Trainingsprogrammen, sowie Schritt-für-Schritt-Anleitungen für die Durchführung von Selbstmordattentaten. In der ersten Ausgabe von al-Battar war zu lesen: »Oh Mujahid brother, in order to join the great training camps you don't have to travel to other lands. Alone in your home or with a group of your brothers, you too can begin to execute the training program. You can all join the Al-Battar Training Camp. $\ll^{79}$

Dabei bot das virtuelle Trainingslager durchaus auch Hilfestellungen für konkrete Anschlagsplanungen, so hat die Analyse von Yassin Musharbash ergeben. Das Magazin enthielt Aufforderungen, die »Vorhaben und Pläne« für »Operationen« per E-Mail an die angegebene Adresse zu schicken, ohne dabei jedoch sensible Informationen preiszugeben: »Wir begutachten sie, suchen die besten zur Verbreitung aus und werden sie mit Anmerkungen versehen«, so versprachen die Autoren von al-Battar. ${ }^{80}$ Musharbash zufolge würde es daher »nicht verwundern, wenn das Netzwerk auf diesem Wege tatsächlich eine gewisse Anzahl neuer, mittlerweile kämpfender Kader gewonnen hätte « ${ }^{81}$. War die Anlehnung an die Welt virtueller Computerspiele hier bereits deutlich, sollte sich dies in weiteren Medienproduktionen der al-Qaida - und insbesondere des Islamischen Staats - in den darauffolgenden Jahren noch verfestigen.

Nach dem Vorbild des Hisbollah-Spiels Special Force machten sich auch alQaida- und IS-Sympathisierende die Bildsprache von Computerspielen zunutze, um für ihre Ziele zu werben. Aus Perspektive der Game Studies wurden die vielfältigen Aneignungsprozesse von Gaming-Elementen in der IS-Propaganda bereits genauer erforscht. ${ }^{82}$ Nico Prucha hat zahlreiche Parallelen zwischen der Online-Präsenz der Gaming-Industrie und der von Dschihadisten herausgestellt. Ähnlich wie die Spieleentwicklung von den Innovationen der User*innen

79 Robert Spencer: »Al-Qaeda's Online Training Camp«, Jihad Watch, 06.01.2004, https://www.jihadwatch.org/ 2004/01/al-qaedas-online-training-camp (zugegriffen am 6.6.2021).

80 Zitiert nach Musharbash: Die neue al-Qaida, S. 124f.

81 Ebd., S. 125.

82 Vgl. insbesondere Cori E. Dauber et al.: »Call of Duty: Jihad - How the Video Game Motif has Migrated Downstream from Islamic State Propaganda Videos«, Perspectives on Terrorism, 13/3 (2019), S. 17-31; Miron Lakomy: »Let's Play a Video Game: Jihadi Propaganda in the World of Electronic Entertainment«, Studies in Conflict \& Terrorism, $42 / 4$ (2017), S. 383-406; Prucha: »Worldwide Online Jihad versus the Gaming Industry Reloaded «. Andreas Rauscher: »Playing Propaganda. Die Games-Appropriationen des IS «, in: Bernd Zywietz (Hg.): Propaganda des »Islamischen Staats«. Formen und Formate, Wiesbaden: Springer VS 2020, S. 161-184. 
profitiert, richtet sich auch die Propaganda der Dschihadisten an ein junges Publikum mit »IT-fluency«, das die dschihadistischen Inhalte im Netz aktiv reproduziert, aneignet und weiterentwickelt. ${ }^{83}$ Viele dieser $»$ Armchair-Dschihadisten $\aleph^{84}$ bedienen sich dabei der Ikonografie beliebter Computerspiele. Auf dschihadistischen Foren zirkulieren zahlreiche Bildmontagen, in denen Screenshots und Werbebilder des Ego-Shooters Call of Duty mit der Flagge des Islamischen Staats im Irak versehen wurden. ${ }^{85}$

\section{Abbildung 4.11: Standbild aus einer Sequenz der Spielemodifikation Iraqi} Resistance, 2006.

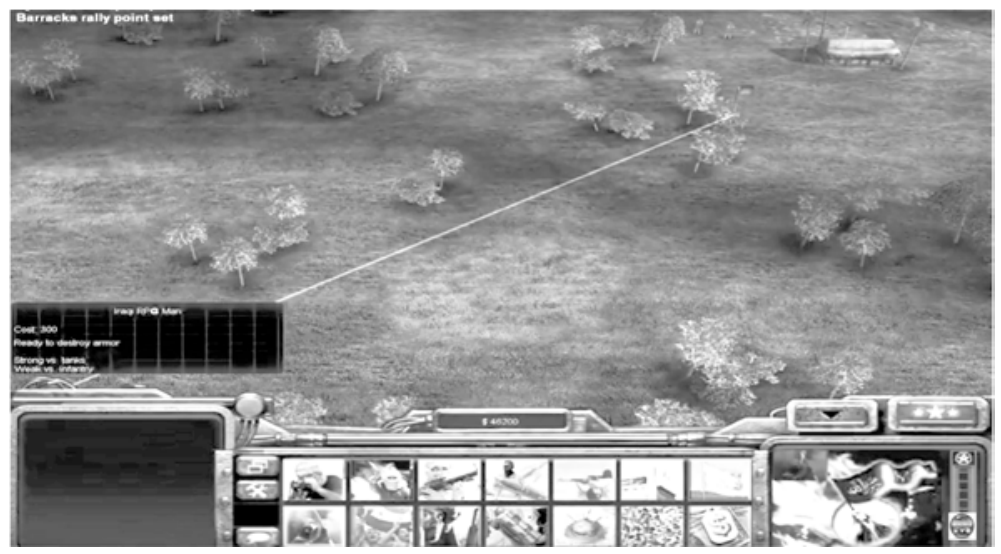

Unter dem Titel Iraqi Resistance kursierte ab 2006 zudem eine Computerspielerweiterung im Internet, die Spielenden die Möglichkeit bot, im Namen des IS zu kämpfen. Es handelte sich um eine Modifikation des US-amerikanischen FirstPerson-Spiels Command and Conquer Generals - Zero Hour (2003), dessen Handlung innerhalb eines militärischen Konflikts im Nahen Osten angesiedelt ist. Während die Gamer*innen im Originalspiel wahlweise die Führung einer »Westlichen Allianz«, eines »Asiatischen Pakts« oder einer an die Taliban erinnernden »Globalen Befreiungsarmee« übernehmen, schlüpfen sie im modifizierten Computerspiel stattdessen in die Rolle eines IS-Kommandanten. Zusammen mit der Erweiterungssoftware installierten die Spielenden zugleich eine veränderte ästhetische Oberfläche mit dem Logo der Majlis Shura al-Mujahideen fi al-Iraq, einer

83 Prucha: »Worldwide Online Jihad versus the Gaming Industry Reloaded«, S. 165.

84 Ebd., S. 156.

85 Ebd., S. 165; vgl. dazu auch Dauber et al.: »Call of Duty: Jihad«. 
Dachorganisation radikal-sunnitischer Milizen im Irak, die im Oktober 2006 durch den Islamischen Staat Irak ersetzt wurde (Abb. 4.11). ${ }^{86}$ Wer diese Modifikation produziert und in Umlauf gebracht hat, ist im Unterschied zum Computerspiel der Hisbollah allerdings nicht zu beantworten. »It remains unclear«, so Nico Prucha, "whether highly engaged fans of Command and Conquer programmed this meticulous set-up modification, or if online jihadists fulfilled their dreams $«{ }^{87}$. Dass Spielemodifikationen im IS-Design nicht zwangsläufig in direkter Verbindung mit einer Top-Down IS-Propaganda stehen, zeigt Andreas Rauscher am Beispiel einer weiteren Modifikation (Iraqi Warfare), die 2014 Aufsehen erregte. Nach kritischen Presseberichten wurde sie von ihrem Entwickler wieder zurückgezogen, der sich entschieden vom IS distanzierte. ${ }^{88}$ Wer auch immer diese >Dschihad-Upgrades` populärer Computerspiele ins Leben gerufen hat: Im Netz aktive IS-Sympathisant*innen haben mehrfach den >Nutzen das Spielen kriegerischer Computerspiele angeblich habe. Dass Ego-Shooter in der Lage seien, »dschihadistische Kompetenzen $«{ }^{89}$ wie Schießen oder Reiten zu erlangen, wird in islamistischen Foren offenbar als Argument für die Verbreitung solcher Spiele angebracht. »[W]e need to learn to shoot with games like Medal of Honor, swimming, shooting and riding the horse (Need for Speed) $[\ldots] \ll^{90}$, so zitiert Prucha beispielsweise einen User, der sich damit gegen eine Fatwa wandte, die das Spielen eines Online-Games verbot.

Neben der Vorstellung, Computerspiele seien nützliche Trainingsfelder für den tatsächlichen militärischen Einsatz, rückt eine weitere Parallele zwischen der Welt des Computerspiels und der Welt des Dschihad in den Fokus: die scheinbare Überwindung des Todes. Bei Special Force 2 gibt es ein zusätzliches Setting, das es den Spielenden erlaubt, alle Levels des Spiels zu durchleben und israelische Soldaten zu töten, ohne dabei selbst getötet zu werden. Diesen Spiel-Modus, den sogenannten »Gott-Modus«, gibt es auch bei anderen Ego-Shootern. Im Spiel der Hisbollah wurde dieser Modus nun allerdings in den »Schahid-Modus«, den

86 Prucha: »Worldwide Online Jihad versus the Gaming Industry Reloaded«, S. 177. Das Emblem der Organisation besteht aus drei Händen, die die schwarze Fahne des Dschihad emporhalten. Eine Abbildung dieses Emblems ist in der Nutzeroberfläche des Computerspiels rechts unten zu erkennen.

87 Ebd., S. 177.

88 Andreas Rauscher: »Playing Propaganda. Die Games-Appropriationen des IS«, S. 166.

89 Zitiert in Prucha: »Worldwide Online Jihad versus the Gaming Industry Reloaded«, S. 174.

90 Zitiert in ebd. 
»Märtyrer-Modus « umbenannt. ${ }^{91}$ Die Spielenden treten damit nicht nur in die Fußstapfen der Hisbollah-Kämpfer, sondern bekommen darüber hinaus die Möglichkeit, den unsterblichen Märtyrer-Status sozusagen probeweise zu durchlaufen. Der Tod bedeutet hier nicht das Ende einer Spielsequenz infolge eines Misserfolgs oder Versagens der Spielfigur. Ganz im Gegenteil eröffnet der Märtyrertod den Spielenden völlig neue Möglichkeiten, die in Special Force 2 einer Allmachtsphantasie gleichkommen. Hier unterscheidet sich das Spiel der Hisbollah wesentlich von anderen Trainingsspielen wie sie etwa vom US-Militär entwickelt wurden. Mit der Verherrlichung des Todes wirbt das Spiel um zukünftige (männliche) Kämpfer, die ihren eigenen Tod nicht nur als notwendiges Übel in Kauf nehmen, sondern als Auszeichnung und mitunter als eigentliches Ziel der Operation verstehen.

Die Überwindung des Todes kann als ein zentrales Charakteristikum von Computerspielen generell gelten. Häufig werden den Spielenden auch nach dem festgestellten Tod der Figur weitere Handlungsalternativen angeboten. Wie der Medienwissenschaftler und Game Designer Frank Furtwängler bemerkt, bemühen sich jüngere Spiele zunehmend um eine $»$ Dynamisierung des Sterbens $\ll^{92}$, die es den Spielenden erlaubt, auf unterschiedliche Art und Weise ihr Spiel im Jenseits fortzusetzen oder die Zeit zurückzudrehen, um in eine frühere Position des Spielverlaufs zurückzuspringen. Der Tod stellt dabei häufig nicht das Ende der Spielsequenz dar, sondern wird für weitere Abläufe innerhalb des Spiels funktionalisiert. Dabei gehe es keineswegs darum, den Tod der Figur abzuschaffen, sondern »ihn als Teil des Spiels noch wesentlicher zu integrieren $\aleph^{93}$. Furtwängler geht sogar so weit »die Todesüberwindung « als »Grunddynamik« der meisten Computerspiele zu diagnostizieren ${ }^{94}$ Der Wiedereinstieg in ein beliebiges Level des Spielverlaufs - und des >Lebens` einer Spielfigur - wird in der Computerterminologie als >Respawn< bezeichnet. Vor diesem Hintergrund erhält die Aussage eines ISKämpfers besondere Brisanz, der den Dschihad gegenüber einem BBC-Reporter

91 Vgl. Vernon Silver: »Hezbollah's Tech-Savvy, Platform-Agnostic Guerrilla Marketing Campaign«, Bloomberg, 06.06.2014, https://www.bloomberg.com/news/articles/201406-05/tech-savvy-hezbollah-goes-multiplatform-to-spread-its-message (zugegriffen am 6.6.2021).

92 Frank Furtwängler: »Kulturtechnik des Sterbens. You are Dead - Continue Yes/No?«, in: Thomas Macho und Kristin Marek (Hg.): Die neue Sichtbarkeit des Todes, München: Fink 2007, S. 559-576, hier S. 574.

93 Ebd.

94 Ebd., S. 561f. 
folgendermaßen erklärte: »This is our call of duty and we respawn in Jannah. $\aleph^{95}$ Der Dschihadist spielt damit auf die US-amerikanische Computerspielreihe Call of Duty an, die er mit seinem Kampf für den IS vergleicht. Sein neues Leben, so versicherte er dem BBC-Reporter weiter, sei »spannender« als das Ego-ShooterSpiel. ${ }^{96}$ Zugleich verweist er mit seiner Aussage auf die Überzeugung, nach seinem Tod im »Paradies« (arab. »Jannah«) weiterzuleben. Wie im Ego-ShooterSpiel endet das Abenteuer für ihn nicht mit dem Tod, sondern bietet die Möglichkeit für einen Respawn, einen >Wiedereinstieg ‘ in ein anderes Level. Die Todesüberwindung im Computerspiel scheint hier eine geradezu ideale Folie für die islamische Märtyrervorstellung zu liefern. Die theologische Rhetorik des Dschihad wird auf die Sprache der Gaming-Community übertragen und damit auch für ein Publikum >attraktiv gemacht, das fernab islamischer Diskurse sozialisiert wurde.

Die ästhetischen (und sprachlichen) Anleihen bei Computerspielen haben sich bis heute als fester Bestandteil der IS-Videotestamente etabliert. Im Vergleich zur Eingangssequenz in Ritter des Zeugnisses 5 (2008) wurden die Animationen in den vergangenen zehn Jahren auch technisch weiterentwickelt, wie eine weitere IS-Produktion aus dem Jahr 2016 verdeutlicht. Das 3:51 min lange Video ist einem Selbstmordattentäter gewidmet, der Anfang desselben Jahres einen Anschlag auf einen PKK-Stützpunkt in Nordsyrien verübte. Dem eingeblendeten Logo zufolge wurde das Video vom Medienbüro Wilāyat ar-Raqqa produziert und trägt den bezeichnenden (arabischen und englischen) Titel The Racers to Paradise Episode 2. ${ }^{97}$ Mit dem Verweis auf einen »Wettlauf« ist der Bezug zum kompetitiven Spiel bereits im Titel angelegt. Dass es sich dabei um eine Serie handelt - das vorliegende Video wird als zweite Episode bezeichnet - zeigt die prinzipielle Unabgeschlossenheit dieses Wettlaufs an, dem scheinbar noch viele weitere Episoden folgen können.

95 Zitiert in Guillaume Paoli: »Nächste Runde: Paradies«, Frankfurter Allgemeine Zeitung, 18.01.2015, http://www.faz.net/1.3376331 (zugegriffen am 6.6.2021). Derselbe Slogan taucht auch als Teil eines Internet-Memes auf, das zwei Kämpfer des IS zeigt, deren Gesichter durch strahlende Lichtpunkte ersetzt wurden. Vgl. Dauber et al.: »Call of Duty: Jihad«, Abb. 1, S. 18.

96 Paoli: »Nächste Runde: Paradies«.

97 Das Video ist online abrufbar unter https://archive.org/details/almtsabkon_ela_aljenan _2_alrakka (zugegriffen am 6.6.2021). Der erste Teil der Serie ist ebenfalls einem Selbstmordattentäter des IS gewidmet und wurde laut Videoeinblendung im Jahr 2014 produziert, vgl. https://azelin.files.wordpress.com/2015/01/the-islamic-state-22theracers-to-paradise-1-wilc481yat-al-raqqah22.3gp (zugegriffen am 14.08.2017, nicht mehr verfügbar). 
Abbildung 4.12 a-b: Islamischer Staat/Medienbüro Wilāyat ar-Raqqa:

The Racers to Paradise - Episode 2, 2016, 3:51 min, arabisch, 2:34-3:05.
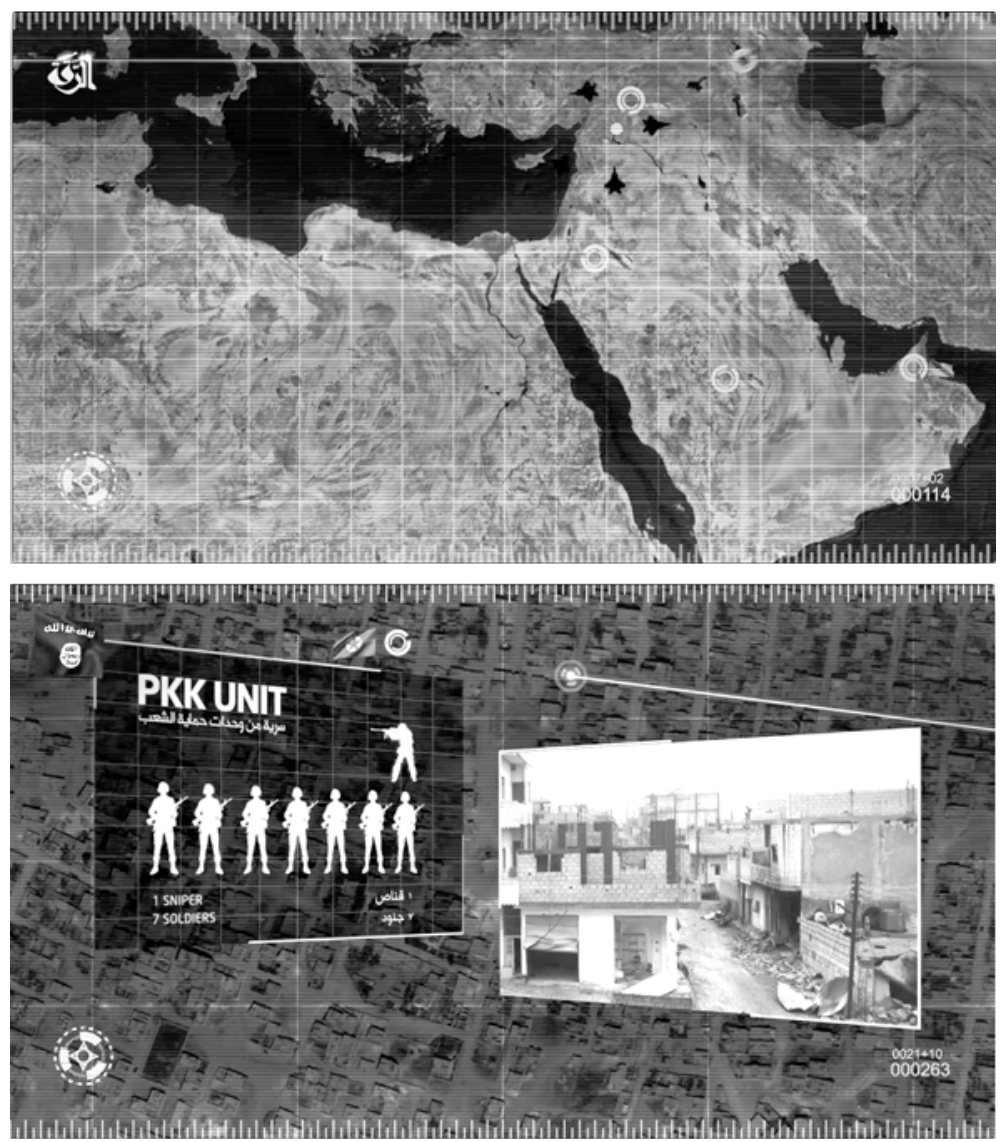

Nach etabliertem Muster wird auch hier zunächst das gesprochene Testament des als Märtyrer geehrten Selbstmordattentäters eingespielt, der hier als Abu al-Mutanna al-Masri vorgestellt wird; darauf folgen Szenen seiner Verabschiedung. In der nachfolgenden Sequenz (02:34-03:37 min) wird dann eine digitale Karte der MENA-Region eingeblendet, die mit Rasterdaten und Kompass versehen ist und wohl an eine Satellitenaufnahme erinnern soll (Abb. 4.12 a). Die ästhetische Nachahmung einer grobkörnigen, scheinbar verpixelten Aufnahme in Grautönen verstärkt diesen Eindruck zusätzlich. Über die Karte bewegt sich ein Fadenkreuz und platziert verschiedene Zielpunkte, die als pulsierende Kreise auf dem Satellitenbild sichtbar bleiben. Durch mehrere Zoom-Schritte wird schließlich auf einen dieser Punkte in Nordsyrien fokussiert, der sich als das Angriffsziel des 
Selbstmordattentäters entpuppt. Ähnlich wie bei einem Computerspiel werden nun verschiedene Bildebenen und Metadaten auf der Bedienungsoberfläche sichtbar: Zum einen wird die geografische Position des fahrenden LKWs scheinbar in Echtzeit auf dem gerasterten Satellitenbild verfolgt - angezeigt durch eine rot blinkende Markierung. Gleichzeitig wird auf der rechten Seite ein Bildrahmen eingeblendet, der unterschiedliche Kameraperspektiven >on the ground zur Auswahl stellt (Abb. 4.12 b). Durch die Art und Weise wie sich die Videoclips von oben in den Rahmen schieben, wird ein interaktives Handeln suggeriert, als könnten die Betrachtenden vor dem Bildschirm beliebig zwischen verschiedenen Ansichten hin- und herwechseln. Im Sinne eines diegetischen Tons werden die Klick- und Zoombewegungen auf der Bedienungsoberfläche zusätzlich durch elektronische Geräusche verstärkt, die der virtuellen Bildhandlung eine scheinbar physische Faktizität verleihen. Auf der linken Seite wird außerdem eine schematische Darstellung der Truppenstärke einer PKK-Einheit eingeblendet, die offenbar das Ziel des Selbstmordangriffs darstellt: »1 Sniper, 7 Soldiers«. Der pulsierende rote Farbkreis, der die aktuelle Position des fahrenden LKW anzeigen soll, wird schließlich von einem eindringlichen Pulsschlag begleitet, in dessen Takt kurze Videobilder von Kampfszenen aufscheinen. Die tiefen Herztöne scheinen auf die affektiv-körperliche Perspektive des Selbstmordattentäters zu verweisen, dessen Selbstmordattentat nun kurz bevorsteht. Im nächsten Moment geht die Markierung auf der digitalen Satellitenkarte in gleißendes Licht auf und wird mit dem Video der tatsächlichen Explosion überblendet. Die Aufnahme des eigentlichen Sprengstoffattentats wird dann zurückgespult, angehalten und erneut (teilweise in Zeitlupe) abgespielt, um die >erfolgreiche< Detonation vor Augen zu führen.

Die ästhetische Gestaltung dieses Videotestaments erinnert an das Interface und die Funktionsweise von Computerspielen. So lassen sich etwa Parallelen zur oben beschriebenen Spielmodifikation Iraqi Resistance erkennen (vgl. Abb. 4.11). Bei Iraqi Resistance stehen dem IS-Avatar sämtliche Waffen und militante Taktiken zur Auswahl; unter anderem verfügt er frei über den Einsatz von Selbstmordattentaten gegen die westlichen Besatzungsmächte. Auf ganz ähnliche Weise wird die Selbstmordoperation in The Racers to Paradise - Episode 2 als interaktive Bildoperation präsentiert, die scheinbar vom Bildschirm aus kontrolliert und gesteuert wird. Die audiovisuelle Gestaltung dieser Sequenz vermittelt den Eindruck als hätten die Bewegungen des Cursors auf der interaktiven Bildoberfläche direkte Auswirkungen auf das Attentat selbst. Unsere Perspektive als Betrachtende deckt sich dabei mit der Perspektive des fiktiven Bild-Operators. Im Gegensatz zur FirstPerson-Szene im Videotestament von 2008 (Abb. 4.7) geht es hier allerdings nicht darum, eine perspektivische Immersion im Stil eines Ego-Shooter-Spiels zu 
simulieren. Stattdessen wird eine weitere Bildsprache aufgerufen, die vielmehr an die Bildoperationen bei Drohnenangriffen erinnert.

Neben der Verbindung zum Computerspiel drängt sich daher eine zweite, machtpolitische Lesart auf. Durch den Rekurs auf Satelliten-, bzw. Drohnenbilder eignet sich der IS die Bildsprache zeitgenössischer Kriegsführung an, die bislang vor allem durch das US-amerikanische Militär geprägt war. Die westliche Wahrnehmung des ersten Golfkriegs (1990-91) als scheinbar >sauberem Technokrieg< verdankte sich in erster Linie einer Ästhetik der Distanzierung, die das tatsächliche Leid der betroffenen Opfer aus dem Bildraum verbannte. Ikonisch wurden einerseits Satellitenbilder und die vom Flugzeug aus gefilmten Videos des nächtlichen Himmels über Bagdad unter Bombenbeschuss, andererseits die grobkörnigen Schwarz-Weiß-Bilder sogenannter `Missile Cams $\triangleleft$, die direkt an den Bomben selbst angebracht waren und die Flugbahn einer Rakete bis kurz vor der Explosion aufnahmen.$^{98}$ Die distanzierte, von menschlichen Akteur*innen (zumindest teilweise) losgelöste Sicht >von oben ‘ fand in der Drohnentechnologie schließlich ihren Höhepunkt. Insbesondere seit dem US-geführten Krieg gegen den Irak ab 2003 wurde die Drohne zu einer »Ikone der Supermacht «99, so Tom Holert. Für die (westlichen) Befürworter*innen der Technologie verheißt die Drohnenperspektive Kontrolle, Präzision und Souveränität im Kontext neuer Kriegsschauplätze, die ansonsten meist unsichtbar bleiben und sich vor allem durch unvorhersehbare und chaotische Strukturen auszeichnen. ${ }^{100}$

98 Vgl. Inge Baxmann: »Ästhetisierung des Raums und nationale Physis«, in: Karlheinz Barck und Richard Faber (Hg.): Ästhetik des Politischen - Politik des Ästhetischen, Würzburg: Königshausen \& Neumann 1999, S. 79-95, hier S. 90f. In Bezug auf die Bilder des Zweiten Golfkrieges nahm Jean Baudrillard die wohl radikalste Position ein, indem er die Beziehung zwischen Realität und Bild grundsätzlich in Frage stellte. In seinem 1995 erschienen Text »The Gulf War Did Not Take Place« demontierte er den Wahrheitsanspruch der Fotografie und sprach von einem »virtuellen Krieg«, bei dem das Ereignis selbst zugunsten seiner medialen Simulation verschwindet. Jean Baudrillard: The Gulf War Did Not Take Place, Bloomington: Indiana University Press 1995.

99 Tom Holert: »Sensorship: The Seen Unseen of Drone Warfare«, in: Jens Eder und Charlotte Klonk (Hg.): Image Operations. Visual Media and Political Conflict, Manchester: Manchester University Press 2016, S. 101-117, hier S. 104.

100 Von Politiker*innen wurde der Drohnenkrieg als besonders präzise Form des Tötens angesehen, die gezielt nur militante Akteur*innen ins Visier nehme, zivile Opfer hingegen verschone. Wie zahlreiche Fälle gezeigt haben, trifft diese Annahme jedoch keineswegs zu. Von Gegner*innen wurde der Drohnenkrieg von Beginn an dafür 
Die Taktik des Selbstmordattentats kann in dieser Hinsicht als kontrastierender Gegenentwurf zum Drohnenangriff gelten: Zielen letztere gerade auf eine größtmögliche (räumliche und affektive) Distanzierung der Todesschütz*innen von ihren Angriffszielen ab, zeichnen sich Selbstmordoperationen ganz im Gegenteil durch eine körperliche Verschmelzung von Attentäter*in und Opfer aus. Die hochtechnologische und netzwerkbasierte Welt des Drohnenkriegs, in der Drohnenpilot*innen ähnlich wie bei einem virtuellen Computerspiel von einem Bildschirm aus agieren, steht einer brachialen Guerilla-Strategie gegenüber, die mit denkbar einfachen Mitteln und Technologien auskommt. Auf den ersten Blick mag es daher verwundern, dass der Islamische Staat für die Visualisierung seines Autobombenattentats an die operative Hightech-Bildwelt des Drohnenkriegs anknüpft. Gleichzeitig kann es jedoch kaum überraschen, dass sich der IS eine Ästhetik aneignet, die in der öffentlichen Wahrnehmung mit technologischer wie militärischer Überlegenheit verknüpft wurde. Die Bildoperation, die der virtuelle Controller bzw. die virtuelle Controllerin im Videotestament vollzieht, wird damit zugleich zu einer machtpolitischen Geste, die die Vorherrschaft der US-Armee herauszufordern scheint. Eine Vorherrschaft, die eben auch durch Bilder demonstriert und behauptet wird. Ähnlich wie bei einer militärischen Drohnenoffensive vermittelt das IS-Video letztlich den Eindruck, als liege zwischen dem Handeln im virtuellen Bild und dem Durchführen der tatsächlichen Operation nur noch ein kleiner Schritt.

Wie die Beispiele dieses Kapitels verdeutlichen, werden die Bildbetrachter*innen auf ganz unterschiedliche Art als aktiv Handelnde in das militante Geschehen einbezogen: Die First-Person-Perspektive, die in Computerspielen, aber auch in einigen Videotestamenten generiert wird, bietet den Betrachtenden die Möglichkeit, den Standpunkt der Kämpfer und Attentäter einzunehmen und damit selbst eine emotionale Erfahrung des Krieges zu machen. Andere Videotestamente, so auch diejenigen der IS-Reihe The Racers to Paradise, rekurrieren stattdessen auf die netzwerkbasierte Hightech-Bildwelt des Drohnenkriegs und rücken die Videorezipient*innen an die Stelle souverän agierender Bild-Operateure. Auch wenn die computeranimierten Sequenzen der zwei besprochenen Videotestamente ihr digitales >Gemachtsein` regelrecht ausstellen und keineswegs vorgeben, Zeugnisse einer faktischen Realität zu sein, bleiben sie stets auf tatsächliche Anschläge bezogen. Indem fiktive Computersimulation und Videodokument mit Zeugnisanspruch nebeneinandergestellt werden, wird die Grenze zwischen Spiel

kritisiert, Menschen zu abstrakten Zielpunkten auf einer Karte zu reduzieren und sie damit ihrer Menschlichkeit und Individualität zu berauben. Vgl. Holert: »Sensorship: The Seen Unseen of Drone Warfare«, S. 102f. 
und Attentat, zwischen Handeln im Bild und Handeln durch das Bild zunehmend verwischt.

\section{Die computersimulierte Operation: Überzeugen statt Bezeugen}

Interessant ist in diesem Zusammenhang ein weiteres Video des Islamischen Staats, das - anders als die oben diskutierten Beispiele - keinen direkten Bezug mehr zu einem tatsächlichen Selbstmordattentat aufweist. Unter dem englischen Titel All praise is due to Allah veröffentlichte die IS-Medienstelle Al-Haqq Mujahideen im Jahr 2017 ein Videotestament, das im Vergleich zu den zuvor veröffentlichten Postproduktionen noch einen entscheidenden Schritt weiter ging. ${ }^{101}$ Mit der Produktion führt der Islamische Staat gewissermaßen sein militärisches Spektrum vor, das (angeblich) von Drohnenanschlägen über Selbstmordattentate bis hin zu Hinrichtungen reicht. Das eigentlich Erstaunliche dieser 6:38 min langen Produktion ist, dass es sich um ein ausschließlich computersimuliertes Artefakt handelt, das auf den Einsatz von Video-Footage vollständig verzichtet. Die Produktion zeigt unter anderem den Autobombenanschlag eines Selbstmordattentäters und stellt gängige Konventionen bisheriger Videotestamente mit digitalen Mitteln nach.

Zunächst ist ein verhüllter und bewaffneter Kämpfer zu sehen, der in einen LKW einsteigt, seine Hand zum Gruß erhebt, das Fahrzeug startet und bei der Abfahrt von seinen Kameraden verabschiedet wird (Abb. 4.13 a-b). Aus unterschiedlichen Perspektiven wird der LKW dann auf seiner Fahrt durch die in ein stimmungsvolles, rötliches Licht getauchte Wüstenlandschaft verfolgt (Abb. 4.13 c-d). Am unteren Bildrand erscheint schließlich der englische Untertitel »May Allah accept our brother«, sowie eine weitere Aufnahme des Attentäters, die offensichtlich auf sein Videotestament als Märtyrer verweisen soll (Abb. $4.13 \mathrm{c}$ ). Wie in den Videoaufnahmen tatsächlicher Selbstmordattentäter wird auch die Todesfahrt des virtuellen IS-Kämpfers von einem arabischsprachigen Naschid begleitet. Der vom IS selbst produzierte Naschid Oh Triumph desjenigen, der das Martyrium wahrhaftig erlangt hat findet gerade in Märtyrervideos sehr häufig Verwendung, so hat die Religionssoziologin Alexandra Dick gezeigt. ${ }^{102}$ Im Kontext der

101 Ich danke Simon Menner für die Bereitstellung dieses Videos.

102 Der arabische Originaltitel lautet yā fawz man nāl al-shahāda șādiqan. Derselbe, vom saudi-arabischen Sänger Maher Mesh 'al performte Naschid kommt beispielsweise in dem 2014 vom al-Hayat Media Center veröffentlichten Märtyrervideo Al-GhurabaThe Chosen Few of Different Lands vor. Vgl. Dick: »Anāshīd und der mediale Jihad des Islamischen Staates«, S. 61. 
Computersimulation kann der Naschid folglich als Verbindungsglied zwischen dem virtuellen Avatar und einer Reihe von Individuen gelten, die vom IS und seinem Unterstützerkreis als Märtyrer verehrt werden.

Abbildung 4.13 a-e: Islamischer Staat/Medienbüro Al-Haqq Muhahideen, All praise is due to Allah, 2017, 06:38 min, arabisch mit englischen

Untertiteln, 3:54-5:07.
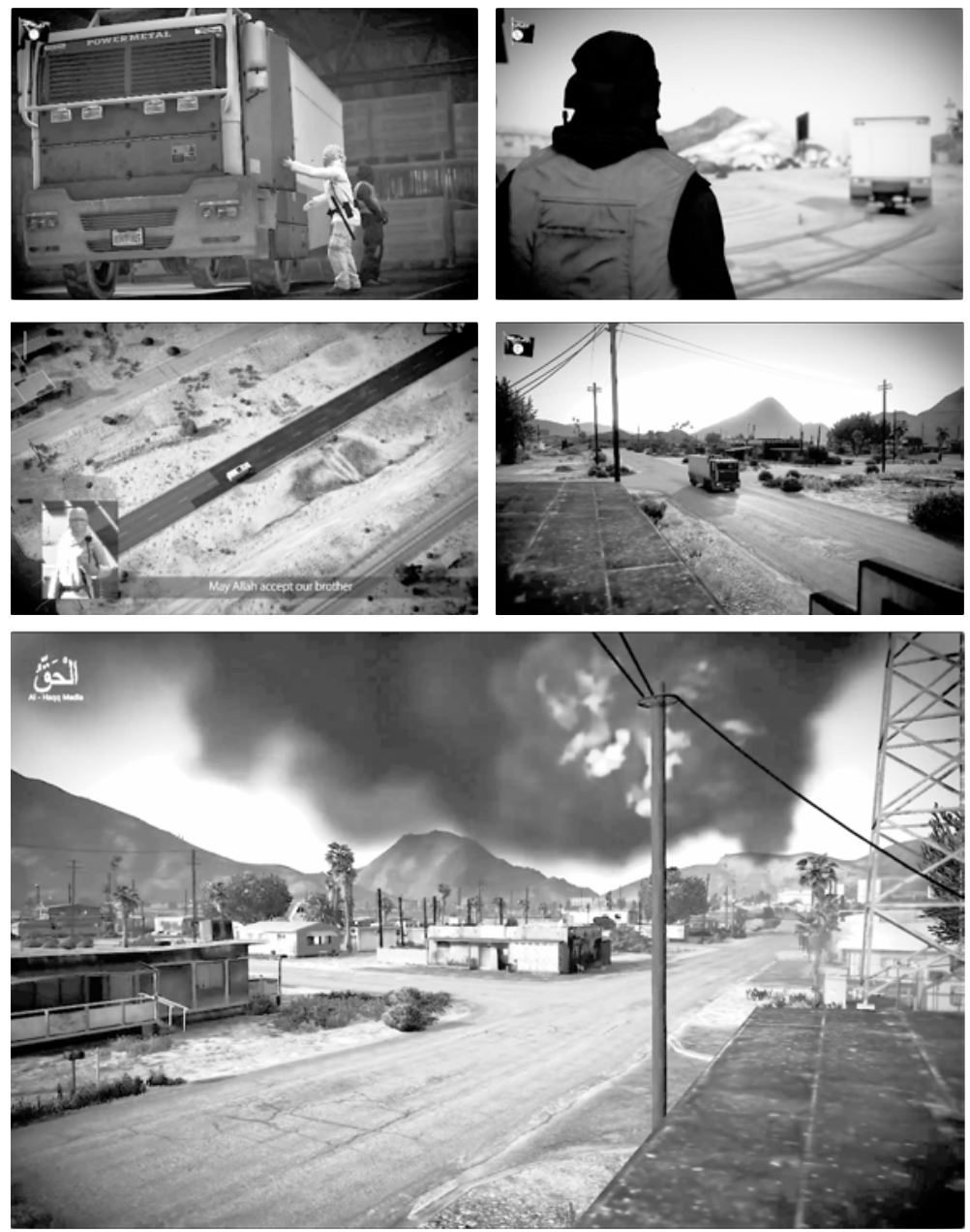

Im Laufe des Gesangs werden sämtliche Vorzüge aufgezählt, die das Paradies für den (männlichen) Märtyrer bereithalte. Die Rede ist sowohl von der Beseitigung 
aller Sünden und der Erlösung von der Grabespein, ${ }^{103}$ aber auch von Belohnungen wie »Häuser«, »Kameraden« und einer weiteren »Quelle von Schätzen«, zu denen auch die »schönen Paradiesjungfrauen « gehören, die den Märtyrer »zufriedenstellen «. ${ }^{104}$ Der Einsatz von digitalem Hall verleiht dem Naschid eine transzendentale, ätherische Wirkung.

Dies korrespondiert nicht nur mit der besungenen (und betörenden) Paradiesvorstellung, sondern auch mit der friedlichen Abendstimmung der computergenerierten Landschaft, die trotz der naturalistischen Darstellung wie durch einen rötlichen Farbfilter seltsam entrückt erscheint. Der Naschid endet zusammen mit dem dramaturgischen Höhepunkt der Computersimulation, der Explosionsszene. Im Gegensatz zu den ansonsten sehr realitätsnah gestalteten Sequenzen, in denen insbesondere die Licht- und Schattenverhältnisse der bewegten Körper, die perspektivische Unschärfe des inszenierten Kamerabildes, sowie einzelne Details der Landschaft möglichst exakt nachgeahmt werden, verblüfft diese Szene durch ihre auffallend realitätsferne Darstellung. Die dunkle Rauchwolke der Detonation löst sich innerhalb von nur wenigen Sekunden vollständig im Himmel auf und gibt den Blick auf die umstehenden Gebäude frei, die keinerlei Spuren der Zerstörung aufweisen (Abb. 4.13 e). Als wäre nichts geschehen, erscheint die unversehrt gebliebene Gebäudekette kurze Zeit nach dem Anschlag wieder im rötlichen, warmen Licht der Abendsonne.

Umso mehr drängt sich hier die Frage auf, was dieses >Videotestament< eigentlich zeigen - oder bezeugen - soll. Denn führt der IS damit nicht gerade die Ineffizienz seiner eigenen Militäroperation vor Augen? Offenbar geht es hier weder um die Legitimierung eines tatsächlichen Selbstmordanschlags, noch um die Betonung der militärischen und materiellen Resultate einer solchen Operation. Das Autobombenattentat bleibt ohne sichtbare Folgen und erhält damit den Charakter einer fiktiven Übungssequenz, die immer wieder aufs Neue durchgespielt werden kann. Im Sinne eines >als ob wird die Computersimulation hier zu einer Chiffre aller vergangenen und zukünftigen Selbstmordanschläge. Das Bild des Attentäters als heldenhafter und unsterblicher Avatar bedient Allmachtsphantasien, die einmal mehr die Welt des Gaming mit der Welt des Dschihad verbinden und

103 Die Grabespein ist fester Bestandteil des islamischen Auferstehungsglaubens. Die besondere Position von Märtyrer*innen besteht darin, auf direktem Weg und ohne Erleiden der Grabespein in den Garten des Paradieses einzutreten. Für eine ausführliche Diskussion der islamischen Todes- und Auferstehungsvorstellung vgl. Smith und Haddad: The Islamic Understanding of Death and Resurrection.

104 Ich danke Alexandra Dick für die Bereitstellung ihrer deutschen Übersetzung dieses Naschids. 
sich an ein junges, medienaffines Publikum richten. Wie in einem Computerspiel kann jede Person in die Rolle dieses Avatars schlüpfen, so scheint das Video zu suggerieren. Es geht nicht mehr um die Frage nach der `Beweiskraft<, sondern allein um den propagandistischen Zweck dieser Bilder, um ihre Fähigkeit zu überzeugen. Für die Propagandamaschinerie des IS spielt es offensichtlich keine Rolle mehr, ob die Bilder auf einen tatsächlich verübten Anschlag verweisen oder nicht. Die Imagination der Tat scheint hier wichtiger zu werden als das Bezeugen der Tat selbst.

\section{Das Selbstmordattentat als immersive Erfahrung im Kunstraum}

Am Beispiel der partizipativen Installation Vested (2009) soll an dieser Stelle erneut ein Rahmenwechsel vollzogen werden, der es erlaubt, die bisher verhandelten Themen aus anderer Perspektive neu zu beleuchten und in Bewegung zu bringen. Mit seiner Multimediaarbeit Vested hat der kanadische, in Berlin lebende Künstler Don Ritter ein interaktives und digitales Environment entworfen, das die Ausstellungsbesucher*innen selbst in die Rolle von Selbstmordattentäter*innen versetzt. Die interaktive Vision eines simulierten Suizidanschlags scheint damit auch Einzug in den Raum der Kunst erhalten zu haben.

Die Installation war erstmals 2009 als Teil der Ausstellung Move - New European Media Art in Halle zu sehen. Im darauffolgenden Jahr wurde sie in das künstlerische Begleitprogramm der Olympischen Winterspiele in Vancouver aufgenommen, das unter dem Ausstellungstitel Code Live Positionen zeitgenössischer Medienkunst versammelte. Die Arbeit setzt sich aus drei monumentalen Bildschirmen zusammen, die in einem vollständig abgedunkelten Raum über den Köpfen des Publikums nebeneinander angeordnet sind. Zu Beginn wird eine Ausstellungsbesucherin oder ein Ausstellungsbesucher aufgefordert, eine mit InfrarotSensoren und Batterien bestückte Weste anzulegen, an deren Seite ein großer roter Knopf angebracht ist. Nicht zufällig erinnert das khakifarbene, verkabelte Kleidungsstück an die Sprengstoffweste bei Selbstmordattentaten (Abb. 4.14). Per Knopfdruck, so erfahren die präparierten Personen schließlich im Ausstellungsraum, lassen sich virtuelle Explosionen auslösen, die auf den riesigen Bildschirmen in Echtzeit zu sehen sind. Bei Betreten der Installation erscheinen auf den drei Projektionsflächen zunächst Panoramen politisch oder kulturell bedeutsamer Gebäude. Darunter sämtliche Regierungsgebäude westlicher Staaten wie das Weiße Haus in Washington, Westminster Abbey in London oder der Berliner Reichstag, architektonische Wahrzeichen wie der Eiffelturm, aber auch prominente Kunstinstitutionen wie der Louvre und das Centre Pompidou in Paris, das New Yorker Metropolitan Museum of Art oder der Hamburger Bahnhof in Berlin, 
sowie historisch bedeutsame Kirchen und Tempel aus aller Welt. Abhängig von den Bewegungen der verkabelten Akteur*innen verändert sich auch die Sicht auf die Panoramen, die durch eine Feedbackschleife mit den Sensoren der Weste verbunden sind. Die aktuelle Position der >aktivierten` Person wird zusätzlich durch zwei grüne Spotlights verfolgt und für das umstehende Publikum nachvollziehbar gemacht.

Abbildung 4.14 und 4.15: Don Ritter, Vested, 2009, interaktive Installation, $12 \times 19$ m, Ansichten während der Ausstellung Code Live, Vancouver, 2010.
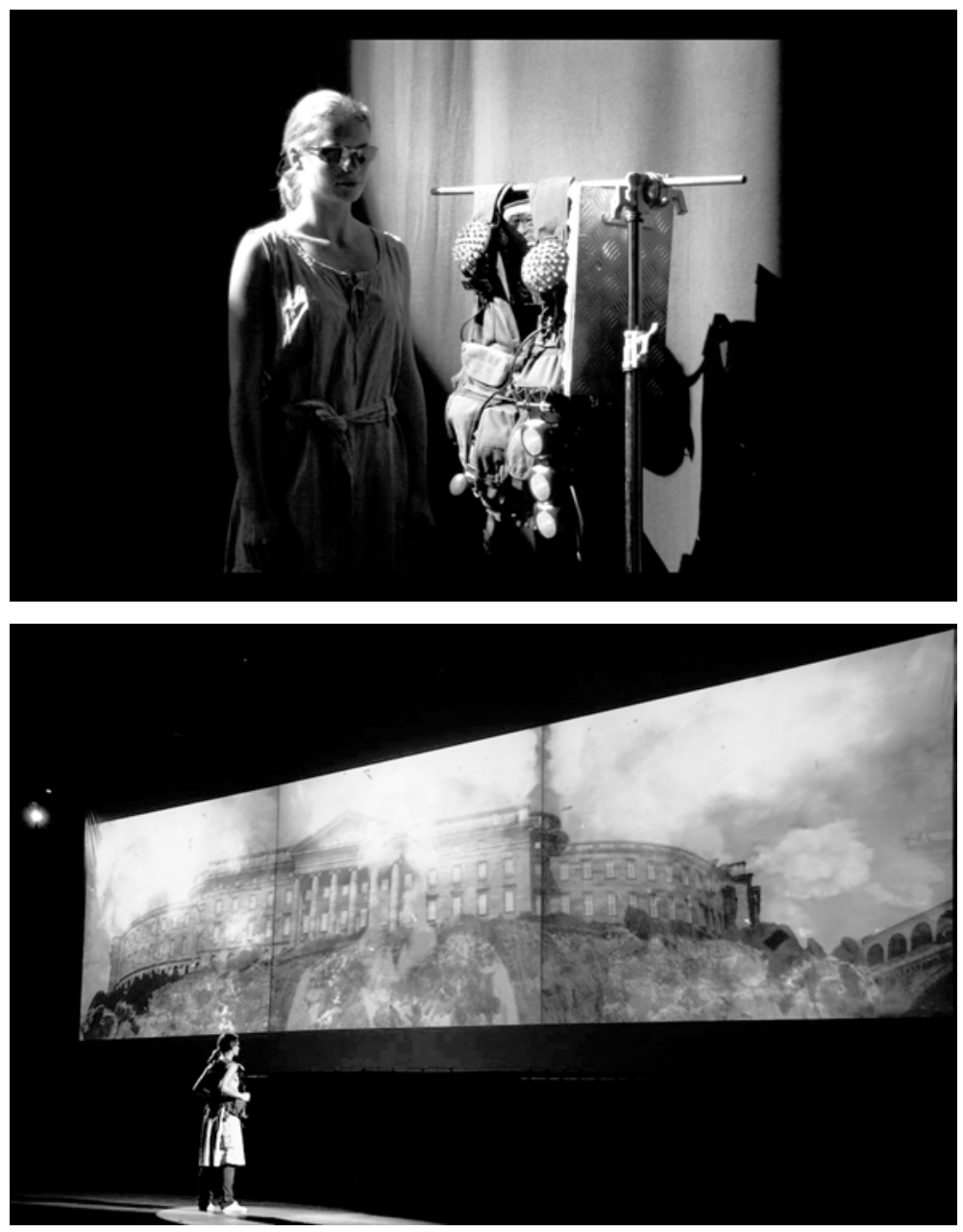
In dem Moment, in dem sich die Partizipierenden dafür entscheiden, den roten Knopf zu drücken, ertönen durch die Lautsprecher im Ausstellungsraum imposante Explosionsgeräusche und die dargestellten Gebäude werden von Flammen und Rauchwolken überblendet. Gleichzeitig erscheint auf den Projektionswänden auch das Bild der jeweiligen, für das virtuelle Attentat verantwortlichen Person. Zusammen mit den Gebäuden scheint auch das eigene Portrait, das von einer Kamera live im Ausstellungsraum aufgenommen wird, in Flammen aufzugehen (Abb. 4.15).

Die interaktive Medienerfahrung, die Ritter dem Publikum von Vested ermöglicht, erinnert abermals an das Erlebnis eines First-Person-Computerspiels, das sich nun jedoch im physischen Raum realisiert. Im Unterschied zu den Immersionsangeboten der Terrormilizen geht es hier jedoch keineswegs darum, die Grenze zwischen realer und virtueller Welt zu vermischen. Im Gegenteil: Dass es sich beim virtuellen Sprengstoffattentat nur um ein fiktives und absolut folgenfreies Spiel handelt, wird von Vested an keiner Stelle in Frage gestellt. Obwohl der Bezug zu realen Gebäuden und Kulturgütern gegeben ist, sind die Bilder der Sprengstoffattentate kaum realistisch genug als dass sie im Sinne einer immersiven Einbindung für die Spielenden als >Schockbilder schlagsziele werden zwar von beeindruckenden Flammen und Rauchwolken überlagert, scheinen davon jedoch keine materiellen Schäden davonzutragen oder gar einzustürzen. Auch menschliche Opfer bleiben in diesen virtuellen Attentatsszenarien vollständig unsichtbar. Selbst das an die Wand projizierte Bild der jeweligen >Attentäterin ২ bzw. des jeweiligen >Attentäters $<$ bleibt abgesehen von den umgebenden Flammen unberührt. Der >Als ob<-Charakter dieses Selbstmordanschlags wird durch die Art der Darstellung geradezu betont und regelrecht ausgestellt. Die virtuelle Immersionserfahrung zielt hier also gerade nicht darauf ab, sich in die >Innenwelt $<$ eines Selbstmordattentäters oder einer Selbstmordattentäterin zu versetzen. Ebenso wenig geht es bei Vested darum, die Schnittstelle zwischen virtueller und realer Gewalt in den Blick zu nehmen, die anhand der militanten Online-Trainingslager und Computerspiele im vorherigen Unterkapitel diskutiert wurde. Die Folgenlosigkeit des Handelns im Bild bleibt in der Ausstellung unbestritten und es ließe sich kritisch fragen, ob dies nicht zu einer Verharmlosung virtueller Gewaltexzesse beiträgt.

Stattdessen regt Vested jedoch ganz andere Denkprozesse an. Vordergründig scheint es bei dieser immersiven Installation zunächst um die moralische Frage zu gehen, warum wir offensichtlich Lust an der kulturellen und persönlichen Selbstzerstörung verspüren - selbst wenn diese nur im Rahmen einer künstlerischen Fiktion ausagiert wird. Wie Ritters Beobachtung gezeigt hat, drücken fast alle aktiv Partizipierenden irgendwann den Auslöser für die Sprengungen und zeigen 
teilweise regelrechten $\mathrm{Spa} ß$ an den multiplen Explosionen. ${ }^{105}$ Doch auch wenn die Teilnehmer*innen frei wählen können, wie und wo sie sich im Raum bewegen und ob sie den Detonationsknopf auslösen oder nicht, wird schnell deutlich, dass es sich dabei nur um eine vordergründige Entscheidungsfreiheit handelt. Zum einen ist es der suggestive rote Knopf, vor allem aber die gespannte Erwartung der umstehenden Zuschauer*innen, die dazu führt, dass fast alle Verkabelten die virtuellen Sprengungen aktivieren. Die moralische Frage, die Vested aufwirft, bezieht sich daher weniger auf die Intentionen und Beweggründe derjenigen, die das Attentat verüben. Die eigentliche Protagonistin seiner interaktiven Installation, so betont Ritter, «is not the person wearing the vest. It's the people who are standing around and watching, waiting for that explosion. $\aleph^{106}$ Der Fokus liegt folglich weniger auf der immersiven Erfahrung eines Selbstmordattentats aus Tätersicht, sondern auf den Dynamiken der Medienrezeption. In einem Videointerview erinnert Ritter daran, dass Gewalttaten und die daraus resultierenden menschlichen Tragödien seit jeher als »Form der Unterhaltung« angesehen wurden: angefangen mit den Gladiatorenkämpfen im antiken Rom, bis hin zu jüngsten Medienereignissen wie den Attentaten vom 11. September 2001. ${ }^{107}$ Auch die interaktive Ausstellungssituation scheint deutlich zu machen, dass erst die Anwesenheit des umstehenden (Medien-)Publikums, das voller Spannung darauf wartet, dass retwas passiert und `etwas zu sehen ist‘, den eigentlichen Auslöser für die virtuelle Gewalt bildet. In diesem Sinne könnte Ritters Installation als Versuchsanordnung für das Funktionieren der Gewalt- und Medienmaschinerie beschrieben werden, die gerade durch das voyeuristische, massenhafte Betrachten immer weiter angetrieben wird (siehe Kapitel 1.2). Dennoch bleibt fraglich, ob dies im Ausstellungsraum tatsächlich zu einer (Selbst-)Reflexion des (eigenen) Medienumgangs bei Gewaltspektakeln führt. Gerade indem die Installation ihren Fiktionscharakter so deutlich zur Schau stellt, wird es den Partizipierenden leicht gemacht, im Modus des Spiels zu verharren und eine innere Distanz zu den Medienerfahrungen realer Selbstmordattentate zu bewahren.

$105 \gg$ Some people love it, and start running around, hitting the button over and over and laughing.« Don Ritter zitiert in Pinchin, Karen: »Explosive Material«, Winter Olympics Cultural Olympiad, Vancouver, Canada (2010), https://www.aesthetic-machinery.com/documents_pdf/Ritter_Pinchin_Olympics.pdf(zugegriffen am 6.6.2021).

106 Pinchin: »Explosive Material«, o.S.

107 Videointerview mit Ritter anlässlich der Ausstellung in Halle, in: https://www.aesthetic-machinery.com/vested.html (zugegriffen am 6.6.2021). 


\subsection{MEDIENZEUGENSCHAFT. ETHIK UND SELBSTREFLEXION}

Mit seiner Kunstaktion stellt Don Ritter unter anderem die zentrale Frage nach der Verantwortung, die wir beim Betrachten medialer Gewaltdarstellungen tragen. Auch wenn diese Frage nur schwer zu beantworten ist, soll sie im letzten Teil dieses Kapitels zum Anlass dienen, die Position der Rezipierenden noch einmal aus einer anderen Perspektive in den Blick zu nehmen und mit ethischen und selbstreflexiven Überlegungen zu verbinden.

In den vorangegangenen Kapiteln wurde Zeugenschaft als relationaler Prozess diskutiert, der eine Vielzahl von Zeugenfiguren und Zeugnissen zueinander in Verbindung setzt: Das eigentliche >Blutzeugnis` der Selbstmordattentäter*innen (martyr), deren antizipiertes Überlebenszeugnis (superstes), die Aufnahmen der Tat als scheinbar objektive Form der Augenzeugenschaft (testis), sowie audiovisuelle Verfahren der Postproduktion, die ihrerseits auf unterschiedliche Weise an den Prozessen des Bezeugens, Erzeugens und Überzeugens beteiligt sind. Dass die Betrachtenden teilweise selbst als scheinbar Handelnde angesprochen werden, verweist zum einen auf das propagandistische Ziel dieser Bilder - auf ihr Begehren zu überzeugen. Die Perspektivverschiebung auf die Seite der Rezeption rückt aber auch eine weitere Modalität der Zeugenschaft in den Fokus, die bislang nur implizit aufschien: die der Medienzeugenschaft.

Die Figur des Medienzeugen erhält einen expliziten Auftritt in einem Videotestament des IS, das vom Produktionsbüro Wilayat al-Barqah am 16. Januar 2016 veröffentlicht wurde. Das 15:09 min lange Video mit dem Titel The Meaning of Stability \#2 dokumentiert neben Gefechten und Trainingseinheiten auch den Autobombenanschlag eines Selbstmordattentäters. ${ }^{108}$ Die typischen Kameraaufnahmen seiner letzten Worte und Verabschiedungen werden hier zusätzlich durch die Bilder eine Drohne ergänzt, die den Attentäter auf seinem Weg zum Anschlagsziel verfolgt. Die gleitende Bewegung der Drohne und die hohe Bildqualität ihrer Aufnahmen vermitteln einmal mehr den Eindruck einer Hightech-Operation, die scheinbar durch fortschrittlichste Medientechnologie gesteuert wird. Kurz vor der Detonation des sprengstoffbeladenen LKWs erfolgt allerdings wieder ein Schnitt

auf die Bilder einer wackligen Handkamera, die das Display eines Samsung Smartphones abfilmt. Darauf sind dieselben, kurz zuvor eingeblendeten

108 Das Video wurde zur Verfügung gestellt von http://jihadology.net/2016/01/16/newvideo-message-from-the-islamic-state-binghazi-the-meaning-of-stability-2-wilayatal-barqah/https://videopress.com/v/ZZ3JS2az (zugegriffen am 27.8.2017, nicht mehr verfügbar). 
Drohnenbilder zu erkennen (Abb. 4.16). Die Luftaufnahmen sind eingebettet in das Interface einer Übertragungssoftware, die zusätzlich Metadaten wie Entfernung, Höhe und Geschwindigkeit der Drohne anzeigt. Auf dem Display des Smartphones spiegeln sich schemenhaft die Umrisse zweier Männer, die das Geschehen scheinbar live am mobilen Bildschirm mitverfolgen. Die medial übertragene Explosion wird schließlich von mehreren lauten »Allahu Akbar«-Rufen, sowie den nervösen Bewegungen der Handkamera begleitet; die Erregung der umstehenden Männer angesichts der betrachteten Bilder wird dadurch geradezu körperlich nachvollziehbar.

Abbildung 4.16: Islamischer Staat/Medienbüro Wilayat al-Barqah, The Meaning of Stability \#2, veröffentlicht am 16. Januar 2016, 15:09 min.

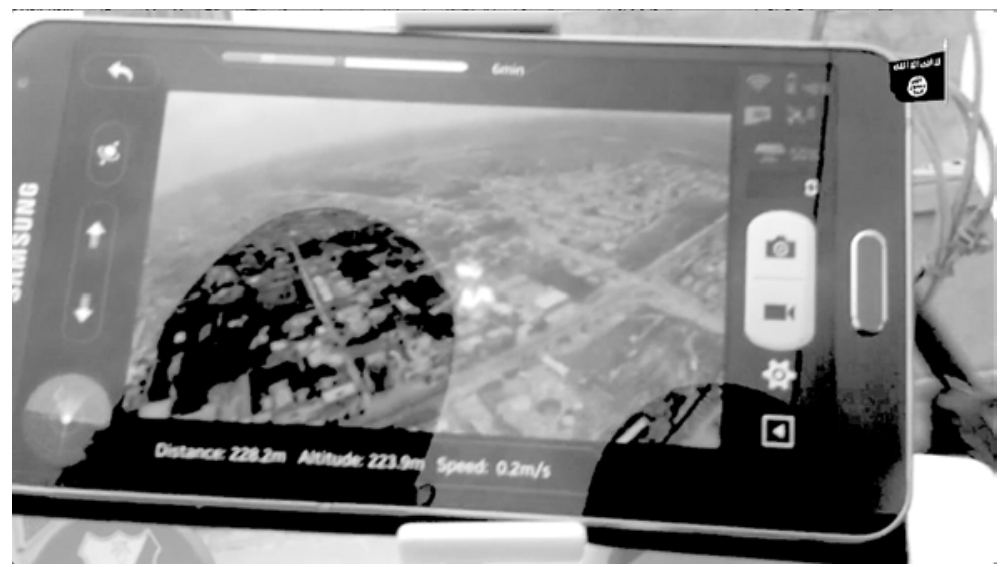

Durch die Perspektive der unbemannten Drohne wird erstmals ein nicht-menschlicher Akteur in den Prozess der Zeugenschaft integriert. Dadurch verändert sich auch die Rolle der IS-Männer vor Ort: Statt das Selbstmordattentat `mit eigenen Augen zu sehen und zu filmen, rücken sie in die Position von Medienzeugen, die das Geschehen aus zweiter Hand, vermittelt durch die Aufnahme der Drohne bezeugen. Eine physische (Sicht-)Nähe zum Ort des Anschlags wird dadurch obsolet; die Drohnenbilder könnten potenziell auf jeden, noch so weit entfernten Bildschirm in Echtzeit übertragen werden. Das mediale Bezeugen der IS-Kämpfer scheint die Praxis von Medienrezipient*innen generell widerzuspiegeln, die online gepostete Videos - in diversen Internetforen, auf Twitter, Facebook und YouTube, aber auch auf den Webseiten internationaler Nachrichtendienste wie Al Jazeera - am eigenen Bildschirm betrachten. Das Video stößt damit eine Reihe von selbstreflexiven Fragen an: Werden wir allein durch das Rezipieren dieser 
Videos - ähnlich wie die dargestellten Zeugen im Video - zu Medienzeug*innen der Tat? Welche Verantwortung erwächst aus dieser Mit-Zeugenschaft?

Der Medienwissenschaftler und Fernsehproduzent John Ellis hat in seinem Buch Seeing Things: Television in the Age of Uncertainty (2000) als einer der ersten die These vertreten, dass das Fernsehen uns zu Augenzeug*innen entfernter Ereignisse macht. ${ }^{109}$ Die zunehmende Bedeutung fotografischer und videografischer Berichterstattung habe eine neue Form der Zeugenschaft hervorgebracht, so Ellis:

»Through the photographic image, we are drawn into the position of being witnesses ourselves to the events that took place in front of the camera. We are witnesses in another time and another space: we see the wars in the former Yugoslavia, genocide in Rwanda, the Vietnam War, Hiroshima and Belsen whilst we are in London, New York, Rio or Hong Kong. $\ll^{110}$

Es war insbesondere das Fernsehen, das mit seinem Versprechen der Live-Übertragung die Erfahrung des Medienpublikums auf eine neue Stufe hob, so Ellis. Die Essenz dieser neuen Modalität von Zeugenschaft liegt Ellis zufolge in der Verantwortung, die sich für die Betrachtenden daraus ergibt. Weil wir nicht mehr sagen können \Ich habe davon nichts gewusst‘, treten wir unweigerlich in ein Verhältnis der Komplizenschaft mit den dargestellten Ereignissen: »We are necessarily accomplices because we have seen the evidence and sometimes even the events themselves. ${ }^{111}$ Obwohl Ellis Medienzeugenschaft in erster Linie als Erfahrungsmodus, als "particular mode of experience ${ }^{112}$ beschreibt, liegt seiner Herangehensweise ein grundlegender Glaube an die Evidenz fotografischer und filmischer Medien zugrunde. Fotografien und Videos werden von Ellis als »quasi-physische Dokumentationen « einer Realität verstanden, die uns eine Sicht auf die Ereignisse »von Angesicht zu Angesicht« ermöglichten. ${ }^{113}$ Im Kontext der Videotestamente erscheint eine solche Sichtweise problematisch: Denn wie in den vorausgehenden

109 John Ellis: Seeing Things: Television in the Age of Uncertainty, London: I.B. Tauris 2000.

110 Ebd., S. 10.

111 Ebd., S. 9.

112 Ebd., S. 14.

$113 »$ We live in an era of information, and photography, film and television have brought us visual evidence. Their quasi-physical documentation of specific moments in specific places has brought us face to face with the great events, the banal happenings, the horrors and the incidental cruelties of our times.« Ebd., S. 9. 
Kapiteln mehrfach gezeigt wurde, sind die Bildzeugnisse der Milizen auf unterschiedliche Weise auch an der Erzeugung von Realitäten beteiligt. Nicht einmal die scheinbar objektiven Videodokumentationen der Sprengstoffexplosionen können als belastbare Indizien gelten, die über das tatsächliche Ausmaß der Zerstörung und des zugeführten Leids Auskunft geben. Dass uns die Videotestamente keineswegs mit dem Ereignis an sich in Verbindung bringen, sollte in den vorangegangenen Bildanalysen deutlich geworden sein. Für diejenigen Medienzeug*innen, die der dargestellten Gewalt ablehnend gegenüberstehen, sind die Videotestamente gerade deshalb so verstörend, da sie uns weniger mit dem Leid der Opfer, sondern mit der Zeugenperspektive der Täter*innen konfrontieren. Damit rückt gerade die interpretative Rahmung der medial vermittelten Zeugnisse in den Vordergrund, die eine komplexere Sicht auf das Verhältnis zwischen den Betrachtenden, den dargestellten Zeug*innen, sowie den Bildzeugnissen selbst notwendig machen.

Im Anschluss an die Thesen von John Ellis waren es vor allem Paul Frosh und Amit Pinchevski, die den Begriff der Medienzeugenschaft prägten und grundlegend erweiterten. ${ }^{114}$ Die moralische Verantwortung, die sich beim Betrachten bestimmter Bilder oder Texte einstellt, wird auch von Paul Frosh als das zentrale Kriterium von Zeugnissen beschrieben: »Feeling that a text imposes an obligation towards the events or people it depicts is part of what enables readers to judge that it is a witnessing text. « ${ }^{115}$ Ebenso wie John Ellis plädiert auch Paul Frosh für einen rezeptionsorientierten Zugriff auf Zeugenschaft, der bei ihm jedoch weitaus radikaler formuliert ist. Frosh geht es weniger um einen objektivierbaren Wahrheitsbezug der Zeugnisse (im Sinne der Frage: >Ist das was wir im Bild sehen tatsächlich passiert?〈), sondern darum, ob etwas für wahr gehalten wird oder nicht (〉Betrachten wir es als etwas das wirklich passiert ist oder nicht?〈). ${ }^{116}$ Das Zeugnis wird Frosh zufolge dann zum Zeugnis, wenn es von den Rezipierenden aufgrund bestimmter Faktoren (wie diskursiver und institutioneller Rahmungen) als solches angesehen und mit einem entsprechenden Verantwortungsbewusstsein verknüpft wird. Ähnlich wie die unter der >Assurance View $<$ zusammengefassten Positionen (vgl. S. 136), wendet sich auch Frosh von einer rein evidenziellen und ontologischen Lesart des Zeugnisses ab und beschreibt Medienzeugenschaft stattdessen

114 Vgl. Paul Frosh und Amit Pinchevski (Hg.): Media Witnessing: Testimony in the Age of Mass Communication, New York: Palgrave Macmillan 2009.

115 Paul Frosh: »Telling Presences: Witnessing, Mass Media, and the Imagined Lives of Strangers«, Critical Studies in Media Communication 23/4 (2006), S. 265-284, hier S. 274.

116 Vgl. ebd., S. 275. 
als genuin sozialen und kommunikativen Prozess. Aus dieser sozialen Relationalität - und nicht aus dem Status des Zeugnisses als Beweis - erwächst Frosh zufolge die moralische Verantwortung der Medienzeugenschaft. Diese ist für ihn nicht nur eine vermittelte (mitunter abgeschwächte) Form der Augenzeugenschaft, sondern birgt ganz neue Erfahrungen und Möglichkeiten des Bezeugens.

Paul Frosh und Amit Pinchevski formulieren eine Definition von »media witnessing «, die Ellis’ Verständnis einer 〉Second-Hand〈-Zeugenschaft entschieden weiterentwickelt. Die Autoren unterscheiden zwischen drei, häufig parallel ablaufenden Prozessen der Medienzeugenschaft: »the witnessing performed in, $b y$, and through the media«. ${ }^{117}$ Mit dem Bezeugen »durch« Medien beziehen sich Frosh und Pinchevski zunächst auf die von Ellis vorgestellte These, dass wir allein durch das Betrachten von Bildern zu Zeug*innen entfernter Ereignisse werden. Eine zweite Dimension richtet sich hingegen auf das Bezeugen, das »in« den Medien stattfindet. Hier geht es um die Frage, wie Medien uns in Verbindung mit (räumlich und zeitlich) entfernten Zeug*innen bringen: Im Fall der besprochenen Videotestamente sind dies einerseits die Attentäter*innen selbst, die mit ihrem Zeugnis auf das eigene Martyrium vorausgreifen (Kapitel 3.1), aber auch die umstehenden Augen-, beziehungsweise Medienzeug*innen, die wie im oben diskutierten Beispiel teils in den Videos direkt sichtbar werden. Was Frosh und Pinchevski schließlich als »witnessing by the media « bezeichnen meint die Art und Weise wie Medien und ihre Produkte selbst an Prozessen des Bezeugens beteiligt sind. »>Bearing witness, $<$ then, is an act performed not by a witness but by a witnessing text ${ }^{118}$, so schreibt Frosh. In diesem Sinne können die Bilder selbst - auch jenseits ihres Repräsentationsgehalts - als Zeugen wahrgenommen werden, die eine bestimmte Interpretation der Ereignisse liefern. Diese Dimension der Medienzeugenschaft korrespondiert im Wesentlichen mit den Überlegungen, die anhand der postproduzierten Bildelemente in diesem Kapitel fokussiert wurden.

Gerade die letzten beiden Dimensionen verdeutlichen, dass das Verhältnis zwischen Rezipierenden und medialem Zeugnis weitaus komplexer ist, als Ellis dies beschreibt. Die Rezipient*innen der Videos kommen weniger in Kontakt mit dem Selbstmordattentat an sich (sofern die Tat selbst überhaupt dargestellt ist), sondern vor allem mit der Art und Weise wie diese Tat durch die verschiedenen Zeug*innen dargestellt, gerahmt, interpretiert und konstruiert wird. Das Betrachten der Videos macht uns daher zu Medienzeug*innen zweiter Ordnung: Wir

117 Paul Frosh und Amit Pinchevski: „Why Media Witnessing? Why Now?«, in: Dies. (Hg.): Media Witnessing: Testimony in the Age of Mass Communication, New York: Palgrave Macmillan 2009, S. 1-19, hier S. 1 [Herv. i.O.].

118 Frosh: »Telling Presences«, S. 174. 
bezeugen das Bezeugen (und gleichzeitig auch das Erzeugen und Überzeugen) der anderen, das in und mit medialen Mitteln stattfindet. Dies schließt an die Überlegungen Judith Butlers an, die in Frames of War argumentiert, dass es bei Fotografien von Gewalt nicht nur darum geht, was sie zeigen, sondern wie sie etwas zeigen und wie diese, ins Bild selbst eingeschriebenen, interpretativen Rahmungen unser Denken und Fühlen über das Gezeigte beeinflussen: »The photograph is not merely a visual image awaiting interpretation; it is itself actively interpreting, sometimes forcibly so. $\ll^{119}$ Das »Gewaltsame« dieser bildlich vorgegebenen Interpretationen ist im Fall der Videotestamente unverkennbar. Je nach Perspektive und Position der Betrachtenden kann dies jedoch äußerst heterogene Reaktionen provozieren. Während Unterstützer wie die im Video dargestellten IS-Medienzeugen die Explosionsszene offenbar als Indiz für das erfolgte Martyrium und den Triumph des Islamischen Staats anerkennen, wird dasselbe Videomaterial für ISGegner*innen stattdessen zum Zeugnis einer zerstörerischen Ideologie, die zum (Selbst-)Mord anstiftet. Was Letztere an den Videozeugnissen verstört, ist nicht nur die Gewalt des Selbstmordattentats an sich, sondern auch (und vielleicht sogar primär) die Gewalt, die durch die verherrlichende Darstellung ausgeübt wird. Zunächst lässt sich also festhalten, dass die ethische Involvierung in den Prozess der Zeugenschaft von den jeweiligen Deutungsmustern der Rezipierenden abhängt: Das für die Medienzeugenschaft konstitutive Verantwortungsgefühl (»we cannot say that we do not know $\left.\ll{ }^{120}\right)$ kann im Fall der Videotestamente sowohl als Aufforderung zur Nachahmung, aber auch als Verpflichtung zur Gegenwehr wahrgenommen werden.

Die Frage, wie wir - als räumlich entferntes und den Selbstmordattentaten ablehnend gegenüberstehendes Medienpublikum - mit dieser moralischen Verantwortung umgehen können, ist damit allerdings noch nicht beantwortet. Folgt man John Ellis, so wird das Bedürfnis, angesichts der medial bezeugten Gewalttaten etwas zu tun, in den allermeisten Fällen enttäuscht: »The feeling of witness that comes with the audio-visual media is one of separation and powerlessness: the events unfold, like it or not. « ${ }^{121}$ Die Verantwortung der Betrachtenden führe daher nicht automatisch auch zu einem ethischen Handeln, sondern resultiere stattdessen in Gefühlen der Ohnmacht, Gleichgültigkeit oder Schuld: »So for the viewer, powerlessness and safety come hand in hand, provoking a sense of guilt and disinterest. ${ }^{122}$ Ellis' kulturpessimistische Sicht auf das Fernsehen scheint an eine der

119 Butler: Frames of War, S. 71.

120 Ellis: Seeing Things, S. 1.

121 Ebd., S. 11.

122 Ebd. 
zentralen Thesen Susan Sontags anzuschließen, die in ihrem 1977 veröffentlichten Buch On Photography ebenfalls davon ausgeht, dass Fotografien der Gewalt unsere moralische Handlungsfähigkeit unterminieren und unser Gewissen abstumpfen lassen. ${ }^{123}$ Folgt man diesen Einschätzungen, so führt die Verantwortung der Medienzeugenschaft gleichzeitig (und paradoxerweise) zu einer Haltung der Distanz und Passivität. Die grundlegende Skepsis gegenüber dem ethischen Potenzial von Gewaltbildern wird schließlich von Sontag selbst, zumindest teilweise, wieder revidiert. In ihrem 26 Jahre später erschienenen Buch Regarding the Pain of Others (2003) räumt sie ein, dass Bilder der Gewalt durchaus wichtige Funktionen der Erinnerung und Mahnung erfüllen: »The images say: This is what human beings are capable of doing - may volunteer to do, enthusiastically, self-righteously. Don't forget. « ${ }^{124}$ Sie kommt daher zu dem Schluss: »Let the atrocious images haunt us. « ${ }^{125}$ Denn obwohl Bilder von Gräueltaten an unserer Ohnmacht und Ignoranz angesichts dieser Taten nichts änderten, so könnten sie uns immerhin dazu bringen, aufmerksam zu werden, das Dargestellte zu reflektieren oder daraus zu lernen. ${ }^{126}$ Was Sontag dabei jedoch nicht beantwortet, so hat Charlotte Klonk auf den Punkt gebracht, »ist, welche Bilder uns in dieser Weise betroffen machen sollen und welche nicht. « ${ }^{127}$ In ihrem Buch Terror - Wenn Bilder zu Waffen werden (2017) regt die Kunsthistorikerin eine differenziertere Diskussion über den ethischen Umgang mit Bildern des Terrors an. Ob das Betrachten eines Bildes zum kritischen Nachdenken anregt oder stattdessen die Opfer weiter entwürdigt und letztlich nur den Täter*innen nützt, muss je nach Bild, Gebrauch und Kontext in jedem Fall neu entschieden werden, so stellt Klonk in ihrer Studie eindrücklich dar. $^{128}$

Was bedeutet dies nun für eine kritische Medienpraxis in Bezug auf die Videotestamente? Selbst wenn wir davon ausgehen, dass eine Auseinandersetzung mit der Zeugenperspektive der Attentäter*innen als Mahnung und Anlass kritischer Reflexion dienen kann, müssen wir uns dennoch der Frage stellen: Bereiten wir nicht durch das Anklicken, Herunterladen, Teilen und Weiterverbreiten der Märtyrerbilder zugleich eine Bühne für deren verherrlichende Selbstdarstellung und

123 Susan Sontag: On Photography [1977], New York: Picador 2001.

124 Susan Sontag: Regarding the Pain of Others, New York: Picador 2003, S. $114 f$.

125 Ebd., S. 114.

126 »Such images cannot be more than an invitation to pay attention, to reflect, to learn, to examine the rationalizations for mass suffering offered by established powers." Ebd., S. 117.

127 Klonk: Terror: Wenn Bilder zu Waffen werden, S. 244.

128 Ebd. 
damit für die Überzeugungsmacht dieser Bilder? Gerade im Zeitalter Sozialer Medien wird deutlich, dass ein reines Rezipieren der Bilder nicht mehr möglich ist. Allein indem wir die Klickzahl eines Videos erhöhen, vor allem aber durch Praktiken des Likens, Teilens und Kommentierens sind wir immer auch an der Produktion von Inhalten beteiligt. Sich in einem passiven Sinne von den Bildern »heimsuchen $\aleph^{129} \mathrm{zu}$ lassen, ist im Internet unmöglich geworden. Während häufig die ökonomische Dimension betont wird, die sich aus dieser beständigen Co-Produktion von Inhalten ergibt, also die Verschiebung von Konsumenten zu Prosumenten im Netz, ${ }^{130}$ drängt bei den hier diskutierten Beispielen vor allem die ethische und moralische Beteiligung des Medienpublikums in den Vordergrund. Das ethische Dilemma der Medienzeugenschaft - das heißt unsere Komplizenschaft mit der Zeugenperspektive der Urheber*innen - rückt damit umso drängender in den Vordergrund. ${ }^{131}$ Nehmen wir unsere moralische Verantwortung gegenüber dem Bezeugten ernst, können wir die Bilder aber auch nicht ignorieren. Gerade aufgrund der stark normativen Perspektivierung der Märtyrerzeugnisse - die das zu betrauernde Leid der Anschlagsopfer gerade nicht zeigen und uns stattdessen zu Medienzeug*innen zweiter Ordnung machen - ist eine kritische Rahmung und Kontextualisierung der Bilder umso notwendiger. »Even if one decides to listen to the perpetrators«, so betont auch Sibylle Schmidt mit Blick auf die moralischen Implikationen von Täterzeugnissen, »they should not have the last word « ${ }^{132}$. Andersherum ließe sich daher fragen: Wie kann man die Zeugnisse öffentlich betrachten und diskutieren, ohne dabei die Autorität der Zeug*innen zu stärken und ihrer Version der Geschehnisse zusätzliches Gewicht zu verleihen? Generell lässt

129 Susan Sontag: Regarding the Pain of Others, New York: Picador 2003, S. 114

130 Vgl. dazu etwa Birgit Blättel-Mink und Kai-Uwe Hellmann: Prosumer Revisited. Zur Aktualität einer Debatte, Wiesbaden: VS Verlag für Sozialwissenschaften 2010.

131 In gesteigertem Maße ist dies beim Betrachten von Enthauptungsvideos der Fall. Da die Videoaufnahme hier den eigentlichen Anlass für das Töten liefert, bedeutet »jeder Klick auf den entsprechenden Internetseiten, jede Betrachtung der Aufnahmen ein Ansporn zu weiteren Taten« so Klonk. Die Bilder »zwingen zur unfreiwilligen Komplizenschaft und haben Mord als Konsequenz«. Klonk: Terror: Wenn Bilder zu Waffen werden, S. 135. Der Umstand, dass Menschen »gefoltert und ermordet werden, um als Bilder eingesetzt werden zu können« wird von Bredekamp als Form des »substitutiven Bildakts« beschrieben. Horst Bredekamp: Das Beispiel Palmyra, Köln: Verlag der Buchhandlung Walther König 2016, S. 23.

132 Sibylle Schmidt: »Perpetrators' Knowledge. What and How Can We Learn from Perpetrator Testimony?«, Journal of Perpetrator Research 1/1 (2017), S. 85-104, hier S. 101. 
sich dies sicher nicht beantworten - und man muss wohl anerkennen, dass jede noch so kritische Diskussion nicht verhindern kann, dass allein die Aufmerksamkeit, die auf die Bilder gerichtet wird, den Zielen der militanten Gruppen mitunter in die Hände spielt. Dennoch haben gerade die Aneignungen im Kunstkontext gezeigt, dass Neurahmungen durchaus zu veränderten Lesarten der Märtyrerbilder führen können, die auch Bewertungen ermöglichen, die den Intentionen der Urheber*innen entgegenstehen (Kapitel 2.6, Kapitel 3.2 und 3.4). Mitunter verweisen die Adaptionen im Kunstraum aber auch auf unsere eigenen Interpretationsmuster beim Betrachten der Videotestamente (Rabih Mroué, On Three Posters) oder lenken den Blick auf unsere Verantwortung als Medienzeug*innen (Don Ritter, Vested). Wie Judith Butler am Beispiel der Folterbilder aus Abu Ghraib gezeigt hat, kann ein Wechsel des Kontextes dazu führen, die diskursiven, medialen und operativen Bedingungen der Bilder selbst in den Blick zu bekommen. Erst wenn diese Rahmen sichtbar werden, die die Interpretation und moralische Bewertung der Bilder bestimmen, wird eine neue, kritische Sichtweise möglich. »That scene [der sadistische, triumphierende Blick der Fotografierenden] now becomes the object, « so schreibt Butler über die kuratorische Neukontextualisierung der AbuGhraib-Fotografien im Museum, «and we are not so much directed by the frame as directed toward it with a renewed critical capacity «. ${ }^{133}$ Folgt man Butler, so mündet Medienzeugenschaft nicht zwangsläufig in einem Gefühl von Schuld und Ohnmacht oder einer Haltung der Passivität. Stattdessen betont sie gerade das subversive Potenzial, das von einem aktiven, veränderten Gebrauch der Bilder ausgeht. Dies gilt nicht nur für die künstlerischen Bearbeitungen, sondern auch für eine wissenschaftliche Auseinandersetzung. Wenn es in den vorangegangenen Kapiteln in erster Linie darum ging, die Bildoperationen des Selbstmordattentats im Zusammenhang der jeweiligen Konflikte zu verstehen, war damit ein ganz ähnliches Anliegen verbunden. Das Sichtbarmachen der medialen und operativen Rahmen dieser Zeugnisse, das Aufzeigen ihrer Entstehungs- und Handlungszusammenhänge, scheint die Voraussetzung für einen kritischen Umgang mit ihnen zu sein. Mit Frosh und Pinchevski gesprochen ließe sich daher auch sagen: Erst wenn das ")witnessing in, by, and through the media « ${ }^{134}$ in all seinen Dimensionen in den Blick kommt, können wir beginnen, unsere ethische Verantwortung gegenüber diesen Bildzeugnissen zu verstehen.

133 Butler: Frames of War, S. 96 [meine Hervorhebung].

134 Frosh und Pinchevski (Hg.): Media Witnessing: Testimony in the Age of Mass Communication, S. 1. 



\section{Schluss: Das Märtyrerzeugnis als Selfie im Livestream}

Bildzeugnisse des Selbstmordattentats haben seit den 1970er Jahren eine facettenreiche Entwicklung erfahren - von der Plakatierung von Märtyrerpostern im Stadtraum, dem Verkauf von VHS-Kassetten, über die Ausstrahlung von Videotestamenten im Fernsehen, bis hin zur Zirkulation digitaler, teils computergenerierter Aufnahmen im Internet. Ein Ziel der vorangegangenen Analysen war es, die mediale und ästhetische Bandbreite dieser (audio-)visuellen Genres aufzuzeigen. Dabei wurde vor allem eines deutlich: Die Art und Weise wie das Selbstmordattentat im Bild erscheint, lässt sich nicht auf einen einfachen Nenner bringen. Unter den Märtyrerinszenierungen finden sich teils Bilder mit künstlerischem Anspruch, die eine distinkte Ikonographie erkennen lassen und singuläre Ikonen schufen (Kapitel 2.3, 2.4). Häufig etablierten sich aber auch austauschbare Schablonen (Kapitel 2.1, 2.5) und rhetorische wie visuelle Inszenierungsmuster (Kapitel 3.1), die immer wieder nachgeahmt wurden und zur Herausbildung wiedererkennbarer, wenngleich dynamischer Genres geführt haben.

Auch auf der Ebene der technischen Professionalität lassen sich erhebliche Unterschiede ausmachen: Erinnerten die frühen libanesischen Videotestamente an simple >Home Videos`, die in einer einzigen Einstellung aufgenommen wurden und mit wenigen Schnitten auskamen (Kapitel 3.1), produzierte die Hisbollah bereits in den 1990er Jahren dramaturgisch durchdachte Videos, die weitere Szenen und Schauplätze integrierten und durch eigene TV-Formate verbreitet wurden (Kapitel 3.3). Gleichzeitig schlossen aber auch diese Aufnahmen an eine betont amateurhafte Guerilla-Ästhetik an, die den Widerstandskampf >von unten`zum Ausdruck bringen sollte. Mit den Selbstmordattentaten der al-Qaida und des Islamischen Staats kommen seit mehreren Jahren schließlich Videotestamente in Umlauf, die ganz im Gegenteil an die professionelle Bildsprache der Massenmedien, sowie an Virtual Reality-Szenarien anschließen und zahlreiche Effekte der Postproduktion nutzen (Kapitel 4.1 und 4.2). Neben den eigentlichen Bekenntnissen 
der Akteure kommen hier auch technische, auf Satellitenbilder rekurrierende Grafiken zum Einsatz, die Selbstmordanschläge als Resultat präziser Rechenoperationen erscheinen lassen und an die Ästhetik aktueller Hightech-Kriege anknüpfen. Gleichzeitig fällt auf, dass die jüngsten Videos - ähnlich wie schon die palästinensischen Märtyrerposter der 1970er Jahre - auf eine internationale, popkulturelle Bildsprache rekurrieren (Kapitel 4.3). Einmal mehr wird hier deutlich, dass das Bild des Selbstmordattentäters als Märtyrer (und auch der Selbstmordattentäterin als Märtyrerin) als transkulturelles Phänomen zu begreifen ist das unsere globalisierte Medienrealität prägt und durchdringt.

Beim Versuch, eine Bildgeschichte dieser speziellen Märtyrerinszenierungen nachzuzeichnen, drängen zwei Gegenüberstellungen besonders in den Vordergrund: Der Vergleich zwischen den Darstellungen säkularer und islamischer Gruppierungen, sowie zwischen den Bildern männlicher und weiblicher Selbstmordattentäter*innen. Während die Forschung zum Suizidanschlag größtenteils eine islamisch-schiitische Genealogie des Märtyrerkults behauptet (Kapitel 1.4), zeigte ein bildhistorischer Blick sowohl Kontinuitäten als auch Brüche zu säkularen Vorbildern auf. So scheint vieles dafür zu sprechen, dass die ersten Märtyrerposter schiitisch-libanesischer Selbstmordattentäter von den popkulturellen Postern palästinensischer Gruppierungen inspiriert waren (Kapitel 2.4). Auch die Aufnahme von Videotestamenten kann als Innovation säkularer Widerstandsparteien gelten, die anschließend die Vorlage für die Produktionen der Hisbollah lieferten. Seit der Aneignung durch die >Partei Gottes` wurde das Genre aber auch um eine dezidiert schiitische Bildsprache erweitert (Kapitel 3.3), die wiederum von säkularen Parteien (wie der Fatah) oder sunnitischen Milizen (wie der Hamas) übernommen wurde (Kapitel 3.4). Durch solche Übernahmen ist es zu erklären, dass eigentlich schiitische Märtyrersymbole wie die rote Tulpe oder das Märtyrerstirnband schließlich auch Einzug in die Videotestamente des sunnitisch-salafistischen Islamischen Staats erhielten (Kapitel 4.2). Es lassen sich folglich eine Vielzahl von Konvergenzen und Aneignungsbewegungen erkennen, die eine klare Abgrenzung der Bildgenres entlang konfessioneller Linien unmöglich machen.

Kontinuitäten und Brüche lassen sich ebenso mit Blick auf die Videotestamente weiblicher Selbstmordattentäterinnen ausmachen. Während säkulare Parteien Frauen wie Männer gleichermaßen für Selbstmordoperationen rekrutierten (Kapitel 3.1), wurde die Frage nach dem Geschlecht insbesondere von religiösen Akteur*innen kontrovers diskutiert. Am Beispiel der Palästinenserinnen, die sich während der zweiten Intifada erstmals auch im Namen islamischer Parteien in die Luft sprengten, wurde die heterogene (Selbst-)Inszenierung der weiblichen Märtyrerin offenkundig. Mitunter erschienen die Portraits der Frauen in denselben Poster-Schablonen, die auch für männliche Märtyrer verwendet wurden (Kapitel 
2.1). Gleichzeitig grenzten sich viele der Attentäterinnen aber auch von den Vorbildern der Männer ab. In ihren Videotestamenten formulierten sie teils explizite Geschlechterkritiken und führten neue visuelle Elemente ein, die mit der Ikonographie des männlichen Märtyrers brachen (Kapitel 3.4).

Eine Bildgeschichte des Selbstmordattentats schließt notwendigerweise auch die vielfältigen Appropriationen, Umdeutungen und Neukontextualisierungen mit ein, die diese Märtyrerdarstellungen erfahren haben. Sie bildeten einen wichtigen Bestandteil der vorangegangenen Analysen. Gerade in Zeiten der digitalen Zirkulation im Internet wird deutlich, dass die Grenze zwischen Produktion und Rezeption zunehmend verschwimmt. Im Internet verbreitete Märtyrermontagen können prinzipiell von jeder Person, überall auf der Welt hergestellt und weiterbearbeitet werden. Die von den militanten Gruppen verbreiteten Bilder haben auf diese Weise immer wieder neue Bedeutungszuschreibungen erfahren und wurden für ganz unterschiedliche politische Zwecke instrumentalisiert (Kapitel 3.4). Den künstlerischen Aneignungen kommt dabei eine besondere Rolle zu. Die teils medienkritischen und (selbst-)reflexiven Zugriffe tragen mitunter dazu bei, die Rahmungen dieser Märtyrerbilder selbst in den Blick zu bekommen und neue Lesarten zu eröffnen.

\section{Die Operationen der Bilder}

Wie in dieser Arbeit gezeigt wurde, sind mit den unterschiedlichen Aufnahmetechnologien, ihren ästhetischen Formen, sowie den Medien der Verbreitung auch unterschiedliche Bildoperationen verbunden. Die zentrale Frage danach, was diese Bilder tun, inwiefern sie aktiv in das militante Geschehen eingreifen, dieses verändern oder beeinflussen, muss daher je nach medialem Kontext anders beantwortet werden.

Die Analysen des zweiten Kapitels haben deutlich gemacht, dass die nach Selbstmordanschlägen produzierten Poster weitaus mehr sind als Nachrufe oder Medien der Bekanntgabe. Sie funktionieren als sekundäre Zeugnisse, die das Martyrium (das eigentliche >Blutzeugnis $\prec$ ) der Verantwortlichen visuell beglaubigen - und damit erst konstituieren und erzeugen. Die Märtyrerposter operieren im Sinne einer epistemischen Kausalität: Durch Mittel der Bildmontage werden >Wahrheiten geschaffen, die je nach Perspektive und politischer Agenda der Bezeugenden ganz anders aussehen können. Die Poster greifen somit interpretierend - und mobilisierend - in das Feld politischer Konflikte ein, auch wenn sie zeitlich erst nach der eigentlichen Selbstmordoperation entstehen und diese nicht direkt beeinflussen. Die Operationen der Poster weisen aber auch weit über den Bildraum hinaus - so hat insbesondere die massenhafte Plakatierung von Postern 
während des libanesischen Bürgerkriegs gezeigt. Märtyrerposter dienten hier teilweise der Markierung geografischer Territorien und waren damit ganz physisch durch ihre materielle Präsenz vor Ort - in die militanten Gewalthandlungen eingebunden.

Mit dem Aufkommen von Videotestamenten ab Mitte der 1980er Jahre wurden Selbstmordattentäter*innen erstmals selbst zu Zeug*innen ihres eigenen Martyriums (Kapitel 3). Die besondere agency der Videotestamente liegt nicht nur in ihren sprachlichen Botschaften, in ihren Drohgebärden oder vielfältigen Aufrufen zur Nachahmung. Ihre Wirkmacht als Akteure zeigt sich bereits im Moment der Videoaufnahme, in der Performance vor der Kamera und für die Kamera. Durch den Sprechakt `Ich bin der Märtyrer/Ich bin die Märtyrerin`nehmen die Dargestellten ihr eigenes Martyrium bereits vorweg. Die Videotestamente wurden in dieser Arbeit daher als antizipative Zeugnisse konzeptualisiert. Im Unterschied zu den posthum produzierten Postern geht das, was durch die Videos erzeugt wird, weit über die Konstitution des jeweiligen Martyriums hinaus. Durch die performative Vorwegnahme verpflichten sich die Individuen zur bevorstehenden Tat und schaffen zugleich ein audiovisuelles Beweismittel, das ihre Verantwortung vertraglich besiegelt. Die Videoaufnahme wird zum Startpunkt, zum Katalysator für die eigentliche Märtyrertod-Operation und ist damit auf erschreckend direkte Art und Weise in das Feld realpolitischer Konflikte verwickelt.

Die Zeugen-Performance der zukünftigen Selbstmordattentäter*innen rückt in den jüngsten Videotestamenten jedoch zunehmend in den Hintergrund. In den Videotestamenten von al-Qaida und IS gewinnen stattdessen aufwendige Nachbearbeitungsprozesse wie Bluescreen-Montagen, visuelle Spezialeffekte oder computergenerierte Sequenzen an Bedeutung (Kapitel 4). Diese Videotestamente scheinen vor allem auf der Ebene des postproduzierten Bildes zu operieren: Teils werden virtuelle Auferstehungsvisionen entworfen, die das eigentliche Zeugnis für das Martyrium der Dargestellten schaffen und etwa deren Eintritt ins Paradies vor Augen stellen. Das digitale, mitunter sogar vollständig computersimulierte und online verbreitete Videotestament 2.0 zielt aber auch auf eine zunehmende Aktivierung der Betrachtenden ab. Diese werden durch immersive First-Person-Perspektiven in den Videos häufig direkt angesprochen und so in den Prozess der Märtyrertod-Operation involviert. Die Grenze zwischen virtuellen und realen Attentaten, zwischen einem Handeln im Bild und einem Handeln durch das Bild wird von den verantwortlichen Milizen zunehmend verwischt. Die ÜberzeugungsMacht der Videotestamente zeigt sich hier in einer neuen Dimension.

Die Zusammenhänge zwischen >Bildoperation und `Märtyrertod-Operation sind folglich äußerst vielschichtig. Je nachdem welche Ebene man in den Blick nimmt - die Performance vor der Kamera, die (audio-)visuelle Postproduktion 
oder die Prozesse der Rezeption - treten andere operative Funktionen der Bilder zum Vorschein. Dabei zeigt sich, dass diese mit jeder medientechnologischen Innovation in Bewegung geraten und sich das Forschungsobjekt dadurch kontinuierlich verändert.

\section{Das Märtyrerzeugnis als Selfie im Livestream}

In einer Zeit, in der internetfähige Handykameras allgegenwärtig geworden sind und Soziale Medien ständig neue Wege der Kommunikation bereitstellen, scheint sich auch die Entwicklung des Videotestaments auf beispiellose Weise zu beschleunigen. Welche Tendenzen lassen sich innerhalb dieses Bildgenres gegenwärtig ausmachen? Inwiefern muss dadurch auch die operative Funktion dieser Bilder anders gedacht werden? Am Beispiel des Selfie-Videotestaments im Livestream will ich diese Fragen zum Schluss anstoßen und einen Ausblick auf weitere Problemfelder geben.

Am 13. Juni 2016 sollte ein Attentäter zum ersten Mal das von Facebook neu eingeführte Live-Feature für die Aufnahme und Verbreitung seines Testaments nutzen. Mit der Einführung der neuen Streaming-Funktion im Dezember 2015 verband Facebook wohl vor allem das Ziel, an die populären Echtzeitformate des Fernsehens anzuschließen und von den damit verbundenen höheren Werbeeinnahmen zu profitieren. Das Posten eines Videos wird zu einem singulären Event, das dadurch besondere Aufmerksamkeit generiert. Personalisierte Live-Feeds versprechen darüber hinaus einen Mehrwert an Intimität und Authentizität und scheinen damit das Selbstverständnis des Unternehmens auf ideale Weise zu verkörpern. Das Ziel von Facebook Live, so betonte Mark Zuckerberg im Februar 2016, kurz nachdem das Feature für alle US-amerikanischen Nutzer*innen verfügbar wurde, sei es, »die persönlichste, emotionalste, roheste und instinktivste Art der Kommunikation ${ }^{1}{ }^{2} \mathrm{zu}$ unterstützen. Dabei war es vor allem das »Rohe« dieser Kommunikationsform, das Schlagzeilen machen sollte. Von Beginn an wurde Facebook Live auffallend häufig als Plattform für Gewalttaten genutzt. ${ }^{2}$ So auch am Abend des 13. Juni 2016, als bei einem Anschlag im Pariser Vorort Magnanville

1 Zitiert in Mat Honan: »Why Facebook and Mark Zuckerberg Went All In On Live Video«, BuzzFeed News, 06.04.2016, https://www.buzzfeednews.com/article/mathonan/why-facebook-and-mark-zuckerberg-went-all-in-on-live-video (zugegriffen am 6. 6.2021).

2 Vgl. Noah Kulwin: »Facebook Live has a Big Problem: Livestreamed Violence«, Vice News, 06.01.2017, https://news.vice.com/en_us/article/mb985y/facebook-live-has-abig-problem-livestreamed-violence (zugegriffen am 6.6.2021). 
ein französischer Polizist mit mehreren Messerstichen vor seinem Haus ermordet wurde. Der Täter war ein den französischen Behörden bekannter Dschihadist, Larossi Abballa, der Augenzeugenberichten zufolge kurz vor dem Mord laut »Allahu Akbar« gerufen haben soll. ${ }^{3}$ Anschließend stürmte er das Haus des Ermordeten, tötete auch dessen Ehefrau mit einem Schnitt durch die Kehle und nahm deren dreijährigen Sohn als Geisel. Daraufhin drohte Abballa der Polizei, sich selbst zusammen mit seiner Geisel in die Luft zu sprengen. ${ }^{4}$ Noch während sich Abballa am Tatort befand und die Polizei versuchte, mit ihm zu verhandeln, streamte er um 20.52 Uhr ein rund 13 Minuten langes Video auf Facebook Live. Einer der wenigen, die das gesamte Video im Live-Feed gesehen haben, ist der Journalist und Dschihadismus-Experte David Thomson, auf dessen Augenzeugnis sich die meisten Medienberichte beziehen.

\section{Abbildung 5.1: Videotestament von Larossi Abballa, am 13. Juni 2016 per} Facebook Live verbreitet, 13 min, französisch.

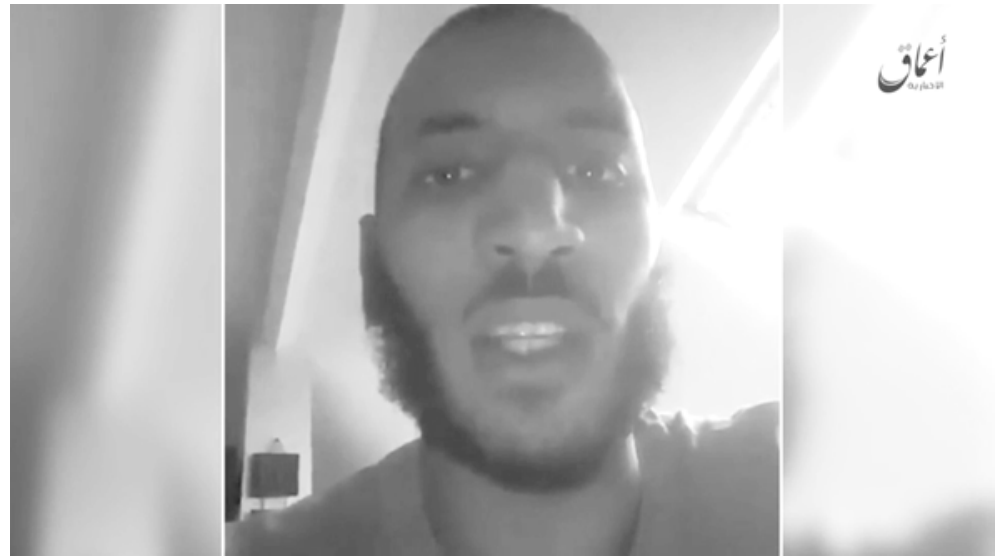

Auch wenn das Video zusammen mit dem Account des Attentäters nach rund 11 Stunden von Facebook gelöscht wurde, sind mehrere kürzere Ausschnitte bis

3 Vgl. Martina Meister: »Mörder rief >Allahu akbar« und stach zu«, Die Welt, 15.06.2016, https://www.welt.de/print/welt_kompakt/print_politik/article156231947/Moerder-riefAllahu-akbar-und-stach-zu.html (zugegriffen am 6.6.2021).

4 Vgl. Michaela Wiegel: »Polizistenmord nahe Paris: Einer von 8250 Islamisten«, Frankfurter Allgemeine Zeitung, 14.06.2016, http://www.faz.net/1.4287226 (zugegriffen am 6.6.2021). 
heute im Internet zu finden. ${ }^{5}$ Das mit seinem Smartphone aufgenommene SelfieVideo zeigt den 25-jährigen Abballa, der eine offenbar zuvor geschriebene Botschaft auf Französisch verliest (Abb. 5.1). Das für Selfies typische extreme CloseUp des Gesichts verleiht dem Video eine geradezu intime Wirkung, während die leichte Untersicht den Attentäter zugleich dominant und bedrohlich erscheinen lässt. In seinem vorgetragenen Testament bekannte sich Abballa unter Berufung auf den Islamischen Staat zu den gerade verübten Taten und sprach weitere Drohungen aus. Angesichts der laufenden Fußballeuropameisterschaft kündigte er etwa weitere Anschläge an, die Europa »in einen Friedhof verwandeln « sollten. ${ }^{6}$ Darüber hinaus enthielt sein Monolog eine persönliche Ansprache an den damaligen französischen Präsidenten François Hollande, sowie Hasstiraden auf weitere Persönlichkeiten des öffentlichen Lebens, die er in seinem Video namentlich nannte und zu deren Ermordung er aufrief. »Es ist ganz einfach«, so seine Botschaft an weitere Einzeltäter: »Es reicht, vor ihren Büros auf sie zu warten. Lasst ihnen keine Zeit. « ${ }^{7}$ Schließlich forderte er »seine 160 Freunde und noch deutlicher seine Kontakte beim IS zu einem Bekennerschreiben für seinen Angriff auf $\ll^{8}$, so Thomson. Als ein Sondereinsatzkommando der Polizei das Haus bereits umstellte, bat er seine »Brüder«, sie mögen für ihn zu Allah beten, dass er als »Märtyrer« sterben werde. ${ }^{9}$ Nur kurze Zeit nach Veröffentlichen des Videos stürmten die Polizisten das Haus und töteten den Attentäter, während der Junge lebend gerettet werden konnte. Auch wenn Abballa nicht als Selbstmordattentäter im engeren

5 Die Onlineausgabe der britischen Daily Mail veröffentlichte etwa einen 37 Sekunden langen Ausschnitt in Peter Allen, Chris Summers und Julian Robinson: »Pictured: Islamist Posts Facebook Video Saying He Slaughtered Couple«, 13.06.2016, https://www.dailymail.co.uk/news/article-3639878/Policeman-stabbed-death-outsideParis-home-attacker-holding-officer-s-wife-son-hostage.html (zugegriffen am 6.6. 2021).

6 Siehe den englisch untertitelten Ausschnitt des Videos in Allen/Summers/Robinson: »Pictured: Islamist Posts Facebook Video Saying He Slaughtered Couple«.

7 Zitiert in Alissa J. Rubin und Lilia Blaise: »Killing Twice for ISIS and Saying So Live on Facebook«, The New York Times, 14.06.2016, https://www.nytimes.com/2016/ 06/15/world/europe/france-stabbing-police-magnanville-isis.html (zugegriffen am 6.6. 2021).

8 Thomson zitiert nach Stern: »Islamist zeigte Video der Tat auf Facebook«, 14.06.2016, https://www.stern.de/politik/ausland/attentat-von-magnanville--islamist-stellte-videoder-tat-auf-facebook-6900008.html (zugegriffen am 6.6.2021).

9 Thomson zitiert in Rubin/Blaise: »Killing Twice for ISIS and Saying So Live on Facebook «. 
Sinne eines ssuicide bombers ment nahe, dass er seinen Tod zu diesem Zeitpunkt bereits als beschlossene Sache sah und das kommende »Martyrium « nicht nur in Kauf nahm, sondern gezielt anstrebte (und die Selbstsprengung der Polizei auch konkret androhte). Einer weiten Definition folgend ist sein Attentat also durchaus als Selbstmordoperation zu bezeichnen (vgl. Kapitel 1.3, S. 22f.).

In seinem Videotestament zeigt sich einmal mehr die Bandbreite appellativer Funktionen, die von Drohungen und Einschüchterungsversuchen gegenüber dem Feind, über direkte Aufforderungen zur Nachahmung, der Bitte um Anerkennung seiner Tat durch den Islamischen Staat, bis hin zum Gebet für sein Martyrium vor Allah reichen. Sind die wörtlich vorgetragenen Appelle dieses Videotestaments durchaus mit früheren Beispielen vergleichbar, so stellt uns die räumliche und zeitliche Situation dieser Aufnahme vor ganz neue Herausforderungen.

Zum ersten Mal wurde ein Videotestament am Tatort selbst aufgenommen, zu einem Zeitpunkt als die beiden Morde bereits verübt, der Anschlag aber noch in vollem Gange war. Habe ich Videotestamente bislang als antizipative Bildzeugnisse beschrieben, so trifft dies hier nicht länger zu. Abballas Videoaufnahme funktioniert nicht mehr als quasi-vertragliche Eigenverpflichtung, als Druckmittel oder Motor für eine zukünftige Tat. Stattdessen nutzt der Attentäter die Selbstinszenierung, um mit seinen Taten im Hier und Jetzt zu prahlen: »Wir sind gnadenlos und herzlos... ich war gerade gnadenlos gegenüber diesem Polizisten und seiner Frau. $«{ }^{10}$ Die Inszenierung schließt an die situative Praxis des Selfies an. Damit steht das Video in einem starken Widerspruch zum Großteil der bisher diskutierten Videotestamente des IS, die meist vor generischen Kulissen aufgenommen wurden und damit den Eindruck einer maximalen Ortlosigkeit vermitteln. Das Selfie erhält seinen Sinn hingegen gerade durch seinen Kontext, in dem es aufgenommen wird und zu dem sich die darstellende Person ins Verhältnis setzt. ${ }^{11}$ Im Hintergrund des verwackelten Videos sind immer wieder persönliche Gegenstände (z.B. an der Wand hängende rote Taschen) der Opfer zu sehen. Auch unabhängig von der verlesenen Botschaft vollzieht die situierte Selbstdarstellung im SelfieModus - und insbesondere der selbstherrliche Blick in die Kamera - eine Herabwürdigung der Opfer. Die Grenzüberschreitung des Mordens setzt sich in der

10 Zitiert in Allen/Summers/Robinson: »Pictured: Islamist Posts Facebook Video Saying He Slaughtered Couple«.

11 Vgl. Paul Frosh: »The Gestural Image: The Selfie, Photography Theory, and Kinesthetic Sociability«, International Journal of Communication, 9 (2015), S. 1607-1628, hier S. 1610; André Gunthert: Das geteilte Bild: Essays zur digitalen Fotografie, Göttingen: Konstanz University Press 2019, S. 154. 
medialen Inszenierung fort, indem der Attentäter in den Privatraum der Ermordeten eindringt und diesen zynischerweise als Schauplatz für seine Märtyrerdarstellung wählt. Der für Selfies typische Gestus \Schaut her, hier bin ich ‘ kann in diesem Fall als Zeugnis der Eroberung und Unterwerfung gedeutet werden.

Die Frage, was dieses Videotestament `tut‘, auf welche Art und Weise es die Ereignisse beeinflusst, muss jedoch vor allem mit Blick auf die Live-Übertragung neu gestellt werden. Im Unterschied zu bisherigen Videotestamenten fallen Produktion und Rezeption dieses Testaments mit dem Vollzug des Attentats zusammen. Durch die Wahl des Livestream verstärkt sich die kommunikative Funktion, die schon für unbewegte Selfies als charakteristisch hervorgehoben wurde. ${ }^{12}$ Folgt man dem Bericht von Thomson, war an einer Stelle im Laufe der Videoaufnahme der verstörte, dreijährige Sohn des Polizistenpaars im Hintergrund zu erkennen. »Ich weiß noch nicht, was ich mit ihm mache ${ }^{13}$, so teilte Abballa seinen Facebook-Freunden mit. Im Moment der Videoausstrahlung war der Ausgang des Attentats noch offen und das Schicksal des Jungen noch unentschieden. All jene, die das Video live am Bildschirm verfolgten (nach Angaben von David Thompson waren es 98 Menschen), ${ }^{14}$ wurden damit augenblicklich in die Situation vor Ort involviert. Die zeitliche Ko-Präsenz mit dem Attentäter auf Facebook versetzte die User*innen zumindest prinzipiell in die Lage, mit ihm in Kontakt zu treten, das Video unmittelbar zu kommentieren und damit aktiv in den Verlauf des Geschehens einzugreifen. Kommentare oder Emoticons, die während eines Livestreams auf Facebook Live gepostet werden, erscheinen in Echtzeit für alle sichtbar im Bildfeld und ermöglichen prompte Reaktionen von Seiten des Senders. Wurde die Selbstdarstellung des Attentäters durch Likes affirmiert? Gab es auch kritische Kommentare, die das Vorgehen des Täters in Frage stellten? Welchen Einfluss hatte die Echtzeitkommunikation auf die Entscheidung des Attentäters, den Sohn der Ermordeten am Leben zu lassen? Inwiefern es in diesem Fall tatsächlich zu einer interaktiven Face-to-Face Situation zwischen dem Attentäter und seinem Medienpublikum kam, ist im Nachhinein nur noch schwer zu

12 Die kommunikative, zur Interaktion aufrufende Funktion des Selfie-Formats wurde in der Forschung mehrfach hervorgehoben. Vgl. Frosh: »The Gestural Image«, S. 1621; Gunthert: Das geteilte Bild, S. 158; Wolfgang Ullrich: Selfies. Berlin: Wagenbach 2019, S. 54.

13 Zitiert in Rubin/Blaise: »Killing Twice for ISIS and Saying So Live on Facebook«.

14 Vgl. Stern: »Islamist zeigte Video der Tat auf Facebook«. 
rekonstruieren. ${ }^{15}$ Allein die Möglichkeit, vom eigenen Bildschirm aus zu intervenieren, verdeutlicht jedoch, dass mit dem Betrachten eines live geposteten Videotestaments eine besondere Verantwortung einhergeht. Die ethische Dimension der Medienzeugenschaft, wie sie in Kapitel 4 bereits diskutiert wurde, rückt hier umso deutlicher in den Vordergrund. Es geht nicht mehr nur darum, dass die Betrachtenden zu (unfreiwilligen) medialen Augenzeugen und Multiplikatoren einer Gewalttat werden. Als Teilnehmende eines auf Interaktion angelegten Livestreams werden die User*innen auf weitaus direktere Art und Weise zu (potenziellen) Akteure*innen in einem Geschehen, das vom physischen Tatort in die digitale Sphäre erweitert wird. Die appellative Macht des Videotestaments zeigt sich hier in einem beispiellosen und gesteigerten Ausmaß. Sobald man die Tragweite dessen begreift, was in Echtzeit bezeugt wird, ist ein Wegklicken, ein Wegsehen nicht mehr möglich. ${ }^{16}$

Obwohl Abballa seine Botschaft offensichtlich vorformuliert hatte und von einem Zettel ablas, zeichnet sich jede Liveübertragung gerade durch das Unvorhergesehene, Spontane und Nicht-Planbare aus. Wie in den vergangenen Kapiteln deutlich wurde, waren bisherige Videotestamente Produkt sorgfältiger Vorbereitungen: Bis zur finalen Version wurden meist mehrere Takes aufgenommen, in denen die Ansprache immer wieder verändert und `geprobt` wurde (siehe Kapitel 3.2); auch die Settings waren in der Regel bis ins Detail geplant und von den Organisationen mit Parteiemblemen, Waffen oder Postern ausstaffiert. Vor der Veröffentlichung durchliefen die Videos außerdem zahlreiche Nachbearbeitungsprozesse, die weitere Möglichkeiten der Rahmung, Aneignung und Instrumentalisierung im Sinne der jeweiligen parteipolitischen Agenda boten. Während ein live gepostetes Videotestament gerade durch die Singularität, die vermeintliche Authentizität und Direktheit eine besondere Anziehungskraft ausübt, entzieht es sich gleichzeitig auch der Kontrolle der sich verantwortlich erklärenden Organisation.

15 Damit ist auch ein grundlegendes methodisches Problem angesprochen, da die Interaktionen während Livestreams, die anschließend von Facebook gelöscht wurden, nur noch durch Screenshots oder Augenzeugenberichte von Live-Usern zugänglich sind.

16 Umso brisanter wird dies beim Betrachten eines Livestreams, der das Töten selbst ins Blickfeld der Kamera rückt. So etwa die mit Helmkameras live übertragenen rechtsextremen Attentate in Christchurch und Halle im Jahr 2019. Vgl. dazu meine Ausführungen an anderer Stelle: Verena Straub: »Töten im Livestream. Facebook Live und ein neuer `invective gaze in den Sozialen Medien«, in: Elisabeth Heyne und Tanja Prokic (Hg.): Invective Gaze - Das digitale Bild und die Kultur der Beschämung. Bielefeld: transcript 2021 (i.E.). Da es sich bei diesen Videos nicht um >Märtyrerzeugnisse 〈 handelt, sollen sie im Kontext dieser Arbeit nicht näher betrachtet werden. 
Auch für den Islamischen Staat schien das unautorisierte Videotestament Abballas offenbar mit besonderen >Risiken « verbunden gewesen zu sein, so zeigte der nachträgliche Umgang damit. Obwohl sich der IS nur kurze Zeit später über seine Nachrichtenagentur Amaq offiziell zum Attentat in Magnanville bekannte, wurde das Videotestament des Attentäters nur in gekürzter Version verbreitet. Der Teil, in dem der dreijährige Sohn der Ermordeten zu sehen war und in dem Abballa seine Unentschiedenheit im Hinblick auf dessen Schicksal zum Ausdruck brachte, war in der IS-Version nicht zu sehen. ${ }^{17}$ Nach Angaben der New York Times entbrannte auf Twitter eine Debatte über die Gründe für diese Entscheidung. Wurde einerseits darüber spekuliert, ob die Bilder eines wehrlosen Kleinkindes selbst für die Standards des Islamischen Staats zu weit gingen, vermuteten andere, dass das Zögern des Attentäters, den Jungen ebenfalls zu ermorden, vom IS als Schwäche ausgelegt wurde. ${ }^{18}$ Was auch immer den Ausschlag gegeben hatte: Für die Propagandamaschinerie des Islamischen Staates schien das Bild des verängstigten Jungen jedenfalls wenig nützlich gewesen zu sein. Dass das Opfer eines Anschlags noch dazu ein unschuldiges Kleinkind, das naturgemäß Mitgefühl erregt - ins Bildfeld eines Videotestaments rückt, war in der Tat neu. Es bleibt fraglich, ob diese Art der Inszenierung vom Attentäter so geplant war. Seine vorformulierte Selbstdarstellung als skrupelloser Rächer wurde jedenfalls durch die (anscheinend unvorhergesehene) Anwesenheit des Dreijährigen irritiert und gestört.

Das auf Facebook Live gepostete Selfie-Videotestament ist ein Beispiel dafür wie neue Medientechnologien sowohl die Ästhetik, als auch die operative Funktion dieser Bildzeugnisse prägen und verändern. Insgesamt fällt auf, dass neben den technisch hochprofessionellen Märtyrerzeugnissen des Islamischen Staats (Kapitel 4) immer häufiger solche amateurhaften Selfies in Umlauf kommen (auch wenn diese nicht im Livestream gesendet, sondern >klassischerweise ২ vor dem Anschlag aufgenommen wurden). Der Attentäter von Würzburg, der am 18. Juli 2016 mit Axt und Messer bewaffnet mehrere Menschen in einer Regionalbahn schwer verletzte und anschließend von der Polizei getötet wurde, nahm per Smartphone ein verwackeltes, teils unscharfes Video von sich auf, in dem er sich zum Islamischen Staat bekannte und - mit einem Küchenmesser wild gestikulierend den kommenden Anschlag androhte. ${ }^{19}$ Auch der Selbstmordattentäter, der sich am

17 Vgl. Rubin/Blaise: »Killing Twice for ISIS and Saying So Live on Facebook«.

18 Rubin/Blaise: »Killing Twice for ISIS and Saying So Live on Facebook«.

19 Das Video wurde offenbar an Kontakte des IS geschickt und anschließend von dessen Nachrichtenagentur Amaq in Umlauf gebracht. Vgl. Jörg Diehl: »IS-Propaganda: Die Medienmaschinerie des Terrors«, Spiegel Online, 20.07.2016, http://www.spiegel.de/ 
24. Juli 2016 nahe eines Musikfestivals im bayrischen Ansbach mit einer Splitterbombe in die Luft sprengte und dabei 15 Personen teils schwer verletzte, hinterließ ein Videotestament im Selfie-Format. In seiner Videoansprache trat der 27-jährige Täter allerdings vermummt vor die Kamera, ${ }^{20}$ was einerseits die >bezeugende> Funktion des Videotestaments unterläuft, ${ }^{21}$ zum anderen den interaktiven und >authentischen Charakter des Selfie-Formats konterkariert. Als weiteres Beispiel in der Reihe kann schließlich das Videotestament von Anis Amri gelten, der am 19. Dezember 2016 einen Anschlag auf den Berliner Weihnachtsmarkt am Breitscheidtplatz verübte. Obwohl es sich hier - wie bei den Anschlägen in Magnanville und Würzburg - nicht um ein Selbstmordattentat im engeren Sinne handelte, da Amri auf der Flucht von der Polizei in Madrid getötet wurde, hinterließ auch er ein Selfie-Videotestament, in dem er seine Absicht äußerte, als »Märtyrer« des Islamischen Staats zu sterben. ${ }^{22}$ Wie die Analyse von Lydia Korte und Bernd Zywietz zeigt, liegt die Spezifik dieses Selfie-Videotestaments gerade im »abwesenden« Blick des Attentäters, der »zwischen Persona-Präsentationsblick (in die Kameralinse) und Inszenator-Kontrollblick (auf das Display, auf dem er im Moment der Aufnahme sich selbst wie in einem Spiegel sieht) hin und her irrt « ${ }^{23}$. Ähnlich wie Rabih Mroué dies mit Blick auf die Videotakes von Jamal Sati beschrieben hat (Kapitel 3.2), rücken auch in den jüngsten Selfies der Attentäter gerade die Fehlbarkeiten, Unsicherheiten und Störungen - das »Stottern« der Selbstinszenierung im weitesten Sinne - in den Fokus. Ob dies von Sympathisant*innen als Zeichen der Unentschlossenheit und Unehrlichkeit gelesen wird, oder - im Gegenteil - den Authentizitätsanspruch der Selfie-Videos weiter verstärkt und zu einer gesteigerten Identifikation mit den Attentätern führt, bleibt fraglich. ${ }^{24}$

politik/deutschland/wuerzburg-und-nizza-so-funktioniert-die-is-propaganda-a-1103930. html (zugegriffen am 6.6.2021).

20 Vgl. Frankfurter Allgemeine Zeitung: »Selbstmordanschlag in Ansbach: IS-Sprachrohr veröffentlicht Bekennervideo« 26.07.2016, https://www.faz.net/aktuell/politik/inland/ is-bekennervideo-soll-attentaeter-von-ansbach-zeigen-14357797.html (zugegriffen am 6.6.2021).

21 Vgl. dazu das Videotestament einer vermummten palästinensischen Attentäterin in der Nachfolge von Wafa Idris, Abb. 2.3, S. 50.

22 Vgl. Lydia Korte und Bernd Zywietz: »Selfie-Video als Format propagandistischer Bekennerbotschaft. Bildstrategien im Fall Anis Amris«, in: Bernd Zywietz (Hg.): Propaganda des »Islamischen Staats«. Formen und Formate, Wiesbaden: Springer VS 2020, S. 217-241, hier S. 227.

23 Ebd., S. 238.

24 Vgl. ebd., S. 239. 
Ebenso wie bei Abballa ist bei vielen dieser Attentäter nicht klar, ob sie nach direkten Anweisungen des Islamischen Staats handelten oder ob ihre Taten zwar durch die IS-Propaganda inspiriert, aber eigeninitiativ geplant waren (selbst wenn sich der IS im Nachhinein offiziell für die Anschläge verantwortlich erklärte). Ist die simple, scheinbar amateurhafte Machart dieser Selfie-Testamente dementsprechend als Ergebnis fehlender organisatorischer Planung zu betrachten? Wie Yassin Musharbash nahelegt, sind solche Einzeltäter, sogenannte »lone wolves«, allerdings viel seltener als gemeinhin angenommen. ${ }^{25}$ In den meisten Fällen gibt es deutliche Hinweise darauf, dass Kontakte zu offiziellen Drahtziehern bestanden, die die Anschläge im Hintergrund steuerten. Ebenso ließe sich daher vermuten, dass die Verbreitung des Videotestaments als Selfie in den Sozialen Medien nicht nur den alltäglichen Mediengewohnheiten der Attentäter entspricht, sondern auch - trotz oder vielleicht gerade wegen aller Unwägbarkeiten und >Risiken « als Teil einer gezielten IS-Propagandastrategie zu werten ist.

Das Genre des >Märtyrer<-Videotestaments hat sich als verstörender Teil unserer globalisierten Medienrealität etabliert. Wie die jüngsten Veröffentlichungen des IS zeigen, erreichen uns heute sowohl technisch versierte Produktionen als auch simple Handyvideos. Während einige Videotestamente an computergenerierte Gaming-Szenarien anschließen und das Selbstmordattentat als High-TechOperation imaginieren, rekurrieren andere auf populäre Bildpraktiken der Sozialen Medien. Gerade die Gleichzeitigkeit unterschiedlicher Inszenierungsmodi macht deutlich, dass die Bildgeschichte des Selbstmordattentats nicht als teleologische Entwicklung zu begreifen ist, bei der eine Form die andere notwendigerweise ablöst, sondern als Prozess der zunehmenden Ausdifferenzierung. Wie genau sich die Funktionen und Formen dieser Märtyrerbilder in Zukunft präsentieren, bleibt offen. Solange das Selbstmordattentat ein Teil unserer Realität bleibt, solange werden wir uns auch den Bildern nicht entziehen können, die dadurch generiert werden.

25 Yassin Musharbash: ")Lone wolves« sind extrem selten«, Zeit Online, 23.03.2017, https://www.zeit.de/politik/ausland/2017-03/london-anschlag-birmingham-internationaler-terrorismus-motive-taeter (zugegriffen am 6.6.2021). 



\section{Literatur}

Abou Taam, Marwan, Claudia Dantschke, Michael Kreutz und Aladdin Sarhan: »Anwerbungspraxis und Organisationsstruktur», in: Janusz Biene et al. (Hg.): Salafismus und Dschihadismus in Deutschland: Ursachen, Dynamiken, Handlungsempfehlungen, Frankfurt: Campus Verlag 2016, S. 79-158.

Abrahamian, Ervand: »Ali Shari'ati: Ideologue of the Iranian Revolution«, in: Edmund Burke und Ira M. Lapidus (Hg.): Islam, Politics, and Social Movements, Comparative Studies on Muslim Societies, Berkeley: University of California Press 1988, S. 289-297.

Abu Hashhash, Mahmoud: »On the Visual Representation of Martyrdom in Palestine«, Third Text 20/3-4 (2006), S. 391-403.

Agamben, Giorgio: Was von Auschwitz bleibt: Das Archiv und der Zeuge (Homo sacer III), Frankfurt am Main: Suhrkamp 2003.

Allen, Lori A.: »The Polyvalent Politics of Martyr Commemorations in the Palestinian Intifada«, History and Memory 18 (2006), S. 107-138.

Allen, Peter, Chris Summers und Julian Robinson: »Pictured: Islamist Posts Facebook Video Saying He Slaughtered Couple«, 13.06.2016, https://www.dailymail.co.uk/news/article-3639878/Policeman-stabbed-death-outside-Parishome-attacker-holding-officer-s-wife-son-hostage.html (zugegriffen am 6.6.2021).

Altwegg, Jürg: »Vom Martyrium der Opfer ist keine Rede. Frankreichs Juden protestieren gegen eine Fotoausstellung, die Selbstmordattentäter als Helden feiert«, Frankfurter Allgemeine Zeitung, 13.06.2013, S. 31.

American Psychological Association: Technical Report on the Review of the Violent Video Game Literature, 2015, http://www.apa.org/news/press/releases/2015/08/technical-violent-games.pdf (zugegriffen am 6.6.2021).

Anker, Elisabeth, Silvia Arzt, Kirstin Eckstein und Julia Neissl (Hg.): Männerkrieg und Frauenfrieden: Geschlechterdimensionen in kriegerischen Konflikten, Wien: Promedia 2003. 
Araj, Bader: »The Motivations of Palestinian Suicide Bombers in the Second Intifada (2000 to 2005)«, Canadian Review of Sociology and Anthropology 49/3 (2012), S. 211-233.

Arraf, Suha (Regie): »Women of Hamas«, Dokumentarfilm, 56 min, Israel 2010. Asad, Talal: On Suicide Bombing, New York: Columbia University Press 2007. Assmann, Aleida: »Vier Grundtypen von Zeugenschaft«, in: Michael Elm und Gottfried Kössler (Hg.): Zeugenschaft des Holocaust. Zwischen Trauma, Tradierung und Ermittlung, Frankfurt am Main: Campus 2007, S. 33-51.

Atwan, Abdel Bari: Islamic State: The Digital Caliphate, Berkeley: University of California Press 2015.

---: The Secret History of Al-Qa'ida, London: Saqi 2006.

Austin, John L.: Zur Theorie der Sprechakte, hg. von Eike Savigny, Stuttgart: Reclam 1972.

Barthes, Roland: Die helle Kammer. Bemerkungen zur Photographie, Frankfurt am Main: Suhrkamp 1985.

Batty, David und Kevin Toolis (Regie): »The Cult of the Suicide Bomber. Ex-CIA Agent Robert Baer Uncovers the Mystery of This Weapon of Terror«, Dokumentarfilm, 96 min, Vereinigtes Königreich 2005.

Baudrillard, Jean: The Gulf War Did Not Take Place, Bloomington: Indiana University Press 1995.

Baxmann, Inge: »Ästhetisierung des Raums und nationale Physis«, in: Karlheinz Barck und Richard Faber (Hg.): Ästhetik des Politischen - Politik des Ästhetischen, Würzburg: Königshausen \& Neumann 1999, S. 79-95.

Behrend, Heike und Tobias Wendl (Hg.): 9/11 and its Remediations in Popular Culture and Arts in Africa, Berlin: LIT Verlag 2015.

Behrmann, Carolin und Elisabeth Priedl: »Vor Augen stellen. Zeugenschaft und Imitation «, in: Dies. (Hg.): Autopsia: Blut- und Augenzeugen: Extreme Bilder des christlichen Martyriums, München: Wilhelm Fink 2014, S. 9-19.

Belting, Hans: Bild-Anthropologie: Entwürfe für eine Bildwissenschaft, München: Fink 2001.

Bennacer, Dominika: »Bearing Witness to the (In)visible: Activism and the Performance of Witness in Islamic Orthopraxy«, Performance Research 13/3 (2008), S. 64-76.

Berkowitz, Daniel: »Promised Virgins and Princess Warriors: News and Mythical Archetypes of Palestinian Suicide Bombers«, Vortragsmanuskript, Jahrestreffen der International Communication Association, New Orleans, 27.05.2004, http://www.allacademic.com/meta/p112565_index.html (zugegriffen am 12.4.2016). 
Beyer, Andreas und Markus Lohoff (Hg.): Bild und Erkenntnis: Formen und Funktionen des Bildes in Wissenschaft und Technik, München: Deutscher Kunstverlag 2005.

Bild: »Das Pentagon kurz nach dem Anschlag. FBI veröffentlicht noch nie gesehene Aufnahmen von 9/11«, 31.03.2017, https://www.bild.de/news/ausland/terroranschlag-911/fbi-veroeffentlicht-aufnahmen-das-pentagon-kurznach-dem-anschlag-51088436.bild.html (zugegriffen am 6.6.2021).

Blair, David: »Revenge Sparked Suicide Bombing«, The Daily Telegraph, 06.10.2003.

Blättel-Mink, Birgit und Kai-Uwe Hellmann: Prosumer Revisited. Zur Aktualität einer Debatte, Wiesbaden: VS Verlag für Sozialwissenschaften 2010.

Bloom, Mia: Dying to Kill: The Allure of Suicide Terror, New York: Columbia University Press 2005.

---: »Terror's Stealth Weapon: Women«, Los Angeles Times, 29.11.2005, http://articles.latimes.com/2005/nov/29/opinion/oe-bloom29 (zugegriffen am 6.6.2021).

Bourriaud, Nicolas: Postproduction: Culture as Screenplay: How Art Reprograms the World, 2. Aufl., New York: Lukas \& Sternberg 2007.

Bradley, Kim: »Review: Ahlam Shibli«, Art in America (2013), http://www.artinamericamagazine.com/reviews/ahlam-shibli/ (zugegriffen am 6.6.2021).

Bredekamp, Horst: Theorie des Bildakts, Frankfurt am Main: Suhrkamp 2010.

---: Das Beispiel Palmyra, Köln: Verlag der Buchhandlung Walther König 2016.

Brunner, Claudia: Männerwaffe Frauenkörper? Zum Geschlecht der Selbstmordattentate im israelisch-palästinensischen Konflikt, Wien: Braumüller 2005.

---: Wissensobjekt Selbstmordattentat: Epistemische Gewalt und okzidentalistische Selbstvergewisserung in der Terrorismusforschung, Wiesbaden: VS Verlag für Sozialwissenschaften 2011.

Butler, Judith: Frames of War: When is Life Grievable?, London und New York: Verso 2010.

Cavell, Stanley: Pursuits of Happiness: The Hollywood Comedy of Remarriage, Cambridge: Harvard University Press 2003.

Chad, Elias: »Review: Signs of Conflict: Political Posters of Lebanon's Civil War (1975-1990)«, Journal of Visual Culture 8/1 (2009), S. 116-120.

---: »Martyrdom and Mediation«, in: Ders. (Hg.): In Focus: On Three Posters 2004 by Rabih Mroué, London: Tate 2014, https:/www.tate.org.uk/research/publications/in-focus/on-three-posters-rabih-mroue/martyrdom-and-mediation (zugegriffen am 6.6.2021), o.S.

---: »Interview with Rabih Mroué«, in: Ders. (Hg.): In Focus: On Three Posters 2004 by Rabih Mroué, London: Tate 2014, https://www.tate.org.uk/research/ 
publications/in-focus/on-three-posters-rabih-mroue/interview-with-rabihmroue (zugegriffen am 6.6.2021).

---: »Stage and Screen«, in: Ders. (Hg.): In Focus: On Three Posters 2004 by Rabih Mroué, London: Tate 2014, https://www.tate.org.uk/art/research-publications/rabih-mroue-on-three-posters/stage-and-screen-r1144499 (zugegriffen am 6.6.2021).

Chelkowski, Peter und Hamid Dabashi: Staging a Revolution: The Art of Persuasion in the Islamic Republic of Iran, New York: New York University Press 1999.

Chicago Project on Security and Terrorism (CPOST): Suicide Attack Database, 2016, http://cpostdata.uchicago.edu (zugegriffen am 6.6.2021).

Cicek, Hüseyin I.: Martyrium zwischen Gewalt und Gewaltfreiheit. Eine Kriteriologie im Blick auf Christentum, Islam und Politik, Berlin: LIT Verlag 2011.

Claudet, Sophie: »More Palestinian Women Suicide Bombers Could Be on the Way«, Agence France Presse, 28.02.2002, http://www.metimes.com/2k2/issue2002-9/women/morepalestinianwomen.htm (zugegriffen am 23.4.2017, nicht mehr verfügbar).

CNN: »New Bin Laden Tape Surfaces. Separate Video Apparently Shows September 11 Hijacker«, 16.04.2002, http://edition.cnn.com/2002/WORLD/ meast/04/15/terror.tape/index.html (zugegrifen am 16.9.2018).

---: »Al-Jazeera: Bin Laden Tape Praises Hijackers«, 09.09.2002, http://articles.cnn.com/2003-09-12/us/hijack.tape_1_al-jazeera-bin-hijackers?_s=PM:US (nicht mehr verfügbar).

---: »Video is Said to Show Bin Laden Preparing for 9/11 Attacks«, 08.09.2006, http://www.cnnworldclass.com/2006/WORLD/meast/09/07/alqaeda.911/ index.html (nicht mehr verfügbar).

---: »New Bin Laden Video Surfaces«, 11.09.2007, http://edition.cnn.com/2007/ WORLD/meast/09/11/binladen.video/index.html (nicht mehr verfügbar).

Cook, David und Olivia Allison: Understanding and Addressing Suicide Attacks: The Faith and Politics of Martyrdom Operations, Westport: Praeger 2007.

Croitoru, Joseph: Der Märtyrer als Waffe: Die historischen Wurzeln des Selbstmordattentats, München: Hanser 2003.

Curtis, Robin: »Immersion und Einfühlung: Zwischen Repräsentationalität und Materialität bewegter Bilder«, montage AV. Zeitschrift für Theorie und Geschichte audiovisueller Kommunikation 17/2 (2008), S. 89-107.

Czirak, Adam, Sophie Nikoleit, Friederike Oberkrome, Verena Straub und Robert Walter-Jochum: »(P)Reenactment«, in: Jan Slaby und Christian von Scheve (Hg.): Affective Societies - Key Concepts, London: Routledge 2019, S. 200209. 
Dabashi, Hamid: The World of Persian Literary Humanism, Cambridge: Harvard University Press 2012.

Darwisch, Machmud: Ein Gedächtnis für das Vergessen. Beirut, August 1982, übers. von Kristina Stock, Basel: Lenos Verlag 2001.

Dauber, Cori E.: YouTube War: Fighting in a World of Cameras in Every Cell Phone and Photoshop on Every Computer, Carlisle: Strategic Studies Institute, U.S. Army War College 2009, http://purl.access.gpo.gov/GPO/LPS117266 (zugegriffen am 6.6.2021).

Dauber, Cori E., Mark D. Robinson, Jovan J. Baslious and Austin G. Blair: »Call of Duty: Jihad - How the Video Game Motif has Migrated Downstream from Islamic State Propaganda Videos«, Perspectives on Terrorism, 13/3 (2019), S. 17-31.

Davis, Margaret: »He Saw It Coming: An Interview with Jack Thorpe«, in: Dies. (Hg.): America's Army PC Game: Vision and Realization: A Look at the Artistry, Technique, and Impact of the United States Army's Groundbreaking Tool for Strategic Communication, Monterey: United States Army and the MOVES Institute 2004, S. 30-32.

Demos, T. J.: »Disappearance and Precarity: On the Photography of Ahlam Shibli«, in: MACBA (Museu d'art contemporani de Barcelona), Jeu de Paume und Museu de arte contemporanea de serralves (Hg.): Ahlam Shibli. Phantom Home, Ausst.-Kat., Ostfildern: Hatje Cantz 2013, S. 11-26.

Dick, Alexandra: »Anāshīd und der mediale Jihad des Islamischen Staates«, Zeitschrift für Semiotik 39/3-4 (2017), S. 55-70.

Diehl, Jörg: »IS-Propaganda: Die Medienmaschinerie des Terrors«, Spiegel Online, 20.07.2016, http://www.spiegel.de/politik/deutschland/wuerzburg-undnizza-so-funktioniert-die-is-propaganda-a-1103930.html (zugegriffen am 6.6.2021).

Difraoui, Abdelasiem El: Al-Qaida par l'image: La prophétie du martyre, Paris: Presses Universitaires de France 2013.

Dobson, Christopher und Ronald Payne: The Carlos Complex: A Pattern of Violence, London: Hodder and Stoughton 1977.

Dulong, Renaud: Le témoin oculaire. Les conditions sociales de l'attestation personelle, hg. von l'École des hautes etudes des sciences sociales, Paris 1998.

Economist: »A World Wide Web of Terror«, 12.07.2007, http://www.economist.com/node/9472498 (zugegriffen am 6.6.2021).

Edelson, Daniel: »Pictures of 〉Holy Terrorists « to Be Removed From Exhibition«, Ynetnews, 03.09.2009, http://www.ynetnews.com/articles/0,7340,L-377166 7,00.html (zugegriffen am 6.6.2021). 
Eder, Jens und Charlotte Klonk: »Introduction«, in: Dies. (Hg.): Image Operations. Visual Media and Political Conflict, Manchester: Manchester University Press 2016, S. 1-22.

Eder, Jens: Vorüberlegungen zu »Image Operations. Visual Media and Political Conflict«. Unveröffentlichtes Manuskript, 2016, o.S.

El Houri, Walid: The Meaning of Resistance: Hezbollah's Media Strategies and the Articulation of A People, Amsterdam: Rozenberg 2012.

El Houri, Walid und Dima Saber: »Filming Resistance: A Hezbollah Strategy«, Radical History Review 106 (2010), S. 70-85.

Ellis, John: Seeing Things: Television in the Age of Uncertainty, London: I.B. Tauris 2000.

Exum, Andrew: »The Spectacle of War: Insurgent Video Propaganda and Western Response, 1990 - Present«, Arab Media and Society 5 (2008).

Ezzati, Abul: »The Concept of Martyrdom in Islam«, Al-Islam 12 (1986), www.al-islam.org/al-serat/vol-12-1986/concept-martyrdom-islam (zugegriffen am 6.6.2021).

Faramazi, Scheherezade: »Girl Who Crashed Car Bomb Into Israelis First Sent Mother Present«, Associated Press, 11.04.1985.

Farrell, William R.: Blood and Rage: The Story of the Japanese Red Army, Lexington: Lexington Books 1990.

Fassin, Didier: »The Humanitarian Politics of Testimony: Subjectification through Trauma in the Israeli-Palestinian Conflict«, Cultural Anthropology 3 (2008), S. 531-558.

Federal Bureau of Investigation (FBI): »Press Release: FBI Announces List of 19 Hijackers«, Pressemitteilung vom 14. September 2001, https://web.archive.org/web/20080305093133/http://www.fbi.gov/pressrel/pressrel01/091401hj.htm (zugegriffen am 6.6.2021).

Felman, Shoshana und Dori Laub: Testimony: Crises of Witnessing in Literature, Psychoanalysis, and History, London: Routledge 1992.

Ferrero, Mario: »Martyrdom Contracts«, Journal of Conflict Resolution 50/6 (2006), S. 855-877.

Frankfurter Allgemeine Zeitung: »Selbstmordanschlag in Ansbach: IS-Sprachrohr veröffentlicht Bekennervideo« 26.07.2016, https://www.faz.net/aktuell/politik/inland/is-bekennervideo-soll-attentaeter-von-ansbach-zeigen14357797.html (zugegriffen am 6.6.2021).

Friedman, Marilyn: »Female Terrorists: Martyrdom and Gender Equality«, in: Ibrahim A. Karawan, Wayne McCormack und Stephen E. Reynolds (Hg.): Values and Violence. Intangible Aspects of Terrorism, Heidelberg: Springer 2008, S. 43-62. 
Frosh, Paul: »Telling Presences: Witnessing, Mass Media, and the Imagined Lives of Strangers«, Critical Studies in Media Communication 23/4 (2006), S. 265284.

Frosh, Paul und Amit Pinchevski (Hg.): Media Witnessing: Testimony in the Age of Mass Communication, New York: Palgrave Macmillan 2009.

---: »Why Media Witnessing? Why Now?«, in: Dies. (Hg.): Media Witnessing: Testimony in the Age of Mass Communication, New York: Palgrave Macmillan 2009, S. 1-19.

Fuchs, Simon: »Relocating the Centers of Shī'̄i Islam: Religious Authority, Sectarianism, and the Limits of the Transnational in Colonial India and Pakistan«, Dissertation, Princeton University 2015.

Furtwängler, Frank: »Kulturtechnik des Sterbens. You are Dead - Continue Yes/No?«, in: Thomas Macho und Kristin Marek (Hg.): Die neue Sichtbarkeit des Todes, München: Fink 2007, S. 559-576.

Gambetta, Diego: „Can We Make Sense of Suicide Missions?«, in: Ders. (Hg.): Making Sense of Suicide Missions, Oxford: Oxford University Press 2005, S. 259-300.

Gambill, Gary C.: »Sponsoring Terrorism: Syria and the PFLP-GC«, Middle East Intelligence Bulletin 4/9 (2002), https://www.meforum.org/meib/articles/0209_s1.htm (zugegriffen am 6.6.2021).

Garrin, Paul: »The 1988 Tompkins Square Police Riot - A Video Point of View«, Tactical Media Files (2011), http:/www.tacticalmediafiles.net/articles/3460/ The-1988-Tompkins-Square-Police-Riot-_-A-Video-Point-of-View (zugegriffen am 6.6.2021).

Gell, Alfred: Art and Agency: An Anthropological Theory, Oxford: Clarendon Press 1998.

Genet, Jean: »Affirmation of Existence through Rebellion«, Journal of Palestine Studies 12(3) (1987), S. 64-84.

Gerloff, Johannes: Die Palästinenser: Volk im Brennpunkt der Geschichte, 2. Aufl., Holzgerlingen: SCM Hänssler 2011.

Gertz, Nurith und George Khleifi: Palestinian Cinema: Landscape, Trauma and Memory, Bloomington: Indiana University Press 2008.

Givoni, Michal: »Witnessing/Testimony«, Mafte'akh. Lexical Review of Political Thought (2011), S. 147-174.

Goodman, Hirsh: »Eighteen Murdered in Kiryat Shmona Terror. Three Arabs Butcher Women and Children, then Die in Blast«, Jerusalem Post, 12.04.1974, Titelseite.

Graitl, Lorenz: Sterben als Spektakel: Zur kommunikativen Dimension des politisch motivierten Suizids, Wiesbaden: Springer 2012. 
Grau, Oliver: Virtual Art: From Illusion to Immersion, Cambridge: MIT Press 2003.

---: »New Perspectives for the (Digital) Humanities«, in: G. Ulrich Großmann und Petra Krutisch (Hg.): The Challenge of the Object: 33rd Congress of the International Committee of the History of Art, Nürnberg: Verlag des Germanischen Nationalmuseums 2013, S. 990-994.

Groys, Boris: »The Fate of Art in the Age of Terror«, in: Manon Slome und Joshua Simon (Hg.): The Aesthetics of Terror, Mailand: Charta 2009, S. 54-59.

Grusin, Richard A.: Premediation: Affect and Mediality after 9/11, New York: Palgrave Macmillan 2010.

Guerin, Francis und Roger Hallas: The Image and the Witness: Trauma, Memory and Visual Culture, London: Wallflower Press 2007.

Guevara, Ernesto Che: Venceremos! The Speeches and Writings of Che Guevara, hg. von John Gerassi, London: Panther Books 1969.

Günther, Christoph und Simone Pfeifer (Hg.): Jihadi Audiovisuality and its Entanglements: Meanings, Aesthetics, Appropriations, Edinburgh: Edinburgh University Press 2020.

Günther, Christoph: „Corpus delicti - der Körper als Tatwerkzeug. Märtyreroperationen im irakischen Kontext«, Arbeitstitel. Forum für Leipziger Promovierende 3, Heft 1 (2011), S. 21-33.

---: Ein zweiter Staat im Zweistromland? Genese und Ideologie des »Islamischen Staates Irak«, Würzburg: Ergon-Verlag 2014.

Guthrie, Basma: »Embodying a Stateless Nation: A Closer Look at Representations of Palestinian Women in Nationalist Posters - 1960's-1980's«, The Palestine Poster Project (2012), http://www.palestineposterproject.org/poster/ embodying-a-stateless-nation-a-closer-look-at-representations-of-palestinianwomen-in (zugegriffen am 6.6.2021).

Hafez, Mohammed M.: Manufacturing Human Bombs: The Making of Palestinian Suicide Bombers, Washington, D.C.: United States Institute of Peace Press 2006.

---: »Dying to Be Martyrs: The Symbolic Dimension of Suicide Terrorism«, in: Pedahzur, Ami (Hg.): Root Causes of Suicide Terrorism: The Globalization of Martyrdom, London: Routledge 2006, S. 54-80.

Harrison, Mark: »An Economist Looks at Suicide Terrorism«, World Economics 7/3 (2006).

Hassan, Nasra: "An Arsenal of Believers«, The New Yorker (2001), http://www.newyorker.com/magazine/2001/11/19/an-arsenal-of-believers (zugegriffen am 6.6.2021). 
Hasso, Frances S.: »Discursive and Political Deployments by/of the 2002 Palestinian Women Suicide Bombers/Martyrs«, Feminist Review (2005), S. 23-51.

Hoffman, Bruce: Terrorismus. Der unerklärte Krieg, Frankfurt am Main: Fischer Taschenbuch Verlag 2008.

Holert, Tom: »Sensorship: The Seen Unseen of Drone Warfare«, in: Jens Eder und Charlotte Klonk (Hg.): Image Operations. Visual Media and Political Conflict, Manchester: Manchester University Press 2016, S. 101-117.

Honan, Mat: »Why Facebook and Mark Zuckerberg Went All In On Live Video«, BuzzFeed News, 06.04.2016, https:/www.buzzfeednews.com/article/mathonan/why-facebook-and-mark-zuckerberg-went-all-in-on-live-video (zugegriffen am 6.6.2021).

Horowitz, Michael C.: The Diffusion of Military Power: Causes and Consequences for International Politics, Princeton: Princeton University Press 2010.

Independent (London): "Shia Makes Suicide Attack on Israeli Convoy«, 10.08.1989.

Institute of Contemporary Arts (ICA): »Simon Tyszko, Suicide Bomber Barbie«, London 2002, in: Simon Tyszko: »Suicide Bomber Barbie«, http://www.theculture.net/barbie/index.html\#texts (zugegriffen am 6.6.2021).

Isbister, Katherine: How Games Move Us: Emotion by Design, Cambridge: MIT Press 2016.

Issacharoff, Avi: »The Palestinian and Israeli Media on Femal Suicide Terrorists «, in: Yoram Schweitzer (Hg.): Female Suicide Bombers. Dying for Equality?, Tel Aviv 2006, S. 43-50.

Johnson, Nels: Islam and the Politics of Meaning in Palestinian Nationalism, London: KPI Limited 1982.

Jorisch, Avi: Beacon of Hatred: Inside Hizballah's Al-Manar Television, Washington, D.C.: Washington Institute for Near East Policy 2004.

---: »Al-Manar: Hizbullah TV, 24/7«, Middle East Quarterly XI(1) (2004), S. 1731, online abrufbar unter http://www.meforum.org/583/al-manar-hizbullahtv-24-7 (zugegriffen am 6.6.2021), hier o.S.

Juul, Jesper: Half-Real: Video Games Between Real Rules and Fictional Worlds, Cambridge: MIT Press 2005.

Kechichian, Sevag: »The Many Faces of Violence and the Social Foundations of Suicide Bombings, Lebanon 1981-2000«, http://cas.uchicago.edu/workshops/cpolit/papers/kechichian1.doc (nicht mehr verfügbar).

Khalili, Laleh: Heroes and Martyrs of Palestine: The Politics of National Commemoration, Cambridge: Cambridge University Press 2007.

Khatib, Lina: Image Politics in the Middle East: The Role of the Visual in Political Struggle, London: I.B. Tauris 2013. 
Klonk, Charlotte: Terror: Wenn Bilder zu Waffen werden, Frankfurt am Main: S. Fischer Verlag 2017.

Koch, Sophie und Sven Felix Kellerhoff: »11. September 2001: Das Protokoll des Tages, der die Welt veränderte«, Die Welt, 09.09.2011, https://www.welt.de/ kultur/history/article13589616/Das-Protokoll-des-Tages-der-die-Welt-veraenderte.html (zugegriffen am 6.6.2021).

Koerner, Brendan I.: »Why ISIS Is Winning the Social Media War«, WIRED (2016), https://www.wired.com/2016/03/isis-winning-social-media-war-heres-beat/ (zugegriffen am 6.6.2021).

Korte, Lydia und Bernd Zywietz: »Selfie-Video als Format propagandistischer Bekennerbotschaft. Bildstrategien im Fall Anis Amris«, in: Bernd Zywietz (Hg.): Propaganda des »Islamischen Staats«. Formen und Formate, Wiesbaden: Springer VS 2020, S. 217-241.

Kramer, Martin: »Hisbollah: The Calculus of Jihad«, in: Martin E. Marty und R. Scott Appleby (Hg.): Fundamentalisms and the State: Remaking Polities, Economies, and Militance, Bd. 3, Chicago: University of Chicago Press 1993, S. 539-556.

---: »Sacrifice and \Self-Martyrdom〈 in Shi'ite Lebanon«, in: Ders. (Hg.): Arab Awakening and Islamic Revival: The Politics of Ideas in the Middle East, New Brunswick: Transaction Publishers 1996, S. 231-243, http://martinkramer. org/sandbox/reader/archives/sacrifice-and-self-martyrdom-in-shiite-lebanon/ (zugegriffen am 6.6.2021), hier o.S.

Krauss, Rosalind: »Anmerkung zum Index: Teil 1 und Teil 2 [1976/77]«, in: Dies.:

Die Originalität der Avantgarde und andere Mythen der Moderne, Amsterdam/Dresden: Verlag der Kunst 2000, S. 249-276.

Kulwin, Noah: »Facebook Live Has a Big Problem: Livestreamed Violence«, Vice News, 06.01.2017, https://news.vice.com/en_us/article/mb985y/facebook-live-has-a-big-problem-livestreamed-violence (zugegriffen am 6.6. 2021).

Lakomy, Miron: »Let's Play a Video Game: Jihadi Propaganda in the World of Electronic Entertainment«, Studies in Conflict \& Terrorism, 42/4 (2017), S. 383-406.

Lenoir, Timothy und Luke Caldwell: »Image Operations: Refracting Control From Virtual Reality to the Digital Battlefield«, in: Jens Eder und Charlotte Klonk (Hg.): Image Operations. Visual Media and Political Conflict, Manchester: Manchester University Press 2016, S. 89-100.

Maas, Georg und Achim Schudack: Musik und Film - Filmmusik, Mainz: Schott 1994. 
Maasri, Zeina: Off the Wall: Political Posters of the Lebanese Civil War, London: I.B. Tauris 2009.

MACBA (Museu d'art contemporani de Barcelona), Jeu de Paume und Museu de arte contemporanea de serralves (Hg.): Ahlam Shibli. Phantom Home, Ausst.Kat., Ostfildern: Hatje Cantz 2013.

Matar, Dina und Farah Dakhlallah: »What it Means to Be Shiite in Lebanon: Al Manar and the Imagined Community of Resistance«, Westminster Papers in Communication and Culture 3/2 (2006).

Medalia, Hilla (Regie): »To Die in Jerusalem«, Dokumentarfilm, 40 min, Israel/USA 2007.

Meister, Martina: »Mörder rief >Allahu akbar« und stach zu«, Die Welt, 15.06.2016, https://www.welt.de/print/welt_kompakt/print_politik/article156 231947/Moerder-rief-Allahu-akbar-und-stach-zu.html (zugegriffen am 6.6. 2021).

Melman, Yossi: »Swedish Envoy: We Cannot Constitutionally Remove Exhibit«, Haaretz, 19.01.2004, http://web.archive.org/web/20040201210331/http:// www.haaretzdaily.com/hasen/spages/383944.html (zugegriffen am 6.6.2021).

Merari, Ariel, Jonathan Fighel, Boaz Ganor, Ephraim Lavie, Yohanan Tzoreff und Arie Livne: »Making Palestinian >Martyrdom Operations $</>$ Suicide Attacks $<$ : Interviews With Would-Be Perpetrators and Organizers«, Terrorism and Political Violence 22/1 (2009), S. 102-119.

Middleton, Paul: Martyrdom: A Guide for the Perplexed, London: Bloomsbury Publishing 2011.

Milton-Edwards, Beverley: Islamic Politics in Palestine, London: I.B. Tauris 1996.

Mirzoeff, Nicholas: »Von Bildern und Helden. Sichtbarkeit im Krieg der Bilder«, in: Lydia Haustein, Bernd M. Scherer und Martin Hager (Hg.): Feindbilder: Ideologien und visuelle Strategien der Kulturen, Göttingen: Wallstein 2007, S. $135-156$.

Mitchell, W. J. T.: What Do Pictures Want? The Lives and Loves of Images, Chicago: The University of Chicago Press 2005.

Moghadam, Assaf: »Defining Suicide Terrorism«, in: Ami Pedahzur (Hg.): Root Causes of Suicide Terrorism. The Globalization of Martyrdom, London: Routledge 2006, S. 13-24.

---: »The Roots of Suicide Terrorism: A Multi-Causal Approach«, in: Ami Pedahzur, (Hg.): Root Causes of Suicide Terrorism: The Globalization of Martyrdom, London: Routledge 2006, S. 81-108.

---: The Globalization of Martyrdom: Al Qaeda, Salafi Jihad, and the Diffusion of Suicide Attacks, Baltimore: John Hopkins University Press 2008. 
Mroué, Rabih: »The Fabrication of Truth«, in: Fundació Antoni Tàpies (Hg.): Tamass: Contemporary Arab Representations, Bd. 1, Barcelona: Fundació Antoni Tapies 2002, S. 114-117.

---: »1000 Words«, Artforum 48/3 (2009), S. 194.

---: »Three Posters. Reflections on a Video-Performance«, in: CA2M Centro de Arte Dos de Mayo (Hg.): Rabih Mroué. Image(s), mon amour. Fabrications, Ausst.-Kat., Madrid: CA2M Centro de Arte Dos de Mayo 2013, S. 302-314.

---: »The Inhabitants of Images«, in: CA2M Centro de Arte Dos de Mayo (Hg.): Rabih Mroué. Image(s), mon amour. Fabrications, Ausst.-Kat., Madrid: CA2M Centro de Arte Dos de Mayo 2013, S. 338-356.

Mroué, Rabih und Elias Khoury: »Three Posters: Reflections on a Video/Performance«, The Drama Review 50/3 (2006), S. 182-191.

Münkler, Herfried: Die neuen Kriege, Hamburg: Rowohlt 2003.

Musharbash, Yassin: Die neue al-Qaida: Innenansichten eines lernenden Terrornetzwerks, Köln: Kiepenheuer \& Witsch 2006.

---: ")Lone wolves« sind extrem selten«, Zeit Online, 23.03.2017, https://www.zeit.de/politik/ausland/2017-03/london-anschlag-birminghaminternationaler-terrorismus-motive-taeter (zugegriffen am 6.6.2021).

Musharbash, Yassin und Behnam Said: »Der Soundtrack des Dschihad«, Zeit Online, 01.07.2016, http://www.zeit.de/2016/28/islamismus-anaschid-musik/komplettansicht?print (zugegriffen am 6.6.2021).

Naaman, Dorit: »Brides of Palestine/Angels of Death: Media, Gender, and Performance in the Case of the Palestinian Female Suicide Bombers«, Signs 32/4 (2007), S. 933-955.

Nacos, Brigitte L.: »The Portrayal of Female Terrorists in the Media: Similar Framing Patterns in the News Coverage of Women in Politics and Terrorism«, Studies in Conflict \& Terrorism 28 (2005), S. 413-419.

Nasrallah, Rafiq (Hg.): Al Muqawama al-Wataniyya al-Lubnaniyya 1982-1985: Al-Amaliyyat al-Istishhadiyya - Wathai'q wa Suwar (Lebanese National Resistance 1982-1985: Martyrdom Operations - Documents and Images), Beirut: Al-Markaz al-Arabi lil-Ma'lumat 1985.

Neuwirth, Angelika: »Blut und Tinte - Opfer und Schrift: Biblische und koranische Erinnerungsfiguren im vorderasiatischen Märtyrerdiskurs«, in: Andreas Kraß und Thomas Frank (Hg.): Tinte und Blut. Politik, Erotik und Poetik des Martyriums, Frankfurt am Main: S. Fischer Verlag 2008, S. 25-58.

Oliver, Kelly: Women as Weapons of War: Iraq, Sex, and the Media, New York: Columbia University Press 2007.

O'Loughlin, Ben: »Images as Weapons of War: Representation, Mediation and Interpretation «, Review of International Studies 37/1 (2011), S. 71-91. 
Pannewick, Friederike: »Tödliche Selbstaufopferung in der arabischen Literatur. Eine Frage von Macht und Ehre?«, in: Christina von Braun u.a. (Hg.): >Holy War` and Gender. >Gotteskrieg` und Geschlecht. Berlin: LIT Verlag 2006, S. 93-119.

---: »Wafa Idris. Eine Selbstmordattentäterin zwischen Nationalheldin und Heiliger«, in: Sigrid Weigel (Hg.): Märtyrer-Porträts. Von Opfertod, Blutzeugen und Heiligen Kriegern, München: Wilhelm Fink 2007, S. 110-116.

Paoli, Guillaume: »Nächste Runde: Paradies«, Frankfurter Allgemeine Zeitung, 18.01.2015, http://www.faz.net/1.3376331 (zugegriffen am 6.6.2021).

Pape, Robert: Dying to Win: The Strategic Logic of Suicide Terrorism, New York: Random House 2005.

Paret, Rudi (Hg.): Der Koran. Kommentar und Konkordanz von Rudi Paret, 8. Aufl., Stuttgart: Kohlhammer 2001.

Paul, Gerhard: Der Bilderkrieg. Inszenierungen, Bilder und Perspektiven der >Operation Irakische Freiheit`, Göttingen: Wallstein Verlag 2005.

Pedahzur, Ami: Suicide Terrorism, Cambridge: Polity Press 2005.

---: Root Causes of Suicide Terrorism: The Globalization of Martyrdom, London: Routledge 2006.

Peirce, Charles S.: Semiotische Schriften Bd. I-III, hg. von Christian J. W. Kloesel und Helmut Pape, Frankfurt am Main: Suhrkamp 2000.

Perlmutter, David D.: Photojournalism and Foreign Policy. Icons of Outrage in International Crises, Westport: Praeger 1998.

Pinchin, Karen: »Explosive Material«, in: Winter Olympics Cultural Olympiad, Vancouver, Canada (2010), https:/www.aesthetic-machinery.com/documents_pdf/Ritter_Pinchin_Olympics.pdf (zugegriffen am 6.6.2021).

Pipes, Daniel: »Radical Politics and the Syrian Social Nationalist Party«, International Journal of Middle East Studies 20/3 (1988), S. 303-324.

Poole, Deborah: Vision, Race, and Modernity: A Visual Economy of the Andean Image World, Princeton: Princeton University Press 1997.

Prucha, Nico: »Hijacked Islam«, Online Jihad: Monitoring Jihadist Online Communities (18.11.2010), https://onlinejihad.net/2010/11/18/hijacked-islam/ (zugegriffen am 6.6.2021).

---: »Worldwide Online Jihad versus the Gaming Industry Reloaded - Ventures of the Web«, in: Rüdiger Lohlker (Hg.): New Approaches to the Analysis of Jihadism: Online and Offline, Göttingen: V\&R Unipress 2012, S. 153-182.

Rauscher, Andreas: »Playing Propaganda. Die Games-Appropriationen des IS «, in: Bernd Zywietz (Hg.): Propaganda des »Islamischen Staats«. Formen und Formate, Wiesbaden: Springer VS 2020, S. 161-184. 
Razzouk, Nayla: »Hezbollah Says 30 Wounded in Attack«, United Press International (UPI), 26.04.1995.

Ricoeur, Paul: »The Hermeneutics of Testimony«, in: Lewis S. Mudge (Hg.): Essays on Biblical Interpretation, London: SPCK Publishing 1981, S. 119-154.

Ricolfi, Luca und Paolo Campana: »Suicide Missions in the Palestinian Area: A New Database«, 2004, https://www.prio.org/Global/upload/CSCW/Violence $\% 20 \mathrm{in} \% 20 \mathrm{civil} \%$ 20war/ suicide_missions.pdf (zugegriffen am 6.6.2021).

Roger, Nathan: Image Warfare in the War on Terror, New York: Palgrave Macmillan 2013.

Ross, Angus: »Why Do We Believe What We Are Told?«, Ratio 28/1 (1986), S. 69-88.

Rubin, Alissa J. und Lilia Blaise: »Killing Twice for ISIS and Saying So Live on Facebook«, The New York Times, 14.06.2016, https://www.nytimes.com/ 2016/06/15/world/europe/france-stabbing-police-magnanville-isis.html (zugegriffen am 6.6.2021).

Saade, Bashir: »Martyrology and Conceptions of Time in Hizbullah's Writing Practices«, International Journal of Middle East Studies 47/4 (2015), S. $723-$ 744.

Said, Behnam: »Hymns (Nasheeds): A Contribution to the Study of the Jihadist Culture«, Studies in Conflict \& Terrorism 35/12 (2012), S. 863-879.

---: Hymnen des Jihads: Naschids im Kontext jihadistischer Mobilisierung, Würzburg: Ergon Verlag 2016.

Salloum, Raniah: »Rekruten für den `Islamischen Staat $:$ Die Weltkarte des Terrors«, Spiegel Online, 28.11.2014, http://www.spiegel.de/politik/ausland/isislamischer-staat-zehntausende-auslaendische-kaempfer-machen-mit-a1001193.html (zugegriffen am 6.6.2021).

Sayigh, Yezid: Armed Struggle and the Search for State: The Palestinian National Movement 1949-1993, Oxford: Clarendon Press 1997.

Schade, Sigrid und Silke Wenk: Studien zur visuellen Kultur: Einführung in ein transdisziplinäres Forschungsfeld, Bielefeld: transcript 2011.

Schankweiler, Kerstin, Verena Straub und Tobias Wendl: »Introduction«, in: Dies. (Hg.): Image Testimonies - Witnessing in Times of Social Media, London: Routledge 2019.

Scheiwiller, Staci Gem: »In the House of Fatemeh: Revisiting Shirin Neshat's Photographic Series Women of Allah«, in: Dies. (Hg.): Performing the Iranian State: Visual Culture and Representations of Iranian Identity, London/New York: Anthem Press 2013, S. 201-220. 
Scherrer, Lucien: »Das Leben des Jihad Mansour«, Neue Zürcher Zeitung, 25.01.2016, http://www.nzz.ch/zuerich/das-leben-des-jihad-mansour-1.1868 2946\#kommentare (zugegriffen am 12.5.2016, nicht mehr verfügbar).

Schleifer, Ronald: »Psychological Operations: A New Variation on an Age Old Art: Hezbollah versus Israel«, Studies in Conflict \& Terrorism 29/1 (2006), S. 1-19.

Schmidt, Sibylle: Ethik und Episteme der Zeugenschaft, Konstanz: Konstanz University Press 2015.

---: »Perpetrators' Knowledge. What and How Can We Learn from Perpetrator Testimony?«, Journal of Perpetrator Research 1/1 (2017), S. 85-104.

Schmidt, Sibylle, Sybille Krämer und Ramon Voges (Hg.): Politik der Zeugenschaft: Zur Kritik einer Wissenspraxis, Bielefeld: transcript 2011.

Schweitzer, Yoram: »Suicide Terrorism. Development and Main Characteristics«, in: ICT/ADL (Hg.): Countering Suicide Terrorism, Herzliya: ICT/ADL 2002, S. 77-88.

---: »Palestinian Female Suicide Bombers: Reality vs. Myth«, in: Yoram Schweitzer (Hg.): Female Suicide Bombers. Dying for Equality?, Tel Aviv 2006, S. $25-41$.

Seja, Silvia: Handlungstheorien des Bildes, Köln: Halem Verlag 2009.

Shapin, Steven: A Social History of Truth: Civility and Science in SeventeenthCentury England, Chicago: University of Chicago Press 1994.

Silver, Vernon: »Hezbollah's Tech-Savvy, Platform-Agnostic Guerrilla Marketing Campaign«, Bloomberg, 06.06.2014, https:/www.bloomberg.com/news/ articles/2014-06-05/tech-savvy-hezbollah-goes-multiplatform-to-spread-itsmessage (zugegriffen am 6.6.2021).

Simon, Joshua: »Thoughts on the Aesthetics of Terror in General and Suicide Bombers' Videos in Particular«, in: Joshua Simon und Manon Slome (Hg.): The Aesthetics of Terror, Mailand: Charta 2009, S. 28-47.

Sisler, Vit: »Digital Arabs: Representation in Video Games«, European Journal of Cultural Studies 11/2 (2008), S. 203-220.

Sköld-Feiler, Gunilla: »Who is Snow White?«, Avantart (o.J.), S. 1-8, http://www.avantart.com/music/feiler/snowwhite.htm (zugegriffen am 6.6. 2021).

Slome, Manon: »The Aesthetics of Terror«, in: Joshua Simon und Manon Slome (Hg.): The Aesthetics of Terror, Ausst.-Kat., Mailand: Charta 2009, S. 8-29.

Smith, Jane Idleman und Yvonne Yazbeck Haddad: The Islamic Understanding of Death and Resurrection, Oxford: Oxford University Press 2002.

Sontag, Susan: On Photography [1977], New York: Picador 2001.

---: Regarding the Pain of Others, New York: Picador 2003. 
Spencer, Robert: »Al-Qaeda’s Online Training Camp«, Jihad Watch, 06.01.2004, https://www.jihadwatch.org/2004/01/al-qaedas-online-training-camp (zugegriffen am 6.6.2021).

Spiegel Online: »Video-Premiere: Der letzte Wille von Mohammed Atta«, 01.10.2006, http://www.spiegel.de/panorama/video-premiere-der-letzte-wille -von-mohammed-atta-a-440208.html (zugegriffen am 6.6.2021).

Spielmann, Yvonne: Video: Das reflexive Medium, Frankfurt am Main: Suhrkamp 2005.

Stern: »Islamist zeigte Video der Tat auf Facebook«, 14.06.2016, https:// www.stern.de/politik/ausland/attentat-von-magnanville--islamist-stellte-video-der-tat-auf-facebook-6900008.html (zugegriffen am 6.6.2021).

Steyerl, Hito: Die Farbe der Wahrheit: Dokumentarismen im Kunstfeld, Wien: Turia \& Kant 2008.

Straub, Verena: »Lebende Tote? Die (Selbst-)Inszenierungen der palästinensischen Selbstmordattentäterinnen «, in: Philipp Stoellger und Jens Wolff (Hg.): Bild und Tod. Grundfragen der Bildanthropologie, Bd. I, Tübingen: Mohr Siebeck 2016, S. 401-424.

---: »The Making and Gendering of a Martyr: Images of Female Suicide Bombers in the Middle East«, in: Jens Eder und Charlotte Klonk (Hg.): Image Operations. Visual Media and Political Conflict, Manchester: Manchester University Press 2016, S. 137-150.

---: »A Gallery of Martyrs - The Martyr in the Gallery: Public Display and the Artistic Appropriation of Martyr Images in the Middle East «, in: Elena Stylianou und Theopisti Stylianou-Lambert (Hg.): Museums and Photography: Displaying Death, London: Routledge 2017, S. 179-199.

---: »)Living Martyrs $<$ - Testifying What is to Come«, in: Kerstin Schankweiler, Verena Straub und Tobias Wendl (Hg.): Image Testimonies - Witnessing in Times of Social Media, London: Routledge 2019, S. 139-153.

---: »Digitale Postproduktionen. Die Zirkulation von Bildern palästinensischer Selbstmordattentäterinnen im Internet, in: Isabelle Busch, Uwe Fleckner und Judith Waldmann (Hg.): Nähe auf Distanz. Eigendynamik und mobilisierende Kraft politischer Bilder im Internet, Hamburger Forschungen zur Kunstgeschichte, Berlin: De Gruyter 2020, S. 157-175.

---: »Töten im Livestream. Facebook Live und ein neuer sinvective gaze in den Sozialen Medien«, in: Elisabeth Heyne und Tanja Prokic (Hg.): Invective Gaze - Das digitale Bild und die Kultur der Beschämung. Bielefeld: transcript 2021 (i.E.).

Taheri, Amir: Holy Terror: The Inside Story of Islamic Terrorism, London: Hutchinson 1987. 
Toolis, Kevin (Regie): »Cult of the Suicide Bomber 2«, Dokumentarfilm, 106 min, Vereinigtes Königreich 2006.

--- (Regie): «Cult of the Suicide Bomber 3«, Dokumentarfilm, 48 min, Vereinigtes Königreich 2007.

Toufic, Jalal: »I Am the Martyr Sanâ' Yûsif Muhaydlî«, in: Maria Hlavajova, Jill Winder und Cosmin Costinas (Hg.): Rabih Mroué: A BAK Critical Reader in Artists' Practice, Utrecht/Rotterdam: BAK 2012, S. 126-143.

Tzoreff, Mira: »The Palestinian Shahida: National Patriotism, Islamic Feminism, or Social Crisis«, in: Yoram Schweitzer (Hg.): Female Suicide Bombers. Dying for Equality?, Tel Aviv 2006, S. 12-23.

United Press International (UPI): »Lebanon Bomber Attacks Israeli Convoy«, 20.03.1996.

Venus, Jochen: »Gewalt«, in: Benjamin Beil, Thomas Hensel und Andreas Rauscher (Hg.): Game Studies, Film, Fernsehen, Neue Medien, Wiesbaden: Springer 2018, S. 331-342.

Victor, Barbara: Army of Roses: Inside the World of Palestinian Women Suicide Bombers, Emmaus: Rodale 2003.

Viehoff, Reinhold: »Programmierte Bilder. Gedanken zur ritualisierten Zirkelstruktur von Wahrnehmung und Inszenierung durch die Bild(schirm)medien«, in: Ludwig Fischer (Hg.): Programm und Programmatik. Kultur- und medienwissenschaftliche Analysen, Konstanz: UVK 2005, S. 113-131.

Viner, Katherine: $» I$ Made the Ring From a Bullet and the Pin of a Hand Grenade«, The Guardian, 26.01.2001, http://www.guardian.co.uk/world/2001/jan/26/israel (zugegriffen am 6.6.2021).

Vykoukal, Monika: »Review: Ahlam Shibli. Phantom Home«, Springerin 3 (2013), https://www.springerin.at/2013/3/review/ahlam-shibli/ (zugegriffen am 6.6.2021).

Waldmann, Peter: Terrorismus. Provokation der Macht [1998], 3. Aufl., Hamburg: Murmann 2011.

Walzer, Michael: Arguing About War, New Haven: Yale University Press 2004.

Weigel, Sigrid (Hg.): Märtyrer-Porträts. Von Opfertod, Blutzeugen und Heiligen Kriegern, München: Wilhelm Fink 2007.

---: »Schauplätze, Figuren, Umformungen. Zu Kontinuitäten und Unterscheidungen von Märtyrerkulturen«, in: Sigrid Weigel (Hg.): Märtyrer-Porträts. Von Opfertod, Blutzeugen und Heiligen Kriegern, München: Wilhelm Fink 2007, S. 11-38.

Weimann, Gabriel: Terror on the Internet: The New Arena, the New Challenges, Washington, D.C: United States Institute of Peace Press 2006. 
Wiegel, Michaela: »Polizistenmord nahe Paris: Einer von 8250 Islamisten«, Frankfurter Allgemeine Zeitung, 14.06.2016, http://www.faz.net/1.4287226 (zugegriffen am 6.6.2021).

Wiemer, Serjoscha: »Zeit. Ein Schlüsselbegriff für die Computerspielforschung«, in: Benjamin Beil, Thomas Hensel und Andreas Rauscher (Hg.): Game Studies, Film, Fernsehen, Neue Medien, Wiesbaden: Springer 2018, S. $27-45$.

Winter, Charlie: Documenting the Virtual `Caliphate〈, Quilliam Foundation 2015, http://www.quilliaminternational.com/wp-content/uploads/2015/10/FINALdocumenting-the-virtual-caliphate.pdf (zugegriffen am 6.6.2021).

World Net Daily (WND): »Hezbollah's New Computer Game«, 2003, http://www.wnd.com/2003/03/17550/ (zugegriffen am 6.6.2021).

Wüschner, Philipp: »Widerstand als Ereignis? Der Märtyrer als Beispiel für einen nicht-intentionalen, nicht-subjektiven Widerstandsbegriff«, in: Junk, Julian und Christian Volk (Hg.): Macht und Widerstand in der globalen Politik, Baden-Baden: Nomos 2013, S. 31-48.

Ya'ari, Ehud: »Behind the Terror«, The Atlantic 259/6 (1987), S. 18-22, https://www.theatlantic.com/magazine/archive/1987/06/behind-the-terror/376326/ (zugegriffen am 6.6.2021).

Yadlin, Rivka: »Female Martyrdom: The Ultimate Embodiment of Islamic Existence?«, in: Yoram Schweitzer (Hg.): Female Suicide Bombers. Dying for Equality?, Tel Aviv 2006, S. 51-61.

Zelin, Aaron Y.: »Picture Or It Didn't Happen: A Snapshot of the Islamic State's Official Media Output«, Perspectives on Terrorism 9/4 (2015), S. 85-97.

Ziolkowski, Britt: Palästinensische Märtyrerinnen. Selbstdarstellung und innerislamische Wahrnehmung weiblicher Selbstmordattentäter, Berlin: Klaus Schwarz 2012.

Zywietz, Bernd (Hg.): Propaganda des »Islamischen Staats«. Formen und Formate, Wiesbaden: Springer VS 2020. 


\section{Abbildungsnachweis}

\section{Märtyrerposter als sekundäre Zeugnisse}

Abbildung 2.1: Fatah/Al-Aqsa-Märtyrer Brigaden: Märtyrerposter von Wafa Idris, Januar 2002. Foto (C) Johannes Gerloff.

Abbildung 2.2: Hamas: Al-īstishādiāt, digitale Montage mit dem Portrait von Wafa Idris (zweite Reihe rechts). Quelle: http:/goodaelhashmya.blogspot.de/ 2012/01/blog-post_04.html (zugegriffen am 6.6.2021).

Abbildung 2.3: Standbild aus einem undatierten und anonymen Videotestament mit zwei Märtyrerpostern von Wafa Idris im Hintergrund. Quelle: Joshua Simon »Shahids 2003-2008«, DVD, Laufzeit 52:04 min, hier 15:32.

Abbildung 2.4: Fotografie der Kirjat-Schmona-Attentäter, am 12. April 1974 auf der Titelseite von Al-Anwar abgedruckt. Al-Anwar, 2. April 1974.

Abbildung 2.5: Fotografie der Kirjat-Schmona-Attentäter, am 12. April 1974 auf der Titelseite von An-Nahar abgedruckt. An-Nahar, 12. April 1974.

Abbildung 2.6: Fotografie der Kirjat-Schmona-Attentäter, am 13. April 1974 in al-Anwar abgedruckt. Al-Anwar, 13. April 1974.

Abbildung 2.7: Fotografie der Attentäter der Om El Aakareb-Operation, am 14. Juni 1974 auf der Titelseite von al-Anwar abgedruckt. Al-Anwar, 14. Juni 1974.

Abbildung 2.8: Kamikaze-Piloten der 72. Shinbu-Staffel, Fotografie vom 26. Mai 1945, erschienen in Asahi Shimbun. Quelle: http://historienblog.blogspot.de/ 2014/08/kamikaze-machs-gut-kleiner-welpe-liebes.html (zugegriffen am 6.6. 2021).

Abbildung 2.9: Poster zu Ehren der drei Attentäter von Kirjat Schmona, PFLPGC, o.D. (C) Abboudi Bou Jawdeh.

Abbildung 2.10: Poster anlässlich des vierten Jahrestages der Operation von Kirjat Schmona, PFLP-GC, April 1978. (C) Abboudi Bou Jawdeh. 
Abbildung 2.11: Poster anlässlich des sechsten Jahrestages der Operation von Kirjat Schmona, PFLP-GC, April 1980. (C) Abboudi Bou Jawdeh.

Abbildung 2.12: Poster anlässlich des sechsten Jahrestages der Om El Aaakareb Operation, PFLP-GC, Juni 1980. (C) Abboudi Bou Jawdeh.

Abbildung 2.13: Poster zu Ehren der Om El Aaakareb-Operation am 13. Juni 1974, PFLP-GC, o.D. (C) Abboudi Bou Jawdeh.

Abbildung 2.14: Poster zu Ehren des Anschlags vom 11.3.1978, Fatah, 1978.

Quelle: Palestine Poster Project, http://www.palestineposterproject.org/poster/ dalal-and-her-comrades (zugegriffen am 6.6.2021).

Abbildung 2.15: Bildmontage mit Portraits von Dalal Mughrabi und Selbstmordattentäterinnen der zweiten Intifada, Facebook Fatah, Juli 2014. Quelle: http://www.safsaf.org/01_11_06/shaheedat.htm (zugegriffen am 6.6.2021).

Abbildung 2.16: Nabil Kdouh (Künstler), Poster zu Ehren des Anschlags von Bilal

Fahs, Amal, 1984. Quelle: http://signsofconflict.com/Archive/poster_details/1755 (zugegriffen am 6.6.2021). (C) Signs of Conflict.

Abbildung 2.17: Märtyrerposter zu Ehren des Anschlags von Ahmad Qasir, 50 x $70 \mathrm{~cm}$, Hisbollah, Mai 1985 oder November 1984. Quelle: http://www.signsofconflict.com/Archive/poster_details/1865 (zugegriffen am 6.6.2021). (C) Signs of Conflict.

Abbildung 2.18: Märtyrerposter der Hisbollah, 40 x $55 \mathrm{~cm}$, 1986. Quelle: http://www.signsofconflict.com/Archive/poster_details/1941 (zugegriffen am 6.6.2021). (C) Signs of Conflict.

Abbildung 2.19: Märtyrerposter der Hisbollah, 40 x 55 cm, 1986. Quelle: http://www.signsofconflict.com/Archive/poster_details/1808 (zugegriffen am 6.6.2021). (c) Signs of Conflict.

Abbildung 2.20: Märtyrerposter der Hisbollah, Beirut, 2006, Fotografie aus Rabih Mroué: The Inhabitants of Images (2009). (C) Rabih Mroué.

Abbildung 2.21: Ahlam Shibli, untitled (Death no. 22), Al-Am'ari Flüchtlingslager nahe Ramallah, 18.10.2011, Chromogendruck, 38 x $57 \mathrm{~cm}$. Quelle: MACBA et al. (Hg.): Ahlam Shibli. Phantom Home, Ausst.-Kat., Ostfildern: Hatje Cantz 2013, S. 74. (C) Ahlam Shibli.

Abbildung 2.22: Ahlam Shibli, Untitled (Death no. 53), 22.11.2011, 57 x $38 \mathrm{~cm}$, Balata Flüchtlingslager, Chromogendruck. Quelle: MACBA et al. (Hg.): Ahlam Shibli. Phantom Home, S. 136. (C) Ahlam Shibli.

Abbildung 2.23: Untitled (Death no. 37), 12.2.2011, 100 x 66,7 cm, Balata Flüchtlingslager, Chromogendruck. Quelle: MACBA et al. (Hg.): Ahlam Shibli. Phantom Home, S. 107. (C) Ahlam Shibli. 
Abbildung 2.24: Ahlam Shibli, Untitled (Death no. 33), Old Askar Flüchtlingslager, 15.2.2012, Chromogendruck, 38 x $57 \mathrm{~cm}$. Quelle: MACBA et al. (Hg.): Ahlam Shibli. Phantom Home, S. 96. (c) Ahlam Shibli.

Abbildung 2.25: Rabih Mroué, The Inhabitants of Images, Lecture Performance, 2009. (C) Rabih Mroué.

Abbildung 2.26: Rabih Mroué, The Inhabitants of Images, Lecture Performance, 2009, Detail. C Rabih Mroué.

\section{Videotestamente. Das eigene Martyrium bezeugen?}

Abbildung 3.1 a-c: Videotestament von Sana Muhaydli, SSNP, Aufnahme am oder vor dem 9. April 1985, 16:28 min, arabisch. Quelle: VHS-Kopie (33:28 min) aus dem Büro der SSNP in Beirut, zur Digitalisierung zu Verfügung gestellt von Kevin Toolis.

Abbildung 3.2: Videotestament von Wajdi al-Sayigh, SSNP, Aufnahme am oder vor dem 12.3.1985, Ausschnitt, 4:55 min, arabisch. Quelle: VHS-Kopie (33:28 min) aus dem Büro der SSNP in Beirut, zur Verfügung gestellt von Kevin Toolis.

Abbildung 3.3: Poster zu Ehren von Sana Muhaydli, SSNP, 1985, 51 x $71 \mathrm{~cm}$. Quelle: Webseite der SSNP, http://www.ssnp.com/new/posters/full_size/ sanaa_01.jpg (zugegriffen am 16.3.2018, nicht mehr verfügbar).

Abbildung 3.4 a-d: Videotestament von Sana Muhaydli: Die Braut des Südens, SSNP, 16:28 min, arabisch, o.D. Quelle: VHS-Kopie (33:28 min) aus dem Büro der SSNP in Beirut, zur Verfügung gestellt von Kevin Toolis.

Abbildung 3.5: Videotestament von Malek Wehbi, SSNP, Aufnahme am oder vor dem 20. April 1985, Ausschnitt, 1:58 min, arabisch. Quelle: VHS-Kopie (33:28 min) aus dem Büro der SSNP in Beirut, zur Verfügung gestellt von Kevin Toolis.

Abbildung 3.6: Videotestament von Wafa Noureddine, LCP, Aufnahme am oder vor dem 9. Mai 1985, 4:30 min, arabisch. Quelle: https://www.youtube. com/watch? $v=$-zarM1kW28s, hochgeladen am 29.5.2009 von »Johny Nacouzi« (zugegriffen am 6.6.2021).

Abbildung 3.7: Videotestament von Jamal Sati, LCP, Aufnahme am oder vor dem 6. August 1985, Ausschnitt, 5:07 min, arabisch. Quelle: https://www.youtube. com/watch?v=mlsynVNS1uk, hochgeladen am 29.5.2009 von »Johny Nacouzi« (zugegriffen am 6.6.2021).

Abbildung 3.8: Videotestament von Elias Harb, LCP, Aufnahme im Oktober 1985, arabisch. Quelle: Standbild aus Rabih Mroué: »The Inhabitants of Images«, in: CA2M Centro de Arte Dos de Mayo (Hg.): Rabih Mroué. 
Image(s), mon amour. Fabrications, Ausst.-Kat., Madrid: CA2M Centro de Arte Dos de Mayo 2013, S. 338-356, hier S. 355.

Abbildung 3.9: Videotestament von Khaled al-Azraq, SSNP, Aufnahme am oder vor dem 9. Juli 1985, Ausschnitt, 0:29 min, arabisch. Quelle: VHS-Kopie (33:28 min) aus dem Büro der SSNP in Beirut, zur Verfügung gestellt von Kevin Toolis.

Abbildung 3.10: Videotestament von Mohammed Mahmoud Qanaa, SSNP, Aufnahme am oder vor dem 8. Juli 1986, Ausschnitt, 0:17 min, arabisch. Quelle: VHS-Kopie (33:28 min) aus dem Büro der SSNP in Beirut, zur Verfügung gestellt von Kevin Toolis.

Abbildung 3.11: Märtyrerposter von Mohammed Mahmoud Qanaa, SSNP, 1986, $45 \times 60 \mathrm{~cm}$. Quelle: http://www.signsofconflict.com/Archive/poster_details/2053 (zugegriffen am 6.6.2021). (C) Signs of Conflict.

Abbildung 3.12-3.14: Elias Khoury und Rabih Mroué, Three Posters, 2000, Performance, Ayloul Festival Beirut. (C) Rabih Mroué.

Abbildung 3.15: Rabih Mroué, On Three Posters, 2004, Video, 17 min. (C) Rabih Mroué.

Abbildung 3.16: Videotestament von Assad Barru, Hisbollah, Aufnahme am oder vor dem 9. August 1989, Ausschnitt, 1:26 min, arabisch mit englischen Untertiteln. Quelle: https://www.shiatv.net/view_video.php?viewkey=63c90e 74d8761976f322, hochgeladen am 2.1.2012 von »Montazir« (zugegriffen am 6.6.2021).

Abbildung 3.17 a-b: Videotestament von Salah Ghandour, Hisbollah, Aufnahme am oder vor dem 25. April 1995, Ausschnitt, 3:11 min, arabisch mit englischen Untertiteln. Quelle: https://www.shiatv.net/video/424bc78667f18017 bdf4, hochgeladen am 2.1.2012 von »Montazir« (zugegriffen am 6.6.2021).

Abbildung 3.17 c-d: Videotestament von Salah Ghandour, Hisbollah, Aufnahme am oder vor dem 25. April 1995, Ausschnitt, 3:43 min, arabisch. Quelle: https://www.shiatv.net/view_video.php?viewkey=be6d993ec2acbc865fa1\& page $=\&$ viewtype $=\&$ category, hochgeladen am 6.9.2013 von $» M e d L e b \ll(z u-$ gegriffen am 6.6.2021).

Abbildung 3.17 e-h: Videotestament von Salah Ghandour, Hisbollah, Aufnahme am oder vor dem 25. April 1995, Ausschnitt, 0:35 min, arabisch. Quelle: https://www.youtube.com/watch? $\mathrm{v}=-1 \mathrm{sxBfbCTb} 0$, hochgeladen am 5.3.2011 von »Ansar14Masoum « (zugegriffen am 29.9.2018, nicht mehr verfügbar).

Abbildung 3.18 a-c: Videotestament von Ali Munif Ashmar, Hisbollah, Aufnahme am oder vor dem 20. März 1996, Ausschnitt, arabisch. Quelle: https://www.youtube.com/watch?v=v2OSsLU-MPI (zugegriffen am 9.2. 2018 , nicht mehr verfügbar). 
Abbildung 3.18 d: Videotestament von Ali Munif Ashmar, Hisbollah, Aufnahme am oder vor dem 20. März 1996, Ausschnitt, 9:48 min, arabisch. Quelle: https://www.youtube.com/watch?v=v3P9S6K6aZs, hochgeladen am 18.4. 2013 von »Haj Jawad Di« (zugegriffen am 29.9.2018, nicht mehr verfügbar). Abbildung 3.18 e: Videotestament von Ali Munif Ashmar, Hisbollah, Aufnahme am oder vor dem 20. März 1996, Ausschnitt, 3:24 min, arabisch. Quelle: https://www.shiatv.net/view_video.php?viewkey=e7d30e573244fd7c6e0f\&p age $=\&$ viewtype $=\&$ category $=$, hochgeladen am 19.9.2013 von »MedLeb« $(z u-$ gegriffen am 6.6.2021).

Abbildung 3.19 a-d: Videotestament von Darin Abu Aisheh, al-Aqsa Märtyrer Brigaden, Aufnahme am oder vor dem 27. Februar 2002, Ausschnitt, 0:57 min, arabisch. Quelle: KAM (Komitee zur Achtung der Märtyrer der islamischen Bewegung), Dāhtarān-e Zaitūn, CD-Rom, Teheran, o.D., zur Verfügung gestellt von Britt Ziolkowski.

Abbildung 3.20: Fotografie von Darin Abu Aisheh, von ihrer Familie inNablus am 28. Februar 2002 verbreitet. Quelle: http://palvoice.com/forums/showthread.php?t=226791 (zugegriffen am 14.8.2011, nicht mehr verfügbar).

Abbildung 3.21 a-b: Videotestament von Ayat al-Akhras, al-Aqsa Märtyrer Brigaden, Aufnahme am oder vor dem 29. März 2002, 0:31 min, arabisch. Quelle: https://www.youtube.com/watch?v=sm5S0RRd3uM (zugegriffen am 23.7. 2016, nicht mehr verfügbar).

Abbildung 3.22: Ayat al-Akhras, Fotografie am oder vor dem 29. März 2002 entstanden. aus: Hilla Medalia (Regie): »To Die in Jerusalem«, Dokumentarfilm, $40 \mathrm{~min}$, Israel/USA 2007, 16:18.

Abbildung 3.23: Leila Khaled, Fotografie aus den 1970er Jahren, unbekannter Fotograf. Quelle: https://www.dailymail.co.uk/news/article-6069013/Corbynfaces-fresh-questions-links-terrorists-pictures-emerge-plane-hijacker.html (zugegriffen am 6.6.2021). (C) Getty Images.

Abbildung 3.24: Marc Rudin, Consolidating the Struggle for Equality, Poster der PFLP, 1985, ca. 58 x 40,5 cm. Quelle: Palestine Poster Project, http://www.palestineposterproject.org/poster/consolidating-the-struggle (zugegriffen am 6.6.2021).

Abbildung 3.25: Videotestament von Rim Riyashi, Hamas, Aufnahme am oder vor dem 14. Januar 2004, arabisch. Quelle: http://alqassam.ps/arabic/video.php?id=32 (zugegriffen am 27.5.2013, nicht mehr verfügbar).

Abbildung 3.26: Fotografie von Rim Riyashi mit ihrer Tochter, am 26. Januar 2004 von der Hamas verbreitet. Quelle: http://www.paldf.net/forum/showthread.php?t=549634 (zugegriffen am 21.6.2013, nicht mehr verfügbar). 
Abbildung 3.27 a-b: Fotografien von Rim Riyashi mit ihren Kindern, am 26. Januar 2004 von der Hamas verbreitet. Quelle: https://avax.news/sad/Reem Riyashi.html (zugegriffen am 6.6.2021). (C) Getty Images.

Abbildung 3.28: Adnan al-Sharif: The Women Struggle a Corner Stone on the Road to Liberation, Poster der Fatah, 1976. Quelle: Palestine Poster Project, https://www.palestineposterproject.org/poster/the-womans-struggle, (zugegriffen am 6.6.2021).

Abbildung 3.29: Marc Rudin, The Land, Poster der PFLP, 1986. Quelle: Palestine Poster Project, http://www.palestineposterproject.org/poster/the-land (zugegriffen am 6.6.2021).

Abbildung 3.30: Anonyme, undatierte Montage mit Fotos palästinensischer Selbstmordattentäterinnen (2002-2006). Quelle: http://e7sasmero.blogspot.de (zugegriffen am 6.6.2021).

Abbildung 3.31: Galina Bleikh und Lilia Chak, Ferror (Female Terror), 2009, digitale Montage mit einem Foto von Darin Abu Aisheh, Druck auf Leinwand, 180 x $96 \mathrm{~cm}$. (C) Galina Bleikh und Lilia Chak.

\section{Digitale Postproduktionen. Simulation und Interaktivität im Videotestament 2.0}

Abbildung 4.1: Al-Qaida/Medienbüro as-Saḥāb, Videotestament von Ahmed Ibrahim al-Haznawi, arabisch mit englischen Untertiteln, am 16. April 2002 veröffentlicht. Quelle: https://archive.org/details/hznwiwill (zugegriffen am 6.6.2021).

Abbildung 4.2: Al-Qaida, Videotestament von Abdulaziz al-Omari, am 9. September 2002 auf Al Jazeera veröffentlicht. Quelle: Standbild aus http://www.911myths.com/index.php?title=File:Abdul_Aziz_Alomari_3.jpg (zugegriffen am 6.6.2021).

Abbildung 4.3: Al-Qaida, Videotestament von Hamza Al-Ghamdi, am 7. September 2006 auf Al Jazeera veröffentlicht. Quelle: Standbild aus Abdelasiem El Difraoui: Al-Qaida par l'image: La prophétie du martyre, Paris: Presses Universitaires de France 2013, Abb. 125.

Abbildung 4.4 a-d: Al-Qaida/Medienbüro as-Saḥāb, East Riyadh's Martyrs Wills, 2003, 45:21 min, arabisch. Quelle: https://archive.org/details/MuKhLsS_004 (zugegriffen am 6.6.2021).

Abbildung 4.5 a-d: Al-Qaida im Irak, Videotestament von Abu Zubayr, 8. Juli 2005, 4:24 min. Quelle: https://archive.org/details/Chohada_04/044.avi (zugegriffen am 6.6.2021). 
Abbildung 4.6 a-h und 4.7 a-d: Islamischer Staat im Irak/Medienbüro al-Furqān: Ritter des Zeugnisses 5, 2008, 45:17 min, arabisch. Quelle: https://archive.org/details/Forsan-Ashahada5 (zugegriffen am 6.6.2021).

Abbildung 4.8: Islamischer Staat/Medienbüro Wilayat Halab, Syrien, Video veröffentlicht am 4. August 2016, 12 min, arabisch. Quelle: https://www.zero censorship.com/uncensored/isis/first-person-shooter-style-syria-combat-footage-suicide-bombers-video-304429 (zugegriffen am 20.8.2017, nicht mehr verfügbar).

Abbildung 4.9 a-d: Islamischer Staat im Irak/Medienbüro al-Furqān: Ritter des Zeugnisses 5, 2008, 45:17 min, arabisch. Quelle: https://archive.org/details/Forsan-Ashahada5 (zugegriffen am 6.6.2021).

Abbildung 4.10 a: Hisbollah, Computerspiel Special Force 1, 2003, Cover. Quelle: Vit Sisler: »Digital Arabs: Representation in Video Games«, European Journal of Cultural Studies 11/2 (2008), S. 203-220.

Abbildung 4.10 b: Hisbollah, Computerspiel Special Force 2, 2007, Standbild einer Spielsequenz. Quelle: https://hg101.kontek.net/spf2/pics/spf2-1.png (zugegriffen am 6.6.2021).

Abbildung 4.11: Standbild aus einer Sequenz der Spielemodifikation Iraqi Resistance, 2006. Quelle: https://www.youtube.com/watch?v=U4Ka-jgJny0, hochgeladen am 11.5.2017 von »ZEIDGS« (zugegriffen am 6.6.2021).

Abbildung 4.12 a-b: Islamischer Staat/Medienbüro Wilāyat ar-Raqqa: The Racers to Paradise - Episode 2, 2016, 3:51 min, arabisch, 2:34-3:05. Quelle: https://archive.org/details/almtsabkon_ela_aljenan_2_alrakka (zugegriffen am 6.6.2021).

Abbildung 4.13 a-e: Islamischer Staat/Medienbüro Al-Haqq Muhahideen, All praise is due to Allah, 2017, 06:38 min, arabisch mit englischen Untertiteln, 3:54-5:07. Quelle: Archiv von Simon Menner, Video wurde von ihm heruntergeladen am 27.5.2017, Internetquelle nicht mehr verfügbar, siehe Emailkorrespondenz mit der Autorin vom 2.9.2017.

Abbildung 4.14 und 4.15: Don Ritter, Vested, 2009, interaktive Installation, $12 \mathrm{x}$ 19 m, Ansichten während der Ausstellung Code Live, Vancouver, 2010. Quelle: https://www.aesthetic-machinery.com/vested.html (zugegriffen am 6.6.2021). (C) Don Ritter.

Abbildung 4.16: Islamischer Staat/Medienbüro Wilayat al-Barqah, The Meaning of Stability \#2, veröffentlicht am 16. Januar 2016, 15:09 min. Quelle: http://jihadology.net/2016/01/16/new-video-message-from-the-islamic-statebinghazi-the-meaning-of-stability-2-wilayat-al-barqah/https://videopress. com/v/ZZ3JS2az (zugegriffen am 27.8.2017, nicht mehr verfügbar). 


\section{Schluss: Das Märtyrerzeugnis als Selfie im Livestream}

Abbildung 5.1: Videotestament von Larossi Abballa, am 13. Juni 2016 per Facebook Live verbreitet, $13 \mathrm{~min}$, französisch. Quelle (gekürzte Version): https://www.independent.co.uk/news/world/europe/video-shows-isis-supporter-who-stabbed-french-police-officer-and-wife-to-death-paris-magnanvillea7081816.html (zugegriffen am 6.6.2021). 


\section{Dank}

Die vorliegende Untersuchung zum »Selbstmordattentat im Bild « wurde als Dissertation an der Humboldt-Universität zu Berlin eingereicht und dort am 12. Juli 2019 erfolgreich verteidigt. Die langjährige Arbeit an diesem Buch wäre ohne die Unterstützung zahlreicher Personen nicht möglich gewesen. Besonderer Dank gilt Charlotte Klonk, deren Betreuung über viele Jahre hinweg von unschätzbarem Wert war. Ihre Forschung zur Rolle von Bildern des Terrors stellte eine wesentliche Inspirationsquelle dar, mich den verstörenden Bildern des Selbstmordattentats zu stellen. Für ihre wertvollen Ideen, ihre konstruktive und genaue Kritik sowie das beständige Vertrauen in mein Projekt möchte ich ihr von ganzem Herzen danken. Viele wichtige Hinweise verdanke ich auch meinem Zweitbetreuer Tobias Wendl, der mit seiner Begeisterung für das Thema immer wieder neue Denkanstöße gab. Das gemeinsame Forschungsprojekt, das ich zusammen mit ihm und meiner lieben Kollegin Kerstin Schankweiler an der FU Berlin bearbeiten durfte, erwies sich in vielerlei Hinsicht als äußerst produktiv. Insbesondere der intensive Austausch zum Thema der Bildzeugenschaft lieferte wichtige theoretische Impulse für meine Arbeit. Kerstin Schankweiler hat diese Arbeit nicht nur durch die vielen anregenden Gespräche und Ideen bereichert; sie stand mir auch stets mit freundschaftlichem Rat zur Seite. Ganz besonders danken möchte ich auch den beiden Kolloquien von Charlotte Klonk und Tobias Wendl. Das kritische Feedback und die Anregungen, die ich in vielen Diskussionen dort erhielt, leisteten von Anfang an einen wichtigen Beitrag.

Meine Forschung zu diesem Buch fand im Kontext zweier Institutionen und Projekte statt, die die finanziellen und intellektuellen Rahmenbedingungen schufen: Das Exzellenzcluster »Bild Wissen Gestaltung« der Humboldt Universität zu Berlin und der Sonderforschungsbereich $1171 »$ Affective Societies« an der Freien Universität Berlin. Beide dieser DFG-geförderten Programme haben mir nicht nur anregende Arbeitsbedingungen, sondern auch Arabischsprachkurse und Forschungsaufenthalte im Libanon und in Palästina ermöglicht, denen ich 
unverzichtbare Einblicke und Erkenntnisse verdanke. Insbesondere die dort geführten Gespräche mit Bader Araj und Mahmoud Abu Hashhash haben meine Perspektive auf die regionalen Konflikte entschieden erweitert. In Beirut hatte ich das Glück, den Publizisten Abboudi Bou Jawdeh kennenzulernen. Ohne dessen großzügige Bereitschaft sein einzigartiges Archiv politischer Poster für mich zu öffnen, wäre ein wesentlicher Teil dieser Arbeit nicht entstanden. Entscheidend war ebenso der Austausch mit dem Londoner Journalisten Kevin Toolis, der mir seine umfangreiche Sammlung von Videokassetten zur Digitalisierung und Forschung bereitstellte. Doch nicht nur das Bildmaterial, auch viele der damals geführten Gespräche erwiesen sich im Laufe des Schreibprozesses als äußerst bereichernd. Rabih Mroué hat mir nicht nur sein Bildmaterial zur Verfügung gestellt, sondern in vielen Gesprächen seine Begeisterung und seinen künstlerischen Blick mit mir geteilt.

Ganz besonders danken möchte ich außerdem Christoph Günther, der mich im Rahmen unserer gemeinsamen Projektarbeit wesentlich bei der Recherche von Videomaterial unterstützte und mit seiner Expertise und Sprachkenntnis wichtige Kontexte für mich erschloss. Zahlreiche Impulse aus islamwissenschaftlicher Perspektive verdanke ich außerdem Olmo Gölz, der mir ein Fellowship am Sonderforschungsbereich $948 »$ Helden - Heroismen - Heroisierungen« der Albert-Ludwigs Universität Freiburg ermöglichte.

Ohne die präzisen Übersetzungen von Shahed Naji, der viele der analysierten Videos aus dem libanesischen Arabisch übertragen hat, wäre diese Arbeit so nicht möglich gewesen. Ein großer Dank geht auch an Linda Huke und Tina Mamczur. Sie haben die Arbeit Korrektur gelesen und mit ihrem genauen Blick die Endfassung entscheidend mitgeprägt.

Die Produktionskosten für dieses Buch wurden durch den großzügigen $\mathrm{Zu}-$ schuss des Sonderforschungsbereichs $1171 »$ Affective Societies« getragen. Dem Vorstand möchte ich an dieser Stelle herzlich für das entgegengebrachte Vertrauen und die vielfache Unterstützung meines Projekts danken.

Den abschließenden und nachhaltigsten Dank möchte ich schließlich meiner Familie und meinen Freunden aussprechen - insbesondere für die Geduld und das unermüdliche Interesse, sich immer wieder aufs Neue mit einem so schwierigen Thema auseinanderzusetzen. Ganz besonderer Dank gilt meinem Partner Landon Little, der die Höhen und Tiefen dieser Arbeit wie kein anderer miterlebt hat und dabei immer verständnisvoll und unterstützend an meiner Seite war. Zu guter Letzt möchte ich auch unserer gemeinsamen Tochter Helma danken, in deren Erwartung ich die Dissertation 2018 zu Ende schreiben konnte und deren Anwesenheit die Arbeit an diesem Buch seither aufs Schönste begleitet hat. 


\section{Kunst- und Bildwissenschaft}

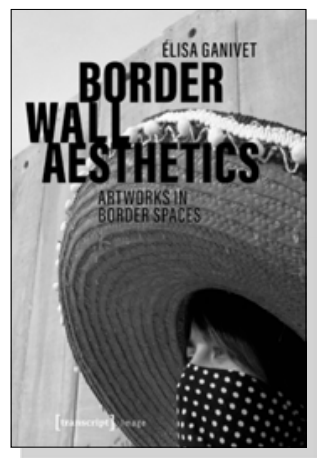

Elisa Ganivet

Border Wall Aesthetics

Artworks in Border Spaces

2019, 250 p., hardcover, ill.

79,99€ (DE), 978-3-8376-4777-8

E-Book:

PDF: 79,99€ (DE), ISBN 978-3-8394-4777-2

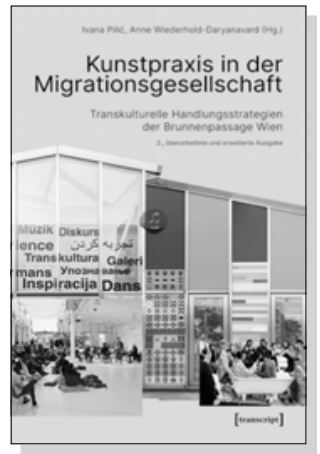

Ivana Pilic, Anne Wiederhold-Daryanavard (Hg.)

Kunstpraxis in der Migrationsgesellschaft

Transkulturelle Handlungsstrategien

der Brunnenpassage Wien

März 2021, 244 S., kart.

29,00€ (DE), 978-3-8376-5546-9

E-Book:

PDF: 25,99 € (DE), ISBN 978-3-8394-5546-3

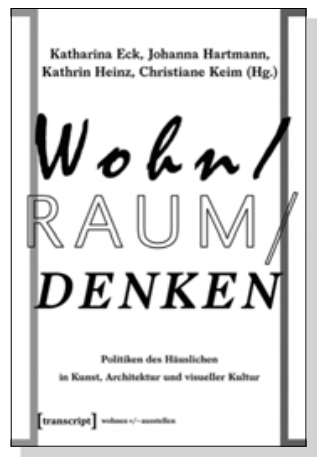

Katharina Eck, Johanna Hartmann,

Kathrin Heinz, Christiane Keim (Hg.)

\section{Wohn/Raum/Denken}

Politiken des Häuslichen in Kunst,

Architektur und visueller Kultur

April 2021, 376 S., kart., 90 SW-Abbildungen

35,00€ (DE), 978-3-8376-4517-0

E-Book:

PDF: 34,99€ (DE), ISBN 978-3-8394-4517-4 


\section{Kunst- und Bildwissenschaft}

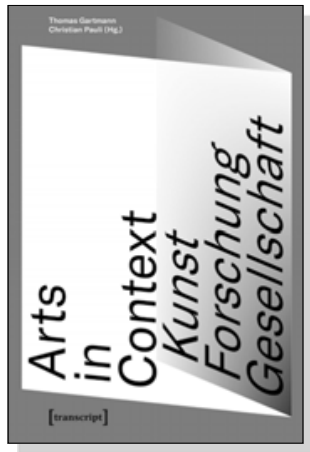

Thomas Gartmann, Christian Pauli (Hg.)

Arts in Context - Kunst, Forschung, Gesellschaft

2020, 232 S., kart.

39,00€ (DE), 978-3-8376-5322-9

E-Book: kostenlos erhältlich als Open-Access-Publikation

PDF: ISBN 978-3-8394-5322-3

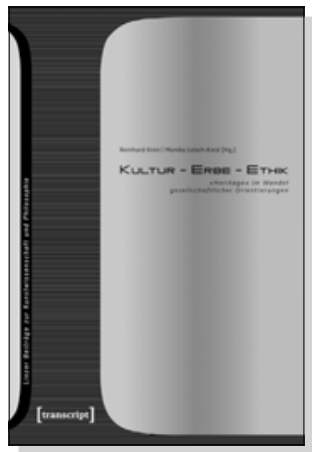

Reinhard Kren, Monika Leisch-Kiesl (Hg.)

\section{Kultur - Erbe - Ethik}

"Heritage" im Wandel gesellschaftlicher Orientierungen

2020, 486 S., kart.

49,00€ (DE), 978-3-8376-5338-0

E-Book:

PDF: 49,99€ (DE), ISBN 978-3-8394-5338-4

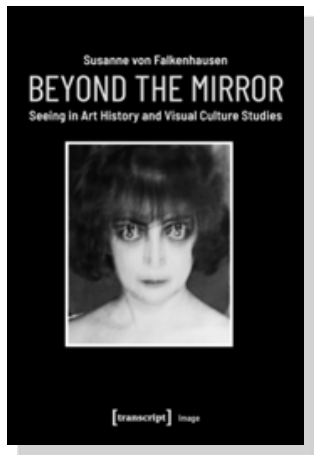

Susanne von Falkenhausen

\section{Beyond the Mirror}

Seeing in Art History and Visual Culture Studies

2020, 250 p., pb., ill.

$60,00 €(D E), 978-3-8376-5352-6$

E-Book: available as free open access publication

PDF: ISBN 978-3-8394-5352-0 